\title{
Knowledge flows and networks in the ICT sector : the case of Pakistan
}

Citation for published version (APA):

Qazi, A. B. (2015). Knowledge flows and networks in the ICT sector : the case of Pakistan. [Doctoral Thesis, Maastricht University]. Datawyse / Universitaire Pers Maastricht. https://doi.org/10.26481/dis.20151216aq

Document status and date:

Published: 01/01/2015

DOI:

10.26481/dis.20151216aq

Document Version:

Publisher's PDF, also known as Version of record

\section{Please check the document version of this publication:}

- A submitted manuscript is the version of the article upon submission and before peer-review. There can be important differences between the submitted version and the official published version of record.

People interested in the research are advised to contact the author for the final version of the publication, or visit the DOI to the publisher's website.

- The final author version and the galley proof are versions of the publication after peer review.

- The final published version features the final layout of the paper including the volume, issue and page numbers.

Link to publication

\footnotetext{
General rights rights.

- You may freely distribute the URL identifying the publication in the public portal. please follow below link for the End User Agreement:

www.umlib.nl/taverne-license

Take down policy

If you believe that this document breaches copyright please contact us at:

repository@maastrichtuniversity.nl

providing details and we will investigate your claim.
}

Copyright and moral rights for the publications made accessible in the public portal are retained by the authors and/or other copyright owners and it is a condition of accessing publications that users recognise and abide by the legal requirements associated with these

- Users may download and print one copy of any publication from the public portal for the purpose of private study or research.

- You may not further distribute the material or use it for any profit-making activity or commercial gain

If the publication is distributed under the terms of Article $25 \mathrm{fa}$ of the Dutch Copyright Act, indicated by the "Taverne" license above, 
0

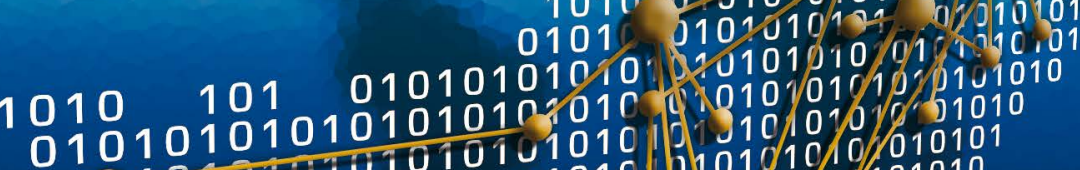

101010101010
101010101010

01010110101010

$10101 / 10101010$

$010 / 0.010101010$

1019. 10101010101

010101010101010101010

010100101

010101012101

1010 - 4010

$101040 \times 10$

$010101010 \times 1$

01010 a 10 (a)

101010 ar

1010

. 1 .

10

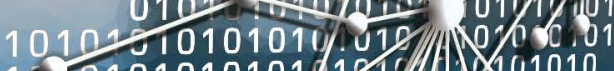

1001010101010181 (1) 01010

$101010101910 \% 5101$ doxis101

$1010^{2} 2190101010$.

1 P

$1010101010101010101810 \% 0 \%$

1010101010101010 )

$1010101010101010 h 011 \%$

$1010101010101010)$

$01010101010101010)=1010$

$101010101010101010) 0101010$

101010101010401010101010101010

1010101010101010101010101010101

$\begin{array}{lr}101010101010101 \\ 1 & 0 \\ 101\end{array}$

\section{Knowledge flows and networks in the ICT sector The case of Pakistan}

Abdul Baseer Qazi 
(C) copyright Abdul Baseer Qazi, Maastricht 2015

Printing: Datawyse | Universitaire Pers Maastricht

ISBN 9789461595089 


\title{
Knowledge flows and networks in the ICT sector: The case of Pakistan
}

\author{
DISSERTATION \\ to obtain the degree of Doctor at Maastricht University, \\ on the authority of the Rector Magnificus Prof. dr. L. L. G. Soete, \\ in accordance with the decision of the Board of Deans, \\ to be defended in public on Wednesday $16^{\text {th }}$ December 2015 , at 15:45 hours
} by

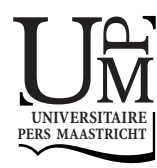




\section{Supervisor}

Prof. dr. Adam Szirmai

Prof. dr. Robin Cowan

\section{Assessment Committee}

Prof. dr. Bart Verspagen (Chair)

Dr. Effie Kesidou

Dr. Huub Meijers

Prof. dr. Jo Ritzen 


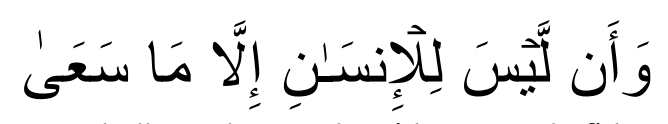

And that a man shall not deserve but (the reward of) his own effort

(TMQ Surah Najam: 39)

To my wife and children, without whom...

I would have finished much earlier (but wouldn't have found the motivation and strength to start with)!!! 



\section{Acknowledgements}

The list of all the people whom I want to thank is not only long and spread over 4 continents, but I must admit that over the years I've even forgotten the names of some. Therefore I would like to take this opportunity to show my gratitude to all those people who in so many different ways helped me during my PhD. There were those whole helped me with their brilliant ideas and those who comforted me with their kind words and those who showed their belief in my abilities and those who provided me with data and those who on many different occasions provided me with accommodation and those who just listened to me and those who read what I wrote. I'm even grateful to those who discouraged me because that always made me renew my resolve and determination.

I want to express special gratitude to those people without whom I would have never achieved what I did. First and foremost my parents whose upbringing taught me not to be complacent. They were very serious about education and shaped their lives and routines so that there was no compromise on studies. Without pushing too hard, they somehow managed to make me want flying higher. At times their prayer were my only hope.

I am also thankful to my elder brother, Sami, and younger sister, Huma, who have been comforting to me in times when I felt worried. They have both provided me great support by taking care of the parents whenever I wasn't there for them.

A word of gratitude for my supervisors. Eddy is truly larger than life. His dedication, patience, kindness, positivity, response time and eye for detail are unmatched. I'm sure had it not been for his constant motivation, I wouldn't have found my way back into the thesis after my return to Pakistan and a gap of over a year. Robin too has been very supportive from day one and I'm glad that he suggested an extension to my questionnaire which resulted not only in a major chapter but influenced the overall direction so much that 'networks' is now part of the title.

I would also like to acknowledge the kind support of the four Assessment committee members. Not only did they meticulously review the manuscript but gave valuable suggestions for improving its quality even further.

A word of gratitude for all the staff at UNU-MERIT. Eric, Marc, Wilma, Howard, Ad, Monique, Mourik, and Herman. Your help and support contributed in different ways to my work and wellbeing in Maastricht. The numerous colleagues at UNU-MERIT deserve a thanks as well. Of them, three were very close to me, Bilal, Ibrahim and Shafique and of course Mohsin and Abidi from UM. Their company was always a 
source of joy and relaxation. Discussions with them helped me refine my ideas and enabled me to articulate in a better way.

Another colleague, Abdul Waheed, deserves a special mention. His selfless guidance, especially in econometrics, has been a source of great help and support.

How can I forget the backbone of our institute, the always beaming Eveline. If I could only figure out where she gets the enthusiasm and energy from which she spreads all over the institute.

A big thanks to all those managers at ICT firms in Pakistan who generously gave up their time for me to interview them.

A few friends in Pakistan and Germany have been a great moral support. These include Baber, Fakharuddin, Waheed, Asad, Inamullah, Nematullah and Yunus Khan.

At my current job in Pakistan, all my colleagues have been very supportive but 2 particularly stand out. Nadeem for designing a complicated reward and penalty mechanism (on which one could write a scholarly article) which kept me motivated to daily spend long hours working on my thesis and Salman for all the chatter-breaks in which we poured our hearts out.

Last but not least, my wife, Mamoona. Publications usually have second authors and these can be anyone who has contributed. If the same would be possible in a PhD thesis, my wife's name would have definitely appeared on it. She stood by my side through thick and thin (and trust me there was more of thick than thin). She comforted me whenever I was worried and encouraged me whenever I lost hope. She made up for any of the responsibilities which I, as a son, husband or father would neglect while analyzing loads of quantitative data. At times she singlehandedly took care of Aafreen, Burhan and Salahuddeen so that I could focus on completing this dissertation. 


\section{Table of Contents}

$\begin{array}{ll}\text { Chapter 1. Introduction } & 19\end{array}$

Chapter 2. Literature Review: Spillovers 25

2.1 Introduction ................................................................................................25

2.2 Types/Conceptualization of Spillovers .....................................................27

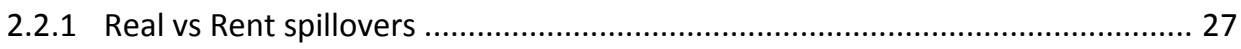

2.2.2 Pure versus market spillovers ....................................................................... 28

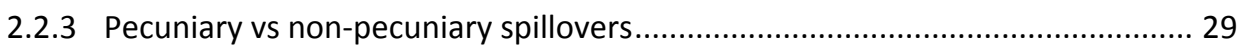

2.2.4 The role of proximity: MAR vs Jacobs Spillovers.............................................. 29

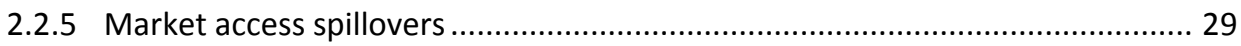

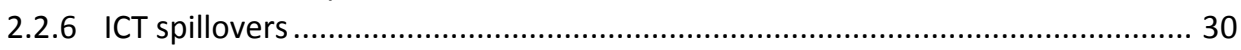

2.3 Intra-sectoral, inter-sectoral and international spillovers ...........................31

2.3.1 Inter-sectoral vs intra-sectoral spillovers ....................................................... 32

2.3.2 Intra-national vs Inter-national (cross border) spillovers ............................... 32

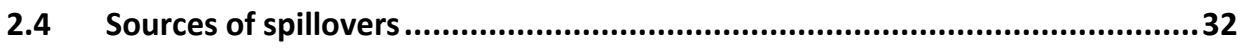

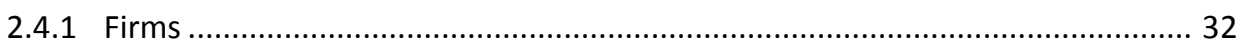

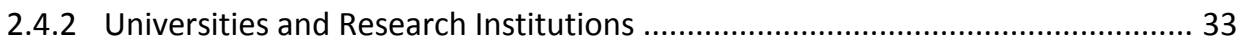

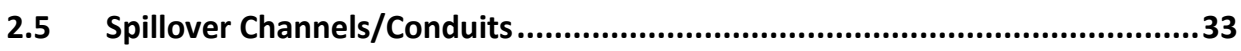

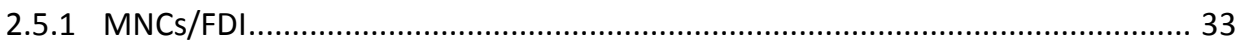

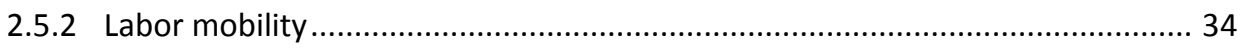

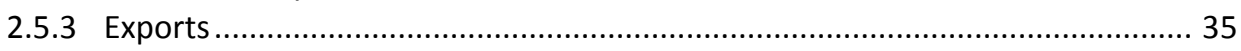

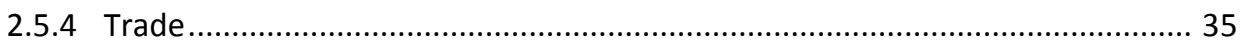

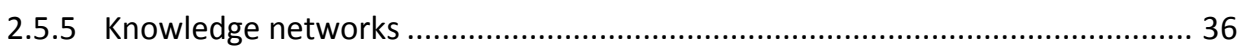

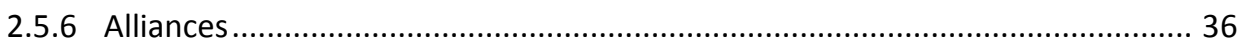

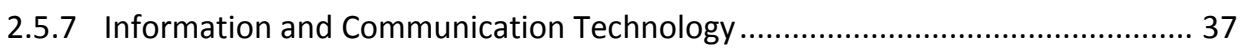

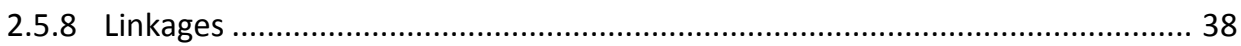

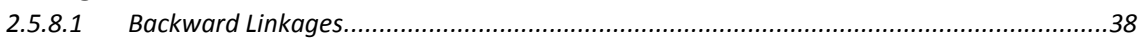

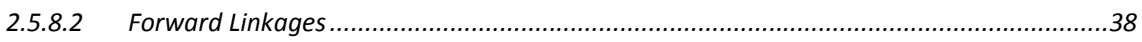

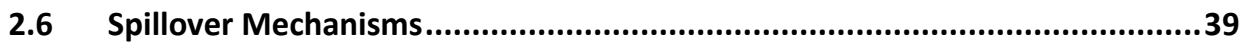

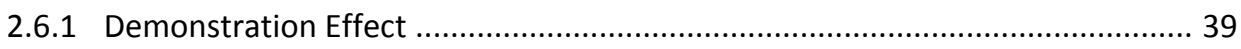

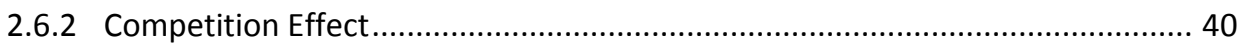

2.7 Spillover Facilitators ........................................................................ 41

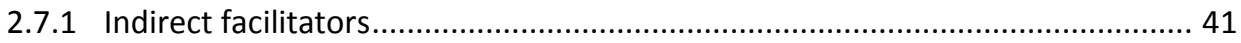

2.7.1.1 Size

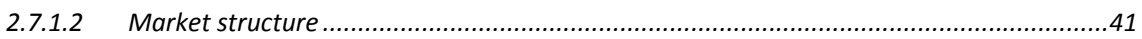

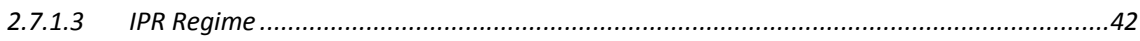

2.7.2 Direct facilitators ............................................................................ 43

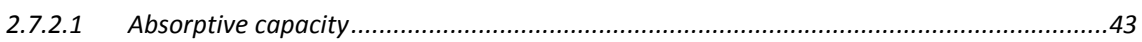

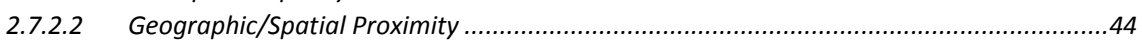

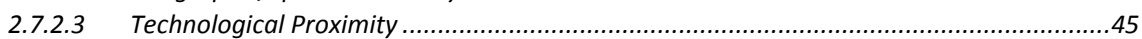


2.8 Measurement Methods .........................................................................45

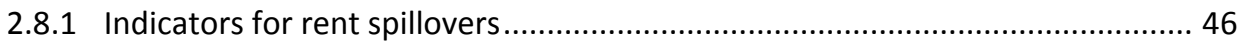

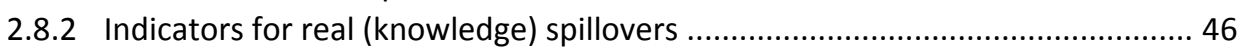

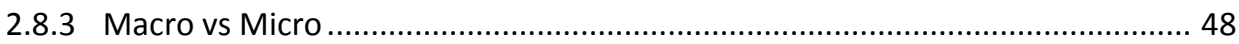

2.8.4 Direct vs Indirect approaches ................................................................. 48

2.8.5 Some stylized facts to take into account while measuring spillovers................ 51

2.9 The next step ...........................................................................................52

Chapter 3. Pakistan's Economic and Political Backdrop 53

Introduction ...................................................................................................5

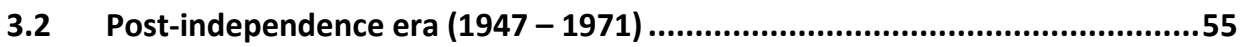

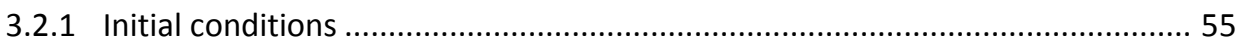

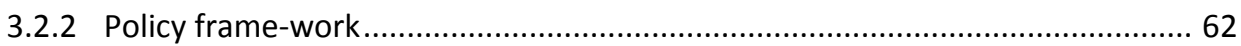

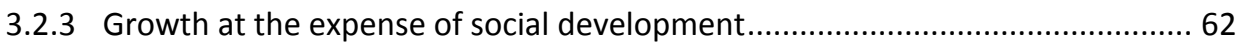

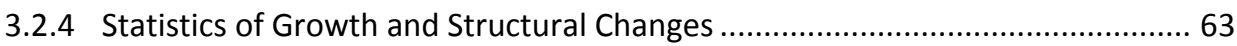

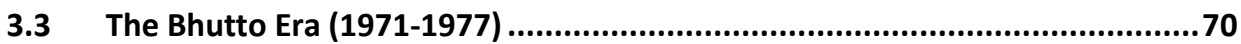

Zia-ul-Haq Era (1977-1988) ..............................................................73

3.5 Political Musical Chairs Era (1988-1999) ...................................................77

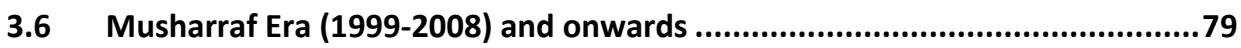

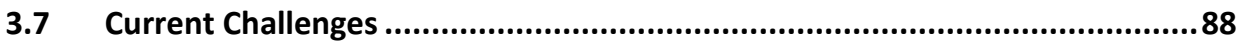

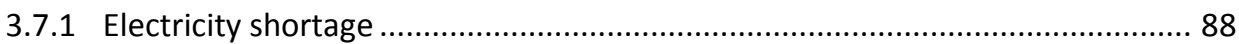

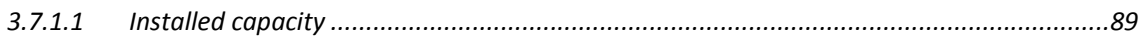

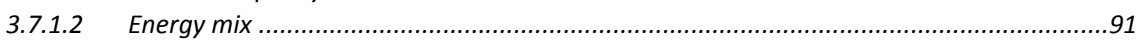

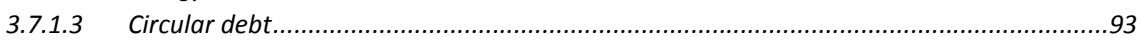



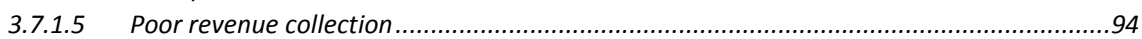

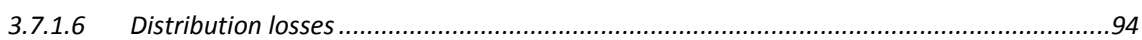

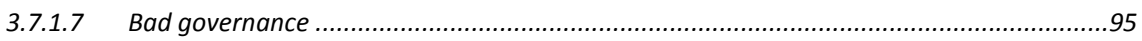

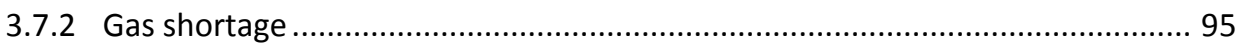

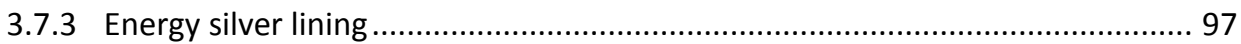

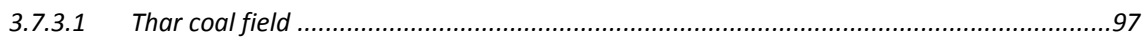

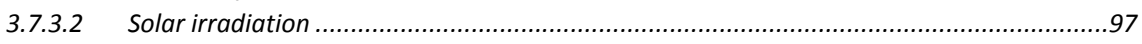

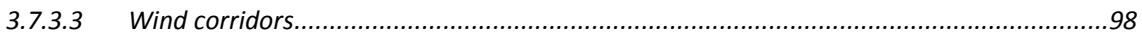

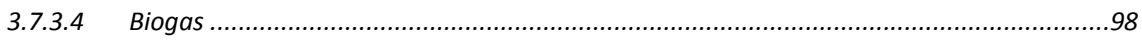

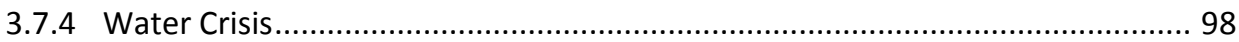

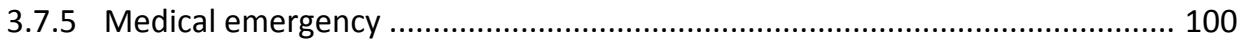



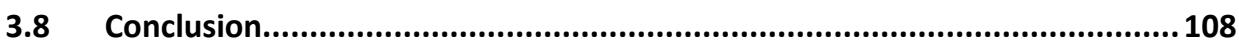

Chapter 4. Productivity growth and structural change 109

4.1 Introduction .................................................................................................... 109

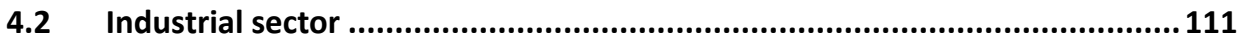

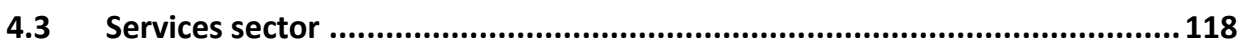

4.4 Growth and productivity studies of Pakistan........................................120 
4.5 Structural Change and Productivity Growth .......................................123

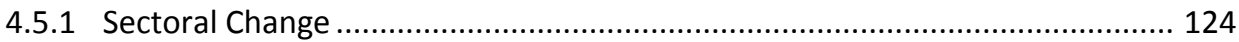

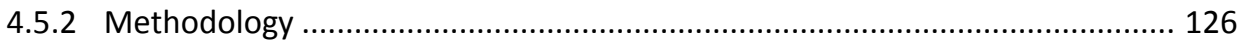

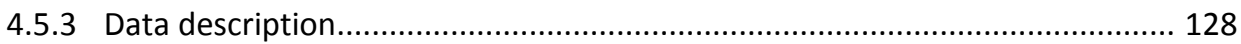

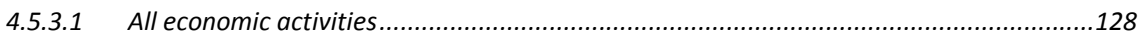

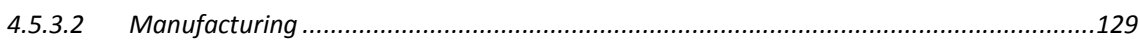

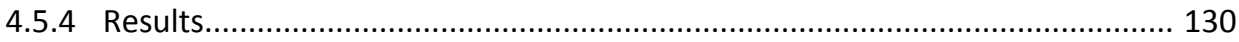

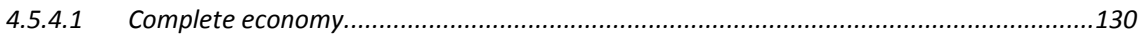

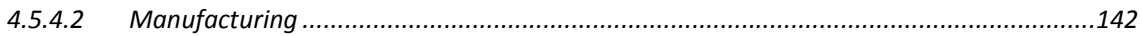

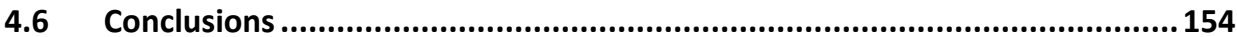

Chapter 5. Pakistan's ICT Landscape 157

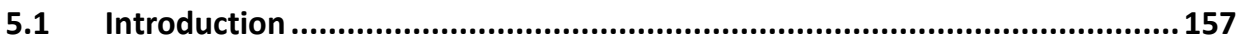

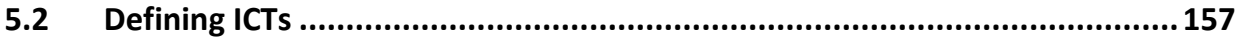

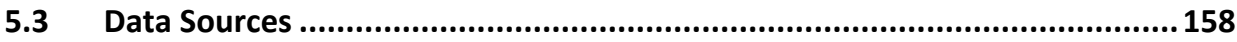

5.4 Emergence of Pakistan's ICT sector .................................................. 159

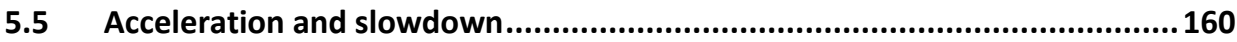

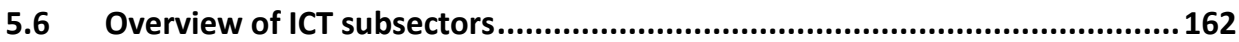

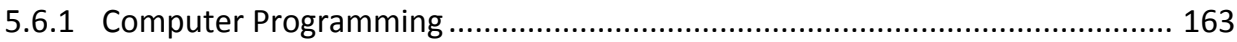

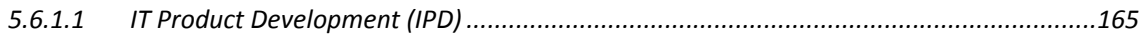

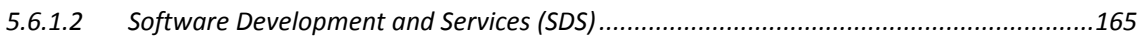

5.6.1.3 Mobile Applications, Gaming and Animation (MGA) ……......................................166

5.6.1.4 IT Enabled Services - Business Process Outsourcing (ITES-BPO)....................................166

5.6.1.5 System Integration, Consulting, and Embedded Systems (SICES) .................................166

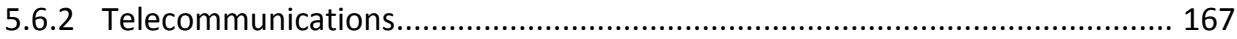

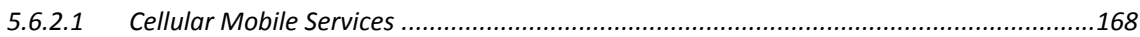

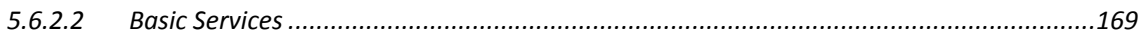

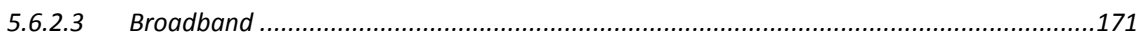







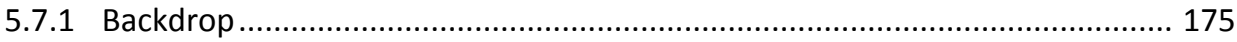

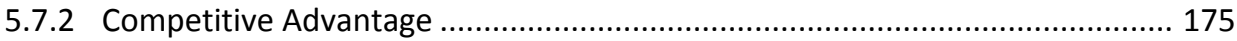



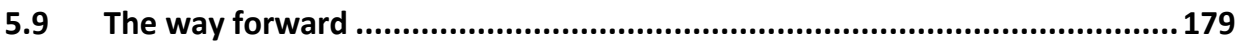

Chapter 6. Ascertaining and measuring spillovers 181

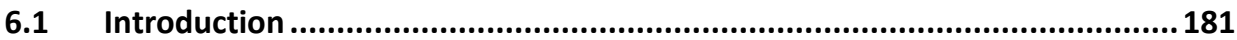

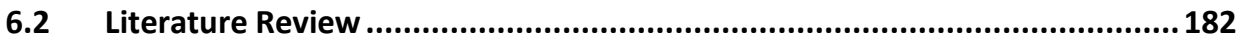

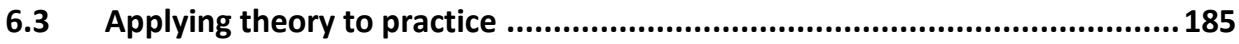

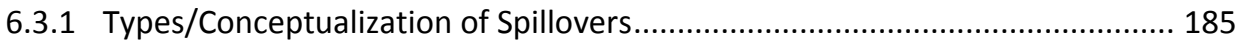

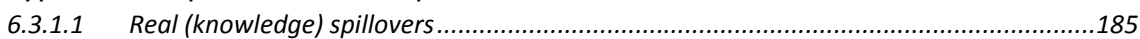

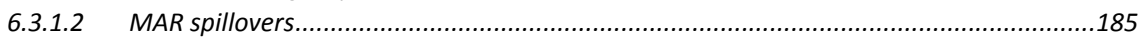



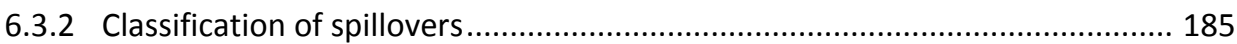


6.3.2.1 Inter-sectoral vs intra-sectoral spillovers...............................................................185

6.3.2.2 Intra-national vs Inter-national (cross border) spillovers .............................................186

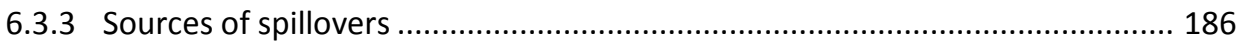

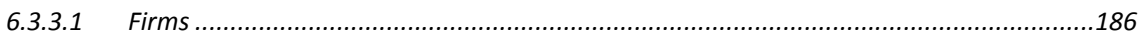

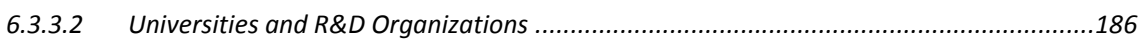

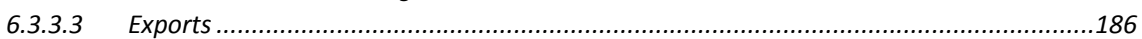

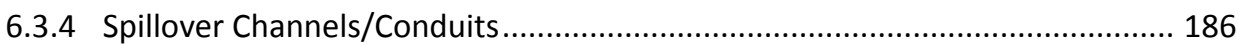

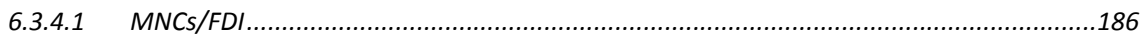

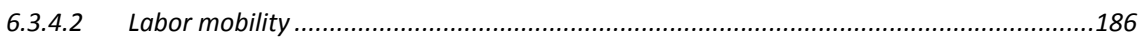

6.3.4.3 Information Technology .......................................................................................186

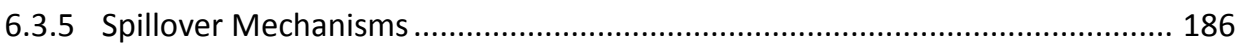

6.3.5.1 Demonstration Effect .............................................................................................186

6.3.5.2 Competition Effect .................................................................................................... 187

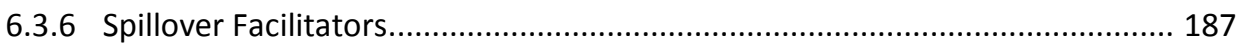

6.3.6.1 Size ..................................................................................................................... 187

6.3.6.2 Absorptive Capacity ........................................................................................... 187

6.3.6.3 Geographical/Spatial Proximity ..................................................................................187

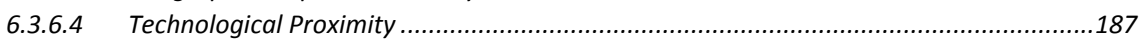



6.4 Research Questions and Hypotheses ..................................................... 188

6.4.1 Firm Characteristics as determinants of firm performance.............................. 188

6.4.2 Innovative Performance and productive performance ................................ 188

6.4.3 Absorptive Capacity and firm performance.................................................... 189

6.4.4 Labor Mobility Spillovers .......................................................................... 190

6.4.5 Spillovers (through Demonstration Effect) ............................................... 190

6.5 Sampling Technique and Target Population ......................................... 190

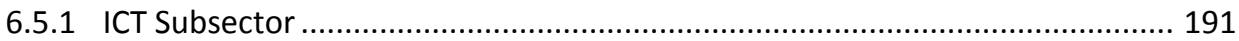

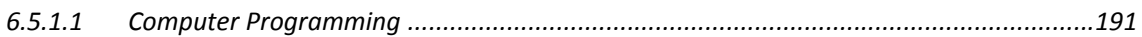

6.5.1.2 Telecommunications ..............................................................................................192

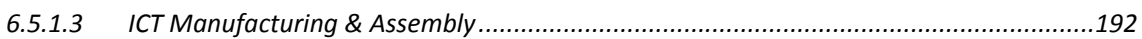

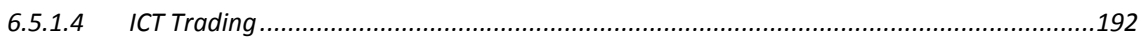



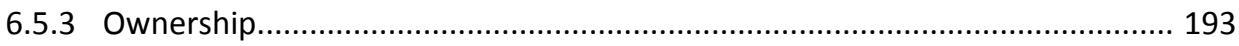

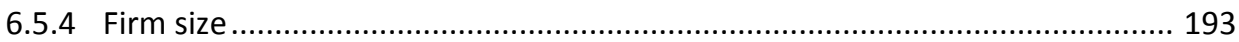

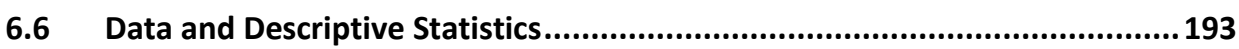

6.7 Model specification ......................................................................... 199

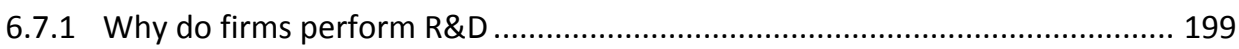

6.7.2 What are the determinants of innovation? ...................................................... 200

6.7.3 What are the determinants of firm productivity? ......................................... 201

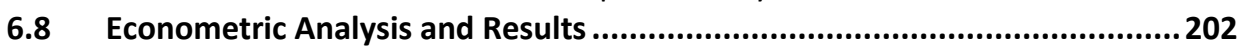

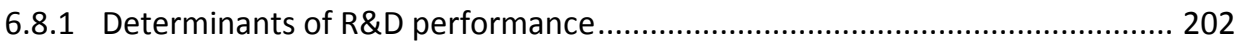

6.8.2 Determinants of Innovation Output ............................................................... 203

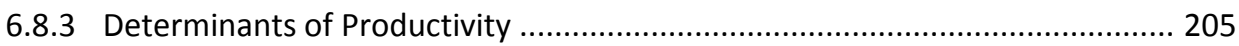

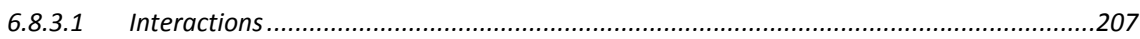

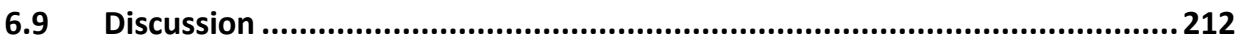

6.9.1 Basic Firm Characteristics ...................................................................... 213 
6.9.2 Innovative Performance

6.9.3 Absorptive Capacity and Human Capital ..................................................... 215

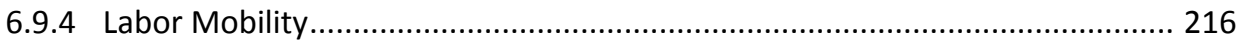

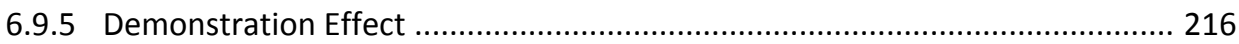

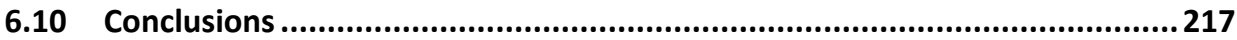

Chapter 7. Social capital, networks and firm performance 219

7.1 Introduction ................................................................................................219

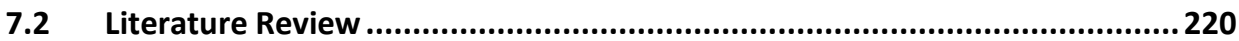

7.2.1 Advantages from position in a network: (General embeddedness) ................. 221

7.2.2 Advantages from structure/configuration of a network: (Structural embeddedness)

7.2.3 Advantages from relation quality with other actors of the network: (Relational embeddedness)

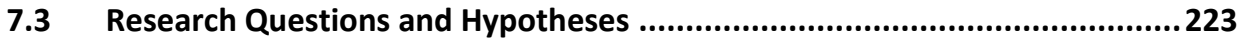

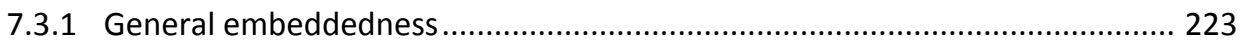

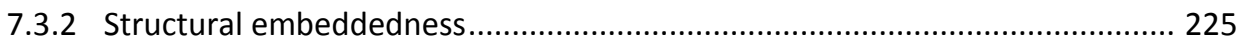

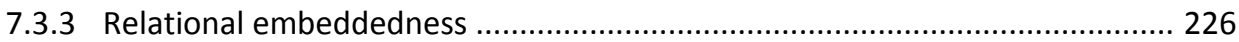

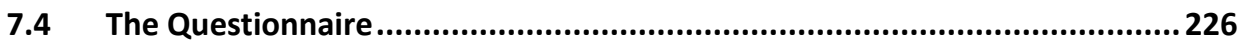

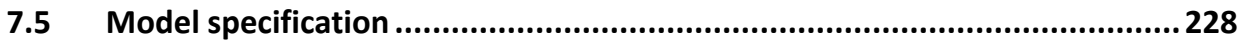

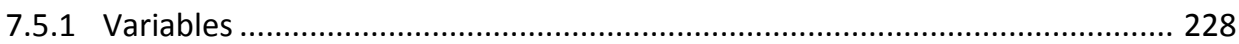

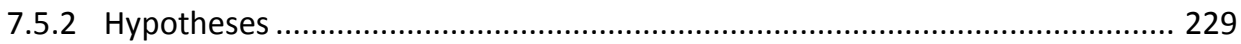

7.5.2.1 Hypothesis 1a: More central firms are more innovative .............................................229

7.5.2.2 Hypothesis 1b: More central firms are more productive ............................................230

7.5.2.3 Hypothesis $2 a / 2 b$ : Less constrained firms are more innovative/productive ....................230

7.5.2.4 Hypothesis $3 a / 3 b$ : More frequent interaction is positively related to positive innovative/economic performance .....................................................................230

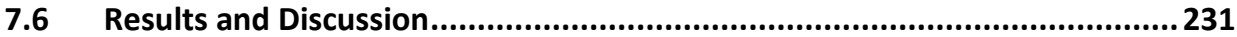

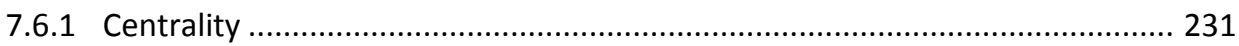

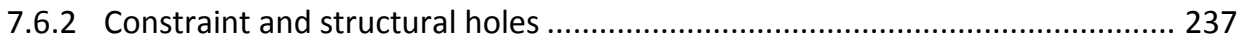

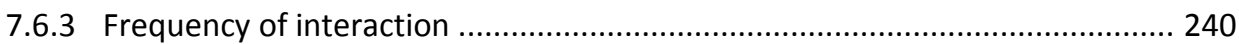

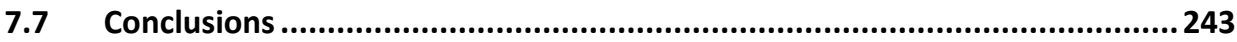

Chapter 8. Concluding Remarks 245

Chapter 9. Valorization 249

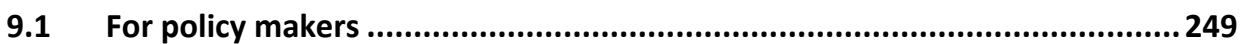



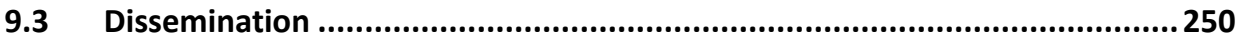

Bibliography 253 
$\begin{array}{ll}\text { Appendices } & 271\end{array}$

Appendix I: Pakistan's Horizontal Irradiation ...................................................2271

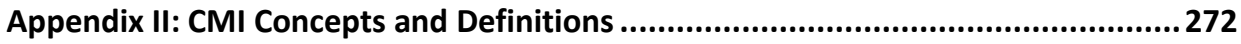

Appendix III: ISIC Broad Structure...............................................................2 276

Appendix IV: ISIC of All Economic Activities, Rev.3 ........................................ 277

Appendix V: Data sources chapter 5 ......................................................... 280

Appendix VI: Questionnaire for Survey of ICT Firms in Pakistan ............................283

Appendix VII: Concordance table for various data sources ....................................302

Appendix VIII: Correlation tables corresponding to the regression tables................303

Summary $\quad 309$

About the author 313 


\section{List of Tables}

Table 3.1 Major Conflicts between India and Pakistan, 1947 - Present ........................................57

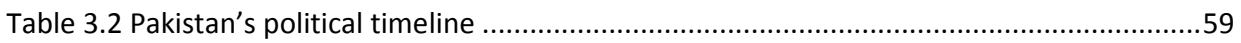

Table 3.3 GDP, GDP per Capita and Sectoral Average Growth Rates under Different Leadership

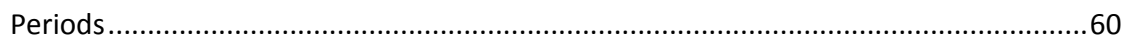

Table 3.4 GNP/GDP Annual Growth Rates under Different Plan Periods ....................................60

Table 3.5 Sectoral Value Added (Rs Million) and Sector shares in GNP (at 1959- 60 factor cost),

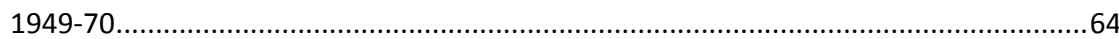

Table 3.6 Annual compound growth rates of population, GNP and GNP per capita at 1959-60



Table 3.7 Shares of selected commodities in total exports (percentages) ......................................68

Table 3.8 Share of some commodity groups in total imports (percentages) .................................69

Table 3.9 Saving, investment, import and export as percentages of GNP at current prices .........70

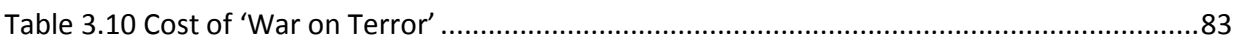

Table 3.11 GDP, GDP per Capita and Sectoral Value Added Annual Growth Rates (at constant

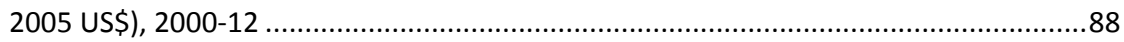

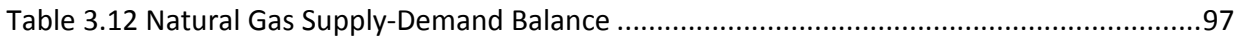

Table 3.13 Measles cases and deaths caused in Pakistan .............................................................103

Table 4.1 Era-wise averaged sectoral value added shares in GDP (\%) ........................................113

Table 4.2 Era-wise averaged sectoral employment shares in GDP (\%) .......................................113

Table 4.3 Sectoral Growth rates (Valued Added), 1961-2012 (\%) ..............................................114

Table 4.4 Sectoral employment shares growth rates, 1978-2012 (\%) ..........................................114

Table 4.5 Sector-wise average labor shares (\%) , 1973-2007 ........................................................132

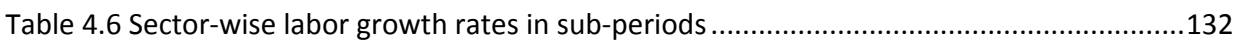

Table 4.7 Sector-wise average value added shares (\%), 1973-2007 .........................................132

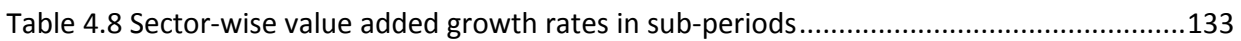

Table 4.9 Sector-wise labor productivity growth rates in sub-periods.....................................133

Table 4.10 Sector-wise productivity levels per period in terms of aggregate productivity (\%),



Table 4.11 1973-78 Productivity Decomposition using Standard Shift-share model ..................136

Table 4.12 1978-88 Productivity Decomposition using Standard Shift-share model ....................136

Table 4.13 1988-99 Productivity Decomposition using Standard Shift-share model ..................137

Table 4.14 1999-07 Productivity Decomposition using Standard Shift-share model ...................137

Table 4.15 1973-07 Productivity Decomposition using Standard Shift-share model ..................138

Table 4.16 1973-78 Productivity Decomposition using Ark and Timmer model ..........................139

Table 4.17 1978-88 Productivity Decomposition using Ark and Timmer model ...........................140

Table 4.18 1988-99 Productivity Decomposition using Ark and Timmer model ...........................140

Table 4.19 1999-07 Productivity Decomposition using Ark and Timmer model .........................141

Table 4.20 1973-07 Productivity Decomposition using Ark and Timmer model .........................141

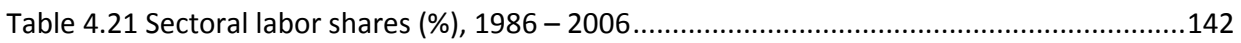

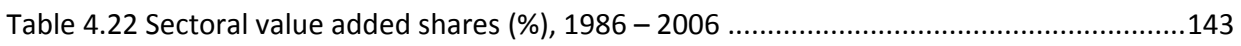

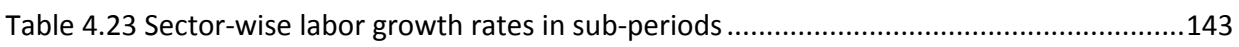

Table 4.24 Sectoral value added growth rates in sub-periods ................................................144 
Table 4.25 Sector-wise labor productivity growth rates in sub-periods. .145

Table 4.26 1986-91 Productivity Decomposition using Standard Shift-share model ...................146

Table 4.27 1991-96 Productivity Decomposition using Standard Shift-share model ...................147

Table 4.28 1996-01 Productivity Decomposition using Standard Shift-share model ...................148

Table 4.29 2001-06 Productivity Decomposition using Standard Shift-share model ..................148

Table 4.30 1986-06 Productivity Decomposition using Standard Shift-share model ..................149

Table 4.31 1986-91 Productivity Decomposition using Ark and Timmer model ...........................151

Table 4.32 1991-96 Productivity Decomposition using Ark and Timmer model ...........................151

Table 4.33 1996-01 Productivity Decomposition using Ark and Timmer model ...........................152

Table 4.34 2001-06 Productivity Decomposition using Ark and Timmer model .........................153

Table 4.35 1986-06 Productivity Decomposition using Ark and Timmer model ..........................153



Table 6.1 Variable description and descriptive statistics.........................................................194

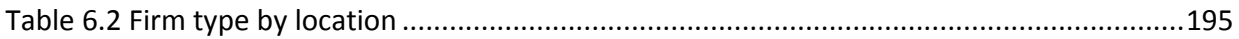

Table 6.3 Firm type distribution by principal subsector ...........................................................196

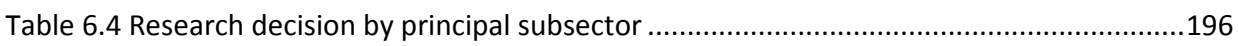

Table 6.5 Product Innovation dummy by principal subsector ...................................................196

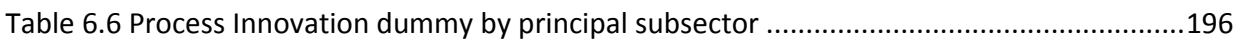

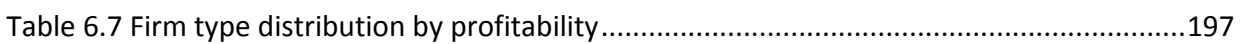

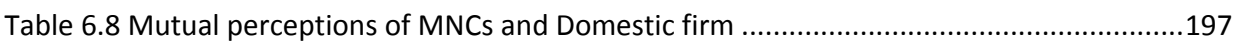

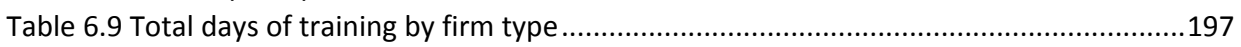

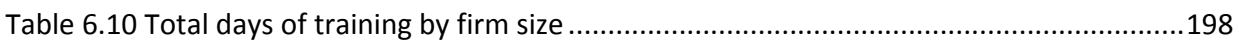



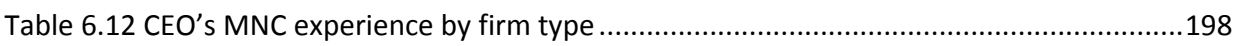

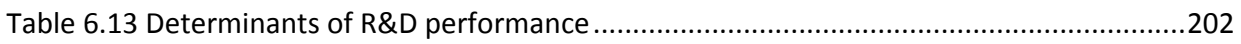

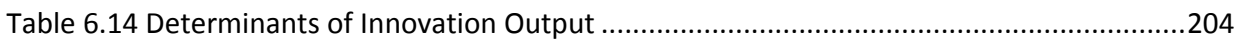

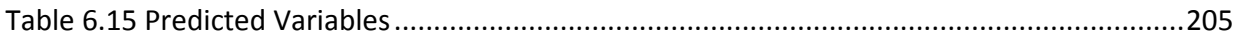

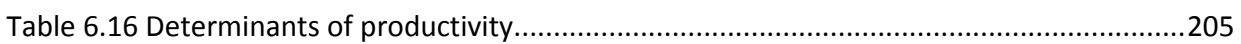

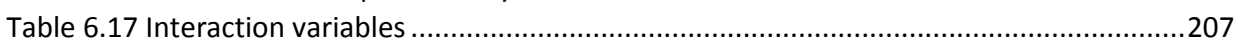

Table 6.18 Determinants of productivity with interactions: Firm Type......................................208

Table 6.19 Determinants of productivity with interactions with Sub-sector dummies...............210

Table 6.20 Determinants of productivity with interactions: Sub-sector dummies........................211

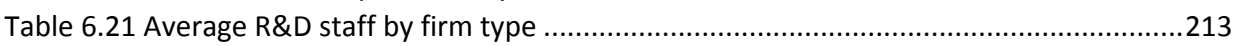

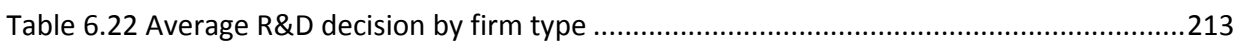

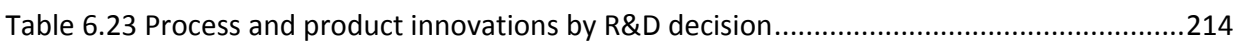

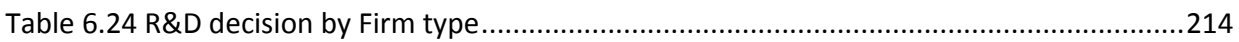

Table 6.25 Process and product innovations by Firm type.......................................................214

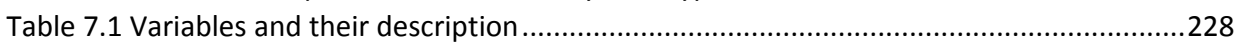

Table 7.2 Centrality (Out-degree) and Innovative Performance .............................................231

Table 7.3 Centrality (Out-closeness) and Innovative performance .............................................232

Table 7.4 Centrality (Out-degree and Out-closeness) and Economic Performance ......................233

Table 7.5 Durbin-Wu-Hausman test for endogeneity of centrality metrics with innovative

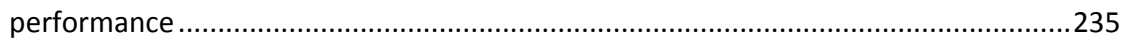

Table 7.6 Durbin-Wu-Hausman test for endogeneity of centrality metrics with economic

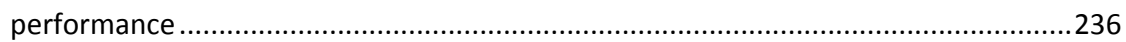

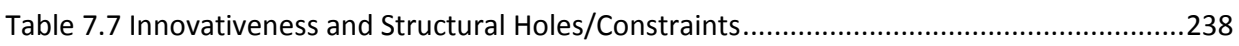


Table 7.8 Productivity and Structural Holes/Constraints 239

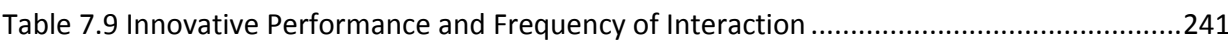

Table 7.10 Productivity and Frequency of Interaction

\section{List of Figures}

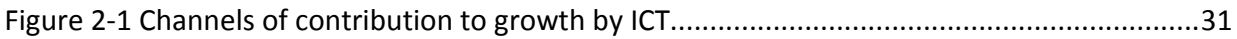

Figure 3-1 Gross national product (at 1959- 60 factor cost in Rs. million) ...................................64

Figure 3-2 Sector shares in GNP (at 1959-60 factor cost) (\% shares in GNP) ..............................65

Figure 3-3 Gross national product, population and per capita income (at 1959-60 factor cost) ..65



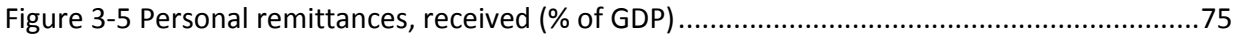

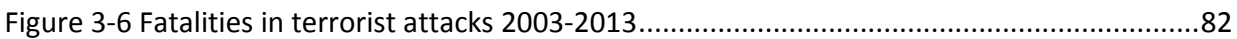

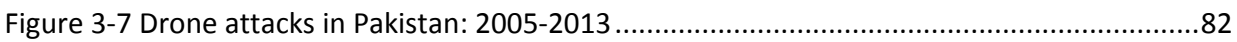



Figure 3-9 Unemployment with tertiary education (\% of total unemployment) ...........................84

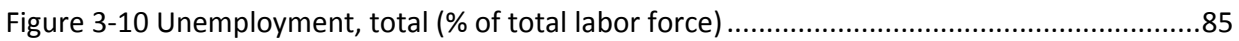

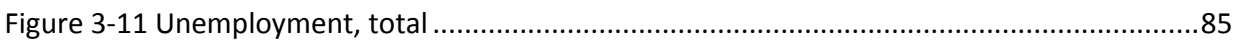

Figure 3-12 Long-term unemployment (\% of total unemployment) ..........................................86

Figure 3-13 US Military and Civilian Aid to Pakistan (in constant 2011 US\$ Million) ......................86

Figure 3-14 Total Electricity Installed Capacity (Million Kilowatts) …........................................90



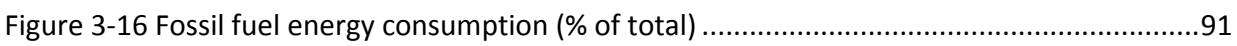

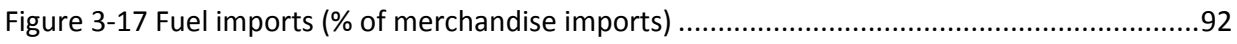

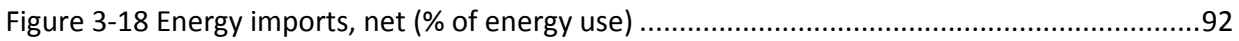

Figure 3-19 Electricity production from hydroelectric sources (\% of total)..................................93

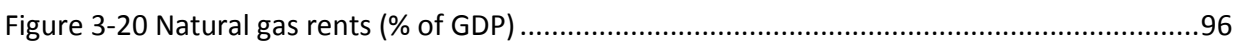

Figure 3-21 Electricity production from natural gas sources (\% of total) ......................................96

Figure 3-22 Total renewable water resources per capita (actual) (m3/inhab/yr) ........................99

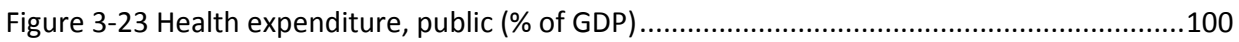

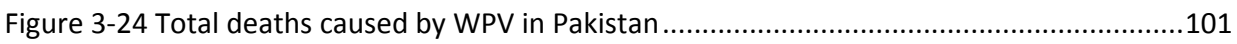

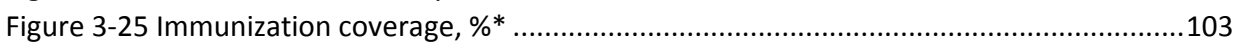

Figure 3-26 Infant mortality rate, infant (per 1,000 live births) ...............................................104

Figure 3-27 Maternal mortality ratio (modeled estimate, per 100,000 live births) .....................104

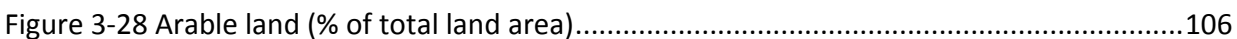

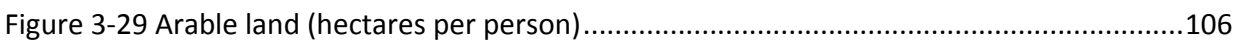

Figure 3-30 Depth of the food deficit (kilocalories per person per day) ....................................107

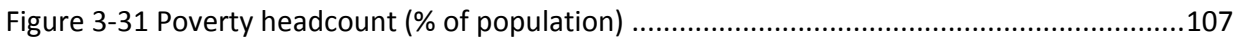

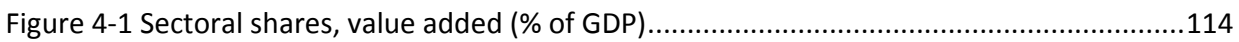

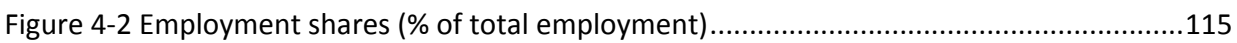

Figure 4-3 Manufacturing, value added (constant 2005 million US\$) .........................................116

Figure 4-4 Value added by the manufacturing sector as percent of GDP...................................116

Figure 4-5 Value added by the manufacturing sector as percent of GDP................................117

Figure 4-6 Manufacturing value added million USD per capita ................................................117 
Figure 4-7 Services, value added (constant 2005 million US\$) ................................................119

Figure 4-8 ICT service exports, ICT commodity exports and imports .......................................120

Figure 4-9 Period-wise productivity decomposition using Standard Shift-share model..............135

Figure 4-10 Period-wise productivity decomposition using by Ark and Timmer model..............139

Figure 4-11 Period-wise productivity decomposition using the Standard model........................146

Figure 4-12 Period-wise productivity decomposition using Ark and Timmer model...................150

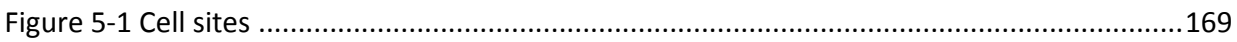

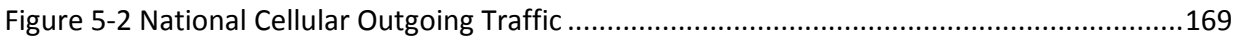

Figure 5-3 Aggregate ICT Developments in Pakistan, 2000 - 2012 ..........................................171

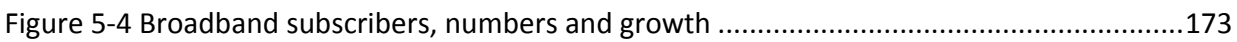

Figure 5-5 Pakistan and India comparison: Fixed telephone subscriptions ................................177

Figure 5-6 Pakistan and India comparison: Fixed broadband subscriptions...............................177

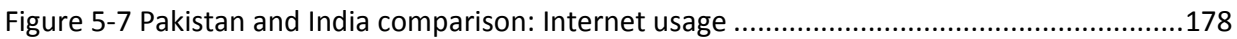

Figure 5-8 Pakistan and India comparison: Mobile-cellular phone subscriptions .......................178 


\section{Chapter 1. Introduction}

Modern economic theory has long established that innovation and technological change boost economic growth, since they create conditions of increasing returns in production (Romer, 1986, 1990); (Griliches, 1992). The importance of technology is also highlighted by researchers claiming that up to half of the economic growth is attributed to technological change (Denison, 1985; Fan, 1991; Fare and Grosskopf, 1994; Greenwood, Hercowitz, and Krusell, 1997). While creating technology provides the long-term solution, in the short term the more viable option for developing countries remains acquiring it. The different means to acquire technology mainly comprise of deliberate acquisition of technology by procurement, licensing, reverse engineering and turnkey projects and the not so deliberate or unintended accumulation of technology and its associated knowledge pool through FDI (foreign direct investment). Certainly MNCs (multinational corporations) do not only bring-in superior technology to the host country (Blomström and Sjöholm, 1999) but they also create learning opportunities for domestic firms resulting in increased TFP (total factor productivity) (Bayoumi, Coe and Helpman, 1999). This way, FDI is eventually expected to add some value to the host economy, either directly through job creation and tax revenues, or indirectly by productivity and knowledge spillovers to local firms (Jacob and Szirmai, 2007; Suyanto, Salim, and Bloch, 2009).

Governments the world over compete in offering hefty subsidies to attract FDI (Haaland and Wooton, 1999), in anticipation of technology spillovers to augment the direct benefits of an FDI boost to national income, however the empirical evidence for them is far from conclusive (Farla, Crombrugghe and Verspagen, 2013; Görg and Greenaway, 2004; Huber, 2011). Similarly, the mechanisms through which spillovers occur and are realized are still an open subject for research (Audretsch and Feldman, 2004; Desrochers and Leppala, 2010). One thing which is clear from recent empirical studies on FDI spillovers is that we still have insufficient evidence to draw firm conclusions. One of the few factors about which there is empirical consensus concerns the importance of absorptive capacity of domestic firms (Fu, Pietrobelli and Soete, 2011). The key challenge now is to expand our understanding of spillovers and their determinants. Against this backdrop, we focus our attention on investigating the existence of positive productivity spillovers from FDI in a developing country context. We set out with the research aim to assess the benefits from FDI inflows in a high-tech sector. The motivation behind this is manifold. We want to examine whether FDI inflows help the host economy in terms of learning and increased productivity and at the same time we also wanted to find out if such effects are pronounced in the ICT sector. The ICT sector provides developing countries like Pakistan a level playing field for expanding their 
activities and becoming competitive, unlike sectors which are more capital and infrastructure intensive. Furthermore we are interested in finding out the determinants of such knowledge flows in order to be able to better harness them.

However, in order to put the economy in general and the ICT sector in specific into the broader context of development and growth, it is necessary that we first understand the historical background of the economy as a whole. Therefore, we take a step back and first study the initial conditions right from the creation of Pakistan, in order to understand the historical context and how it shaped Pakistan's growth trajectory. We continue by looking at the various regimes which ruled the country and analyze how their policies affected growth and development. Here our research questions are about the role of initial conditions, the external environment and policy choices in subsequent periods.

The importance of industrialization as an engine of growth for the economic development of a country cannot be overstated. However, it is well established in literature that the resulting productivity enhancements alone are not enough for sustained economic growth and catching up. Structural changes in the shares of various sectors are essential for attaining high per capita growth rates (Kuznets, 1979). The structural change hypothesis is a central tenet of the growth-accounting literature (Maddison, 1987). It states that when surplus labor (and capital) is shifted from non-productive sectors (e.g. agriculture) to productive and capital intensive sectors (e.g. manufacturing), it will be beneficial towards productivity increases at the aggregate level. A massive literature exists which analyses the productivity differences and employment changes in agriculture, manufacturing and services (McMillan and Rodrik, 2011; Rowthorn and Ramaswamy, 1997). Not only have the structural changes from traditional to industrial economies, driven by the manufacturing sector, been remarkable in helping developing countries converge and catch-up, but even the industrial revolution in the mid-eighteenth century was all about this very phenomenon.

Recent developments in the structural change patterns reveal yet another trend; that of developed countries transforming from manufacturing centric to services centric economies. Now an even more recent development - the growth of information and communications technology (ICT) - has enabled developing countries to compete with the more established economies because ICT (being a modern technological development) lends a relative level-playing field to countries irrespective of their prior level of development. In this context it would be interesting to observe whether or not Pakistan is going through such a phase where high-productivity activities in manufacturing are assuming a more central role. Or even more pertinent, whether developing countries like Pakistan, which before the advent of ICT focused on shifting from an agrarian economy to a manufacturing one, are now following their developed counterparts in the trend to become service economies. This forms our second line of investigation, as in light of the above, we start our analysis of the Pakistani economy by 
focusing on industrial sectors. ${ }^{1}$ We attempt to fill this gap in literature by studying the changes in the sectoral composition of value added and employment, and the way these interact with the pattern of productivity growth. We analyze the impact of structural change on aggregate industrial performance. Due to data limitations we only analyze changes in the sector structure of production. ${ }^{2}$ We employ the conventional shift-share analysis introduced by Fabricant (1942) to analyze the effects of shifting labor shares on productivity. Such an analysis can be helpful in a plethora of ways, for instance by helping industries identify productive regions or sectors for investing which have a competitive advantage as compared to the rest of the economy. A shift-share analysis takes the differential of an economic variable over time, and breaks down that change into various components. The most common variable used is employment within industrial sectors of a regional economy. The regional changes are divided into three components while using a traditional shift-share model, however, evolved models split the decomposition into additional components. For these reasons the shiftshare technique is still a frequently utilized to decompose aggregate productivity growth. Here the most important research questions are about the role of different sectors in economic development, and their relative importance of within sector productivity trends and intersectoral shifts for aggregate productivity change.

Though the shift-share analysis can explain structural change reasonably well it does not capture the effects of inter-sectoral knowledge spillovers. One such case is that of the importance of the ICT (information and communication technologies) sector for developing countries, which may actually be larger than what is calculated by shift-share methods (Fagerberg, 2000; Peneder, 2003). This downward bias is caused by the potential for significant externalities in ICT. In a nutshell, the shift-share method is helpful in understanding the relationship between structural change and growth, but the estimates should be seen as leaning towards the lower end. The next logical step as researchers would be to understand what causes such externalities (technology spillovers) to occur and look for a sector where the likelihood for technology spillovers would be high. This forms the basis of our third area of investigation.

We attempt to identify and explain those characteristics whose presence (or absence) induces spillovers to local firms. These characteristics could be those of the MNCs, local firms or government policies. However the scarcity of official data, especially for developing countries, makes it difficult to present an econometrically plausible assessment based on standard economic indicators. For this reason and to capture the spillover effects, we further our study by analyzing the ICT sector directly. To contribute in filling the gaps in literature about the inconclusiveness of spillovers and ambiguity about their mechanisms, we design our own survey questionnaire to capture

\footnotetext{
${ }^{1}$ We have used data of 7 industrial sectors comprising of agriculture, mining, manufacturing, construction, wholesale and retail, financing, transport and community \& others. The detailed ISIC 3 definitions of these sectors can be seen in Appendix II and III.

${ }^{2}$ The ownership structure and the regional structure cannot be analyzed due to this unavailability of data.
} 
information which is usually unavailable, especially for developing countries. Our survey attempts to gather reliable micro (firm) level data, from the ICT sector about, Basic firm characteristics, Economic performance, Innovative performance, Absorptive capacity and Spillovers. The target populations of the survey are MNC and domestic ICT firms in 4 major cities of Pakistan. Four types of firms are included in the survey sample, those which had their principal sub-sector activity in Software development and consulting, Hardware manufacturing and assembly, Telecommunications and ICT trading. The survey is discussed in the annex to this chapter. Here the research questions are about identifying the various determinants of firm level innovation and firm level performance in the ICT sector and the relative importance of FDI spillovers as compared to other factors.

Having conducted a shift-share analysis of the industrial and manufacturing sectors while accounting for growth and having analyzed a high-tech sector for technology spillovers' role in enhancing innovative and economic performance, we shift our focus to the final dimension of our investigation, that of social capital. Advances in knowledge about the process of economic growth and development calls for a periodic redefinition of the concept of capital. What was limited to physical inputs in the 1950s, added the concept of human capital later in the 1960s and knowledge capital in the 1990 s in order to better explain growth. In recent years, 'social capital' has been employed in a similar fashion. Although there are many differing definitions of social capital, one common notion among them all is the understanding of it as the control of resources that are essentially linked to having a relationship network which can be drawn upon for accessing technology, technical information and/or market information. More recently the concept of social capital has gained phenomenal importance in economics research literature. The causal link between social capital and economic growth is well established in literature (see Durlauf and Fafchamps (2003) for an overview). Scholars have attempted to explain both economic performance (Akçomak and Weel, 2009; Knack and Keefer, 1997) and innovative performance (Dakhli and Clercq, 2004; Kesidou and Szirmai, 2008), in terms of social capital. Two different approaches have evolved for measuring or assessing social capital from the network related data of countries or other economic actors like firms or individuals. One is called the socio-centric or macro perspective, which focuses on the pattern of connections in the network as a whole (be it among countries, firms or individuals), as being the distinctive contribution of social capital (Barnes, 1974). The other, termed as egocentric or the micro perspective is when one seeks to anchor social networks around particular points of reference which could be countries, firms or individuals (Mitchell, 1969). Strong parallels can be seen between the micro concept of social capital and the economic phenomenon of human and physical capital. Both require investment of scarcely available resources, primarily time, and the resulting opportunity cost.

Within the micro perspective it is well understood that the creation and maintenance of networks is a costly affair, i.e. big is not always better when it comes to networks. A 
whole new strand of literature is concerned with such 'constraints' resulting from bigger and denser ego-networks. Our study follows the ego-centric approach and we too explore the notion of constraint in relation to innovative and economic performance of firms. The economic actors we analyze from a network perspective are the same 94 firms which we interviewed during our survey of the ICT industry in Pakistan. The research questions we investigate here pertain to the finding the impact of network structure on innovative and economic performance.

To sum up our research questions, we are primarily interested in assessing the role of FDI and its associated spillovers within a high-tech sector where the likelihood of knowledge flows and learning is the highest. Given the special nature of ICT - both in terms of attracting FDI and its potential for spillovers - we focus on the ICT sector in Pakistan. However, in order to put the ICT sector into the broader context of development, it is necessary to understand the historical background of the economy as a whole. Therefore, we take a step back and first study the role of the initial conditions, which have significantly shaped Pakistan's growth and development trajectory. Here the research questions are: What role do the initial conditions, external environment and policy choices in subsequent periods have on the socio-economic development of Pakistan? We then aim to do a shift-share analysis in an attempt to answer the research question: What is the role of different sectors in economic development? What is their relative importance of within sector productivity trends and intersectoral shifts for aggregate productivity change? We look at the broader structural change and thereby attempt to quantify the contribution of the ICT sector, but the weakness of the underlying data on the ICT component of services prevents us from singling out the contribution of this sector to structural change. In our pursuit of spillovers from ICT and to understand the causes of such externalities we then empirically estimate the existence, channels and mechanisms of spillovers based on primary data. Here we ask: What are the various determinants of firm level innovation and firm level performance in the ICT sector? What is the relative importance of FDI spillovers as compared to other factors? Lastly, we look at the spillover debate from a social capital perspective. The broad research question here is: What is the impact of network structure on innovative and economic performance?

The remainder of this thesis is structured as follows:

Chapter 2 presents an in-depth literature review encompassing all the key concepts surrounding spillovers. The various methods for measuring and assessing spillovers are also discussed in this chapter. Chapter $\mathbf{3}$ gives an overview of long-term economic and political developments in Pakistan which provides a background for the subsequent analysis of Pakistan's sectoral productivity and the performance of the Pakistan IT sector (based on a sample of surveyed firms). Economic developments are discussed in the context of various civilian and military ruled periods. Towards the end some of the most important challenges faced by the country are highlighted together with a discussion of how they came into being. While Chapter 3 concentrates mainly on the 
different periods and their salient policy features, Chapter 4 takes the discussion into inter and intra sectoral productivity with the aim to understand the trends in two particular sectors, manufacturing and services. The reasons why we are interested in understanding the evolution of these two sectors in particular are two-fold. Firstly, empirical evidence unequivocally advocates the role of manufacturing for development. Developing countries which have managed to converge towards a developed economy have mostly gone through a more or less similar process during their transition period. The second reason has to do with the more recent trend; developed countries transforming from manufacturing centric into services centric economies. Another recent development is the rapidly increasing role of information and communications technologies (ICTs) for growth. The chapter employs the shift and share analysis to account for productivity growth on a dataset of all industrial sectors spanning over 3 decades with the goal to observe if the economy has been shifting resources from an agrarian economy to a manufacturing one, and more recently in becoming a service-oriented economy. The special role which the service sector in general and ICT in particular has played in helping countries catch up is one reason for the special attention which is given to the ICT sector. Another reason is its relevance to FDI; it being the sector with the most inflows by far. Last but not least, the sector is important because ICTs, by virtue of being general purpose technologies, are closely related with productivity growth in the wider economy. Chapter 5 thus provides an overview of the ICT sector of Pakistan. It serves as a backdrop for our survey in this sector. It also presents a historical perspective highlighting some important events that led to the evolution (and later decline) of this sector. Chapter 6 undertakes an empirical examination of spillovers in the Pakistan ICT sector and its subsectors. ICT being an advanced technology sector makes it more likely for innovations resulting in knowledge spillovers. In this context, the chapter aims to first answer whether there are positive productivity spillovers from FDI in the ICT sector. Secondly, the research sheds light on the mechanisms and channels of spillovers and provides new insights by segregating MNCs and domestic firms by using interaction terms. Last but not least, we attempt to identify and interpret the factors that affect the presence (or absence) of spillovers. These could be characteristics of the MNCs, local firms or could be related to government policies. Chapter 7 looks at the spillover debate from a social capital perspective. Network data gathered through our extended questionnaire is analyzed for two distinct features of social capital. Firstly the network of contacts which grants individuals access to resources belonging to their contacts, and secondly the quality and quantity of those resources. Our methodology, in a way, combines both structural elements of a network and the resource dimension. We achieve this by using variables which represent structural information like constraint and centrality (degree, closeness and betweenness) but construct these variables using matrices which contain resource exchange weights and frequencies, both being dimensions which shed light on the strength of ties, not the structural characteristics as such. The final chapter (8) draws summarizes the conclusions emerging from our empirical analysis. 


\section{Chapter 2. Literature Review: Spillovers}

\subsection{Introduction}

This chapter provides a review of the literature on spillovers, which serves as a background for the empirical analysis in the subsequent chapters.

The entry "spillover" at the Merriam-Webster's online dictionary yields the following result:

\'spil-,ō-vər \noun, often attributive: something that flows out of or spreads beyond a container, space, area, etc. In a similar way, economists use the term "knowledge spillovers" to refer to those indirect economic benefits which result from research and development (R\&D) and other investments in innovation of economic agent $A$ but can't be completely utilized or captured by it. They 'spill over' to economic agent B without $A^{\prime}$ 's intention and without any financial transactions. Economic agents are most commonly firms, countries or geographical regions. In case of multinational actors, these benefits are in addition to the direct effects of MNCs on the technological capabilities of the host country. Much of this chapter will discuss the literature on knowledge spillovers, but the discussion is not limited to knowledge spillovers. Other types of positive externalities will also be examined.

The concept of knowledge spillovers is related to the public good characteristics of knowledge. In their cost/benefit calculations, firms don't consider the benefits of investment in knowledge for the society and the economy at large. Projects are selected purely based on their anticipated private returns and therefore projects yielding lesser private returns are not taken up and remain underprovided. This is an instance of 'market failure' in a laissez-faire market system and it is the task of governments to avoid such failures by deploying the correct policy interventions which would encourage knowledge creation through R\&D and other innovative efforts. Luckily, unlike activities such as building infrastructure or garbage collection, the benefits of R\&D to the private agents undertaking it are, in most of the cases, sufficient and therefore market forces generate those activities. The debate whether the social rate of return of R\&D (through spillovers) exceeds its private rate of return seems to have settled in the affirmative (Griliches, 1992). Griliches asserts that "R\&D spillovers are present, their magnitude may be quite large, and social rates of return remain significantly above private rates." Even more, this "excess of the social rate of return over the private rate of return enjoyed by innovating firms" is seen as the economists' definition of spillovers (Jaffe 1996). Throughout this chapter we will refer to knowledge generating or 
innovating firms alluding to spillover sending firms and to those firms which benefit from the knowledge and innovations created by others alluding to spillover recipient firms. This does not exclude recipient firms from engaging in R\&D activities or other such knowledge creating activities themselves. But analytically it makes sense to distinguish a 'supply side' and a 'demand side' of spillovers. Belderbos \& Mohnen, (2013) write: "While difficult to separate, conceptually it makes sense to model spillovers as a function of supply, demand and the presence of different transfer mechanisms, which will allow for greater precision in knowledge spillover estimations." (pp. 6) According to the authors, knowledge spillovers can be seen to be a function of:

1. The 'supply' of spillovers, which is taken to mean the magnitude of knowledge outflows from the 'sending' firm. The determinants of such flows are a firm's ability to create knowledge (usually measured as R\&D expenditure) and the degree of its 'openness' (given by the use of secrecy or technological complexity to shield knowledge from leaking out).

2. Various 'mechanisms' such as labor mobility, peer networks of researchers, conferences and trade fairs, inter-firm trade, etc. that help the knowledge outflows to 'spread' to other firms.

3. The ability and need of other firms to receive and absorb knowledge for the sake of utilizing it ('effective demand' for spillovers). This will be related to internal R\&D expenditures of the receiving firm and the technological proximity or overlap between the firms.

In order to develop a deeper understanding of spillovers one needs to first comprehend various phenomena surrounding them. This includes understanding what facilitates spillovers, how to classify them, what are their sources, what are their types, which channels do they use, what are their mechanisms, which indicators can be used as proxies to measure them and last but not least which methods are available for assessing their occurrence. In this chapter we undertake to study and analyze the concept of spillovers from all these perspectives and dimensions. We present an in-depth and up to date literature review with scholarly references pertaining to all the concepts discussed. The remainder of this chapter is structured as follows. We start by distinguishing different types of spillovers (section 2.1) and spillover classifications (section 2.2). In section 2.3 we discuss different sources of spillovers, moving on to a discussion of the channels and mechanisms through which spillovers take place in sections 2.4 and 2.5. Section 2.6 focuses on the various indirect and direct facilitators of spillovers. The final section (2.7) discusses measurement issues. 


\subsection{Types/Conceptualization of Spillovers}

Spillovers can be conceptualized as per their realization, which occurs in the manners discussed below. These conceptualizations are often referred to as types of spillovers in literature.

\subsubsection{Real vs Rent spillovers}

Griliches (1979) distinguishes between two types of spillover effects: real (knowledge) spillovers and rent spillovers. Knowledge spillovers, according to him, occur when knowledge is transferred without a market transaction, whereas rent spillovers arise through the transfer of economic benefits embodied in business transactions such as the purchase of equipment or services. Verspagen (1997b) terms pure spillovers as the true externalities, which in principle do not involve any market transactions and stem from the non-rival and non-excludable character of technology. Commenting on this terminology he argues that though the term 'spillover' is less appropriate while used together with rent spillovers, there is no need to abandon the terminology as long as it is clear that they involve a different process than pure spillovers. Rent spillovers ${ }^{3}$ can be further subdivided into two categories. Firstly, they could occur as a result of quality improvements of traded goods which are not fully reflected in price increases because prices fail to entirely embody the quality improvement due to competitive forces in the innovating industry. Secondly, they could arise from trade related exposure of a firm's products which can be imitated by the importing firm/country. Such imitation is euphemistically termed as 'reverse engineering'. Mohnen (1996) aptly sums it up stating, "... rent spillovers are also a fact of life; if the innovator could perfectly discriminate, no rent spillovers would occur." Griliches (1979) views rent spillovers as a case of improper pricing due to inadequate measurement of capital equipment and materials and hence he regards them as insignificant as compared to real spillovers which are also interchangeably termed as true, knowledge or disembodied spillovers. But other authors suggest that rent spillovers may be quite important.

Traded goods form one channel through which rent spillovers work, which is especially stressed in the open economy endogenous growth models pioneered by Grossman and Helpman (1991). Coe and Helpman (1995) found evidence for the existence and importance of rent spillovers between countries. Coe, Helpman and Hoffmaister (1997) studied the effect of trade-embodied knowledge flows in developing countries concluding that substantial spillover gains take place. Furthermore, rent spillovers are usually relevant for developing countries when they occur at the international level i.e. technological imports to the domestic economy (Jacob and Szirmai, 2007).

\footnotetext{
${ }^{3}$ Rent spillovers are also referred to as user-producer spillovers by a select few scholars. (see: Cerulli \& Poti, 2009; Cincera \& Potterie, 2001; Verspagen, 1997b)
} 
The concept of real spillovers hinges on the concept of learning. In turn, real spillovers contribute towards productivity improvements and thereby technological progress (Engelbrecht, 1997; O’Mahony \& Vecchi, 2009; Verspagen, 1997a). Romer (1990) attempted to model pure spillovers in his seminal work on this subject. Griliches (1992) sees real spillovers as "... ideas borrowed by research teams of industry i from the research results of industry j." It is possible to 'borrow' such ideas free of cost because practically the appropriability of knowledge is imperfect and knowledge associated with innovations is no exception despite multiple legal and administrative measures to restrict the costless flow of knowledge. The patent system ${ }^{4}$, reverse engineering and the inability to keep innovations secret, all lead to the leakage of R\&D outputs.

Contrary to rent spillovers, real spillovers are not necessarily related to economic transactions or pricing that does not capture the full value of what has been commercially traded, resulting from measurement errors or other sources.

\subsubsection{Pure versus market spillovers}

A distinction similar to that between real and rent spillovers is that of pure and market spillovers. Jaffe (1996) distinguishes between those knowledge spillovers which "occur in the absence of a market interaction between the innovator and the spillover beneficiary" and those which "result from a market interaction between them". He terms the former as pure knowledge spillovers, emphasizing that the spillover receiving firm is not active in the same market and the latter as market spillovers, emphasizing the market interaction and perhaps also the market imperfection that creates the market spillover. To further elaborate on this subtle distinction made by Jaffe, in case of market spillovers, it is not the 'knowledge flow' even within the same market which is the determining factor, rather it is the operation of market forces which cause a "leakage of benefits" to occur. Hence, for market spillovers to be realized, commercialization is a must, whereas pure knowledge spillovers could even be the result of basic research or R\&D efforts not leading to a market product. Moreover, the benefit in case of market spillovers are enjoyed by the consumers and is also called 'consumer surplus' by economists. This is the value that customers of a product enjoy after accounting for the price they paid for it. It is noteworthy that most researchers have not considered or even discussed this distinction ${ }^{5}$.

\footnotetext{
${ }^{4} \mathrm{~A}$ patent system could be either weak in protecting the patented works and therefore others might infringe on it or this could also mean the voluntary disclosure of knowledge in a patent document which is a requirement for a patent to be granted. This can be seen as a quid pro quo for awarding monopoly rights by the society in order to make the new knowledge public to facilitate other innovative applications, but at the same time protect the inventor from any kind of infringements.

${ }^{5}$ It might also be worth mentioning that Jaffe (1996) also classifies spillovers as 'network spillovers' whereas these are usually called network externalities or more aptly termed as the network effect. We, however don't consider them to be a typical case of spillovers in the context of our discussion.
} 


\subsubsection{Pecuniary vs non-pecuniary spillovers}

Another characterization of spillovers in the literature is done on the basis of their monetary contribution. In contrast to pure knowledge spillovers (non-pecuniary), pecuniary spillovers operate through prices rather than through real resource effects. They do not impact the production function of the benefiting agent, but affect the profits by either revenue increases or cost reductions. Pecuniary spillovers can occur when multinationals increase the market size for domestic suppliers which can encourage the entry, survival or growth of domestic firms. Pecuniary externalities or those externalities pertaining to money, arise from vertical linkages (with suppliers and buyers) formed by the investing firm. Such linkages are commonly a result of a particular MNC or its affiliates exerting influence on the demand or supply conditions intermediate goods and services. Dunning and Lundan (2008) argue that merely the increase in demand of such intermediate products without any knowledge transfer can improve the cost competitiveness of supplier firms due to economies of scale. According to them, knowledge transfers or incentive structures to its suppliers to meet its quality specifications could further enhance the performance of suppliers. In simple terms, when multinationals grow, their demand for intermediate products supplied by firms in the host economy increases. This increase allows domestic suppliers to utilize economies of scale, bringing down costs, not only for their multinational clients, but also other domestic players. (Caniëls and Romijn, 2003, 2005; Görg and Strobl, 2005a; Markusen and Venables, 1999). Note that pecuniary spillovers can be knowledge spillovers, but that they also involve other positive externalities such as linkage effects or economies of scale.

\subsubsection{The role of proximity: MAR vs Jacobs Spillovers}

Synthesizing the Marshall-Arrow-Romer views on knowledge spillovers they were collectively termed as MAR spillovers by Glaeser et al. (1991). The MAR spillover definition views proximity of firms within a common industry as a determining factor of how well knowledge travels among firms to facilitate innovation and growth. It is asserted that the closer firms are to one another, the greater will be the spillovers as knowledge flows take place in the form of idea exchanges from employees of one firm to those of another.

The Jacobs spillover view is essentially the same as MAR with the difference that instead of intra-industry, the proximity of firms from different industries is considered.

\subsubsection{Market access spillovers}

MNCs are able to enter world markets due to their established distribution networks and experience of international marketing. These competitive advantages often trans- 
late into export operations which in turn might pave the way for domestic firms to enter the same export markets, due to leakage of information about foreign markets. These knowledge externalities have been called 'market access spillovers' by Blomstrom and Kokko (1998) who give the example of Swedish furniture giant, IKEA, whose export success has given its sub-contractors access to large foreign markets. Aitken and Harrison (1999) confirmed the existence of market access spillovers by showing that knowledge spillovers from MNCs benefit domestic firms' export performance.

\subsubsection{ICT spillovers}

In the literature special attention has been paid to ICT spillovers. Stiroh (2002) divides the ways in which ICTs influence economic growth into three distinct channels as depicted in Figure 2.1. The first one is technological progress in the production of ICT goods, primarily explained by "Moore's Law", according to which the computing power of integrated circuits (ICs) is doubled every 18 months. Such performance enhancements, it is argued, contribute to rapid TFP growth in ICT-producing sectors, which in turn increase the average TFP growth of the economy (arrow 1).

The second channel where ICT can influence productivity is called capital deepening or development. Capital deepening occurs when better products at lower prices result from higher levels of financial investment in ICT. This may lead to a raised capital stock per worker-that is, ICT-related capital deepening across the economy (implying a lowering of the marginal cost of capital) (arrow 2).

The third channel is that of ICT spillovers, and the topic of our discussion. ICT spillovers are hard to identify and measure, yet their long-term effects might be the strongest. Advances in ICT have shown the potential to revolutionize how goods and services are produced and distributed, ushering in a new era of growth (arrow 3). ICT applications have been creating new markets, new products and new ways of organizing how society interacts and functions-in much the same way the steam engine, the electric motor, and the computer chip have done in previous centuries. It is not without reason that researchers are talking of another industrial revolution, and have called it 'The New Economy'. Many authors have studied the direct relationship between ICT capital and productivity at a firm level, industry level, or a country level (for a review see Dedrick et al. (2003)).

The most commonly used approach to estimate ICT spillovers so far focuses on industry or firm-level data, which suggests TFP growth is strongly influenced by innovations in ICTs (Brynjolfsson and Hitt, 2000). The benefits of ICT spillovers are not confined only to national territories. In a globalized world, one would expect that spillovers operate beyond physical borders. The existence of spillovers ensures that the enhanced national knowledge capital derived from national ICT may increase the produc- 
tivity of foreign countries. Moreover, ICT itself may act as a channel to transfer knowledge across countries through communication networks ${ }^{6}$.

Figure 2-1 Channels of contribution to growth by ICT

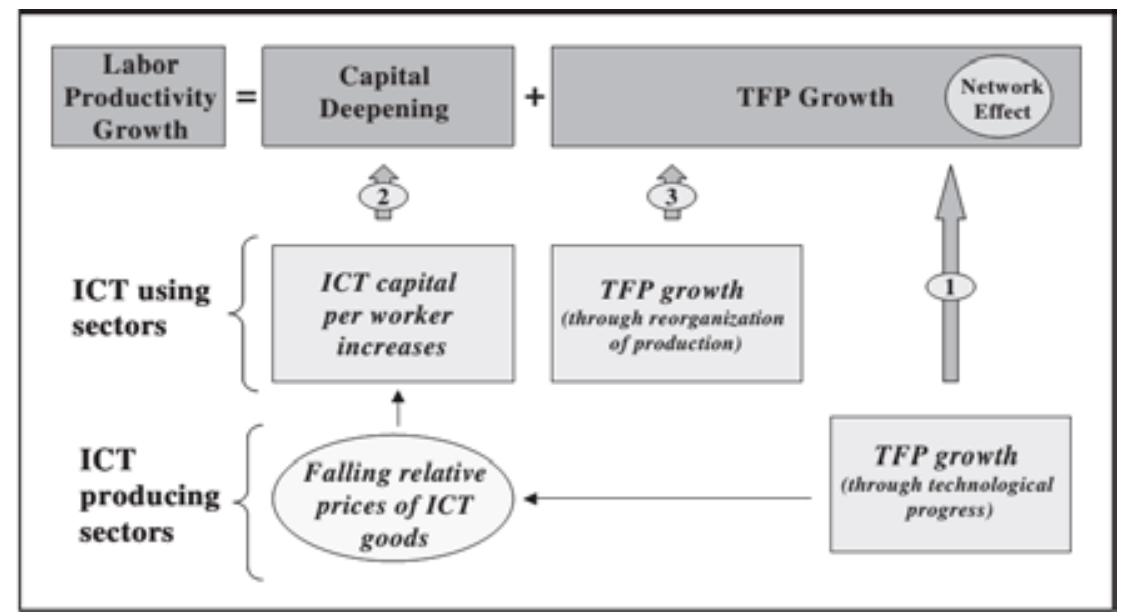

Source: (Qiang et al., 2004)

Dedrick et al. (2003) state that ICT capital is similar to knowledge capital, due to its informational and transformational roles. Firm-level studies show that the use of ICT is only part of a much broader range of performance enhancing changes. Therefore, ICT is key to the innovation process and has become a tool to accelerate innovation. ICT increases the scope and scale of R\&D, enabling the creation and evolution of innovation clusters, learning communities and knowledge network (Bresnahan and Trajtenberg, 1995; Hanna, 2003). Madden and Savage (2000) believe that the sources for TFP growth may vary over time and across countries. Nonetheless, technological change and innovation are generally acknowledged as determinants of TFP growth, and ICT has been considered a major form of technological change in recent decades.

Venturini (2015), using country-level data, investigates the determinants of productivity in emerging knowledge economies by estimating the spillovers associated with investment in R\&D and Information Technology. His study establishes that both forms of technically advanced capital (R\&D and IT) matter for long-run TFP growth.

\subsection{Intra-sectoral, inter-sectoral and international spillovers}

In literature, spillovers have also been categorized based on sectoral and geographical/spatial divides, as discussed below.

\footnotetext{
${ }^{6}$ This role of ICT is discussed in another section, "Channels/Conduits of Spillovers".
} 


\subsubsection{Inter-sectoral vs intra-sectoral spillovers}

Intra-sectoral or intra-industry spillovers refer to those spillovers which occur in the same sector or industry. The beneficiaries of these spillovers could be competitors, suppliers or customers. Inter-sectoral or inter-industry spillovers are those spillovers which flow across sectoral boundaries. These spillovers could benefit sectors other than the one in which the spillover source is operating. Measuring them is more difficult and researchers have to consider all related sectors as well.

The earliest statistical analyses of intra-industry spillovers include studies by (Caves 1974; Globerman 1979; Blomström and Persson 1983). These studies establish the existence of spillovers by testing whether foreign presence influences labor productivity in domestic firms of the same sector. The foreign share of each industry's employment or value added is taken as a proxy for foreign presence.

\subsubsection{Intra-national vs Inter-national (cross border) spillovers}

Another classification of spillovers in literature is done according to national boundaries. If the spillover source (e.g. the MNC or a domestic firm) and the spillover absorbing agent (domestic firm) are both co-located in the same country, the resulting spillovers are termed as intra-national spillovers. Inter-national spillovers on the other hand flow across the national borders, benefiting firms located in countries other than the spillover source. Various researchers have studied agglomeration of production and innovation in space, measuring intra-national versus inter-national knowledge spillovers (Branstetter, 2001; Coe and Helpman, 1995; Keller, 2001).

\subsection{Sources of spillovers}

\subsubsection{Firms}

When sources of spillovers are discussed in literature, they usually refer to the sources from where the knowledge which spills over is originating. We differentiate between spillover sources and spillover channels ${ }^{7}$. Sources refer to those economic agents which themselves produce or create knowledge whereas a channel or conduit does not necessarily create that knowledge but facilitates its flow. ${ }^{8}$ First and foremost the role of firms as sources of spillovers can't be emphasized enough. Having said that, researchers do differentiate between the types of relationship between sources and receivers of spillovers. These different relationships could between competitors or

\footnotetext{
${ }^{7}$ Spillover channels, also called spillover conduits, are discussed in detail in the next section

${ }^{8}$ It could well be that a firm acts as a channel. In this case it is not the source of knowledge. It has acquired the knowledge through some means, which could include spillovers.
} 
between suppliers and their customers. The potential spillovers from competitors are well known as firms try to benefit from their rivals through imitation and reverse engineering. Spillovers from supplier-firm (backward linkages) benefit in reducing the risks associated with new product launches by suppliers and can therefore result in higher demand and sales. In mature industries supplier involvement can even lead to more innovative products (Eisenhardt and Tabrizi, 1995). Similarly spillovers obtained from firm-customer (forward linkages) may result in improved processes for the production of existing products and improved products, e.g. in terms of design (Suzuki, 1993). This is particularly true for products that require adaptations in their use due to their innovativeness and intricacy (Herstatt and Hippel, 1992; Hippel, 2007).

\subsubsection{Universities and Research Institutions}

Cantwell and Piscitello (2005) link spillovers with the "presence of a munificent scientific and educational infrastructure". More specifically, scholars point out universities and other private or public research institutions as an important source of knowledge spillovers.

Baba et al., (2009) find that research output of universities plays a complementary role together with firms' own knowledge stocks in creating innovations. Thursby and Thursby (2006) conducted a survey of over 200 MNCs which underlines the role of universities in the global innovation system asserting that even key innovations rely on academic research.

Highly innovative firms per se are already at the knowledge frontier in their industry thus industry-wide spillover benefits are marginal at best. In their pursuit of new forms of academic knowledge they usually collaborate with foreign universities and this way derive the most benefits (Monjon \& Waelbroeck, 2003).

\subsection{Spillover Channels/Conduits}

\subsubsection{MNCs/FDI}

One of the important channels of international knowledge spillovers identified in the literature is foreign direct investment (FDI) (Javorcik, 2004). FDI is defined as "investment made to acquire lasting interest in enterprises operating outside of the economy of the investor." The FDI relationship consists of a parent enterprise and its foreign affiliate in the host country which together form a Multinational corporation which is referred to as simply ' $M N C$ ' in our text. The foreign assets could be invested into domestic equipment, structures and organizations. Foreign investments into the stock markets however do not qualify as FDI. Countries prefer FDI over equity investments in its companies because these are potentially volatile and therefore termed 'hot mon- 
ey', since it normally is the first to leave at signs of trouble. In contrast FDI is durable and generally useful for the host country, in all market conditions, due to the longterm nature of the investment itself.

It is worth noting that indirect interregional FDI spillover effects can play out negatively. This is explained by the fact that FDI in one region attracts resources from other regions with less FDI, creating a drain of resources and thereby negatively influencing growth in those regions (Wang, Meijers, \& Szirmai, 2013).

\subsubsection{Labor mobility}

Labor mobility, as is clear from the name, refers to the knowledge spillovers which use labor of one firm switching to another or opening their own firm as a channel. One type of labor mobility is of particular interest in the context of a developing economy, namely that between MNCs and domestic firms. it is well documented that MNCs can bring superior technology to the host country (Blomström \& Sjöholm, 1999). It is also known that MNCs as compared to local firms prioritize human capital investment (Patibandla \& Petersen, 2002). A higher skill level on part of their employees as compared to their local counterparts is therefore inevitable. This investment in human capital is 'embodied' in people and therefore can spillover to local firms in two ways namely by employees of one firm (usually an MNC) moving to another firm (usually domestic) by switching jobs or by them opening up their own businesses in the host country. By this they would carry the knowledge to their new employer/company and thereby knowledge spills over to the new employer/company (Fosfuri, Motta, \& Rønde, 2001; Glass \& Saggi, 2002; Rasiah, 1995). Researchers investigating spillover mechanisms, which were initially treated as a black-box, have started developing theoretical models treating labor mobility as one of the prime carriers of knowledge.

The empirical studies pertaining to labor mobility can be divided into two categories, those which hint at the potential of labor mobility spillovers and those which attempt to measure them directly with micro-level data. The former would either take steeper wage profiles of highly skilled labor in MNCs as a proxy for them being more productive as compared to their domestic counterparts with same training levels (Görg \& Strobl, 2005b) or they would show a positive relation between inward FDI and domestic wage increases as a proxy for productivity from labor mobility (Aitken \& Harrison, 1999; Girma, 2001; Lipsey \& Sjöholm, 2004). Some surveys have also established the importance labor mobility for start-ups as was highlighted by Bhide's (2000) finding where he surveyed founders of fastest growing companies in the United States and noted that $71 \%$ "replicated or modified an idea encountered through previous employment."

These studies model trained staff from MNCs as 'knowledge spillover agents' and show that while moving from MNCs to local firms (by taking up jobs there or starting up their own companies) they 'carry' valuable technical knowledge to domestic firms 
which they acquired by virtue of training at or working for their respective MNCs. This knowledge helps the domestic firm increase their productivity in various manners like developing new products or services.

Kesidou and Romijn (2008) assert that different channels of knowledge spillovers appear to be important for different aspects of a firm's innovative performance. They find that labor mobility in a developing country setting matters for technological innovation performance.

One explanation for higher wages sometimes called 'efficiency wages' paid out by MNCs is to restrict this undesired worker mobility or 'human capital spillover'. Empirical evidence for this is found by Saggi (2002) while examining data from South Korean firm Daewoo's activities in Bangladesh. Geographical proximity is also understood to play an important role in human capital spillover because labor turnover is more than often regionally confined.

\subsubsection{Exports $^{9}$}

Broadly, literature points out two different kinds of spillovers pertaining to exports, the difference lying mainly in who benefits from them. In one case, commonly referred to as 'learning by exporting' (LBE), it is the exporting firm itself which benefits or 'receives' the spillovers. LBE is found to be significant both indirectly, through increased competition from foreign producers and directly, through buyer-seller relationships. Specifically, exporters can learn from their foreign clients and competitors by optimizing shipment size, improving product quality or, even more directly, by investing in particular projects (Almodóvar, Saiz-Briones, \& Silverman, 2013; Loeckera, 2013; Silva, Afonso, \& Africano, 2012). In the other kind the focus is on firms other than the exporting firm which benefit due to the exporting firms export endeavors (Alvarez \& López, 2008). These cases can be further divided into two groups, first when the exporting firm is an MNC and secondly when it is a domestic firm (Aitken, Hanson, and Harrison, 1997). MNCs have a multi-market presence and are therefore a natural conduit for information about customers, markets, and technology in a country other than their host country. This way they provide access to domestic firms by which domestic they can distribute their products.

\subsubsection{Trade}

A number of scholars have established International trade as a channel for R\&D spillovers, both qualitatively and quantitatively. While there is a complete consensus on the qualitative conclusion, the quantitative estimates differ in terms of the magnitude of spillovers between countries (Zhu \& Jeon, 2007). Grossman \& Helpman (1991) in their

\footnotetext{
${ }^{9}$ Some scholars discuss export related spillovers under trade (see for instance Falvey et al., 2004), we however prefer to treat them separately.
} 
seminal work on spillovers were the first ones to model commodity traders as a "conduit for information flow."

Xu \& Wang (1999) find trade in capital goods to be a significant channel of spillovers. However, they conclude that in the OECE countries the majority of spillovers are disseminated through other channels.

Zhu \& Jeon (2007) compare the elasticity of TFP with respect to FDI and bilateral trade. On average, the FDI elasticity of TFP is less than $1 \%$, while the trade elasticity is $2 \%$. They conclude that this calls for further liberalization of trade and making it a top priority if countries want to benefit from the foreign R\&D spillovers, thereby increasing their productivity.

\subsubsection{Knowledge networks}

One aspect of knowledge networks are the firms which it is comprised of. These firms are a source of spillovers and are discussed in the section where various sources are discussed. Another aspect pertaining to knowledge networks is the embeddedness of a firm within a network and that is discussed in detail in Chapter 7 where we also estimate the impact of embeddedness on innovation and economic performance. A third aspect is the role of knowledge networks as channels for spillovers. Owen-Smith and Powell (2004) (pp. 5-6) while discussing knowledge networks posit that they qualify “...as channels that diffusely and imperfectly direct transfers between nodes, facilitating information spillovers (and other externalities) that benefit both loosely connected and centrally positioned organizations." In a way knowledge networks just facilitate the transfer of knowledge but their role is similar to that of trade fairs and conference because they are brining firms (and their employees) together, giving them the possibility to exchange knowledge.

Boschma and ter Wal (2007) demonstrate that innovative performance was linked to a strong local and extra-local network position of a firm. In their words, "...it mattered being connected either locally or non-locally: being co-located was surely not enough."

\subsubsection{Alliances}

Since the beginning of the 1980s, there has been a virtual explosion of strategic alliance formation, driven by the growth and pace of globalization. This has led to a growing trend for the activities of firms to be undertaken through what has been coined as 'alliance capitalism' (Dunning, 1995, 1997; Gerlach, 1992). The number of such alliance agreements have increased at an average rate of $9.8 \%$ annually between 1980 and 1994 (Narula and Hagedoorn, 1999). Alliance capitalism refers to the growing use of non-market, quasi-formal modes of corporate activity, whereby firms do not completely internalize their value added activities, but utilize a variety of collaborative and 
cooperative associations with other firms to achieve the same goals (Dunning, 1995). Although the use of such collaborative and cooperative associations as a means of protecting or advancing the competitiveness of the participating firms has been known to exist for quite some time, the tendency of firms to ride the alliance tide has increased unprecedentedly by the end of the $20^{\text {th }}$ century (Narula and Dunning, 1998). This trend can be rationalized by the Cassiman and Veugelers's (1998) finding that cooperating firms have better access to spillovers and higher protection of their own knowledge stock, indicating that alliances may serve as a vehicle to manage information flows.

Veugelers and Backer (1999) however challenge the alliance argument after analyzing a data-set of 588 inter- and intra-industry R\&D and non-R\&D alliances. They find that industry R\&D levels accessed through inter- and intra-industry R\&D alliances have a negative effect on productivity growth, while this effect is positive only for industries with non-R\&D intra-industry alliances.

\subsubsection{Information and Communication Technology}

Information and communication technology (ICT) is regarded as another channel for international knowledge spillovers. ICT has brought down the cost of communication and monitoring among distant firms and made production more efficient (Jeon, Tang, and Zhu, 2005). It is the lynchpin of Globalization, which enables knowledge to be disseminated more efficiently over computer networks. Though transferring tacit knowledge (knowledge that is not codifiable) requires "person-to-person" communication, we know that international travel is a costly affair. By providing comparable substitutes such as teleconferencing, ICT reduces communication costs and facilitates the worldwide dissemination of tacit knowledge without personal contact. This way, ICT facilitates cross-border learning.

While examining international spillovers, (Madden and Savage, 2000) use import statistics of ICT equipment and find them to be positively correlated.

(Keller, 2001) finds communication patterns to be crucial among OECD countries for international technology diffusion. He calculates the geographic half-life of spillovers i.e. the distance at which half of the spillovers disappear, to be only $1200 \mathrm{~km}$. Moreover, he estimates that communication flows account for as much as $15 \%$ of spillovers.

Using tele-density (number of telephone lines per 100 residents) as an indicator for IT usage, (Zhu and Jeon, 2007) find that IT use in a company significantly enhances R\&D spillovers and they have increased faster in the 1990s than in the 1980s. They find that the elasticity of TFP is between $0.7 \%$ and $2 \%$ with respect to IT. This, they infer, should be reason enough for countries wanting to benefit from international spillovers to develop their IT infrastructure which would lead to enhanced TFP. 


\subsubsection{Linkages}

Linkages are taken to refer to the input-output relationships between firms or sectors (Hirschman, 1958). Such linkages can also act as channels for the transfer of knowledge. Industrial linkages are of two types, horizontal, also known as intraindustry linkages and vertical, also called inter-industry linkages. Horizontal linkages are linkages between firms in the same industry and manifest themselves as business transactions which, similar to trade, can act as a spillover channel. Blyde, Kugler, \& Stein (2004) summarize the differences between them stating that the likelihood of horizontal linkages involving sector-specific technical knowledge that would benefit the competition is higher. Therefore, there is a substantial inducement for MNCs to preclude such spillovers. Hiring of human capital (labor mobility), and imitation (demonstration effect) are the possible channels through which spillovers of this type might take place. Vertical linkages, in contrast, usually pertain to general rather than sector specific technological knowledge. These can further be classified as backward and forward linkages. Backward linkages benefit firms in upstream industries (suppliers) and are called backward spillovers whereas forward linkages benefit downstream industries (buyers) also known as forward spillovers. In case of MNCs these firms don't classify as direct competitors. For this reason, the MNCs, while trying to boost their own productivity, may be willing to share their technical know-how with them. The importance of vertical linkages between foreign and domestic firms for spillovers has been studied and highlighted by several authors (Dunning, 1997; Markusen \& Venables, 1999; Rodriguez-Clare, 1996).

\subsubsection{Backward Linkages}

Backward linkages are a result of contacts between firms and their domestic suppliers. In the case of MNCs and their domestic suppliers, backward spillovers can take place through all or any of the following transactions in the context of MNCs and their domestic suppliers (Javorcik, 2004; Jordaan, 2005):

(i) direct knowledge transfer from MNC to domestic suppliers, (ii) requirements of quality, quantity, delivery time and price by MNCs, pushing domestic firms to upgrade their technology and knowledge stock, and (iii) increased demand for intermediate products due to MNC entry, which enables domestic suppliers to benefit from economies of scale.

\subsubsection{Forward Linkages}

Javorcik (2004) finds that linkages established between MNCs and their domestic business customers may render the latter more productive and competitive as a result of gaining access to new, improved, or less costly intermediate inputs produced by the MNC. Sale of these inputs by MNCs is often accompanied by complementary services that may not be available with direct imports. 
Dunning and Lundan (2008) list the most commonly discussed types of MNC related forward linkages in the literature as follows:

1. The secondary processing of primary value-added activities. Examples include oil refining and metal production.

2. Buying technically complicated products (where, for example, advice on how to use and maintain machinery and equipment that is given by the MNC to convince the buyer of the products' superior features and value.

3. Marketing outlets buying motor vehicles, domestic electrical appliances and agricultural machinery, where, for example, the MNCs may provide information and offer functional guidance about the technical characteristics and usage of the products being sold and their software and servicing requirements.

\subsection{Spillover Mechanisms}

Spillover mechanisms have kept researchers wondering for quite a while. Early spillover researchers were more focused on first verifying the existence of spillovers, then measuring them, then finding out which conditions contribute positively towards the occurrence of spillovers. It was only around the turn of the century that much research was conducted on understanding the mechanisms of spillover. Summing up the economic literature, two distinct mechanisms or modes of occurrence of spillovers can be identified (Blomstrom \& Kokko, 1998; Fuentes, 2008; Görg \& Greenaway, 2004; Pesola, 2006). ${ }^{10}$ These are demonstration also known as imitation effects and inter-firm competition.

\subsubsection{Demonstration Effect}

The same motivation which drives local firms to improve their efficiency, hire skilled (and MNC trained) workers and adopt new technologies can also lead them to imitate the superior process and product technologies, efficient organizational practices and global market knowledge possession. These 'demonstration spillovers' can be a result of reverse engineering and industrial espionage or imitation of any knowledge created by other economic agents and available publically. Discovering and reproducing the technological principles of a device through analysis of its structure, function and operation by taking that device apart and analyzing its workings in detail is known as reverse engineering. Domestic firms may profit from the access to such new technology by adopting the products to their local needs through copying or reverse engineer-

\footnotetext{
${ }^{10}$ Many authors usually mention more than these 2 spillover mechanisms. It should however be noted that the other mechanisms discussed mostly qualify more as channels in our opinion and have therefore been categorized under that section. These include labor mobility, exports, skill acquisition, backward and forward linkages.
} 
ing (Huizinga, 1995; Wang \& Blomström, 1992). Jenkins (1990) notes that "over time, where foreign and local firms are in competition with each other, producing similar products, on the same scale and for the same market, there is a tendency for local firms to adopt similar production techniques to those of the MNCs. Indeed this is part of a general survival strategy, whereby in order to compete successfully with the MNCs local capital attempts to imitate the behavior of the MNCs."

Geographical proximity also plays an important role in demonstration spillovers as observation and industrial espionage becomes impractical over longer distances.

\subsubsection{Competition Effect}

The increase in competition due to the presence of firms with superior qualities, be they in terms of technology, products, efficiency or management, is known as 'competition effect'. The challenge posed by such firms' superior qualities can potentially lead other firms to adopt new technologies, innovate themselves and work harder. ${ }^{11}$ In the case of MNCs, this positive externality of competition created by MNCs on domestic firms has been investigated and confirmed by (Blomström \& Kokko, 1997; Blomstrom \& Kokko, 1998). Similarly Sjöholm (1999) finds that high levels of competition increase the degree of spillovers from MNCs. Depending on the size of this gap (or conversely the absorptive capacity) the local firms try to balance out these disadvantages by increased efforts to defend their market-share thereby triggering competition. Since competition spillover is positively affected from the level of new technology imports by MNCs into the host economy, Blomstrom (1992) concludes that the higher the competition between MNC and domestic firms, the higher the spillovers. It is possible though, that in case of a too big technological and structural gap between the domestic firm and MNC, the domestic firms are driven out of business as noted by Wang \& Blomström (1992). In most studies using secondary data, the only way to find out if competition spillovers exist is an indirect approach. If spillovers are more significant in non-exporting firms compared to exporting ones, it is understood to indicate that competition between firms for the local market is higher due to MNC as the exporters already faced international competition Blomström \& Sjöholm (1999). This approach is criticized for its correctness and only primary level data can bring clarity by carefully formulating explicit questions related to competition, pre and post MNC entry.

Chang and $\mathrm{Xu}$ (2008) show that nationally domestic firms profit from foreign entrants' increased presence, but in regional markets it negatively affects their survival rates. They also find that foreign entrants are crowded out not only by their peers, but also by reformed local firms at both the national and regional levels.

\footnotetext{
${ }^{11}$ Positive competition effects include knowledge spillovers but are broader. For instance, firms may become leaner and more efficient in their operations without necessarily implementing new technologies.
} 


\subsection{Spillover Facilitators}

Spillover facilitators are catalyst-like factors - which could either denote a characteristic of the spillover-receiving agent or be a property of the environment - the presence of which, in either case, would contribute to increasing the likelihood of spillover occurrence. In other words they are determinants of spillovers, determining whether, how much and what kind of spillovers take place. These catalysts could indirectly or directly influence spillover occurrence. Indirectly would mean that these factors influence the probability of knowledge creation. As knowledge creation is the first step before it can spill over to others, we regard this as an important precursor to spillover generation. This would entail factors that influence FDI in a country or a firm's decision to do R\&D. As we know both FDI and R\&D are not only highly correlated with spillovers, they are deemed as a precondition for them. On the other hand, with direct facilitators we mean characteristics which if present, the spillovers generated by the knowledge creating or innovating agent are more likely to be absorbed by the spillover-receiving agent.

\subsubsection{Indirect facilitators}

\subsubsection{Size}

Literature regards firm size as an important predictor for both innovation inputs (R\&D) and outputs (innovations), the two main measures for innovative performance. On one hand it is argued that smaller firms are more flexible and adaptable to changes and therefore they are more innovative. They innovate for their survival. On the other hand larger firms have more resources (human and capital) to spare for innovative activities.

On the empirical front, though a few researchers have found a negative relationship between firm size and innovation output (Hansen, 1992; Stock, Greis, \& Fischer, 2002), in broad terms there seems to be a consensus on the positive effect of firm size on both innovation input (Cohen, Levin, \& Mowery, 1987; Lunn \& Martin, 1986) and output (Acs \& Audretsch, 1987; Pavitt, Robson, \& Townsend, 1987).

Kumar \& Saqib (1996) find that for the case of developing countries firm size has an inverted-U relationship with the likelihood of R\&D activities; however if intensity of $R \& D$ is taken instead, firm size gives a linear and positive relationship. Similarly, for innovation output literature observes a generally positive relationship with firm size too ((Mel, McKenzie, \& Woodruff, 2009); (Benavente, 2006a)).

\subsubsection{Market structure}

Like firm size, market structure also influences innovative activities of the participating firms. Here too the argument can be formulated both ways. Firstly that monopoly power grants a firm such a strong financial position which is favorable for conducting 
$R \& D$ and consequently innovating. On the other hand, it is argued that the monopolist firm would direct its effort to maintain the status quo, not necessarily through innovation, but more so by raising the non-technology-intensive entry barriers like marketing and picket fence patenting. In the worst case, this could push the market down to a low technology equilibrium.

Empirically, the relationship of R\&D input and output and market concentration has also been studied. In terms of R\&D input, Hamberg (1964) observed a weakly positive relationship between R\&D and market concentration. Scherer (1967) and Levin et al. (1985) found an inverted-U relationship between innovative activities and market concentration. On the other hand Subodh (2002), based on a sample of two most innovative industries in India, found that the decision to perform R\&D or R\&D intensity are not influenced by market concentration. This finding could be attributed to the developing country context of the study.

For an output measure, Acs \& Audretsch, (1988) found that the number of innovations in one year decreased with the four-firm concentration ratio. However, (Lundvall \& Kristensen, 1997), (Blundell, 1999) and (Tang, 2006) found a generally positive relationship between competition and innovation. Similary, an inverted-U relationship is also a commonly found pattern between innovation output and market competition (Aghion, Bloom, Blundell, Griffith, \& Howitt, 2002). To summarize, with regards to competition, it would be safe to state that a moderately competitive market structure is more suitable for innovative activities than either a monopoly or perfect competition $^{12}$.

\subsubsection{IPR Regime}

A strong intellectual property regime in an economy would enable innovators to fully appropriate the returns to their R\&D investments. This could positively influence MNCs decision to invest in the respective economy. More importantly, it might also encourage them to transfer their R\&D to such a country, especially if the country has the necessary ingredients for such a transfer, the foremost being the availability of cheap knowledge workers (Fink \& Maskus, 2005). Stiglitz (2008) argues to the contrary, challenging the dynamic gains of a strong IPR regime to be less than assumed and also forwarding the idea of static inefficiencies as a result of it. From this perspective too strong IPRs limit international knowledge flows (Verspagen, 2003). Though this debate is far from settled, a few stylized facts can be drawn from literature. Firstly, that a weak IPR regime in a country leads to reduced knowledge-related inward FDI (Braga \& Fink, 1998). Furthermore, a strong IPR regime does not just mean the necessary legal framework, but also a commitment from the government to enforce the laws and penalize violators (Stiglitz, 2008). Moreover, in an environment of weak IPRs, foreign investors shun away from investing in technology-intensive areas and would

\footnotetext{
${ }^{12}$ Gilbert (2006) provides a comprehensive literature review of the relationship of R\&D with market structure and size.
} 
rather undertake projects focusing on distribution instead of local production or would use their innovations internally (Javorcik, 2004; Nicholson, 2007; Zhao, 2006). This could hamper the flow of knowledge to other firms consequently containing spillovers. All in all, though a strong IPR regime helps to elicit FDI, policy makers should also be wary of firms using the legal framework as a tool to impede innovation by employing anti-competitive practices like Microsoft. ${ }^{131415}$ In such a case, the patenting firm would alter the market structure in such a way that it gains monopoly power. As discussed in the previous section, this could trap the market in a low technology equilibrium.

\subsubsection{Direct facilitators}

\subsubsection{Absorptive capacity}

Absorptive capacity is the ability of firms to appropriate knowledge created by others. It has been defined by Cohen \& Levinthal (1990) as a firm's "ability to recognize the value of new information, assimilate it, and apply it to commercial ends" ${ }^{16}$. By increasing its absorptive capacity a firm positions itself to effectively assimilate and apply external knowledge for its own use. Not only that, but many scholars see a firm's own knowledge stocks as a precondition to absorbing external knowledge (Fabrizio, 2009; Nieto \& Quevedo, 2005). Fabrizio (2009) further asserts that a firm's efforts to form collaborations with universities in order to enhance their own knowledge stock also enhance its innovative performance. This way, firms' absorptive capacity paves the way for them to create radical innovations (Ritala \& Hurmelinna-Laukkanen, 2013).

Sjöholm (1999) finds that high competition and a higher technology gap increase the degree of spillovers from FDI. His results regarding the effect from technology gap suggest that larger differences in technology produce larger spillovers provided the receiving firm has sufficient absorptive capacity, however the result is sensitive to how technology gap is measured.

This concept of absorptive capacity (at firm level) is similar to Gerschenkron's (1962) hypothesis according to which larger technology gaps between countries provide more opportunities for knowledge to be sourced and for growth. Therefore, it is inferred, that in case of MNC mediated spillovers the presence of highly productive MNCs may particularly benefit the host economy relative to local firms (Peri \& Urban, 2006). One should note here that though the technological gap is of importance, it does not imply that the absorbing firm's (which in this case could be a domestic firm) ability to exploit external knowledge is absent altogether or even low in absolute terms (Kubielas, 2009). To the contrary, a minimal level of absorptive capacity is not

\footnotetext{
${ }^{13}$ United States v. Microsoft Corp., 253 F.3d 34 (D.C. Cir. 2001).

${ }^{14}$ Commission Decision Case COMP/C-3/37.792, Microsoft of 24 March 2004

${ }^{15}$ Korea Fair Trade Commission, The Findings of the Microsoft Case (Dec. 7, 2005)

${ }^{16}$ For a critical review of the literature on absorptive capacity please see Lane, Koka, \& Pathak (2006)
} 
only beneficial but a prerequisite for assimilating and exploiting external knowledge (Nieto \& Quevedo, 2005; Szirmai, 2008).

Positioning in the so-called knowledge or network space is another well-known dimension which grants firms access to external knowledge thereby enhancing their innovation capability. Interestingly, these positional benefits are also found to be dependent on a firm's absorptive capacity (Tsai, 2001).

Unfortunately, developing countries are usually unable to further their absorptive capacity owing to their lower internal knowledge threshold. Similarly, the advantage of above discussed "near-knowledge-spillover" is also lesser for developing countries because of the overall lower knowledge base within the country resulting in fewer opportunities to learn from one another. Moreover, Girma \& Görg (2005) argue that insufficient absorptive capacity is also a primary reason in domestic firms not being able to benefit from FDI spillovers spillover. This is also validated empirically where Girma \& Görg (2005) and Girma (2005) find evidence for a u-shaped relationship between FDI interacted with absorptive capacity and productivity growth. Kinoshita (2001), employing firm-level panel data, found that the productivity-enhancing effects of foreign presence in a sector were dependent on the local firms' R\&D investment. Similar results were found by Kesidou and Szirmai (2008) for a sample of firms from a Uruguayan software cluster. They conclude that for a firm to be able to forge formal relationships internationally and gain from them in terms of accessing external knowledge, it needs to be R\&D oriented and large.

\subsubsection{Geographic/Spatial Proximity}

Research shows that geographic proximity between firms can act as a catalyst and consequently lead to spillovers. This notion has led to the formation of so called 'clusters' of organizations which usually included private firms, Universities and R\&D institutes. Malecki (1997) studied the importance of skilled labor for knowledge transfer in science-driven industrial clusters. He found out that for certain science-driven industries the geographical location choices of innovating firms were influenced by the location choices of scientists. Zucker, Darby, and Brewer (1994) and Prevenzer (1997) observe that in industries based mainly on scientific and technological innovations (e.g. biotechnology), firms tend to gather in just a few locations and find that this is due to the location of what they call as "star scientists". These are highly capable individuals who are able to appropriate their knowledge through start-up firms. Audretsch and Stephan (1996), who examine the geographic locations of scientists working with biotechnology firms, corroborate this finding. They conclude that scientists play a key role in making geographic proximity important for spillovers.

Kesidou and Szirmai (2008) investigate local knowledge spillovers due to agglomeration by focusing on a software cluster in Uruguay. Theirs results support the presence of local knowledge spillovers and their positive influence upon the innovation of firms within the cluster. 


\subsubsection{Technological Proximity}

Technological proximity means firms being close in the technology space, and it is found that under special circumstances it increases the likelihood of spillovers occurring. These special circumstances have mainly to do with the spatial proximity of those firms. Autant-Bernard (2001a, 2001b) and Orlando (2000) model the relationship between technological and geographic proximity for inter-firm spillovers. They find geographic proximity for spillovers to be dependent on the tendency of related industrial activity to cluster geographically.

\subsection{Measurement Methods}

Complexity is not just a hallmark of the concept of spillovers, but also of the methods used to measure them. As spillovers are not recorded anywhere in the data, one has to measure their proxies (FDI, trade and patents) and their outcomes (innovative and economic benefits). In recent empirical studies scholars have employed a number of different approaches to quantify and qualify the existence and intensity of spillovers and the resulting productivity growths across countries (or firms). In the discussion below we present the various methods of measuring spillovers along with their shortcomings and assumptions.

Measuring spillovers is a complex task, primarily because just like knowledge, knowledge flows are also intangible and they leave no visible traces. Now in order to be able to measure spillovers one would need good indicators or proxies of knowledge flow. For this, it is important to understand how knowledge gets accumulated and how learning occurs. Absorptive capacity should be seen as the prerequisite of learning, but even its presence won't lead to leaps of wisdom and learning would rather be a gradual and cumulative process. New knowledge is created upon the foundations of previous knowledge in an evolutionary process (Nelson \& Sidney, 1982; Usher, 2013). Similarly knowledge is characterized by a certain degree of 'tacitness' owing to elements of knowledge which cannot be codified (Polanyi, 1967). Both the cumulative and tacit nature of knowledge render spillovers and innovation a local dimension (Audretsch \& Feldman, 1996; Jaffe, Trajtenberg, \& Henderson, 1992; Lawson \& Lorenz, 1999). Hence, this bounded mobility restrains spillovers within regions or other clusters which share common features such as technology, culture, language etc.

While looking for the right indicators one needs to distinguish between the conceptualizations of spillovers in order to aptly measure them. The next sections present a discussion on the indicators chosen according to the main conceptualizations of spillovers. 


\subsubsection{Indicators for rent spillovers}

Among the various types of spillovers, rent spillovers are the easiest to find indicators for, given their embodied nature. Generally they are measured through input-output flows or flows of international trade.

Terleckyj (1974) derived the estimates of R\&D embodied in purchased goods by summing the R\&D of the conducting industries, redistributing it in proportion to their respective sales as given in the Department of Commerce input-output matrices for intermediate and capital flows among industries within the national boundaries. Scherer (1984) uses linked patent and R\&D data in order to measure inter-industry technology flows within the USA. His method formed the basis for the 'Yale matrix', which is constructed on the basis of data from the Canadian Patent Office which in addition to allocating International Patent Classification (IPC) codes also assigns principal user and producing sectors to each patent. The Yale matrix method of measuring technology flows is presented by Putnam \& Evenson (1994). Coe \& Helpman (1995) use R\&D embodied in bilateral trade flows between countries to signify rent spillovers. DeBresson (1999) points out that because firms are in search of knowledge and partners across nationalistic boundaries for their innovative endeavors, I/O analysis may not be the indicator of choice due to its national, or at best, regional confinement. DeBresson \& Hu (1999) find that I/O-based indicators for spillovers are in general not very reliable for small, open economies.

Using patent data to measure rent spillovers has two problems as pointed out by (Verspagen, 1997b). Firstly, because they are focused on user-producer relationships, they have the tendency to ignore other forms of interactions like those which result from inter-sectoral technological linkages. Verspagen explains this by giving the example of a patent on fertilizers which may also be useful to sectors other than the one in which it is applied. The second issue in using patent data for constructing spillover matrices is that at least some features of pure knowledge spillovers are captured because the producer and user might also be related through a technological link rather than by just an economic transaction.

\subsubsection{Indicators for real (knowledge) spillovers}

Finding indicators for pure knowledge spillovers is trickier, given their intangible nature. Researchers however have used a number of proxies for measuring the impact knowledge spillovers have on the economic performance of a firm. Jaffe (1986) quantifies the effects on the productivity of firms' R\&D using research activity of its neighbors in the 'technology space' as a proxy for knowledge spillovers. Firms' pair-wise extent of overlap of their patents' technological classification characterizes this proximity in the technological space which he terms 'technological proximity'. 
Jaffe et al. (1992) and Jaffe \& Trajtenberg $(1996,1999)$ have used patent citation data as an indicator of knowledge spillovers. Patent documents, in principle, are exhaustive in terms of referencing earlier patent documents which in any way have contributed in the making of the patented invention. Therefore, they argue, it would not be wrong to interpret these citations as "...spillovers from the knowledge described in the cited patent to the knowledge in the citing patent." Maurseth and Verspagen, (2002) used the same approach to find out whether inter-country or intra-country technology flows are easier and likelier, and to measure the impact of geographical distance on these flows.

Based on the following criticisms, patents are at times precluded to be used as an output measure: Firstly, not all inventions are patented. Secondly, even if a patent is granted, it might not be commercialized. Lastly, industries vary in the degree of their patenting activities as some technologies are traditionally patented more than others.

Grossman \& Helpman (1991) in their work on spillovers assume commodity traders to be a proxy for knowledge flows, however they admit that their, "...approach has been too simple and too extreme".

Jaffe et al. (1992) use citations in patents for testing knowledge spillover localization highlighting that knowledge flows do 'leave a paper trail' unlike Krugman's (1991) assertion. Fritsch and Franke (2004) use R\&D expenditure of other firms to indicate spillovers and then measure its impact on the spillover receiving firm. Variables for both technological proximity and physical proximity are used as indicators by Bottazzi and Peri (1999) in their search for knowledge spillovers in European regions. Physical proximity is especially important for tacit type of knowledge. However the importance of physical proximity, even for transmission of tacit knowledge, has been challenged by Amin and Cohendet (2004). They emphasize the importance of "organizational, cognitive or relational proximity" for the transfer of tacit knowledge. Cohendet (2005) asserts that this type of proximity is present among individuals that belong to the same professional communities which could be communities of practice or epistemic communities and are referred to as 'knowing communities'.

Dumont \& Tsakanikas (2001) view technological proximity to be a more suitable indicator for the absorptive capacity of firms than for inter-firm spillovers. They altogether question the wisdom of using supplier-buyer linkages or patent data as a proxy measurement of spillovers and suggest using the mapping of inter-firm R\&D collaborations instead. They argue that this is a straightforward measure of knowledge spillovers which can complement or even readjust some of the findings that have resulted from using other indicators of knowledge spillovers. Verspagen (1997) compares technology matrices based on patent data to I/O-based matrices and concludes that $\mathrm{I} / \mathrm{O}$ based measures of spillovers do not capture knowledge spillovers well enough. 


\subsubsection{Macro vs Micro}

Apart from the conceptualization of spillovers, another distinction/qualification among the methods used to measure spillovers is with regards to it being a macro or micro approach. Macro or aggregate approaches use country-wide aggregate data (e.g. productivity) in order to analyze it for the presence of the spillover effect, whereas micro studies utilize firm-level data - in most cases Community Innovation Surveys asking firms which sources of knowledge they have found useful in their innovation process (Crespi, Criscuolo, and Haskel, 2008; Kaiser, 2002). The survey approach often has the drawback that it is not available systematically at an industry level or across countries and therefore custom-designed firm surveys are to be carried out by researchers, especially for developing countries. All the studies which we will discuss would fall into either the macro or the micro tradition in addition to another classification criterion, discussed below. We therefore will give references of studies not only based on micro/macro approach, but together with the other dimension.

\subsubsection{Direct vs Indirect approaches}

The direct and indirect approach for measuring spillovers differs in the way each looks at the way spillover measurement is possible. The indirect approach is based on the assumption that spillovers can't be measured directly. Economists, therefore, look for alternative ways to measure spillovers indirectly while using more or less crude proxy variables. We discussed the various proxies for spillovers in the section above, titled "Measures/Indicators of Spillovers". In the words of Crespo and Fontoura (2007), "the knowledge content of the spillover effect is inherently an abstract concept and thus not directly measurable, the approach usually adopted in the empirical literature consists in capturing the spillover effect in the framework of an econometric analysis in which labor productivity (or total factor productivity) of domestic firms is regressed on a number of covariates assumed to have an effect on productivity, including the presence of foreign firms." A common approach to the study of spillovers therefore requires the use of secondary data and the analysis of this data with the use of statistical methods. The earliest statistical analyses of intra-industry spillovers was conducted by Caves (1974) on Australian data, Globerman (1979) on Canadian data, and by Blomström and Persson (1983) on Mexican data. These researchers check for spillovers by investigating whether labor productivity in domestic firms are influenced by foreign presence using a production function framework. Foreign presence, expressed in terms of foreign share of each industry's employment or value added, is used as an explanatory variable in a multiple regression setting together with other firm and industry characteristics. This indirect approach can be further subdivided into two general methods. The first method analyzes the association of productivity of subject (e.g. country, industry, firm) $j$ and the $R \& D$ activity in subjects other than $j$ that are linked to 
the former via the various channels of spillovers, i.e. FDI, trade or technologi$\mathrm{cal} / g e o g r a p h i c a l$ proximity or where the various mechanisms of spillovers i.e. labor mobility, competition effect or demonstration effect are observed to play a role. R\&D activity could be measured in input terms, which would translate to man-hours or budget, or output, which would mean using number of innovations or patents etc. as indicators. The basic features of this approach were pioneered by Coe and Helpman (1995) in a very widely cited paper. Ever since, the basic empirical procedure for this approach is to estimate some variant of the following regression equation:

$$
\text { Productivity }_{j}=\text { Function }\left(X_{J}, R \& D_{j}, R \& D_{\text {spillovers }}\right)
$$

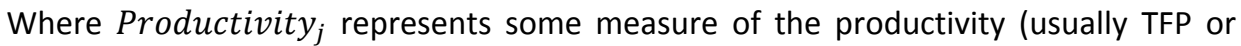
labor productivity) of subject $\mathrm{j}$, the vector $X_{J}$ is an array of subject features pertaining to its productivity, $R \& D_{j}$ is a measure of subject j's R\&D activity and $R \& D_{\text {spillovers }}$ is a weighted sum of R\&D activity in other subjects.

$R \& D_{\text {spillovers }}$ is given by

$$
R \& D_{\text {spillovers }}=\sum_{i \neq j} m_{i}(R \& D)_{i}
$$

Where $m_{i}$ give the weights and are constructed such that they reflect the intensity of potential spillover channels or the spillover mechanisms taking place between the receiving subject $\mathrm{j}$, and the sending subjects i. Coe and Helpman (1995) used the share of imports from country $j$ among trade partners of country $i$ in order to construct $m_{i}$. This way they take imports to be a channel and relevant proxy for spillovers. Later researchers have substituted weights to capture other potential spillover channels and mechanisms. Share of FDI from country $j$ in total capital formation of country $i$, share of imports of capital goods (rather than all goods) and share of direct and thirdcountry mediated trade have been the most common alternative measures of the weights. Geographical proximity between country j and i was used by Keller (2002) to construct the weights. This approach is based on the assumption that geographical proximity enhances spillovers through various channels and mechanisms.

The second indirect approach for measuring spillovers directly considers the relationship between the presence/intensity of the different channels and mechanisms of spillovers related to FDI and the productivity of the receiving subject there. This approach assumes that the raison d'etre of FDI is transferring technology across national borders through knowledge flows. Though the intention of MNCs in this regard could be doubted but the outcome is certainly undebatable (Blomström 1997). Researchers are interested in measuring the productivity benefits to the receiving country and in finding out those characteristics or policies of the receiving country which increase the benefits from technology spillovers. Various theoretical models have emerged recently that argue that MNCs generate technology spillovers to local firms through a variety of 
mechanisms and firm-level data has been used to study these mechanisms in detail. Labor mobility, demonstration effect and competition effect are considered as the most important ones.

The most commonly used empirical approach for detecting technological spillovers directly through the presence of various spillovers channels and mechanisms estimates the following model:

$$
\text { Productivity }_{j k}=\text { Function }\left(X_{j}, S C_{k}\right)
$$

Where Productivity $_{j k}$ measures the productivity of firm $\mathrm{j}$ in sector $\mathrm{k}$ as a function of a vector of firm characteristics $X_{j}$ and of some measure of the presence and intensity of FDI related spillover channels in sector $k, S C_{k}$. Country subscripts are usually not required as firm-level data for one country is analyzed in these studies. The most commonly considered spillover channels are geographical proximity (Bönte, 2008; Breschi \& Lissoni, 2001; Oerlemans \& Meeus, 2005; Rallet \& Torre, 1999) and linkages to MNCs. Similarly the most commonly studied spillover mechanism is labor mobility (Balsvik, 2011; Jaffe \& Trajtenberg, 1996; Kesidou \& Romijn, 2008; Maliranta, 2009). Though theoretical largely treats the channels through which spillovers may occur as a black box, researchers have explored these channels in a bit more detail with the help of customized surveys. For instance, the labor mobility channel for spillovers has been underscored both in the empirical literature (Görg \& Greenaway, 2004) and in theoretical models (Fosfuri et al., 2001; Glass \& Saggi, 2002). Görg and Strobl (2005b) in a first of its kind study use a firm level data set from Ghana with details of its owners' previous MNC experience. This information is taken as indicative of a firm-specific link between the domestic firm and its multinational counterparts. The study finds a positive relation between managers' previous MNC experience and the productivity of domestic firms. Balsvik (2011) includes such indicators in a Cobb-Douglas production function framework to study labor mobility's effect on productivity spillovers.

Both the approaches discussed above establish the presence of spillovers indirectly from the productivity benefits of the receiving economy/firm. The limitation however of this approach is that spillovers are established based on correlations and determining the direction of causation is quite complex.

The direct approach is aimed at directly identifying any available trails that reveal the existence of knowledge and technology spillovers. Most commonly, patent citations to previously issued patents are analyzed, assuming them to be an econometrically legitimate indicator of knowledge spillovers ( Jaffe, Trajtenberg, and Fogarty 2000). The basic idea behind this approach is that when a new patent cites an older patent, this is an acknowledgement of the contribution of the older patent to the development of the new idea. Hence, the citation reference indicates a spillover and is therefore also referred to as a paper trail (Jaffe, Trajtenberg, and Henderson 1992). 
Patent citation data can be used as a proxy for knowledge flows in two different ways. One can either use the intensity of patent citations between firms as a measure of 'closeness' facilitating knowledge flows or the number of citations can be used as an imperfect proxy for the actual volume of knowledge flows. Despite all its shortcomings there is evidence that patent-based indicators are better in capturing knowledge spillovers than trade-based indicators (Belderbos and Mohnen 2013). This method emphasizes the geographic localization of technology spillovers. Though patent citations can be seen to reflect knowledge flows, it must be noted that they cover only a small spectrum of all actual and potential knowledge flows. Moreover, this method is not an alternative for the other methods, as it only identifies the characteristics and intensity of technological spillovers but is unable to quantify benefits from productivity (Peri, 2009).

\subsubsection{Some stylized facts to take into account while measuring spillovers}

Based on the review of the literature, Belderbos and Mohnen (2013) summarize a number of stylized facts that measures of spillovers should take into account:

- $\quad$ Despite the theoretical distinctions made between rent or pecuniary spillovers and pure or non-pecuniary spillovers it should be noted that this distinction is difficult to make empirically.

- It is possible to measure knowledge spillovers directly (through surveys or patent citations). Similarly their intensity can be estimated from various measures of 'proximity' (physical or technology) between economic agents (e.g. firms, countries), and/or various interaction measures and transfer mechanisms (e.g. FDI, trade).

- $\quad$ Backward spillovers (from customers to consumers) seem to have been ignored in literature despite their importance in the FDI literature. Customers' targeted demands can be a source of spillovers.

- $\quad$ Both inward and outward FDI can be a source of international spillovers. Similarly both imports and exports induce spillovers.

- $\quad$ Robust comparative evidence on the different mechanisms of knowledge spillovers and their relative roles are hard to find.

- While comparing with trade data, patent citation data appear to be a better measure of international knowledge diffusion, mainly because trade data can be biased in physical space due to practical cross-border barriers.

- Magnitude of spillovers are dependent on the quality of the R\&D of the sender (i.e. firms, industries, countries closer to the technology frontier will generate more spillovers). 
- As spillovers are dependent on the absorptive capacity of the receiving firms/countries, developed countries benefit more from international knowledge diffusion than developing countries.

- $\quad$ Spillovers are moderated by technological proximity between the receiving and sending firms or industries.

- $\quad$ Spillovers may be weak or negative between in case firms have highly overlapping knowledge bases (as there is little or nothing to learn), and between firms that are competitors in the same market (through imitation and demonstration effects).

- $\quad$ Spillovers decay over distance due to their localized nature, particularly the sticky nature of knowledge (tacit knowledge).

\subsection{The next step}

Having discussed all the possible definitions and classifications of spillovers along with the methods available to measure them, the obvious question now is which of these are relevant for our work and which methods are we going to use for qualifying and quantifying spillovers.

As highlighted in the introduction, we take three different and unique approaches in this study. The first one is about identifying structural changes in the various industrial sectors and that doesn't utilize the spillover phenomenon. The next approach used is about ascertaining and measuring the impact of spillovers, mainly from FDI. Here onwards the study is set in the micro tradition. The last approach gives us a networks perspective of intra-firm knowledge flows. We attempt to estimate what it means to be 'better connected'. The spillover concepts discussed here, be it the various conceptualizations, classifications, channels or the mechanisms, have guided us in designing our questionnaire and then later in analyzing the data for the presence of these very concepts. Please refer to Chapter 6 (Section 6.3) for a detailed discussion of the relevant theory and its importance for our research. 


\section{Chapter 3. Pakistan's Economic and Political Backdrop}

\subsection{Introduction}

The aim of this chapter is to provide an overview of long-term economic and political developments in Pakistan. This provides a background for the subsequent analysis of performance of the Pakistan IT sector and the firms in this sector.

Despite achieving steady long-term economic growth and making a successful transition from a purely agricultural to an industrial country, Pakistan still faces many of the same problems it was born with. Considerable achievements in technology and commerce have been overshadowed by its dismal performance on social indicators like poverty, health and education. Pakistan's geostrategic location - it is dubbed as the 'fulcrum of Asia' - as well as its colonial history culminating in the troubled and violent independence as a nation in 1947 have been deeply influential in determining its future course. It is impossible to understand Pakistan's current achievements, or for that matter its problems, without this geostrategic and historical context. Even more so is it important to highlight the circumstances around the country's inception and the formative years (Blood, 1996).

The partition plan for the Indian sub-continent was drawn up by the British in an atmosphere of urgency as a wave of ethnic and religious turmoil shook the colony. Lord Louis Mountbatten, the last British viceroy of India, was given the contentious task of carving out one country from another. Eventually, the British Raj was dismantled on $14^{\text {th }}$ August 1947, with it being partitioned into two sovereign states, India and Pakistan. Pakistan comprised the north-eastern and north-western parts of what was previously known as British India. As the two regions were separated by over a thousand miles of Indian land, they came to be known as East Pakistan and West Pakistan. East Pakistan included the major portion of Bengal and its contiguous district of Sylhet from Assam. The territories of Baluchistan, Khyber-Pukhtunkhwa ${ }^{17}$, Sindh, and the western part of the Punjab formed West Pakistan. With a total population of approximately 75 million and a cumulative territory of 420,655 square miles, Pakistan at birth was the seventh most populous country in the world, larger in size than any European country except Russia. This experiment of joining two territories separated not only by land, but also by language, culture and interests was doomed to fail. The perception, at times justified, of the West wing prospering as a metropolitan area and the more pop-

\footnotetext{
${ }^{17}$ Khyber Pukhtunkhwa (KPK) was formerly known as North-West Frontier Province (NWFP)
} 
ulous East being left deprived and neglected only added fuel to fire. In 1971, after an uprising of the people of East Pakistan followed by a war with India, that supported the East Pakistani cause, another sovereign state, Bangladesh, was born. The 'new' Pakistan consists of what was West Pakistan at Independence in 1947.

In this overview, we have divided Pakistan's economic history into the following six distinct eras:

- $\quad$ Post-independence Era (1947-1971): This section spans from independence in 1947 till 1971 when East Pakistan separated from West Pakistan to form a sovereign state. We start with discussing the initial conditions right after partition as understanding the circumstances of that particular time is paramount in order to be able to appreciate Pakistan's growth and development trajectory.

- Bhutto Era (1971-1977): From 1971 till 1978 when the charismatic Zulfiqar Ali Bhutto, founder of the Pakistan People's Party (PPP) was Pakistan's Prime Minister and introduced socialist economic policies.

- Zia-ul-Haq Era (1977-88): From 1978 till 1988 when General Zia, as a result of a bloodless coup against the Bhutto government, usurped power only to relinquish after 11 years when he was killed under mysterious circumstances in a mid-air explosion.

- $\quad$ Political Musical Chairs Era: From 1988 till 1999 when Mrs. Benazir Bhutto and Mr. Mian Nawaz Sharif were alternating power every 2 to 3 years and both were elected to office twice as Prime Ministers.

- Musharraf Era (1999-2008): This is the period when the country was ruled by the Army ruler, General Pervez Musharraf, who came into power by staging a bloodless coup against the then Prime Minister Mian Nawaz Sharif.

- Zardari Era (2008-2013): The widower of Benazir Bhutto, Mr. Asif Ali Zardari secured a majority in parliament as the co-chairperson of Pakistan People's Party. He chose to become the President, more of a symbolic post, and held the reins of power by installing his close aides in all posts of power including that of Prime Minister.

These eras are based on the various political and military regimes which have ruled the country since 1947 . The political dimension is important in understanding economic progress and more so in Pakistan where changing regimes have been the prime reason behind disruption of economic policies. Similarly, often times the motivation behind economic policies can only be understood by the political motives of the respective regime and the prevailing political context. In this spirit, in this chapter we first discuss the post-partition period starting with the initial conditions and how these have shaped the economic policies adopted at that time and their long-term impact. We discuss the imposition of Pakistan's first Martial Law and how the economic policies of that period contributed towards growth. The reasons, specially related to economic and political dimensions of disparity, which led to the rebellion and eventual breakaway of East Pakistan into a separate country are also discussed in detail. We then focus 
on the post-Bangladesh partition era which was a turning point in Pakistani's economic history because of Bhutto's socialist leaning policies. We then cover the era of Zia's military dictatorship, which happens to be the longest in Pakistan's history. Wherever necessary for explaining domestic political developments, we bring in the global context as is the case in Bhutto's fall and Zia ascension to power. Zia's sudden demise in a plane-crash was seen by many as an opportunity for democracy to prosper. But in fact, political infighting, widespread corruption and economic failure were hallmarks of the next era, where in the period of 11 years 4 governments were formed and all prematurely dismissed, the last one through a military coup. We also refer to the various 5year development plans in the sidelines of our discussion. Then, we analyze the era when Musharraf took over as chief executive of the state in great detail. This is justified not only by the fact that many reforms were undertaken during his period, but also because the 'new world order' after the 9/11 attacks on the US unfolded during this time and many of its consequences still haunt the Pakistani economy and society today. We discuss not only the policies during that regime, but also all the challenges it faced, be it terrorism, electricity shortages, gas shortages or medical emergencies, because we are convinced that it is not possible to understand economic policies without the broader context of problems in which they are set.

\subsection{Post-independence era $(1947-1971)$}

\subsubsection{Initial conditions}

The account of Pakistan's economy in this section refers to the 'old' Pakistan that existed from August 1947 till 1970. It is no secret that since Pakistan's inception as a sovereign state it has faced counterproductive circumstances that are not conducive for growth ${ }^{18}$. It is also established that partition affected Pakistan much more adversely than India due to various circumstantial factors. The massive movement of refugees out of and into Pakistan created several challenges. Refugees from the Indian state formed 10 percent of Pakistan's total population (20 percent in West Pakistan) ${ }^{19}$. Settling them down and making them part of the economy posed a huge challenge considering the fact that these people had almost no belongings. Similarly, 10 percent of West Pakistan's population left Pakistan for India. Those leaving were mainly Hindus. Muslims have culturally abstained from certain professions and practices, interestbased money lending being one of them. On the other hand, Hindus are known for their banking and commercial acumen and also for their affinity towards Western education, which Muslims at that time shunned. This explains why the emigrants were a huge loss in terms of bankers, businessmen and technical people.

\footnotetext{
${ }^{18}$ Growth here refers to the increase in GDP and would also hold true for other definitions broadly accepted.

${ }^{19}$ India had only 2 percent refugees from Pakistan
} 
Another challenge was posed by the unequal distribution of assets which at the time of partition were either concentrated in areas which were to become the secular republic of India or otherwise were not handed over to the fledgling state of Pakistan. To quote one example, the division of assets and liabilities (including hard money) of the Reserve Bank of India (RBI) remains and unfinished business to this day as per State Bank of Pakistan (SBP) records. According to the SBP, India still owes it a little over Rs. 5.6 billion equivalent to the present-day value (actual amount in 1948 was Rs. 490.8). Each of the SBP issued Statement of Affairs in the last 67 have been listing the unsettled claims on the RBI among its "assets". ${ }^{20}$ While Pakistan inherited primarily agricultural areas which produced raw materials and surplus foodgrains, the great port cities and centers of trade and industry remained in India. In particular, jute- and cotton-growing areas were cut off from their processing centers and also their ports of Calcutta and Bombay in India. Similarly, the lion's share of the subcontinent's resources went into Indian hands. Though it made up only four fifth of population, nine tenths of the industry and almost all the military resources were appropriated by India (Brown, 2006). The banking and other commercial sectors too had a difficult start after partition because most had their head offices in neighboring India. Though the transportation network of West Pakistan was relatively better, East Pakistan inherited a poor road and communication network.

Pakistan's political scene has always been dominated by powerful landlords. This precedes Pakistan's creation. In order to acquire allegiances from leaders within the society, the British rewarded them by allotting them enormous tracts of lands. This was even further aggravated by the 1945 general elections and 1946 provincial elections in India in which land ownership was a condition for standing for political office as a result of which only 15 percent of the population was eligible. Consequently, in Sindh and Punjab assemblies 90 percent elected members were big land lords. This left such a deep impression on Pakistan's electorate that in the nation's first ever general elections held in 1971 more than 80 percent of those elected were landlords.

The nation suffered another setback when its founder, Muhammad Ali Jinnah known respectfully as the Quaid-i-Azam (Great Leader) - passed away only thirteen months after independence, in September 1948. His untimely demise made the nation realize his dominant role in Pakistan's creation as he left behind no peers, only aides. Liaquat Ali Khan was his right hand man and became Pakistan's first prime minister. He was assassinated only 3 years after Jinnah's death, plunging the country into a leadership crisis. The successors were generally lackluster and incompetent politicians willing to give-in to populist demands of a politically immature electorate. National concerns were shunned by these politicians in favor of ethnic and provincial causes.

${ }^{20}$ Details can be read at: http://tribune.com.pk/story/736390/post-partition-india-still-owes-pakistan-alittle-over-rs5-6b-says-state-bank/ 
Another mishap during this unnatural birth of Pakistan was the Kashmir dispute ${ }^{21}$, the consequences of which the nation has borne since its inception and continues to bear today in form of disproportionate spending on defense. Not to mention the impact of three wars which Pakistan and India have fought over Kashmir (see table 3.1 and for a detailed political timeline see table 3.2) and the numerous occasions in the 67 year old history when Pakistani and Indian forces were eyeball to eyeball on their respective boundaries $^{22}$. Kashmir has been the bone of contention between the two neighboring countries and its cost to Pakistan's economy is one which can't be overlooked but still is incalculable (Lavoy, 2005). As a reflection of the seriousness of these perceived threats, in 2013 Pakistan spent US\$7.6 billion on defense, which amounts to 3\% of its GDP and ranks 29th highest in the world both in terms of total spending and military expenditure as a percent of $\mathrm{GDP}^{23}$. This disproportionate defense spending is not new. Data suggest that an arms race ensued between India and Pakistan as early as partition. The first war between the two countries in the Kashmir issue which was fought right after independence is indicative of the motivation behind the arms race early on.

Table 3.1 Major Conflicts between India and Pakistan, 1947 - Present

\begin{tabular}{lll}
\hline & Year & Place \\
\hline First Indo-Pakistani War & $1947-1948$ & Northern Kashmir \\
Second Indo-Pakistani War & 1965 & Punjab and Sind \\
Third Indo-Pakistani War & 1971 & East Pakistan \\
Kargil War & 1999 & Indian-held Kashmir around Kargil \\
\hline
\end{tabular}

Adopted from Hou, (2009)

Pakistan spent $3.1 \%$ of its GNP on defense in 1960 as compared to India's $2 \%$. These figures got further inflated while both the countries pursued covert indigenous programs to develop nuclear weapons and peaked in 1988 when Pakistan's defense spending stood at $6.4 \%$ of its GDP and India's at 3.6\%.

Pakistan officially maintains that it acquired nuclear technology as a 'deterrent' only. However, it has a standing army of over 5 million soldiers and almost the same number of reservists chiefly as a result of the Kashmir issue. Interestingly, the below average health and education spending could be explained by the above average de-

\footnotetext{
${ }^{21}$ Kashmir, with a majority Muslim population had a Hindu ruler at the time of independence who opted to join India. Before any formal decision as to whether Kashmir would join India or Pakistan was made, a war on this broke out abruptly. It lingered on for 16 months, until a ceasefire left Pakistan controlling a third (known in Pakistan as Azad Kashmir) and India two thirds of it. The future of Kashmir as a whole remains unresolved till date. Relations between India and Pakistan have been poisoned ever since, increasing military spending on both sides and enhancing the role of the armed forces in Pakistan even more.

${ }^{22}$ As recently as 1999, there were skirmishes with India in Kargil resulting in a million soldiers deployed across the India-Pakistan border. The costs of such escalations for the respective tax-payers is huge in monetary terms.

${ }^{23}$ SIPRI Military Expenditure Database 1988-2013.
} 
fense spending pattern of Pakistan as compared to other countries, which have been balancing-out each other for decades (Easterly, 2003). The dominant role of the army was formalized early on, when a military coup in 1958 led to the 11-year dictatorial rule of General Ayub Khan, followed by a repetitive pattern of military interventions (1977: General Zia ul-Haq, 11 years, 1999: General Pervez Musharraf, 9 years ${ }^{24}$ ).

The Nuclear Threat Initiative (NTI) ${ }^{25}$ notes that the beginnings of Pakistan's nuclear program date back to the late 1950s. A first step towards this objective was the establishment of the Pakistan Atomic Energy Commission (PAEC) in 1956. Zulfiqar Ali Bhutto is said to be a staunch advocate of the nuclear option and is quoted saying in 1965 as Foreign Minister that "if India builds the bomb, we will eat grass or leaves, even go hungry, but we will get one of our own." (Khan, 2012). This marked the official beginning of the technological nuclear arms race and the resolve to acquire a nuclear capacity only strengthened further after the December 1971 defeat in the conflict with India. A directive was issued by Bhutto ordering the country's military to build a nuclear bomb within three years (Perkovich, 2008). India's detonation of a nuclear device at the Pokhran region of the Rajasthan state in May 1974 codenamed Smiling Buddha was termed a "peaceful nuclear explosion" by the then Indian government. However, according to independent sources, it was actually part of an accelerated covert nuclear program and hence further pushed Islamabad to expedite its nuclear weapons program. Though Pakistan was not to test its nuclear capability for 24 years, both India and Pakistan began to develop nuclear-capable rockets and nuclear military technologies. On May $11^{\text {th }}$ and $13^{\text {th }}, 1998$ India test detonated another 5 nuclear weapons. In a tit-for-tat reaction, Pakistan test detonated 6 nuclear devices on the $28^{\text {th }}$ and $30^{\text {th }}$ of the same month. On the one hand Pakistan would herald this achievement, equaled by only 7 other nations, as a proof of its technological and industrial potential. On the other hand it cast a dark shadow on its integrity as skeptics would question the way the technology was acquired, alleging that this was done through stealing, purchasing on the nuclear black market and financing through nuclear proliferation. Irrespective of how the technology was acquired, the people of Pakistan had to pay a huge price in terms of tax revenues spent on the nuclear program.

\footnotetext{
${ }^{24} \mathrm{He}$ remained the de facto ruler of the country for almost 9 years, whereas calling himself the Chief Executive of the country for the first 2 years of his rule and subsequently being elected as the President.

${ }^{25}$ “Nuclear Threat Initiative (NTI) is a nonprofit, nonpartisan organization with a mission to strengthen global security by reducing the risk of use and preventing the spread of nuclear, biological, and chemical weapons and to work to build the trust, transparency, and security that are preconditions to the ultimate fulfillment of the Non-Proliferation Treaty's goals and ambitions." Source: www.nti.org
} 
Table 3.2 Pakistan's political timeline

\begin{tabular}{|c|c|}
\hline Year & Significant political event \\
\hline 1947 & Pakistan is created. \\
\hline 1948 & First war between Pakistan and India over Kashmir. \\
\hline 1951 & Prime minister Liaqat Ali Khan assassinated. \\
\hline 1958 & After a military coup Field Marshal Ayub Khan takes over. \\
\hline 1965 & Second war between India and Pakistan over Kashmir. \\
\hline 1969 & General Yahya Khan declares martial law and assumes presidency. \\
\hline 1971 & $\begin{array}{l}\text { East Pakistan attempts to break away, leading to civil war in which India intervenes resulting in the } \\
\text { third war between the two which ends in creation of independent Bangladesh. }\end{array}$ \\
\hline 1977 & $\begin{array}{l}\text { General Muhammad Zia ul-Haq overthrows prime minister Zulfiqar Ali Bhutto and declares martial } \\
\text { law. }\end{array}$ \\
\hline 1979 & Zulfiqar Ali Bhutto hanged. \\
\hline 1988 & General Zia dies in a plane crash; Benazir Bhutto becomes prime minister. \\
\hline 1990 & $\begin{array}{l}\text { President Ghulam Ishaq Khan dismisses Benazir Bhutto government; Mian Nawaz Sharif becomes } \\
\text { the next prime minister. }\end{array}$ \\
\hline 1993 & $\begin{array}{l}\text { President Ghulam Ishaq Khan and Prime Minister Nawaz Sharif both resign under military's pres- } \\
\text { sure. Benazir Bhutto becomes prime minister for the second time. }\end{array}$ \\
\hline 1996 & President Farooq Leghari dismisses Bhutto's government. \\
\hline 1997 & Nawaz Sharif elected prime minister for the second time. \\
\hline 1998 & Nuclear tests conducted by Pakistan. \\
\hline 1999 & $\begin{array}{l}\text { Kargil war in Indian held Kashmir. General Pervez Musharraf overthrows Prime Minister Nawaz } \\
\text { Sharif in a military coup. }\end{array}$ \\
\hline 2005 & An estimated 80,000 people in northern Pakistan are killed due to a 7.5 magnitude earthquake. \\
\hline 2007 & $\begin{array}{l}\text { Nawaz Sharif and Benazir Bhutto return to Pakistan after } 7 \text { and } 8 \text { years of forced exile respectively. } \\
\text { Benazir Bhutto is assassinated later the same year. }\end{array}$ \\
\hline 2008 & Asif Zardari, widower of Benazir Bhutto wins presidential election. \\
\hline 2010 & $\begin{array}{l}\text { Heavy rains cause floods submerging one-fifth of Pakistan and affecting } 20 \text { million people directly. } \\
\text { Close to } 2000 \text { people die. }\end{array}$ \\
\hline
\end{tabular}

Source: Author's own compilation 


\begin{tabular}{|c|c|c|c|c|c|c|}
\hline & 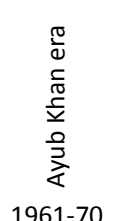 & 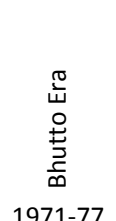 & $\begin{array}{c}\frac{\pi}{\amalg} \\
\stackrel{\pi}{N} \\
1978-88\end{array}$ & 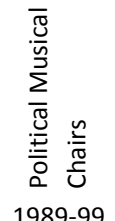 & $\begin{array}{l}\frac{\pi}{4} \\
\frac{1}{\pi} \\
\frac{2}{2} \\
\frac{\pi}{5} \\
\frac{5}{3} \\
\stackrel{5}{\Sigma}\end{array}$ & 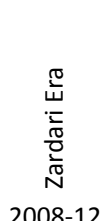 \\
\hline & & & & & & \\
\hline GDP growth (average \%) & 7.2 & 3.6 & 6.9 & 4.1 & 5.0 & 2.6 \\
\hline GDP per capita growth (average \%) & 4.5 & 0.6 & 3.4 & 1.3 & 3.0 & 0.8 \\
\hline Agriculture, growth (average \%) & 5.1 & 1.6 & 3.9 & 4.5 & 3.4 & 2.2 \\
\hline Industry, growth (average \%) & 11.0 & 4.8 & 8.6 & 4.7 & 6.6 & 2.8 \\
\hline Manufacturing, growth (average \%) & 9.9 & 3.8 & 9.2 & 4.3 & 8.7 & 1.6 \\
\hline Services, etc., growth (average \%) & 6.8 & 5.7 & 7.3 & 4.5 & 5.5 & 3.8 \\
\hline
\end{tabular}

Source: Author's own computation from World Bank national accounts data, and OECD National Accounts data files

Table 3.4 GNP/GDP Annual Growth Rates under Different Plan Periods

\begin{tabular}{|c|c|c|c|c|c|c|c|c|c|c|c|}
\hline & 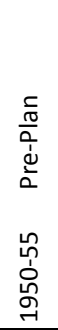 & 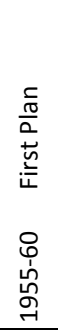 & 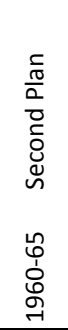 & 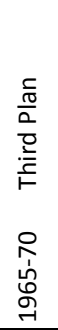 & 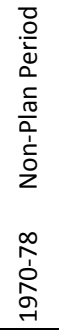 & 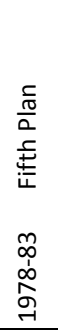 &  & 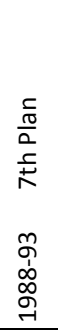 & 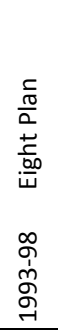 & 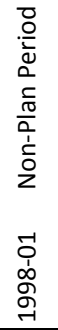 & 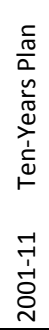 \\
\hline GNP (Factor Cost) & - & 3 & 6.8 & 6.7 & 5.2 & 6.4 & 5 & 4.2 & 3.9 & 3.4 & 5.3 \\
\hline GDP (Factor Cost) & 3.1 & 3 & 6.8 & 6.6 & 4.4 & 6.6 & 6.2 & 4.8 & 4.3 & 3.5 & 5.4 \\
\hline \multicolumn{12}{|l|}{ Sectors } \\
\hline Agriculture & 1.2 & 2 & 3.8 & 6.3 & 1.8 & 4.5 & 3.5 & 4 & 5.9 & 1.8 & 3.8 \\
\hline Manufacturing & 4.4 & 5.2 & 11.7 & 8.1 & 4.5 & 9.9 & 8.2 & 5 & 3.6 & 4.3 & 6.9 \\
\hline Others & 3.9 & 3.5 & 8.3 & 6.5 & 6.2 & 6.9 & 7 & 5.2 & 3.8 & 4.1 & 5.9 \\
\hline
\end{tabular}

Source: Author's own computation from World Bank national accounts data, and OECD National Accounts data files

Though detailed data on the economy and its structure are limited for the period before 1949-50, it is known that the annual per capita income equivalent to roughly US\$ 60 (current) at partition was not enough to keep the newly formed state off the list of the world's poorest countries (Raychaudhuri et al., 1983). Despite Pakistan's sizeable population, the low per capita income resulting from low productivity and traditional peasant agriculture - which engaged about 75 percent of the entire population and accounted for 60 percent of total GNP - further contributed to a slow start and unimpressive growth. The over-reliance on agriculture, despite it being uncompetitive, had 
to do with the fact that Pakistan had almost no significant industrial sector or any known (at that time) natural resources. On the other hand it was so well endowed with agricultural resources that despite its low productivity (when compared to other countries, especially in the region) and the resulting low yields, there was net surplus of foodgrain and other cash crops. Moreover, West Pakistan was known for its well laid-out irrigation network and East Pakistan would fulfill its irrigation needs from the monsoon rains and river flooding. West Pakistan mainly cultivated wheat and cotton, exporting the surplus of grains and cotton. East Pakistan produced rice and jute, meeting domestic requirements of rice and exporting all the jute produced. As the major port cities, trade centers and industrial hubs were in the Indian territory, Pakistan's major trade was with India, who would then utilize the processing centers which it inherited and export the finished goods through its ports of Calcutta and Bombay. Pakistan would exchange its exports against mainly consumer goods, imported from India. This symbiotic relationship didn't last long due to the belligerent stance of the countries to each other and the resulting political and military adventurism. The three wars fought in the next 3 decades bear witness to the level of hostility. The cessation of trade between the two countries hit Pakistan harder than India and it was the main reason behind disappearance of the export markets of jute, rice, cotton and wheat.

These are just a few of the problems which confronted Pakistan from the very beginning. There were many others like the internal strife between different ethnicities, sectarianism, lack of a concept of nation-hood ${ }^{26}$, and feuds between Mohajir (emigrants from India) and Sindhi (local population of the Sindh Province), which are not discussed here.

Despite challenging initial circumstances, it is argued that some hardships also had some advantages in the longer run. For instance, as the whole industrial and commercial structure was left in tatters and had to be built from scratch, it gave enterprising entrepreneurs more opportunities. As Pakistan had virtually no industry or commerce at the time of partition, it could be argued that the advantages of backwardness (copying the rest of the world) outweighed its disadvantages (greater difficulties in resource mobilization). Immigrants are known to be more enterprising and energetic than people who have always stayed home. This was proven by Pakistan's new industrialists who mostly belonged to Indian refugees. Similarly, the exodus contributed towards Pakistan achieving land reforms quicker than India.

In terms of initial conditions there have been a few favorable factors which are also worth mentioning here. Half of West Pakistan's agricultural land was irrigated at the time of partition which in the 1970s increased to three quarters. Also, there are fewer traditional and cultural obstacles, as compared to India. For instance there are

\footnotetext{
${ }^{26}$ The 'two nations' theory (which was the founding principle and argument in favor of a separate homeland, Pakistan) could not for long cover up the fact that the people actually belonged to at least six distinct linguistic groups; Bengalis, Balochis, Pashtuns, Punjabis, Sindhis and Urdu speakers emigrated from India (Mohajirs).
} 
no caste restrictions or taboos on animal husbandry. Similarly the notorious monsoon floods of East Pakistan are not as bad as India's droughts. Moreover, in terms of receiving foreign aid, especially from the USA, Pakistan has outperformed its neighbor due to its geostrategic location as a South Asian frontier located at the juncture of Central Asia, South Asia and West Asia.

\subsubsection{Policy frame-work}

Pakistan's economic growth has been slower than the average pace for developing countries, and the gap cannot be explained solely by the above mentioned unfavorable initial conditions and other exogenous constraining factors. Scholars have therefore inferred that Pakistan's economic policy making process and the policies themselves were deficient right from the beginning and have identified the following main deficiencies:

i. Lack of a clear economic policy for development till 1958

ii. Imposition of price controls which were a severe deterrent to agriculture

iii. A thorough mechanism of industrial control which harmed allocation of domestic resources

iv. Maintenance of highly overvalued exchange rates

v. Trade erosion with India due to tariff and non-tariff barriers erected by both countries. Consequently increased trade with other foreign countries, many of which were far away, incurring higher costs.

vi. Military-civilian games of musical chairs over the executive

vii. Interference of bureaucratic-military elite in governance even during civilian rule

\subsubsection{Growth at the expense of social development}

Another feature of Pakistan's growth, apart from it being slow, has been the fact that it was achieved at the expense of social development. Maddison (2013) terms this tradeoff as "functional inequality" arguing that Pakistani policy-makers saw a conflict between equity and growth with the belief that growth in the longer run would compensate for social development. On ground facts however prove this wrong and paint a rather bleak picture of all social indicators. Some examples of such pro-growth and anti-equity policies are low income taxes, a free hand to develop monopolistic groups, no nationalization, no village uplift programs, and imprisonment of trade-union leaders. Furthermore, the ceiling of holdings as a result of a land reform program was fixed at 500 acres instead of the 50 acres generally the case in neighboring India. Beyond doubt, it was for such policies that the main benefits of the expansion in agricultural output in West Pakistan in the 1960s have gone to the large capitalist farmers. 


\subsubsection{Statistics of Growth and Structural Changes}

Pakistan's economic performance started out very well and it impressed economists for years. When seen in a regional context, Pakistan had the highest growth rate in South Asia for the 20 years after its independence. According to a World Bank (2002) report, Pakistan exported more manufactures than Indonesia, Malaysia, Philippines, Thailand and Turkey combined in 1965. Annual GNP data is available starting from 1949-50 as shown in table 3.5. Manufacturing accounted for 5.9 percent of the total, of which large-scale was only 1.5 percent and the remaining 4.4 percent comprised small scale. This low share gets explained by the fact that in addition to a small oil refinery and a few cotton textile mills, sugar mills and a couple of cement plants, there were only agricultural processing industries installed at that time. Among them were jute baling, cotton ginning, wheat milling, rice husking and tea processing.

Though agricultural output was growing initially, population growth outpaced it (see table 3.6). Later, in the 1950's agriculture growth came to near-stagnation only to be revived in the 1960's through the 'Green Revolution' program which introduced new technologies in agriculture, the most prominent of which was high yielding varieties (HYV) of foodgrains (Jalal, 2012). The agricultural output changed dramatically, with a 3-6 percent annual increase during the period 1961-1965 with the peak annual increase being 15 percent from 1967-1968 (Child \& Kaneda, 1975). Along with an increase in crops, there was an increase in the technologies that are necessary for farming. Pakistan saw an increase in supply water, tube wells and ground water supply during the period of 1967-1976, allowing for better irrigation of the agricultural lands (Byerlee \& Siddiq, 1994).The increase in agricultural demand made the production of more crops a priority to the Pakistan government; as more crops meant more money. Wheat in particular was very profitable and its production nearly doubled from 1960 to 1970. Unfortunately the advantages of the Green Revolution were a short-run phenomena, the reasons for which have long been a source of debate (Ahmad, Shah, \& Zahid, 2004).

Table 3.5 shows the output of the economy and its distribution among major sectors at five-yearly intervals from 1949-50 through 1969-70. Table 3.3 and Figure 3.2 give the percentage shares of sectors in terms of their real output. It is clear from the two figures that in the longer run the manufacturing sector has been growing, in part at the expense of agriculture. Large scale manufacturing grew at a tremendous rate initially bringing manufacturing growth as a whole to substantial levels. The Pakistan Bureau of Statistics defines large-scale manufacturing as those units employing twenty or more workers and using power to operate their machinery. Towards 1970 the share of large-scale manufacturing had increased six fold. The disruptions caused by partition, the overvalued exchange rate, and the strict control of imports necessitated the stimulation of private industry. Moreover, Pakistan's efforts to quickly shift away trade from India, resulted in incentivizing domestic manufacturing, though at the cost of 
agriculture. At the time of partition, much of the economy, especially industry, was dominated by a small group of emigrants from India, the muhajirs. These were largely traders and they settled in Pakistan's cities, especially Karachi. These refugees initially started trading firms with their modest amounts of capital. Many of these trading firms transformed into industrial units in the 1950s as a response to industry-friendly government policies. The major part of investment and ownership in manufacturing during the first twenty years after independence was accounted for by these businessmen, largely using their own resources.

Table 3.5 Sectoral Value Added (Rs Million) and Sector shares in GNP (at 1959- 60 factor cost), 1949-70

\begin{tabular}{lcccccccccc}
\hline & \multicolumn{2}{c}{$1949-50$} & \multicolumn{2}{c}{$1954-55$} & \multicolumn{2}{c}{$1959-60$} & \multicolumn{2}{c}{$1964-65$} & \multicolumn{2}{c}{$1969-70$} \\
\hline Agriculture & 14669 & 60.0 & 15654 & 56.1 & 16753 & 53.3 & 19761 & 47.8 & 24501 & 46.2 \\
large-scale manufacturing & 346 & 1.5 & 1002 & 3.6 & 1565 & 5.0 & 3156 & 7.6 & 5083 & 9.6 \\
small-scale manufacturing & 1087 & 4.4 & 1218 & 4.4 & 1365 & 4.3 & 1555 & 3.8 & 1769 & 3.3 \\
Other & 8364 & 34.1 & 10034 & 35.9 & 11756 & 37.4 & 16894 & 40.8 & 23149 & 40.9 \\
& & 100 & & 100 & & 100 & & 100 & & 100 \\
\hline
\end{tabular}

Sources: GNP from Pakistan, Central Statistical Office, 25 Years of Pakistan in Statistics, 1947-1972, Karachi, 1972. Population from Pakistan, Planning Commission. Data include East Pakistan.

The differential rates of growth of industry and agriculture explain structural changes in the economy. The share of agriculture in total GNP fell from 60 per cent in 1949-50 to a little over 53 per cent in 1959-60, and the share of manufacturing in total GNP increased from below 6 per cent to over 9 per cent in the same period.

Figure 3-1 Gross national product (at 1959- 60 factor cost in Rs. million)

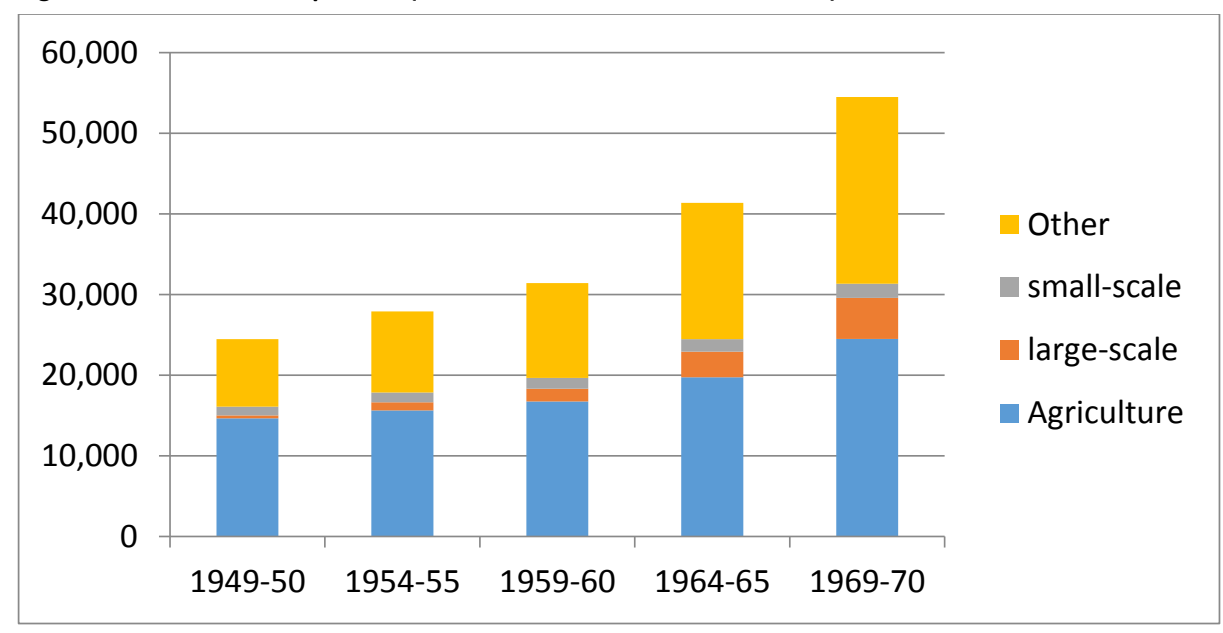

Adopted from Raychaudhuri et al., (1983), Sources: GNP from Pakistan, Central Statistical Office, 25 Years of Pakistan in Statistics, 1947-1972, Karachi, 1972.. Small scale refers to small scale manufacturing, large scale to large scale manufacturing. 
Figure 3-2 Sector shares in GNP (at 1959-60 factor cost) (\% shares in GNP)

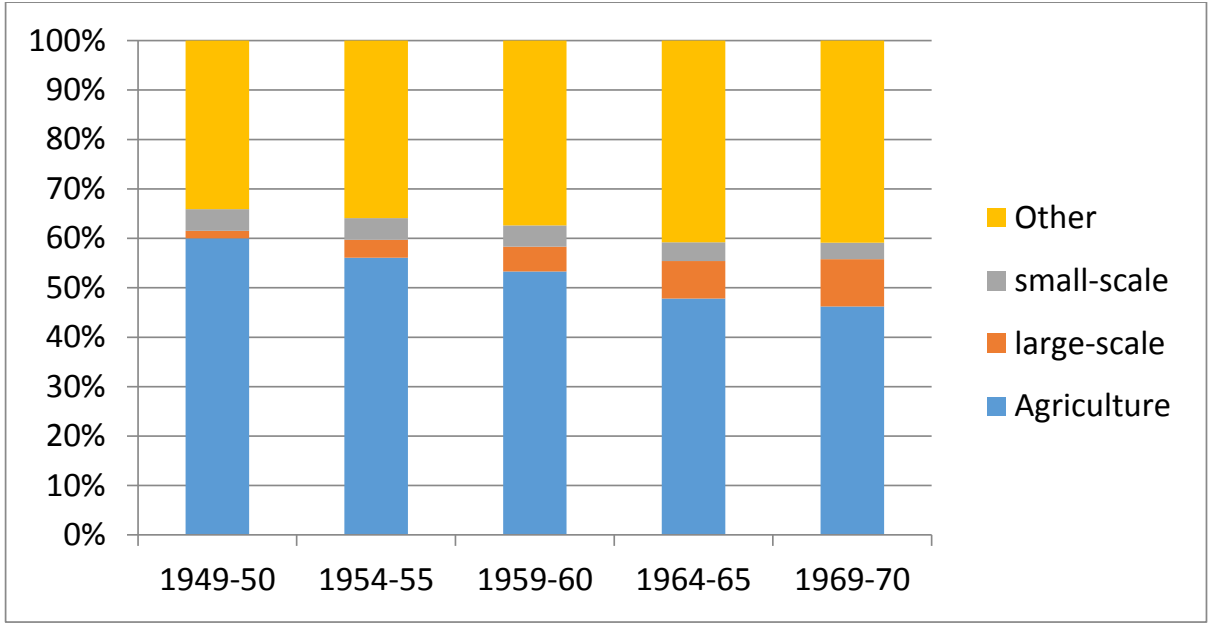

Adopted from Raychaudhuri et al., (1983), Sources: GNP from Pakistan, Central Statistical Office, 25 Years of Pakistan in Statistics, 1947-1972, Karachi, 1972.

Figure 3-3 Gross national product, population and per capita income (at 1959-60 factor cost)

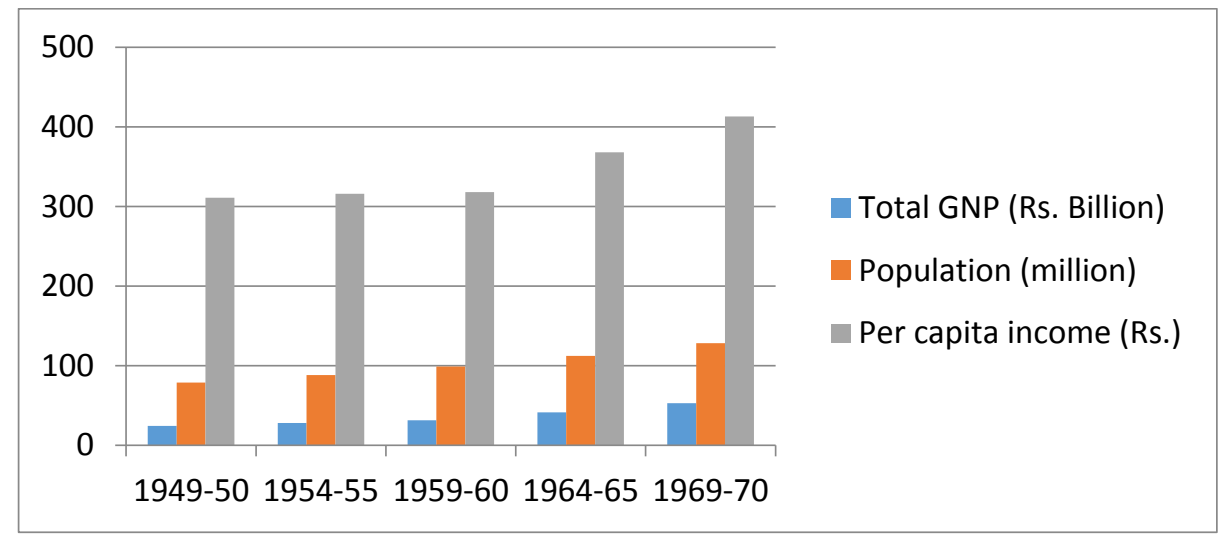

Adopted from Raychaudhuri et al., (1983), Sources: GNP from Pakistan, Central Statistical Office, 25 Years of Pakistan in Statistics, 1947-1972, Karachi, 1972. Population figures from Pakistan Planning Commission. 
Table 3.6 Annual compound growth rates of population, GNP and GNP per capita at 1959-60 factor cost (\%)

\begin{tabular}{lcccc}
\hline & $\begin{array}{c}1949-50 \\
\text { to } 1954-55\end{array}$ & $\begin{array}{c}1954-55 \\
\text { to } 1959-60\end{array}$ & $\begin{array}{c}1959-60 \\
\text { to 1964-65 }\end{array}$ & $\begin{array}{c}1964-65 \\
\text { to 1969-70 }\end{array}$ \\
\hline Agriculture & 1.3 & 1.4 & 3.6 & 4.8 \\
Manufacturing & 11.0 & 6.4 & 12.2 & 9.1 \\
$\quad$ large-scale & 37.9 & 11.2 & 20.3 & 12.2 \\
$\quad$ small-scale & 2.4 & 2.4 & 2.8 & 2.8 \\
Other & 4.0 & 3.4 & 8.7 & 7.4 \\
Total & 2.8 & 2.5 & 6.3 & 5.6 \\
Population (million) & 2.4 & 2.4 & 2.7 & 2.8 \\
Per capita of income (Rs.) & 0.3 & 0.1 & 3.1 & 2.4 \\
\hline
\end{tabular}

Adopted from Raychaudhuri et al., (1983), Sources: Calculated from Figure 3.1, 3.2 and 3.3

It can be taken from table 3.6 that the two decades covered can be divided into two periods. The first period comprises the decade from 1949-50 till 1959-60 and is marked by stagnation of the economy, especially in agriculture. The second decade, from 1959-60 to 1969-70 yielded significant growth in all sectors. The trend in structural change remained the same in this decade with the share of agriculture in GNP declining from a little over 53 percent in 1959-60 to 46 percent at the end of this period and the share of manufacturing rising from 9 percent in 1959-60 to about 13 percent in 1969-70.

Foreign capital inflows have often been used to explain Pakistan's growth and development patterns. Domestic investment, has systematically exceeded domestic savings right after independence, with inflows of foreign capital accounting for the difference. Scholars assert that this dependence on foreign finance has not only been a determining factor of growth but also domestic and foreign policies (McCartney, 2011). The period under Field Marshal Ayub Khan (1958-1968) is often mentioned as a proof of this hypothesis. Pakistan's alignment with the US during the cold war saw a surge in capital inflows which led to an average of 6 percent GDP growth, with manufacturing value added growing at over ten per cent. The investment boom came to an end only with the 1965 war with India (Gardezi \& Rashid, 1983).

Figure 3.4 presents the population growth rates. The rapid rate of population growth - mainly due to the falling death rates - reduced the growth of income per capita. As the growth of employment in the industrial sector was lagging behind population growth, most of the surplus population remained in rural areas further overcrowding agriculture. In consequence, 85 per cent of Pakistan's population in 1969-70 was in rural areas and about 70 per cent of the labor force was engaged in agriculture. 


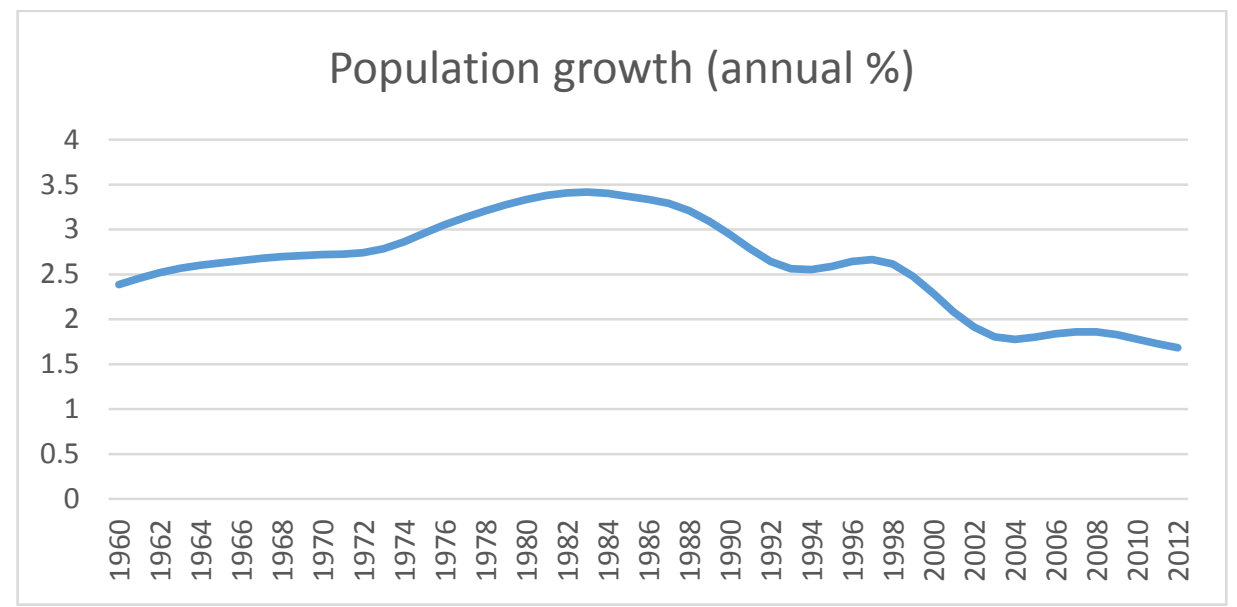

Source: Derived from total population. Population source: (1) United Nations Population Division. World Population Prospects, (2) United Nations Statistical Division. Population and Vital Statistics Report (various years), (3) Census reports and other statistical publications from national statistical offices, (4) Eurostat: Demographic Statistics, (5) Secretariat of the Pacific Community: Statistics and Demography Programme, and (6) U.S. Census Bureau: International Database.

Structural change were not limited to sectoral shares in GDP, but also affected the structure of imports and exports. Table 3.8 gives the import shares of four selected commodity groups. It can be seen that for almost a decade after independence there was no need to import food-grains and flour but later, due to slow growth of agricultural productivity and production lagging behind population growth, a substantial part of the total imports comprised food-grains and flour. But except for cotton, yarn and cloth, the imports of other commodities also grew rapidly. It is noteworthy that during the 1960's iron and steel, machinery and equipment made up half the import bill as this is explained by the rapid industrialization process. 


\begin{tabular}{|c|c|c|c|c|c|c|c|}
\hline & 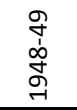 & $\begin{array}{l}\text { 우 } \\
\text { ơ } \\
\text { જे }\end{array}$ & 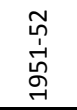 & 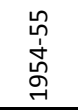 & 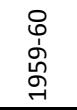 & 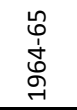 & $\begin{array}{l}\text { 옹 } \\
\text { જે } \\
\text { જ్ }\end{array}$ \\
\hline Raw jute & 26 & 44 & 50 & 49 & 40 & 35 & 23 \\
\hline Raw cotton & 21 & 33 & 39 & 25 & 11 & 13 & 7 \\
\hline Raw wool, hides and skins & 4 & 6 & 3 & 6 & 8 & 3 & 2 \\
\hline Tea & 2 & 4 & 2 & 5 & 2 & - & - \\
\hline Jute manufactures & - & - & - & 2 & 12 & 13 & 24 \\
\hline Cotton manufactures & - & - & - & - & 13 & 11 & 16 \\
\hline Other exports & 5 & 13 & 6 & 13 & 14 & 25 & 28 \\
\hline Total value of commodity exports (Rs. millions) & 1871 & 1218 & 2009 & 1223 & 1843 & 2408 & 3337 \\
\hline
\end{tabular}

Notes:'-' means nil or negligible.

Adopted from Raychaudhuri et al., (1983),Sources: Composition of exports during 1948-9 and 1949-50 from Pakistan, The First Five-Year Plan, 1955-60; all other data from Pakistan, Central Statistical Office, 25 Years of Pakistan in Statistics, 1947- 1972 (Karachi, 1972).

Table 3.9 shows how the export shares of selected commodities changed in the years after independence. Raw jute and cotton accounted for up to 90 percent of total exports during the peak years of the early 1950's, after which there was a downward trend. This was partly replaced by jute and cotton manufactures' exports, thanks to rapid industrialization. The increased share of 'other exports' can be attributed to fish and fine quality rice exports.

Economic policies in the first two decades after independence have been marked by neglect of agriculture and favorable tariffs and other favorable conditions for industrial entrepreneurs. Though Pakistan's economy was agriculture based and controlled by feudal elites, after independence, the agriculture sector was never given due importance. There could be many explanations for this, but the fact that Pakistan even today utilizes only half of its arable land is striking. This might be due to the skewed distribution of ownership of total arable land. Though there are no reliable statistics about this, it is often mentioned in the media that about 6000 big landlords own 40 percent of the total agricultural land. Obviously, the lion's share of the total agricultural income goes to these handful landlords and only a petty amount trickles down to the 72 per cent rural population who toil hard to get a living from the land (Mohmand \& Ghazdar, 2007). 


\begin{tabular}{|c|c|c|c|c|c|c|c|}
\hline & $\begin{array}{l}\stackrel{9}{+} \\
\dot{\infty} \\
\stackrel{5}{+} \\
\stackrel{్}{+}\end{array}$ & 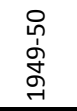 & 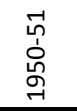 & $\begin{array}{l}\text { นn } \\
\text { ஸे } \\
\text { ஸे } \\
\text { Oे }\end{array}$ & $\begin{array}{l}\text { 오 } \\
\text { ᄋે } \\
\text { گે } \\
\text { ને }\end{array}$ & 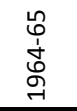 & 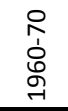 \\
\hline Foodgrain and Flour & - & - & - & - & 14.6 & 12.7 & 8.7 \\
\hline Cotton Yarn and Cloth & 33.8 & 28 & 28.7 & 5.9 & - & - & - \\
\hline Iron, steel and manufactures thereof & 6 & 6 & 7.4 & 6.4 & 8.7 & 16.4 & 11 \\
\hline Machinery, transport and electrical equipment & 10 & 12 & 13.4 & 34.8 & 31.6 & 33.5 & 36.5 \\
\hline Total value of imports (Rs. Millions) & 1487 & 1284 & 2237 & 1103 & 2461 & 5374 & 5098 \\
\hline
\end{tabular}

Notes: Till the end of 1954-5 the exchange rate was Rs. $3.31=\$$ US 1, afterwards Rs. $4.76=\$$ US 1 .

'-' means nil or negligible.

Adopted from Raychaudhuri et al., (1983), Sources: Commodity composition of imports during 1948-9 and 1949-50 estimated roughly from, State Bank of Pakistan, Report on Currency and Finance, 1953-4;

All other data from Pakistan Central Statistical Office, 25 Years of Pakistan in Statistics, 19471972 (Karachi, 1972).

The inequitable distribution of wealth plagued the country from the onset and policy makers have failed to rectify this. Already in 1959 it was found by the Credit Inquiry Committee of the State Bank of Pakistan that 66 percent of the total credit offered by Pakistan's banking system was being benefited by around 222 account-holders. It was also found that 98 of 197 non-financial companies, accounting for 53 per cent of total assets were being controlled by 43 families. The top four families (Saigols, Dawood, Adamjee and Amin) ${ }^{27}$ owned $20 \%$ of the total listed assets, whereas $33 \%$ were owned by the top 10 families and $50 \%$ of total assets were owned by the top 30 families. Studies by economists in the 1960 s pointed out that more than $50 \%$ of private domestic assets and $42 \%$ of the nation's industrial assets were concentrated in the hands of 40 industrial giants. A majority of commercial banks in the country were also controlled by these same families. Mahbub ul Haq, then chief economist of the Planning Commission, warned of the dire consequences resulting from concentration of wealth in his speech held in 1968. He highlighted that Pakistan's economic growth had left the living standard of the common man unchanged and that the "trickle- down approach to development" had only accumulated wealth in the hands of "22 industrial families." Such claims were like fuel to the fire of growing popular dissatisfaction. Though Haq' claims of the extent of the concentration of wealth may have been exaggerated, the public-opinion damage for the government was already done. His call for government intervention in the economy to correct free market's natural tendency to concentrate wealth in the hands of the rich was met with piecemeal reforms. At the policy level this

\footnotetext{
${ }^{27}$ These are the family names but their respective business empires are also known by the same names. Amin Saigol was the founder of the Saigol dynasty, Ahmed Dawood was the founder of the Dawood Group. Haji Dawood was the founder of Adamjee Group, named after his son, Sir Adamjee and Moulvi Mohamad Amin founded Amin Group of Companies.
} 
included setting minimum wages, promoting collective bargaining for labor, designing an equitable tax structure, and rationalizing salary structures. However, implementation between 1968 and 1971 was so weak that the 1971 elections saw both major parties from East Pakistan (Awami League) as well as West Pakistan (Pakistan People's

Party) come to power chanting slogans of nationalization.

Another negative force, which policy makers failed to deal with and even aggravated with their West-Pakistan-centric policies, was the unequal treatment of East and West Pakistan. Some argue that it is the unequal distribution of wealth, which was concentrated in mainly non-Bengali families, which fueled separatist sentiments. These and other disparities led to increasing tensions between the two regions culminating in the separation of East Pakistan as a sovereign state. Whatever development there was in the first two decades was actually taking place in West Pakistan. The respective per capita incomes of East and West Pakistan followed a divergent path. Comparing the import surplus of both regions, where West Pakistan's was over 4 times that of East Pakistan, it can be argued that the lavish inflows of foreign aid were mainly absorbed by West Pakistan. The US's search for military allies in the South-Asian region during the Cold War proved to be a blessing for Pakistan's economy. At a time when India was aligned to Russia and the Arab countries were seeing a revival of Arab nationalism, Pakistan was to be the best choice for US policy-makers due to its strategic geographical location between Afghanistan, India, and Iran and its closeness to China, Russia and the Middle East. During 1960 to 1998, Pakistan was the third largest recipient of development aid from the world, after India and Egypt (Easterly, 2003). The role of foreign aid was not restricted to balancing the deficit on the current account of the balance of payments, but the wide gap between savings and investment in the 1960s too was financed by it which was estimated as high as 7.3 percent of GNP in 1964-5, gradually dropping to 3 percent at the end of the decade as shown in table 3.9.

Table 3.9 Saving, investment, import and export as percentages of GNP at current prices

\begin{tabular}{lccccc}
\hline & $1949-50$ & $1954-55$ & $1959-60$ & $1964-55$ & $1969-70$ \\
\hline Gross domestic saving & 4.6 & 6.8 & 8.6 & 11.1 & 12 \\
Gross domestic investment & 4.6 & 8 & 11.7 & 18.4 & 15 \\
Imports of goods and services & 5 & 5.5 & 9.6 & 13.5 & 8.2 \\
Exports of goods and services & 5 & 4.4 & 6.5 & 6.2 & 5.2 \\
External resources & 0 & 1.1 & 3.1 & 7.3 & 3 \\
\hline
\end{tabular}

Adopted from Raychaudhuri et al., (1983).

\subsection{The Bhutto Era (1971-1977)}

The first democratic elections of Pakistan held in 1970 resulted in a clear victory for the East Pakistani Sheikh Mujibur Rahman-led Awami League against the West Paki- 
stani Zulfiqar Ali Bhutto-led Pakistan People's Party. This outcome was not accepted by the political and civilian leadership of West Pakistan, as they did not want to relinquish power to an East Pakistani leader. Bengali armed personnel and civilians demanding that West Pakistani ruling elite accept the results were suppressed by the use of ruthless force. The inevitable happened and Civil war broke out on 26 March 1971, when Yahya Khan, the then Pakistani President ordered the military to restore the government's writ by launching Operation Searchlight. In response to this operation Bengali politicians and army officers declared Bangladesh an independent state. The exile government of Bangladesh was set up in the city of Calcutta in the Indian State of West Bengal. India entered this armed conflict on $3^{\text {rd }}$ December 1971. Pakistani forces collapsed within two weeks after being overwhelmed by two war fronts. On $16^{\text {th }}$ December, Pakistan was defeated in the east by the Allied Forces of Bangladesh and India. The surrender of Pakistani forces resulted in the largest number of prisoners-of-war since the Second World War. The physical peculiarities combined with the policy failures led to the inevitable, the secession of East Pakistan as an independent state named Bangladesh in 1971. The human cost of this avoidable crisis was 1 million people who died and 10 million who sought refuge in India, but the cost in monetary terms is still unknown. Later, a War Inquiry Commission was formed to find reasons and culprits for this political and military fiasco. What came to be known as the Hamoodur Rahman Commission (named after the head of the commission), submitted its findings in 1974 which weren't made public until 2002. It concluded that the complete failure of civilian and martial law leadership were responsible for the loss of East Pakistan.

Bhutto, a former foreign minister in the government of Ayub Khan, became the first leader of a divided Pakistan. In-line with his election campaign slogans after coming to power he promised an equitable development policy. Yet he gave little importance to economic planning and relied on ad hoc decisions instead, giving rise to many irregularities.

Economic performance under Bhutto's regime, particularly in agriculture and manufacturing, was inferior as compared to both the previous and following eras. Table 3.3 shows that the average annual growth rate in agriculture during 1971-1978 was 1.6 percent, and in manufacturing 3.8 percent, compared to about 10 percent during Ayub's era. Per capita agricultural output decreased during his term. The GNP growth rate of 5.3 percent was largely due to a 6.2 percent growth rate in other sectors (about 8.9 percent in construction and 4.4 percent in the trade sector) (Husain, 2000). Defense and public administration were the fastest growing sectors of the economy. With the loss of East Pakistan, West Pakistan lost a market for 50 percent of its goods and 20 percent of its imports. Though this was not the only exogenous shock the Bhutto regime had to deal with. The four-fold increase in oil prices following the 1973 'oil price shock' and the consequent stagflation (the 1970s phenomenon of falling or stagnating output and rising prices), made Pakistan's import bill skyrocket and export earnings plunge because of the global economic downturn that followed. This 
resulted in serious 'balance of payments' crisis. Repeated pest attacks, bad weather, and floods during 1973-76 badly harmed agriculture. However the adverse effects of the nationalization policy, which led to dwindling private investment and politicization of public enterprises, most significantly impacted economic performance. Moreover, all promises regarding economic and social reforms remained on paper. Thus this period was marred by income inequality and social injustice.

Despite all the policy blunders and neglect Bhutto managed to remain popular and sustain support for his party because the economic rights of the poor were at least acknowledged (Noman, 1990). The nationalization of large private financial and manufacturing organizations remains a defining factor of Bhutto's economic policies. The nationalization drive was carried out in two phases, the first of which began in 1972, affecting 32 large manufacturing plants in 8 major industries. ${ }^{28}$ Elites of rural Sindh, the home ground of Bhutto's left-leaning political party, staunchly supported the nationalization policy as it didn't affect them. Though the masses remained convinced that it was an attempt to reduce concentration of wealth in the handful of families, left-wing ideologues within the People's Party were sidelined and distributional concerns were not topping the agenda anymore by 1974. The second phase of nationalization (19731976) began with an altogether different motivation. It was more of a reaction to the various crises faced and a way to political point scoring. The destructive floods of 1973 resulted in a 3-fold increase in vegetable oil prices mainly due to hoarding practices of oil producers. The government responded by nationalization of the vegetable oil industry. This sent ripples through the private sector because the vegetable oil industry was owned by small and medium-sized capitalists, not the handful of rich families. The nationalization of domestically owned private banks and insurance companies followed in 1974. Despite assurances of no further nationalizations, grain milling, cottonginning, and rice-husking mills were nationalized in 1976. The devastating results of the nationalization drive were a flight of capital out of the country or into real estate and small-scale manufacturing, reduced private investment, and a harmful reversal in the mix of public and private investment. The former increased by about 19 times between 1971 and 1975 (from Rs. 58 million to Rs. 1,085 million) and the latter dropped to a quarter of its value (from Rs. 700 million to Rs. 183 million). The share of private investment in total decreased from 51.3 percent during the Ayub era to 33.8 percent in the Bhutto era (Husain, 2000).

Pakistan never fully recovered from this legacy of the Bhutto era which is marked by mistrust in the minds of private investors regarding democratically installed governments. The share of large-scale manufacturing in GDP declined from 12.6 to 10.7 percent in the period 1971-1977. However, as private investment got diverted to small-scale enterprises, their share in GDP rose from 3.8 to 4.5 percent during the period (Husain, 2000). The combination of inefficient appointees, overstaffing and

\footnotetext{
${ }^{28}$ These industries were iron and steel, heavy engineering, basic metals, motor vehicle and tractor assembly and manufacture, petroleum and chemicals, cement and public utilities.
} 
inappropriate location choices affected efficiency and growth. Resultantly, losses; budget deficits, falling growth rates and inflation were unavoidable. Bhutto rose to power riding the slogan of 'roti, kapra, makan' (bread, cloth and shelter) signifying social justice and equality. However during his period in office the income inequality actually grew. The Gini coefficient increased by nearly 22 percent for rural areas, 10 percent for urban areas, and about 14 percent for all areas during his period (Husain, 2000). The inflation rate, which was at $5 \%$ in the 1960 s climbed to $16 \%$ during Bhutto's era. The opposition movement that eventually led to the sacking of Bhutto comprised politicians (who resented Bhutto's authoritarianism) and small entrepreneurs, traders, and industrialists (who were badly affected by the second phase of nationalization). General Ziaul Haq, whom Bhutto had appointed chief of the army, overriding senior generals, toppled Bhutto in a bloodless military coup. Bhutto was hanged and Ziaul Haq was to continue in power for over a decade.

Although the rural elite and large landowners emerged as the real winners from the Bhutto regime, there was a difference from the beneficiaries of earlier periods. It was only members of Bhutto's PPP (Pakistan People's Party), particularly large landowners of Sindh and Punjab, who gained, as they were spared from the land reforms. Landlords from Balochistan and Khyber-Pukhtunkhwah on the other hand, were affected by the land reforms which were used to either win them over in the party or punish them. But the real losers were entrepreneurs and industrialists, mostly Muhajirs from Karachi. Nationalization of schools rendered quality of education poor and a reduction of subsidies on consumer goods made life for the middle class more difficult as compared to the 1960 s.

Low-income laborers and government employees made significant gains due to an increase in their wages under the new labor laws. In fact, Bhutto's pro-poor attitude, whether real or perceived, was instrumental in his unmatched popularity among the poor masses, even after his death.

\subsection{Zia-ul-Haq Era (1977-1988)}

On 5 July 1977, the government of Prime Minister Zulfiqar Ali Bhutto was overthrown in an operation codenamed "Fair Play" led by then chief of army staff, Muhammad Zia ul-Haq. While announcing Marshal Law, Zia promised "free and fair elections" within 90 days, only to be held in 1985 after repeated postponements. Zia himself stayed in power for eleven years until his death in a plane crash.

Zia had a two pronged approach to revive the otherwise declining economy. These were the Islamization and at the same time liberalization of the economy. Regardless of these policies, unprecedented remittances during his era improved the economic indicators such that it is reminiscent of the economic revolution under the Ayub regime. The cash inflows were not limited to expats working in the Middle East and elsewhere, but also constituted U.S. aid in support of the Afghan war in which 
Pakistan was involved as a US proxy. The overall performance of the economy was impressive during this period, with an average annual growth rate of more than 6 percent in GDP, 4 percent in agriculture, and about 9 percent in manufacturing during the Fifth and Sixth Plan periods, 1978-1988. Although the Planning Commission became active again, policy formulation was not given the same importance as it was under the Ayub regime. Kalashnikov and drug culture, religious intolerance, ethnic violence, and curtailed rights of women are some of the dark legacies of Zia's era. The gaps in the balance of payments kept widening and deficits in current accounts kept increasing. Private enterprises assumed a greater role in the economic policies of the Zia era. This was achieved by the reversal of Bhutto's nationalization policies (except banks) and unprecedented liberalization of the economy. Private sector confidence was restored by formulating investor-friendly industrial and trade policies. Liberalization policies included fewer regulatory controls, streamlining investment-licensing procedures, granting fiscal incentives in the form of tax holidays and correcting price distortions. Smaller industrialists were the first to respond to these incentives, while the big ones initially exercised a bit of caution. Investments in the Bhutto era were redirected from large-scale to small-scale industry in the wake of the nationalization policy. This capital infusion combined with the policy incentives provided small-scale manufacturing the much needed boost. Overall, private investment grew from $33 \%$ of total investment in 1980 to 46\% in 1989 (Husain, 2000). Performance of the agriculture sector was also impressive, with average annual growth rates of $4 \%$. The production of major crops (wheat, rice, cotton, and sugarcane) achieved record levels in 1981 and 1982. In addition to the encouraging policies, suitable weather also contributed to this performance. The agricultural sector was liberalized too. The Agricultural Development Bank of Pakistan (ADBP) increased access to credit, with double the loans disbursed between 1980 and 1983. There were certain shortcomings as well. For instances small farmers didn't benefit much from the loans, export taxes on agriculture were imposed, wheat shortages (due to an increased focus on cotton production) required increased imports, land reforms were repealed and total development expenditure in agriculture fell from 20 to $13 \%$ during Zia's era (Husain, 2000).

The Islamization of the economy, regarded as a policy innovation, was actually initiated to improve the tarnished image of the army after the lost war of 1971. This was done by asking a group of prominent Islamic scholars how to 'Islamize' the economy. This exercise concluded with recommendations of Zakat and Ushr Ordinances, which were enacted in 1980 . Zakat, levied at 2.5 percent annually on savings to help 8 categories of needy people, is one of the five pillars of Islam, and it is a religious obligation on every eligible ${ }^{29}$ Muslim. Ushr, a land tax, levied at 5 percent on agricultural produce, is to be paid in cash by the owner or lessee of land, and its proceeds were

\footnotetext{
${ }^{29}$ Eligibility here means a person being mature, sane, free and meeting the minimum financial standards after which it is mandatory for him or her to pay zakat.
} 
deposited in the Zakat fund to help the needy. Ushr replaced the land tax (revenue) levied by the provincial governments.

As shown in figure 3.4, the Zia years were phenomenal in terms of remittance inflows from expats. Averaging at US $\$ 3.2$ billion per year for most of the 1980s, these remittances were quite substantial, particularly in relation to the size of the economy. They accounted for around 10 percent of GDP and 40 percent of total foreign exchange earnings (Husain, 2000). By 1984, remittances financed about 86 percent of the trade deficit and closed the 6 percent gap between savings and investment and were the largest single source of foreign exchange earnings.

Figure 3-5 Personal remittances, received (\% of GDP)

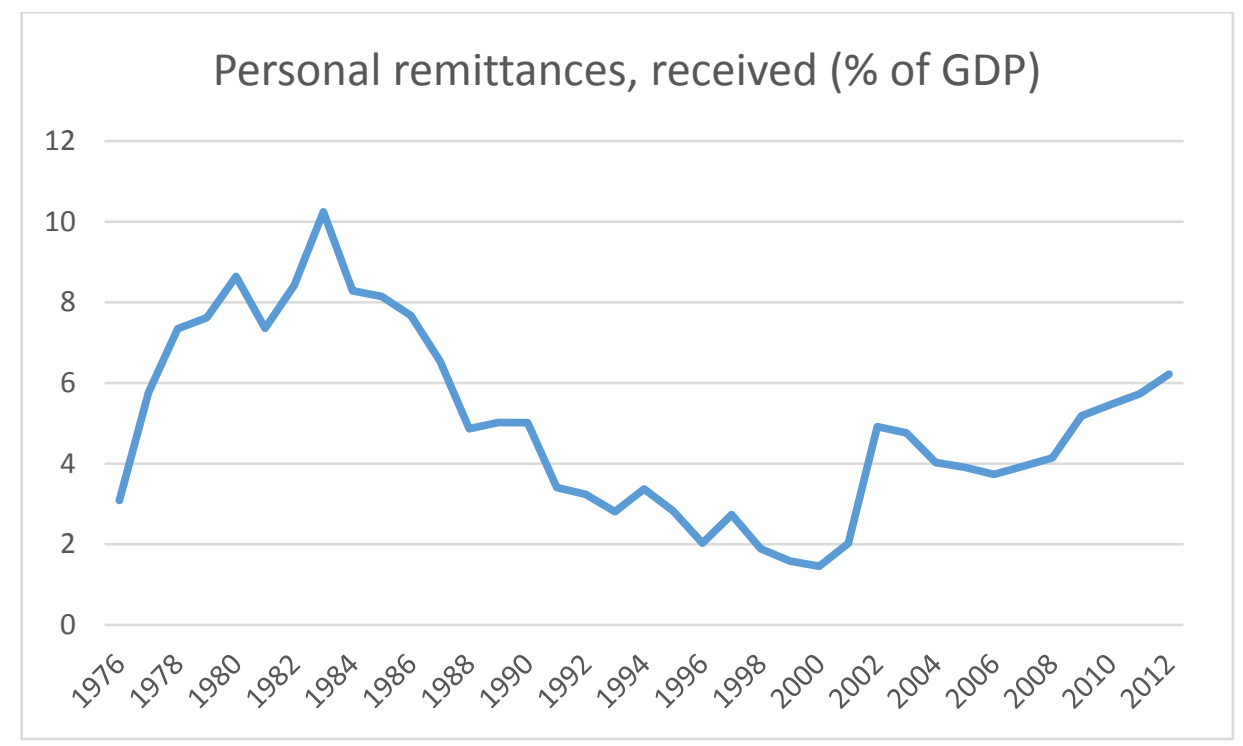

Source: World Bank staff estimates based on IMF balance of payments data, and World Bank and OECD GDP estimates.

They were four times greater than the net aid inflow to Pakistan which is often lauded as the savior of the economy under the Zia regime. They also increased the living standards of the poor since most of these economic migrants belonged to poor families. Their incomes increased about eightfold, regardless of the urban/rural divide. The distributional impact has been far-reaching, with an estimated 10 million people benefiting directly from these remittances, leading to an improved Gini coefficient, and temporarily serving as a substitute for an asset redistribution (land reform) program (Mohiuddin, 2007). However, the spending pattern of families receiving remittances did not increase the national savings rate or enhance the long-term growth of the economy. As an explanation, Husain (2000) points out that about $63 \%$ of remittances were spent on consumption goods (primarily imported luxury goods such as television 
sets, video-recorders and cars), $22 \%$ on real estate, and only $12 \%$ comprised savings. Consequently, the domestic savings rate fell from 7.8\% of GDP in 1977-1978 to 5.4\% by 1982-1983 (Husain, 2000). However, the unemployment problem created by rapidly growing population rates of about $3.1 \%$ during the 1980 s was partially addressed by the manpower migration to the Middle East. Thus, one third of the increase in the labor force was absorbed by manpower export during the Fifth Plan period (19781983). However, migration has not solved the problem of regional imbalances in growth, since most of the migrants come from the Punjab, particularly the urban areas of Faisalabad, Gujranwala, Jhelum, Lahore, Rawalpindi, and Sialkot, as well as from Khyber Pukhtunkhwa, but very few from Sindh, excluding Karachi. The aid inflow due to the Afghan War combined with substantial worker remittances, rescued the Pakistani economy. The darkest legacy of the Zia era was the expanding grey economy, which by some estimates amounted up to $30 \%$ of GDP. It comprised a growing black market, smuggling of drugs and weapons, and bribes to government officials to acquire state contracts. The annual value of the drug trade alone is estimated to be about $8 \%$ of GDP (Mohiuddin, 2007). Pakistan's role as a "frontline" state in the Afghan War against Soviet occupation of Afghanistan supported by the United States, and the resulting massive infusion of U.S. aid to Pakistan were the major cause of the flourishing parallel economy. A part of the aid went to the Pakistan government in order to improve its military capability and to facilitate millions of refugees that kept pouring into Pakistan across the border, but a large portion also went to Mujhahideen based in Pakistan and backed by the US. Some of this money was funneled to the drug and weapons business, which negatively influenced the Pakistani society by creating a gun culture. High crime rates, drug addiction, ethnic and religious violence, and corruption inevitably followed.

At the macroeconomic level, Zia faced two challenges, fiscal deficits and balanceof-payments problems. The current account deficits increased during this period, amounting $8 \%$ of GDP in the second half of the 1980s. In order to avoid inflation, the deficit was not financed by printing money. Similarly, in order to preclude a debt crisis, it was not controlled relying on external financing. Instead, domestic borrowing was used to finance it. In order to attract private savings, higher than market interest rates were offered through various savings schemes. This crowded out private investment in other sectors of the economy which is a typical negative effect of high interest rates. The adverse effects of domestic borrowing on macroeconomic stability manifested themselves later in the 1990s. Moreover, expenditure on education decreased from $2.1 \%$ to $1.5 \%$ of GDP during 1977 and 1983 . The rural rich benefited most from the Zia regime, as they evaded taxation and managed to repeal the land reforms. Both rural and urban poor suffered the most. Skilled laborers, typically belonging to the lower middle class were another group to benefit during this era. Whether it was those who went to the Middle East to work, their families who received their remittances, or those who by staying behind received better pays because of the higher demand due to the flight of the skilled workers. Most from this group belonged to Punjab and a few 
to Khyber-Pukhtunkhwa and Sindh (exclusively Karachi). These people, having witnessed prosperity, could not be mobilized for a mass movement against the Zia's dictatorship by the opposition parties. Members of religious political parties and a select few officers of the army, also benefited from this regime. To sum it up, average incomes increased by about $80 \%$ for the lowest $40 \%$ income group and by 94 percent for the top $20 \%$ (and by $100 \%$ for the top 10\%) of income recipients between 1979 and 1985 (Mohiuddin, 2007). Consequently, income inequality increased but at the same time poverty was reduced, during the Zia era.

\subsection{Political Musical Chairs Era (1988-1999)}

Following Zia's death in a plane crash in 1988, democracy returned to Pakistan from 1988 to 1999. Four elections were held during this period, with both Benazir Bhutto and Nawaz Sharif remaining in power twice. Because none of the elected governments completed its 5-year term, in between there were 4 caretaker governments. Benazir was the first to take turns when her party, the PPP founded by her father, won the elections in 1988. She remained in power as prime minister until 1990 when her government was dismissed. After a brief caretaker period Mian Nawaz Sharif, the leader of Pakistan Muslim League (PML), became the prime minister. He too was sacked, on the basis of corruption accusations, by the then president Ghulam Ishaq Khan in 1993. Again, after a brief caretaker period Benazir Bhutto returned to power in the 1993 elections. She was again dismissed and the caretaker government of Meraj Khalid followed. Nawaz Sharif returned to power for a second time too, only to be toppled by General Musharraf in 1999. The GDP growth rate during these years declined from $6 \%$ or higher in the previous decade to $6 \%$, with agriculture growing at $4 \%$ per year during the Seventh Plan period (1988-1993) and at 5.9\% during the Eighth Plan period (19931998), and manufacturing growing at 5\% per annum in the first phase and $3.6 \%$ in the second phase (see table 3.4). This decline in GDP growth was mainly caused by poor governance and the short lifespans of the various governments. Moreover, income distribution worsened, inflation rose almost doubling poverty, fiscal deficits grew to $7 \%$ of GDP, current account deficit broadened, and external debt servicing almost reached $40 \%$ of export earnings as total external debt became $47.6 \%$ of GDP, up from $\$ 20$ billion to \$43 billion during 1993 and 1998 (Hussain, 2004). Even though a broad consensus on economic policy between Sharif and Benazir can be observed, there was a lack of continuity of programs, politically motivated policy reversals and administrative ad hoc decisions. The first Sharif government began policy reformations starting with privatizations and deregulations. 90 units were sold to private investors after denationalization by 1995, with plans under way for even more. State monopolies in insurance, airlines, power generation, shipping, telecommunications, port operations, and road construction started being abolished. Despite liberalization, the chronically high budget deficits led to inflation and balance-of-payments problems which strained 
financial stability. This resulted in a loss of confidence among foreign aid donors, sowing the seeds for Sharif's removal, who was later in 1993 dismissed by the former president. Moeen Qureshi, a former World Bank consultant led the caretaker government of 1993 and warned that Pakistan was on the way to insolvency. Utility prices were raised, new taxes were imposed and government spending was reduced under his leadership, in order to achieve fiscal stability. The boldest of his newly imposed taxes was an agricultural income tax. This was unprecedented in the history of the country and was fiercely opposed by the rural elite. Benazir got elected again in 1993 and declared the continuation of deregulation, denationalization, and liberalization policies of the Sharif government as well as the stricter fiscal policies of her predecessor. Higher allocations for education and health were promised by her. She also agreed to International Monetary Fund (IMF) backed austerity measures in order to receive the desperately required preferential credit of US\$ 1.4 billion. The IMF further stipulated that the deficit be brought down to $4 \%$ of GDP. This was achieved by increased taxations and reduced government expenditure. Although, additional taxes of Rs. 140 billion were imposed between 1994 and 1997, these were mainly indirect taxes, which did not widen the tax-net. Following in the footsteps of other elected governments, agricultural income tax was not imposed due to the opposition of influential landlords. Utility prices were raised and development budgets curtailed as public expenditure decreased from 9.3\% of GDP in 1981 to a meager 3\% in 1997. The poor and the salaried class suffered disproportionately from these structural adjustments disproportionately, since the reforms did not entail safety nets to avoid these anticipated consequences. The reforms also envisioned privatization of state-owned enterprises (public corporations owned and operated by the government). State monopolies were eliminated and several public-sector enterprises, financial institutions and utilities were privatized. The liberalization of the economy led to layoffs and closure of some industrial units, thus increasing unemployment. Investment and foreign exchange regulations were also liberalized. To arrest the capital flight which started during Zia's era, exchange controls were abolished. The political musical chairs era was characterized by corruption allegations against politicians. Benazir's husband, Asif Ali Zardari, was accused of corruption by the president which led to her dismissal in 1990. Sharif was also not spared from allegations of corruption by the president. Later, Sharif and Bhutto blamed each other. Bribery to government officials was considered to be a routine cost of production, a processing fee to get any contract. In 1996, the Transparency International survey placed Pakistan as the second most corrupt country in world corruption rankings. The 1990s have been characterized as a lost decade because of the "growing burden of debt, fiscal and current account imbalances, lowering of growth rates, poor social indicators, increase in incidence of poverty and higher rate of inflation" (Hussain, 2004). External shocks such as the economic sanctions after Pakistan's nuclear tests in 1998 did also contribute to the economic woes during the late 1990s. But the real causes were largely internal. Regardless of the causes, these factors ruined the investment climate in the country and posed severe external liquidity challenges. 
The international community withdrew its economic assistance, remittances from migrant workers were reduced by $\$ 500$ million, and FDI had fallen by $\$ 600$ million (Hussain, 2004). Estimates show that Pakistan was left with such low reserves that it was unable to meet its short-term debt service obligations and enough only to buy three weeks of imports. In its struggle to overcome these problems, the government signed eight different agreements with the IMF during this era, but they were neither completely implemented, nor were the loans completely drawn, leaving the external liquidity problem unresolved.

\subsection{Musharraf Era (1999-2008) and onwards}

General Pervez Musharraf's military regime's legitimacy was in question when he took over. Similarly, Pakistan's first nuclear test in May 1998 left it economically isolated and unable to meet commitments with international donors and remedy the trust deficit among financial institutions that had led to suspension of aid earlier. Strict performance criteria were stipulated by the IMF to overcome the credibility gap and receive loans. These deep-rooted and wide-ranging reforms included removing subsidies, privileges and exemptions; privatizing energy companies, state-owned banks and other large units; market-based input, output and public utility prices; widening the tax net; relying on markets rather than administrative discretion; and reducing government spending and debts. Social safety nets and targeted interventions had to be an integral part of these structural adjustments since they were likely to hurt the poor. The most significant of financial aid packages came from the World Bank in May 2005, when it extended a three-year, $\$ 4.5$ billion loan to Pakistan (half of which was interest-free). The objective was to help expedite Pakistan's recovery and to support economic development and social sector reconstruction. This loan increased total annual lending to Pakistan from about $\$ 900$ million to $\$ 2.4$ billion.

Economic performance indicators were strong during the period, with an average growth rate of 5\% in GDP annually since 2000 and as high as 7.7\% in 2005. The manufacturing sector has been particularly impressive during this period with the growth rate reaching $15.5 \%$ in 2005 . Agriculture, on the other hand, did not impress with its performance during Musharraf's era (Table 3.9). Kemal (2006) investigates what he calls the "micro enigma" that despite $8.7 \%$ growth in the manufacturing sector on average, investment levels as a ratio of GDP seemed to have fallen. He cautions of the euphoria created by the growth of the manufacturing sector at the rates of $14.0 \%$ and $15.5 \%$ in 2004 and 2005 respectively since investment rates have been trending to a low level. Moreover, he points out various structural problems that the manufacturing sector is suffering from. These include allocative, technical and $\mathrm{X}$-inefficiencies; lack of diversification; poor quality of products, and low levels of R\&D activities. Together these have resulted in declining growth rates of productivity, making Pakistani products uncompetitive in the global market. 
The external sector also showed impressive results: current account balance became positive; exports grew as a percentage of GDP and imports were stable; foreign exchange reserves grew substantially; debts were reduced, and the exchange rate remained stable. The deficit was reduced by almost $2 \%$ (from $7 \%$ of GDP to $5.2 \%$ ), and tax revenues increased more than $28 \%$ within the first two years. GDP and sectoral growth were rather unconvincing until 2002, the reforms and transparency started showing results later, and GDP grew annually at close to 7\% in 2005 and 2006. Selfsufficiency in food was achieved and after a long time Pakistan again became a net exporter of grains as a consequence of increased agricultural productivity owing to the provision of incentives for the agricultural sector. Although, poverty was on the rise, at least until 2002, and unemployment rates remained high, but inflation was brought down from $10 \%$ during $1990-1998$ to less than $5 \%$ in the early years of the Musharraf era already. On the whole, the achievements of the Musharraf era should be seen within the context of the extraordinary domestic and global developments with strong repercussions for Pakistan. Internally, these include a severe drought for three years and the 2005 Kashmir earthquake that killed around 87000 and left 2.8 million displaced. Externally, these comprise the September 11 attacks on US soil, a global recession, the war in Afghanistan and the war against terrorism, and a belligerent relationship with India. The September 11 tragedy deserve special mention as the political context of Musharraf's era was shaped by their consequences more than any other event. After these unprecedented attacks on US soil, Pakistan was given a Manichean choice, to be with or against the US in its war in Afghanistan. President Musharraf succumbed to the pressure and Pakistan soon became a frontline ally of the US in its 'war against terrorism'. Support was extended in terms of providing its air bases, aerial corridors, waterways and other logistic and intelligence support. This was widely seen as an unpopular decision, especially given the fact that Pakistan through its intelligence agency, the ISI (Inter-Services Intelligence) was central to the rise of the Taliban in Afghanistan (Rashid, 1999). Strong opposition, mass protests and attempts on his life could all not deter Musharraf from the unstinting support he had promised to the US secretary of state over a phone call in the wake of the terrorist attacks (Kumar, 2002). A wave of mostly 'suicide' attacks started in 2003, after Musharraf vowed to crack down on Islamists and militants willing to fight in Kashmir (against Indian forces) and in Afghanistan (against US and NATO forces) and only let down recently after multiple military operations in the northern areas of Pakistan. Figure 3.4 shows that the total number of deaths related to this new conflict started gaining pace in 2003 and reached its peak in 2009 when close to 12000 deaths were reported. Another such destabilizing factor has been that of US drone attacks in Pakistan. These strikes have not only further increased the death toll, especially that of civilians in what is termed as collateral damage, but have also led to political instability as the legality of these strikes has been challenged by various political parties on legal as well as ethical grounds. Even the international community and the United Nations have raised their voices against drone strikes, calling them counter-productive and a source of more 
reactionary terrorism. Shah (2010) concludes that, "The justifications for the U.S. drone attacks on Pakistan are convoluted and are hard to sustain under international law". Drone strikes on Pakistani soil started in 2005 and peaked around 2010 when a total of 831 people were killed after which they started declining but continue till date. In addition to the loss of life, this conflict has burdened the economy both directly and indirectly. Massive security related spending, compensations made to the victims of terrorist attacks (civilians directly targeted or collateral damage and servicemen fallen in the line of duty), damage to the infrastructure and interruption of economic activities contribute to the direct costs. Indirect costs include the decline in investment due to the general insecure situation and travel bans imposed by Western governments on their citizens, destruction of domestic/foreign tourism industry, inability to proceed with development work, increase in unemployment, reduced tax collection, reduced privatization opportunities and the high cost of supporting and rehabilitating internally displaced persons $^{30}$ (Ali, 2010; Michael, 2007). The costs have been estimated by the government as given in Table 3.10. The accompanying report ${ }^{31}$ to this table details the causes and reasons of these costs. Firstly, it states that the assumptions based on which Pakistan entered the US-led war on terror - such as a swift end to the war resulting in Taliban's ousting and continuation of low intensity fights - were wrong. Instead, the war kept lingering on resulting in a large portion of Pakistan's resources, both men and material being consumed by this war in the last several years. Still, the security environment in the country kept worsening and as a result, many western countries including the United States continued to impose travel bans for their citizen (investor, importers etc.) to visit Pakistan. This, the report states, "has affected Pakistan's exports, prevented the inflows of foreign investment, affected the pace of privatization program, slowed the overall economic activity, reduced import demand, reduced tax collection, expenditure over-run on additional security spending, domestic tourism industry suffered badly, hundreds; and thousands of jobs could have been created had economic activity not slowed as well as thousands of jobs were lost because of the destruction of domestic/foreign tourism industry; destruction of physical infrastructure (military and civil) massive surge in security related spending; migration of thousands of people from war affected areas and the associated rise in expenditure to support internally displaced persons."

\footnotetext{
${ }^{30}$ As per UNHCR data there were 975,478 IDP's of Pakistani origin residing in Pakistan in June 2013.

${ }^{31}$ The Ministry of Finance report can be downloaded at http://www.finance.gov.pk/survey/chapter_11/Special\%20Section_1.pdf
} 


\section{Fatalities in terrorist attacks 2003-2013}

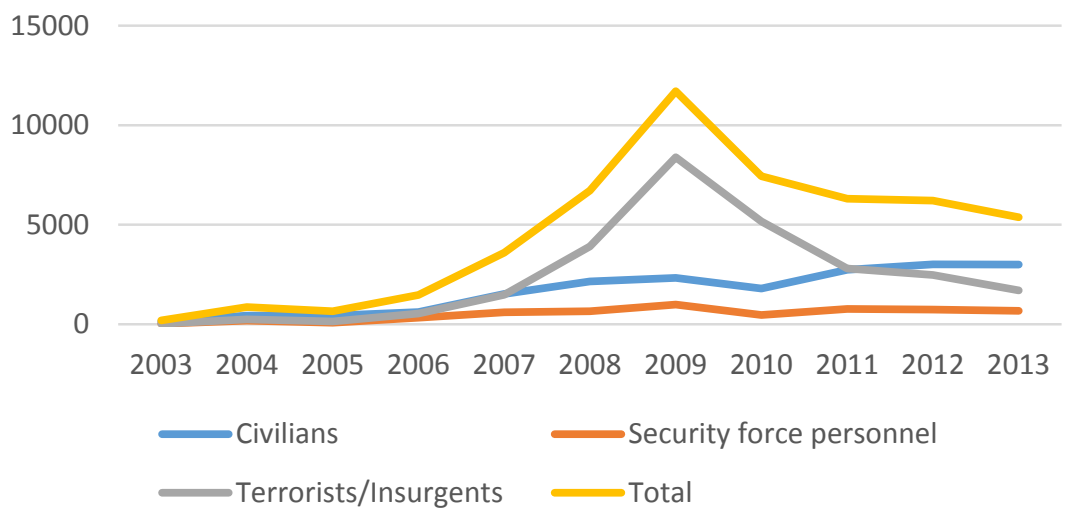

Source: South Asia Terrorism Portal, Institute for Conflict Management

Figure 3-7 Drone attacks in Pakistan: 2005-2013

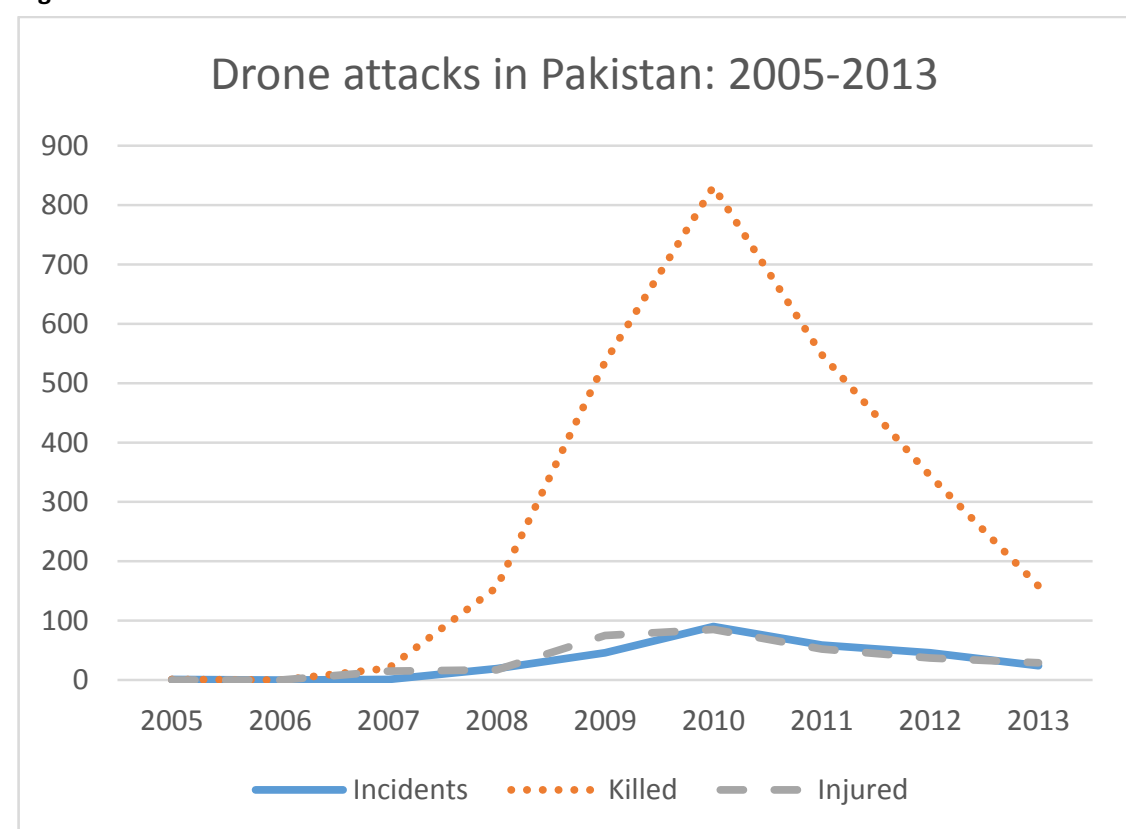

Source: South Asia Terrorism Portal, Institute for Conflict Management 


\begin{tabular}{lcc}
\hline Cost of War Estimate in 2001-02 and 2010-11 (Current US\$ Billion) & $2001-02$ & 2010-11 \\
\hline Exports related losses & 1.4 & 2.9 \\
Compensation to affectees & 0 & 0.8 \\
Physical infrastructure damage & 0 & 1.72 \\
Foreign Investment losses & 0.15 & 2.1 \\
Privatization losses & 0.5 & 1.1 \\
Reduced Industrial output & 0.11 & 1.7 \\
Reduced Tax Collection & 0.25 & 2.1 \\
Cost of Uncertainty & 0.1 & 2.9 \\
Security Expenditure Overrun & 0.11 & 1.6 \\
Others & 0.1 & 0.9 \\
Total & 2.72 & 17.82 \\
\hline
\end{tabular}

Source: Ministry of Finance, Government of Pakistan.

It is interesting to note that the total US aid (both military and civilian) for the time period between 2001 and 2011 comes up to US\$ 8.7 billion as shown in Figure 3.12. This amount is less than half the cost of this conflict born by Pakistan in the year 2011 alone. What makes this comparison interesting is the fact that the domestic proponents of siding with the US in the war on terror often allude to the US aid as a more than commensurate compensation for this alignment whereas those opposed to this war point out its huge cost on the exchequer. Figure 3.7 shows the exponential rise in these costs since 2001, when the conflict and its repercussions started.

Moreover, long-term unemployment has roughly tripled to a staggering $20 \%$ of total unemployment indicating a lack of commercial activities. Another alarming trend is that the percentage of unemployment with tertiary education has gone up from $20 \%$ of total unemployment before the conflict to $28 \%$ in 2008 . Whether the conflict has a causal relation with the unemployment figures is debatable but the positive thing is that the trend of latest years point in the right direction, particularly that of total unemployment (see Figure 3.9 - 3.12). 


\section{Cost of Conflict (2001-2011) Current US\$ Billion}

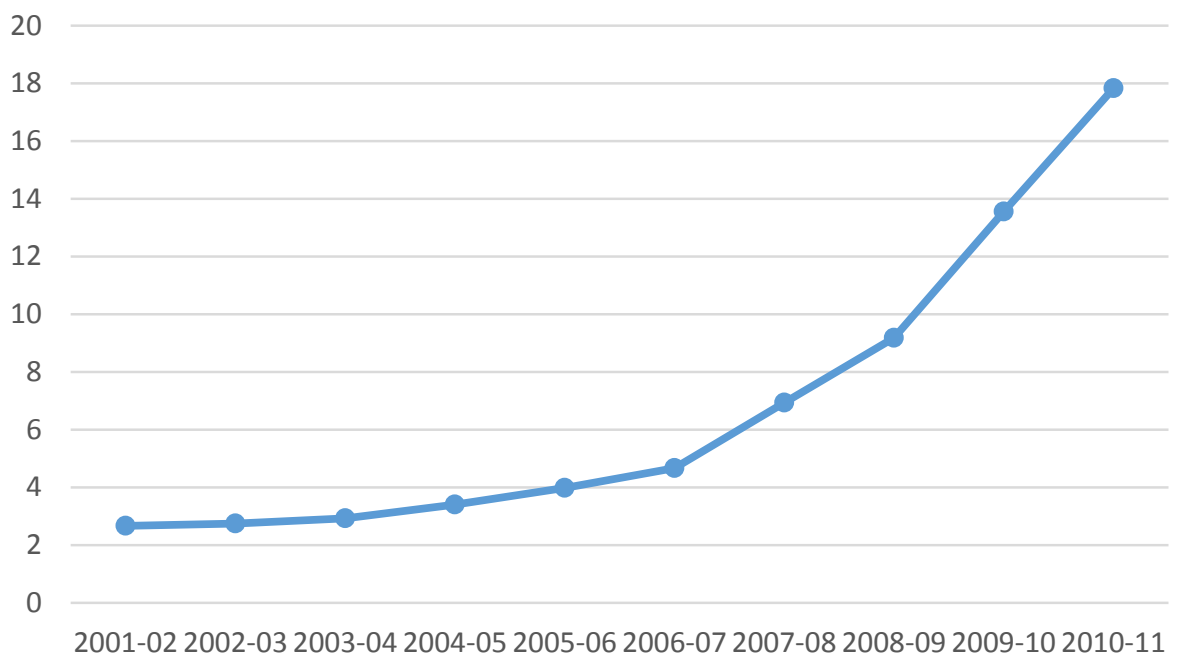

Source: Ministry of Foreign Affairs Joint Ministerial Group, Government of Pakistan

Figure 3-9 Unemployment with tertiary education (\% of total unemployment)

\section{Unemployment with tertiary education \\ (\% of total unemployment)}

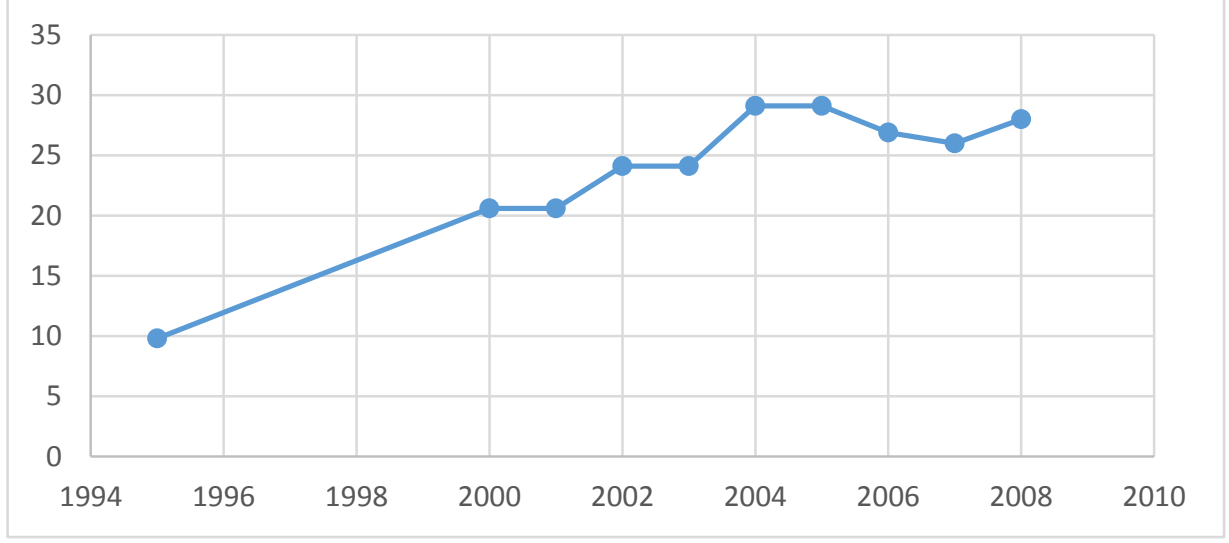

Source: International Labour Organization, Key Indicators of the Labour Market database. 


\section{Unemployment, total (\% of total labor force) (national estimate)}

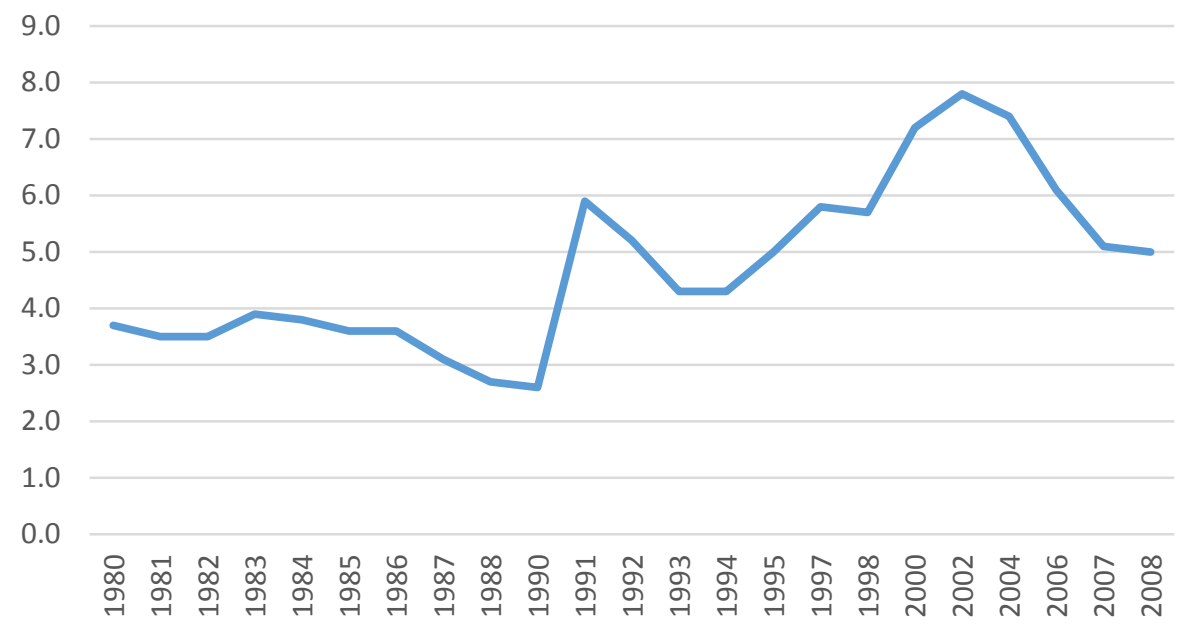

Source: International Labour Organization, Key Indicators of the Labour Market database.

Figure 3-11 Unemployment, total

\section{Unemployment, total}

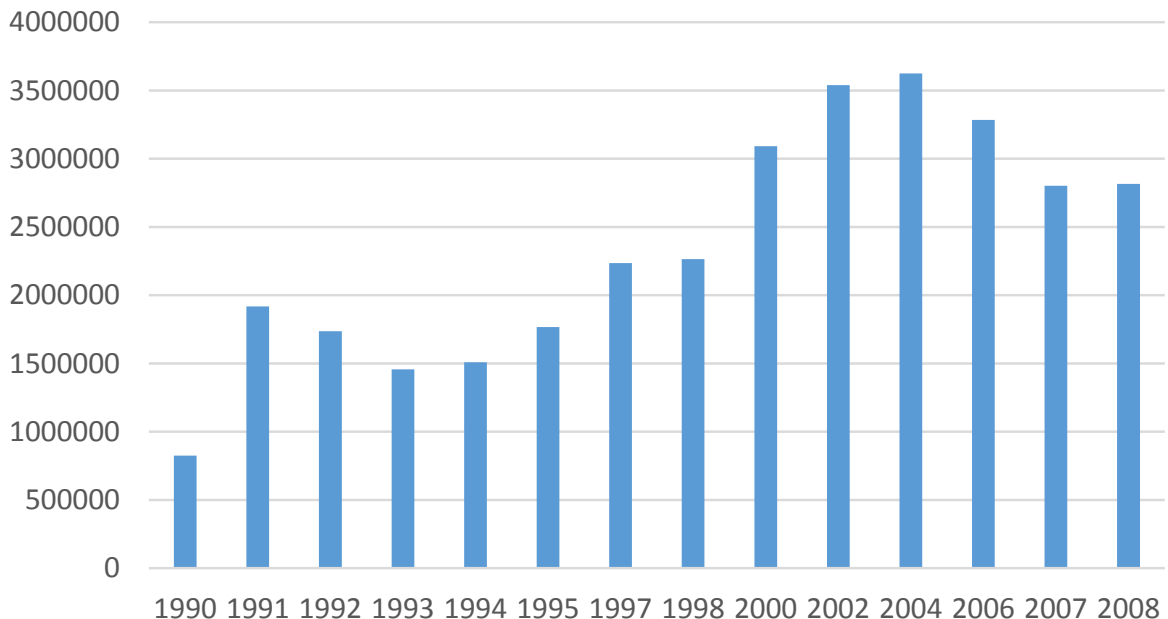

Source: International Labour Organization, Key Indicators of the Labour Market database. 


\section{Long-term unemployment \\ (\% of total unemployment)}

25

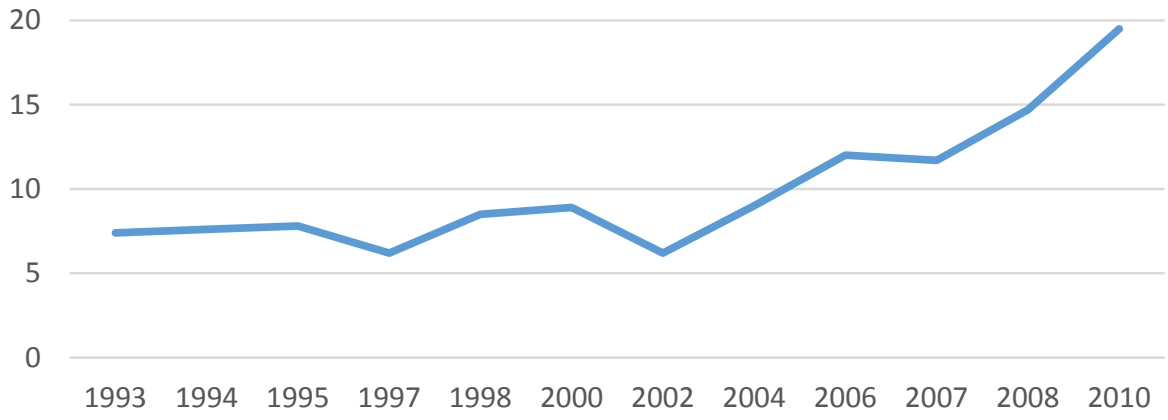

Source: International Labour Organization, Key Indicators of the Labour Market database.

Figure 3-13 US Military and Civilian Aid to Pakistan (in constant 2011 US\$ Million)

\section{US Military and Civilian Aid to Pakistan (in constant 2011 US\$ Million)}

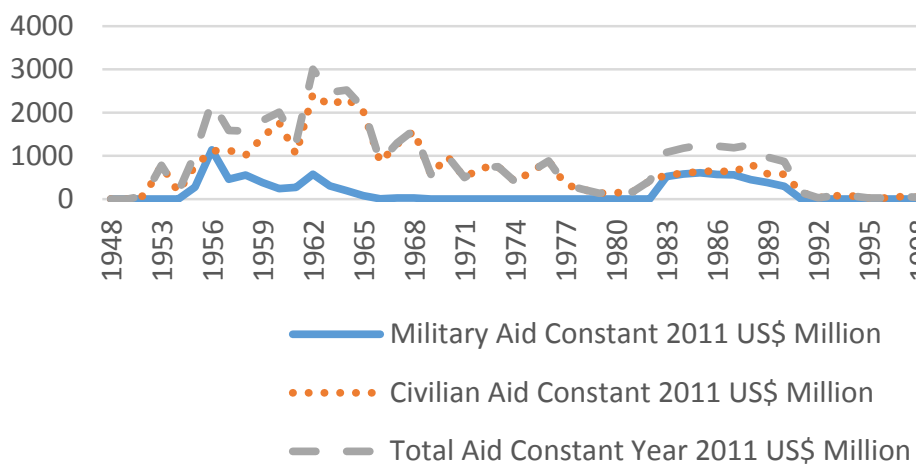

Source: Author's computation, raw data from Economic Analysis and Data Services, U.S. Agency for International Development

Musharraf's key reforms focused on governance issues, and on liberalization and privatization of the economy. The result was a curtailment of discretionary powers, devolution of power to the local governments, greater freedom of the press, and setting up of an accountability process for halting corruption. The privatization process was more 
transparent and was carried out without favoring any groups or individuals, unlike past experiences. Assets were sold to domestic and foreign investors in the oil, gas, energy, banking, telecommunications sectors. To encourage FDI, the foreign exchange regime was liberalized, and remittance restrictions on profits, dividends and import quotas were abolished. All restrictions on the export and import of agricultural products were lifted. Moreover, trade was liberalized and tariff rates were reduced on average from $65 \%$ to $11 \%$. Similarly, interest rates were no longer regulated and commercial banks which were nationalized in previous eras became competitive by closing down their loss-making branches and laying off unnecessary staff. The National Accountability Bureau (NAB) was established to stem corruption and white collar crime. NAB fined and sentenced to prison hundreds of government officials, politicians and businessmen. Moreover, loan and tax defaulters were dealt with for the first time in the country's history, and their outstanding debts were recovered. Overall, Musharraf's regime was successful in meeting most of its objectives, be it macroeconomic stability, improving governance, establishing credibility with international donors and limiting corruption. The IMF has acknowledged this on multiple occasions in form of statements. However, economic reforms such as abolishing subsidies and deregulating petroleum, gas, and energy prices, led to inflation that largely affected the middle class and poor. The safety nets failed in providing relief and the social sectors deteriorated.

Musharraf's era ended marred with controversies, political power struggles and allegations of abuse of power. By August 2007, polls showed 64 percent of Pakistanis did not want another Musharraf term. The nuclear proliferation scandal involving Dr. Abdul Qadeer Khan, the Lal Masjid incident, killing of the Baloch leader Bugti and suspension of Chief Justice Iftikhar Chaudhry had irreversibly tarnished the personal image of Musharraf among the masses. More importantly, popular and mass public movements led by lawyers across the country supporting the ousted Chief Justice called for his impeachment for the controversial actions he took during his presidency. Under this mounting pressure it took him just 8 months to resign. It can be aptly said that his legacy is mixed: his rule saw the emergence of a prosperous middle class, but his authoritarian style weakened the state of Pakistan in such a way that his reform agenda was susceptible of being unwound after him. Many analysts assert that is exactly what happened. 
Table 3.11 GDP, GDP per Capita and Sectoral Value Added Annual Growth Rates (at constant 2005 US\$), 2000-12

\begin{tabular}{|c|c|c|c|c|c|c|c|c|c|c|c|c|c|}
\hline & ○ & ઠ్̊․ & ণ̊ & ஜ̊ & ঠ্ণ & ํㅗㅇ & ๖̊ & 용 & $\stackrel{\infty}{\circ}$ & 옹 & 옹 & 곡 & $\stackrel{\sim}{\sim}$ \\
\hline GDP growth (annual \%) & 4.3 & 2.0 & 3.2 & 4.8 & 7.4 & 7.7 & 6.2 & 4.8 & 1.7 & 2.8 & 1.6 & 2.8 & 4.0 \\
\hline GDP per capita growth (annual \%) & 1.9 & -0.1 & 1.3 & 3.0 & 5.5 & 5.7 & 4.2 & 2.9 & -0.2 & 1.0 & -0.2 & 1.0 & 2.3 \\
\hline Agriculture, value added \% growth & 6.1 & -2.2 & 0.1 & 4.1 & 2.4 & 6.5 & 6.3 & 3.4 & 1.8 & 3.5 & 0.2 & 2.0 & 3.5 \\
\hline Industry, value added \% growth & 1.3 & 4.1 & 2.7 & 4.2 & 16.3 & 12.1 & 4.1 & 7.7 & 8.5 & -5.2 & 3.4 & 4.7 & 2.7 \\
\hline Manufacturing, value added $\%$ growth & 1.5 & 9.3 & 4.5 & 6.9 & 14.0 & 15.5 & 8.7 & 9.0 & 6.1 & -4.2 & 1.4 & 2.5 & 2.1 \\
\hline Services, etc., value added \% growth & 4.2 & 3.1 & 4.8 & 5.2 & 5.8 & 8.5 & 6.5 & 5.6 & 4.9 & 1.3 & 3.2 & 3.9 & J \\
\hline
\end{tabular}

Source: World Bank national accounts data, and OECD National Accounts data files.

\subsection{Current Challenges}

In the previous sections we have discussed the various ruling periods, their circumstances and their most salient policy features. There are however certain challenges which go beyond any particular period as they have been building up over a very long period of neglect and disregard. While they can't be ascribed to any one era, they have become a serious threat to Pakistan's growth and existence.

\subsubsection{Electricity shortage}

The foremost challenge is that of electricity shortage in the country. Though Pakistan has been importing electricity since 2002 (from neighboring Iran), the problem of frequent and unbearable 'brown-outs' or the euphemistically termed 'load-sheddings' i.e. intentional power outage, has in recent times been plaguing the country all of a sudden since 2007. Researchers estimate that population growth alone has been adding $1,000 \mathrm{MW}$ per year to the country's electricity needs, a rate that is not being matched by the rate at which installed capacity is growing (Hothway \& Kugelman, 2009). From Figure 3.13 (Installed capacity) we can compute the projected demand starting from Year 2000 and adding $1000 \mathrm{MW}$ per year. A growth rate of $4.7 \%$ per annum would have been required to meet the demand of the growing population without any improvement in living standards and without improving the access to electricity percentage which in 2011 stood at only $68.6 \%$ of the population. ${ }^{32}$ However real growth in installed capacity has been at a meagerly $1.45 \%$ since 2000 till 2008. If we were to consider the years 2009, 2010 and 2011 as well, which were high growth years, the average improves to $2.29 \%$, still way too short of the required rate. This huge annual deficit led to a shortfall of $3000 \mathrm{MW}$ in winters (when electricity consumption drops

\footnotetext{
${ }^{32}$ International Energy Agency, World Energy Outlook. (IEA Statistics @ $\mathrm{OECD/IEA,} \mathrm{http://www.iea.org/-}$ stats/index.asp).
} 
drastically as gas, wood and other sources are mainly used for heating) swells to about $6000 \mathrm{MW}$ in summers ${ }^{33}, 34$. The people of Pakistan are still learning to adapt to this new life-style with intermittent power supply where in urban areas they face 8-12 hours of announced power outages and in rural areas it averages around 18-22 hours in the peak season ${ }^{35}$. Unannounced and unscheduled outages have even lasted for days, especially in rural areas and have resulted in 'power riots', a rather new and unique phenomenon where people suffering from prolonged hours of load-shedding violently protest and even take staff from their local electricity suppliers hostage. ${ }^{36,37} \mathrm{~A}$ whole new industry of battery-powered inverters called uninterrupted power supplies (UPSs) and diesel, petrol or natural gas powered generators has propped up in the last decade as a result of these outages and given the dependency on electricity. It could be argued that the worst sufferers of this energy crisis are actually not the domestic users but the export oriented industries for whom power is like a life-line without which they cannot operate and alternative solutions like those mentioned above make their products horrendously expensive leaving them uncompetitive on the international market. Researchers estimate the total industrial output loss between 12 and $37 \%$ and an average increase in cost of production for the entire industrial sector of $26.5 \%$ (Siddiqui, Jalil, \& Nasir, 2008). In terms of GDP it has been estimated by governmental bodies as well as independent organizations like the Asian Development Bank that the energy crisis has been holding down the growth rate by 3-4 percentage points in recent years. The closure of hundreds of factories (including more than five hundred alone in Faisalabad, home to Pakistan's export oriented textile industry) are reported, stifling production and leading to more unemployment. The Beaconhouse National University estimates that the outage costs to the economy inclusive of both direct and indirect costs were as high as 7 percent of GDP in 2011-12. In currency terms this amounts to a staggering Rs. 1.4 trillion in 2011-12 (US\$ 13.4). ${ }^{38}$

The power shortage crisis is very complex and its causes are multifold, multilayered and interdependent.

\subsubsection{Installed capacity}

The first layer is that of installed capacity. Though there is an annual increase of $1000 \mathrm{MW}$ in demand due to population growth and urbanization, the supply side is barely keeping up with this trend. To the contrary, the installed capacity remained almost stagnant for too long starting in 1999 till 2008 as can be seen in Figure 3.14

\footnotetext{
${ }^{33}$ On $17^{\text {th }}$ June 2012 the total shortfall peaked at $8500 \mathrm{MW}$ which led to violent protests. The news story can be read at http://www.dawn.com/news/727263/residents-protest-prolonged-loadshedding-in-lahore

${ }^{34}$ Electricity shortfalls reached a peak of 8,500 megawatts (MW) in June 2012 -more than $40 \%$ of national demand.

${ }^{35}$ http://www.dawn.com/news/1109514/power-crisis-worsens

${ }^{36} \mathrm{http}: / /$ www.theguardian.com/world/2012/jun/19/pakistan-power-cut-riots

${ }^{37}$ http://tribune.com.pk/story/532847/power-riots-wapda-complex-attacked-over-loadshedding/

${ }^{38}$ The complete report can be downloaded at http://ippbnu.org/PR/Loadshedding\%20Project\%20Reports/
} 
below. There is no short-term solution to this, as installing new power plants requires time, especially the most feasible ones like hydropower projects. Unfortunately there have been too few initiatives in the last 5 decades. The last big projects were Mangla Dam and Tarbela Dam in 1967 and 1976 respectively, after which no hydropower plant of comparable dimensions has been completed. Though a few projects have been initiated in recent years, but they will most likely prove to be too little, too late.

Figure 3-14 Total Electricity Installed Capacity (Million Kilowatts)

\section{Total Electricity Installed Capacity (Million Kilowatts)}

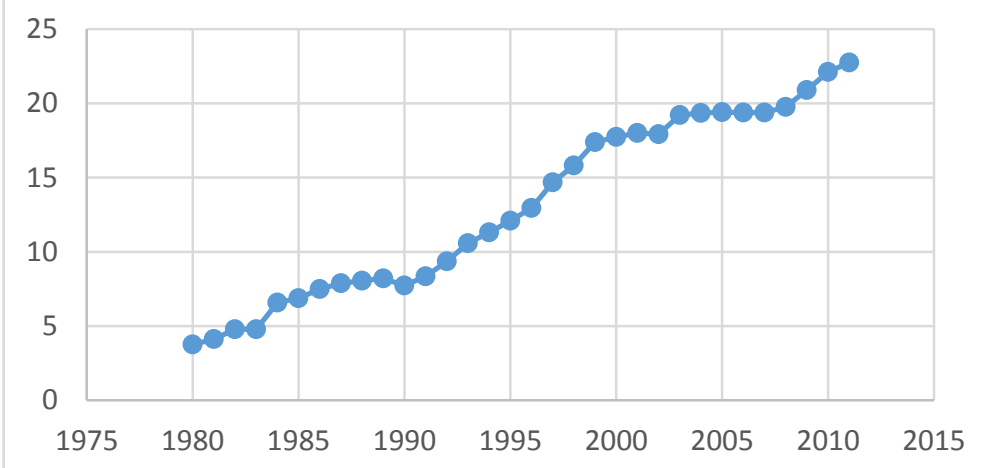

Source: International Energy Data, U.S. Energy Information Administration

Figure 3-15 Installed Capacity Growth \%

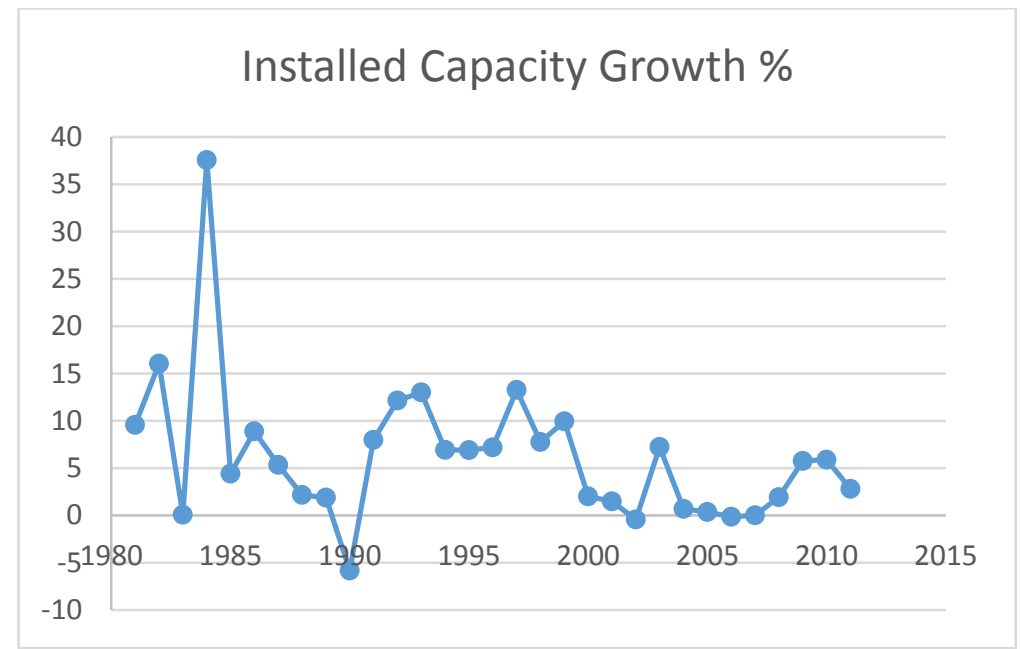

Source: International Energy Data, U.S. Energy Information Administration 


\subsubsection{Energy mix}

The other strategic issue is that of energy mix which in the last few decades has been comprising more and more of fossil fuels rather than renewable sources as was the case in the early years of Pakistan's existence. Figure 3.16 graphically depicts this sad reality by showing that in the last 4 decades the proportion of fossil fuel consumption has almost doubled to a staggering $65 \%$ of total energy consumption. Similarly, the only source of renewable electricity production currently is hydropower and as Figure 3.19 shows, the percentage of electricity production from hydroelectric sources has plunged from its peak value of $61 \%$ in 1978 by half in 2011 . This trend has contributed to driving up the percentage of fuel imports in terms of total imported merchandise. During the same period they have gone up five-times. Another indicative statistic is that of net energy imports in terms of total energy use, which has risen from close to $15 \%$ to almost $25 \%$. This energy mix is unsustainable to say the least. Pakistan is a net importer of fossil fuels and already spends valuable foreign exchange on imports. On the other hand it is rich in natural water resources and could easily expand its hydroelectric production to over 100,000 MW with already identified sites of $59000 \mathrm{MW}$ (WAPDA, 2013).

Figure 3-16 Fossil fuel energy consumption (\% of total)

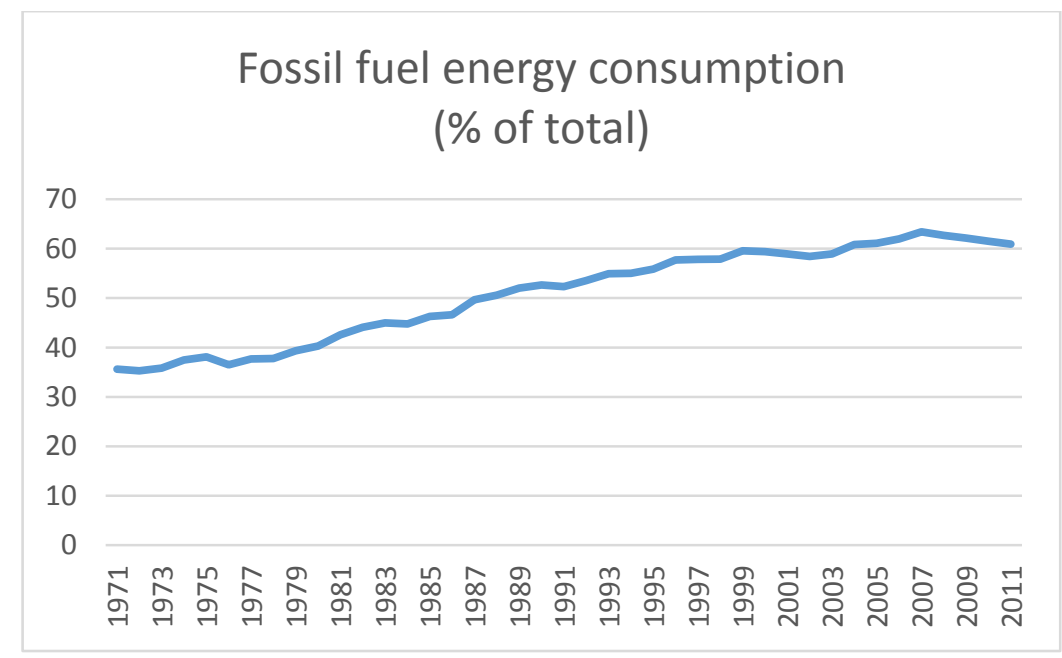

Source: International Energy Agency (IEA Statistics (C) OECD/IEA, http://www.iea.org/stats/index.asp) 


\section{Fuel imports (\% of merchandise imports)}

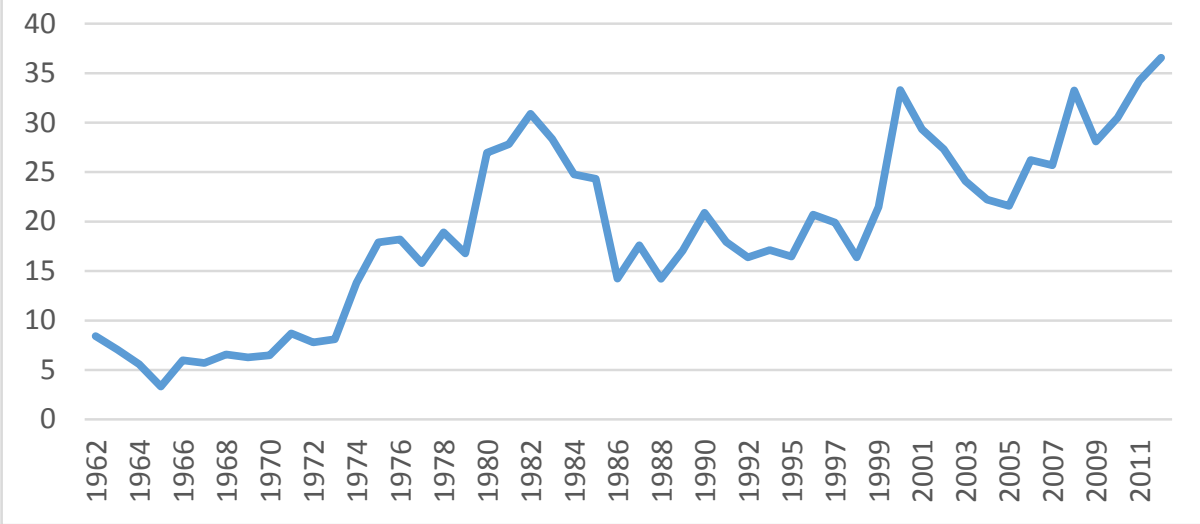

Source: World Bank staff estimates from the Comtrade database maintained by the United Nations Statistics Division.

Figure 3-18 Energy imports, net (\% of energy use)

\section{Energy imports, net (\% of energy use)}

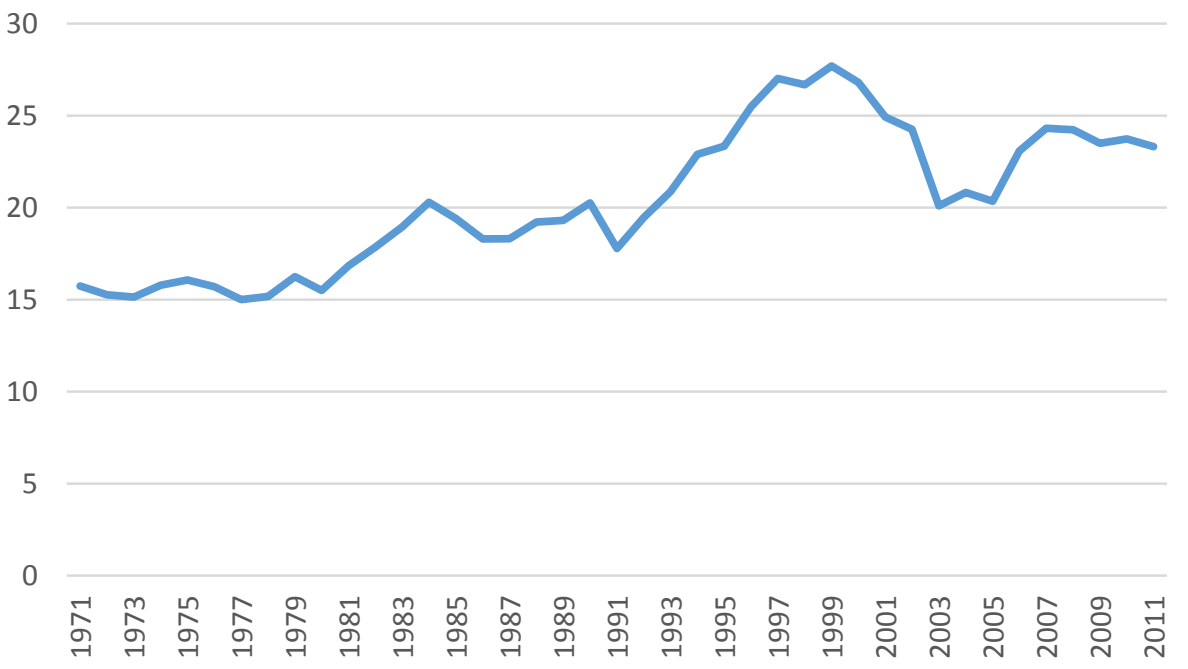

Source: International Energy Agency (IEA Statistics (C) OECD/IEA, http://www.iea.org/stats/index.asp) and United Nations, Energy Statistics Yearbook. 


\section{Electricity production from hydroelectric sources (\% of total)}

70

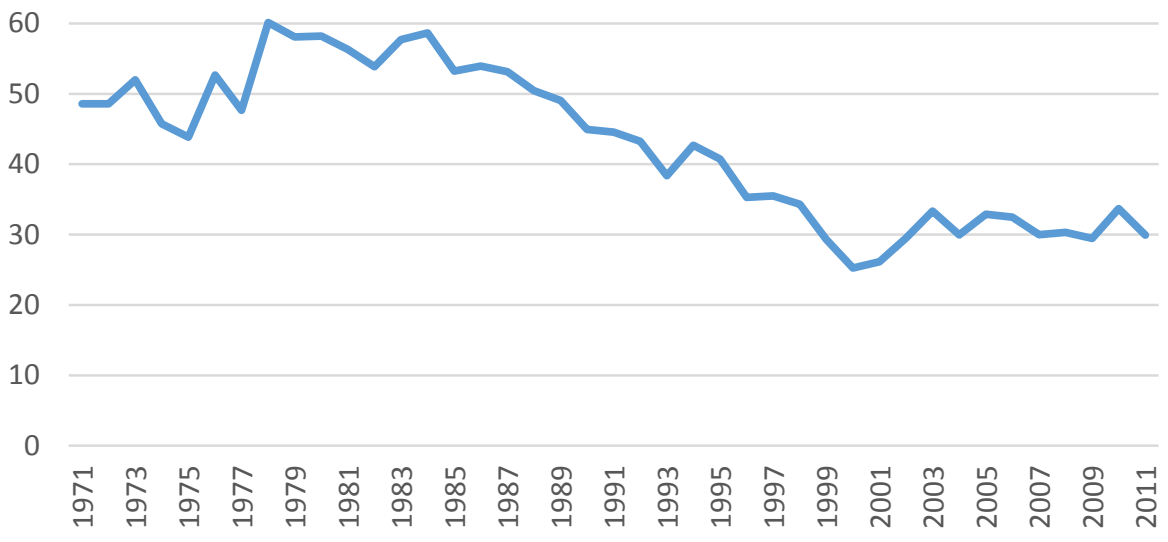

Source: International Energy Agency (IEA Statistics C OECD/IEA, http://www.iea.org/stats/index.asp), Energy Statistics and Balances of Non-OECD Countries

\subsubsection{Circular debt}

Another major cause plaguing the already underpowered power sector is that of circular debt. The amount of cash shortfall which the Central Power Purchasing Agency (CPPA) is unable to pay to power supply companies is termed as circular debt. A report commissioned by the Planning Commission of Pakistan (2013) elaborates that the "shortfall is the result of (a) the difference between the actual cost of providing electricity in relation to revenues realized by the power distribution companies (DISCOs) from sales to customers plus subsidies; and (b) insufficient payments by the DISCOS to CPPA out of realized revenue as they give priority to their own cash flow needs. This revenue shortfall cascades through the entire energy supply chain, from electricity generators to fuel suppliers, refiners, and producers; resulting in a shortage of fuel supply to the public sector thermal generating companies (GENCOs), a reduction in power generated by Independent Power Producers (IPPs), and an increase in load shedding."

Circular debt at the end of 2011 was estimated to be Rs537 billion. A year later it had sky rocketed to Rs872 billion which is approximately 4\% of Gross Domestic Product (GDP). After a payment of Rs480 billion to the CPPA in August 2013, the circular debt has again climbed up to Rs300 billion in 9 months (April 2014). The causes of circular debt also directly contribute to the energy crisis and are discussed below. 


\subsubsection{Corruption}

There are two levels of corruptions. One is at the user level, where the Supply company officials are bribed by users to waive off or reduce their legitimate bill. Similarly at the producer level corruption manifests itself in political supporters winning lucrative contracts without merit or without even producing a megawatt of power. The country's former Prime Minister, Raja Pervez Ashraf, is one such example of a high government official (at the time of the alleged wrongdoing he was the minister for water and power) being implicated and later indicted in corruption related to the power crisis. The national accountability bureau (NAB) has been investigating 12 rental power plant (RPP) cases in which nine firms reportedly received more than Rs22 billion as down payment from the government to commission the projects, but most of them were accused of failing to set up plants which was only possible after the accused allegedly misused his authority to obtain governmental approval for an increase in the mobilization advance from 7 per cent to 14 per cent. On January 16th, 2014 an accountability court in Islamabad indicted him for authorizing the submission of a factually misleading summary on April 13, 2009 to the economic coordination committee (ECC). As a result of these widespread kickback allegations in the RPP case Mr. Raja Pervez Ashraf has been dubbed as "Raja-Rental" by the media.

\subsubsection{Poor revenue collection}

Poor revenue collection from customers (both private and governmental i.e. ministries, hospitals, police stations etc.) is mainly due to political interference, failure to disconnect defaulters, reliance of manual meter-reading, non-automated revenue collection and fear of violence from customers upon disconnection or replacement of faulty meters.

\subsubsection{Distribution losses}

As per definition, the discrepancy between the amount of electricity produced and that consumed is termed as distribution loss also known as line and transmission losses. The losses arise from the fact that the electrical resistance in cables leads to electrical energy being dissipated as heat. However, in Pakistan, it is approximated that $50 \%$ of aggregate distribution losses are non-technical, with theft being the major contributor. In 2013 theft alone contributed to more than Rs150 billion losses in revenues ${ }^{39}$. The 'kunda' (hook) method of theft whereby a hook is connected to the main power line to get illegal access is widespread and electricity officials and police don't remove them in fear of retribution. So much so that legal kundas were promised for two months as concessions to residents for a nominal Rs.700 per month for agreeing to get meters installed. ${ }^{40}$

\footnotetext{
${ }^{39}$ http://www.thenews.com.pk/Todays-News-3-195511-Power-theft,-line-losses-cause-Rs150b-revenue-loss

${ }^{40}$ http://tribune.com.pk/story/697027/by-hook-or-by-pesco-legalises-kunda-connections-in-pk-6-for-twomonths/
} 


\subsubsection{Bad governance}

Bad governance lies at the heart of all the above mentioned issues. Be it at the government (tariffs and subsidies), corporate (accountability of management and staff) or regulatory (licensing rules and performance standards) level.

\subsubsection{Gas shortage}

Plentiful supplies and projected reserves in the 90's led the government to allow and encourage use of natural gas as an alternative fuel for automobiles in form of compressed natural gas (CNG). This decision did give a temporary relief to the otherwise soaring fuel import bill but had many negative repercussions. Not only private vehicles, but the relatively lower priced fuel and indiscriminate promotion also indirectly incentivized public transportation to convert to CNG. The Natural and Bio Gas Vehicle Association (NGVA) estimates that Pakistan with approximately 2.8 million CNG vehicles is only behind Iran in terms of vehicles running on $\mathrm{CNG}^{41}$. This statistic would have been impressive had Sui Northern Gas Pipelines (SNGPL) data not revealed that the current annual production of CNG is increasing by $7 \%$ only, whereas demand is growing at nearly $40 \%$. This brings the annual shortfall of CNG to more than $400 \%$. Population increases and urbanization trends have increased the demand for gas by the domestic sector too. Gas is also the fuel of choice of independent power producers (IPPs). All these factors have pushed per capita gas usage in Pakistan to 225 cubic meters per person, almost twice as much as Bangladesh (125) and four times as much as India (54). ${ }^{42}$ This profuse usage has created a demand-supply gap that has eventually led to massive cuts in gas supply to all sectors. The total output of gas pipeline companies in the country is around 2,000 million cubic feet per day (mmcfd), while demand is $2,800 \mathrm{mmcfd}$.Various gas-pipeline projects to bridge this huge gap in supply and demand are on the cards in acknowledgement of the strategic gas shortage. Imports in gaseous form require multi-billion dollar pipelines to be laid to import natural gas from neighboring countries. Two such projects - Turkmenistan-Afghanistan-Pakistan-India (TAPI) and Iran-Pakistan (IP) pipelines are under consideration but political issues and the huge upfront investment in infrastructure have so far stifled these projects. Imports are also possible in liquid form known as liquid natural gas (LNG) and Pakistan is in talks for a long-term import contract with Qatar. ${ }^{43}$ Until then domestic users should brave for chilling winters, CNG vehicle owners should be ready for kilometer long queues at pumps and the industrial sector should opt for other, more expensive fuels to keep their gears and pulleys moving.

\footnotetext{
${ }^{41}$ Data available at http://www.ngvjournal.com/worldwide-ngv-statistics/

${ }^{42} \mathrm{CIA}$ World Factbook 2012 estimates

${ }^{43}$ http://tribune.com.pk/story/705965/gas-import-qatari-team-coming-govt-to-bargain-over-Ing-price/
} 


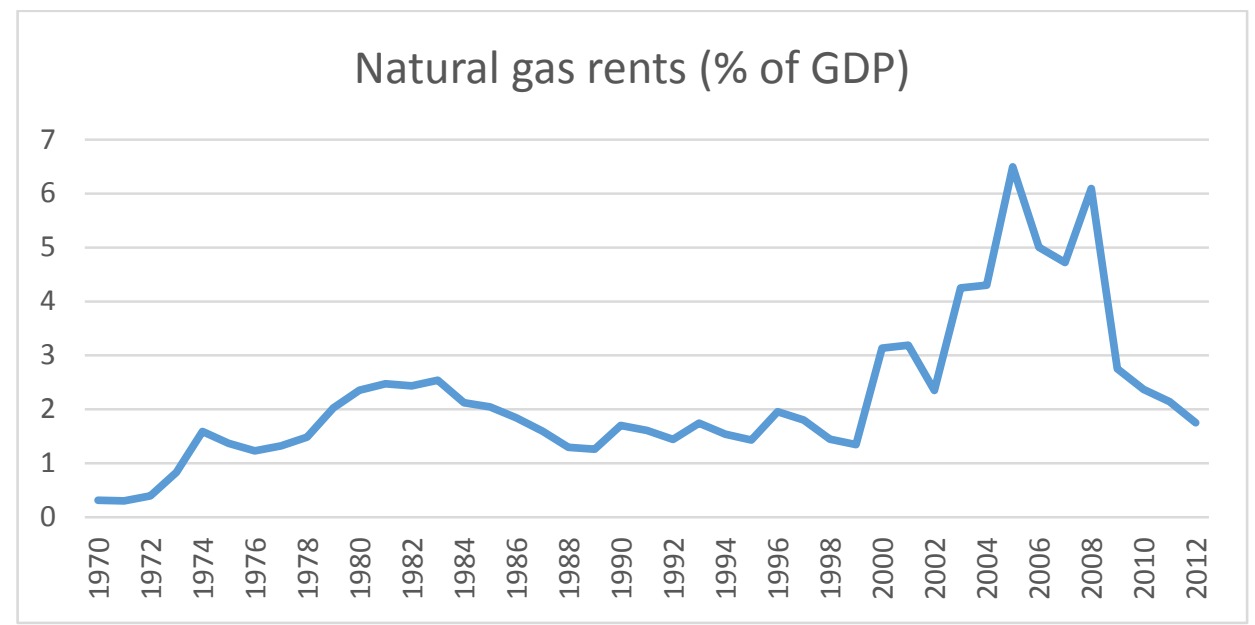

Estimates based on sources and methods described in "The Changing Wealth of Nations: Measuring Sustainable Development in the New Millennium" (World Bank, 2011).

Figure 3-21 Electricity production from natural gas sources (\% of total)

\section{Electricity production from natural gas sources \\ (\% of total)}

60

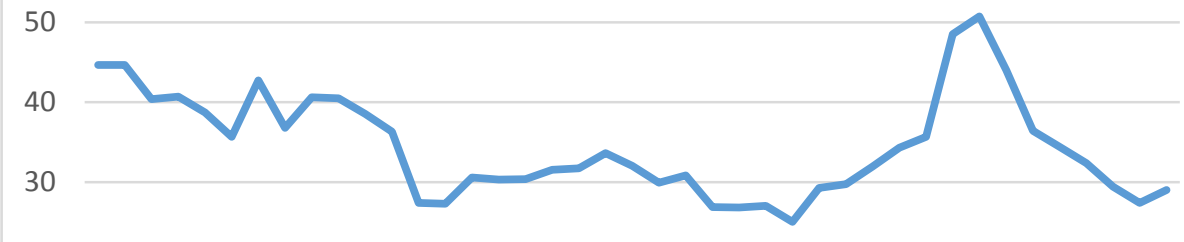

20

10

0

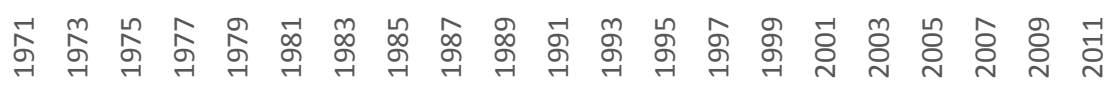

Source: International Energy Agency (IEA Statistics @ OECD/IEA, http://www.iea.org/stats/index.asp) 
Table 3.12 Natural Gas Supply-Demand Balance

\begin{tabular}{lcccccccc}
\hline & 2014 & 2015 & 2016 & 2017 & 2018 & 2019 & 2020 & 2025 \\
\hline Supply & 3,071 & 2,758 & 2,342 & 2,041 & 1,774 & 1,555 & 1,349 & 684 \\
Constrained Demand & 5,797 & 5,978 & 6,147 & 6,311 & 6,501 & 6,692 & 6,889 & 7,938 \\
Shortfall & 2,726 & 3,220 & 3,805 & 4,270 & 4,727 & 5,137 & 5,540 & 7,254 \\
\hline
\end{tabular}

Source: SSGC \& SNGPL

\subsubsection{Energy silver lining}

There are multiple silver linings to the dark cloud of the energy crisis as discussed below.

\subsubsection{Thar coal field}

Though Pakistan is otherwise rich in coal resources, Thar Desert's huge Lignite coal reserves discovered in the 90's are seen by many as the only viable and long-term solution for meeting energy demands of the country. The Geological Survey of Pakistan (GSP) estimates the Thar coal reserves at a staggering 175 billion tons, enough to alone meet the country's energy requirements for centuries. The low calorific value of lignite and the high content of Sulfur in it necessitates under-ground coal gasification, a technology which has yet to be put to large-scale commercial use. However, Pakistan's top brains are working on it and a small $660 \mathrm{MW}$ power project launched in 2014 is to be completed in 2017.

\subsubsection{Solar irradiation}

Solar irradiation or Insolation is the total amount of solar radiation energy received on a given surface area during a given time. It is measured in megajoules per square meter $\left(\mathrm{MJ} / \mathrm{m}^{2}\right)$ and divided by hours or days for hourly or daily irradiation. Megajoules can also be expressed in terms of watts and if divided by the recording time in hours it would give us Irradiance. Pakistan is ideally located to take advantage of any kind of solar technologies due to long hours of sunshine throughout the year. The mean global horizontal irradiation (GHI) in Pakistan is about 200-250 watt $/ \mathrm{m}^{2} /$ day(4.8 - 6.0 expressed in $\mathrm{kWh} / \mathrm{m}^{2} /$ day) (Bhutto, Bazmi, \& Zahedi, 2012). ${ }^{44}$ These values are among the highest in the world and ideal for photovoltaic (PV) and other solar energy applications. These conditions make Pakistan a favorable destination for solar parks not only for domestic use, but also for investments for electricity export purposes. Solar energy is considered an attractive alternative to other more conventional sources because it is a renewable resource, which causes no pollution. Moreover, it eliminates the overhead costs of refining, transporting and distributing fuels and power over long distances.

\footnotetext{
${ }^{44}$ See GHI map of World and Pakistan in Appendix I.
} 


\subsubsection{Wind corridors}

Pakistan has tremendous untapped opportunities for wind energy due to its long and broad wind corridors, especially in the Sindh province. The total exploitable wind power potential for only a small 9700 square-km area in Sindh is estimated at 11000 MW by the Pakistan Meteorological Department. ${ }^{45}$ This is approximately double than the current energy shortfall.

\subsubsection{Biogas}

Being an agricultural country, Pakistan is rich in animal manure. The 60 million cattle and buffalos (Livestock Census 2006) alone produce almost 652 million kg of manure daily which can be used to generate 16.3 million $\mathrm{m}^{3}$ biogas per day and 21 million tons of bio fertilizer per year (Amjid, Bilal, Nazir, \& Hussain, 2011). Please note that Pakistan produces electricity from gas and diesel, the latter being more expensive but as the demand for gas cannot be met locally and imports are not possible without a pipeline which is still under discussion, imported diesel fuel is used to bridge this gap. It is also worth mentioning that the production of fertilizer eats up $20 \%$ of total gas production $^{46}$ and still as gas is diverted to domestic users and the compressed natural gas (CNG) sector for fueling vehicles, Pakistan imported 1.45 tons of urea at the expense of US\$783 million. By investing in bio-gas infrastructure, bio-fertilizer could also be produced at very low cost saving gas for the power sector and other industries.

\subsubsection{Water Crisis}

Another pressing issue the country is currently facing is that of Water crisis. Researchers warn that water shortages jeopardize the viability of Pakistan as a state and a society. Whilst this might be an overly pessimistic perspective, water availability has significantly plummeted in the last 5 decades, down to dangerous levels. Presently it stands at less than 1,400 $\mathrm{m}^{3}$ per capita, down more than one-third from about 5,000 cubic meters $\left(\mathrm{m}^{3}\right)$ per capita in the early 1960 s (see Figure 3.22 ). This brings Pakistan perilously close to becoming a 'water scarce' country (designation for countries with water availability below $1,000 \mathrm{~m}^{3}$ per capita) (Kugelman \& Hathaway, 2009).

The foremost contributors to this downward trend are a burgeoning population, migratory flows (within and into the country), deforestation, global warming and the resulting climate change. Highly toxic run-offs are causing water contamination related diseases and deaths. Nearly 1.2 million people die each year due to water-borne diseases in Pakistan. Amongst these, 250,000 are children under the age of five who succumb to diarrhea, mainly caused by the use of contaminated water. Approximately 60

\footnotetext{
${ }^{45}$ Report downloaded from http://www.pmd.gov.pk/wind/Wind_Project_files/Sindh_Wind-03year.pdf on 4th July 2014.

${ }^{46}$ Total daily gas production is 4.3 Billion Cubic Feet per day (BCFD) out of which 818 Million Cubic Feet per Day (MMCFD) is allocated to the fertilizer sector
} 
percent of child deaths in Pakistan are caused by water-borne illnesses with diarrhea alone killing an estimated 630 children daily. Settled areas like Rawalpindi - the city which houses the powerful Pakistan Army and is known as the twin city of Islamabad) are also vulnerable to water-borne diseases due to supply of untreated water in several parts of the city. It is estimated that about $80 \%$ of the city's population drinks contaminated water. ${ }^{47}$

As compared to the world-average water usage for agriculture of 70 per cent, Pakistan uses nearly 94 per cent. ${ }^{48}$ This is understandable given that Pakistan is a largely arid country with an agriculture-dependent economy. The consequences are borne by the one-third population who don't have access to safe drinking water as a meager 5 per cent is allocated to drinking, household usage and sanitation (and the remaining 1 percent for industrial purposes). Another alarming circumstance is that the storage capacity stands at merely 30 days as opposed to the minimum requirement of 120 days. Compared to its neighbor, India has the ability to store water for 120-220 days. The inadequate and aging infrastructure cannot preclude Pakistan losing 13 million cusecs of water every year into the Arabian Sea.

India is also blamed by many for Pakistan's water woes alleging that India is obstructing the flow and diverting the waters. A $2009 \mathrm{CIA}$ report concluded that "the likelihood of conflict between India and Pakistan over shared river resources is expected to increase".

Figure 3-22 Total renewable water resources per capita (actual) (m3/inhab/yr)

\section{Total renewable water resources per capita (actual) (m3/inhab/yr)}

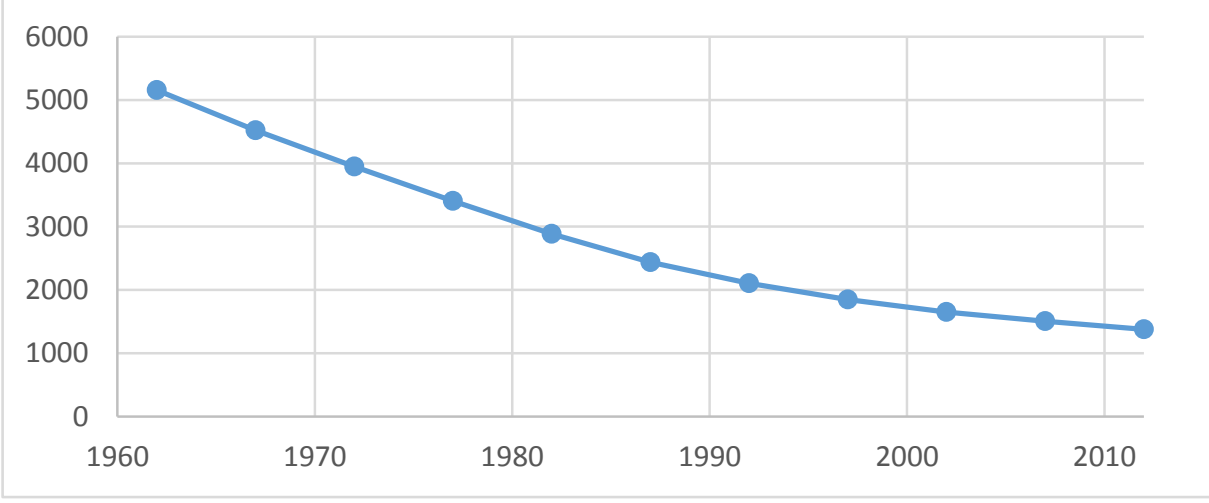

Source: Food and Agriculture Organization, AQUASTAT data.

\footnotetext{
${ }^{47}$ Figures by Head of Community Medicine at Islamabad Medical \& Dental College, Colonel (r) Professor Dr. Muhammad Ashraf Chaudhry while talking to 'The News'

${ }^{48}$ Based on 2011 data from World Development Indicators, The World Bank.
} 


\subsubsection{Medical emergency}

Another problem Pakistan is facing can be termed as the 'medical emergency'. With less than 1 percent share of GDP - a figure almost unchanged since availability of data despite the fast-growing population - public healthcare is in a shambles in Pakistan. This has manifested itself in various forms and shapes. The frequent boycotts by Young Doctors' Associations (YDA) across the country which often turn violent and leave operations suspended at major government hospitals, the failed polio campaigns with coverage rates barely over 50 percent, the 2011 dengue virus outbreak causing over 250 deaths in a single city (Lahore), the fake-medicine crisis of 2012 claiming over 100 lives, and the 2014 measles outbreak in Khyber Pukhtunkhwa province with epidemic proportions, all point towards a looming medical emergency in the country.

Figure 3-23 Health expenditure, public (\% of GDP)

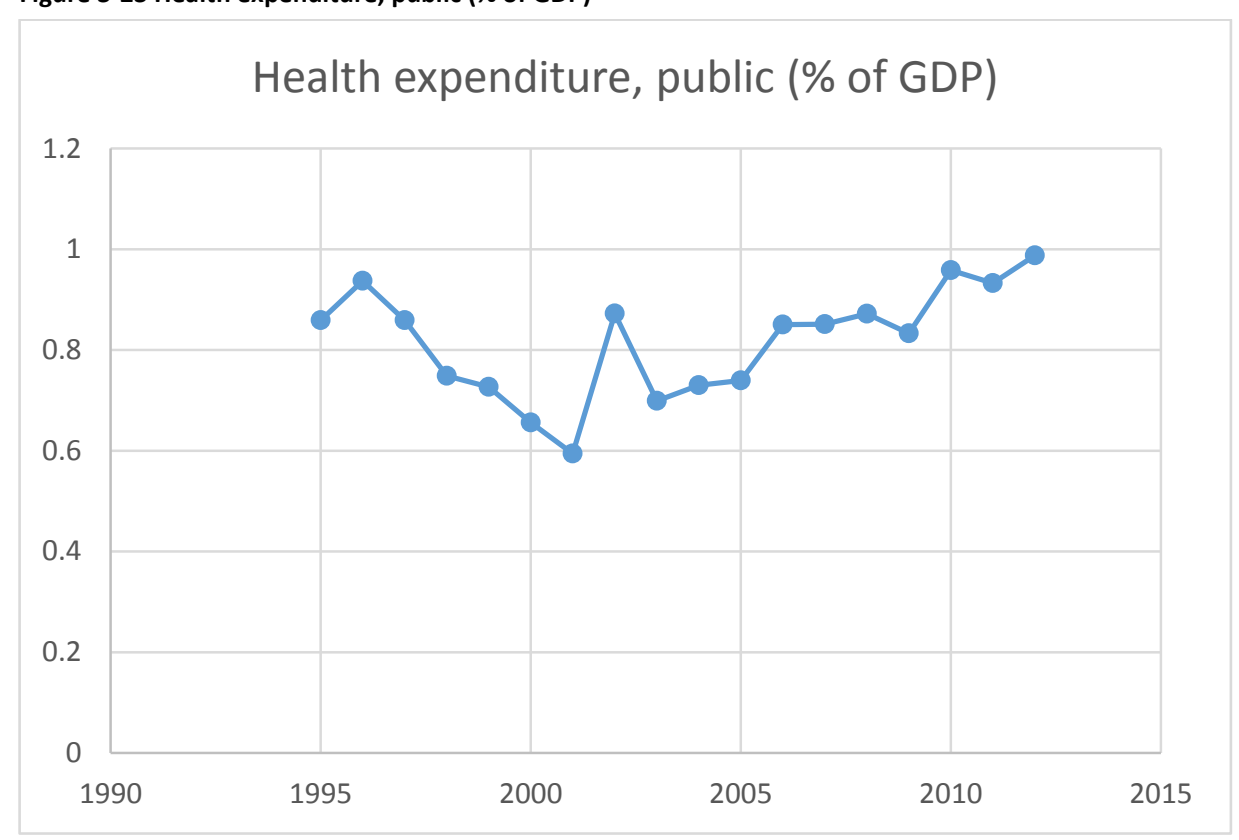

Source: World Health Organization National Health Account database

The strikes in July 2012 by YDA left 11 patients dead and hundreds of thousands suffering without medical care. Doctors' demands for an improved service structure is usually met by deaf ears until they suspend operations at hospitals which then is met by baton charge, suspensions and arrests of protesting doctors. The situation is usually brought under control by restoring out-patient department (OPD) services partly, by calling-in doctors from the Army Medical Corps and conducting double shifts in military hospitals in the cantonment areas. Involvement of the already stretched out army in such day-to-day fire-fighting activities is an unwanted norm. 
The wild poliovirus (WPV) endemic is slowly turning into an epidemic and if left unchecked it has all the potential to become a pandemic. It is therefore that the World Health Organization (WHO) has recommended Pakistan declare a national public health emergency and impose strict travel restrictions on travelers from Pakistan. The recent assassination of polio workers ${ }^{49}$ and the rejection of the polio vaccination campaign by militants in areas ${ }^{50}$ where the government writ can be termed weak at best, are offered as convenient excuses for its failure. The use of a fake immunization campaign by the CIA to gather pre-raid data from the compound where Osama bin Laden was thought to be hiding only lent credibility to the voices calling vaccinations a conspiracy of the West ${ }^{51}$. However, though these immediate challenges have exacerbated the situation, the long-standing issues in procurement, transport, cold-storage systems and coordination remain to be the main factors negatively influencing polio eradication over the past decades (Altaf, 2011). The share of Pakistan in the worldwide WPV cases in 2014 given in Figure 3.24 speaks volumes of this failure.

Figure 3-24 Total deaths caused by WPV in Pakistan

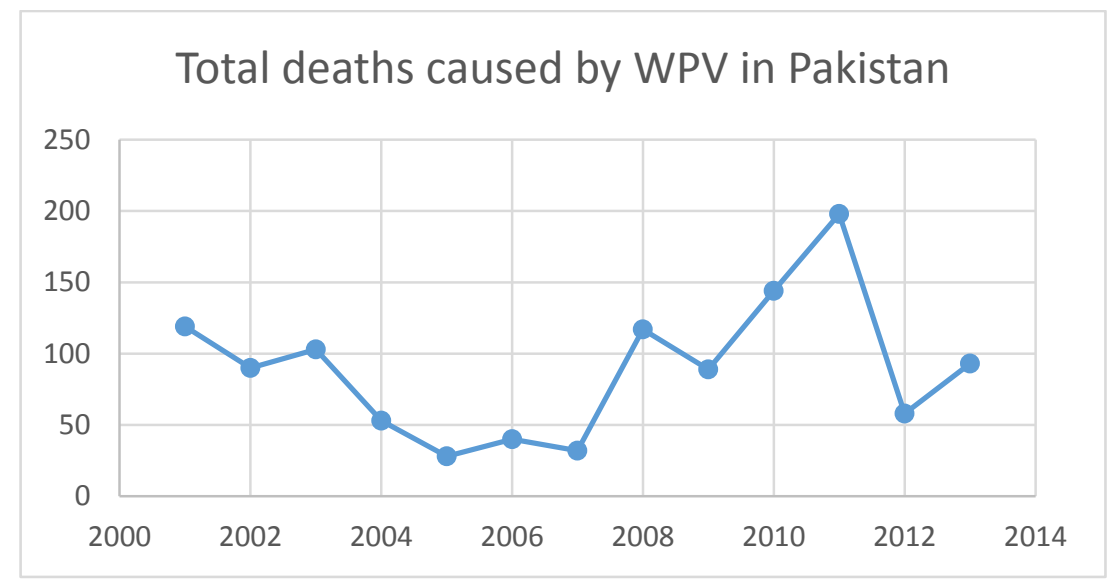

Source: Expanded Programme on Immunization, Government of Khyber Pukhtunkhwa, Pakistan

\footnotetext{
${ }^{49}$ http://centralasiaonline.com/en_GB/articles/caii/newsbriefs/2013/10/24/newsbrief-14\#sthash.CAM8Zdw9.dpuf

${ }^{50}$ http://www.thenews.com.pk/article-54648-Militants-ban-polio-vaccination-in-NWA

${ }^{51}$ http://www.theguardian.com/world/2011/jul/11/cia-fake-vaccinations-osama-bin-ladens-dna
} 


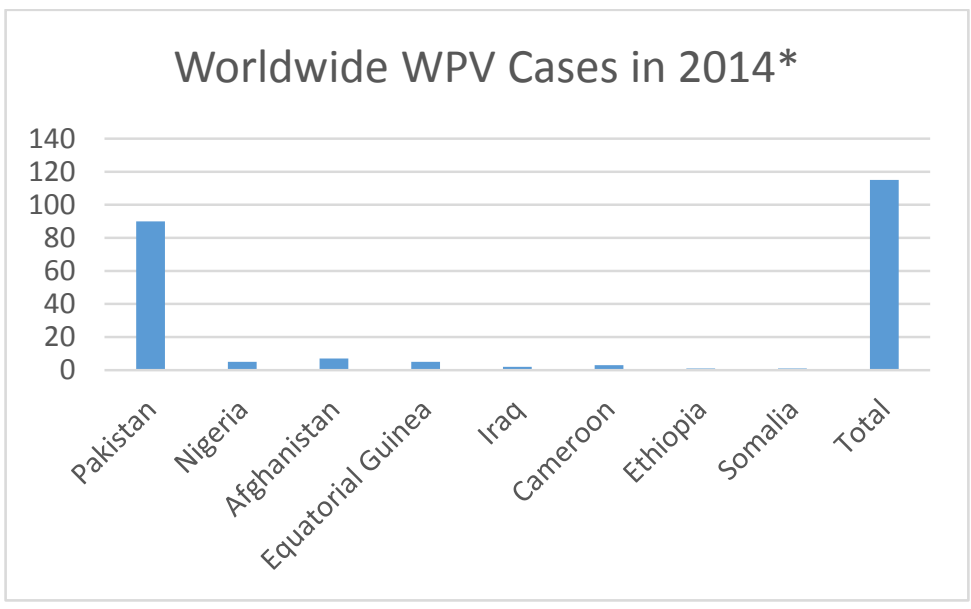

*Data in WHO as of 08 July 2014.

Source: Global Polio Eradication Initiative (GPEI), World Health Organization.

Dengue virus, transmitted by mosquito bites, is a controllable and in principle nonfatal disease with 1 percent mortality rates only in its severe form. However in Pakistan it's been wreaking havoc since 2010 and is often quoted as yet another example of poor governance. The 2010 outbreak had caused 317 deaths. The virus has even caused high-profile deaths like ministers and secretaries in Lahore, the capital of Punjab and home of the now Prime Minister, Nawaz Sharif.

Over 100 cardiac patients under treatment at the Punjab Institute of Cardiology lost their lives after being prescribed and freely provided with counterfeit antihypertensive drugs. The license of the producer of the contaminated drugs had expired months ago but provincial drug inspectors were totally ignorant of this fact. The company continued to manufacture the drugs selling them in the open market and also supplying government hospitals under lucrative contracts indicating systemic failure.

The recent measles outbreaks are another example of a preventable and controllable disease, which has been contained in most parts of the world decades ago, taking precious lives and exposing the weak points of our healthcare system. 79 children died in Khyber Pukhtunkhwa province alone in the last five months (Jan - May 2014) from measles. ${ }^{52}$ The percentage immunization coverage figure below paints a dismal picture, showing the plummeting coverage of almost all vaccines in recent years. Poor health infrastructure and corruption are pointed out as the chief impediments in the vaccination program (Khan \& Qazi, 2014). Reports of children dying from the measles vaccine itself are not helping the cause either. ${ }^{53}$ The situation is further complicated by

\footnotetext{
${ }^{52}$ http://www.medicalnewspk.com/measles-crisis-in-kpk-enquiry-committee-formed/

${ }^{53}$ http://www.thenewstribe.com/2014/06/01/two-more-children-mysterious-die-via-anti-measles-vaccinesin-kpk/
} 
the influx of 0.9 million internally displaced persons (IDPs) so far due to the ongoing military operation against alleged terrorists in the tribal areas. Vaccination coverage is already poor in tribal areas and couple this with the poor hygiene and sanitary conditions in the IDP camps, outbreaks of deadly diseases might just be around the corner in cities like Bannu and Peshawar, hosting these IDPs. ${ }^{54}$

Table 3.13 Measles cases and deaths caused in Pakistan

\begin{tabular}{llll}
\hline Year & 2011 & 2012 & 2013 \\
\hline Approx. cases of measles & 4000 & 14000 & 25000 \\
Deaths caused by measles & 64 & 306 & 321
\end{tabular}

Source: (Riaz, 2013), (Khan \& Qazi, 2014)

Given the facts above, it is no wonder that despite the steady progress Pakistan has been making in terms of some key health indicators like infant mortality and maternal mortality (see Figure 3.26 and 3.27 below), it still ranks $25^{\text {th }}$ among the worst countries in terms of infant mortality rate with 57 deaths per 1000 live births, worse than Bangladesh (45/45 and India 50/43 and $44^{\text {th }}$ in maternal mortality with 260 deaths per 100,000 live births, worse than Bangladesh (49/240) and India (55/200). ${ }^{55}$

Figure 3-25 Immunization coverage, \%*

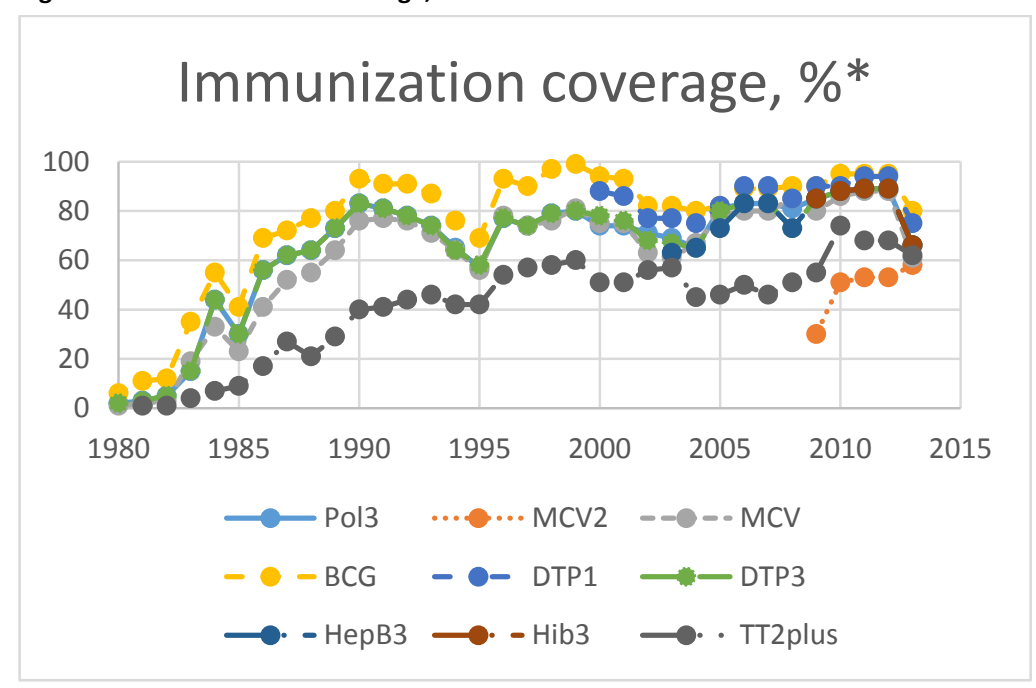

*The coverage figures (\%) are the country official reported figures Source: Annual WHO/UNICEF Joint Reporting Form and WHO Regional offices reports

\footnotetext{
${ }^{54}$ http://www.dawn.com/news/1118810/infections-haunt-idp-children-as-displaced-number-crosses-09m

${ }^{55} \mathrm{CIA}$ World Factbook 2013 estimates available at https://www.cia.gov/library/publications/the-worldfactbook/rankorder/2223rank.html and https://www.cia.gov/library/publications/the-world-factbook/rankorder/2091rank.html
} 
Pol3 Third dose of polio vaccine

BCG Baccille Calmette Guérin vaccine First dose of diphtheria toxoid, tetanus toxoid and pertussis vaccine (data collection started in

DTP1 2000)

DTP3 Third dose of diphtheria toxoid, tetanus toxoid and pertussis vaccine

HepB3 Third dose of hepatitis B vaccine administered to infants

Hib3 Third dose of Haemophilus influenzae type B vaccine

MCV Measles-containing vaccine

MCV2 2nd dose of Measles-containing vaccine (data collection started in 1995)

TT2plus Second and subsequent doses of tetanus toxoid

Figure 3-26 Infant mortality rate, infant (per 1,000 live births)

\section{Mortality rate, infant (per 1,000 live births)}

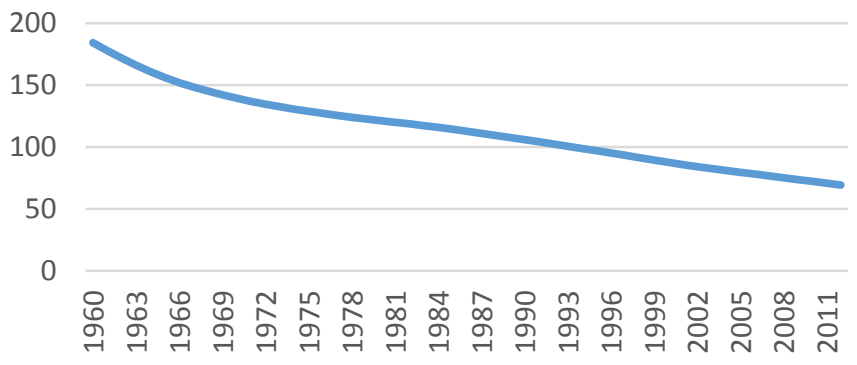

Source: Estimates developed by the UN Inter-agency Group for Child Mortality Estimation (UNICEF, WHO, World Bank, UN DESA Population Division) at www.childmortality.org.

Figure 3-27 Maternal mortality ratio (modeled estimate, per 100,000 live births)

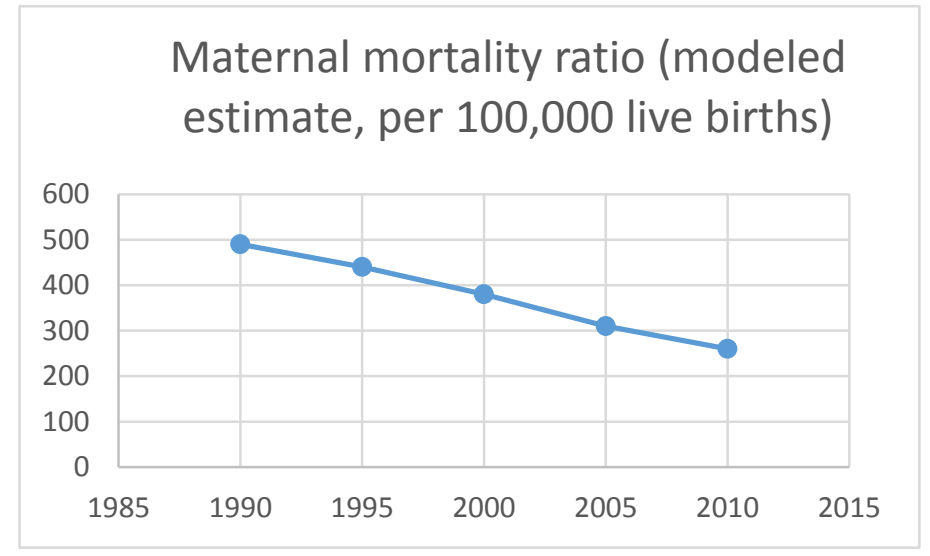

Source: Trends in Maternal Mortality: 1990-2010. Estimates Developed by WHO, UNICEF, UNFPA and the World Bank. 


\subsubsection{Food security}

Another issue of concern for Pakistan is food security or in Pakistan's case food insecurity. According to The Economist Intelligence Unit's (EIU) Global Food Security Index (GFSI), Pakistan ranks $77^{\text {th }}$ among its 109 indexed countries. According to data from Food and Agriculture Organization (FAO) the prevalence of undernourishment in 2013 was 19.9 percent and 43 percent children had stunted growth due to it. ${ }^{56}$ These alarming figures are putting the future generations at severe health risks and thereby compromising productivity and growth.

Pakistan is dependent on its agriculture sector to meet food and fiber requirements of the fast growing population. Although the rate of population increase has considerably slowed down from over 3 percent in 1980s to under 2 percent in 2000s, it is still considered high (see figure 3-4). Even at this rate the population is estimated to double by 2050-pushing Pakistan up from currently the $6^{\text {th }}$ largest nation to the $4^{\text {th }}$ most populous country of the world. The total arable land area has increased by just 5\% during 1960 and 2012, while there has been close to 3 times increase - from 45.5 million in 1960 to 179 million in 2012 - with urban expansion of over sevenfold. Looking at Figure 3.30, the arable land per person has been continuously reducing from 0.36 hectares in 1962 to 0.11 in 2011 . Given the not so impressive evolution of productivity in the agriculture sector this poses a serious threat. Production of wheat, a major food crop, has increased five-fold during the same period-yet the country is still a marginal importer of wheat. Unrelenting efforts are needed both in terms of population control and advances in technology to shrink the food supply-demand gap. Ensuring food security is not only an essential part of the Millennium Development Goals (MDGs) but also a pre-requisite for economic progress (Timmer, 2005). Fullbrook (2010) asserts that even national security is linked to food security, which is a generally ignored aspect. Thus countries which are neither able to produce the needed food nor to buy it from the international market to meet their demand, have their sovereignty at stake. The global price-hike of food items around 2008 raised alarms on food security, particularly for the developing world. Pakistan is no exception.

\footnotetext{
${ }^{56}$ The complete dataset can be downloaded at http://foodsecurityindex.eiu.com/
} 


\section{Arable land (\% of land area)}

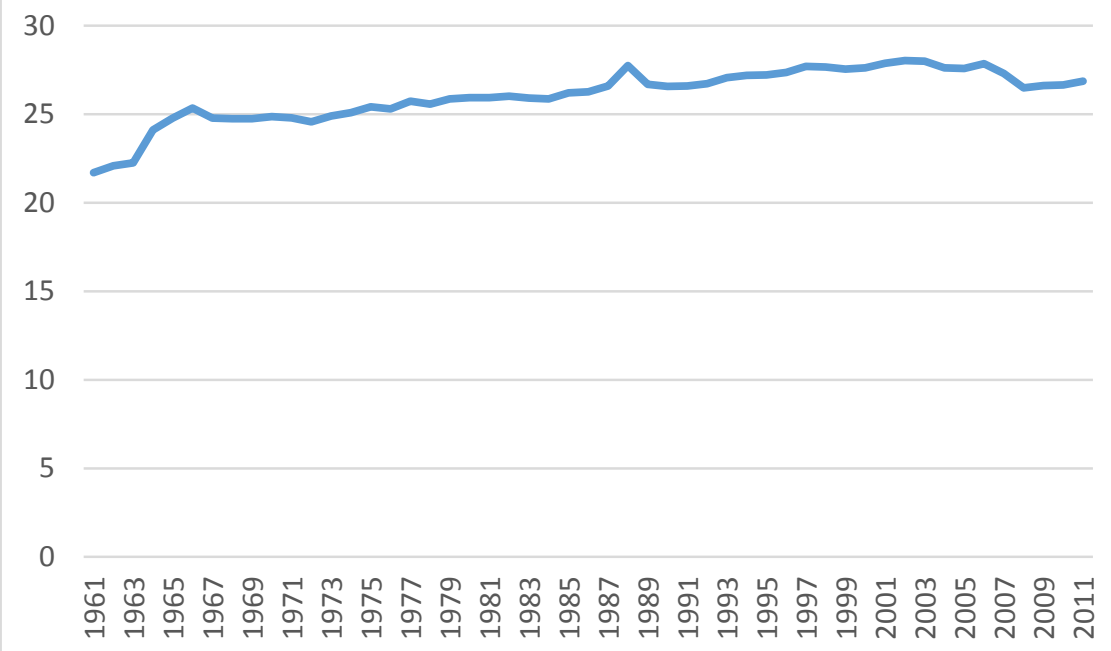

Source: Food and Agriculture Organization, electronic files and web site.

Figure 3-29 Arable land (hectares per person)

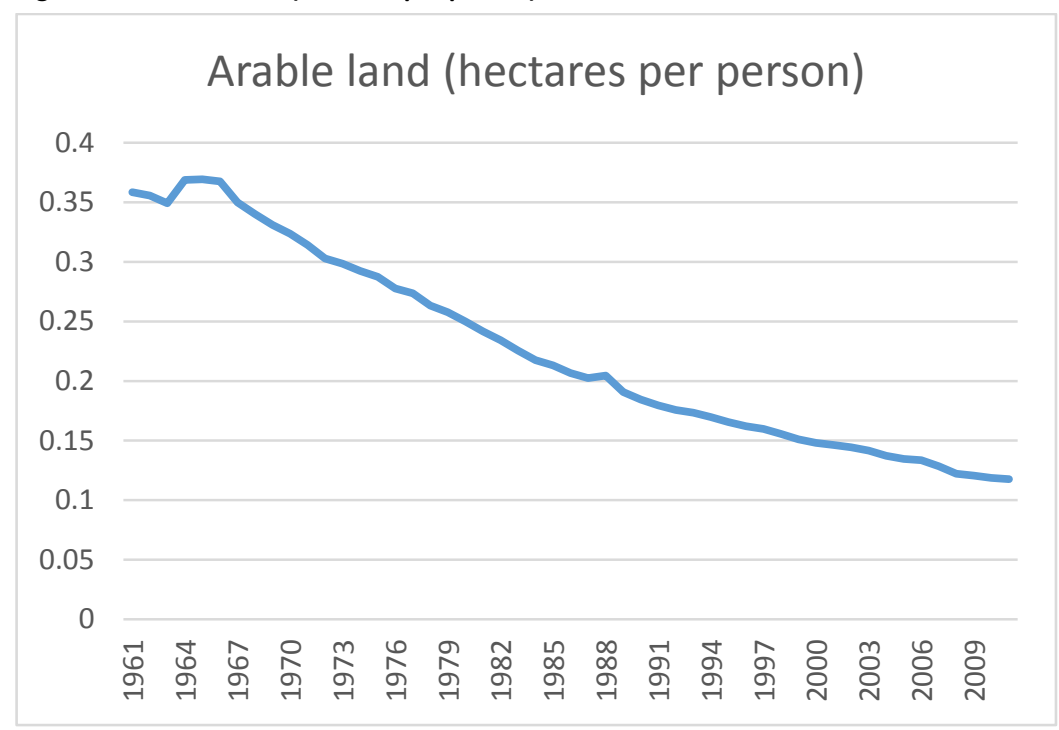

Source: Food and Agriculture Organization, electronic files and web site. 


\section{Depth of the food deficit (kilocalories per person per day)}



Source: Food and Agriculture Organization, The State of Food Insecurity in the World (http://www.fao.org/publications/sofi/food-security-indicators/en/).

Figure 3-31 Poverty headcount (\% of population)

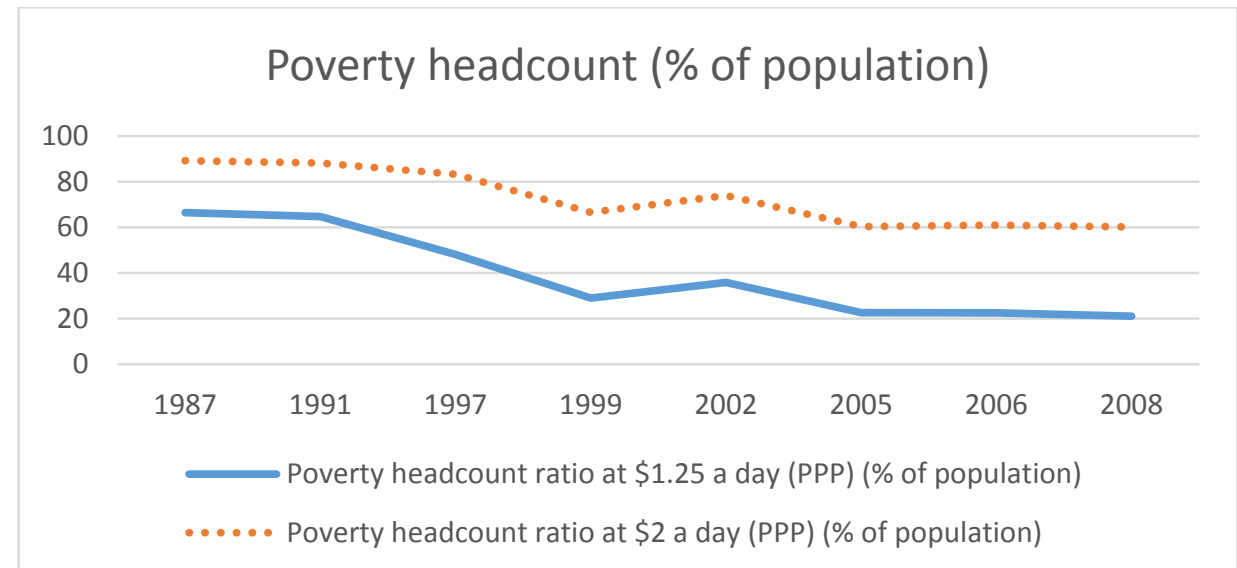

Source: World Bank, Development Research Group. Data are based on primary household survey data obtained from government statistical agencies and World Bank country departments. Data for high-income economies are from the Luxembourg Income Study database. For more information and methodology, please see PovcalNet (http://iresearch.worldbank.org/PovcalNet/index.htm).

\footnotetext{
${ }^{57}$ The depth of the food deficit indicates how many calories would be needed to lift the undernourished from their status, everything else being constant. The average intensity of food deprivation of the undernourished, estimated as the difference between the average dietary energy requirement and the average dietary energy consumption of the undernourished population (food-deprived), is multiplied by the number of undernourished to provide an estimate of the total food deficit in the country, which is then normalized by the total population.
} 
On the FAO's list of countries with depth of food deficit Pakistan ranked $26^{\text {th }}$ in 2014 among the 114 countries with malnourished populations. Figure 3.31 shows that very little improvement has been achieved in reducing this calorie deficit since 1990s. Similarly in terms of poverty headcount, though there has been substantial reduction over the past two decades, the current levels are still unacceptable by any standard.

\subsection{Conclusion}

Pakistan's path to social and economic development has been a bumpy ride to say the least. Unfavorable initial conditions plagued with the dispute over Kashmir and a split geography made governance a challenge from the very beginnings. A lack of policy framework till 1958 was only worsened by the Civil-Military power tussle which started early on and remains a defining characteristic of Pakistani politics till date. Having a permanent foe as a neighbor led to militarization and nuclearization justified by the three full-scale war fought but leaving a heavy dent on the economy. Still, it can't be denied that growth was achieved initially but arguably at the expense of social development as shown by the various indicators. Inequitable distribution of income and wealth at national level was the prime reason behind the splitting of the country and at individual level it still remains a hallmark of the economy.

Ayub's alignment with the US drew economic leverage during the cold war and is still deemed as the most prosperous era.

The nationalization drive by Bhutto's socialist leaning policies struck a fatal blow to private-sector investment. This mistrust, especially from elected governments, has lasted for the decades to come.

Zia's era brought back economic stability on the shoulders of remittances and foreign aid pumped into the economy during the Russian-Afghan war but was eclipsed by a decline in education and health facilities, worsening of the law-and order situation, and the extension of the corruption, arms, and drug culture. Zia's regime is also known for a decline in the status of women.

The political musical chairs era between 1988 and 1999 saw 4 elected governments come and be ousted prematurely on charges of corruption. During this period inflation and fiscal deficits peaked, the current account deficit widened, and external debt servicing rose to almost 40 percent of export earnings as total external debt became 47.6 percent of GDP, up from \$20 billion in 1990 to \$43 billion in 1998 .

Musharraf's impressive economic policies brought stabilization to a number of indicators but his foreign policy alignments deemed by many as 'u-turns' created an internal security situation which was difficult to handle. His fall from power and the return to power of the same faces and political parties to power, whose policies his regime tried to unwind, have reversed many of the advances of his period. 


\section{Chapter 4. Productivity growth and structural change}

\subsection{Introduction}

In the previous chapter we attempted to highlight the economic and political backdrop of the current state of affairs in Pakistan. We did this by focusing on the various leadership periods of either politicians or military administrators depending whether the country in that period was being run by a civilian or military government. Towards the end of the chapter we highlighted some of the most important issues the country is facing while at the same time trying to explain how, when and why they came into being. We focused mainly on the periods and their salient policy features. In this chapter however, we discuss two sectors in particular, manufacturing and services. The reasons why we are interested in understanding the evolution of these two sectors in particular are two-fold. Firstly, empirical evidence strongly advocates the role of manufacturing for development. Developing countries which have managed to converge towards a developed economy have mostly gone through a more or less similar process during their transition period. Naudé \& Szirmai (2012) sum this up by stating that "The structural transformation of a traditional economy dominated by primary activities into a modern economy where high-productivity activities in manufacturing assume an important role remains a defining feature of economic development." The second reason has to do with more recent developments. It is now established that developed countries moved from manufacturing centric toward services centric economies. While examining the economic and industrial structures of developed countries, a decrease in the share of manufacturing is observed. Interestingly, the growing share of the service industry is balancing out this decline. In other words, a clear trend of shifting towards a service economy is visible. However, this trend is advancing at a different pace for each country depending on their internal dynamics.

Scholars have even distinguished between deindustrialization and premature deindustrialization, the former referring to developed countries and the latter to developing countries which are deindustrializing at levels of income per capita which are significantly lower than the levels at which advanced countries deindustrialized (Tregenna, 2011). This raises the debate of the right time for countries to change the focus from a manufacturing economy to a more services centric policy. More recently, the growth of information and communications technology (ICT) has enabled developing countries to compete with the more established economies because ICT is a recent technological development which lends a relative level-playing field to countries, irre- 
spective of their prior level of development. Now in this context it would be of interest to observe whether developing countries like Pakistan, which before the advent of ICT focused on shifting from an agrarian economy to a manufacturing one, are now following their developed counterparts in the trend to become service economies.

Not only have the structural changes from traditional to developed economies, driven by the manufacturing sector, been remarkable in helping developing countries converge and catch-up, but even the industrial revolution in the mid-eighteenth century was all about this very phenomenon. First Britain, and then other European countries and the USA underwent a historically rapid phase of economic development which led to their 'great takeoff' which is loosely referred to as the industrial revolution. Japan and the East Asian Tigers followed this same trajectory in the twentieth century, and most recently it was adopted by China to become known as the workshop of the world (Cantin \& Taylor, 2008). China's entry and subsequent dominance of the manufactured products' market makes it more difficult for late industrializers to enter and compete. This is one of the main reasons why some developing countries have instead chosen the path of becoming industrial or service-oriented knowledge economies and somewhat by-passing pure industrialization. However, the significance of manufacturing development for developing economies trying to catch up with developed countries and to provide increasing standards of living to their people has not faded away till date. On one hand these late entrants realize the need for industrialization, but on the other hand they know that now they face even more challenges than in the past. International competition has been distorted in favor of MNCs with the emergence of global value chains. This way, MNCs influence the access to knowledge and technology in the global economy.

Since the 1850s, countries were either agricultural economies or economies based primarily on industry (Maddison, 1987). Industrialized nations included the Western world and later Japan whereas the colonies and non-colonized countries in the tropics remained largely agrarian or mining economies. Driven by industrial growth, an increasing demand for primary products from developing countries was generated. Rapid advancements in infrastructure, transport and communication technologies increased the opportunities for trade such that the colonial division of labor came into being. This meant developing countries exporting primary agricultural and mining products to the advanced economies and developed countries exporting manufactured goods back to the developing countries. These manufactured goods were mostly finished products made using the raw materials acquired from developing counties. This value addition by the industrialized nations blessed them with economic, technological and political dominance. Industrial development came to be seen as the road leading towards growth and progress. Developing countries were late to set foot on this road till the end of the nineteenth century when only a handful of Latin American countries and India and China treaded this path but focusing more on specializing primary production instead of value addition (Lewis, 1978). Profitability considerations and colonial policies favoring production in Britain were the primary rea- 
sons behind this choice. For instance, textile manufacturing in colonial India suffered severely from such biased colonial policies. Industrialization in these countries only gained pace after they freed themselves from colonial influences and external domination. On the whole, the developing world's overwhelming orientation towards primary production started to change in 1945. Since the Second World War, manufacturing has emerged as a major activity in many developing countries changing the shape and structure of global manufacturing production and trade completely. Thus, the colonial division of labor of the late nineteenth century has been turned upside down with much of manufacturing relocated to developing countries which now export finished goods to their developed counterparts. As a result of this late but successful industrialization some developing countries have been able to rapidly catch-up with other developed countries (Szirmai, 2008).

It is an interesting question whether or not Pakistan is going through such a phase where high-productivity activities in manufacturing are assuming a more central role. Or even more pertinently, whether or not it has already started focusing on the next logical step, that of becoming a service economy? In the next sections we will analyze this question from different perspectives and will employ various tools to search for such patterns in the available data.

\subsection{Industrial sector}

The industrial sector includes manufacturing, mining, construction, electricity and gas. Table 4.1 and figures 4.1 and 4.2 show that in the period 2008-12 it contributed slightly over 21 percent to GDP and employed a similar percentage of the total labor force as can be seen in Table 4.2. ${ }^{58}$ The structure and magnitude of the industrial sector have changed significantly since Pakistan's independence. The share of the industrial sector in terms of value added increased from 15.5 percent in 1960 to 21 percent in 2012, peaking at 27.1 percent in 2005. During the same period, the share of manufacturing in value added increased from 12 to 14.5 percent, peaking in 2005 at 18.6 percent. This clearly makes manufacturing the largest subsector within the industrial sector. Growth of the manufacturing sector has been stable, around an average of 6.7 percent per year, but growth rates were particularly impressive in 1960-1970 at 9.9 percent, and more recently during 2000-2007 at 8.7 percent. In fact, in only three of the studied time periods was growth of the manufacturing sector less than 5 percent. The first was the Bhutto era (1971-77), which was marked by nationalization and consequently experience more capital flight than private investment. The growth rate was an average of 3.8 percent per year. The second slow-growth period was between 1989 and 1999 , which we have called the political musical chairs era, when the growth rate was 4.3 percent, partly owing to the disruptive policies of the more than half dozen succes-

\footnotetext{
${ }^{58}$ This implies that industrial productivity is not higher than the average for all sectors.
} 
sive governments. The latest period is that of the Zardari led PPP government between 2008 and 2012. Manufacturing performance was dismal during this period with a growth rate as low as 1.6 percent. Large exogenous shocks (oil and food), adverse security developments and global financial turmoil buffeted the economy of Pakistan. These shocks, combined with policy inaction during the political transition to a new government and large central bank financing of the growing fiscal deficit led to slower economic growth and higher inflation, both adversely affecting growth of the manufacturing sector and economic performance in general.

The manufacturing sector comprises both small- and large-scale enterprises. Only about 20 to $30 \%$ of average value added in industry from the 1950 s until now constitutes of small-scale manufacturing. Thus, while the share of small-scale manufacturing in value added increased only from 5.6 in 1949 to $5.9 \%$ in 1995, the share of largescale manufacturing increased from 2.2 to $12.1 \%$, during the same period (Mohiuddin, 2007). Fewer than $3 \%$ of the country's workforce are engaged in large-scale industrial sector. Working for large factories entails many benefits, such as unionized jobs, more vacations, higher incomes, and overall better working conditions. But many factoryowners not wanting to give union-scale wages and benefits, hire workers for less than a year, and if required rehire them, because temporary workers are not covered under labor laws. The majority of workers in manufacturing are employed in small-scale industry. They are engaged by small workshops, manufacturing carpets, sports goods, leather goods, knives, furniture etc. 5\% of Pakistan's exports comprise of carpets alone that are made by children under the age of 16 because weaving is best done with nimble fingers. They are paid no more than 50 dollar cents a day, which amounts around one-quarter to one-half the wage for adult males. Similarly, women usually work at home on a piece-rate basis, making garments, gloves, sports goods, baskets, laces, handicrafts and embroidery. The work, as noted by Mohiuddin (2007) "is done along the lines of the putting-out system, where the middleman supplies the home-based producers with the raw materials and later collects the finished product and captures most of the profits." The women are usually paid even less than the carpet-weaving underage children (Mohiuddin \& Kazi, 1991).

It is the large-scale industrial sector however, which has received most of the attention form policy makers in Pakistan. In the 1950s, the pro-industrial policies were heavy protection for infant industries through tariffs, an overvalued exchange rate to make machinery imports artificially cheap, and import licensing to allocate imports. In the 1960s, they comprised suppressing exports of agricultural raw materials and tax incentives for industry. Towards the end of the 1960s, however, the government upon realizing that high GDP growth rates are not sustainable without a strong agricultural sector, adopted a more balanced approach. 


\begin{tabular}{|c|c|c|c|c|c|c|}
\hline & $\begin{array}{l}\frac{0}{4} \\
\frac{1}{0} \\
\frac{7}{\frac{1}{4}} \\
\frac{0}{7} \\
\frac{7}{4}\end{array}$ & 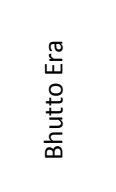 & $\begin{array}{l}\stackrel{0}{W} \\
\stackrel{\mathbb{N}}{N}\end{array}$ & 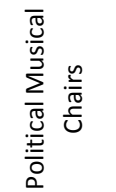 & 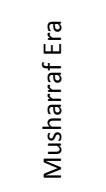 & $\begin{array}{l}\frac{\pi}{2} \\
\frac{1}{2} \\
\frac{\pi}{0} \\
\frac{0}{N} \\
N\end{array}$ \\
\hline$\%$ of GDP & $1960-70$ & $1971-77$ & $1978-88$ & $1989-99$ & 2000-07 & $2008-12$ \\
\hline Agriculture & 40.8 & 34.1 & 29.1 & 26.2 & 23.3 & 24.1 \\
\hline Industry & 19.5 & 22.7 & 23.2 & 24.3 & 23.9 & 21.3 \\
\hline Manufacturing & 14.5 & 16.1 & 15.8 & 16.5 & 15.7 & 14.2 \\
\hline Services & 39.7 & 43.1 & 47.7 & 49.5 & 52.8 & 54.6 \\
\hline
\end{tabular}

Source: Derived from World Bank national accounts files and Food and Agriculture Organization data files ${ }^{59}$

The 1970s saw a reversal of strategy, in which industrial enterprises producing consumer goods as well as capital goods, were nationalized in two different phases. After the fall of Bhutto from power until now, the economic policies by all regimes, civilian or military, elected or caretaker, have been pro-industrial, with increasing privatization, liberalization and de-regulation. The cotton textile industry remains by far the most prominent in Pakistan's manufacturing sector. It is the largest in terms of output, exports and employment. Its output increased from 114 million kilograms of yarn in 1955 to 1,300 million kilograms in 1995, an increase of about 1,000\%, or eleven-fold. One-fourth of Pakistan's industrial workforce is in engaged by this industry, and two fifths of Pakistani exports are from it. However, this also implies a lack of diversification of the industrial base, where just two industry groups, textiles and food processing, account for half of the value added. This is, indeed, the greatest weakness of the industrial sector (Mohiuddin, 2007).

Table 4.2 Era-wise averaged sectoral employment shares in GDP (\%)

\begin{tabular}{|c|c|c|c|c|}
\hline & Zia Era & $\begin{array}{l}\text { Political } \\
\text { Musical Chairs }\end{array}$ & Musharraf Era & Zardari Era \\
\hline Employment share (average) & $1978-88$ & $1989-99$ & $2000-07$ & $2008-12$ \\
\hline Agriculture & 52.0 & 48.0 & 44.3 & 44.9 \\
\hline Industry & 20.0 & 18.7 & 20.0 & 20.4 \\
\hline Services & 27.7 & 33.2 & 35.7 & 33.7 \\
\hline
\end{tabular}

Source: Derived from World Bank national accounts files and Food and Agriculture Organization data files ${ }^{60}$

\footnotetext{
${ }^{59}$ See Appendix I and II for details.

${ }^{60}$ The average for the period $1978-88$ is calculated using the values for years $1980-88$ as our data starts from 1980.
} 
Table 4.3 Sectoral Growth rates (Valued Added), 1961-2012 (\%)

\begin{tabular}{lllllll}
\hline & & & \multicolumn{5}{l}{ Political } \\
& Ayub Khan era & Bhutto Era & Zia Era & \multicolumn{2}{l}{ Musical Chairs } & Musharraf Era Zardari Era \\
& $1961-70$ & $1971-77$ & $1978-88$ & $1989-99$ & $2000-07$ & $2008-12$ \\
\hline GDP & 7.2 & 3.6 & 6.9 & 4.1 & 5.0 & 2.6 \\
GDP per capita & 4.5 & 0.6 & 3.4 & 1.3 & 3.0 & 0.8 \\
Agriculture & 5.1 & 1.6 & 3.9 & 4.5 & 3.4 & 2.2 \\
Industry & 11.0 & 4.8 & 8.6 & 4.7 & 6.6 & 2.8 \\
Manufacturing & 9.9 & 3.8 & 9.2 & 4.3 & 8.7 & 1.6 \\
Services & 6.8 & 5.7 & 7.3 & 4.5 & 5.5 & 3.8 \\
\hline
\end{tabular}

Source: Derived from World Bank national accounts files and Food and Agriculture Organization data files. Percentages refer to average percentual rates of growth.

Table 4.4 Sectoral employment shares growth rates, 1978-2012 (\%)

\begin{tabular}{lllll}
\hline & \multicolumn{5}{l}{ Political } \\
& Zia Era & Musical Chairs Musharraf Era Zardari Era \\
& $1978-88^{61}$ & $1989-99$ & $2000-07$ & $2008-12$ \\
\hline Agriculture & -0.3 & -0.6 & -0.9 & 1.7 \\
Industry & -0.2 & -1.2 & 2.7 & -0.7 \\
Services & 1.1 & 2.0 & 0.0 & -4.7 \\
\hline
\end{tabular}

Source: Derived from World Bank national accounts files and Food and Agriculture Organization data files

Figure 4-1 Sectoral shares, value added (\% of GDP)

\section{Sectoral shares, value added (\% GDP)}

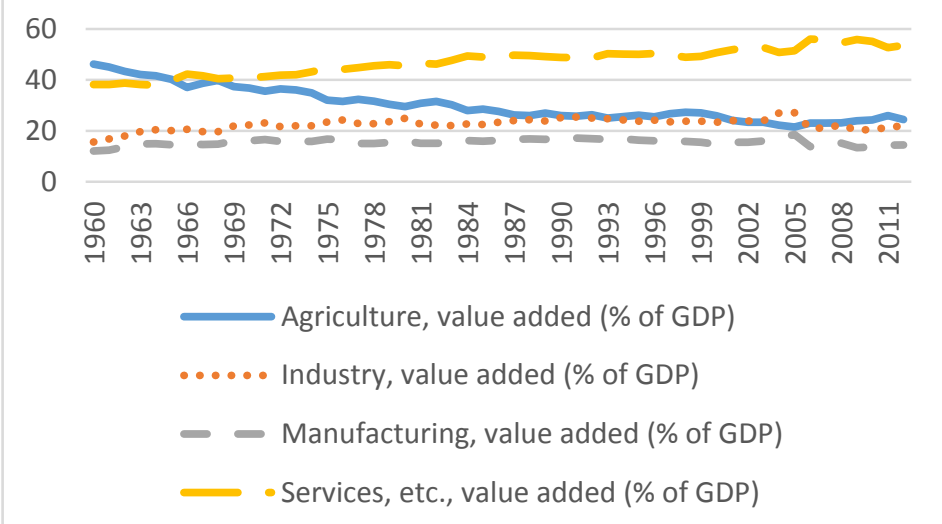

Source: Derived from World Bank national accounts files and Food and Agriculture Organization data files

${ }^{61}$ Data for this period starts from 1980. 


\section{Employment shares (\% of total employment)}

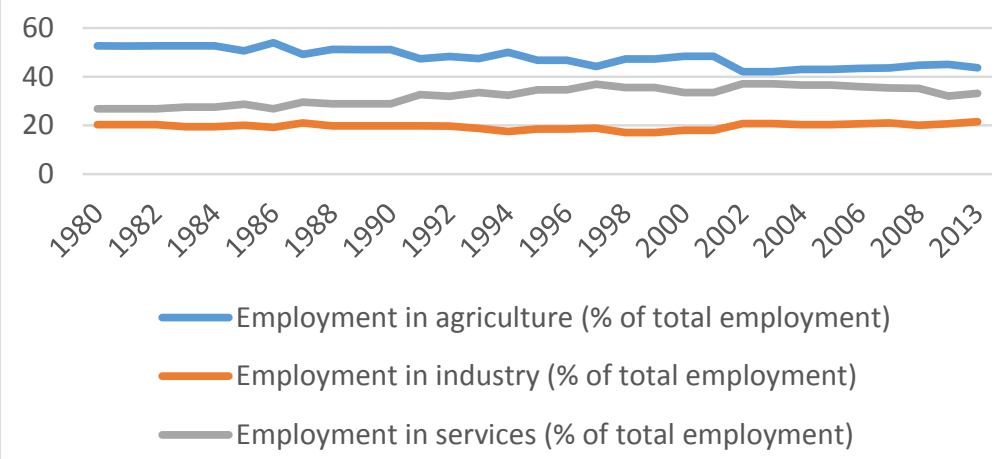

Source: ILO Key Indicators of the Labour Market (KILM).

Figure 4.3 shows the total value added in dollars of the manufacturing sector by year for the period 1960 to 2012 . The sector has grown almost 30-fold in the last 52 years. Figure 4.4 shows that the value added share in terms of GDP rose sharply and peaked during the 2000-2005 period because of the successful policies in the Musharraf era discussed in Chapter 3. Figure 4.5 suggests that in terms of manufacturing shares in GDP, Pakistan is doing rather well in comparative perspective. But in terms of manufacturing value added per capita, Pakistan is far below the world average (figure 4.6), let alone OECD countries, due to low labor productivity. This might be explained by the lack of high-tech industry which is inevitable for adding value and also for sustained growth. The world average value added per capita is at least 10 times as high as in Pakistan. The OECD countries' ratio is a staggering 35 to 1 . This indicates why Pakistan still has to go a long way before becoming the preferred choice for investors and producers in comparison to China and India. This could also be taken as the necessary stimulus to think otherwise, i.e. instead of an all-out pro-manufacturing strategy thinking of services as the sector of choice.

As can be seen in Figure 4.1, the composition of GDP has been changing since 1960. Agriculture, which was the largest sector in the 60s, experienced a sharp decline. It has dropped from an average of 40 percent in the 60 's to roughly half this figure currently. Services steadily gained ground. Though the shifting from agriculture to services and manufacturing is interpreted as positive in standard economics textbooks, for Pakistan it may also have its downsides. This is indicated from the continued dependence on imports of basic staple foods like wheat, sugar-cane and vegetables from neighboring countries. 


\section{Manufacturing, value added (constant 2005 million US\$)}

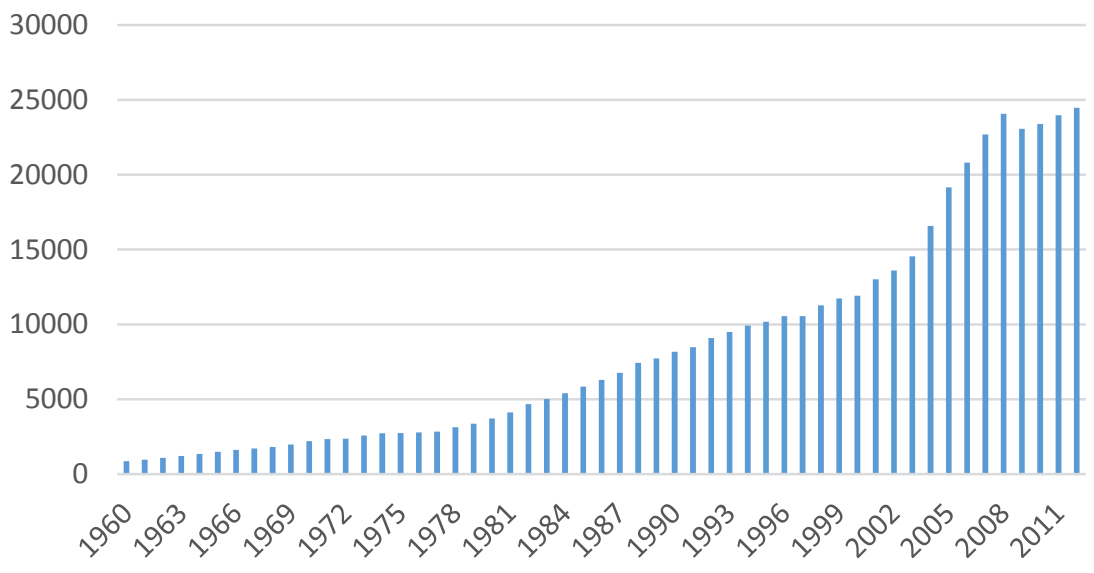

Source: World Bank national accounts data, and OECD National Accounts data files.

Figure 4-4 Value added by the manufacturing sector as percent of GDP

Value added by the manufacturing sector as percent of GDP

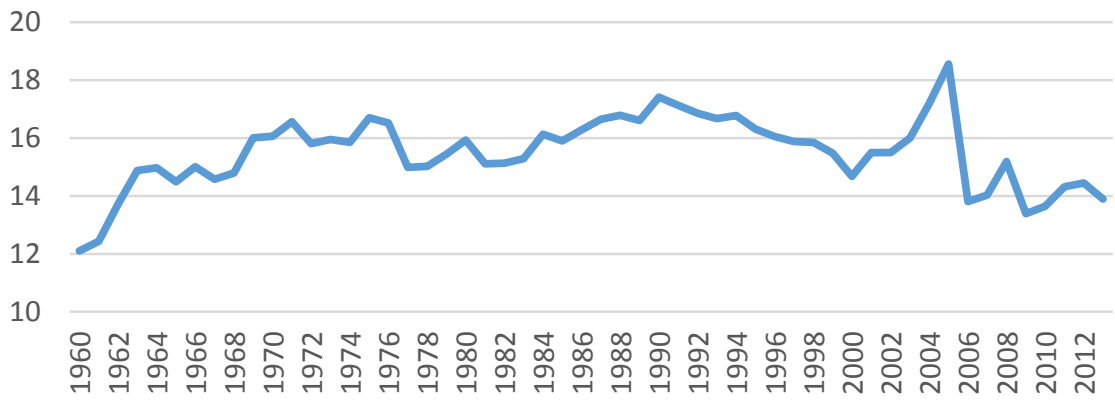

Source: World Bank national accounts data, and OECD National Accounts data files, values are in current US dollars. 


\section{Value added by the manufacturing sector as percent of GDP}

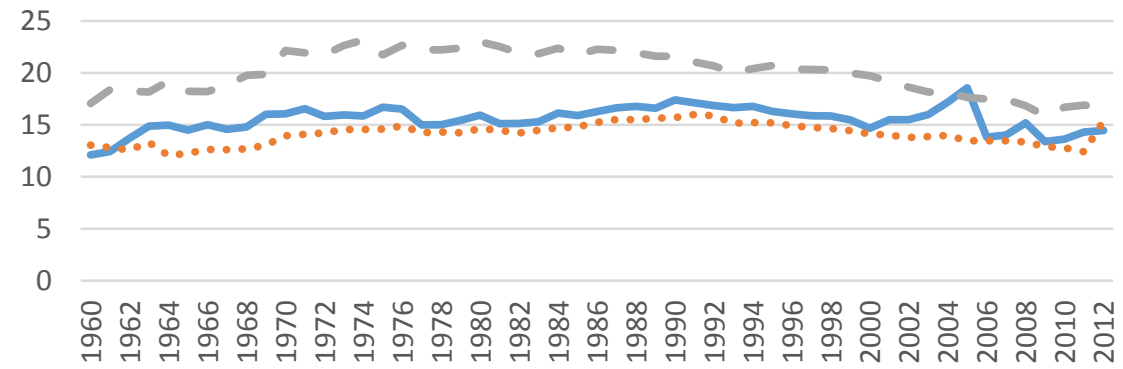

$$
\longrightarrow \text { Pakistan } \ldots . . \text { World }-- \text { OECD }
$$

Source: World Bank national accounts data, and OECD National Accounts data files.

Figure 4-6 Manufacturing value added million USD per capita

\section{Manufacturing value added million USD per capita}

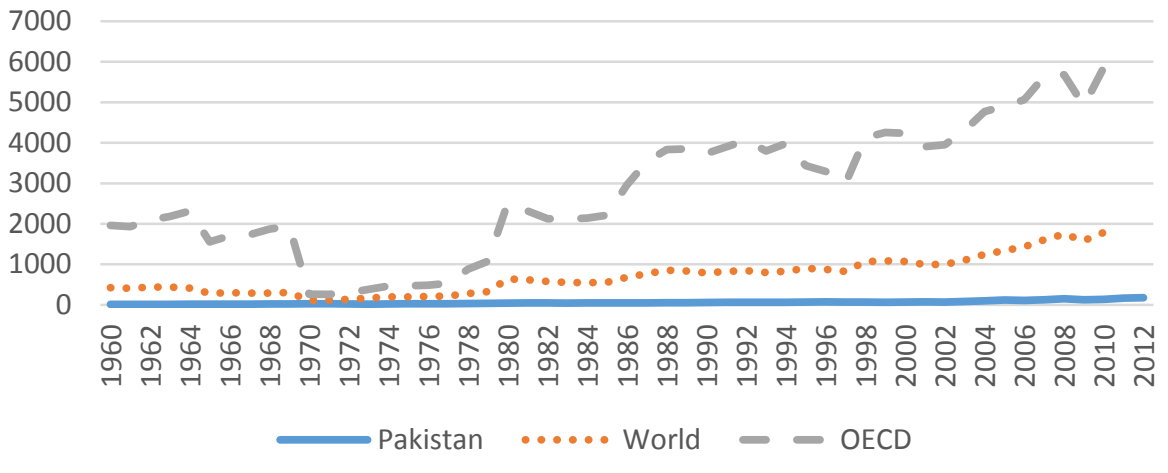

Source: World Bank national accounts data, and OECD National Accounts data files, values are in current US dollars 


\subsection{Services sector}

Figure 4.1 shows that Pakistan, like other countries experiencing sustained growth, has had a falling share of agriculture in total value-added over the decades. The services sector has gained the most part of this share. This makes the services sector by far the largest sector in the Pakistan economy, contributing about 53 percent of GDP and one third of employment in 2013. Figure 4.7 shows that in the past 52 years the services sector has grown almost 18 times in terms of value added.

The sector comprises wholesale and retail sales, telecommunications, tourism, transportation and communications, and personal services. The domestic transportation system includes road, air, and rail networks. In the 1970 s and 1980 s, road and air networks grew faster than the railroads. In 2011, there were 262,567 kilometers of roads in the country and over 35 million motor vehicles on roads. The number of vehicles per 1,000 persons increased from 1 in 1947 to 20 in 2011. Road transport (rickshaws, taxis, minivans, buses, and trucks) is mostly in the private sector ${ }^{62}$, the railroad system is government-owned, and air transport has also been opened to private investors in the 1990s. Till 1993, the government owned Pakistan International Airlines (PIA) was the major airline, serving five domestic airports at Islamabad, Karachi, Lahore, Peshawar, and Quetta, and several international airports. In that year, various domestic private airlines were launched and started their operations while flying on domestic routes. A large part of the services sector is personal services, ranging from maid services by female domestic staff (masees) to hawkers, travel agents, teachers, tutors and street vendors. The growth of these services is largely a result of the economic migrants to the Middle East. A huge demand for services such as air and road transport, travel agencies, hotels, teachers, banks, health clinics, secretarial services, and recruiting agencies is created by the outflow of the workforce. The demand for services such as maid service, personal attendants, tailoring and hairdressing have grown because of the remittances sent home by these workers. The demand for security services of all types has increased due to the worsening law-and-order situation in cities like Karachi since the 1980s. More recently, security services are seeing a boom because of the terrorism related deteriorating law and order situation. Similarly, the rapidly increasing non-governmental organizations (NGOs) and donor aid agencies have created a surge in demand for secretaries and low-level managers. The failing public education system has given rise to private teaching and tutoring services and the spread of private schools and tutoring centers. The broadcasting network constitutes of radio and television, which were traditionally owned and run by government corporations. Until 1992, there was only one TV channel, a second was added in November 1992, and after the deregulation in Musharraf's era multiple private channels have been added by the private sector.

\footnotetext{
${ }^{62}$ The recently launched 'Metro Bus' is an exception, which so far fares in Lahore and Islamabad and other projects are under way.
} 
Finally, the ICT sector has substantially contributed towards the growth of the services sector in recent years. Currently there are 5.8 million telephone lines, and their number per 100 persons increased from 0.15 in 1960 to 3.61 in 2010 where it peaked and has since then started declining gradually due to the popularity of mobile phones and other telephony technologies like Wireless Local Loops (WLL). Another salient feature of the services sector is the heavy investment (and also FDI) going on in the Telecommunication-sector, where Pakistan has one of the fastest growing markets and a huge potential due to its large population.

The services sector, with special emphasis on the software industry is being hailed by many analysts as the sector of the future, with the software industry also picking up again, after its previous surge in the early nineties, which also saw a bigger than normal share of services in the GDP. This trend, especially in the years since 2004, is quite clear from Figure 4.8. Though ICT commodity exports remain negligible even in the recent period, ICT service exports continue an upward trend with almost a quarter share of total service exports in year 2011. The ICT sector, its origin and evolution is discussed in detail in Chapter 5.

Figure 4-7 Services, value added (constant 2005 million US\$)

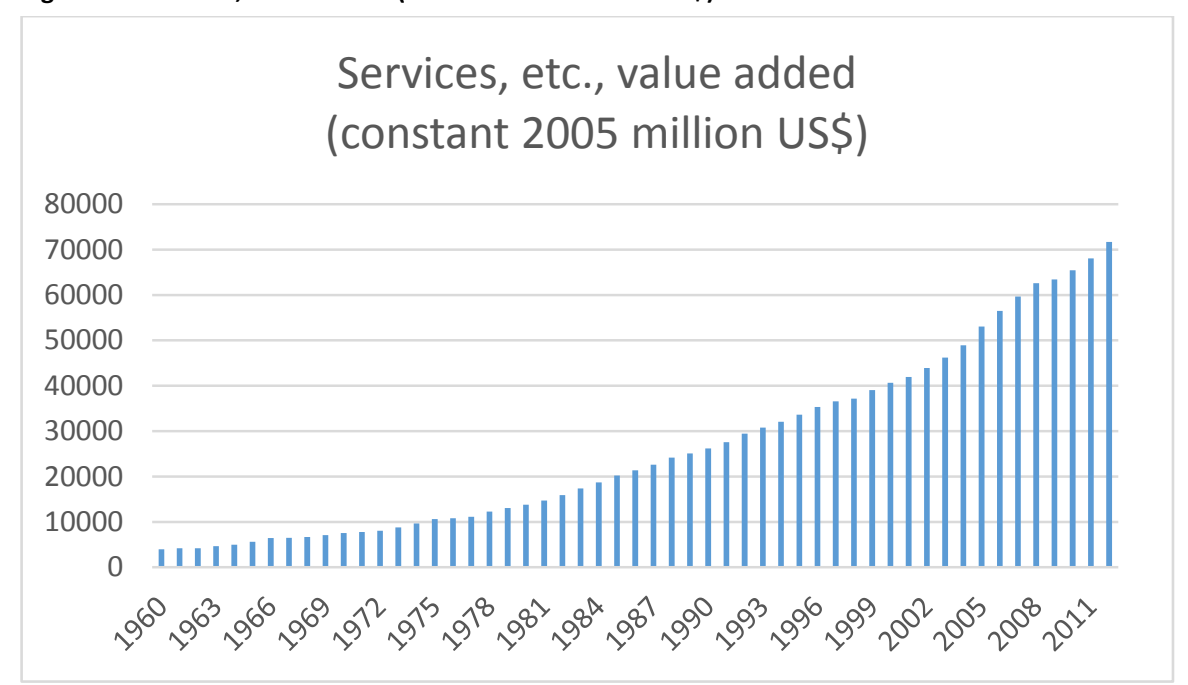

Source: World Bank national accounts data, and OECD National Accounts data files. 


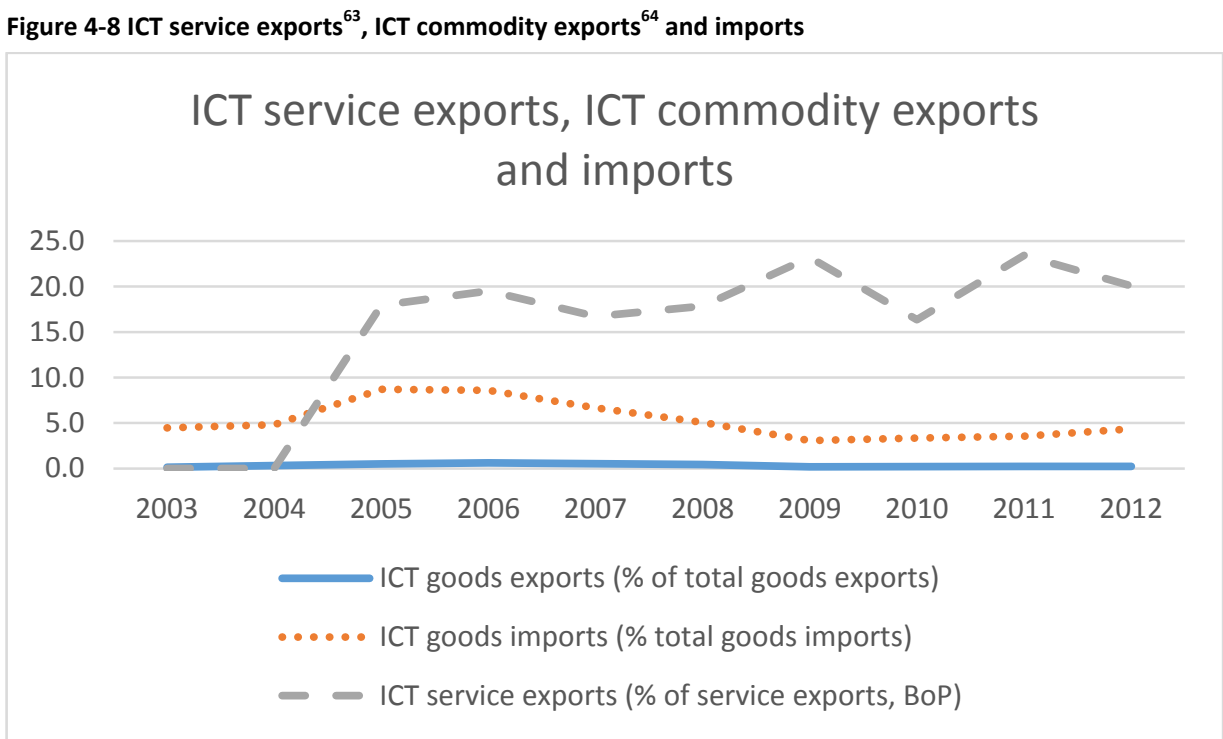

Source: United Nations Conference on Trade and Development's UNCTADstat database and International Monetary Fund, Balance of Payments Statistics Yearbook and data files.

\subsection{Growth and productivity studies of Pakistan}

Various studies have attempted to understand the growth pattern of Pakistan and to identify factors which play a more significant role than others.

Using time series data for the period 1971 to 2002 , Rashid (2004) finds that decline in industrial sector growth rate is the major cause of the decline of average overall GDP growth rate. He establishes this after analyzing growth linkages among agriculture, industry and various segments of the service sector with a view to identify the main growth stimulating sector with the highest level of backward and forward linkages in the economy.

McCartney (2011) while applying a rigorous statistical methodology tests the dependency hypothesis and finds that though growth in Pakistan is influenced by the world economy, it is primarily dependent on domestic factors like policy, weather, and the nature of state-economy relations. The time period analyzed starts from 1951/52 and ends at 2008/09. To negate the dependency hypothesis, the paper points out that the slowdown in the Pakistan economy actually predated the onset of the global crisis and similarly recovery started while the crisis was at its peak elsewhere.

\footnotetext{
${ }^{63}$ ICT service exports include computer and communications services (telecommunications and postal and courier services) and information services (computer data and news-related service transactions).

64 ICT goods exports and imports include telecommunications, audio and video, computer and related equipment; electronic components; and other ICT goods. Software is excluded.
} 
An IMF (2005) study ${ }^{65}$ has similar findings to McCartney's study. It asserts the importance of investment, rainfall and restrained inflation as determinants of growth between the period of 1960 and 2004. According to the study, the two major periods of high-growth rates in the past 50 years actually saw inflation rates significantly reduced. The average inflation rates for the high growth periods (1977-1988 and 20032004) are less than half of the slow-growth periods (1971-1976 and 1991-1999).

Another study (Din, 2007) analyses 4 high-growth periods averaging 7 percent $(1983 / 84,1987 / 88,2002 / 03$ and $2005 / 06)$ to find that while growth in the first two periods was driven more by external factors, it was determined by solid macroeconomic policies and economic reforms in the latter two periods.

Raheman et al. (2008) analyze different firms in manufacturing to identify efficient sectors in terms of TFP and technical efficiency using aggregate firm level data. Using data envelopment analysis as a tool for the measurement of TFP growth for important manufacturing industries listed on Karachi Stock Exchange they find that overall manufacturing sector improved technical efficiency by 1.2 percent while technical change had a negative effect on productivity. As a result overall TFP during 19982007 only increased by 0.9 percent. If TFP and its components in individual years for overall manufacturing sector are taken, a divergent trend is depicted.

Sabir \& Ahmed (2003) compare the average growth rates in GDP, factor inputs and total factor productivity during the period prior to reforms and the reform period, and summarize the historical patterns. ${ }^{66}$ They study the effect of economic reforms on productivity growth directly, and indirectly through other contributors of TFP growth, such as human capital. The authors conclude that except for the agricultural sector, growth in factor inputs is higher during the macroeconomic reform period as compared to the pre-reform period. This increase is particularly noticeable in the manufacturing sector. Agriculture on the other hand shows decreased growth of factor inputs during the reform period. Interestingly, the study finds the growth pattern in inputs to be entirely different than the growth pattern in outputs. For instance, in the agricultural sector, the growth in factor inputs is high in the pre-reform period; however, growth in output is high in the reform period. Similarly, the high growth in factor inputs is not translated into output growth in the manufacturing and services sectors. As a result, output growth declines during the reform period in spite of the growth in factor inputs. This finding indicates that TFP plays an important role in explaining the pattern of growth of the economy. TFP growth too shows a mixed pattern: it is lowest in the services sector during reform and highest in manufacturing sector prior to reform. On average, almost half of the growth in the economy in the pre-reform period is the outcome of growth in TFP and the remaining half is attributable to growth in factor inputs. However, during the reform period, annual average growth in TFP de-

\footnotetext{
${ }^{65}$ The report can be downloaded at http://www.imf.org/external/pubs/ft/scr/2005/cr05408.pdf

${ }^{66}$ The take the pre-reform period between the years $1972-73$ to $1987-88$ and the reform period between 1987-88 to 2001-02.
} 
clines to about one-fourth of the pre-reform value. As a result, the contribution of TFP in overall economic growth also declines one-fourth, which is the main cause of low economic growth during the reform period. The major cause of low growth of TFP is found to be the reduction in research and development budgets, which made negative contributions to TFP growth during reform period.

Khan (2005) estimates TFP in Pakistan by utilizing the conventional growth accounting framework, and also establishes its macro determinants using a data set that spans 1960 to 2003. The results confirm that TFP is influenced by FDI, macroeconomic stability and financial sector development. Interestingly, education expenditures turn out to be insignificant.

Baier et al. (2006) examine the relative importance of the growth of physical and human capital and the growth of total factor productivity (TFP) using newly organized data including that of Pakistan only to find TFP growth to be an unimportant part of average output growth across all countries.

Ahmed \& Hyder (2007) attempt to highlight the effect of fiscal policy, monetary policy and other economic measures on TFP in Pakistan for the period between 1978 and 2002. The employ the growth accounting framework. The results of the manufacturing equation show, like the aggregate equation, that exports of manufactured goods and fiscal policy incentives are the main determinants of TFP.

Falki (2009) investigates the impact of FDI on economic growth in Pakistan, for the period 1980-2006. A production function, based on endogenous growth theory is used to study the relationship between FDI and economy. The study finds that when compared to the contribution of domestic capital and labor, FDI has not contributed much to the economic growth in Pakistan for the time period 1980-2006.

Hamid \& Pichler (2009) analyze the major factors of value-added growth and productivity in the manufacturing sector by using Translog Production Function Technology over the period 1971-72 to 2004-05. They find the contribution of productivity and human capital to be around one- third of the total value-added growth in the manufacturing sector.

From the literature it emerges that the overall GDP growth rate is strongly related to the industrial sector growth rate. Similarly the importance of a strong policy framework, particularly with regards to macro-economic stability has been confirmed by various studies. The role of certain external factors like weather and rainfall has also been significant, whereas the contribution of FDI to growth is secondary when compared to domestic capital and labor.

In our own analysis, we have taken the various periods based on the regimes as our point of departure. In our opinion each regime is characterized by a set of policies which need to be studied and evaluated. Most of the studies we cited here however do not analyze growth and productivity from this perspective. Most of them have pointed out periods of growth and slow-down, irrespective of whether or not they correspond to a certain regime. Still, a rather clear picture emerges about the importance of TFP as compared to traditional inputs, especially in, what one study calls, 
the post-reform period (which began after the end of the period of Martial Law in 1988). This is also more the case for the manufacturing sector than agriculture. The major causes of TFP growth have been highlighted by the various studies as research and development expenditures, exports of manufactures and fiscal incentives. Most studies don't put a lot of emphasis on the importance of global factors.

\subsection{Structural Change and Productivity Growth}

Studies on Pakistan's growth have mostly focused on either factor inputs or TFP as a source. As one can notice from the references in the section above, the recent studies on the sources of growth in Pakistan don't consider the underlying dynamics of changes in productivity growth among sectors (or industries) of the economy. The recent empirical literature on convergence among countries and regions reveals a similar tendency to overlook the importance of the continuous process of sectoral reallocation of resources that accompanies economic growth. In this context, it is important to study the shift of resources from low-productivity to high-productivity sectors also known as structural changes. We raise this issue as the seminal works of Kaldor, Kuznets and Syrquin (1967; Kaldor, 1966; Kuznets \& Murphy, 1966; Kuznets, 1979; Syrquin, 1988) have established that such an approach is helpful in explaining and understanding growth or the lack of it.

There are a multitude of reasons to revisit the role of structural change in productivity and growth. The strong and positive effect of inter-sectoral shifts of factor resources on aggregate productivity growth forms one such reason. The level of development of an economy determines the size of this effect. Van Ark \& Timmer (2003) show that in case of low-income levels, like those in Pakistan, a shift of resources from agriculture to more productive non-agricultural activities can boost growth. They assert that for low income countries in South Asia, this source of growth, which is referred to as the "Lewis effect" is still significant, especially when taking into account the existence of so-called "surplus labor" in the agricultural sector. Further down the development trajectory, resources get concentrated in service and manufacturing industries. Manufacturing has undoubtedly contributed much to aggregate productivity growth, and it appears that it is still quite a strong source even in the most advanced Asian countries. The importance of structural change as a source of growth and productivity improvement is established as a central tenet of the growth-accounting literature (Maddison, 1987).

The opportunities created by the recent rise in importance of ICT call for a refocus on sectoral productivity measures. These opportunities are manifested in both the increased intensity of ICT use as well as in the production of ICT. Moreover, as our focus in the remaining chapters of this study will be on the ICT sector, we would like to map the productivity trend of this and related sectors in order to establish if structural changes have taken place. 
Another reason to bring structural change back on the agenda is that in the context of catch-up it has been argued that convergence through technology transfer and knowledge spillovers takes place product by product, not country by country (Harberger, 1998). Several theoretical and empirical studies show that innovation, and in particular diffusion of technology has significant industry specific characteristics.

We try to fill this gap in literature by studying the changes in the sectoral composition of production and employment, and its interaction with the pattern of productivity growth. This section therefore analyzes the contribution of structural change to aggregate and manufacturing productivity. In light of the above, we start our analysis of the Pakistani economy by focusing on the whole economy. ${ }^{67}$ Due to data limitations we only analyze changes in the sector structure of production. ${ }^{68}$

\subsubsection{Sectoral Change}

The role of industrialization as a 'growth engine' in the process of economic development is well established. Numerous scholars have discussed employment changes in the context of productivity differentials in agriculture, manufacturing, and services sectors (McMillan \& Rodrik, 2011; Rowthorn \& Ramaswamy, 1997). Although the importance of manufacturing for growth in developing countries comes out clearly, not all expectations of the 'growth engine' hypothesis withstand the statistical testing of the data. However, the more general historical evidence clearly rules in favor of the industrialization thesis. Baumol (1967) presents a not so positive assessment of structural change by formulating a two-sector model with limited prospects for productivity growth in the service sector. The increasing share of services ${ }^{69}$ in production therefore results in an overall slowdown in productivity. While studying Asia's productivity, Ark \& Timmer (2003) find some evidence of the Baumol effect in East Asia, however its influence is partly evened out by those service sectors which have productivity levels higher than manufacturing. However, the same paper also establishes the importance of manufacturing as a growth engine in developing countries as positive effects of manufacturing on productivity are found. Structural change literature has focused on major sectoral shifts such as those from agriculture to manufacturing, or manufacturing to services, particularly in a developing country context. In China, where manufacturing is the main force driving the current growth pattern, studies have indicated a continued pattern in the future but perhaps at a slower rate (Holz, 2008). Analyzing Pakistan's economy from this perspective - where the importance of manufacturing has been established over the years but it hasn't grown at the same rate as countries like China

\footnotetext{
${ }^{67}$ We have used data of 7 industrial sectors comprising of agriculture, mining, manufacturing, construction, wholesale and retail, financing, transport and community \& others. The detailed ISIC 3 definitions of these sectors can be seen in Appendix II and III.

${ }^{68}$ The ownership structure and the regional structure cannot be analyzed due to this unavailability of data.

${ }^{69}$ The basic hypothesis was originally developed jointly with William G. Bowen while studying the performing arts sector.
} 
- would be of great interest. In this context, examining the relationship between structural change and productivity within Pakistan's industrial sectors, particularly manufacturing, is of great importance. In this chapter we take the first step in this direction. The existence of sectoral shifts from agriculture to manufacturing, or manufacturing to services could be established. We employ the shift share technique for this task.

The existence of large productivity differentials between the traditional and modern parts of the economy is a matter of fact. Dual economy models typically emphasize productivity gaps between broad sectors of the economy, such as the traditional (e.g. agriculture) and modern (e.g. manufacturing) sectors. More recently, significant productivity differences within modern manufacturing activities have been identified by as well. Similarly, firms within the same industry can have large productivity gaps. These gaps are usually more pronounced in developing economies as compared to developed nations, whether across sectors or between plants. Moreover, these gaps characterize productivity reducing allocative inefficiencies. However economies can benefit from these allocative inefficiencies because they can potentially serve as growth engines. Labor and other resources moving from less productive to more productive sectors result in productivity growth, even if there is no productivity growth within sectors. This kind of growth-enhancing structural change is a typical feature of a developed country's growth trajectory. Interestingly, a substantial part of the growth differential of Asia since 1990, on the one hand, and Latin America and Africa, on the other, is accounted for by the variation in structural change contribution to productivity. McMillan and Rodrik (2011) find that broad patterns of structural change have served to deteriorate, rather than improve, performance in many Latin American and Sub-Saharan African countries. In this chapter, we analyze these productivity differentials with the expectation to find growth enhancing labor flows from low-productivity sectors to high-productivity ones.

Pioneered by Fabricant (1942), the shift share method has since been widely used to analyze economic and productivity growth. The standard shift-share model highlights the shifts of factor inputs by decomposing productivity growth into its respective sources. The standard method to analyze the effects of structural change is to focus on both factor inputs, labor and capital. This way TFP (total factor productivity) is calculated and the effect of labor and capital on TFP is analyzed. This is termed as the 'complete measurement' method. But as indicated earlier, data constraints don't allow us to use this; rather we use the "partial measurement' method which analyses the impacts of shifts of one input factor only, which in our case is labor. Ignoring all inputs other than labor and taking the average product of labor as their productivity indicator, this method helps studying the structural decomposition of positive (expanding sectors) and negative (shrinking sectors) growth.

A shift-share analysis determines what portions of regional economic growth or decline can be attributed to national, sectoral, and regional factors. The analysis can be helpful in identifying where investing in a regional economy is more beneficial than the rest of the economy. In this method, the change over time of an economic varia- 
ble, usually employment, within industrial sectors of a regional economy is taken and split into various components. A traditional shift-share analysis splits these changes into three components, however, evolved models expand the decomposition into additional components.

Regional shift-share analysis is another variant of the standard method. The analysis can be carried out for any given region (town, city, province, country) or statistical area. Employment is usually the variable of choice to measure changes but other economic variables such as firm growth or demographic statistics can also be used. Various economic industries, like those defined by the United Nations' Statistics Division as ISIC (International Standard Industrial Classification) Revision 3 standards are chosen to perform a shift-share analysis. The regional economic changes within each industry are separated into different categories. All the different available versions of a shiftshare analysis identify industry, national and regional factors influencing variable changes.

The traditional form of the shift-share analysis is also called the comparative static model, as changes in the economic variable are examined for a given timeperiod. Changes, which are calculated for each industry in the analysis, are decomposed into three components as discussed below.

Firstly, the component attributed to the aggregate growth of the national economy called the national growth effect. This would be equal to the theoretical change in the regional variable if it increased by the same percentage as the national economy. Then comes the component attributed to the performance of the specific economic industry called the Industry mix effect. This would be equal to the theoretical change in the regional variable if it increased by the same percentage as the industry nationwide, minus the national growth effect.

Lastly, we have the, component attributed to regional influences called the Local share effect. Regional analysts are primarily concerned with this portion of change. It is calculated by subtracting the previous two effects from the actual change in the regional variable.

In the remainder of this chapter, we focus on sectoral shift-share analysis.

\subsubsection{Methodology}

As a crude approximation of the correct measure of the effect of resource shifts on aggregate factor productivity, many authors have tried to attribute part of the growth in aggregate labor productivity (average output per worker) to inter-sectoral labor shifts. In such attempts, inter-sectoral differences in labor are represented by sectoral average productivities of labor. The dispersion of labor productivities across sectors is known to be large in LDCs, partly as a result of disequilibrium in factor markets and the slow operation of the adjustment mechanisms. Because of the shift of labor from low to high (average) productivity sectors, the growth of aggregate labor productivity ex- 
ceeds the weighted average of the corresponding sectoral growth rates. The partial measures are appealing because of the simplicity in their calculation and interpretation. At times they are taken as proxies for the correct measures, even by authors who know the limitations.

Following this tradition, we use the following general formulation of the partial measure shift share model:

$\frac{P^{t}-P^{0}}{P^{0}}=\frac{\sum_{i=0}^{n}\left(P_{i}^{t}-P_{i}^{0}\right) S_{i}^{0}}{P^{0}}+\frac{\sum_{i=0}^{n}\left(S_{i}^{t}-S_{i}^{0}\right) P_{i}^{0}}{P^{0}}+\frac{\sum_{i=0}^{n}\left(P_{i}^{t}-P_{i}^{0}\right)\left(S_{i}^{t}-S_{i}^{0}\right)}{P^{0}}$

Where,

$P^{0}$ is the aggregate labor productivity at year 0 ;

$P_{i}^{0}$ is the labor productivity of sector i at year 0 ;

$S_{i}^{0}$ is the employment share of sector i at year 0 .

$P^{t}$ is the aggregate labor productivity at year $\mathrm{t}$;

$P_{i}^{t}$ the labor productivity of sector $\mathrm{i}$ at year $\mathrm{t}$;

$S_{i}^{t}$ is the employment share of sector $\mathrm{i}$ at year $\mathrm{t}$;

The right-hand side of the decomposition equation (1) comprises three different terms, each denoting a unique effect. The first term captures the within sectors productivity growth effect, the second the static effect of reallocation of labor between sectors with differing levels of labor productivity and the last term is an interaction effect of labor shifts and productivity growth. It can be interpreted as the dynamic effect of shifts towards sectors with either lower or higher than average productivity growth. This term will contribute positively to productivity growth if labor is shifted to sectors where productivity is improving at a higher rate than average productivity. Conversely, it will have a negative impact if labor shifts to sectors where productivity is increasing at a slower rate than the average.

One shortcoming of the standard formulation is that it uses both sectors with decreasing and increasing labor shares to derive the shift effects. Van Ark \& Timmer (2003) point out a scenario where for instance the contribution of the agriculture sector to the shift effect is negative when its labor share is decreasing and its productivity is below average. As this would make it more difficult to analytically interpret the shift effects, they propose a new formulation of equation (2), which distinguishes between the shift effects of sectors with growing or declining labor shares. In their model, shift effects of sectors with declining labor shares are reallocated to the shift effects of those with growing labor shares. Suppose $J$ is the set of sectors with shrinking labor shares and $K$ is the set of sectors with growing labor shares. The decline in the labor share of the shrinking sectors would be equal to the increase of the labor share of the expanding sectors. Therefore, we can use $\left(S_{i}^{t}-S_{i}^{0}\right)\left(\bar{P}_{i}-\bar{P}_{J}\right)$ for expanding sectors which denotes shift effect from expanding and shrinking sectors combined. If average 
productivity $\bar{P}_{i}$ in sectors with growing labor shares is higher than average productivity $\bar{P}_{J}$ in sectors with declining labor shares, this combined shift effect will be positive. Therefore, the contribution of sector $i$ to aggregate labor productivity is given by

$$
\begin{aligned}
& C_{i}=C_{i}^{\text {intra }}+C_{i}^{\text {shift }}=\left(P_{i}^{t}-P_{i}^{0}\right) \bar{S}_{i}+\left(S_{i}^{t}-S_{i}^{0}\right)\left(\bar{P}_{i}-\bar{P}_{J}\right) \quad i \in K \\
& C_{i}=C_{i}^{\text {intra }}=\left(P_{i}^{t}-P_{i}^{0}\right) \bar{S}_{i} \quad i \in J
\end{aligned}
$$

where $S^{0}$ and $S^{t}$ are the labor shares at year 0 and year t respectively, $\bar{P}$ is the average productivity level. where

$S^{0}$ is the labor share at year 0 ;

$S^{t}$ is the labor share at year $\mathrm{t}$;

$\bar{S}$ is average share for the whole period;

$P^{0}$ is the labor productivity at year 0 ;

$P^{t}$ is the labor productivity at year $\mathrm{t}$;

$\bar{P}$ is the average productivity level.

Then the average labor productivity over all shrinking sectors is given by

$$
\bar{P}_{J}=\frac{\sum_{i \in J}\left(s_{i}^{t}-S_{i}^{0}\right) \bar{P}_{i}}{\sum_{i \in J}\left(S_{i}^{t}-S_{i}^{0}\right)}
$$

In this chapter we use the van Ark \& Timmer (2003) model discussed above.

\subsubsection{Data description}

\subsubsection{All economic activities}

For the complete economy with all the sectors we use two datasets, one for value added and the other for labor. The data series on value added is made available ${ }^{70}$ by the Economic Statistics Branch of the United Nations Statistics Division (UNSD) which maintains and annually updates the National Accounts Official Country Data database. This work is carried out in accordance with the recommendation of the Statistical Commission that the Statistics Division of the United Nations should regularly publish the most recent available data on national accounts for as many countries and areas as possible. The value added time series for Pakistan by industries at constant 2005 prices is available starting from 1950 right till 2013. It is provided in International Standard Industrial Classification of All Economic Activities (ISIC) Rev 3.1 categories for all industries. The labor data is taken from LABORSTA ${ }^{71}$. The LABORSTA is an International La-

\footnotetext{
70 Data is available online and can be downloaded from the following link: http://data.un.org/Explorer.aspx?d=SNAAMA

71 Since December 2013, 90\% of the information in LABORSTA have been migrated to ILOSTAT (www.ilo.org/ilostat), ILO's new Statistical Information System.
} 
bor Office (ILO) database operated by the ILO Department of Statistics. This data is available $^{72}$ from 1973 till 2007 also in ISIC Rev 3.1 categories. Data is available annually, whereas we are more interested in particular sub-periods reflecting the various political and military regimes as already discussed and analyzed in this and the previous chapter, we therefore have taken average values for our designated sub-periods and in this way compared these sub-periods with another. Our sub-periods comprise 197378, 1978-1988, 1988-1999 and 1999-2007. These periods reflect the regimes of Bhutto, General Zia, the numerous civilian governments and General Musharraf respectively.

The available value added data is broken down into 8 economic sectors and that for labor into $10^{73}$. There was a complete overlap in 5 out of the 8 and 10 categories of both the National Accounts data for Value Added and the LABORSTA data for employment. The remaining sectors of each data set were merged in order to avoid discrepancies. This way we end up analyzing the shift trends in 7 subsectors. ${ }^{74}$ Our special interested in the ICT sector leads us to pay extra attention to two sections, I (Transport, Storage and Communications) as this section has the division (64) Post and Communications which covers the ' $\mathrm{CT}^{\prime}$ ' of ' $\mathrm{ICT}$ ', and $\mathrm{K}^{75}$ (Real Estate, Renting and Business Activities) which has in it the division (72) Computer and Related Activities which forms 'IT' of 'ICT'.

\subsubsection{Manufacturing}

The manufacturing industries data is made available ${ }^{76}$ by UNIDO (United Nations Industrial Development Organization). The UNIDO Industrial Statistics Database at the 2digit level of ISIC (INDSTAT2) contains time series data on the manufacturing sector for the period 1963 onwards. INDSTAT2 is the largest industrial statistics database of its kind. Unlike others presented by different classification standards for different time periods, INDSTAT2 provides data by a single classification standard for more than 40 years, which makes it particularly valuable for long-term structural analysis. The data are arranged at the 2-digit level of the ISIC Revision 3 pertaining to the manufacturing sector, which comprises 23 industries. In case of Pakistan the available data were disaggregated into 18 industries.

In order to calculate the sectoral shifts we have made use of two main variables from this data sets, Valued Added and the Average Daily Persons Employed referred to

\footnotetext{
72 Data is available online and can be downloaded from the following link: http://data.un.org/Data. $a$ spx $\mathrm{d}=$ =LABORSTA\& $\mathrm{f}=$ tableCode $\% 3 \mathrm{a} 2 \mathrm{~B}$

${ }^{73}$ These industrial categories are each denoted by a single alphabet and are called as sections. These sections are further subdivide into 2-digit divisions. A list of all the ISIC sections and their corresponding divisions is given in Appendix III and IV.

${ }^{74} \mathrm{~A}$ concordance table is given in Appendix VII for clarity.

${ }^{75}$ This section $(K)$ is aggregated with a few other sections J, L, M, N, O and P under the title Other Activities, due to unavailability of disaggregated data.

${ }^{76}$ Data are available online at our UNIDO Statistics Data Portal and on CD ROM. We used the 2013 CD ROM to retrieve the required data.
} 
simply as Labor throughout this chapter. Time series data on working hours is not available for Pakistan. Also, labor input is usually adjusted by a quality change generally measured by the increase in schooling years which is also not available as such for Pakistan. So we rely on simply the number of workers in the economy as a measure of labor input. Labor productivity is therefore given by value added per person engaged, as data for hours worked is not available for Pakistan. The value added data is available in current prices which we have converted to 2005 constant prices using deflators given in the Handbook of Statistics on Pakistan Economy, 2010 issued by the State Bank of Pakistan ${ }^{77}$.

This data is originally collected by the Pakistan Bureau of Statistics (PBS) ${ }^{78}$ which conducts a Census of Manufacturing Industries (CMI) every 5 years. The latest one was conducted in 2011 the data of which however is still not compiled and made public. Because of these limitations i.e. that latest data point available being that of 2006 and older data points being 5 years apart, we couldn't construct our periods corresponding to the periods which we used for our analysis of the Pakistani economy in chapter 3 and also in this chapter for the complete economy. The periods for the manufacturing sector analysis are therefore based on the available CMI surveys and are 1986-91, 1991-96, 1996-01, 2001-06 and the complete period 1986-06.

\subsubsection{Results}

We apply both the Standard shift-share model and the Ark and Timmer shift-share model discussed above to both the national economy dataset and the manufacturing industries data. We separately discuss the results of the 7 major sectors in the period 1978 - 2007 under the heading Complete Economy and the 18 Manufacturing subsectors under the heading Manufacturing.

\subsubsection{Complete economy}

Here we discuss the period-wise results of each of the two methods used separately but start with some descriptive statistics.

The average sectoral labor shares for each studied period are presented in table 4.5. It should be noted that the changes from one period to another in these shares are the result of net job destruction and job creation. Also, interpretation of the shares needs to be done in the context of the aggregate employment growth rate of $2.6 \%$ annually for the complete period as shown in table 4.6. These aggregate changes can be understood in the context of the political history discussed in the previous chapter. Put simply, this means that even small percentage increases actually depict a very strong trend. The substantial increase in aggregate employment however is not only

\footnotetext{
77 The Handbook can be downloaded at http://www.sbp.org.pk/departments/stats/pakEconomy_HandBook/

${ }^{78}$ Formerly known as the Federal Bureau of Statistics
} 
explained by the explosive population growth (at close to $3.5 \%$ annually) in the corresponding periods but also the opening up of the economy and certain investment friendly policies resulting in the deregulation of the ICT sector and thereby record FDI, particularly in the last period. This is evident from the increases in the two sectors which capture ICT activities (as described above), both of which grew faster than the average aggregate growth given in the last row.

Two of the 7 industrial sectors studied ('Mining and Quarrying' and 'Manufacturing') are relatively stable with less than one percentage point of change in their labor shares over 30 years. It can be observed that mining, construction and transport sectors do not engage a lot of labor, unlike agriculture, manufacturing, wholesale and others activities which together comprise close to $90 \%$ of total employment. Even though it is typical of these enclave sectors to operate at high productivity, they are unable to absorb the surplus labor from agriculture. It is noteworthy that the labor share of only four sectors has been increasing throughout the period. A fifth sector, 'Construction' increased its labor share from 1978-88 to 1989-99 but it shrank slightly from 1989-99 to 2000-07. This increase followed by shrinking might be attributable to the focus on construction which is common by elected governments for populist reasons. Looking at the table and focusing on sectors which would fall into the 'services' economy it can be said that Baumol effect is not an issue as the labor share of these sectors remain fairly stable and low.

Table 4.7 establishes the importance of Agriculture, Manufacturing, Wholesale, Transport and Others in terms of being the main contributors to value added. At the same time it is also clear that Agriculture is the only sector which has a diminishing trend over the years and its value added share has dropped from $38.5 \%$ in the first period of analysis to 27.4 in the last two periods. Of this $10 \%$ shift, two percentage points have been shifted to each Mining, Manufacturing and Transport sectors while over three percentage points to Other Activities. Table 4.8 lists the value added growth rates for various periods with the last column showing the growth rate for the complete period. It can be seen that the Manufacturing sector has grown the most in terms of value added followed by Mining and Other Activities. The slowest growth was recorded in Agriculture. The Zia era was the best in terms of aggregate growth rate. The Musharraf era was surprisingly not very impressive in terms of growth, however caution must be practiced in interpreting these figures as they refer to averages and the period of Musharraf comprises 8 years.

Table 4.9 presents the productivity growth rates for various periods. Looking at the last column it becomes clear that Construction, Wholesale and Agriculture are the three sectors with the least growth in productivity over the 34 year period. Manufacturing productivity was in negative during Bhutto's era which can be explained by the infamous Nationalization drive. Productivity in the Construction sector fell during the Zia regime, whereas aggregate productivity was astonishingly low during the Musharraf regime, the Mining sector being the only sector with negative productivity growth. 
Table 4.5 Sector-wise average labor shares (\%) , 1973-2007

\begin{tabular}{lccccc}
\hline & $1973-78$ & $1978-88$ & $1988-99$ & $1999-07$ & $1973-07$ \\
\hline Agriculture, hunting, forestry, fishing (ISIC A-B) & 55.2 & 52.3 & 48.1 & 44.5 & 48.6 \\
Mining, Utilities (ISIC C and E) & 0.7 & 0.9 & 0.9 & 0.8 & 0.9 \\
Manufacturing (ISIC D) & 13.4 & 13.8 & 11.2 & 12.9 & 12.7 \\
Construction (ISIC F) & 4.1 & 5.2 & 6.6 & 6.0 & 5.8 \\
Wholesale, retail trade, restaurants and hotels (ISIC G-H) & 10.9 & 11.5 & 13.4 & 14.4 & 13.0 \\
Transport, storage and communication (ISIC I) & 4.9 & 4.8 & 5.2 & 5.6 & 5.2 \\
Other Activities (ISIC J-P) & 10.9 & 11.5 & 14.6 & 15.8 & 13.8 \\
Total & 100 & 100 & 100 & 100 & 100 \\
Total employment (period average in 000's) & 21169 & 25973 & 31687 & 41087 & 30682 \\
\hline
\end{tabular}

Source: Author's own computation, data made available by LABORSTA database operated by the ILO Department of Statistics

Table 4.6 Sector-wise labor growth rates in sub-periods

\begin{tabular}{lccccc}
\hline & $1973-78$ & $1978-88$ & $1988-99$ & $1999-07$ & $1973-07$ \\
\hline Agriculture, hunting, forestry, fishing (ISIC A-B) & 1.5 & 1.8 & 1.6 & 2.1 & 1.8 \\
Mining, Utilities (ISIC C and E) & -2.4 & 4.0 & 4.1 & 2.7 & 2.7 \\
Manufacturing (ISIC D) & 4.2 & 1.8 & 0.1 & 7.2 & 2.8 \\
Construction (ISIC F) & 6.7 & 6.9 & 2.1 & 3.7 & 4.6 \\
Wholesale, retail trade, restaurants and hotels (ISIC G-H) & 4.8 & 3.3 & 3.7 & 3.6 & 3.7 \\
Transport, storage and communication (ISIC I) & 2.5 & 2.6 & 3.4 & 2.9 & 2.9 \\
Other Activities (ISIC J-P) & 1.5 & 3.8 & 5.0 & 2.6 & 3.6 \\
Aggregate & 2.4 & 2.5 & 2.3 & 3.1 & 2.6 \\
\hline
\end{tabular}

Source: Author's own computation, data made available by LABORSTA database operated by the ILO Department of Statistics

Table 4.7 Sector-wise average value added shares (\%), 1973-2007

\begin{tabular}{lccccc}
\hline & $1973-78$ & $1978-88$ & $1988-99$ & $1999-07$ & $1973-07$ \\
\hline Agriculture, hunting, forestry, fishing (ISIC A-B) & 38.5 & 34.3 & 27.4 & 27.4 & 23.9 \\
Mining, Utilities (ISIC C and E) & 3.2 & 3.4 & 4.6 & 5.3 & 4.4 \\
Manufacturing (ISIC D) & 8.9 & 8.6 & 11.1 & 10.9 & 14.2 \\
Construction (ISIC F) & 2.7 & 3.6 & 3.4 & 2.7 & 2.7 \\
Wholesale, retail trade, restaurants and hotels (ISIC G-H) & 17.4 & 18.1 & 20.4 & 18.9 & 18.5 \\
Transport, storage and communication (ISIC I) & 11.5 & 11.7 & 12.9 & 13.1 & 12.1 \\
Other Activities (ISIC J-P) & 17.9 & 20.5 & 20.3 & 21.6 & 24.3 \\
Total & 100 & 100 & 100 & 100 & 7371724 \\
Total value added (in 000000's) & 1326252 & 1672133 & 3094946 & 4952009 \\
\hline
\end{tabular}

Source: Author's own computation, data made available by Economic Statistics Branch of the United Nations Statistics Division (UNSD). Value added is in constant 2005, local currency units. 
Table 4.8 Sector-wise value added growth rates in sub-periods

\begin{tabular}{lccccc}
\hline & $1973-78$ & $1978-88$ & $1988-99$ & $1999-07$ & $1973-07$ \\
\hline Agriculture, hunting, forestry, fishing (ISIC A-B) & 2.3 & 4.0 & 4.4 & 3.3 & 3.7 \\
Mining, Utilities (ISIC C and E) & 6.0 & 9.8 & 5.7 & 2.6 & 6.2 \\
Manufacturing (ISIC D) & 4.0 & 9.1 & 4.2 & 8.6 & 6.6 \\
Construction (ISIC F) & 10.8 & 5.7 & 2.3 & 4.9 & 5.2 \\
Wholesale, retail trade, restaurants and hotels (ISIC G-H) & 5.5 & 7.7 & 3.7 & 4.8 & 5.4 \\
Transport, storage and communication (ISIC I) & 5.1 & 7.4 & 4.5 & 4.0 & 5.3 \\
Other Activities (ISIC J-P) & 7.6 & 6.3 & 4.9 & 6.7 & 6.1 \\
Aggregate & 4.7 & 6.4 & 4.4 & 5.1 & 5.2 \\
\hline
\end{tabular}

Source: Author's own computation, data made available by Economic Statistics Branch of the United Nations Statistics Division (UNSD). Value added is in constant 2005, local currency units.

Table 4.9 Sector-wise labor productivity growth rates in sub-periods

\begin{tabular}{lccccc}
\hline & $1973-78$ & $1978-88$ & $1988-99$ & $1999-07$ & $1973-07$ \\
\hline Agriculture, hunting, forestry, fishing (ISIC A-B) & 0.9 & 2.1 & 2.8 & 1.2 & 1.9 \\
Mining, Utilities (ISIC C and E) & 8.7 & 5.6 & 1.6 & -0.2 & 3.3 \\
Manufacturing (ISIC D) & -0.2 & 7.1 & 4.2 & 1.3 & 3.7 \\
Construction (ISIC F) & 3.9 & -1.1 & 0.2 & 1.2 & 0.6 \\
Wholesale, retail trade, restaurants and hotels (ISIC G-H) & 0.7 & 4.3 & -0.1 & 1.1 & 1.6 \\
Transport, storage and communication (ISIC I) & 2.6 & 4.7 & 1.1 & 1.1 & 2.4 \\
Other Activities (ISIC J-P) & 6.0 & 2.3 & -0.1 & 4.0 & 2.5 \\
Aggregate & 2.3 & 3.7 & 2.0 & 1.9 & 2.5 \\
\hline
\end{tabular}

Source: Author's own computation, data made available by LABORSTA database operated by the ILO Department of Statistics and Economic Statistics Branch of the United Nations Statistics Division (UNSD). Value added is in constant 2005, local currency units.

Table 4.10 Sector-wise productivity levels per period in terms of aggregate productivity (\%), 1973-2007

\begin{tabular}{lccccc}
\hline & $1973-78$ & $1978-88$ & $1988-99$ & $1999-07$ & $1973-07$ \\
\hline Agriculture, hunting, forestry, fishing (ISIC A-B) & 65.5 & 58.5 & 69.1 & 69.1 & 49.7 \\
Mining, Utilities (ISIC C and E) & 489.9 & 441.3 & 683.1 & 739.2 & 459.8 \\
Manufacturing (ISIC D) & 64.4 & 73.3 & 120.4 & 115.2 & 75.4 \\
Construction (ISIC F) & 79.8 & 66.5 & 57.9 & 51.4 & 45.6 \\
Wholesale, retail trade, restaurants and hotels (ISIC G-H) & 165.8 & 167.1 & 183.3 & 158.6 & 127.7 \\
Transport, storage and communication (ISIC I) & 231.9 & 260.4 & 293.5 & 277.0 & 205.3 \\
Other Activities (ISIC J-P) & 178.4 & 177.0 & 174.6 & 171.5 & 131.5 \\
Aggregate & 100.0 & 100.0 & 100.0 & 100.0 & 100.0 \\
\hline
\end{tabular}

Source: Author's own computation, data made available by LABORSTA database operated by the ILO Department of Statistics and Economic Statistics Branch of the United Nations Statistics Division (UNSD). Value added is in constant 2005, local currency units. 
Table 4.10 depicts the sector-wise productivity levels for the studied periods. This tables gives us a quick overview of the underperforming and overperforming sectors. Looking at the complete period (last column) it is of interest to note that only three sectors (Agriculture, Manufacturing and Construction) perform worse than the aggregate productivity taken here as the benchmark.

Figure 4.9 summarizes the results of the sectoral shift and share analysis at aggregate level using the standard model. For each of the five periods analyzed, the figure depicts total productivity and its decomposition into Intra (intrasectoral productivity growth), Shift (inter-sectoral shift effects) and Interaction (interaction-shift effect a residual term representing the simultaneous effects of intrasectoral and intersectoral shifts). The yellow line depicts the combined contribution of intra, shift and interaction effects. It can be seen from the figure that in terms of productivity growth the Zia era (1978-99) was the most dynamic. It can also be seen that the intrasectoral contribution is substantial throughout all periods making up at least for two-thirds of the total productivity gains. In contrast, the interaction effect is either unimportant or sometimes even negative (third period). The shift effect does contribute. During the third period (1988-99) it accounts for over $8 \%$ of productivity growth. During the fourth period (1988-99) it even accounts for 33 percent.

Tables $4.11-4.15$ present the sector-wise productivity decompositions for the different periods, the last table presenting the whole period. It is clear that the effect of productivity growth within sectors (intra effect) is the dominant contributor towards productivity growth for all periods. The shift effect, which captures the static effect of reallocation of labor between sectors with differing levels of labor productivity contributes positively to productivity growth, but accounts for a modest percentage of the productivity increase except for the Political Musical Chairs era (1988-99) where it contributes $33 \%$. It must be noted that the annual growth rate for this period was one of the lowest (2\%) though. The interaction effect of productivity growth and labor shifts had negative or negligible contributions in all the periods except for the whole period where it accounts for $7.9 \%$ of productivity growth. Productivity growth peaked during Zia's military regime, which is generally lauded for its better performance and less corruption when compared to civilian governments as discussed in Chapter 3.

Each period has one sector with negative productivity growth except for the whole period where all sectors show positive growth. The first period (1973-78), representing the Bhutto regime shows negative productivity growth for the manufacturing sector. This can be explained by the nationalization drive of industries during this period. During Zia's period the construction sector's productivity fell slightly. During the Political Musical chairs period the wholesale sector of the economy lost in terms of productivity and during the Musharraf period (1999-07) the mining sector's productivity declined. Looking at the complete period in table $4.14,66.4 \%$ of the productivity growth can be accounted for by three sectors (Manufacturing, Wholesale and Other Activities). Summing up the productivity gains over the whole period, productivity in the mining and manufacturing sectors increased more than 3-fold. Similarly productivi- 
ty in Transport and Other Activities more than doubled while that of agriculture almost doubled. It is important to note that $13 \%$ of the total contribution in productivity gains is from the agriculture sector alone. The average manufacturing-agriculture productivity ratio is 2.65 , which is typical of developing countries. ${ }^{79}$ It should be noted that the least developed countries are known to have the largest productivity disadvantage of agriculture. Altogether, inter-sectoral productivity gaps markedly characterize underdevelopment. These gaps are bigger for the poorest countries and are significantly reduced by sustained economic growth.

Figure 4-9 Period-wise productivity decomposition using Standard Shift-share model

\section{Period-wise productivity decomposition using Standard Shift-share model}

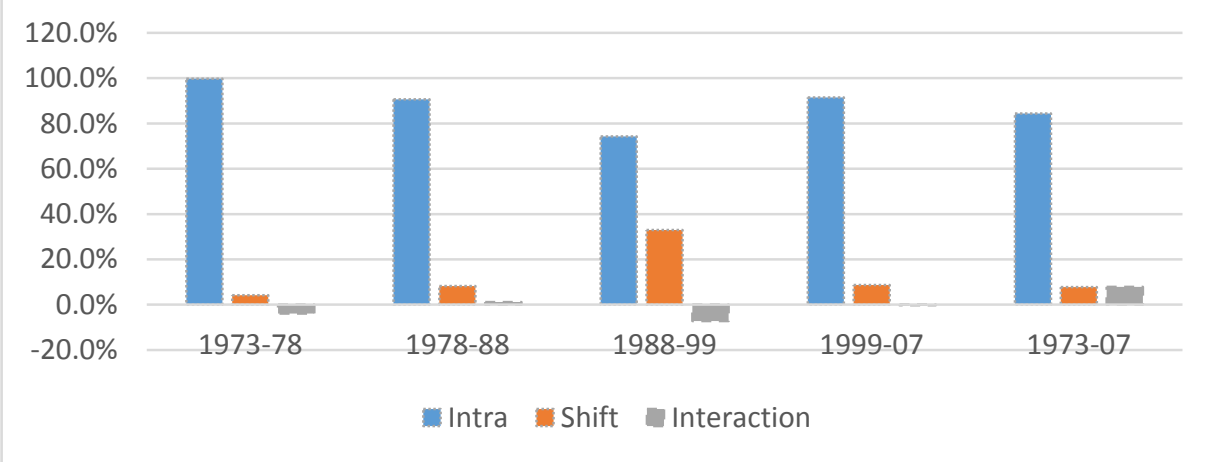

Source: Author's own computation, data made available by LABORSTA database operated by the ILO Department of Statistics and Economic Statistics Branch of the United Nations Statistics Division (UNSD). Value added is in constant 2005, local currency units.

\footnotetext{
${ }^{79}$ McMillan and Rodrik (2011) calculate the average manufactures-agriculture productivity ratio to be 2.3 in sub-Saharan Africa, 2.8 in Latin America and 3.9 in Asia.
} 
Table 4.11 1973-78 Productivity Decomposition using Standard Shift-share model ${ }^{80}$

\begin{tabular}{lccccc}
\hline & \multicolumn{3}{c}{$1973-78$} \\
\cline { 2 - 6 } & $\begin{array}{c}\text { Annual LP } \\
\text { growth rate }\end{array}$ & $\begin{array}{c}\text { Intra } \\
\text { Description }\end{array}$ & $\begin{array}{c}\text { Shift } \\
(\%)\end{array}$ & $\begin{array}{c}\text { Interaction } \\
(\%)\end{array}$ & $\begin{array}{c}\text { Total } \\
(\%)\end{array}$ \\
\hline Agriculture, hunting, forestry, fishing (ISIC A-B) & 0.9 & $14.1 \%$ & $-13.9 \%$ & $-0.6 \%$ & $-0.4 \%$ \\
Mining, Utilities (ISIC C and E) & 8.7 & $13.4 \%$ & $-5.6 \%$ & $-2.9 \%$ & $5.0 \%$ \\
Manufacturing (ISIC D) & -0.2 & $-0.8 \%$ & $6.9 \%$ & $-0.1 \%$ & $6.0 \%$ \\
Construction (ISIC F) & 3.9 & $4.7 \%$ & $5.1 \%$ & $1.1 \%$ & $10.8 \%$ \\
Wholesale, retail trade, hotels (ISIC G-H) & 0.7 & $5.4 \%$ & $17.5 \%$ & $0.7 \%$ & $23.5 \%$ \\
Transport, storage and communication (ISIC I) & 2.6 & $12.8 \%$ & $0.5 \%$ & $0.1 \%$ & $13.4 \%$ \\
Other Activities (ISIC J-P) & 6.0 & $50.1 \%$ & $-6.2 \%$ & $-2.1 \%$ & $41.8 \%$ \\
Total & 2.3 & $99.7 \%$ & $4.2 \%$ & $-3.9 \%$ & $100.0 \%$ \\
\hline
\end{tabular}

Source: Author's own computation, data made available by LABORSTA database operated by the ILO Department of Statistics and Economic Statistics Branch of the United Nations Statistics Division (UNSD). Value added is in constant 2005, local currency units.

Table 4.12 1978-88 Productivity Decomposition using Standard Shift-share model

\begin{tabular}{lccccc}
\hline & \multicolumn{3}{c}{$1978-88$} \\
\cline { 2 - 6 } & $\begin{array}{c}\text { Annual LP } \\
\text { growth rate }\end{array}$ & $\begin{array}{c}\text { Intra } \\
(\%)\end{array}$ & $\begin{array}{c}\text { Shift } \\
(\%)\end{array}$ & $\begin{array}{c}\text { Interaction } \\
(\%)\end{array}$ & $\begin{array}{c}\text { Total } \\
(\%)\end{array}$ \\
\hline Agriculture, hunting, forestry, fishing (ISIC A-B) & 2.1 & $18.1 \%$ & $-5.2 \%$ & $-1.2 \%$ & $11.8 \%$ \\
Mining, Utilities (ISIC C and E) & 5.6 & $5.5 \%$ & $1.1 \%$ & $0.8 \%$ & $7.4 \%$ \\
Manufacturing (ISIC D) & 7.1 & $19.3 \%$ & $-1.3 \%$ & $-1.3 \%$ & $16.6 \%$ \\
Construction (ISIC F) & -1.1 & $-0.9 \%$ & $4.2 \%$ & $-0.4 \%$ & $2.9 \%$ \\
Wholesale, retail trade, hotels (ISIC G-H) & 4.3 & $21.1 \%$ & $3.1 \%$ & $1.6 \%$ & $25.7 \%$ \\
Transport, storage and communication (ISIC I) & 4.7 & $15.5 \%$ & $0.1 \%$ & $0.1 \%$ & $15.7 \%$ \\
Other Activities (ISIC J-P) & 2.3 & $12.0 \%$ & $6.2 \%$ & $1.6 \%$ & $19.8 \%$ \\
Total & 3.7 & $90.7 \%$ & $8.2 \%$ & $1.1 \%$ & $100.0 \%$ \\
\hline
\end{tabular}

Source: Author's own computation, data made available by LABORSTA database operated by the ILO Department of Statistics and Economic Statistics Branch of the United Nations Statistics Division (UNSD). Value added is in constant 2005, local currency units.

\footnotetext{
${ }^{80}$ Note that in case of a negative annual labor productivity growth rate anywhere in the tables $4.11-4.35$, positive percentages of intra, shift and interaction are contributions to productivity decline and vice versa.
} 


\begin{tabular}{lccccc}
\hline & \multicolumn{3}{c}{$1988-99$} \\
\cline { 2 - 6 } & $\begin{array}{c}\text { Annual LP } \\
\text { growth rate }\end{array}$ & $\begin{array}{c}\text { Intra } \\
(\%)\end{array}$ & $\begin{array}{c}\text { Shift } \\
(\%)\end{array}$ & $\begin{array}{c}\text { Interaction } \\
(\%)\end{array}$ & $\begin{array}{c}\text { Total } \\
(\%)\end{array}$ \\
\hline Agriculture, hunting, forestry, fishing (ISIC A-B) & 2.8 & $39.1 \%$ & $-8.5 \%$ & $-3.0 \%$ & $27.5 \%$ \\
Mining, Utilities (ISIC C and E) & 1.6 & $3.6 \%$ & $3.9 \%$ & $0.7 \%$ & $8.3 \%$ \\
Manufacturing (ISIC D) & 4.2 & $25.7 \%$ & $-9.8 \%$ & $-5.5 \%$ & $10.3 \%$ \\
Construction (ISIC F) & 0.2 & $0.3 \%$ & $-0.3 \%$ & $0.0 \%$ & $0.0 \%$ \\
Wholesale, retail trade, hotels (ISIC G-H) & -0.1 & $-0.7 \%$ & $13.7 \%$ & $-0.1 \%$ & $12.9 \%$ \\
Transport, storage and communication (ISIC I) & 1.1 & $6.9 \%$ & $6.4 \%$ & $0.8 \%$ & $14.2 \%$ \\
Other Activities (ISIC J-P) & -0.1 & $-0.6 \%$ & $27.6 \%$ & $-0.2 \%$ & $26.8 \%$ \\
Total & 2.0 & $74.3 \%$ & $33.0 \%$ & $-7.3 \%$ & $100.0 \%$ \\
\hline
\end{tabular}

Source: Author's own computation, data made available by LABORSTA database operated by the ILO Department of Statistics and Economic Statistics Branch of the United Nations Statistics Division (UNSD). Value added is in constant 2005, local currency units.

Table 4.14 1999-07 Productivity Decomposition using Standard Shift-share model

\begin{tabular}{lccccc}
\hline & \multicolumn{3}{c}{$1999-07$} \\
\cline { 2 - 6 } & $\begin{array}{c}\text { Annual LP } \\
\text { growth rate }\end{array}$ & $\begin{array}{c}\text { Intra } \\
(\%)\end{array}$ & $\begin{array}{c}\text { Shift } \\
(\%)\end{array}$ & $\begin{array}{c}\text { Interaction } \\
\text { (\%) }\end{array}$ & $\begin{array}{c}\text { Total } \\
(\%)\end{array}$ \\
\hline Agriculture, hunting, forestry, fishing (ISIC A-B) & 1.2 & $16.6 \%$ & $-12.8 \%$ & $-1.3 \%$ & $2.6 \%$ \\
Mining, Utilities (ISIC C and E) & -0.2 & $-0.4 \%$ & $-0.9 \%$ & $0.0 \%$ & $-1.3 \%$ \\
Manufacturing (ISIC D) & 1.3 & $7.4 \%$ & $23.8 \%$ & $2.7 \%$ & $34.0 \%$ \\
Construction (ISIC F) & 1.2 & $1.6 \%$ & $0.8 \%$ & $0.1 \%$ & $2.5 \%$ \\
Wholesale, retail trade, hotels (ISIC G-H) & 1.1 & $10.9 \%$ & $4.6 \%$ & $0.4 \%$ & $15.9 \%$ \\
Transport, storage and communication (ISIC I) & 1.1 & $7.2 \%$ & $-1.3 \%$ & $-0.1 \%$ & $5.7 \%$ \\
Other Activities (ISIC J-P) & 4.0 & $48.2 \%$ & $-5.4 \%$ & $-2.0 \%$ & $40.7 \%$ \\
Total & 1.9 & $91.5 \%$ & $8.7 \%$ & $-0.2 \%$ & $100.0 \%$ \\
\hline
\end{tabular}

Source: Author's own computation, data made available by LABORSTA database operated by the ILO Department of Statistics and Economic Statistics Branch of the United Nations Statistics Division (UNSD). Value added is in constant 2005, local currency units. 
Table 4.15 1973-07 Productivity Decomposition using Standard Shift-share model

\begin{tabular}{lccccc}
\hline & \multicolumn{3}{c}{$1973-07$} \\
\cline { 2 - 6 } & $\begin{array}{c}\text { Annual LP } \\
\text { growth rate }\end{array}$ & $\begin{array}{c}\text { Intra } \\
(\%)\end{array}$ & $\begin{array}{c}\text { Shift } \\
(\%)\end{array}$ & $\begin{array}{c}\text { Interaction } \\
(\%)\end{array}$ & $\begin{array}{c}\text { Total } \\
(\%)\end{array}$ \\
\hline Agriculture, hunting, forestry, fishing (ISIC A-B) & 1.9 & $26.1 \%$ & $-6.8 \%$ & $-6.2 \%$ & $13.0 \%$ \\
Mining, Utilities (ISIC C and E) & 3.3 & $4.9 \%$ & $0.1 \%$ & $0.3 \%$ & $5.3 \%$ \\
Manufacturing (ISIC D) & 3.7 & $16.2 \%$ & $0.6 \%$ & $1.4 \%$ & $18.1 \%$ \\
Construction (ISIC F) & 0.6 & $0.4 \%$ & $1.9 \%$ & $0.4 \%$ & $2.7 \%$ \\
Wholesale, retail trade, hotels (ISIC G-H) & 1.6 & $9.2 \%$ & $5.9 \%$ & $4.2 \%$ & $19.3 \%$ \\
Transport, storage and communication (ISIC I) & 2.4 & $10.4 \%$ & $1.0 \%$ & $1.2 \%$ & $12.6 \%$ \\
Other Activities (ISIC J-P) & 2.5 & $17.2 \%$ & $5.2 \%$ & $6.7 \%$ & $29.0 \%$ \\
Total & 2.5 & $84.4 \%$ & $7.8 \%$ & $7.9 \%$ & $100.0 \%$ \\
\hline
\end{tabular}

Source: Author's own computation, data made available by LABORSTA database operated by the ILO Department of Statistics and Economic Statistics Branch of the United Nations Statistics Division (UNSD). Value added is in constant 2005, local currency units.

Figure 4.10 shows the results of the sectoral shift and share analysis at aggregate level using the Ark and Timmer model. For each of the five periods analyzed, the figure depicts the contributions of intrasectoral productivity growth (intra), inter-sectoral shift effects (shift) and their sum (total). Expanding sectors are those with highly negative or positive shift effects. It is noteworthy that there are negative contributions to productivity growth from some expanding sectors. If a sector has consistently declining labor shares, the shift effect using equation (2) will be either be zero or close to zero. The results using this model are presented through tables $4.16-4.20$. It can be seen that they are very similar to the results obtained while using the standard model, but are more suited to showing sectoral contributions. Note that as the calculations are based on averages, the interaction effect disappears. 


\section{Period-wise productivity decomposition using by Ark and Timmer model}

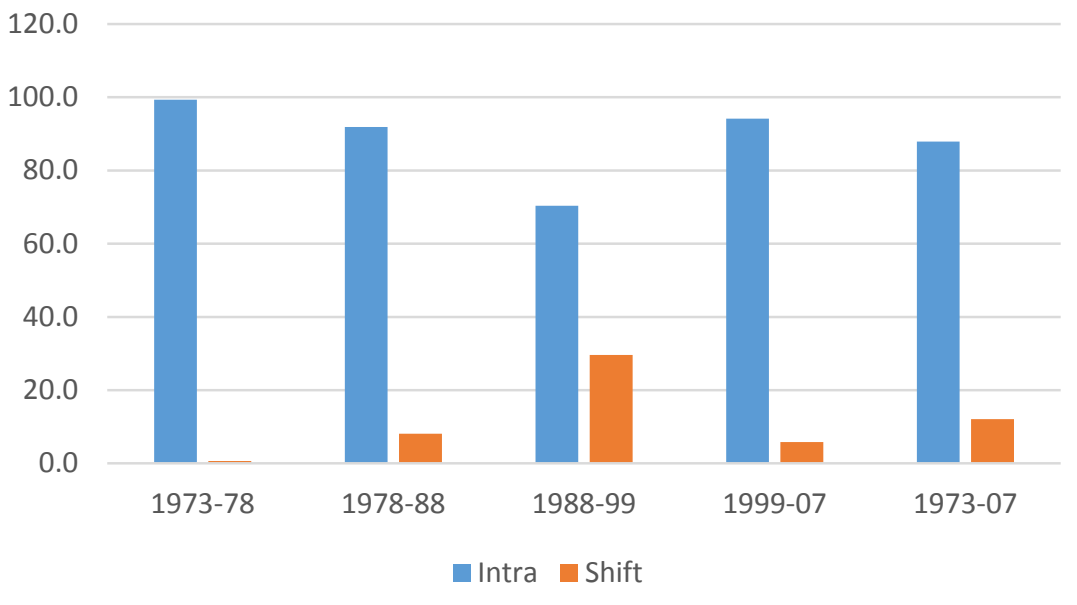

Source: Author's own computation, data made available by LABORSTA database operated by the ILO Department of Statistics and Economic Statistics Branch of the United Nations Statistics Division (UNSD). Value added is in constant 2005, local currency units.

Table 4.16 1973-78 Productivity Decomposition using Ark and Timmer model

\begin{tabular}{lcccc}
\hline & \multicolumn{3}{c}{$1973-78$} \\
\cline { 2 - 5 } & Annual LP & & & \\
& growth rate & Intra \% & Shift \% & Total \% \\
\hline Agriculture, hunting, forestry, fishing (ISIC A-B) & 0.9 & 14.0 & 0.0 & 14.0 \\
Mining, Utilities (ISIC C and E) & 8.7 & 11.3 & 0.0 & 11.3 \\
Manufacturing (ISIC D) & -0.2 & -0.9 & -4.3 & -5.2 \\
Construction (ISIC F) & 3.9 & 5.7 & -1.8 & 3.9 \\
Wholesale, retail trade, restaurants and hotels (ISIC G-H) & 0.7 & 6.1 & 6.5 & 12.6 \\
Transport, storage and communication (ISIC I) & 2.6 & 13.3 & 0.3 & 13.6 \\
Other Activities (ISIC J-P) & 6.0 & 49.7 & 0.0 & 49.7 \\
Total & 2.3 & 99.3 & 0.7 & 100.0 \\
\hline
\end{tabular}

Source: Author's own computation, data made available by LABORSTA database operated by the ILO Department of Statistics and Economic Statistics Branch of the United Nations Statistics Division (UNSD). Value added is in constant 2005, local currency units. 


\begin{tabular}{lcccc}
\hline & \multicolumn{3}{c}{$1978-88$} \\
\cline { 2 - 4 } & $\begin{array}{c}\text { Annual LP } \\
\text { growth rate }\end{array}$ & Intra \% & Shift \% & Total \% \\
\hline Agriculture, hunting, forestry, fishing (ISIC A-B) & 2.1 & 17.0 & 0.0 & 17.0 \\
Mining, Utilities (ISIC C and E) & 5.6 & 7.6 & 1.0 & 8.6 \\
Manufacturing (ISIC D) & 7.1 & 19.2 & 0.0 & 19.2 \\
Construction (ISIC F) & -1.1 & -1.0 & 0.3 & -0.8 \\
Wholesale, retail trade, hotels (ISIC G-H) & 4.3 & 21.5 & 2.3 & 23.8 \\
Transport, storage and communication (ISIC I) & 4.7 & 15.0 & 0.1 & 15.1 \\
Other Activities (ISIC J-P) & 2.3 & 12.7 & 4.4 & 17.1 \\
Total & 3.7 & 91.9 & 8.1 & 100.0 \\
\hline
\end{tabular}

Source: Author's own computation, data made available by LABORSTA database operated by the ILO Department of Statistics and Economic Statistics Branch of the United Nations Statistics Division (UNSD). Value added is in constant 2005, local currency units.

Table 4.18 1988-99 Productivity Decomposition using Ark and Timmer model

\begin{tabular}{lcccc}
\hline & \multicolumn{3}{c}{$1988-99$} \\
\cline { 2 - 5 } & $\begin{array}{c}\text { Annual LP } \\
\text { growth rate }\end{array}$ & Intra \% & Shift \% & Total \% \\
\hline Agriculture, hunting, forestry, fishing (ISIC A-B) & 2.8 & 36.9 & 0.0 & 36.9 \\
Mining, Utilities (ISIC C and E) & 1.6 & 4.5 & 3.6 & 8.1 \\
Manufacturing (ISIC D) & 4.2 & 22.7 & 0.0 & 22.7 \\
Construction (ISIC F) & 0.2 & 0.3 & 0.0 & 0.3 \\
Wholesale, retail trade, hotels (ISIC G-H) & -0.1 & -0.8 & 7.3 & 6.5 \\
Transport, storage and communication (ISIC I) & 1.1 & 7.5 & 4.8 & 12.3 \\
Other Activities (ISIC J-P) & -0.1 & -0.7 & 13.8 & 13.1 \\
Total & 2.0 & 70.4 & 29.6 & 100.0 \\
\hline
\end{tabular}

Source: Author's own computation, data made available by LABORSTA database operated by the ILO Department of Statistics and Economic Statistics Branch of the United Nations Statistics Division (UNSD). Value added is in constant 2005, local currency units. 


\begin{tabular}{lcccc}
\hline & \multicolumn{2}{c}{$1999-07$} \\
\cline { 2 - 4 } & Annual LP & & & \\
& growth rate & Intra \% & Shift \% & Total \% \\
\hline Agriculture, hunting, forestry, fishing (ISIC A-B) & 1.2 & 16.1 & 0.0 & 16.1 \\
Mining, Utilities (ISIC C and E) & -0.2 & -0.4 & 0.0 & -0.4 \\
Manufacturing (ISIC D) & 1.3 & 9.9 & 4.5 & 14.4 \\
Construction (ISIC F) & 1.2 & 1.6 & -0.7 & 0.9 \\
Wholesale, retail trade, hotels (ISIC G-H) & 1.1 & 11.6 & 2.0 & 13.6 \\
Transport, storage and communication (ISIC I) & 1.1 & 7.5 & 0.0 & 7.5 \\
Other Activities (ISIC J-P) & 4.0 & 48.0 & 0.0 & 48.0 \\
Total & 1.9 & 94.2 & 5.8 & 100.0 \\
\hline
\end{tabular}

Source: Author's own computation, data made available by LABORSTA database operated by the ILO Department of Statistics and Economic Statistics Branch of the United Nations Statistics Division (UNSD). Value added is in constant 2005, local currency units.

Table 4.20 1973-07 Productivity Decomposition using Ark and Timmer model

\begin{tabular}{lcccc}
\hline & \multicolumn{3}{c}{$1973-07$} \\
\cline { 2 - 5 } & $\begin{array}{c}\text { Annual LP } \\
\text { growth rate }\end{array}$ & Intra \% & Shift \% & Total \% \\
\hline Agriculture, hunting, forestry, fishing (ISIC A-B) & 1.9 & 21.9 & 0.0 & 21.9 \\
Mining, Utilities (ISIC C and E) & 3.3 & 5.0 & 0.3 & 5.3 \\
Manufacturing (ISIC D) & 3.7 & 16.3 & 0.4 & 16.7 \\
Construction (ISIC F) & 0.6 & 0.7 & -0.2 & 0.5 \\
Wholesale, retail trade, hotels (ISIC G-H) & 1.6 & 11.9 & 5.2 & 17.1 \\
Transport, storage and communication (ISIC I) & 2.4 & 11.1 & 1.2 & 12.3 \\
Other Activities (ISIC J-P) & 2.5 & 20.9 & 5.2 & 26.1 \\
Total & 2.5 & 87.9 & 12.1 & 100.0 \\
\hline
\end{tabular}

Source: Author's own computation, data made available by LABORSTA database operated by the ILO Department of Statistics and Economic Statistics Branch of the United Nations Statistics Division (UNSD). Value added is in constant 2005, local currency units.

We used the Ark and Timmer model to overcome one major shortcoming of the standard formulation that it derives the shift effects both from sectors with shrinking and expanding labor shares. In certain scenarios (e.g. a sector with shrinking labor share and below average productivity will contribute negatively to the shift effect) the shift effects would be more difficult to analytically interpret if derived using the standard model. The Ark and Timmer model, by making a distinction between the shift effects of sectors with decreasing or increasing labor shares avoids this problem. This way, the shift effects of sectors shrinking in terms of labor shares are reallocated to the shift effects of expanding sectors. This can be seen in our results as well where the shift effects for various periods and sectors got pronounced. For instance looking at the 
complete period the shift effect for the aggregate economy comes out at $12.1 \%$ which is quite substantial.

\subsubsection{Manufacturing}

We now shift our focus on manufacturing and its sub-sectors. Table 4.21 lists the sectoral labor shares for the various years. It can be seen that Food and beverages and Textiles together were employing more than half of the labor force in manufacturing and this has grown to over $60 \%$ in the year 2006, mainly because of a 10 percent increase in Textiles' labor share. This gain can be attributed to the losses of labor share in Basic metals, Rubber products and Electrical equipment.

Table 4.21 Sectoral labor shares (\%), 1986 - 2006

\begin{tabular}{|c|c|c|c|c|c|}
\hline & 1986 & 1991 & 1996 & 2001 & 2006 \\
\hline Food and beverages (ISIC 15) & 14.2 & 14.4 & 14.7 & 11.8 & 14.6 \\
\hline Tobacco products (ISIC 16) & 1.9 & 1.0 & 1.0 & 0.6 & 0.5 \\
\hline Textiles (ISIC 17) & 37.1 & 39.9 & 41.9 & 48.0 & 47.1 \\
\hline Wearing apparel, fur, leather and footwear (ISIC 18+19) & 3.2 & 5.5 & 4.8 & 9.7 & 8.5 \\
\hline Wood products (excl. furniture) (ISIC 20) & 0.5 & 0.5 & 0.7 & 0.3 & 0.4 \\
\hline Paper and paper products (ISIC 21) & 1.7 & 1.3 & 1.7 & 1.4 & 1.5 \\
\hline Printing and publishing (ISIC 22) & 1.8 & 1.2 & 1.4 & 0.6 & 0.4 \\
\hline Coke, refined petroleum products, nuclear fuel (ISIC 23) & 0.7 & 0.6 & 0.3 & 0.4 & 0.4 \\
\hline Chemicals and chemical products (ISIC 24) & 8.8 & 7.2 & 8.9 & 7.4 & 7.7 \\
\hline Rubber and plastics products (ISIC 25) & 3.0 & 2.2 & 2.5 & 1.3 & 1.0 \\
\hline Non-metallic mineral products (ISIC 26) & 4.9 & 4.5 & 3.9 & 2.8 & 4.3 \\
\hline Basic metals (ISIC 27) & 8.5 & 7.2 & 6.0 & 3.6 & 2.2 \\
\hline Fabricated metal products (ISIC 27) & 1.7 & 1.9 & 1.1 & 1.5 & 0.9 \\
\hline Machinery, Office and computing machinery (ISIC 29+30) & 3.7 & 4.0 & 3.1 & 2.1 & 2.7 \\
\hline Electrical machinery and Communication equipment (ISIC 31+32) & 3.4 & 3.0 & 3.6 & 2.8 & 1.8 \\
\hline Medical, precision and optical instruments (ISIC 33) & 0.6 & 0.6 & 0.5 & 0.6 & 1.0 \\
\hline Motor vehicles and other transport equipment (ISIC 34+35) & 3.4 & 3.0 & 2.5 & 2.9 & 3.7 \\
\hline Furniture; manufacturing, Recycling (ISIC 36+37) & 1.0 & 2.0 & 1.3 & 2.2 & 1.2 \\
\hline Total & 100 & 100 & 100 & 100 & 100 \\
\hline All Manufacturing (ISIC D) (in 000's) & 506.6 & 622.2 & 561.9 & 689.6 & 931.2 \\
\hline
\end{tabular}

Source: Author's own computation, data made available by UNIDO Industrial Statistics Database INDSTAT2

Table 4.22 lists the sectoral value added shares for all the studied years. Food, Textiles and Chemicals are the three sectors which make up over half of the value added in this sector. Out of these three, Food and Chemicals' share has reduced slightly but Textiles grew from $17.7 \%$ to $24.5 \%$ in 20 years. The sector with the biggest loss is that of Tobacco products which lost over $5 \%$ of its valued added share over the entire period. 
Table 4.22 Sectoral value added shares (\%), 1986 - 2006

\begin{tabular}{|c|c|c|c|c|c|}
\hline & 1986 & 1991 & 1996 & 2001 & 2006 \\
\hline Food and beverages (ISIC 15) & 19.4 & 15.5 & 16.8 & 15.9 & 17.8 \\
\hline Tobacco products (ISIC 16) & 10.2 & 6.4 & 6.2 & 4.9 & 4.6 \\
\hline Textiles (ISIC 17) & 17.7 & 27.5 & 23.5 & 28.3 & 24.5 \\
\hline Wearing apparel, fur, leather and footwear (ISIC 18+19) & 3.1 & 2.9 & 2.7 & 5.0 & 4.3 \\
\hline Wood products (excl. furniture) (ISIC 20) & 0.3 & 0.3 & 0.2 & 0.1 & 0.5 \\
\hline Paper and paper products (ISIC 21) & 1.1 & 1.6 & 1.6 & 1.5 & 2.6 \\
\hline Printing and publishing (ISIC 22) & 1.1 & 2.3 & 2.0 & 0.3 & 0.3 \\
\hline Coke, refined petroleum products, nuclear fuel (ISIC 23) & 7.5 & 3.0 & 3.1 & 4.8 & 5.7 \\
\hline Chemicals and chemical products (ISIC 24) & 16.2 & 15.0 & 16.3 & 16.6 & 14.0 \\
\hline Rubber and plastics products (ISIC 25) & 2.1 & 1.5 & 1.3 & 1.2 & 0.9 \\
\hline Non-metallic mineral products (ISIC 26) & 7.4 & 7.6 & 7.7 & 5.1 & 8.1 \\
\hline Basic metals (ISIC 27) & 4.0 & 5.6 & 4.2 & 4.8 & 4.5 \\
\hline Fabricated metal products (ISIC 27) & 0.9 & 0.9 & 0.7 & 1.5 & 0.8 \\
\hline Machinery, Office and computing machinery (ISIC 29+30) & 2.4 & 2.5 & 1.6 & 1.3 & 1.9 \\
\hline \multicolumn{6}{|l|}{ Electrical machinery and Communication equipment (ISIC } \\
\hline $31+32)$ & 3.4 & 4.1 & 7.7 & 3.6 & 1.9 \\
\hline Medical, precision and optical instruments (ISIC 33) & 0.1 & 0.2 & 0.2 & 0.4 & 0.5 \\
\hline Motor vehicles and other transport equipment (ISIC 34+35) & 2.5 & 2.6 & 3.5 & 3.3 & 6.3 \\
\hline Furniture; manufacturing, Recycling (ISIC 36+37) & 0.4 & 0.7 & 0.9 & 1.4 & 0.6 \\
\hline Total & 100 & 100 & 100 & 100 & 100 \\
\hline All Manufacturing (ISIC D) (in 000000's) & 248774 & 335351 & 387282 & 463049 & 845890 \\
\hline
\end{tabular}

Source: Author's own computation, data made available by UNIDO Industrial Statistics Database INDSTAT2.

Table 4.23 Sector-wise labor growth rates in sub-periods

\begin{tabular}{lccccc}
\hline & $1986-91$ & $1991-96$ & $1996-01$ & $2001-06$ & $1986-06$ \\
\hline Food and beverages (ISIC 15) & 4.5 & -1.5 & -0.4 & 10.9 & 3.2 \\
Tobacco products (ISIC 16) & -9.2 & -0.9 & -5.2 & 0.1 & -3.9 \\
Textiles (ISIC 17) & 5.8 & -1.1 & 7.1 & 5.8 & 4.3 \\
Wearing apparel, fur, leather and footwear (ISIC 18+19) & 16.4 & -4.7 & 19.9 & 3.6 & 8.3 \\
Wood products (excl. furniture) (ISIC 20) & 2.2 & 6.3 & -10.7 & 12.5 & 2.2 \\
Paper and paper products (ISIC 21) & -0.5 & 3.3 & 0.2 & 7.5 & 2.6 \\
Printing and publishing (ISIC 22) & -2.7 & 0.9 & -11.7 & -1.3 & -3.8 \\
Coke, refined petroleum products, nuclear fuel (ISIC 23) & 3.2 & -14.7 & 7.5 & 8.9 & 0.8 \\
Chemicals and chemical products (ISIC 24) & 0.1 & 2.3 & 0.3 & 7.1 & 2.4 \\
Rubber and plastics products (ISIC 25) & -2.7 & 0.7 & -8.0 & 0.3 & -2.5 \\
Non-metallic mineral products (ISIC 26) & 2.8 & -4.9 & -2.4 & 15.7 & 2.5 \\
Basic metals (ISIC 27) & 0.6 & -5.5 & -5.8 & -4.1 & -3.7 \\
Fabricated metal products (ISIC 27) & 6.0 & -11.6 & 10.5 & -3.4 & 0.0
\end{tabular}




\begin{tabular}{lccccc}
\hline & $1986-91$ & $1991-96$ & $1996-01$ & $2001-06$ & $1986-06$ \\
\hline Machinery, Office and computing machinery (ISIC 29+30) & 5.7 & -6.8 & -3.8 & 12.1 & 1.5 \\
Electrical machinery and Communication equipment (ISIC & & & & & -0.2 \\
31+32) & 1.7 & 1.7 & -1.1 & -2.9 & -9.5 \\
Medical, precision and optical instruments (ISIC 33) & 4.4 & -7.1 & 7.1 & 19.2 & 5.5 \\
Motor vehicles and other transport equipment (ISIC 34+35) & 1.4 & -5.8 & 7.6 & 11.5 & 3.5 \\
Furniture; manufacturing, Recycling (ISIC 36+37) & 20.6 & -9.8 & 15.6 & -6.5 & 4.1 \\
All Manufacturing (ISIC D) & 4.2 & -2.0 & 4.2 & 6.2 & 3.1 \\
\hline
\end{tabular}

Source: Author's own computation, data made available by UNIDO Industrial Statistics Database INDSTAT2.

Table 4.24 Sectoral value added growth rates in sub-periods

\begin{tabular}{|c|c|c|c|c|c|}
\hline & $1986-91$ & 1991-96 & 1996-01 & 2001-06 & 1986-06 \\
\hline Food and beverages (ISIC 15) & 1.4 & 4.6 & 2.5 & 15.5 & 5.9 \\
\hline Tobacco products (ISIC 16) & -3.5 & 2.4 & -1.1 & 11.6 & 2.2 \\
\hline Textiles (ISIC 17) & 15.9 & -0.3 & 7.6 & 9.6 & 8.1 \\
\hline Wearing apparel, fur, leather and footwear (ISIC 18+19) & 5.0 & 1.0 & 17.9 & 9.4 & 8.2 \\
\hline Wood products (excl. furniture) (ISIC 20) & 4.8 & 0.4 & -16.7 & 63.0 & 9.3 \\
\hline Paper and paper products (ISIC 21) & 13.4 & 3.4 & 1.5 & 27.1 & 10.9 \\
\hline Printing and publishing (ISIC 22) & 22.0 & 0.5 & -27.0 & 12.0 & 0.0 \\
\hline Coke, refined petroleum products, nuclear fuel (ISIC 23) & -11.8 & 3.5 & 13.6 & 16.5 & 4.8 \\
\hline Chemicals and chemical products (ISIC 24) & 4.6 & 4.5 & 4.1 & 9.1 & 5.6 \\
\hline Rubber and plastics products (ISIC 25) & -1.1 & -0.3 & 2.2 & 7.1 & 1.9 \\
\hline Non-metallic mineral products (ISIC 26) & 6.6 & 3.2 & -4.4 & 23.6 & 6.8 \\
\hline Basic metals (ISIC 27) & 13.3 & -2.8 & 6.5 & 11.4 & 6.9 \\
\hline Fabricated metal products (ISIC 27) & 6.4 & -1.5 & 20.2 & 1.3 & 6.3 \\
\hline Machinery, Office and computing machinery (ISIC 29+30) & 6.9 & -5.9 & -0.9 & 21.5 & 4.9 \\
\hline \multicolumn{6}{|l|}{ Electrical machinery and Communication equipment (ISIC } \\
\hline $31+32)$ & 10.4 & 16.6 & -10.9 & -0.5 & 3.4 \\
\hline Medical, precision and optical instruments (ISIC 33) & 17.2 & 3.9 & 16.6 & 14.1 & 12.8 \\
\hline Motor vehicles and other transport equipment (ISIC 34+35) & 6.8 & 9.3 & 2.2 & 28.6 & 11.3 \\
\hline Furniture; manufacturing, Recycling (ISIC 36+37) & 16.8 & 8.2 & 13.6 & -6.0 & 7.8 \\
\hline All Manufacturing (ISIC D) & 6.2 & 2.9 & 3.6 & 12.8 & 6.3 \\
\hline
\end{tabular}

Source: Author's own computation, data made available by UNIDO Industrial Statistics Database INDSTAT2. Value added is in constant 2005, local currency units.

Table 4.25 shows that the highest productivity growth rate for the whole period was in Basic Metals, followed by Paper, Motor Vehicles, Wood products and Medical equipment.

Figure 4.11 summarizes the results of the sectoral shift and share analysis at aggregate level using the standard model. 
Table 4.25 Sector-wise labor productivity growth rates in sub-periods

\begin{tabular}{|c|c|c|c|c|c|}
\hline & 1986-91 & 1991-96 & 1996-01 & 2001-06 & 1986-06 \\
\hline Food and beverages (ISIC 15) & -3.0 & 6.2 & 2.9 & 4.2 & 2.5 \\
\hline Tobacco products (ISIC 16) & 6.4 & 3.3 & 4.4 & 11.5 & 6.3 \\
\hline Textiles (ISIC 17) & 9.6 & 0.8 & 0.5 & 3.6 & 3.6 \\
\hline Wearing apparel, fur, leather and footwear (ISIC 18+19) & -9.8 & 6.0 & -1.7 & 5.7 & -0.2 \\
\hline Wood products (excl. furniture) (ISIC 20) & 2.6 & -5.6 & -6.6 & 45.0 & 7.0 \\
\hline Paper and paper products (ISIC 21) & 14.0 & 0.1 & 1.3 & 18.3 & 8.1 \\
\hline Printing and publishing (ISIC 22) & 25.4 & -0.4 & -17.4 & 13.4 & 4.0 \\
\hline Coke, refined petroleum products, nuclear fuel (ISIC 23) & -14.6 & 21.4 & 5.6 & 6.9 & 4.0 \\
\hline Chemicals and chemical products (ISIC 24) & 4.5 & 2.2 & 3.8 & 1.8 & 3.1 \\
\hline Rubber and plastics products (ISIC 25) & 1.7 & -1.0 & 11.0 & 6.8 & 4.5 \\
\hline Non-metallic mineral products (ISIC 26) & 3.8 & 8.5 & -2.0 & 6.9 & 4.2 \\
\hline Basic metals (ISIC 27) & 12.6 & 2.9 & 13.1 & 16.2 & 11.1 \\
\hline Fabricated metal products (ISIC 27) & 0.4 & 11.4 & 8.8 & 4.9 & 6.3 \\
\hline \multicolumn{6}{|l|}{ Machinery, Office and computing machinery (ISIC } \\
\hline $29+30)$ & 1.2 & 1.0 & 3.0 & 8.4 & 3.4 \\
\hline $\begin{array}{l}\text { Electrical machinery and Communication equipment } \\
(\text { ISIC } 31+32)\end{array}$ & 8.6 & 14.6 & -9.9 & 2.5 & 3.5 \\
\hline Medical, precision and optical instruments (ISIC 33) & 12.3 & 11.9 & 8.8 & -4.2 & 7.0 \\
\hline \multicolumn{6}{|l|}{ Motor vehicles and other transport equipment (ISIC } \\
\hline $34+35)$ & 5.3 & 16.1 & -5.0 & 15.3 & 7.6 \\
\hline Furniture; manufacturing, Recycling (ISIC 36+37) & -3.2 & 19.9 & -1.7 & 0.6 & 3.5 \\
\hline All Manufacturing (ISIC D) & 1.9 & 5.0 & -0.5 & 6.2 & 3.1 \\
\hline
\end{tabular}

Source: Author's own computation, data made available by UNIDO Industrial Statistics Database INDSTAT2. Value added is in constant 2005, local currency units.

It can be seen from the figure that in terms of productivity the 2001-06 period, which corresponds to Musharraf's era, had the highest productivity for manufacturing. In this period and all others productivity gains can almost exclusively be accounted for by the intrasectoral effect. This is because the Shift and Interaction contributions to productivity have been negative or negligible throughout all periods. The interaction effect is negative in all periods. The shift effect does contribute during the third sub-period where it accounts for over $8 \%$ of productivity growth, but over the whole period its contribution is negative.

Tables $4.26-4.30$ present the sector-wise productivity decompositions for the different periods, the last table presenting the whole period. It is clear that the effect of productivity growth within sectors (intra effect) is the dominant contributor towards productivity growth for all periods except the 1996-01 period where the aggregate intra value is highly negative $(-307 \%)$ and the shift (332\%) and interaction values (75\%) are strongly positive. This however needs to be interpreted with care as this period is characterized by a slight productivity decline (negative annual productivity growth of 
0.5\%). Therefore, a positive decomposition figure contributes to productivity decline whereas a negative figure contributes to productivity growth. In this case it means that the shift effect and the interaction effect are strong and negative, resulting in net productivity declines, while the intra value contributes to growth.

Looking at the complete period, $60 \%$ of the growth can be attributed to three sectors (Textile, Food and Chemicals).

Figure 4-11 Period-wise productivity decomposition using the Standard model $^{81}$

\section{Period-wise productivity decomposition using the Standard model}

$400.0 \%$

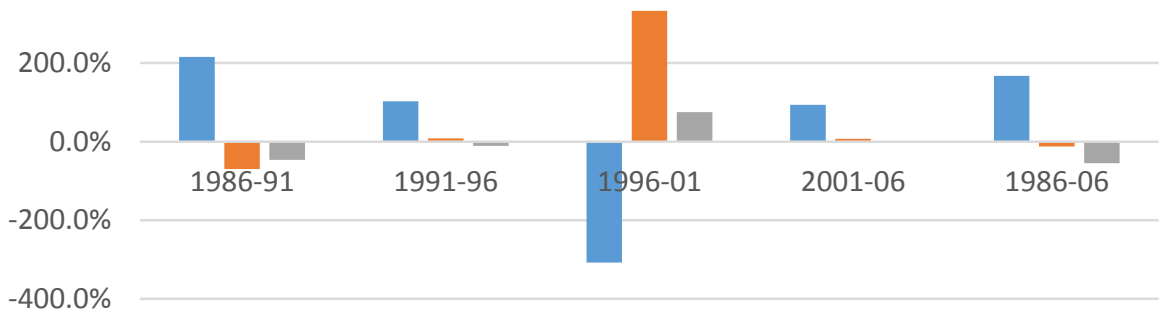

- Intra Shift $\quad$ Interaction

Source: Author's own computation, data made available by UNIDO Industrial Statistics Database INDSTAT2. Value added is in constant 2005, local currency units.

Table 4.26 1986-91 Productivity Decomposition using Standard Shift-share model

\begin{tabular}{lccccc}
\hline & \multicolumn{5}{c}{$1986-91$} \\
\cline { 2 - 6 } & $\begin{array}{c}\text { Annual LP } \\
\text { growth rate }\end{array}$ & $\begin{array}{c}\text { Intra } \\
(\%)\end{array}$ & $\begin{array}{c}\text { Shift } \\
\text { (\%) }\end{array}$ & $\begin{array}{c}\text { Interaction } \\
\text { (\%) }\end{array}$ & $\begin{array}{c}\text { Total } \\
(\%)\end{array}$ \\
\hline Food and beverages (ISIC 15) & -3.0 & $-27.8 \%$ & $3.0 \%$ & $-0.4 \%$ & $-25.2 \%$ \\
Tobacco products (ISIC 16) & 6.4 & $37.9 \%$ & $-52.2 \%$ & $-18.9 \%$ & $-33.2 \%$ \\
Textiles (ISIC 17) & 9.6 & $105.7 \%$ & $14.1 \%$ & $8.2 \%$ & $128.0 \%$ \\
Wearing apparel, fur, leather and footwear (ISIC 18+19) & -9.8 & $-12.7 \%$ & $23.3 \%$ & $-9.4 \%$ & $1.3 \%$ \\
Wood products (excl. furniture) (ISIC 20) & 2.6 & $0.4 \%$ & $-0.3 \%$ & $0.0 \%$ & $0.1 \%$ \\
Paper and paper products (ISIC 21) & 14.0 & $10.7 \%$ & $-2.4 \%$ & $-2.2 \%$ & $6.1 \%$ \\
Printing and publishing (ISIC 22) & 25.4 & $24.4 \%$ & $-3.4 \%$ & $-7.1 \%$ & $13.9 \%$ \\
Coke, refined petroleum products, nuclear fuel (ISIC 23) & -14.6 & $-42.2 \%$ & $-3.5 \%$ & $1.9 \%$ & $-43.7 \%$
\end{tabular}

${ }^{81}$ As productivity growth between 1996 and 2001 is negative, the positive bars represent the contributions to productivity decline, while the - negative - intra effect represents a contribution to productivity growth. 
Chemicals and chemical products (ISIC 24)

Rubber and plastics products (ISIC 25)

Non-metallic mineral products (ISIC 26)

Basic metals (ISIC 27)

Fabricated metal products (ISIC 27)

Machinery, Office and computing machinery (ISIC 29+30)

Electrical machinery and Communication equipment (ISIC

31+32)

Medical, precision and optical instruments (ISIC 33)

Motor vehicles and other transport equipment (ISIC 34+35)

Furniture; manufacturing, Recycling (ISIC 36+37)

All Manufacturing (ISIC D)

$\begin{array}{ccccc}4.5 & 41.2 \% & -30.5 \% & -7.6 \% & 3.1 \% \\ 1.7 & 2.0 \% & -6.4 \% & -0.6 \% & -5.0 \% \\ 3.8 & 15.4 \% & -5.1 \% & -1.0 \% & 9.3 \% \\ 12.6 & 33.3 \% & -6.6 \% & -5.3 \% & 21.5 \% \\ 0.4 & 0.2 \% & 0.8 \% & 0.0 \% & 1.0 \% \\ 1.2 & 1.5 \% & 1.8 \% & 0.1 \% & 3.4 \% \\ & & & & \\ 8.6 & 17.7 \% & -4.0 \% & -2.1 \% & 11.6 \% \\ 12.3 & 1.2 \% & 0.0 \% & 0.0 \% & 1.2 \% \\ 5.3 & 7.6 \% & -3.3 \% & -1.0 \% & 3.3 \% \\ -3.2 & -0.6 \% & 4.7 \% & -0.7 \% & 3.4 \% \\ 1.9 & 215.8 \% & -69.8 \% & -46.0 \% & 100.0 \%\end{array}$

Source: Author's own computation, data made available by UNIDO Industrial Statistics Database INDSTAT2. Value added is in constant 2005 , local currency units.

Table 4.27 1991-96 Productivity Decomposition using Standard Shift-share model

\begin{tabular}{|c|c|c|c|c|c|}
\hline & \multicolumn{5}{|c|}{ 1991-96 } \\
\hline & $\begin{array}{l}\text { Annual LP } \\
\text { growth rate }\end{array}$ & $\begin{array}{l}\text { Intra } \\
(\%)\end{array}$ & $\begin{array}{l}\text { Shift } \\
(\%)\end{array}$ & $\begin{array}{c}\text { Interaction } \\
(\%)\end{array}$ & $\begin{array}{l}\text { Total } \\
(\%)\end{array}$ \\
\hline Food and beverages (ISIC 15) & 6.2 & $19.5 \%$ & $1.5 \%$ & $0.5 \%$ & $21.5 \%$ \\
\hline Tobacco products (ISIC 16) & 3.3 & $4.0 \%$ & $1.3 \%$ & $0.2 \%$ & $5.6 \%$ \\
\hline Textiles (ISIC 17) & 0.8 & $4.1 \%$ & $4.7 \%$ & $0.2 \%$ & $9.0 \%$ \\
\hline Wearing apparel, fur, leather and footwear (ISIC 18+19) & 6.0 & $3.5 \%$ & $-1.4 \%$ & $-0.5 \%$ & $1.7 \%$ \\
\hline Wood products (excl. furniture) (ISIC 20) & -5.6 & $-0.2 \%$ & $0.5 \%$ & $-0.1 \%$ & $0.1 \%$ \\
\hline Paper and paper products (ISIC 21) & 0.1 & $0.0 \%$ & $1.7 \%$ & $0.0 \%$ & $1.7 \%$ \\
\hline Printing and publishing (ISIC 22) & -0.4 & $-0.2 \%$ & $1.3 \%$ & $0.0 \%$ & $1.1 \%$ \\
\hline Coke, refined petroleum products, nuclear fuel (ISIC 23) & 21.4 & $17.5 \%$ & $-5.3 \%$ & $-8.8 \%$ & $3.4 \%$ \\
\hline Chemicals and chemical products (ISIC 24) & 2.2 & $6.2 \%$ & $13.0 \%$ & $1.5 \%$ & $20.7 \%$ \\
\hline Rubber and plastics products (ISIC 25) & -1.0 & $-0.3 \%$ & $0.8 \%$ & $0.0 \%$ & $0.5 \%$ \\
\hline Non-metallic mineral products (ISIC 26) & 8.5 & $13.6 \%$ & $-3.7 \%$ & $-1.9 \%$ & $8.0 \%$ \\
\hline Basic metals (ISIC 27) & 2.9 & $3.0 \%$ & $-3.3 \%$ & $-0.5 \%$ & $-0.8 \%$ \\
\hline Fabricated metal products (ISIC 27) & 11.4 & $2.2 \%$ & $-1.2 \%$ & $-0.9 \%$ & $0.1 \%$ \\
\hline Machinery, Office and computing machinery (ISIC 29+30) & 1.0 & $0.5 \%$ & $-2.0 \%$ & $-0.1 \%$ & $-1.6 \%$ \\
\hline \multicolumn{6}{|l|}{ Electrical machinery and Communication equipment (ISIC } \\
\hline $31+32)$ & 14.6 & $14.4 \%$ & $3.0 \%$ & $3.0 \%$ & $20.4 \%$ \\
\hline Medical, precision and optical instruments (ISIC 33) & 11.9 & $0.6 \%$ & $-0.2 \%$ & $-0.1 \%$ & $0.3 \%$ \\
\hline Motor vehicles and other transport equipment (ISIC 34+35) & 16.1 & $10.3 \%$ & $-1.7 \%$ & $-1.8 \%$ & $6.8 \%$ \\
\hline Furniture; manufacturing, Recycling (ISIC 36+37) & 19.9 & $3.6 \%$ & $-0.8 \%$ & $-1.2 \%$ & $1.6 \%$ \\
\hline All Manufacturing (ISIC D) & 5.0 & $102.5 \%$ & $8.1 \%$ & $-10.6 \%$ & $100.0 \%$ \\
\hline
\end{tabular}

Source: Author's own computation, data made available by UNIDO Industrial Statistics Database INDSTAT2. Value added is in constant 2005 , local currency units. 


\begin{tabular}{|c|c|c|c|c|c|}
\hline & & & $996-01$ & & \\
\hline & $\begin{array}{l}\text { Annual LP } \\
\text { growth rate }\end{array}$ & $\begin{array}{l}\text { Intra } \\
(\%)\end{array}$ & $\begin{array}{l}\text { Shift } \\
(\%)\end{array}$ & $\begin{array}{l}\text { Interaction } \\
\qquad \%)\end{array}$ & $\begin{array}{c}\text { Total } \\
(\%)\end{array}$ \\
\hline Food and beverages (ISIC 15) & 2.9 & $-100.5 \%$ & $131.5 \%$ & $20.4 \%$ & $51.4 \%$ \\
\hline Tobacco products (ISIC 16) & 4.4 & $-57.2 \%$ & $89.9 \%$ & $21.6 \%$ & $54.3 \%$ \\
\hline Textiles (ISIC 17) & 0.5 & $-21.5 \%$ & $-132.7 \%$ & $-3.1 \%-$ & $-157.4 \%$ \\
\hline Wearing apparel, fur, leather and footwear (ISIC 18+19) & -1.7 & $8.3 \%$ & $-104.3 \%$ & $8.4 \%$ & $-87.6 \%$ \\
\hline Wood products (excl. furniture) (ISIC 20) & -6.6 & $2.6 \%$ & $4.9 \%$ & $-1.4 \%$ & $6.1 \%$ \\
\hline Paper and paper products (ISIC 21) & 1.3 & $-4.2 \%$ & $11.1 \%$ & $0.8 \%$ & $7.6 \%$ \\
\hline Printing and publishing (ISIC 22) & -17.4 & $47.7 \%$ & $43.6 \%$ & $-26.8 \%$ & $64.5 \%$ \\
\hline Coke, refined petroleum products, nuclear fuel (ISIC 23) & 5.6 & $-37.1 \%$ & $-20.4 \%$ & $-6.4 \%$ & $-63.9 \%$ \\
\hline Chemicals and chemical products (ISIC 24) & 3.8 & $-128.3 \%$ & $108.7 \%$ & $22.2 \%$ & $2.6 \%$ \\
\hline Rubber and plastics products (ISIC 25) & 11.0 & $-34.1 \%$ & $23.0 \%$ & $15.8 \%$ & $4.6 \%$ \\
\hline Non-metallic mineral products (ISIC 26) & -2.0 & $28.8 \%$ & $82.4 \%$ & $-8.0 \%$ & $103.3 \%$ \\
\hline Basic metals (ISIC 27) & 13.1 & $-136.7 \%$ & $64.0 \%$ & $54.2 \%$ & $-18.6 \%$ \\
\hline Fabricated metal products (ISIC 27) & 8.8 & $-14.0 \%$ & $-9.1 \%$ & $-4.8 \%$ & $-27.9 \%$ \\
\hline Machinery, Office and computing machinery (ISIC 29+30) & 3.0 & $-9.9 \%$ & $20.5 \%$ & $3.2 \%$ & $13.9 \%$ \\
\hline $\begin{array}{l}\text { Electrical machinery and Communication equipment (ISIC } \\
31+32)\end{array}$ & -9.9 & $120.6 \%$ & $67.6 \%$ & $-27.5 \%$ & $160.7 \%$ \\
\hline Medical, precision and optical instruments (ISIC 33) & 8.8 & $-5.0 \%$ & $-1.4 \%$ & $-0.7 \%$ & $-7.2 \%$ \\
\hline $\begin{array}{l}\text { Motor vehicles and other transport equipment (ISIC } \\
34+35)\end{array}$ & -5.0 & $30.5 \%$ & $-23.7 \%$ & $5.3 \%$ & $12.1 \%$ \\
\hline Furniture; manufacturing, Recycling (ISIC 36+37) & -1.7 & $2.8 \%$ & $-23.2 \%$ & $1.9 \%$ & $-18.5 \%$ \\
\hline All Manufacturing (ISIC D) & -0.5 & $-307.4 \%$ & $332.5 \%$ & $74.9 \%$ & $100.0 \%$ \\
\hline
\end{tabular}

Source: Author's own computation, data made available by UNIDO Industrial Statistics Database INDSTAT2. Value added is in constant 2005, local currency units. As aggregate productivity growth is negative, positive figures represent contributions to productivity decline, while the negative figures represent contributions to productivity growth.

Table 4.29 2001-06 Productivity Decomposition using Standard Shift-share model

\begin{tabular}{|c|c|c|c|c|c|}
\hline & \multicolumn{5}{|c|}{ 2001-06 } \\
\hline & $\begin{array}{l}\text { Annual LP } \\
\text { growth rate }\end{array}$ & $\begin{array}{c}\text { Intra } \\
(\%)\end{array}$ & $\begin{array}{l}\text { Shift } \\
(\%)\end{array}$ & $\begin{array}{c}\text { Interaction } \\
(\%)\end{array}$ & $\begin{array}{c}\text { Total } \\
(\%)\end{array}$ \\
\hline Food and beverages (ISIC 15) & 4.2 & $10.2 \%$ & $10.8 \%$ & $2.4 \%$ & $23.4 \%$ \\
\hline Tobacco products (ISIC 16) & 11.5 & $10.0 \%$ & $-3.5 \%$ & $-2.6 \%$ & $3.9 \%$ \\
\hline Textiles (ISIC 17) & 3.6 & $15.6 \%$ & $-1.5 \%$ & $-0.3 \%$ & $13.9 \%$ \\
\hline Wearing apparel, fur, leather and footwear (ISIC 18+19) & 5.7 & $4.5 \%$ & $-1.7 \%$ & $-0.5 \%$ & $2.3 \%$ \\
\hline Wood products (excl. furniture) (ISIC 20) & 45.0 & $1.2 \%$ & $0.1 \%$ & $0.4 \%$ & $1.7 \%$ \\
\hline Paper and paper products (ISIC 21) & 18.3 & $5.4 \%$ & $0.2 \%$ & $0.3 \%$ & $6.0 \%$ \\
\hline Printing and publishing (ISIC 22) & 13.4 & $0.9 \%$ & $-0.3 \%$ & $-0.3 \%$ & $0.3 \%$ \\
\hline Coke, refined petroleum products, nuclear fuel (ISIC 23) & 6.9 & $5.4 \%$ & $1.9 \%$ & $0.7 \%$ & $8.1 \%$ \\
\hline
\end{tabular}




\begin{tabular}{|c|c|c|c|c|c|}
\hline & \multicolumn{5}{|c|}{$2001-06$} \\
\hline & $\begin{array}{l}\text { Annual LP } \\
\text { growth rate }\end{array}$ & $\begin{array}{l}\text { Intra } \\
(\%)\end{array}$ & $\begin{array}{l}\text { Shift } \\
(\%)\end{array}$ & $\begin{array}{c}\text { Interaction } \\
(\%)\end{array}$ & $\begin{array}{c}\text { Total } \\
\text { (\%) }\end{array}$ \\
\hline Chemicals and chemical products (ISIC 24) & 1.8 & $4.5 \%$ & $2.0 \%$ & $0.2 \%$ & $6.7 \%$ \\
\hline Rubber and plastics products (ISIC 25) & 6.8 & $1.3 \%$ & $-0.8 \%$ & $-0.3 \%$ & $0.2 \%$ \\
\hline Non-metallic mineral products (ISIC 26) & 6.9 & $5.7 \%$ & $7.7 \%$ & $3.1 \%$ & $16.5 \%$ \\
\hline Basic metals (ISIC 27) & 16.2 & $15.1 \%$ & $-5.4 \%$ & $-6.0 \%$ & $3.7 \%$ \\
\hline Fabricated metal products (ISIC 27) & 4.9 & $1.1 \%$ & $-1.6 \%$ & $-0.4 \%$ & $-0.9 \%$ \\
\hline Machinery, Office and computing machinery (ISIC 29+30) & 8.4 & $1.8 \%$ & $1.1 \%$ & $0.6 \%$ & $3.5 \%$ \\
\hline \multicolumn{6}{|l|}{ Electrical machinery and Communication equipment (ISIC } \\
\hline $31+32)$ & 2.5 & $1.3 \%$ & $-3.7 \%$ & $-0.5 \%$ & $-2.8 \%$ \\
\hline Medical, precision and optical instruments (ISIC 33) & -4.2 & $-0.2 \%$ & $1.0 \%$ & $-0.2 \%$ & $0.5 \%$ \\
\hline Motor vehicles and other transport equipment (ISIC 34+35) & 15.3 & $9.7 \%$ & $2.5 \%$ & $2.7 \%$ & $14.9 \%$ \\
\hline Furniture; manufacturing, Recycling (ISIC 36+37) & 0.6 & $0.1 \%$ & $-1.9 \%$ & $-0.1 \%$ & $-1.8 \%$ \\
\hline All Manufacturing (ISIC D) & 6.2 & $93.7 \%$ & $7.1 \%$ & $-0.8 \% \quad 1$ & $100.0 \%$ \\
\hline
\end{tabular}

Source: Author's own computation, data made available by UNIDO Industrial Statistics Database INDSTAT2. Value added is in constant 2005, local currency units.

Table 4.30 1986-06 Productivity Decomposition using Standard Shift-share model

\begin{tabular}{|c|c|c|c|c|c|}
\hline & \multicolumn{5}{|c|}{ 1986-06 } \\
\hline & $\begin{array}{l}\text { Annual LP } \\
\text { growth rate }\end{array}$ & $\begin{array}{c}\text { Intra } \\
(\%)\end{array}$ & $\begin{array}{l}\text { Shift } \\
(\%)\end{array}$ & $\begin{array}{c}\text { Interaction } \\
(\%)\end{array}$ & $\begin{array}{c}\text { Total } \\
(\%)\end{array}$ \\
\hline Food and beverages (ISIC 15) & 2.5 & $14.8 \%$ & $0.7 \%$ & $0.5 \%$ & $16.0 \%$ \\
\hline Tobacco products (ISIC 16) & 6.3 & $29.1 \%$ & $-9.1 \%$ & $-21.9 \%$ & $-1.9 \%$ \\
\hline Textiles (ISIC 17) & 3.6 & $21.1 \%$ & $5.7 \%$ & $5.7 \%$ & $32.5 \%$ \\
\hline Wearing apparel, fur, leather and footwear (ISIC 18+19) & -0.2 & $-0.1 \%$ & $6.1 \%$ & $-0.2 \%$ & $5.8 \%$ \\
\hline Wood products (excl. furniture) (ISIC 20) & 7.0 & $1.0 \%$ & $-0.1 \%$ & $-0.2 \%$ & $0.8 \%$ \\
\hline Paper and paper products (ISIC 21) & 8.1 & $5.0 \%$ & $-0.1 \%$ & $-0.5 \%$ & $4.4 \%$ \\
\hline Printing and publishing (ISIC 22) & 4.0 & $1.6 \%$ & $-1.0 \%$ & $-1.2 \%$ & $-0.6 \%$ \\
\hline Coke, refined petroleum products, nuclear fuel (ISIC 23) & 4.0 & $10.6 \%$ & $-3.2 \%$ & $-3.9 \%$ & $3.5 \%$ \\
\hline Chemicals and chemical products (ISIC 24) & 3.1 & $15.9 \%$ & $-2.4 \%$ & $-2.0 \%$ & $11.5 \%$ \\
\hline Rubber and plastics products (ISIC 25) & 4.5 & $3.6 \%$ & $-1.7 \%$ & $-2.4 \%$ & $-0.5 \%$ \\
\hline Non-metallic mineral products (ISIC 26) & 4.2 & $11.1 \%$ & $-1.0 \%$ & $-1.2 \%$ & $8.9 \%$ \\
\hline Basic metals (ISIC 27) & 11.1 & $33.7 \%$ & $-3.5 \%$ & $-25.1 \%$ & $5.1 \%$ \\
\hline Fabricated metal products (ISIC 27) & 6.3 & $2.4 \%$ & $-0.5 \%$ & $-1.1 \%$ & $0.8 \%$ \\
\hline Machinery, Office and computing machinery (ISIC 29+30) & 3.4 & $2.7 \%$ & $-0.8 \%$ & $-0.7 \%$ & $1.2 \%$ \\
\hline \multicolumn{6}{|l|}{ Electrical machinery and Communication equipment (ISIC } \\
\hline $31+32)$ & 3.5 & $4.0 \%$ & $-1.9 \%$ & $-1.9 \%$ & $0.2 \%$ \\
\hline Medical, precision and optical instruments (ISIC 33) & 7.0 & $0.5 \%$ & $0.1 \%$ & $0.3 \%$ & $0.9 \%$ \\
\hline Motor vehicles and other transport equipment (ISIC 34+35) & 7.6 & $9.8 \%$ & $0.2 \%$ & $0.7 \%$ & $10.7 \%$ \\
\hline Furniture; manufacturing, Recycling (ISIC 36+37) & 3.5 & $0.5 \%$ & $0.1 \%$ & $0.1 \%$ & $0.7 \%$ \\
\hline
\end{tabular}




\begin{tabular}{llllll}
\hline & \multicolumn{4}{c}{$1986-06$} \\
\cline { 2 - 6 } & Annual LP & Intra & Shift & Interaction Total \\
& growth rate & $(\%)$ & $(\%)$ & $(\%)$ & $(\%)$ \\
\hline
\end{tabular}

All Manufacturing (ISIC D)

$3.1 \quad 167.2 \%-12.2 \% \quad-55.0 \% \quad 100.0 \%$

Source: Author's own computation, data made available by UNIDO Industrial Statistics Database INDSTAT2. Value added is in constant 2005, local currency units.

In the following tables $(4.31-4.35)$ we repeat the analysis, using the van Ark and Timmer decomposition methods. The main difference here is that the inter-sectoral shift values for the period 1996-01 are even more pronounced than those calculated using the standard model.

In sum, the shift and share analysis of the manufacturing sector leads us to the conclusion that within this sector there has been growth reducing structural change. Though an average productivity growth of 3.1 percent from 1986 to 2005 is a reasonable rate of productivity increase, productive growth would have been much higher in the absence of negative shift and interaction effects.

Figure 4-12 Period-wise productivity decomposition using Ark and Timmer model ${ }^{82}$

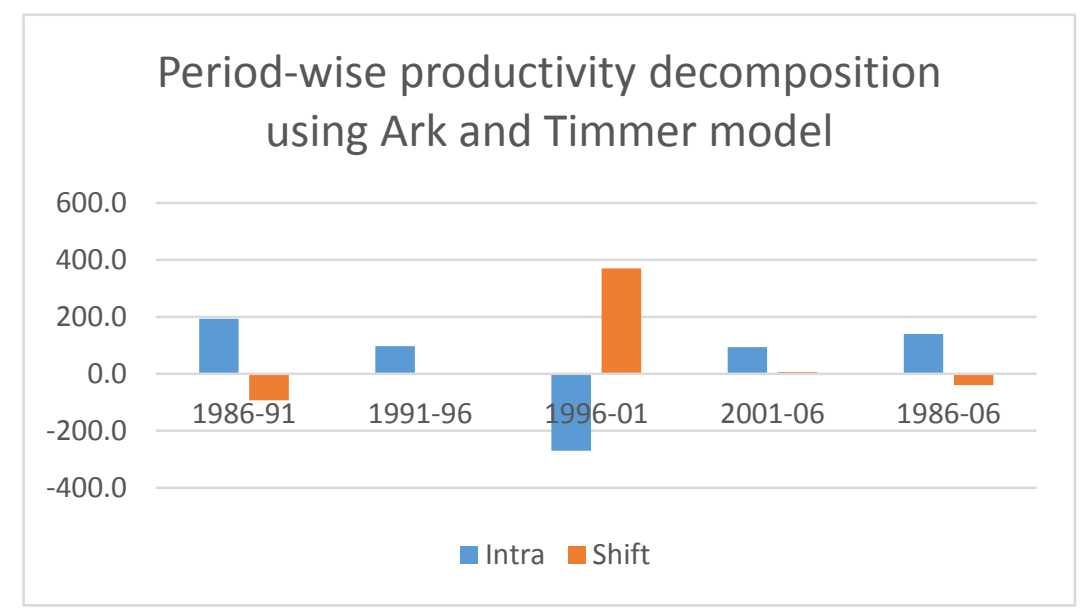

Source: Author's own computation, data made available by UNIDO Industrial Statistics Database INDSTAT2. Value added is in constant 2005, local currency units.

\footnotetext{
${ }^{82}$ As productivity growth between 1996 and 2001 is negative, the shift effect represents the contribution to productivity decline, while the - negative - intra effect represents a contribution to productivity growth.
} 


\begin{tabular}{|c|c|c|c|c|}
\hline & & 198 & & \\
\hline & $\begin{array}{l}\text { Annual LP } \\
\text { growth rate }\end{array}$ & Intra \% & Shift \% & Total \% \\
\hline Food and beverages (ISIC 15) & -3.0 & -28.0 & -1.5 & -29.5 \\
\hline Tobacco products (ISIC 16) & 6.4 & 28.5 & 0.0 & 28.5 \\
\hline Textiles (ISIC 17) & 9.6 & 109.8 & -40.0 & 69.8 \\
\hline Wearing apparel, fur, leather and footwear (ISIC 18+19) & -9.8 & -17.4 & -28.7 & -46.0 \\
\hline Wood products (excl. furniture) (ISIC 20) & 2.6 & 0.4 & 0.0 & 0.4 \\
\hline Paper and paper products (ISIC 21) & 14.0 & 9.6 & 0.0 & 9.6 \\
\hline Printing and publishing (ISIC 22) & 25.4 & 20.8 & 0.0 & 20.8 \\
\hline Coke, refined petroleum products, nuclear fuel (ISIC 23) & -14.6 & -41.2 & 0.0 & -41.2 \\
\hline Chemicals and chemical products (ISIC 24) & 4.5 & 37.4 & 0.0 & 37.4 \\
\hline Rubber and plastics products (ISIC 25) & 1.7 & 1.7 & 0.0 & 1.7 \\
\hline Non-metallic mineral products (ISIC 26) & 3.8 & 14.9 & 0.0 & 14.9 \\
\hline Basic metals (ISIC 27) & 12.6 & 30.7 & 0.0 & 30.7 \\
\hline Fabricated metal products (ISIC 27) & 0.4 & 0.2 & -2.3 & -2.2 \\
\hline Machinery, Office and computing machinery (ISIC 29+30) & 1.2 & 1.6 & -3.5 & -2.0 \\
\hline Electrical machinery and Communication equipment (ISIC & & & & \\
\hline $31+32)$ & 8.6 & 16.7 & 0.0 & 16.7 \\
\hline Medical, precision and optical instruments (ISIC 33) & 12.3 & 1.2 & -0.1 & 1.1 \\
\hline Motor vehicles and other transport equipment (ISIC 34+35) & 5.3 & 7.1 & 0.0 & 7.1 \\
\hline Furniture; manufacturing, Recycling (ISIC 36+37) & -3.2 & -1.0 & -16.7 & -17.7 \\
\hline All Manufacturing (ISIC D) & 1.9 & 192.8 & -92.8 & 100.0 \\
\hline
\end{tabular}

Source: Author's own computation, data made available by UNIDO Industrial Statistics Database INDSTAT2. Value added is in constant 2005, local currency units.

Table 4.32 1991-96 Productivity Decomposition using Ark and Timmer model

\begin{tabular}{lcccc}
\hline & \multicolumn{3}{c}{$1991-96$} \\
\cline { 2 - 4 } & $\begin{array}{c}\text { Annual LP } \\
\text { growth rate }\end{array}$ & Intra \% & Shift \% & Total \% \\
\hline Food and beverages (ISIC 15) & 6.2 & 19.8 & -0.1 & 19.7 \\
Tobacco products (ISIC 16) & 3.3 & 4.2 & 1.2 & 5.3 \\
Textiles (ISIC 17) & 0.8 & 4.2 & -4.2 & 0.0 \\
Wearing apparel, fur, leather and footwear (ISIC 18+19) & 6.0 & 3.3 & 0.0 & 3.3 \\
Wood products (excl. furniture) (ISIC 20) & -5.6 & -0.3 & -0.7 & -1.0 \\
Paper and paper products (ISIC 21) & 0.1 & 0.0 & -0.2 & -0.2 \\
Printing and publishing (ISIC 22) & -0.4 & -0.2 & 0.3 & 0.2 \\
Coke, refined petroleum products, nuclear fuel (ISIC 23) & 21.4 & 13.1 & 0.0 & 13.1 \\
Chemicals and chemical products (ISIC 24) & 2.2 & 6.9 & 5.6 & 12.5 \\
Rubber and plastics products (ISIC 25) & -1.0 & -0.3 & -0.7 & -1.0
\end{tabular}




\begin{tabular}{lcccc}
\hline & \multicolumn{3}{c}{$1991-96$} \\
\cline { 2 - 4 } & $\begin{array}{c}\text { Annual LP } \\
\text { growth rate }\end{array}$ & Intra \% & Shift \% & Total \% \\
\hline Non-metallic mineral products (ISIC 26) & 8.5 & 12.7 & 0.0 & 12.7 \\
Basic metals (ISIC 27) & 2.9 & 2.8 & 0.0 & 2.8 \\
Fabricated metal products (ISIC 27) & 11.4 & 1.8 & 0.0 & 1.8 \\
Machinery, Office and computing machinery (ISIC 29+30) & 1.0 & 0.4 & 0.0 & 0.4 \\
Electrical machinery and Communication equipment (ISIC 31+32) & 14.6 & 15.9 & 1.6 & 17.5 \\
Medical, precision and optical instruments (ISIC 33) & 11.9 & 0.6 & 0.0 & 0.6 \\
Motor vehicles and other transport equipment (ISIC 34+35) & 16.1 & 9.4 & 0.0 & 9.4 \\
Furniture; manufacturing, Recycling (ISIC 36+37) & 19.9 & 3.0 & 0.0 & 3.0 \\
All Manufacturing (ISIC D) & 5.0 & 97.2 & 2.8 & 100.0 \\
\hline
\end{tabular}

Source: Author's own computation, data made available by UNIDO Industrial Statistics Database INDSTAT2. Value added is in constant 2005, local currency units.

Table 4.33 1996-01 Productivity Decomposition using Ark and Timmer model

\begin{tabular}{|c|c|c|c|c|}
\hline & \multicolumn{4}{|c|}{ 1996-01 } \\
\hline & $\begin{array}{l}\text { Annual LP } \\
\text { growth rate }\end{array}$ & Intra \% & Shift \% & Total \% \\
\hline Food and beverages (ISIC 15) & 2.9 & -90.3 & 0.0 & -90.3 \\
\hline Tobacco products (ISIC 16) & 4.4 & -46.5 & 0.0 & -46.5 \\
\hline Textiles (ISIC 17) & 0.5 & -23.1 & 191.8 & 168.7 \\
\hline Wearing apparel, fur, leather and footwear (ISIC 18+19) & -1.7 & 12.5 & 159.6 & 172.0 \\
\hline Wood products (excl. furniture) (ISIC 20) & -6.6 & 1.9 & 0.0 & 1.9 \\
\hline Paper and paper products (ISIC 21) & 1.3 & -3.8 & 0.0 & -3.8 \\
\hline Printing and publishing (ISIC 22) & -17.4 & 34.3 & 0.0 & 34.3 \\
\hline Coke, refined petroleum products, nuclear fuel (ISIC 23) & 5.6 & -40.3 & -20.6 & -61.0 \\
\hline Chemicals and chemical products (ISIC 24) & 3.8 & -117.2 & 0.0 & -117.2 \\
\hline Rubber and plastics products (ISIC 25) & 11.0 & -26.2 & 0.0 & -26.2 \\
\hline Non-metallic mineral products (ISIC 26) & -2.0 & 24.8 & 0.0 & 24.8 \\
\hline Basic metals (ISIC 27) & 13.1 & -109.7 & 0.0 & -109.7 \\
\hline Fabricated metal products (ISIC 27) & 8.8 & -16.4 & 9.0 & -7.4 \\
\hline Machinery, Office and computing machinery (ISIC 29+30) & 3.0 & -8.2 & 0.0 & -8.2 \\
\hline Electrical machinery and Communication equipment (ISIC 31+32) & -9.9 & 106.8 & 0.0 & 106.8 \\
\hline Medical, precision and optical instruments (ISIC 33) & 8.8 & -5.4 & 2.1 & -3.3 \\
\hline Motor vehicles and other transport equipment (ISIC 34+35) & -5.0 & 33.1 & 1.9 & 35.1 \\
\hline Furniture; manufacturing, Recycling (ISIC 36+37) & -1.7 & 3.8 & 26.2 & 29.9 \\
\hline All Manufacturing (ISIC D) & -0.5 & -269.9 & 369.9 & 100.0 \\
\hline
\end{tabular}

Source: Author's own computation, data made available by UNIDO Industrial Statistics Database INDSTAT2. Value added is in constant 2005, local currency units. 


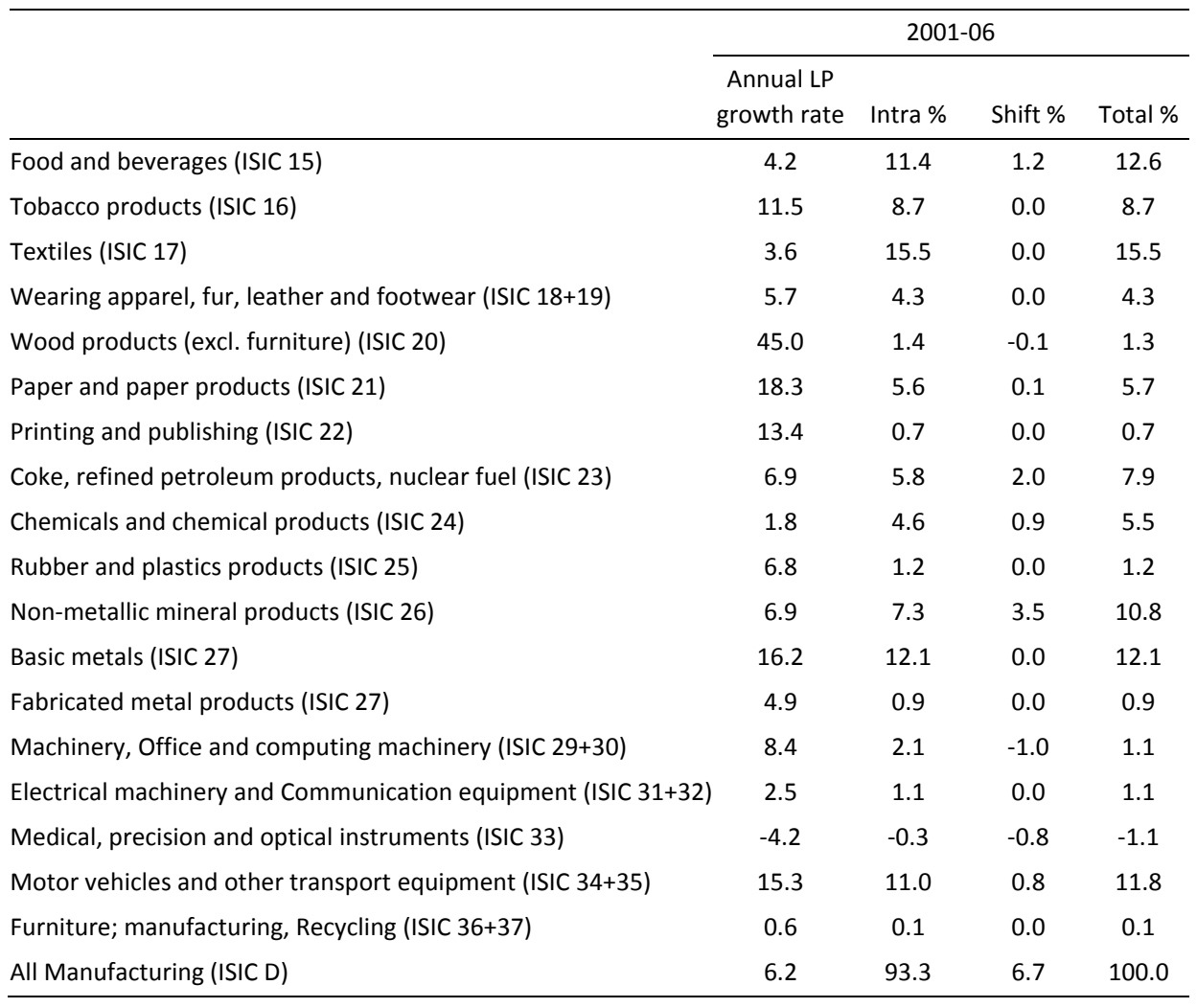

Source: Author's own computation, data made available by UNIDO Industrial Statistics Database INDSTAT2. Value added is in constant 2005, local currency units.

Table 4.35 1986-06 Productivity Decomposition using Ark and Timmer model

\begin{tabular}{lcccc}
\hline & \multicolumn{3}{c}{$1986-06$} \\
\cline { 2 - 4 } & $\begin{array}{c}\text { Annual LP } \\
\text { growth rate }\end{array}$ & Intra \% & Shift \% & Total \% \\
\hline Food and beverages (ISIC 15) & 2.5 & 15.0 & -0.5 & 14.5 \\
Tobacco products (ISIC 16) & 6.3 & 18.1 & 0.0 & 18.1 \\
Textiles (ISIC 17) & 3.6 & 24.0 & -25.3 & -1.3 \\
Wearing apparel, fur, leather and footwear (ISIC 18+19) & -0.2 & -0.2 & -12.0 & -12.2 \\
Wood products (excl. furniture) (ISIC 20) & 7.0 & 0.9 & 0.0 & 0.9 \\
Paper and paper products (ISIC 21) & 8.1 & 4.8 & 0.0 & 4.8 \\
Printing and publishing (ISIC 22) & 4.0 & 1.0 & 0.0 & 1.0 \\
Coke, refined petroleum products, nuclear fuel (ISIC 23) & 4.0 & 8.7 & 0.0 & 8.7 \\
Chemicals and chemical products (ISIC 24) & 3.1 & 14.9 & 0.0 & 14.9 \\
Rubber and plastics products (ISIC 25) & 4.5 & 2.4 & 0.0 & 2.4 \\
Non-metallic mineral products (ISIC 26) & 4.2 & 10.5 & 0.0 & 10.5
\end{tabular}




\begin{tabular}{lcccc}
\hline & \multicolumn{3}{c}{$1986-06$} \\
\cline { 2 - 5 } & $\begin{array}{c}\text { Annual LP } \\
\text { growth rate }\end{array}$ & Intra \% & Shift \% & Total \% \\
\hline Basic metals (ISIC 27) & 11.1 & 21.1 & 0.0 & 21.1 \\
Fabricated metal products (ISIC 27) & 6.3 & 1.8 & 0.0 & 1.8 \\
Machinery, Office and computing machinery (ISIC 29+30) & 3.4 & 2.3 & 0.0 & 2.3 \\
Electrical machinery and Communication equipment (ISIC 31+32) & 3.5 & 3.1 & 0.0 & 3.1 \\
Medical, precision and optical instruments (ISIC 33) & 7.0 & 0.6 & -1.0 & -0.4 \\
Motor vehicles and other transport equipment (ISIC 34+35) & 7.6 & 10.2 & -0.3 & 9.9 \\
Furniture; manufacturing, Recycling (ISIC 36+37) & 3.5 & 0.6 & -0.6 & 0.0 \\
All Manufacturing (ISIC D) & 3.1 & 139.7 & -39.7 & 100.0 \\
\hline
\end{tabular}

Source: Author's own computation, data made available by UNIDO Industrial Statistics Database INDSTAT2. Value added is in constant 2005 , local currency units.

\subsection{Conclusions}

In this chapter we started with an overview of the industrial and services sector of the economy. We introduced the shift-share technique to explore the sectoral dimension of change and for that we looked separately at both the complete economy and manufacturing sector in particular. Data limitations however precluded us from taking the same time-periods for both the analysis.

Our main goal here was to assess the impact of structural changes within the economy on productivity. For the whole economy we find that structural changes do contribute positively to productivity, but that these contributions are mostly very small. It is clear that the effect of productivity growth within sectors (intra effect) is the dominant contributor towards productivity growth for all periods. The shift effect also contributes positively to productivity growth, in almost all studied periods however the contributions are modest except for the Political Musical Chairs era (1988-99) where it contributes $33 \%$. This period is however has the slowest annual productivity growth rate of $2 \%$ which lessens the importance of this contribution. This slowing down of productivity growth is in-line with the discussion in chapter 3 about this era which was marked by political infighting, instability and corruption. The interaction effect of productivity growth and labor shifts had negative or negligible contributions in all the periods except for the whole period where it accounts for $7.9 \%$ of productivity growth. Productivity growth peaked during Zia's military regime. This too is in-line with our discussion on military regimes generally outperforming civilian governments due to less corruption and more stability of tenures.

As for the sectors within the complete economy, in the first period (1973-78), shows negative productivity growth for the manufacturing sector. This can be explained by the nationalization drive of industries during this period. During Zia's period 
(1977-88) the construction sector's productivity fell slightly. During the Political Musical chairs period (1988-99) the wholesale sector of the economy lost in terms of productivity and during the Musharraf period (1999-07) the mining sector's productivity declined.

By and large, inter-sectoral productivity gaps are indicative of underdevelopment. These gaps are biggest for the poorest countries and tend to diminish as a result of sustained economic growth.

The contributions of inter-sectoral shifts for manufacturing are either negligible or even negative except for the period 1996-01 where the aggregate intra value is highly negative (-307\%) and the shift (332\%) and interaction values (75\%) are strongly positive. Due to the negative productivity growth of this period the shift effect and the interaction effect are interpreted as strong and negative, resulting in net productivity declines, and the intra value is interpreted as contributing towards growth, but not enough in order to cancel out the negative shift and interaction effect overall. For the manufacturing it can be safely concluded that within this sector there has been growth reducing structural change, except for the 1996-01 period. Though an average productivity growth of 3.1 percent from 1986 to 2005 is reasonable, productivity growth would have been much higher in the absence of negative shift and interaction effects.

Though the shift-share method can explain structural change reasonably well it is unable to capture the impact of inter-sectoral technology spillovers. One such case is that of the importance of the ICT sector for developing economies, which may actually be more than what is calculated using shift-share methods because of the potential for significant externalities (Fagerberg, 2000; Peneder, 2003). To summarize, the shiftshare method provides valuable insights in the sectoral contributions to growth. Though the importance of structural change is highlighted from these estimates, they should however be seen as lower-bound figures. For this reason and to capture the spillover effects, in our next chapter we attempt to analyze the ICT sector directly by conducting our own firm-level survey, measuring growth and identifying spillover channels and mechanisms. 



\section{Chapter 5. Pakistan's ICT Landscape}

\subsection{Introduction}

This chapter provides an overview of the ICT sector of Pakistan. It serves as a backdrop of our survey in this sector. It also presents a historical perspective highlighting some important events that led to the evolution (and later decline) of this sector. However the scarcity of official data makes it difficult to present a chronologically coherent assessment based on standard economic indicators.

\subsection{Defining ICTs}

The definition of ICT has evolved over the years. ICT is an acronym and stands for Information and Communications Technology. There have been multiple attempts by researchers to define this term. Broadly, it refers to developing and using technology to process information and aid communications. The combination of both terms i.e., "information and communication" - the building block of the now ubiquitous umbrella term ICT - took place in the 1980 s to emphasize the merging of both technologies. As the field of ICT has been ever evolving and so has its definition, which today encompasses more and more technologies. To mention a few, radio, television, Internet, cellular phones, computers, network hardware and software and satellite systems, and all the services and applications associated with them such as videoconferencing, elearning, e-government, e-health and cloud computing etc.

The Free Online Dictionary Of Computing (FOLDOC) notes that "ICT is often used as an extended synonym for information technology (IT), but is a more specific term that stresses the role of unified communications and the integration of telecommunications (telephone lines and wireless signals), computers as well as necessary enterprise software, middleware, storage, and audio-visual systems, which enable users to access, store, transmit, and manipulate information." ${ }^{\prime 3}$

The acronym ICT has been in use by academic researchers since long but its usage became widespread after it appeared in a report to the UK government by Dennis Stevenson in 1997 and in the revised National Curriculum for England, Wales and Northern Ireland in 2000 (Commission, 1997). The term "ICT" has been replaced by the

\footnotetext{
${ }^{83}$ This definition is available at various instances online and hence the exact source is unclear. We have retrieved it from http://foldoc.org/Information+and+Communication+Technology on $21^{\text {st }}$ March 2014.
} 
broader term "computing" in the UK National Curriculum since September 2013. (Government, 2013).

The term ICT is now also used to refer to the convergence computer networks with audio-visual, building management, surveillance and telephone networks through a single mechanism of cabling, signal distribution and management. This way, the elimination of the telephone network would lead to tremendous economic benefits such as reduced operational and infrastructural costs.

OECD member countries reached an agreement in 1998 in defining the ICT sector as "a combination of manufacturing and services industries that capture, transmit and display data and information electronically. This definition, based on an international standard classification of activities (ISIC Rev. 3), was considered to be a first step towards obtaining some initial measurements of ICT sector core indicators.

The principles underlying the definition are the following:

For manufacturing industries, the products:

- Must be intended to fulfill the function of information processing and communication including transmission and display.

- Must use electronic processing to detect, measure and/or record physical phenomena or control a physical process.

For services industries, the products:

- Must be intended to enable the function of information processing and communication by electronic means." (OECD, 2002)

\subsection{Data Sources}

Research on Pakistan's ICT industry, especially in international comparative perspective, is limited because there are no officially established periodic surveys to gather industry statistics of this particular sector. The main sources of information for the ICT industry are industry studies usually undertaken by industry associations and market research companies or in some cases by the regulatory authorities. The major sources of data are Pakistan Software Export Bureau (PSEB), Pakistan Software Houses Association (PASHA) and PTA. It is noteworthy that all three of these organizations were established in the 1990's (PASHA 1992, PSEB 1995 and PTA 1997), and were fully functional and active in the role of data gatherer only after the turn of the century. This chapter draws on the data gathered from a number of reports and surveys by these organizations and a market research company (Gartner) to discuss the salient features of Pakistan's ICT sector. Details of these reports and surveys are provided in Appendix V. 


\subsection{Emergence of Pakistan's ICT sector}

Pakistan's ICT sector had humble beginnings. In 1947, the year when Pakistan was born as a sovereign nation state, the telecom base in the country comprised just 7000 landlines. These were mainly meant to service the needs of the government sector and came under the Posts \& Telegraph Department. The process of computerization in Pakistan started in 1957, when a private company, 'Packages Ltd.' started using computers. It is considered the first company in Pakistan, which started using computers (Shaukat, 2009).

The year 1962 marks the beginnings of ICT in Pakistan when the Pakistan Telephone \& Telegraph Department was created in order to separate telecom services from postal services. Later, this department evolved into the state-owned Pakistan Telecommunication Corporation (PTC) under the Pakistan Telecommunications Corporation Act of 1991. Like most developing countries, ICT picked up very slowly in the early years of its introduction but gradually governments started paying more attention. Realizing the 'general purpose technology' nature of ICTs, successive governments started incentivizing its usage, development and importance. Pakistan didn't remain isolated from the PC revolution of the 1980s, when PC use started to be introduced to governmental offices and organizations.

Even though no formal "ICT Policy" existed till 2000, the Telecommunication Act of 1991 was the primary source for ICT friendly policies in the country. It encouraged private sector participation and resulted in the awarding of licenses for mobile phone operators, card-operated payphones, paging and, later, data communication services. In 1991-92, computers and related equipment were exempted from import duties, by declaring them to be duty-free items and encouraging their imports. A further impetus to the ICT sector came with the introduction of Satellite Communications technology in Pakistan in the early 1990s. Another step towards modernization was the conversion of approximately $90 \%$ of the telephone lines from analog to digital. The introduction of the Internet by PTCL in 1995 gave birth to a whole new market and private Internet Service Providers (ISPs) started mushrooming and competing for market share. This rapid growth has led to the provision of internet services to more close to $10 \%$ of the population in 2012, catered to by approximately 50 ISPs operating all across the country. With a total of $18,960,037$ users Pakistan ranked $27^{\text {th }}$ in $2012^{84}$. The government of Pakistan also announced its plans to privatize the Pakistan Telecommunication Corporation in 1991, resulting in the formation of a privately owned Pakistan Telecommunication Corporation Limited (PTCL) in 2003. Till that year, PTCL remained a public limited company and hence enjoyed a monopoly over basic telephony infrastructure much to the detriment of an already weak market structure. Due to this monopoly, the cost of various services for operators other than PTCL remained too high. Telephony

\footnotetext{
${ }^{84}$ Calculated using penetration rate and population data from "Countries and Areas Ranked by Population: 2012", Population data, International Programs, U.S. Census Bureau.
} 
however, till then was only exclusively operated by PTCL and during the 1990's a call to the US cost \$5 per minute. Similarly, customer services were so poor that the response time to a complaint was 10 to 15 days. Despite this, custmoers were forced to continue using PTCL, as no other options were available.

The Pakistan Telecommunication Ordinance issued in 1994 laid down the primary regulatory framework for the telecommunications industry. Thereafter, the Telecommunication Reorganization Act number XVII was promulgated in 1996. One of the major goals therein was to reorganize the telecom sector of Pakistan with the establishment of the Pakistan Telecommunication Authority (PTA) which was realized in January 1997. PTA's charter includes regulating the establishment, operations and maintenance of telecommunication systems, and the provision of telecom services. All these administrative endeavors to boost the ICT sector did not prove enough to take the number of Internet users beyond the 10,000 mark in 1998. Moreover, the users were not only few, but also clustered in only ten major cities with a meagerly teledensity of $2.3 \%$. Imran-Net was the first to offer dial up E-mail services in 1992-93. The state-owned PTCL started offering dial-up internet access via its countrywide telephone network in 1995.

\subsection{Acceleration and slowdown}

The first formal ICT policy (called IT Policy and Action Plan 2000) was drafted in 2000, laying the seeds for opening up the ICT sector for privatization (Baqir \& Parvez, 2000). Furthermore, with the expiry of the exclusive rights of Pakistan Telecommunication Company Limited on $31^{\text {st }}$ December 2002 for providing basic telephony services (local, long distance, international and leased line services), which it was granted under The Pakistan Telecommunication Reorganization Act 1996, the road was paved for privatization and liberalization of the ICT sector. As a result, the 'Deregulation Policy for the Telecommunication Sector' was introduced in July 2003 and consequently licenses were given to private operators for ICT operations in the same year. As a result of the deregulation 2 categories of basic service licenses were established: Local loop (LL), for fixed line connectivity within the 14 regions defined by PTCL, and Long-distance and International (LDI), for communication between regions. The regulatory authority laid down two sets of criteria before permission to start operations was granted. These criteria were meant to guarantee quality of service (QOS) and raise enough funds (through a license issuance fee). PTCL remains a major player due to its vast infrastructure throughout Pakistan but a number of private ventures were launched. According to PTA's statistics, teledensity in 2013 (including landlines and cellular phones) stands at $75.2 \%$, but internet penetration is still low with only 128,689 broadband connections with 3.5 million dial-up internet users. Micronet Broadband pioneered DSL internet services in 2001. NayaTel became the first company to offer Fiber to the User (FTTU) triple-services in the capital city of Islamabad in 2006. Today, most Pakistani 
companies, governmental departments and educational institutions maintain websites, increasing the demand for Internet access even further. As of now, broadband internet access is available in all major cities, Wireless Local Loop (WLL) companies have introduced wireless broadband Internet in some of the main cities, and Worldwide Interoperability for Microwave Access (WiMAX) networks are being aggressively installed.

While the bandwidth for wired and wireless systems is reasonable by international standards, the Quality of Service (QoS) is very low. Moreover, Internet service is not reliable for a number of reasons. International connectivity through submarine fiber optic cable is frequently disrupted due to ship anchors and shark bites. The latest of such disruptions occurred on $26^{\text {th }}$ March 2013, affecting 50\% of Pakistan's internet traffic. This incident was only ten days apart from another such incident of damage to the submarine fiber optic cable affecting internet traffic in Pakistan ${ }^{85}$. Similarly, dial-up connections are not too reliable because of aging copper-pairs that provide last-mile connectivity. However, when compared to the dismal 1990's in terms of performance, the new millennium has truly changed the pace of progress in this sector as elaborated in the upcoming sections.

LIRNEasia's Telecommunications Regulatory Environment (TRE) index summarizes stakeholders' perceptions of the regulatory and policy environment and analyzes the environment for its conduciveness for development and growth. Pakistan was one of the eight Asian countries surveyed by it in July 2008. The survey measured the following seven parameters for the fixed, mobile, and broadband sectors: market entry; interconnection; tariff regulation; access to scarce resources; universal services; anticompetitive practices; and quality of service. The survey found that in Pakistan the most active sector was that of mobile telephony, followed by broadband internet; while the fixed-line sector remained lackluster (Wilson, 2008). The parameters that witnessed an improvement when compared to a similar survey carried out in 2006 were as follows: In the mobile sector they were tariff regulation, interconnection, universal service obligation and regulation of anti-competitive practices. In the fixedline sector they were regulation of anti-competitive practices, market entry, universal service obligations and interconnection. A low market entry score in the mobile sector is perhaps explained by the exorbitantly high cost of new licenses for mobile telephony, thus being a genuine barrier to entry. However, the very recent (2014) auction of $3 G$ and $4 G$ spectrum might be seen as evidence to the contrary. But it can be argued that no new entrants acquired new spectrum and hence market entry does have steep barriers. Since the auction, Telenor, a telco which bought 36 spectrum, has become the second largest (in terms of subscribers) mobile network operator in the country.

Prior to this, a 'Mobile Cellular Policy' was announced in 2004 with the intention to draw new investors into the mobile phone sector. For this purpose the policy clearly

\footnotetext{
${ }^{85}$ The news story can be read at http://tribune.com.pk/story/527148/undersea-internet-cable-cut-effects50-of-pakistans-traffic/
} 
stated its objective to issue new, technology neutral licenses for which existing licensees were prohibited from bidding. The new policy resulted in international companies Telenor (Norway) and Warid (UAE) set up operations in the country in 2005.

The World Economic Forum, assessing the development of Information and Communication Technology in the country ranked Pakistan $105^{\text {th }}$ among 144 countries in the Global Information Technology report of 2013. Some of the areas where Pakistan lost its ICT competitiveness include government procurement of advanced technologies, which ranked $109^{\text {th }}$ in 2013 as compared to $91^{\text {st }}$ in 2012. Another area where Pakistan lost ground was the importance of ICTs to the government's vision, where it went down from $92^{\text {nd }}$ in 2012 to $117^{\text {th }}$ in 2013 . This shows that ICT is very low on the government's agenda.

The significant gains made in the last decade when Pakistan embraced mobile communications technology and led the region by providing human capital and technical know-how to the global pool of mobile operators was undone by static policies towards technology adoption. In this context, the recent 3G/4G auctions are being deemed as 'too late, too little' by experts. Still, there are some areas where Pakistan has shown improvement, such as fixed broadband internet tariff where it ranked the 68th most competitive broadband provider in the world. Similarly, in the area of business and innovation environment, Pakistan ranked $83^{\text {rd }}$, an improvement of 10 points. This is largely due to the business sector which has made available most innovative ICT technologies.

\subsection{Overview of ICT subsectors}

Our study focuses on the ICT sector as a whole. But, this doesn't preclude us from discussing its various subsectors and also from ensuring that our survey sample includes firms from each of the subsectors. However, we do this in order to make our sample truly representative of the ICT sector as a whole. Our focus and conclusions continue to be based on the entire ICT sector instead of its individual components or subsectors like Computer programming, ICT manufacturing and assembly, ICT trading and Telecommunications etc. We argue that separating one from the other is not practically possible due to the pervasive and intertwined nature of these technologies. Moreover, as we are interested in identifying and measuring spillovers, it is worth mentioning that knowledge and technology from one of the subsectors might spill over to another. Our literature review highlights the importance of backward and forward linkages for spillovers in general. In the special case of the ICT industry, this is intuitive as the hardware producers supply hardware to both software developers and telecom operators. Similarly software developers develop software for applications to be used by the Computer programming sector but also for the telecom operators. The same holds true for telecom operators, whose products and services are used by software developers and hardware manufacturers. 
The ICT sector can be subdivided into the following sub-sectors:

- Computer Programming

- Telecommunications

- $\quad$ ICT manufacturing and assembly

- $\quad$ ICT trading

\subsubsection{Computer Programming}

Providing a picture of Pakistan's Software industry is a daunting task for a plethora of reasons. First, no periodic data gathering exercise is in place. Second, most of the industry actors are private companies, which unlike public ventures are under no legal obligation to provide verifiable and audited data on their operations and finances. Third, the tax culture in the country allows us to assume that a substantial number of firms operating in this sector are not registered firms and are hence part of the informal economy. Lastly, owing to the very dynamic nature of this sector, new firms are being formed while old ones close down frequently thus making it difficult to keep track of the number of firms existing within the industry.

Pakistan's Software / BPO industry can still be considered as emerging when relative to other countries. Attempts to collect data on the industry started around 2003, only to be discontinued after the worldwide economic slump which seriously affected the domestic software industry. In the years between 2005 and 2010 a number of serious efforts were made to gauge the industry's performance. These efforts used a variety of methods to calculate the industry's size and other such characteristics, at various points in time. The results of these studies are often not reconcilable due to the variations of methodology. In particular, five different studies, summarized below, have recently sought to estimate the software industry's size. Estimates of software revenues vary from a minimum of $\$ 81.5$ million in 2004 to a maximum of 819 million in 2010 (or something like this). 
Table 5.1 Software revenue estimates by various sources

\begin{tabular}{|c|c|c|}
\hline Revenue Estimate & Software/BPO Export & \\
\hline Source & Estimate and Year & Estimation Methodology \\
\hline PSEB 2005 & 2004 - Software: $\$ 81.5 \mathrm{~m}$ & Survey based extrapolation \\
\hline Bearing Point 2005 & 2005 - IT/BPO Export: $\$ 100 m\left(\right.$ Total $\left.^{86}: \$ 700 \mathrm{~m}\right)$ & Multiples and Rules of Thumb \\
\hline PSEB 2006 & 2006 -Export Earnings: $\$ 150 m\left(\right.$ Global $\left.^{87}: \$ 600 \mathrm{~m}\right)$ & Rules of Thumb \\
\hline P@SHA 2008 & 2007 - Domestic Spending: \$269m (Global: \$640m) & Survey based extrapolation \\
\hline PSEB 2010 & 2008 - Domestic Spending: \$441m (Global: \$819m) & Stratified medians method \\
\hline State Bank of Pakistan & 2009 - Software: $\$ 115.95 m$, Call Centers: $\$ 17.52 m$ & Compilation of BOP data \\
\hline
\end{tabular}

Source: PSEB IT Market Assessment (2010)

The Technomics' survey titled "PSEB IT Market Assessment (2010)" of PSEB Member Companies, which forms the basis for this section, was conducted between 2009 and 2010. These data are the most recently available till date as no other official survey was carried out after it.

The de-regulation policies of the ICT sector elicited a new era of growth even in the software sector. FDI rose from previously negligible values to thousands of millions of dollars in a matter of months and weeks. Rapid growth in teledensity remains another reason that made Pakistan a country of choice for software development.

Despite a promising start after the de-regulation policies, the global context has hampered growth in the software industry domestically too at the end of the last decade. The years 2007-09 have seen the software industry struggle globally mainly due to the global recession triggered by the so called credit crunch of 2008 . The recession sent ripples throughout the world affecting the services sector the most with reduced demand for IT and IT-enabled services worldwide. Most companies have therefore attempted to maintain the status quo in terms of market share and sales by focusing primarily on the preserving existing customers and maintaining profit margins rather than expanding.

Eastern countries, particularly in Asia and the Pacific, were spared from West-like massive lay-offs but still experienced a slowdown in terms of growth in not only the IT sector but the economy in general. This was the result of job losses, high unemployment rates and a decline in demand for IT products and services in the West.

From its humble start in the late 1980s, today the industry's largest players are valued at hundreds of million dollars, and are USD 15-25 million in revenues. The industry has grown at a whopping $38 \%$ in the FY 2007-08. Altogether, the industry is

\footnotetext{
${ }^{86}$ Total figure includes domestic revenues.

${ }^{87}$ Global refers to Global Revenue Impact of Pakistani IT companies, a concept which was introduced to "address the challenge of attributing the portion of revenue of a Pakistani company but that was never brought into the country to Pakistani exports. Bearing Point Study of 2006 had estimated the global revenue of Pakistani companies to be four times what was brought into Pakistan. The Global Revenue Impact metric went a step further by attributing to the Pakistani company a share of the overall revenue of its foreign parent based on its contribution to the creation of those revenues." (PSEB, 2010)
} 
generating over USD 2 billion per year in revenue, a remarkable increase from the less than a billion dollars a few years ago. Almost half of this growth is coming from foreign projects, both in software and high-end services. Multinational computing giants like Microsoft, Cisco and IBM are aggressively expanding their operations in Pakistan while several domestic startups are now winning the backing of Venture Capitalists based in Pakistan as well as abroad. Projections and forecasts based on recent trends indicate that the industry will exceed the 11 Billion USD mark within the next 5 years. This growth rate is unprecedented within this sector and quite impressive when compared to other sectors of the economy.

To sum it up, the Pakistani software industry has come a long way from what it was in the 1980's and 1990's. PASHA's current membership exceeds 370 firms while it was made up of only 4 founding member firms in 1994. From an aggregate employment of 4,200, its current employment stands tall at 12,000 and is on the rise.

The software sector in Pakistan comprises the following 5 main activity areas as per classification of PSEB ${ }^{88}$.

\subsubsection{IT Product Development (IPD)}

IT Product Development (IPD) is defined as a business process (function), by which product ideas in the very early stage are validated and successfully transformed into finished software products. The various types of businesses involved in IPD include, hardware vendors who rely on sophisticated software as part of their offerings, Independent Software Vendors (ISVs), and other companies whose services or products employ software technologies, in part or entirely. IPD is seen as an important growth area for Pakistan's IT industry. This sub-sector within Pakistan's IT industry has rapidly grown in the last decade and it exhibits signs of maturity. Software vendors develop products for various industries, some of which are Financial, Healthcare, Enterprise Resource Planning (ERP), New media and Internet.

IPD should not be confused with Customized Software Development and Deployment (discussed in the next section), as it requires completely different approaches and skills.

\subsubsection{Software Development and Services (SDS)}

SDS is a critical sub-sector of Pakistan's IT industry and it includes two different types of businesses. Firstly providing customized software development and installation using 3rd party software tools and platforms (such as Oracle, SAP, Microsoft etc. also referred to as software customization and deployment services (SCDS). Secondly, providing on-demand software development or application management services mainly as an off-shoring operation. It is important to note that intellectual property (or

${ }^{88}$ PSEB Pakistan IT Market Assessment - 2010 
proprietary software) of their own is not produced by companies in the SDS subsector. ${ }^{89}$

\subsubsection{Mobile Applications, Gaming and Animation (MGA)}

MGA is the most dynamic and perhaps fastest growing activity area in Pakistan's IT industry today. This is the result of certain unique characteristics of the Pakistani IT market. Pakistan's large mobile subscriber base - according to some analysts the largest among the developing world if not overall - obviously plays to its favor. ${ }^{90}$

Moreover, the otherwise late entry of Pakistan to the software and outsourcing business in general does not significantly handicap its businesses in the mobile applications industry as the gap with global players is smaller and entry barriers are fewer.

\subsubsection{IT Enabled Services - Business Process Outsourcing (ITES-BPO)}

ITES-BPO represents a sub-sector with lot of potential however Pakistan's performance has been rather dismal, especially when compared to neighboring India. India has been able to position itself as a low-cost destination amidst corporate cost cuttings resulting from the 2000 recession in the United Sates and much of Western Europe. Witnessing India's success, Pakistan followed suit, seeking ITES-BPO business and achieving significant success initially. Call centers and data entry business opened up all over the country and the legal and medical transcription business flourished phenomenally. However, the excitement soon ran out of steam due to a combination of several factors. Vulnerability (due to lack of redundancy) of the country's internet backbone, shortage of English-speaking workforce, downtime resulting from load-shedding and difficulties in securing contracts due to the tough competition have all threatened the future of this nascent business. In the larger context, the worldwide perception of Pakistan as a geopolitical "hotspot" has further hampered growth of this particular sub-sector. These hurdles stymied the building of big enough ITES-BPO operations that could have reaped the benefits of economies of scale. However, a small number of companies have managed to defy the odds and succeed with the help of their powerful business models. These companies have also succeeded in getting around some of the problems pointed out above in creative ways.

\subsubsection{System Integration, Consulting, and Embedded Systems (SICES)}

PSEB reports that SICES has, for a long time, been a neglected sector in Pakistan's IT industry. While every IT company is enticed by the opportunity to make money selling the intangible code, the real value is generated from delivering a service by bundling software with hardware. This is where the role of system integration comes to the fore. Tens of thousands of such integrated systems are in use by us in our daily lives,

\footnotetext{
${ }^{89}$ For a discussion on the pros and cons of product and service based businesses and the related organizational characteristics and challenges see Cusumano (2004).

${ }^{90}$ For detailed statistics on size of the telecommunications market please see next section.
} 
most of them unnoticed. For instance the over a century old automobile is today equipped with a plethora of systems-on-chip, some to prevent skidding while braking, others to deploy the life-saving airbags in the hapless event of a crash.

Surveys indicate that despite being a largely neglected sector in Pakistan, there have been some successful companies in systems integration. However, the relatively higher dependence on government policy and procurement decisions makes systems integration companies doubly vulnerable. First, because the main customers of systems integration firms are governments and defense organizations. Secondly, the fact that the primary focus of systems integration companies is domestic rather than international, ties their success to the domestic policy instruments. Some companies have defied this trend by forming a direct and strong relationships with the defense establishment. Others have piggy-backed on the growth of the telecommunications sector. Hoping that the per capita public sector spending is bound to grow in order match other countries, there is a promising future for this sub-sector.

\subsubsection{Telecommunications}

Statistics of the telecommunications subsector are relatively better recorded than for any of the other ICT subsectors. Since the formation of PTA in 1997, it issued an annual report comprising not only statistics but also other important milestones achieved and challenges faced. The first annual report was published at the end of 2001 covering the 2000-2001 fiscal year. This report focused more on the structure, policies, tariffs and other operational details of the PTA and gave little statistical data. But the subsequent annual reports started giving more and more data on economic indicators of the sector. In this section we start by presenting and discussing some basic performance parameters from the available annual reports and then shed some lights on the structure and composition of the telecommunications subsector.

The Telecom Sector grew faster in the fiscal year 2012-13 with major indicators showing significant improvement as compared to last year. Telephone density, also called 'teledensity', reached $75.21 \%$ (135 million subscribers combining Cellular, WLL \& $\mathrm{LL}$ ) with the cellular sector contributing the most and revenues up at an all-time high of Rs. 445.7 billion, out of which Rs. 124 were contributed to the national exchequer. There are 35,889 cell sites installed by cellular operators covering $92 \%$ of land area across Pakistan. The Local loop sector has performed well as the teledensity of FLL (Fixed Local Loop) and WLL services combined reached 3.6\% at the end of FY 2012-13. Teledensity is basically a measure of how many people have access to basic telephony and data communication networks. PTA's teledensity data, which is obtained by dividing number of active phone connections by country population, is misleading because a large number of ICT users have multiple phones. This discrepancy could wrongly push the figure upwards. While teledensity itself is not a direct indicator of ICT penetration, it is considered as a reasonable proxy for measuring ICT penetration. The ra- 
tionale of using teledensity as a proxy lies in the fact that people cannot have access to sophisticated ICT such as the Internet if they do not have access to basic voice telephony and data communication systems. Though the reverse is not necessarily true (i.e. those having a phone or mobile connection must be using ICT), it is a precursor to doing so.

With 2.72 million subscribers and $30 \%$ growth during the FY2012-13, the broadband sector is also not lagging behind. However with a penetration level of $1.52 \%$ the sector has yet to evolve. The remarkable growth of wireless technologies is encouraging and puts the broadband sector on the right track.

Cellular mobile companies and commercial banks have joined hands to ensure and expedite mobile banking facilities in Pakistan. PTA too has been actively pursuing this agenda and in this regard has collaborated with the State Bank of Pakistan (SBP) to guarantee the 'Technical Implementation of Mobile Banking Regulations'. The MBanking sector has grown exceptionally between the last successive fiscal years. Mbanking agents increased from 26,792 to 64,716 , a growth of $141.6 \%$, and m-wallet accounts went up from 1.4 million to 2.4 million a growth of $126.4 \%$. The huge growth potential of the M-banking segment can only be fully exploited with a strong will of the operators to deliver and support from the two regulatory bodies (PTA and SBP). In this regard, PTA has already developed a complaint registration system which also incorporates the resolution process. Total investment in the ICT sector was US \$472 million in the FY2012-13, and FDI kept decreasing as compared to the last years. Telecom equipment imports stood at US $\$ 918$ million for the same period. In order to attract FDI and investment there is a need of innovation in this sector. Initial surveys show that the 2014 auction of the long pending 3G and 4G spectrum licenses have stirred the market ${ }^{91}$. This could give the sector an economic stimulus as well as upgrade its technological capabilities.

\subsubsection{Cellular Mobile Services}

There are a total of 6 Cellular operators in Pakistan. The cellular mobile operators have achieved network coverage of $92 \%$. The total number of cell sites grew from 33,920 in FY 2011-12 to 35,889 by the end of June, 2013, a growth of $5.8 \%$, as shown in Figure 5.1.

Short Message Service (SMS) exchanges were at a record high with 315.7 billion SMSs sent by mobile users, an increase of $13.6 \%$ over the previous year. Similarly, a record outgoing traffic of 294.2 billion minutes was generated by the mobile companies. National outgoing traffic between mobile networks has shown massive growth, resulting in an increase of over 52\% compared to the previous fiscal year when outgoing traffic was 192.9 billion minutes, as shown in Figure 5.2. This tremendous growth in national cellular mobile outgoing traffic is mainly attributed to new subscribers dur-

\footnotetext{
${ }^{91}$ The 2014 auction of $3 G$ and 4G spectrum by PTA generated US \$1.1 billion in revenue.
} 
ing that period but also attractive call packages and bundle offers put forward by cellular operators in face of the cut-throat competition.

Figure 5-1 Cell sites

\section{Cell Sites}



Source: PTA Annual Report 2013

Figure 5-2 National Cellular Outgoing Traffic

Minutes in Billion

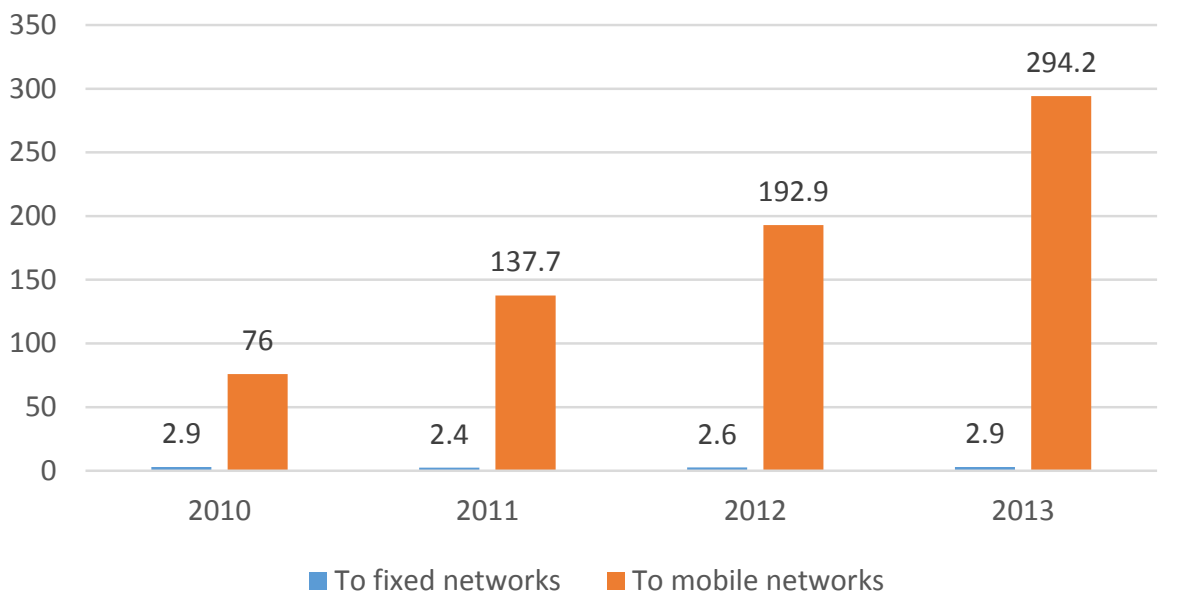

Source: PTA Annual Report 2013

\subsubsection{Basic Services}

Basic telecom services in Pakistan include Fixed Local Loop (FLL), Wireless Local Loop (WLL) and Long Distance International (LDI) services. 


\section{Fixed Local Loop (FLL) and Wireless Local Loop (WLL)}

Fixed Lines are the pioneering communication medium as voice started travelling long distances on cords/cables. FLL services, also called local loop services, were the only viable and practical alternative for voice communications over longer distances till a few decades ago. It was later that wireless means of communications began surfacing. The Local loop sector of Pakistan has faced a number of issues as a result of which only a few of the large number of licensed companies has become operational. To date only 10 out of 38 companies have become operational. Extra duties and taxes on import of communication equipment, high connectivity charges and obstacles in right of way and co-location are a few of the hurdles impeding growth in this segment. A look at ITU's statistics for Pakistan in Figure 5.3 shows that fixed line users were marginally higher in number than cellular users back in 2001, but the gap between fixed line and cellular subscribers is huge now as the latter's penetration rate is close to $67 \%$ while fixed line stands at only $3.2 \%$. It is interesting to note that among all of the major ICT indicators, the number of fixed line subscribers is the only indicator experiencing a gradual decline. The swift adoption of cellular mobile services around the globe has been the cause of this trend as this new technology, though not truly disruptive, makes FLL superfluous, especially after comparable call rates and voice quality. Pakistan too has followed this global trend in recent years and the current level of FLL penetration remains fairly low, though it has recently shown signs of recovery, perhaps due to PTA's watchful eye, which has ensured that all possible efforts were made to raise the penetration level of local loop services.

Wireless local loop services were introduced in Pakistan in 2004. Currently, there are five operational companies in the WLL market including PTCL, Telecard, Worldcall, Great Bear and Burraq. This segment experienced reasonable growth over the past year as the number of FLL users has risen slightly. By June 2013, there were 6.38 million subscribers, FLL and WLL together, as compared to 5.87 million in the previous year. PTCL has a more than $95 \%$ share in the FLL customer base while in the WLL sector, it holds almost $37 \%$ of the market share. The local loop segment has performed well as the combined teledensity of FLL and WLL services reached 3.6\% in FY2012-13.

\section{Long Distance International (LDI)}

Like the FLL and WLL segments, LDI too has shown remarkable growth over the last few years. Carrying voice traffic from one telecom region to another and also connecting Pakistan to the rest of the world is done by LDI operators. However, initiating and terminating calls within the region is beyond the authority of LDI operators as this can only be done by Local Loop operators. LDI operators guarantee efficient international connectivity by obtaining access to submarine cable systems and installing groundstations for satellite transmission, after reaching agreements with the operators of such facilities. During the FY2012-13, the total international traffic carried to and from Pakistan was lesser than during the year before. It dropped from a total of 20.2 Billion minutes in the previous fiscal year to 14.4 Billion minutes in FY2012-13, a decline of 
29\%. Decomposing total international traffic into its 2 components, the incoming international traffic on the LDI networks shows a decline of $26 \%$ with total 11.9 billion minutes in FY2012-13 whereas outgoing international traffic shows a decline of $39 \%$ with a total output of 2.4 billion minutes. This decline in international traffic can be attributed to several factors such as the establishment of International Clearing House $(\mathrm{ICH})$, an increasing trend of gray traffic and technological innovations in the field of online communications etc. Technological innovations have provided users with various alternatives for cheaply and easily interacting with the global community, including Skype, Viber, Tango, What's App and other VolP based calling services to mention just a few which are commonly used for voice calls. Moreover, other online services like social networking sites (Facebook, Twitter, Linkedln etc.) are also widely used nowadays for communications in addition to email services. The only requirement for using these services is a high-speed and stable internet connection.

Figure 5-3 Aggregate ICT Developments in Pakistan, 2000 - 2012

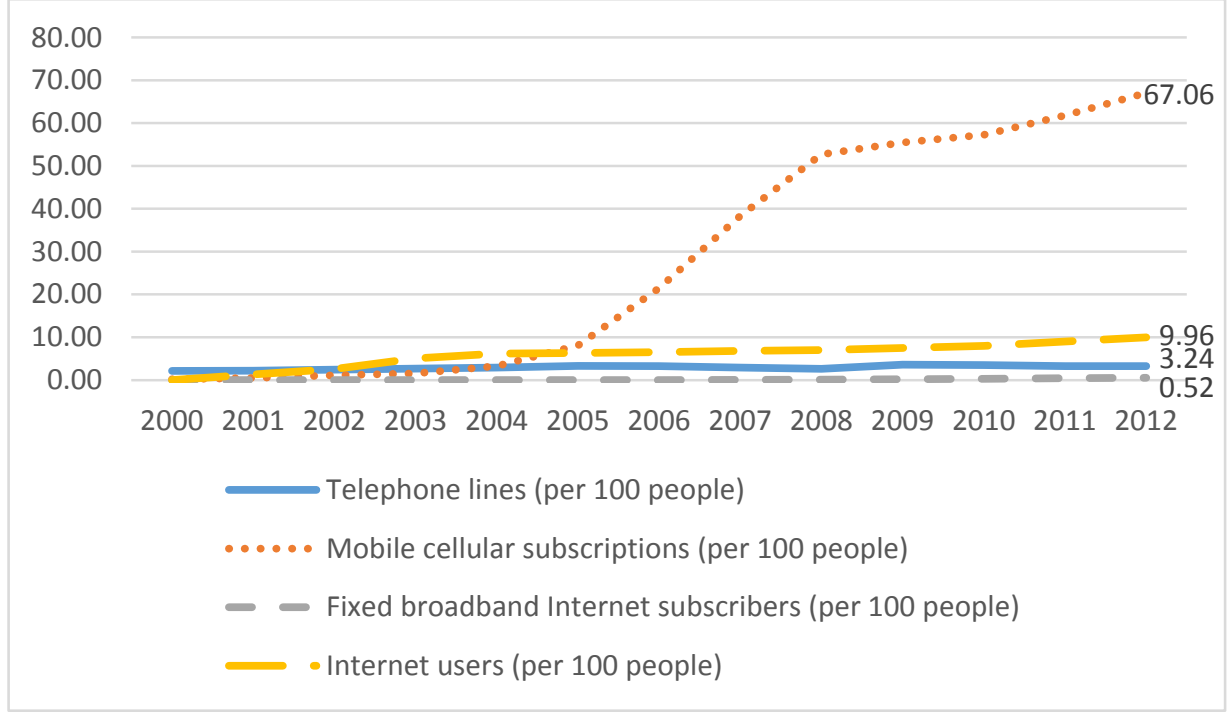

Source: International Telecommunication Union, World Telecommunication/ICT Development Report and database, and World Bank estimates.

\subsubsection{Broadband}

The corner stone of the ICT revolution has been the internet and the limiting factor of the internet remains its 'speed'. It should be noted however, that information signals generally travel at about $50 \%$ of the speed of light, irrespective of the bit-rate. This highlights the not so inadvertent misnomer of higher and faster speeds used by marketers while referring to connections of higher bit-rates. On the other hand, it would be correct to say that a file of given size would typically require less time to download (or upload) while using a broadband connection. Broadly, this term refers to the 
bandwidth of a transmission channel and its ability to carry (send or receive) multiple signals and traffic types simultaneously and efficiently. The channel's medium can be coaxial cable, twisted pair, optical fiber, DSL local telephone networks or wireless (Carty, Illustrator-Mueller, \& Illustrator-Coda, 2002). The term gained popularity in the 1990 s as a marketing buzzword for Internet access that was faster than dialup access, the pioneering Internet access technology, which was limited to $56 \mathrm{kbps}$. So a reference to 'speed' which is more relevant in the context of its original technical comparison, is by far the most popular feature of broadband internet, especially among users.

Technically speaking, communication bandwidths of at least 256k bit per second qualify as broadband. The telecommunication standardization sector of ITU defines "broadband service" as transmission channels capable of supporting bit rates greater than the primary rate which ranges from about 1.5 to $2 \mathrm{Mbit} / \mathrm{s}$ (International Telecommunication Union, 1997). Broadband internet access has been growing pervasively over the years. When only $3 \%$ of US users had access to a broadband connection privately in 2000, in 2013 more than 70\% of US users have broadband access from the comfort of their homes. Worldwide, the number of broadband subscribers crossed the 650 million mark in March, 2013 already.

In Pakistan, broadband penetration levels are moving up, but slowly. Currently, 1.52 per capita have subscribed to broadband services in Pakistan at the end of FY 2012-13 as compared to 1.20 per capita, as of June, 2012. Reasons for the slow adoption of this technology are costly tariffs, low literacy rates, and power shortages ${ }^{92}$. The broadband subscriber base grew 30\% from 2.1 million at the end of FY2012 to 2.7 million at the end of FY2013 as shown in Figure 5.4. Although the growth rate is on decline, still, the average annual growth rate of the last 6 years has remained above $100 \%$ in the broadband sector. It is important to note that one broadband subscription can be catering the needs of a multiple people in a house or business facility; therefore, the actual number of broadband users is higher than just the number of broadband connections.

The underlying technology to deliver a broadband connection is dependent on the provider's business model and the subscribers' preferences. Copper based DSL has long been dominating the broadband technology arena, however, the world is shifting towards other fixed (HFC, FTTH) and wireless (WiMAX, EvDO) solutions as is evident from the dropping DSL-copper subscriptions in contrast to overall growing broadband adoption rates in recent years.

\footnotetext{
${ }^{92}$ Dial-up connections can be used irrespective of power availability whereas broadband equipment requires power supply.
} 
Figure 5-4 Broadband subscribers, numbers and growth

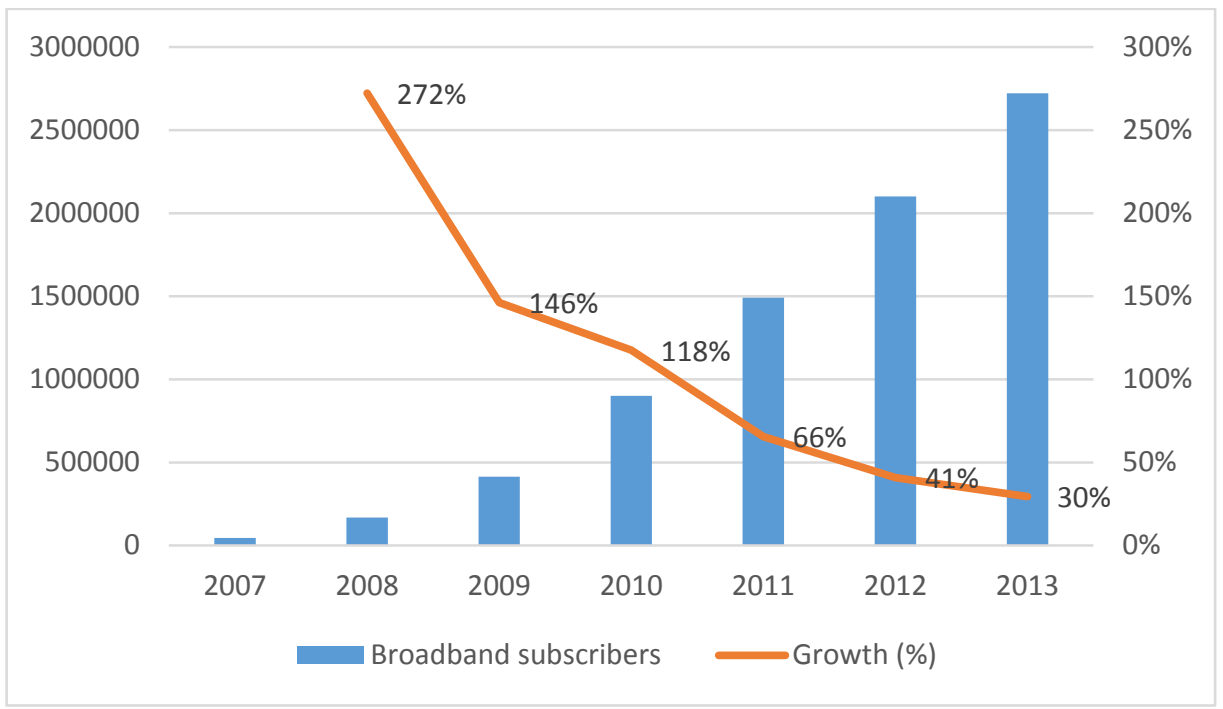

Source: PTA Annual Report 2013

\section{G (Third Generation)}

$3 G$ refer to the third generation of developments in wireless technology, especially mobile communications. The third generation, as its name suggests, follows the first generation (1G) and second generation (2G) in wireless communications and includes capabilities and features such as:

In technical terms, 1900 to 2100 megahertz $(\mathrm{MHz})$ is the spectrum bandwidth that is most popular for $3 \mathrm{G}$ services while $1800 \mathrm{MHz}$ is typical for $4 \mathrm{G}$ services. Simply put, $3 G$ services, as compared to $2 \mathrm{G}$, offer higher data transfer rates for internet services such as web surfing, downloading, uploading, video-conferencing and live streaming. Similarly, in case of $4 \mathrm{G}$ the data transfer rates are even higher than 3G. 3G provides better voice service (voice calls) as compared to existing services offered by the $2 \mathrm{G}$ network. However, currently Pakistan has deployed the $2.5 \mathrm{G}$ technology called Enhanced Data Rate for Global Evolution (EDGE). EDGE is a technology that gives Global Systems for Mobile Communications (GSM) the capacity to handle 36 services of mobile communications. The data capacity of EDGE is 3 times higher than that of General Packet Radio Service (GPRS). This means, using EDGE operators can handle 3 times more subscribers than GPRS; triple their data rate per subscriber, or add extra capacity to their voice communications.

Pakistan plans to issue its first three licenses for third generation (3G) mobile telecoms service soon ${ }^{93}$. In this regard an Information Memorandum (IM) prepared by

\footnotetext{
${ }^{93}$ Plagued with huge delays, the 36 spectrum auction was finally held in April 2014. It was coupled with the launch of $4 \mathrm{G}$ services for which the spectrum was also auctioned on the same day. As this was not the case at
} 
a consortium of international consultants was released by the PTA on $25^{\text {th }}$ February 2014. The IM is a policy document that sets out rules and processes for the upcoming $3 \mathrm{G}$ license auctions. The document reveals that an open bidding will only be conducted if the demand exceeds supply, i.e. the number of organizations aspiring to acquire a license is more than the available licenses. The federal government also recently announced that it would auction three 3G licenses (\$295 million each), two 4G licenses (\$210 million each) and one license of a defunct mobile operator (\$291 million) to a new entrant. It is estimated to generate revenue of $\$ 1.6$ billion through the auction process.

As per PTA's plans, initially, those winners of $3 G$ licenses who are existing operators will be obligated to roll out $3 \mathrm{G}$ services within six months of the start of their contract in the five major cities (Karachi, Islamabad, Lahore, Quetta, Peshawar) and 10 other cities, with one city located in each of the four provinces. These conditions are relaxed for new entrants, who will have one year to cover these cities. In the second phase, the existing operators will have one and a half years to provide coverage to $80 \%$ of the district headquarters.

\subsubsection{ICT Manufacturing}

ICT manufacturing is not a formal or very active sector in Pakistan. Still, lots of small startups and a few large organizations are involved in manufacturing activities. These activities mainly comprise assembly and fabrication of computer and telecommunications equipment. Original Equipment Manufacturing (OEM) is seldom carried out in Pakistan. Moreover, it should be noted that firms categorized in our sample as ICT Manufacturing (or for that matter any of the other three sub-sectors) could well be active in other subsectors too, as this is only an indication of their 'principal' subsector.

According to the P@SHA Annual Review (2008) report, the domestic hardware market generates an estimated revenue of $\$ 300-500$ million.

\subsubsection{ICT Trading}

Another sub-sector we explored in our survey is that of ICT trading. This is quite an active sector as it consists of importers and representatives of MNCs who are not directly present in Pakistan. As one would expect, a lot of companies would like to sell their ICT products in an emerging and huge economy like Pakistan. However, the security and political situation has, over the past years, been quite challenging and that has kept many companies from making the move to Pakistan. In order to still tap the market, many of such aspirants are selling their products through dealerships and other

the time of writing of this thesis and because updated statistics and data are not yet available, we have not discussed this development in detail. 
such business arrangements with local businesses. Another reason to include ICT trading companies in our survey is that as this is the principal activity, such firms can possibly be involved in other ICT activities such as hardware manufacturing and software programing. Official statistics of this sub-sector are not gathered in any of the PBS's censuses or surveys. Moreover, ICT trading is also not represented by the various reports and market estimates conducted by PSEB, PASHA, PTA and other private market research organizations.

\subsection{Competitiveness}

Research on the ICT industry, especially international comparisons, are limited because there are no officially established periodic surveys to gather industry statistics of this particular sector. As the main sources of statistical data for the ICT industry are studies usually undertaken by industry associations and market research companies or in some cases the regulatory bodies, we have to rely on these and other publically available international data sources to establish the competitiveness of this sector.

\subsubsection{Backdrop}

Understanding the economic context of Pakistan is paramount for understanding the performance of the ICT sector. In the last decade, Pakistan's economy faced a lot of challenges due to a plethora of issues, be they domestic, international or natural. These issues have been discussed in detail in Chapter 3.

\subsubsection{Competitive Advantage}

In 2007, Gartner released a report titled, "Analysis of Pakistan as an Offshore Service Location" ${ }^{94}$ which placed Pakistan in the First Category destinations and also acknowledged its labor costs to be $30 \%$ lower than those of its fiercest competitor, India. Moreover, it also reported that the Telecom costs in Pakistan are the lowest among all other outsourcing destination. Another report published the same year by the World Bank ranked Pakistan at number 74 globally among 159 countries and number 2 in South Asia in terms of 'ease of doing business' ${ }^{95}$. It also acknowledged that the costs for setting up and doing business here are relatively low, lower than China and India. The Karachi Stock Exchange has the lowest listing costs in the region, which is remarkable considering an active trading history with more than 600 listed securities. In addi-

\footnotetext{
94 The report can be purchased and downloaded at https://www.gartner.com/doc/545418/analysispakistan-offshore-services-location

95 The report can be downloaded at http://siteresources.worldbank.org/SOUTHASIAEXT/Resources/Publications/448813-1171300070514/complete.pdf
} 
tion to the impressive telecom infrastructure and lower costs both for IT services and skilled human resource, there are some other competitive advantages key to Pakistan's rapid growth as an emerging global destination for IT services and products. A sizeable and growing English speaking workforce, effective programs for HR development, favorable policy instruments like 100 percent repatriation of the foreign investors' profits ownership of equity and ownership of equity, as well as tax exemption on these investments and exported IT products until 2016 are but a few to mention. The country is also investing heavily in creating a critical mass necessary for transitioning into a knowledge economy. Having one of the world's most ambitious higher education investment programs tasked by the Higher Education Commission (HEC) is proof to this resolve. Under various HEC programs, about 3,000 indigenous PhD scholarships have been awarded and another 5,000 MS to PhD and PhD foreign scholarships were awarded for study in technologically advanced countries. Attracted by the country's promising economic indicators and demographic features, a number of MNCs, angel investors and venture capitalists have set foot in the country. Direct foreign investment boomed in the years preceding the global economic slowdown. Companies like Etisalat - the state-owned Telecom provider of the UAE and one of the leading brands in the Middle East, acquired a majority share in the country's largest telecom operator, PTCL for US \$2.6 billion in 2007. Other renowned IT companies expanding or entering in Pakistan include Dell, Cisco, Terradata, Microsoft, IBM, HP, Oracle, SAP, NCR, Orascom, OmanTel, Telenor and China Telecom

The Indian National Association of Software and Services Companies (NASSCOM) estimates that India alone had a market share of 58 percent of the global sourcing industry in 2011. This and other such indicators where India stands tall and the fact that Pakistan and India are neighboring countries with quite similar societal makeup, call for the comparison of both in terms of ICT infrastructure. The following graphs are an attempt to highlight the similarities in this regard, which suggest that Pakistan is in a position to compete with India. 
Figure 5-5 Pakistan and India comparison: Fixed telephone subscriptions

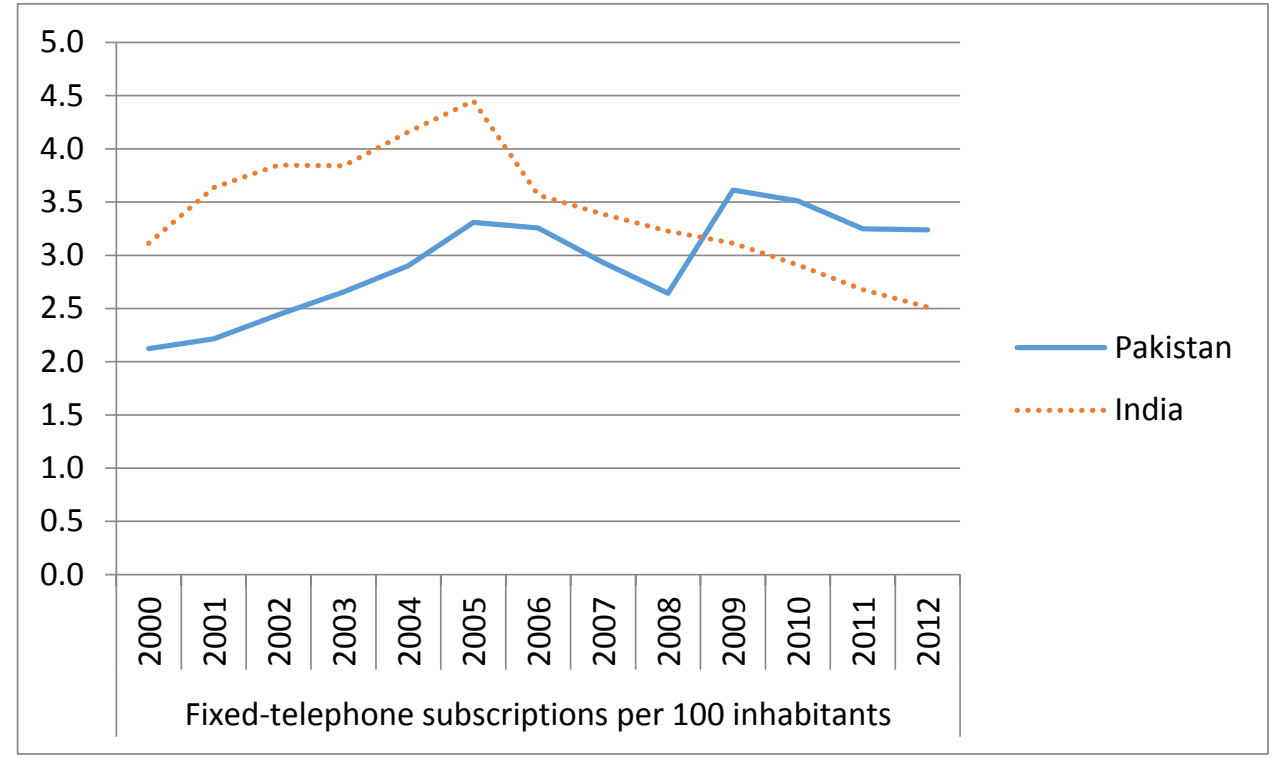

Source: ITU's statistical data portal

Figure 5-6 Pakistan and India comparison: Fixed broadband subscriptions



Source: ITU's statistical data portal 


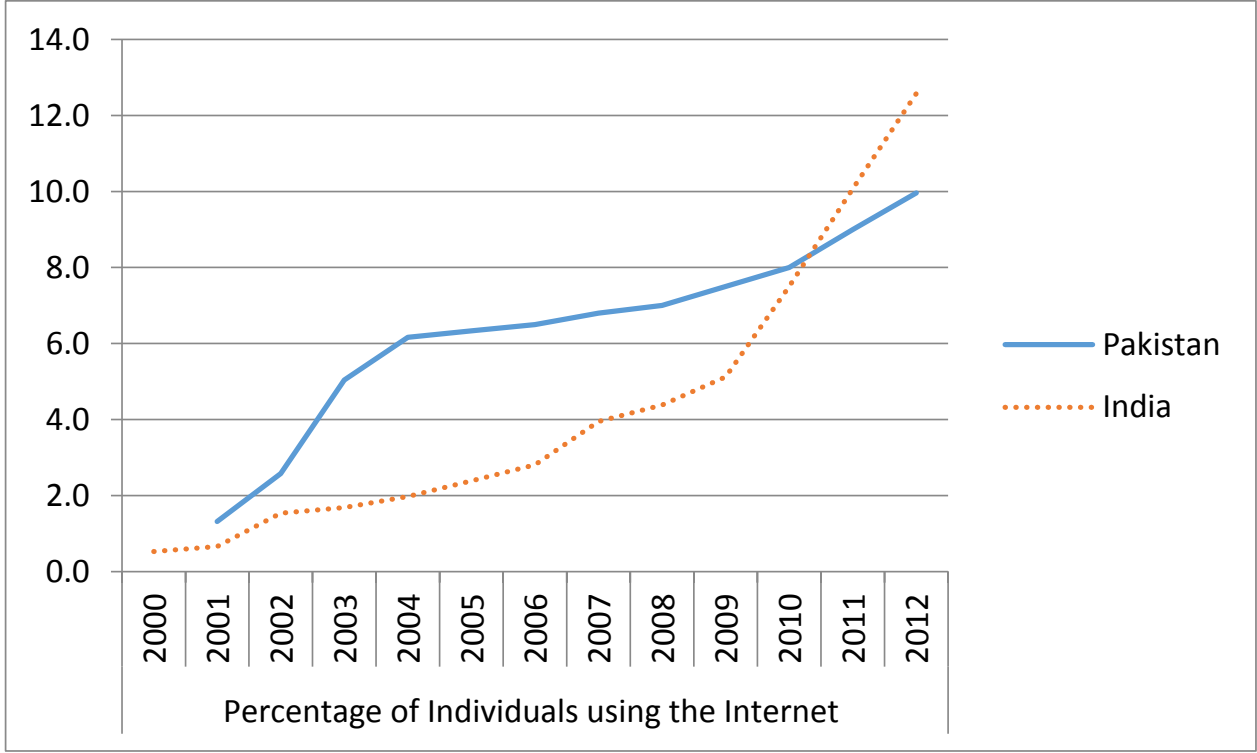

Source: ITU's statistical data portal

Figure 5-8 Pakistan and India comparison: Mobile-cellular phone subscriptions

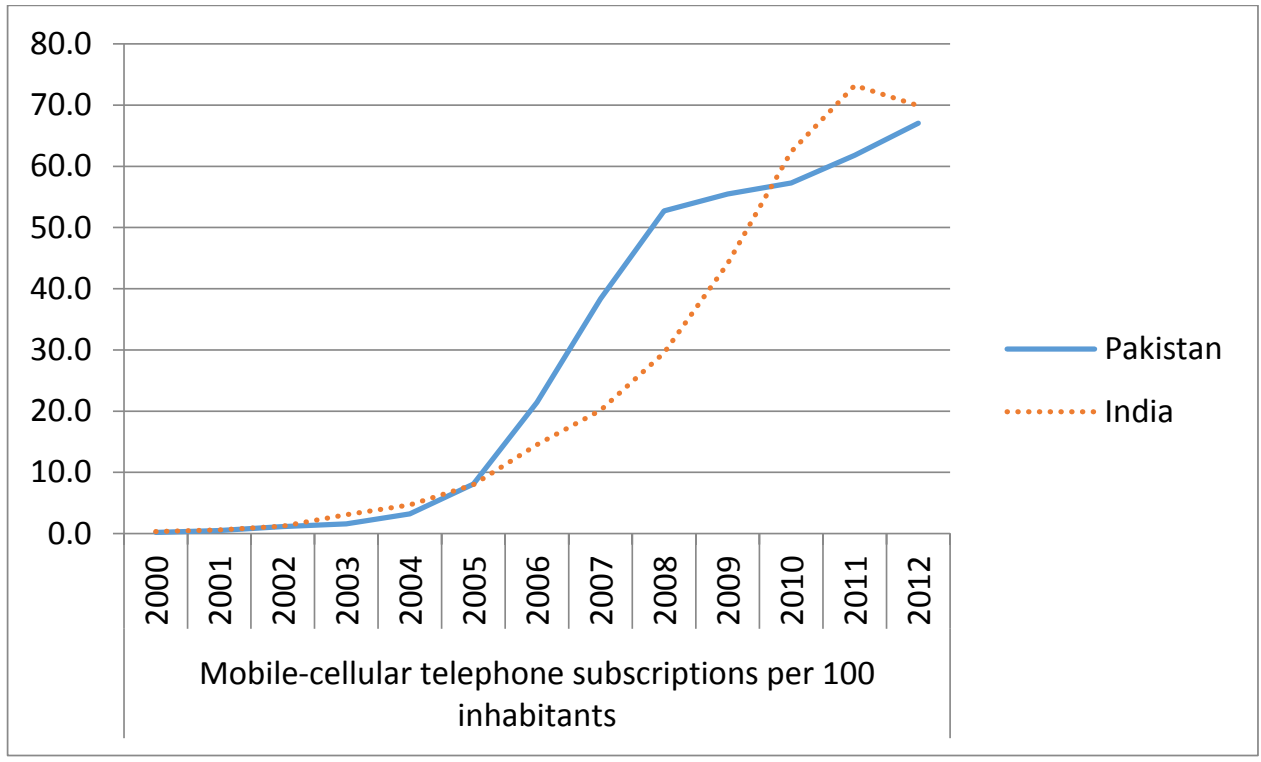

Source: ITU's statistical data portal 


\subsection{The dark side of ICT}

As any other technology, there is a negative side to the ICT-coin as well. The possible negative impacts of ICT have been explored from very different perspectives, ranging from the negative fallout on environment from its excessive use (Plepys \& Boada, 2005) to increasing the digital divide (Dijk \& Hacker, 2003). In the context of developing countries in general and Pakistan in particular, a few issues need mentioning here. Rural areas have experienced a growing digital divide as a result of the growth in ICT services, infrastructure and access which has overwhelmingly been urban focused. As a consequence, the less educated, non-English speaking and those not possessing access to ICT have been socially excluded as a marginalized group. Moreover, cyber-crimes and privacy breaches are on the rise. Reports suggest that those youth who are unable to effectively use ICT to benefit from it due to lack of education and skills usually waste hours aimlessly surfing, chatting or by visiting adult content. Policy makers have responded to these developments by preparing a "Draft Prevention of Electronic Crimes Bill 2012" with input from various stakeholders. PASHA and Internet Service Providers Association of Pakistan (ISPAK) have been instrumental in this effort while the National Response Center for Cyber Crimes of the Federal Investigation Agency (FIA) and Ministry of Information Technology (MOIT) were also consulted.

\subsection{The way forward}

This chapter establishes that though the ground work for transitioning to a knowledge economy is laid, in order to be able to become competitive at the level of existing global players like India and China, a lot of hard work needs to be put in. These efforts cannot just be limited to the organizational domain but rather would need strong support from the policy makers. The right set of policy instruments would not just focus on pushing from the outside e.g. encouraging more FDI, but also pulling from the inside i.e. to devise a framework which would help firms to absorb spillovers. This is where our study fits in, to ascertain spillovers and their mechanisms. The forthcoming chapters will discuss the method adopted for the measurement of spillovers and will also present our results. 



\section{Chapter 6. Ascertaining and measuring spillovers $^{96}$}

\subsection{Introduction}

In this chapter, we provide an empirical examination of spillovers in the Pakistan ICT sector and its subsectors. The study of this sector is important because ICTs, by virtue of being general purpose technologies, are closely related with productivity growth in the wider economy. Similarly, it being an advanced technology sector makes it more likely for innovations resulting in knowledge spillovers. Especially the software services sub-sector has proven to be optimally suited for developing economies in the context of knowledge spillovers (Kesidou \& Szirmai, 2008).

The elusive nature of spillovers, in terms of measurement, creates great empirical difficulties for researchers. Dunning \& Lundan (2008) discuss three major concerns. The first concern in such measurement studies is the use of labor productivity as a proxy for measuring all components of total factor productivity. The second concern is the neglect of inter-industry spillovers which might be substantial. The third concern regards the sensitivity of the conclusions to sampling bias where for instance including or excluding the smallest or the young firms could affect the results. In our study, we attempted to address some of these concerns by designing an appropriate methodological framework based on data gathered from our own survey which minimizes these effects. More specifically, we have not only focused on labor productivity in our questionnaire/study, but also on innovation outputs and inputs. Next, though we have focused on only one sector, that of ICT, but pay special attention to its sub-sectors in order not to neglect the spillovers occurring among the various sub-sectors. This is important for two reasons, firstly the ICT industry is not only a huge industry itself, but its sub-sectors are very different. For instance Telecommunications and Computer programming have less in common and could well be classified as separate sectors. Secondly, many spillover studies have focused on a specific subsector. Finally, on one hand our sample includes both very young and very small firms, while also including very old and established firms.

Against this backdrop, this chapter aims to first answer whether there are positive productivity spillovers from FDI in the ICT sector in a developing country context. Secondly, the research sheds light on the mechanisms and channels of spillovers and provides new insights by also taking smaller local firms into consideration. Last but not

\footnotetext{
${ }^{96}$ An earlier version of this chapter was published as Qazi (2011).
} 
least, we attempt to identify and interpret the factors that affect the presence (or absence) of spillovers from MNCs to local firms. These could be characteristics of the MNCs, local firms or could be related to government policies.

Our approach in this chapter is to build on the existing empirical literature by focusing on a sector which is highly likely to generate spillovers per se and by choosing a country where FDI in that given sector has been substantial not only in terms of its total share but also in absolute terms. Our objective is two-fold, we start by identifying the determinants of the decision to perform R\&D (what makes one firm opt for doing formal research and not the other) and research intensity (how much effort, in terms of staff or budget, does a firm put into formal $R \& D$ ). As literature disregards $R \& D$ as a determinant for innovation in a developing country context (Benavente, 2006b; Lee, 2011) we were motivated to test this hypothesis as well, by including an R\&D variable. However, as the endogenous nature of R\&D for innovative productivity is well established in literature - does R\&D lead to more innovation or more innovation determines whether or not a firm does R\&D and how much intensively (Crepon, Duguet, \& Mairessec, 1998; Griffith \& Huergo, 2006) - we address this concern by taking the predicted values of the $R \& D$ variable as the explanatory variable. As a second step, we estimate the innovation equation where we include variables for absorptive capacity and labor mobility in addition to the control variables of firm age and firm size. The third step is to find the determinants of economic performance of the surveyed firms. For this purpose we estimate a Cobb-Douglas production function by augmenting innovative performance, absorptive capacity and labor mobility to it. Given the endogenous nature of innovative performance in economic performance equation, we instrumented innovative performance by using its predicted values. The predicted values were acquired from the previous regression equation of innovative performance as a dependent variable. Thus we implement a 3-stage least squares (3SLS) approach.

The remainder of this chapter is organized in the following manner: Section 2 gives a brief literature review, Section 3 presents the salient and relevant (to this chapter) features of the Questionnaire, Section 4 discusses the data and summary statistics, Section 5 details the econometric models used, Section 6 explains the methodology and gives the econometric analysis, Section 7 discusses the results and Section 8 draws the conclusions.

\subsection{Literature Review}

In Chapter 2 we presented an in-depth literature review encompassing all the key concepts surrounding spillovers. The various methods for measuring and assessing spillovers are also discussed in this chapter. Our aim there was to lay the basis and establish the context for a discussion on spillovers. Here however we take the discussion further and focus on the most important and relevant findings to our work in literature. 
In a developing country context, an important focus of empirical studies has been on absorptive capacity and technological gap between the MNC or MNC affiliates and local firms. Empirical results solidify the importance of absorptive capacity for better access to external knowledge (Kesidou \& Szirmai, 2008). Moreover, R\&D has been found to be an important determinant of absorptive capacity, one leading towards innovative output (Griffith, 2003; Kinoshita, 2001; Leahy \& Neary, 2007).

Another major focus of many empirical studies on spillovers remains the presence of MNCs or FDI. Blomström \& Sjöholm (1999) found that MNCs were more productive as compared to domestic firms based on cross-sectional data of Indonesia from 1991. Spillovers measured in terms of labor productivity were positively correlated with degree of foreign presence. The results also pointed out that domestic exporters were the major beneficiaries from these spillovers.

Chuang \& Lin (1999) used Taiwanese cross-sectional data from the 1991 industrial and commercial census. They found positive productivity spillovers from FDI, measured as the share of foreign assets at the industry level.

Haddad \& Harrison (1993) pioneered in using firm-level panel data by studying the manufacturing sector in Morocco in 1985-1989. They also found that foreign firms had higher total factor productivity as compared to domestic firms but concluded that there was no significant relationship between such a presence and productivity growth in domestic firms.

Aitken \& Harrison (1999) found that a foreign equity participation in a joint venture had a positive effect on the productivity of the local venture partner, but with weak results for small firms in Venezuela. Their study found a negative effect of foreign presence when measured in terms of total factor productivity of domestic firms.

Kathuria (2002) measured the productivity gains of local firms listed on the Bombay Stock Exchange from economic reforms in India under the liberal regime. Though the overall effect on domestic firms from the foreign presence was found to be negative, there were certain sectors (e.g. ICT) in which firms with certain level of absorptive capacity benefited from knowledge spillovers from foreign firms.

Wei \& Liu (2006) studied more than 10,000 domestic and foreign owned firms in China and found no FDI related intra-industry productivity spillovers across regions, but positive spillovers within and across industries within regions. Their study reveals that investors from OECD countries have a stronger effect on inter-industry spillovers than Hong Kong, Macao and Taiwan.

Though the debate about positive spillovers from FDI is far from settled in the literature, we are starting to know more about the channels of such spillovers. The treatment of spillovers as a black-box, as it's often called, is now uncommon as more and more researchers are attempting to analyze its various channels of occurrence. $A$ variety of spillover channels have been discussed in chapter 2, including MNCs/FDI, Labor mobility, and ICTs. Amongst these channels, labor or worker mobility is one of the most prominent and promising and will receive special attention in our study. Findings on labor mobility are discussed below. 
MNC investment in human capital is 'embodied' in people and therefore can spill over to local firms in two ways, namely by MNC employees moving to local firms by switching jobs or by them starting up their own businesses in the host country. Doing this workers would transfer knowledge to their new employer/company and thereby knowledge spills over to the new employer/company (Fosfuri et al., 2001; Glass \& Saggi, 2002; Rasiah, 1995). Both types of labor mobility lead to the diffusion of knowledge and skills acquired explicitly or tacitly while working at the MNC. One explanation for higher wages, sometimes called 'efficiency wages', paid by the MNCs is that these serve to restrict undesired worker mobility or 'human capital spillover'. Empirical evidence for this is found by Saggi (2002) while examining data from South Korean firm Daewoo's activities in Bangladesh. Geographical proximity is also understood to play an important role in human capital spillovers, because labor turnover is more than often regionally confined (Girma, 2005).

Fosfuri et al. (2001) analyze technological spillovers from FDI when MNC-trained managers are later hired by a local firm. They find that benefits for the host economy may also take the form of the rent that trained managers receive by the MNC.

Gorg \& Strobl (2005) found that domestic firms owned by ex-employees of MNCs working in the same industry immediately prior to opening up their own firm have higher productivity growth than other domestic firms. This, in their view is suggestive of these entrepreneurs bringing with them some of the knowledge accumulated in the multinational which can be usefully employed in the domestic firm.

Balsvik (2006) explored labor mobility flows from MNCs to domestic firms in Norwegian manufacturing during the 1990s. He found a significantly positive correlation between the share of workers with MNE-experience and the productivity of domestic firms.

Kesidou et. al. (2009), (2008), (2008) conducted an econometric analysis with primary data gathered through a survey of Uruguayan software firms in Montevideo shows that spillovers have a significantly positive impact on firms' innovative performance. The spillover channels identified by them are labor mobility, company spinoffs, and informal interactions among actors.

Using panel data Maliranta et. al (2009) found that though hiring workers from others' R\&D labs to one's own does not seem to be a significant spillover channel, hiring them for one's non-R\&D activities, however, boosts both productivity and profitability.

The ICT spillover debate is marked by the question whether ICT has the characteristics of traditional forms of capital or whether it is more like knowledge capital. If it is like traditional capital investment, this implies that returns benefit mainly the firm or the industry. On the other hand, knowledge capital used by multiple parties simultaneously, results in spillovers. Lee \& Guo (2004) argue that ICT capital has aspects of both forms of capital. They state, "As a production technology, it is similar to traditional forms of capital. In its informational and transformational roles, it is similar to knowledge capital, which associates ICT with knowledge spillovers". Their pioneering 
study establishes the existence of ICT spillovers across country borders. Their empirical study also reveals that less developed countries (e.g. India or Turkey) could reap more benefits from the ICT spillover, than advanced economies. Meijers (2007) also confirmed the existence of both local and international spillovers from ICT in a study based on a panel study for EU-14 plus the USA covering the period 1990 until 2004. He found both domestic spillovers from IT Hardware and International spillovers from IT Software.

\subsection{Applying theory to practice}

This section provides a connection between concepts discussed in the literature review and those we used in designing our study.

\subsubsection{Types/Conceptualization of Spillovers}

\subsubsection{Real (knowledge) spillovers}

The main type of spillovers our study deals with and tries to quantify are real (knowledge) spillovers. As we don't investigate whether or not a market transaction has occurred between the surveyed firms, we are looking at real spillovers or in Verspagen's (1997b) terms, pure spillovers, the 'true externalities'.

\subsubsection{MAR spillovers}

We have assessed geographical proximity of firms with respect to other MNCs and other domestic firms. We were interested in seeing if proximity with the respective firms facilitates innovation and productivity.

\subsubsection{Non-pecuniary spillovers}

Another characterization of spillovers in the literature is done on the basis of their monetary contribution. In contrast to knowledge spillovers (non-pecuniary), pecuniary spillovers operate through prices rather than through real resource effects. They do not impact the production function of the benefiting agent, but affect the profits by either revenue increases or cost reductions. Pecuniary spillovers can occur when multinationals increase the market size for domestic suppliers which can benefit entry, survival and growth of domestic establishments.

\subsubsection{Classification of spillovers}

\subsubsection{Inter-sectoral vs intra-sectoral spillovers}

In terms of classification, in our work we have looked at intra-sectoral spillovers. The sector we considered was ICT, which has very unique and to some degree mutually exclusive subsectors. 


\subsubsection{Intra-national vs Inter-national (cross border) spillovers}

All the firms included in our sample were based in Pakistan and therefore our study is an intra-national study.

\subsubsection{Sources of spillovers}

\subsubsection{Firms}

All respondents in our sample of 93 are firms.

\subsubsection{Universities and R\&D Organizations}

Although we have not interviewed any university or R\&D organization directly, we did inquire whether or not the interviewee received valuable information from such organizations. This way we have considered universities and R\&D organizations as a source of spillovers.

\subsubsection{Exports}

As we measured the share of exports in the total sales, we tested this variable to check whether higher shares of exports cause higher productivity.

\subsubsection{Spillover Channels/Conduits}

\subsubsection{MNCs/FDI}

MNCs/FDI was the main channel of spillovers that we investigated as roughly onefourth of our sample were MNCs.

\subsubsection{Labor mobility}

We have focused in great detail on labor mobility, both from MNCs to domestic firms and vice versa. This is one of the channels which is not researched much yet and needs further investigation.

\subsubsection{Information Technology}

In our survey we try to assess whether or not more frequent interaction leads to more spillovers. While doing so, we also check for which the most important 'modes of interaction' are. We include telephone and email due to the knowledge gathered from literature about IT's role as a spillover channel.

\subsubsection{Spillover Mechanisms}

\subsubsection{Demonstration Effect}

In order to test for demonstration effect we ask the interviewees how much importance do they associate (on a Likert scale) with various sources of information. In the information sources we have MNCs as well with the assumption that firms which 
associate more importance with MNCs as a source of information are actually benefitting from their products or services by copying them or learning from them.

\subsubsection{Competition Effect}

In our survey we tried to capture, at least in part, the competition effect by asking the respondents whether they increased their innovative activities due to the presence of MNCs or Domestic firms depending on whether we are asking a Domestic firm or MNC respectively.

\subsubsection{Spillover Facilitators}

\subsubsection{Size}

We have included the firm size variable in our study in order to test if there is a 'right size' that would facilitate spillovers.

\subsubsection{Absorptive Capacity}

We have included multiple questions to make a clear picture of the firms' absorptive capacity. These include questions about the educational attainment of technical employees and even more detailed questions about the CEO (related to his education and previous experience).

\subsubsection{Geographical/Spatial Proximity}

As discussed above for MAR spillovers, we have attempted to capture geographic proximity.

\subsubsection{Technological Proximity}

As our questions include questions asking firms about their inclusion in an 'ICT cluster', this gives us a rough estimate of that firms technological proximity to its counterparts.

\subsubsection{Measurement Methods}

Our study is set in the micro tradition. We utilize firm-level data from our customdesigned survey - based on Community Innovation Surveys - asking firms which sources of knowledge they have found useful in their innovation process.

Moreover, our approach of measuring spillovers entails the indirect method which relies on evaluating the association between the presence/intensity of the different channels and mechanisms of spillovers (labor mobility, demonstration effect and competition effect) related to FDI and the productivity of the receiving firms. 


\subsection{Research Questions and Hypotheses}

In line with the literature review, we have explored the presence of spillovers by formulating various research questions. Before doing so, we first attempt to find out which basic firm-characteristics are conducive for innovative and economic performance. Literature is full of discussions on firm size, firm age and firm type being predictors of innovativeness and productivity (Damanpour, 1992; Haltiwanger, Lane, \& Spletzer, 1999). We deem it necessary not only from the perspective of adding these characteristics as control variables but also so that our regressions are not affected from omitted variable bias. Along the process we also were able to validate the importance of some of these characteristics through our survey data. Secondly, before moving on to the main spillover variables, we also don't neglect the importance of absorptive capacity for innovativeness and growth with the same reasoning in mind (Castellani \& Zanfei, 2003; Cohen \& Levinthal, 1990; Fosfuri \& Tribó, 2008; Vinding, 2006). Therefore, we have organized our research questions and hypotheses in five sections, each representing a separate area of literature and ongoing research, where we attempt to contribute with this study.

\subsubsection{Firm Characteristics as determinants of firm performance}

We identify three research questions regarding the relationships between firm characteristics and firm performance. For each research question, we specify our expectations or hypotheses.

RQA1 Are MNCs more innovative and more productive than their domestic counterparts? Does this relationship differ from sub-sector to sub-sector?

HypA1 MNCs are more innovative and productive as compared to their domestic counterparts.

RQA2 Are bigger firms more innovative and more productive as compared to their smaller counterparts?

HypA2 Bigger firms are more innovative and productive.

RQA3 Are younger firms more innovative and more productive as compared to their older counterparts?

HypA3 Younger firms are more innovative and productive as compared to their older counterparts.

\subsubsection{Innovative Performance and productive performance}

We formulate one research question regarding the relationship between innovative and productive performance.

RQB1 Are more innovative firms more productive? If so, for which sub-sectors does this hold true and are the effects same in MNCs and domestic firms? 
HypB1 More innovative firms are more productive than less innovative firms.

\subsubsection{Absorptive Capacity and firm performance}

We formulate six research questions about the relationship between absorptive capacity and innovative and productive performance. Human capital is interpreted as one of the indicators of human capital.

RQC1 Are firms which are led by CEOs with more years of education and relevant technical degrees more innovative and more productive?

HypC1 Firms which are led by CEOs with more years of education and relevant technical degrees are more innovative and more productive than other firms.

RQC2 Are firms which are led by CEOs with more diverse job experiences (in terms of number of firms) more innovative and more productive?

HypC2 Firms which are led by CEOs who have previously served at more firms are more innovative and more productive.

RQC3 Does the presence of more foreign qualified technical staff make a firm more innovative and more productive?

HypC3 The presence of more foreign qualified (MS and PhD degree holders) is associated with better innovative and productive performance.

RQC4 Does the presence of more foreign experienced technical staff make a firm more innovative and more productive?

HypC4 The presence of more foreign experienced technical staff would make a firm more innovative and more productive.

RQC5 Are firms which provide more training opportunities to their technical staff more innovative and more productive?

HypC5 Firms which train their technical staff for more days per year are more innovative and more productive.

RQC6 Are firms with higher technical staff to employee ratios more innovative and productive?

HypC6 Firms with higher technical staff to employees ratio are more innovative and productive.

RQC7 Are firms who perform formal R\&D more innovative than those that don't?

HypC7 The R\&D decision is positively associated with innovative performance.

RQC8 Does R\&D intensity (measured in terms of number of R\&D employees or R\&D budget) predict innovativeness?

HypC8 Firms that are more R\&D intensive (either in terms of R\&D staff or budget) are more innovative. 


\subsubsection{Labor Mobility Spillovers}

If labor mobility results in better performance, we interpret this as evidence for labor mobility spillovers. We formulate three research questions.

RQD1 Are firms which are led by CEOs with previous MNC experience more innovative and more productive?

HypD1 Firms that are led by CEOs who have previous MNC experience are more innovative and productive.

RQD2 Does the presence of more MNC experienced technical staff make a firm more innovative and more productive?

HypD2 Firms with more MNC experienced technical staff are more innovative and more productive.

RQD3 Are firms which are led by CEOs with previous foreign experience more innovative and more productive?

HypD3 Firms which are led by CEOs who have prior foreign experience are more innovative and more productive.

\subsubsection{Spillovers (through Demonstration Effect)}

RQE1 Are firms which associate more importance with MNCs as an information source more innovative and more productive?

HypE1 We hypothesize that firms which associate more importance with MNCs as a source of technology are more productive and innovative.

\subsection{Sampling Technique and Target Population}

As it is practically not possible to survey the complete population (time and money constraints), we had to rely on sampling. A small, but carefully chosen sample can be used to represent the population. If chosen correctly, the sample reflects the characteristics of the population from which it is drawn. Econometrically speaking, random sampling technique (probability sampling) should have been the method of choice because each member of the population has a known and equal chance of being selected. This gives the advantage that the sampling error - the degree to which a sample might differ from the population - can be calculated. Random sampling requires the population to be known beforehand, both in terms of numbers and identifiers (e.g. firm names) so that samples can be drawn from the list using some algorithm for random selection. However as is clear from the discussion above, unregistered firms make it impossible to estimate the total number of firms in our population let alone ascertain their names. This leaves us with the option to adopt a non-probability sampling 
technique, which is as representative as possible. Purposive sampling techniques have also been referred to as nonprobability sampling or purposeful sampling or "qualitative sampling." As noted above, purposive sampling techniques involve selecting certain units or cases "based on a specific purpose rather than randomly" (Abbas \& Charles, 2003, p. 713). Of the multiple categories of purposive sampling based on the specific types of strategies we want to achieve representativeness. Following this strategy, we select a purposive sample that represents a broader group of cases as closely as possible. All firms were visited in person and after gathering lists of registered and unregistered firms (through personal knowledge, friends and other registered firms) we shortlisted firms which would meet our criteria in order to ensure representativeness of the sample. Then, using a system of references we approached these firms to setup a meeting. This route through a reference warranted that only about 2-5 firms declined our request for an interview. Moreover, if we had insufficient numbers in one category, we would continue to prioritize firms in that category for interviews. Unlike random sampling, which deliberately includes a diverse cross section population characteristics, the idea behind purposive sampling is to concentrate on firms with particular characteristics which will enable us to answer our research questions. These characteristics are discussed below.

\subsubsection{ICT Subsector}

Our target population comprises a mix of registered and unregistered firms in 4 ICT subsectors included in our study. These subsectors are Computer Programming, Telecommunications, ICT Manufacturing \& Assembly and ICT Trading. It is important to mention that firms in the ICT sector usually don't fall in one neat category but the nature of this sector is such that a telecommunications firm might be doing computer programming as well and a manufacturing firm might be trading equipment as well. Considering this we categorize the firms according to their 'principal subsector' i.e. the sector which they are active in primarily. Below we discuss the subsectors with respect to their populations:

\subsubsection{Computer Programming}

There are a total of 1082 registered computer programming related firms in Pakistan out of which 60 are MNCs according to the Pakistan Software House Association (PASHA) (2008). In addition to these registered firms there are a lot of (especially young and small) unregistered firms. This has to do with the fact that registering your firms is not a condition for starting operations or opening a bank account in Pakistan. Hence, startups avoid or delay registering their firms in order to escape the governmental taxation net and the associated paperwork especially in their initial, mostly unproductive period. Such firms are mostly founded around a new idea or technology in are therefore very knowledge intensive. Wary of these facts, we ensured that some 
of such unregistered but promising startups were included in our sample because they are at times the most innovative of all.

\subsubsection{Telecommunications}

The telecommunications subsector has two kinds of firms, the big MNCs which are telecom operators ${ }^{97}$ and network equipment providers $^{98}$, and the smaller domestic firms which are their contractors and suppliers. Here again we faced a situation similar to the computer programming subsector that the smaller contractors and suppliers are usually not registered firms. Moreover, unlike computer programming, there is no body or association of telecom operators or their contractors which would keep a record of all registered firms.

\subsubsection{ICT Manufacturing \& Assembly}

ICT firms doing primarily industrial level manufacturing are very few in Pakistan. There are no semiconductor device fabrication labs and very few hardware manufacturing industries. The focus in this subsector was more on assemblers, firms that put together various imported parts to manufacture an end-product. These firms usually have their sales outlets clustered together in one big shopping plaza or market in the main cities. ${ }^{99}$ Here too there is no single authority listing and keeping a record of all firms which makes it difficult to access to total number of firms active in this subsector.

\subsubsection{ICT Trading}

ICT trading firms are those firms which are the principals and distributors of foreign firms without a direct presence in Pakistan. These trading firms at times bring-in the most innovative and technologically advanced products. They usually provide limited direct support and in case of problems refer their clients back to the manufacturing firm. These firms don't form a monolithic block themselves and could be represented in the chamber of commerce or be part of importers. Again, unregistered firms and having no single repository of firms makes it impossible in this subsector too to estimate the population.

Now the objective of our sampling technique was not only to have a representation of all these 4 subsectors but also in the following categories:

\subsubsection{Geographical locations}

As a big majority of the firms within the population are located within three major cities (Karachi, Lahore and Islamabad) we chose all three cities to conduct our survey

\footnotetext{
${ }^{97}$ Out of the 5 telecom operators (Zong, Mobilink, Telenor, Warid and Ufone) 4 are MNCs and one is a domestic firm

${ }^{98}$ Which include but are not limited to ZTE, Huawei, NokiaSiemens Mobile, Ericsson etc.

${ }^{99}$ Hafeez center in Lahore and Gul Haji plaza in Peshawar, Blue Area market in Islamabad are examples of that.
} 
and ensured that all three cities are represented. The importance of each city is unique. Islamabad hosts the most MNCs and had therefore to be a part of the survey. Karachi is the financial and industrial capital of the country and therefore home to many ICT firms. Lahore is the provincial capital of Punjab, the biggest province in terms of resources and also the most forward looking in terms of technology and entrepreneurship.

\subsubsection{Ownership}

Our research has a special interest in investigating the relationship of MNCs and domestic firms. For this reason we made sure that our sample consists of a significant number of MNCs in addition to domestic firms.

\subsubsection{Firm size}

As various firms across the sub-sectors differ in firm size measured in number of employees, we selected firms with as few as one employee (computer programming) and went up to firms with thousands of staff (Telecommunications).

\subsection{Data and Descriptive Statistics}

Our data consists of a total of 94 firms, out of which 21 are MNCs and the remaining 73 are domestic ICT firms. The data was gathered primarily in face-to-face interviews of CEOs or other high ranking official within the firm. Some key variables, used for descriptive statistics as well as for the econometric analysis are explained below. Table 6.1 below lists and describes all the variables used in our subsequent model discussion and econometric analysis. 
Table 6.1 Variable description and descriptive statistics

\begin{tabular}{|c|c|c|c|c|c|c|}
\hline Variable & Obs. & Mean & S. Dev. & Min & Max & Description \\
\hline LnProd & 78 & 0.78 & 1.55 & -2.3 & 5.18 & Ln of turnover per employee in current prices 2010 \\
\hline $\mathrm{RnD}$ & 93 & 0.16 & 0.37 & 0 & 1 & $R \& D$ dummy where doing $R \& D$ is $R n D=1$ \\
\hline RnD_Stf & 92 & 1.6 & 6.6 & 0 & 50 & Number of R\&D staff \\
\hline LnEmp & 86 & 3.12 & 1.91 & 0 & 8.41 & Ln of total employees in 2010 \\
\hline Age & 93 & 9.72 & 9.42 & 1 & 59 & Age of firm in years \\
\hline MNC & 93 & 0.25 & 0.43 & 0 & 1 & Firm type dummy where Domestic $=0, M N C=1$ \\
\hline CMExpD & 93 & 0.21 & 0.41 & 0 & 1 & CEO's MNC experience dummy \\
\hline CFExp & 93 & 0.46 & 1.24 & 0 & 9 & Number of foreign jobs the CEO has previously held \\
\hline CEdu & 93 & 5.66 & 3.32 & 1 & 14 & $\begin{array}{l}\text { Education of CEO } \\
\text { Diploma IT=1, Simple Bachelors =2, Simple Masters=3, } \\
\text { Chartered Accountant=4, M.Sc. =5, BCS=6, B.Sc. } \\
\text { Engineering=7, M. Phil.=8, MBA=9, MCS=10, M.Sc. } \\
\text { Engineering=11, M.Sc. Engineering (Foreign)=12, PhD } \\
\text { Engineering=13, PhD Engineering (Foreign)=14 }\end{array}$ \\
\hline MncExp & 76 & 10.81 & 17.52 & 0 & 75 & Percentage of MNC experienced technical staff \\
\hline Source_Mnc & c 93 & 2.92 & 1.52 & 0 & 5 & $\begin{array}{l}\text { Level of importance associated with MNCs as a source of } \\
\text { information for innovation }\end{array}$ \\
\hline FExp & 77 & 21.55 & 25.62 & 0 & 100 & Percentage of Technical staff who have foreign experience \\
\hline FEdu & 67 & 8.70 & 16.78 & 0 & 100 & $\begin{array}{l}\text { Percentage of technical staff who have foreign MS and/or } \\
\text { PhD degrees }\end{array}$ \\
\hline Training & 93 & 6.60 & 9.20 & 0 & 40 & Total days of internal and external trainings per year \\
\hline TechStaff & 85 & 0.59 & 0.24 & 0.1 & 1 & $\begin{array}{l}\text { Ratio of technical staff to total employees (technical staff } \\
\text { intensity) }\end{array}$ \\
\hline CExp & 93 & 1.81 & 2.05 & 0 & 10 & Total number of previous jobs held by CEO \\
\hline Gov_Loan & 93 & 5.05 & 1.95 & 1 & 6 & Governments role to assist innovation: Loans \\
\hline Lnlnvest & 86 & -2.36 & 1.77 & -6.8 & 69 & $\begin{array}{l}\text { Ln of total amount in Rupees invested in FY 2009-10 divided } \\
\text { by total employees }\end{array}$ \\
\hline Procln & 93 & 0.43 & 0.50 & 0 & 1 & $\begin{array}{l}\text { Process Innovation Dummy }=1 \text { if firm had at least } 1 \text { process } \\
\text { innovation in last } 5 \text { years }\end{array}$ \\
\hline Prodln & 93 & 0.83 & 0.38 & 0 & 1 & $\begin{array}{l}\text { Product Innovation Dummy }=1 \text { if firm had at least } 1 \text { process } \\
\text { innovation in last } 5 \text { years }\end{array}$ \\
\hline Export & 80 & 19.75 & 31.55 & 0 & 100 & Percentage of sales from exports in FY 2009-10 \\
\hline MNC_Exp & 93 & 0.22 & 0.41 & 0 & 1 & $\begin{array}{l}\text { Dummy variable for CEO MNC experience (Experience }=1 \text {, } \\
\text { No experience }=0 \text { ) }\end{array}$ \\
\hline Mnc_Prox & 93 & 0.16 & 0.37 & 0 & 1 & MNC Proximity Dummy = 1 if firm located close to a MNC \\
\hline Dom_Prox & 93 & 0.18 & 0.39 & 0 & 1 & $\begin{array}{l}\text { Domestic Proximity Dummy = } 1 \text { if firm located close to a } \\
\text { Domestic firm }\end{array}$ \\
\hline FDegree & 68 & 2.94 & 8.60 & 0 & 60 & $\begin{array}{l}\text { Total number of staff who have a foreign (Masters or PhD) } \\
\text { degree }\end{array}$ \\
\hline
\end{tabular}




A survey was conducted in three major cities of Pakistan, Islamabad (federal capital), Lahore (capital of biggest province Punjab) and Karachi (industrial capital and capital of the province Sindh). Together these cities accommodate up to $90 \%$ percent of ICT firms in Pakistan and the remaining ones are dispersed equally all over the remaining cities. Approximately $25 \%$ firms in our sample are MNCs and the remaining $75 \%$ are domestic players. Considering the fact that the total population of MNCs in the Pakistani ICT sector is less than 70 firms, we have succeeded in including almost $30 \%$ of the total population. This was important because we were interested in knowledge and labor flows 'from' MNCs. The highest number of registered firms, especially MNCs is in Islamabad. This is also reflected in our sample. Table 6.2 shows that a big majority of MNCs surveyed were located in Islamabad, which is not surprising given the fact that Islamabad is the capital and is the best in terms of security and other such factors important for MNCs and not so well catered for in other major cities of Pakistan.

Table 6.2 Firm type by location

\begin{tabular}{lcccc}
\hline Firm type & \multicolumn{3}{c}{ Location } & Total \\
\cline { 2 - 4 } & Islamabad & Lahore & Karachi & 23 \\
\hline MNC & 15 & 2 & 6 & 100 \\
Domestic & 65.22 & 8.7 & 26.09 & 71 \\
\% & 24 & 22 & 25 & 100 \\
Total & 33.8 & 30.99 & 35.21 & 94 \\
\hline
\end{tabular}

As mentioned earlier, the ICT sector encompasses four principal subsectors ${ }^{101}$, Manufacturing, Trading, Computer programming and Telecommunications, we also characterized firms on these lines as shown in Table 6.3. As typical for developing countries, the ICT industry in Pakistan too is geared towards computer programming and consulting. In addition to this, telecommunications has been the main sub-sector where FDI has flown-in in form of big MNC telecommunications firms to benefit from the deregulation policies of recent years and the growing demand for communications in an emerging economy and exploding population. ICT manufacturing should be seen as any kind of manufacturing or assembly of electronic components and parts. ICT trading firms are those which mainly import hardware from abroad and sell it in the Pakistani market.

\footnotetext{
${ }^{101}$ Principal subsector refers to one of the 4 subsectors in which the interviewed firm is primarily active. These are ICT Manufacturing \& Assembly, ICT Trading, Computer programming and Telecommunications. It is quite possible that a firm is also active in one, two or all three of the remaining subsectors.
} 
Table 6.3 Firm type distribution by principal subsector

\begin{tabular}{lccccc}
\hline & \multicolumn{5}{c}{ Principal Subsector } \\
\cline { 2 - 6 } Firm type & $\begin{array}{c}\text { ICT } \\
\text { Manufacturing }\end{array}$ & $\begin{array}{c}\text { Computer } \\
\text { Programming }\end{array}$ & ICT Trading & Telecom & Total \\
\hline MNC & 4 & 0 & 7 & 12 & 23 \\
$\%$ & 17.4 & 0 & 30.4 & 52.2 & 100 \\
Domestic & 17 & 10 & 37 & 7 & 71 \\
$\%$ & 23.9 & 14.1 & 52.1 & 9.9 & 100 \\
Total & 21 & 10 & 44 & 19 & 94 \\
$\%$ & 22.3 & 10.6 & 46.8 & 20.2 & 100 \\
\hline
\end{tabular}

Table 6.4 Research decision by principal subsector

\begin{tabular}{lccc}
\hline & \multicolumn{3}{c}{ Firm R\&D Decision } \\
\cline { 2 - 4 } Principal Subsector & No & Yes & Total \\
\hline ICT Manufacturing & 11 & 10 & 21 \\
ICT Trading & 10 & 0 & 10 \\
Computer Programming & 41 & 2 & 43 \\
Telecommunications & 16 & 3 & 19 \\
Total & 78 & 15 & 93 \\
\hline
\end{tabular}

Table 6.4 shows that ICT manufacturing firms most often decide in favor of formal R\&D activities. As one would expect the ICT traders don't opt for R\&D at all. Judging by research output, Computer Programming is the subsector with the most product and process innovations as shown in Table 6.5 and 6.6.

Table 6.5 Product Innovation dummy by principal subsector

\begin{tabular}{lcc}
\hline & \multicolumn{2}{c}{ Product Innovations } \\
\hline Principal_Subsector & No & Yes \\
ICT Manufacturing \& Assembly & 3 & 18 \\
ICT Trading & 1 & 9 \\
Computer Programming etc. & 11 & 32 \\
Telecommunications & 1 & 18 \\
\hline
\end{tabular}

Table 6.6 Process Innovation dummy by principal subsector

\begin{tabular}{lcc}
\hline & \multicolumn{2}{c}{ Process Innovations } \\
\hline Principal_Subsector & No & Yes \\
ICT Manufacturing \& Assembly & 12 & 9 \\
ICT Trading & 6 & 4 \\
Computer Programming etc. & 28 & 15 \\
Telecommunications & 7 & 12 \\
\hline
\end{tabular}


A larger percentage of MNCs surveyed were profitable in the last fiscal year as compared to domestic firms, as shown in Table 6.7.

Table 6.7 Firm type distribution by profitability

\begin{tabular}{lcccc}
\hline & \multicolumn{3}{c}{ Profitability } \\
\cline { 2 - 5 } & Increased & Constant & Decreased & Total \\
\hline MNC & 13 & 7 & 3 & 23 \\
Domestic & 56.5 & 30.4 & 13.0 & 100 \\
$\%$ & 21 & 36 & 14 & 71 \\
Total & 29.6 & 50.7 & 19.7 & 100 \\
$\%$ & 34 & 43 & 17 & 94 \\
\hline
\end{tabular}

$($ Pearson chi2 $(2)=5.4752 \operatorname{Pr}=0.065)$

Table 6.8 can be interpreted to mean that domestic firms overwhelmingly perceive their MNC counterparts as a threat due to the increased competition which could be associated with their superior technology and better trained workforce.

Table 6.8 Mutual perceptions of MNCs and Domestic firm

\begin{tabular}{lccc}
\hline & & Counterpart perceived & \\
\cline { 2 - 4 } Firm type & Threat & Opportunity & Total \\
\hline MNC & 2 & 21 & 23 \\
$\%$ & 8.7 & 91.3 & 100 \\
Domestic & 42 & 29 & 71 \\
$\%$ & 59.2 & 40.9 & 100 \\
Total & 44 & 50 & 94 \\
$\%$ & 46.8 & 53.2 & 100 \\
\hline
\end{tabular}

$($ Pearson $\operatorname{chi} 2(1)=17.7653 \mathrm{Pr}=0.000)$

Table 6.9 validates the claim in literature that MNCs train their staff more than domestic firms as it can be seen that half of the surveyed domestic firms don't train their staff at all whereas only $17 \%$ of MNCs refrain from trainings.

Table 6.9 Total days of training by firm type

\begin{tabular}{lccccc}
\hline & \multicolumn{3}{c}{ Total days of training } \\
\cline { 2 - 6 } Firm type & None & $1-10$ & $11-30$ & $>31$ & Total \\
\hline MNC & 4 & 12 & 6 & 1 & 23 \\
$\%$ & 17.4 & 52.2 & 26.1 & 4.4 & 100 \\
Domestic & 35 & 25 & 10 & 1 & 1.4 \\
$\%$ & 49.3 & 35.2 & 14.1 & 2 & 100 \\
Total & 39 & 37 & 16 & 2.1 & 94 \\
$\%$ & 41.5 & 39.4 & 17 & 100 \\
\hline
\end{tabular}

(Pearson chi2(3) $=7.7078 \mathrm{Pr}=0.052)$ 
Table 6.10 Total days of training by firm size

\begin{tabular}{lccccc}
\hline & \multicolumn{5}{c}{ Total Days of Training of Average Tech. Staff } \\
\cline { 2 - 6 } No of Employees & 0 days & $1-10$ days & $10-30$ days & 30 or more & Total \\
\hline $1-5$ & 14 & 6 & 0 & 0 & 20 \\
$6-10$ & 7 & 3 & 1 & 0 & 11 \\
$11-20$ & 4 & 6 & 3 & 0 & 13 \\
$21-100$ & 7 & 13 & 4 & 1 & 25 \\
$101-250$ & 1 & 2 & 3 & 0 & 6 \\
$251-1000$ & 1 & 2 & 3 & 1 & 5 \\
$1001-4500$ & 0 & 2 & 2 & 2 & 86 \\
Total & 34 & 34 & 16 & & 6
\end{tabular}

Table 6.10 shows that larger firms don't necessarily train their technical staff more when compared to smaller firms. Table 6.11 shows that the percentage of technical staff with prior MNC experience is much higher in MNCs, but there is a reasonable percentage of such staff even in domestic firms. This makes it more relevant and interesting to test whether this outflow of experienced technical labor to domestic firms can predict higher productivity.

Table 6.11 Mean value of MNC trained technical staff by firm type

\begin{tabular}{lccc}
\hline & \multicolumn{3}{c}{ MNC Experienced Tech Staff Percentage } \\
\cline { 2 - 4 } Firm type & Mean & Count & Missing \\
\hline MNC & 25.8 & 23 & 9 \\
Domestic & 7.3 & 71 & 8 \\
\hline
\end{tabular}

The importance of CEO's who have prior MNC experience was established by Görg \& Strobl (2005b). Table 6.12 shows us that $11 \%$ of the domestic firms in our sample do have CEOs with prior MNC experience. This variable will also be tested for significance in predicting higher productivity.

Table 6.12 CEO's MNC experience by firm type

\begin{tabular}{lccc}
\hline & & CEO's MNC Experience & \\
\cline { 2 - 4 } Firm type & No experience & MNC Experience & Total \\
\hline MNC & 11 & 12 & 23 \\
$\%$ & 47.8 & 52.2 & 100 \\
Domestic & 63 & 8 & 71 \\
$\%$ & 88.7 & 11.3 & 100 \\
Total & 74 & 20 & 94 \\
$\%$ & 78.7 & 21.3 & 100
\end{tabular}


The descriptive statistics suggest that MNC'S CEOs and Technical Staff usually have more prior MNC experience and training. Similarly there is evidence that suggests that substantive labor mobility takes place from MNCs to Domestic firms. Therefore we have reason enough to econometrically verify the relation between MNC experienced labor stock and productivity. In the next section we present our results and their interpretation.

These descriptive statistics provide preliminary evidence in support of the idea that firms who have managers who moved from multinationals to domestic firms perform "better" than others. This may indicate that such individuals bring some of the knowledge from their previous experience with them, which then "spills over" to the new firm. The figures are, of course, averages over fairly heterogeneous firms and the summary statistics may confound the effects of different sector, firm or owner characteristics. We therefore turn to an econometric analysis in order to disentangle the effect of foreign experience/training from other variables impacting on firm productivity.

\subsection{Model specification}

\subsubsection{Why do firms perform R\&D}

As discussed earlier, we first need to relate the firm's R\&D input to its determinants. For this purpose do so, we use a probit model since R\&D decision $\left(r d^{*}\right)$ is a dummy variable.

In particular, we assume that the ith firm's R\&D decision is based on some latent selection criterion which has the following form:

$$
r d_{i}^{*}=x_{0 i} \beta_{0}+\varepsilon_{0 i}
$$

where $x_{0 i}$ is the vector of determinants of R\&D decision, $\beta_{0}$ is the vector of corresponding coefficients, and $\mathcal{E}_{0 i}$ is an error term.

Since the only observable information for research decision is whether the firm chooses to do research or not, we define, for the ith firm, the unobserved utility of carrying out R\&D as:

$$
R n D_{i}^{*}=x_{i}^{\prime} \beta+\varepsilon_{i}, \varepsilon_{i} \sim \operatorname{NID}(0,1)
$$

where similar to equation $6.1, \beta$ is the vector of corresponding coefficients, $\varepsilon_{i}$ is a normally and independently distributed error term and $x_{i}^{\prime}$ is a vector of all potential predictors in our regression as follows, which can explain this utility difference 
$x_{i}=($ LnEmp, Age, Type, Training, CEdu, CMExpD, Mnc_Prox, Dom_Prox, MncExp)

A firm carries out $R \& D$, if the utility derived from performing $R \& D$ exceeds a certain threshold level, and we assume this threshold level to be zero. Hence, the Probit model can be written as:

$$
\begin{array}{ll}
R n D_{i}=1(\text { firm does } R n D) & \text { if } R n D_{i}^{*}>0 \\
R n D_{i}=0(\text { firm doesn't do } R n D) & \text { if } R n D_{i}^{*} \leq 0
\end{array}
$$

Another dependent variable used was the (RnD_Stf) which is a continuous variable and therefore the simple OLS regression was used to find its determinants. We kept all the independent variables unchanged for this model.

\subsubsection{What are the determinants of innovation?}

As a second step we regress R\&D output (innovative performance) on R\&D and other probable determinants of innovative performance which contribute to its variability. We follow (Griffith et al., 2006) and (Hall et al., 2009), in that we use both product and process innovations to indicate the innovative performance. Hence, our model of R\&D output for the ith firm is the following:

$$
\begin{array}{ll}
p d_{i}=1 & \text { if } \quad p d_{i}^{*}=r d_{i} \alpha+y_{i} \gamma+u_{1 i}>c \\
p c_{i}=1 & \text { if } \quad p c_{i}^{*}=r d_{i} \alpha+y_{i} \gamma+u_{2 i}>c
\end{array}
$$

where $r d_{i}$ here is either the predicted value of R\&D Dummy $(\mathrm{RnD})$ or the predicted value of R\&D Staff (RnD_Stf) computed from the R\&D equation. Predicted values from equation (6.2) are used to instrument the R\&D input variables (research decision and research staff) in order to avoid endogeneity bias which can be expected given the endogenous nature of $R \& D$ input variables in the R\&D output equation. We dropped some explanatory variables from the R\&D equation in order to avoid the innovation equation to be unidentified. $p d_{i}$ and $p c_{i}$ are product and process innovation dummies (i.e., Procln and Prodln) and each takes the value 1 if the corresponding latent variables $\left(p d_{i}^{*}\right.$ and $\left.p r_{i}^{*}\right)$ are greater than some threshold level $c$. The vector $y_{i}$ is a vector of covariates (other than R\&D decision) which influences both product and process innovation, and $\gamma$ is the vector of corresponding coefficients.

The explanatory variables included as covariates are:

$y_{i}=($ LnEmp, TechStaff, CExp, FDegree, Age, MNC, Training, CEdu, MncExp, RnD)

Similar to the R\&D equation, we enter LnEmp to control for the size specific characteristics of the firm. We also include other commonly used variables like Age to control 
for those firms which are in business since long and TechStaff which identifies firms which are dense in technical staff, a catalyst for innovative activities. Furthermore, we assume that if a firm has an educated workforce, especially foreign qualified, its stock of absorptive capacity would be higher thereby increasing its probabilities to innovate; the variables FDegree and CEdu are included to capture this information. The effects of a firm's training investment in terms of days are captured in Training. Furthermore, effects of labor mobility, especially from MNC to domestic firms are captured in MncExp. We anticipate that CEOs' experience level will have a positive effect on a firm's innovative performance, as found in literature; therefore we attempt to capture that in CExp.

\subsubsection{What are the determinants of firm productivity?}

The final equation for our model is the productivity output equation 6.7. We use the Cobb-Douglas production function, augmented with product and process innovation to formulate this equation. To follow (Griffith et al., 2006) and (Hall et al., 2009), we also use both innovation outputs (Process and Product) together in one equation. Furthermore, we use two different specifications, one with the predicted innovation derived from $(\mathrm{RnD})$ and the other derived from (RnD_Stf). Therefore, two separate productivity equations for the ith firm are formulated as:

$$
\begin{aligned}
& \operatorname{lprd}_{i}=l_{i} \alpha_{1}+m_{i} \alpha_{2}+\operatorname{prd}_{i} \lambda_{1}+\operatorname{prc}_{i} \lambda_{2}+z_{i} \varsigma+\xi_{1 i} \\
& \operatorname{lprds}_{i}=l_{i} \alpha_{1}+m_{i} \alpha_{2}+\operatorname{prds}_{i} \lambda_{1}+\operatorname{prcs}_{i} \lambda_{2}+z_{i} \varsigma+\xi_{2 i}
\end{aligned}
$$

where $\operatorname{lprd}_{i}$ is the productivity (total sales per total employment, in logarithm) and labeled as (LnProd), $l_{i}$ is the (log of) total employment in 2010, i.e. (LnEmp). Conventionally the Cobb-Douglas production function would have the typical production inputs: raw material cost and net book value, but due to our data restrictions (firms shy away from revealing these figures, especially in a third world country context due to tax reasons), we have relied on a proxy of these inputs in form of log of total investment in the last fiscal year divided by the total number of employees in that year, labeled as (LnInvest). In our equation the variable $m_{i}$ corresponds to this investment input. This is similar to what Hall \& Mairesse (1995) have attempted. For prd $_{i}$ and $p r d s_{i}$, we use the predicted values of Prodln from the equations using $(\mathrm{RnD})$ and (RnD_Stf) as one of the predictors respectively. Similar is the case for $\operatorname{prc}_{i}$ and $\operatorname{prcs}_{i}$. The benefit of using predicted values of innovation output is to control for the endogeneity of these variables in the productivity equations. All our production func- 
tion specifications include the firm type dummy (MNC) and the principal subsector manufacturing dummy (SManu). Moreover, we use interactions (slope shift dummies) of these variables in order to highlight difference in productivity with regards to firm type (domestic vs. MNC) and principal subsector (manufacturing vs. nonmanufacturing).

\subsection{Econometric Analysis and Results}

\subsubsection{Determinants of R\&D performance}

We first discuss the model with RnD_Stf as the dependent variable (see table 6.13) ${ }^{102}$. We anticipated a priori that those firms which have a more educated CEO would be more R\&D intensive and that is reflected from the significance and positive sign of CEdu's coefficient, whereas the same doesn't hold true for the CEO's previous experience in MNEs (CMExpD), which is negative and highly significant. The effect of firm size (as measured by the log of number of workers) on RnD_Stf is positive and significant. Another plausible finding is the highly significant and positive coefficient of MNC, depicting that MNCs are more likely to have more R\&D workers (RnD_Stf).

The results for the R\&D probit model are similar with regard to employment size, CEO education. In addition, there are positive effects of firm age, days of training per year and proximity to multinationals. So in case of the RnD decision, a firm's age, the total days of yearly training and being located close to a MNC are determining factors. Interestingly, whether or not the firm is a multinational is no longer significant.

Table 6.13 Determinants of R\&D performance

\begin{tabular}{lll}
\hline & $\begin{array}{l}\text { Dependent 1 } \\
\text { RnD_Stf } \\
\text { OLS }\end{array}$ & $\begin{array}{l}\text { Dependent 2 } \\
\text { RnD }\end{array}$ \\
\hline Independent Variables & $1.243^{*}$ & Probit \\
LnEmp & $(0.661)$ & $1.100^{* *}$ \\
Age & 0.0932 & $(0.523)$ \\
Export & $(0.116)$ & $0.0859^{*}$ \\
& -0.0113 & $(0.0518)$ \\
MNC & $(0.0243)$ & -0.0411 \\
& $7.070^{* * *}$ & $(0.0258)$ \\
Training & $(2.470)$ & 0.650 \\
& 0.103 & $(2.599)$ \\
\hline 102 Correlation tables for the corresponding regression tables are given in Appendix VIII.
\end{tabular}




\begin{tabular}{lll}
\hline & Dependent 1 & Dependent 2 \\
& RnD_Stf & RnD \\
& OLS & Probit \\
\hline CEdu & $(0.0865)$ & $(0.0444)$ \\
& $0.435^{*}$ & $0.409^{*}$ \\
& $(0.251)$ & $(0.214)$ \\
CMExpD & & \\
& $-6.737^{* * *}$ & $-2.544^{* *}$ \\
Mnc_Prox & $(2.350)$ & $(1.278)$ \\
& -1.664 & $2.474^{*}$ \\
Dom_Prox & $(2.662)$ & $(1.462)$ \\
MncExp & 0.226 & 1.484 \\
& $(1.919)$ & $(1.070)$ \\
Constant & 0.0166 & -0.00303 \\
& $(0.0580)$ & $(0.0390)$ \\
& $-6.009^{* * *}$ & $-10.19^{* *}$ \\
Observations & $(2.089)$ & $(4.334)$ \\
R-squared & & 70 \\
\hline
\end{tabular}

Standard errors in parentheses

${ }^{* * *} \mathrm{p}<0.01,{ }^{* *} \mathrm{p}<0.05,{ }^{*} \mathrm{p}<0.1$

\subsubsection{Determinants of Innovation Output}

Table 6.14 shows the results of the innovation equation. We estimate two innovation specifications for Product Innovation and two for Process Innovation: each one with predicted values of RnD or predicted values of RnD_Stf, as determinants of innovation output. We distinguish specifications where we use the predicted values based on the R\&D decision (columns 2 and 4 of table 6.14) or those based on R\&D staff (columns 1 and 3 of table 6.14). We use the predicted values of (RnD) and (RnD_Stf) generated by using the R\&D equation discussed in the previous section in a probit regression respectively. In case of Process Innovation, the size of the firm, labeled as LnEmp, predicted $R \& D$ decision and predicted R\&D staff have significant positive effects. Larger firms with more R\&D efforts tend to engage more in more process innovations. Age is negatively associated with process innovations, which suggests that younger or newer firms tend to be more innovative. This is what one would expect in this high-tech sector where more and more new firms come into being mostly because of some innovative ideas. Somewhat unexpectedly, the CEO's education (CEdu) and technical staff's previous MNC experience (MncExp) negatively influence process innovation. The finding that CEO's education is negatively associated with the innovative performance of firms 
might be explained by the fact that formal education does make you a better manager but probably is a hindrance in innovative endeavors which require out of the box and creative thinking. This rationale also seems to hold true in case of the foreign qualified technical staff (FDegree) which is negatively correlated with both Product and Process innovation.

In the case of product innovation, there are no significant effects of R\&D efforts, otherwise than in the case of process innovation. Product Innovation is positively influenced by the number of technical staff (TechStaff) which is in line with our expectations. Also otherwise than in the case of process innovation, there is a significant positive effect of CEO experience (CExp). Training is also positively associated with product innovation.

Another intriguing result is the negatively significant coefficient of previous MNC trained technical staff percentage, which is negatively correlated with both Product and Process Innovative Performance (but as we shall see later is positively related to productivity). This suggests that as MNCs' focus in developing countries is not to innovate, but rather to be productive, their technical staff gets groomed in those skills and labor mobility (at technical staff level) doesn't really benefit innovation. Being a multinational ( $\mathrm{MNC}=1$ i.e. $\mathrm{MNC}$ ) also influences both product innovation and process innovation negatively which is in line with our reasoning that MNCs are not playing the role of innovators in the host economy.

Table 6.14 Determinants of Innovation Output

\begin{tabular}{lllll}
\hline & $(1)$ & $(2)$ & $(3)$ & $(4)$ \\
Independent variables & Procln & Procln & $\begin{array}{l}\text { Prodln } \\
\text { (Probit) }\end{array}$ & $\begin{array}{l}\text { Prodln } \\
\text { (Probit) }\end{array}$ \\
\hline LnEmp & (Probit) & (Probit) & 0.168 & 0.185 \\
TechStaff & $0.441^{*}$ & $0.599^{* * *}$ & $(0.500)$ & $(0.362)$ \\
& $(0.227)$ & $(0.230)$ & $3.664 * * *$ & $3.654^{* *}$ \\
CExp & -0.474 & -0.464 & $(1.422)$ & $(1.482)$ \\
& $(1.039)$ & $(1.174)$ & $0.803^{*}$ & $0.798^{* *}$ \\
FDegree & 0.137 & 0.222 & $(0.428)$ & $(0.385)$ \\
& $(0.125)$ & $(0.135)$ & $-0.150 * * *$ & $-0.149 * * *$ \\
Age & -0.0263 & $-0.0471 * *$ & $(0.0442)$ & $(0.0456)$ \\
& $(0.0206)$ & $(0.0192)$ & -0.0656 & -0.0647 \\
MNC & $-0.177^{* *}$ & $-0.236 * * *$ & $(0.0975)$ & $(0.0982)$ \\
Training & $(0.0748)$ & $(0.0896)$ & -2.673 & $-2.512^{* *}$ \\
& $-1.387^{*}$ & -0.839 & $(1.742)$ & $(1.247)$ \\
& $(0.817)$ & $(0.743)$ & $0.187^{* *}$ & $0.180^{*}$ \\
& 0.00374 & -0.00732 & $(0.0896)$ & $(0.102)$ \\
& $(0.0225)$ & $(0.0215)$ & -0.213 & $-0.204^{*}$ \\
& $-0.224 * * *$ & $-0.211^{* *}$ & $(0.130)$ & $(0.117)$ \\
& $(0.0847)$ & $(0.0903)$ & &
\end{tabular}




\begin{tabular}{lllll}
\hline & $\begin{array}{l}(1) \\
\text { Procln } \\
\text { (Probit) }\end{array}$ & $\begin{array}{l}\text { (2) } \\
\text { Procln } \\
\text { (Probit) }\end{array}$ & $\begin{array}{l}\text { (3) } \\
\text { Prodln } \\
\text { (Probit) }\end{array}$ & $\begin{array}{l}\text { (4) } \\
\text { Prodln } \\
\text { (Probit) }\end{array}$ \\
\hline MncExp & $-0.0368^{* *}$ & $-0.0355^{*}$ & $0.109^{* *}$ & $0.105^{* * *}$ \\
& $(0.0180)$ & $(0.0189)$ & $(0.0510)$ & $(0.0380)$ \\
RnD_Stf & $0.225^{* * *}$ & & 0.0189 & \\
& $(0.0861)$ & & $(0.197)$ & \\
RnD & & $3.974^{* * *}$ & & 0.977 \\
Constant & & $(1.249)$ & & $(1.776)$ \\
& $1.418^{*}$ & 1.083 & -0.786 & -0.883 \\
& $(0.839)$ & $(0.808)$ & $(1.757)$ & $(1.021)$ \\
Observations & & & & 58 \\
\hline
\end{tabular}

Robust standard errors in parentheses

*** $p<0.01,{ }^{* *} p<0.05, * p<0.1$

\subsubsection{Determinants of Productivity}

The last and main objective of this chapter is to explore the determinants of a firm's productivity, with innovation performance as one of its probable inputs. The traditional Cobb-Douglas model is employed for this purpose. All of our subsequent productivity specifications use the predicted values of process innovation (Procln) and product innovation (ProdIn), as possible determinants of productivity.

Table 6.15 Predicted Variables

\begin{tabular}{ll}
\hline Variable Name & Description \\
\hline PrInDRHat & Predicted values of Product Innovation using predicted values of RnD \\
PrclnDRHat & Predicted values of Process Innovation using predicted values of RnD \\
PrInDRsHat & Predicted values of Product Innovation using predicted values of RnD staff \\
PrclnDRsHat & Predicted values of Process Innovation using predicted values of RnD staff \\
\hline
\end{tabular}

Table 6.16 Determinants of productivity

\begin{tabular}{lll}
\hline & $(1)$ & $(2)$ \\
VARIABLES & $\begin{array}{l}\text { LnProd } \\
(\text { OLS })\end{array}$ & $($ OLS $)$ \\
\hline LnEmp & 0.0619 & 0.0158 \\
& $(0.181)$ & $(0.185)$ \\
Age & 0.0116 & 0.0390 \\
& $(0.0291)$ & $(0.0303)$ \\
MNC & $-0.691^{*}$ & $-0.611^{*}$
\end{tabular}




\begin{tabular}{|c|c|c|}
\hline & (1) & (2) \\
\hline \multirow[t]{2}{*}{ VARIABLES } & $\begin{array}{l}\text { LnProd } \\
\text { (OLS) }\end{array}$ & $\begin{array}{l}\text { LnProd } \\
\text { (OLS) }\end{array}$ \\
\hline & $(0.380)$ & $(0.374)$ \\
\hline \multirow[t]{2}{*}{ CFExp } & $0.520 * * *$ & $0.468 * * *$ \\
\hline & $(0.160)$ & $(0.148)$ \\
\hline \multirow[t]{2}{*}{ CEdu } & $0.0642^{*}$ & $0.0852 * *$ \\
\hline & $(0.0374)$ & $(0.0406)$ \\
\hline \multirow[t]{2}{*}{ MncExp } & 0.0204 & $0.0288^{*}$ \\
\hline & (0.0169) & $(0.0166)$ \\
\hline \multirow[t]{2}{*}{ Source_Mnc } & $0.308^{* * *}$ & $0.320 * * *$ \\
\hline & $(0.0876)$ & $(0.0918)$ \\
\hline \multirow[t]{2}{*}{ FExp } & $-0.00862^{* * *}$ & $-0.0101 * * *$ \\
\hline & $(0.00289)$ & $(0.00301)$ \\
\hline \multirow[t]{2}{*}{ FEdu } & $0.0131^{* * *}$ & $0.0140 * * *$ \\
\hline & (0.00339) & $(0.00407)$ \\
\hline \multirow[t]{2}{*}{ Training } & $-0.0388 * *$ & $-0.0426 * *$ \\
\hline & $(0.0180)$ & $(0.0187)$ \\
\hline \multirow[t]{2}{*}{ TechStaff } & $-2.025 * * *$ & $-1.796 * *$ \\
\hline & $(0.713)$ & (0.729) \\
\hline \multirow[t]{2}{*}{ CExp } & $-0.167^{*}$ & -0.155 \\
\hline & $(0.0966)$ & $(0.0982)$ \\
\hline \multirow[t]{2}{*}{ Gov_Loan } & $-0.258 * * *$ & $-0.261 * * *$ \\
\hline & $(0.0855)$ & $(0.0845)$ \\
\hline \multirow[t]{2}{*}{ SManu } & $0.981^{* *}$ & $0.872 * *$ \\
\hline & $(0.364)$ & $(0.344)$ \\
\hline \multirow[t]{2}{*}{ LnInvest } & 0.00927 & 0.0605 \\
\hline & $(0.201)$ & $(0.207)$ \\
\hline \multirow[t]{2}{*}{ PrInDRHat } & 0.462 & \\
\hline & $(0.655)$ & \\
\hline \multirow[t]{2}{*}{ PrclnDRHat } & -0.562 & \\
\hline & $(0.549)$ & \\
\hline \multirow[t]{2}{*}{ PrInDRsHat } & & -0.00233 \\
\hline & & $(0.693)$ \\
\hline \multirow[t]{2}{*}{ PrclnDRsHat } & & 0.293 \\
\hline & & $(0.618)$ \\
\hline \multirow[t]{2}{*}{ Constant } & $2.087^{* * *}$ & $1.816^{* * *}$ \\
\hline & $(0.695)$ & $(0.668)$ \\
\hline Observations & 58 & 58 \\
\hline
\end{tabular}




\begin{tabular}{lll}
\hline & $(1)$ & $(2)$ \\
& $\begin{array}{l}\text { LnProd } \\
\text { (OLS) }\end{array}$ & $\begin{array}{l}\text { LnProd } \\
\text { (OLS) }\end{array}$ \\
\hline RARIABLES & 0.801 & 0.797 \\
\hline
\end{tabular}

Standard errors in parentheses

$* * * p<0.01, * * p<0.05, * p<0.1$

Table 6.16 presents the results for labour productivity without interaction terms. Here the CEOs' foreign experience (CFExp), CEOs' education (CEdu), importance associated with MNCs as a source of information (Source_Mnc), foreign qualified technical staff (FEdu) have positive and significant coefficients. Several indicators of learning experience and absorptive capacity all impact positively on firm productivity. Perhaps not surprisingly, the manufacturing subsector has significantly higher productivity than other subsectors, as indicted by the coefficients of the dummy SManu. We have tried using dummies for each of the other three subsectors but none has yielded significant results so we dropped them in our final specification.

On the other hand, other indicators of education and experience have significant negative results. These include foreign experienced technical staff (FExp), total days of training for technical staff per year (Training), technical staff to employees ratio (TechStaff). This suggests that the returns to certain types of investment in human capital are not positive.

Finally, none of the coefficients for the predicted values of process and product innovation are significant. This is an important finding, which suggests that there is no direct link between innovation output and productivity.

\subsubsection{Interactions}

To further explain the role of the explanatory variables we have interacted them with the firm type (MNC) and all sub-sector dummies (SManu, STelco, SSoft, STrad). This is done in tables 6.18 to 6.20 where we introduce the interaction terms (slope shift dummies) in our regression specifications. The interactions with firm type (MNC) reveal whether the underlying effect is different for MNCs versus domestic firms. Similarly the interactions with the principal sub-sector dummies help us understand the results in context of how the effects of our explanatory variables differ for the various sub-sectors. Table 6.16 includes an overview of the interaction terms used in the subsequent regression tables.

Table 6.17 Interaction variables

\begin{tabular}{ll}
\hline Variable Name & Description \\
\hline Manu* MNC & Table 6.17 \\
TSR* MNC & Subsector Manufacturing x Firm Type Dummy \\
& Tech Staff to Employment Ratio x Firm Type Dummy \\
& Table 6.18
\end{tabular}




\begin{tabular}{ll}
\hline Variable Name & Description \\
\hline TSEmpR*Manu & Tech Staff to Employment Ratio x Subsector Manufacturing \\
CEdScr*Manu & CEO Edu Score x Subsector Manufacturing \\
Training*Manu & Total Training Days x Subsector Manufacturing \\
CPJobs*Manu & CEO Previous Jobs x Subsector Manufacturing \\
& Table 6.19 \\
ForETSP*Manu & Foreign Experienced Technical Staff x Percentage Subsector Manufacturing \\
CFExp*Manu & CEO Foreign Experience x Subsector Manufacturing \\
TSr_Mnc*Manu & Technology Source MNC (level of importance) x Subsector Manufacturing \\
Training*Software & Total Training Days x Subsector Computer programming \\
\hline
\end{tabular}

Table 6.18 contains interactions with the MNC dummy (multinationals - nonmultinationals), which is interacted with all the remaining explanatory variables (after dropping insignificant variables, including the predicted innovation variables). The coefficients of the main independent variables show what effect the variable has on productivity for domestic firms (MNC $=0$ ), whereas the coefficients for the interaction terms show whether there is a significant difference in the relationship between a given variable and productivity between MNCs and domestic firms.

Table 6.18 Determinants of productivity with interactions: Firm Type

\begin{tabular}{lll}
\hline & $(1)$ & $(2)$ \\
Variables & LnProd & LnProd \\
\hline LnEmp & -0.00351 & 0.0804 \\
& $(0.0971)$ & $(0.0970)$ \\
Age & 0.0294 & $0.0447^{*}$ \\
& $(0.0264)$ & $(0.0268)$ \\
MNC & $-0.645^{*}$ & $-2.289^{* *}$ \\
& $(0.357)$ & $(0.921)$ \\
CFExp & $0.465^{* * *}$ & $0.350^{* * *}$ \\
& $(0.120)$ & $(0.129)$ \\
CEdu & $0.0751^{*}$ & 0.0646 \\
& $(0.0381)$ & $(0.0397)$ \\
MncExp & $0.0270^{* * *}$ & $0.0220^{* *}$ \\
& $(0.00932)$ & $(0.00942)$ \\
Source_Mnc & $0.307^{* * *}$ & $0.233^{* *}$ \\
& $(0.0896)$ & $(0.0945)$ \\
FExp & $-0.00988^{* * *}$ & $-0.00888^{* *}$ \\
& $(0.00334)$ & $(0.00353)$ \\
FEdu & $0.0138^{* *}$ & $0.0155^{* *}$
\end{tabular}




\begin{tabular}{lll}
\hline & $(1)$ & $(2)$ \\
Variables & LnProd & LnProd \\
\hline \multirow{2}{*}{ Training } & $(0.00628)$ & $(0.00646)$ \\
& $-0.0401^{* * *}$ & $-0.0342^{* * *}$ \\
TechStaff & $(0.0122)$ & $(0.0125)$ \\
& $-1.774^{* * *}$ & $-3.992^{* * *}$ \\
CExp & $(0.592)$ & $(1.208)$ \\
& -0.148 & -0.109 \\
Gov_Loan & $(0.0944)$ & $(0.0963)$ \\
& $-0.252^{* * *}$ & $-0.245^{* * *}$ \\
Manu* MNC & $(0.0653)$ & $(0.0679)$ \\
& $0.897^{* * *}$ & \\
TSR*MNC & $(0.313)$ & \\
& & $3.000^{* *}$ \\
Constant & & $(1.370)$ \\
& $1.977^{* * *}$ & $3.163^{* * *}$ \\
Observations & $(0.602)$ & $(0.911)$ \\
\hline squared & & \\
\hline
\end{tabular}

Standard errors in parentheses

$* * * p<0.01, * * p<0.05, * p<0.1$

The results show that the interaction of firm type dummy (MNC) and principal subsector manufacturing (SManu) gives a positively significant coefficient. This shows that though MNCs are in general less productive than non-MNCs (see coefficient of type), MNCs active in the manufacturing sector are relatively more productive compared to their domestic counterparts. In general, foreign multinationals pay $40 \%$ higher in average wages than domestic firms, and this gap is even bigger in low-income countries of Asia and Latin America. This salary bonus is said to help minimize worker turnover and reduce monitoring costs (Hijzen \& Swaim, 2008). Similarly, when compared to domestic firms, they usually pay higher taxes because their domestic counterparts often times operate without being registered and that is not possible for an MNC. However these disadvantages fade away when it comes to ICT manufacturing, where the competition for skilled labor is very high and even domestic players are big and properly registered. Moreover, customers are much more brand conscious while buying ICT hardware (e.g. a laptop computer) as compared to when the engage in other ICT subsectors. Similarly the interaction of technical staff to employee ratio (TechStaff) and 
firm type dummy gives a positively significant coefficient showing that the positive effect of technical staff to employee is stronger within the MNC category.

In tables 6.19 and 6.20, we present specifications including interactions with (Manu) which shows whether effects of variables on productivity are different in the subsector manufacturing from those in the other sectors (reference category Manu = $0)$. In addition there is one significant interaction term with the Computer programming sector (Training*Software).

Table 6.19 Determinants of productivity with interactions with Sub-sector dummies

\begin{tabular}{|c|c|c|c|c|}
\hline & (1) & $(2)$ & (3) & (4) \\
\hline Variables & LnProd & LnProd & LnProd & LnProd \\
\hline \multirow[t]{2}{*}{ LnEmp } & 0.00210 & 0.0233 & -0.0272 & 0.0531 \\
\hline & $(0.0985)$ & (0.0979) & $(0.0964)$ & $(0.0986)$ \\
\hline \multirow[t]{2}{*}{ Age } & 0.0292 & 0.0301 & 0.0346 & 0.0241 \\
\hline & $(0.0269)$ & $(0.0272)$ & $(0.0255)$ & $(0.0293)$ \\
\hline \multirow[t]{2}{*}{ MNC } & $-0.612 *$ & -0.469 & $-0.593^{*}$ & -0.522 \\
\hline & $(0.361)$ & (0.359) & $(0.346)$ & $(0.370)$ \\
\hline \multirow[t]{2}{*}{ CFExp } & $0.453 * * *$ & $0.496^{* * *}$ & $0.407^{* * *}$ & $0.498 * * *$ \\
\hline & $(0.122)$ & $(0.126)$ & $(0.117)$ & $(0.131)$ \\
\hline \multirow[t]{2}{*}{ CEdu } & $0.0674^{*}$ & 0.0322 & $0.0708^{*}$ & $0.0695^{*}$ \\
\hline & $(0.0387)$ & $(0.0430)$ & $(0.0373)$ & $(0.0400)$ \\
\hline \multirow[t]{2}{*}{ MncExp } & $0.0266^{* * *}$ & $0.0255^{* *}$ & $0.0306 * * *$ & $0.0255^{* *}$ \\
\hline & $(0.00946)$ & $(0.00949)$ & $(0.00935)$ & (0.00981) \\
\hline \multirow[t]{2}{*}{ Source_Mnc } & $0.288^{* * *}$ & $0.255^{* * *}$ & $0.253 * * *$ & $0.279 * * *$ \\
\hline & (0.0904) & $(0.0918)$ & $(0.0875)$ & $(0.0934)$ \\
\hline \multirow[t]{2}{*}{ FExp } & $-0.0108 * * *$ & $-0.0111 * * *$ & $-0.0104 * * *$ & $-0.0112 * * *$ \\
\hline & $(0.00338)$ & $(0.00342)$ & $(0.00326)$ & $(0.00352)$ \\
\hline \multirow[t]{2}{*}{ FEdu } & $0.0128^{*}$ & $0.0119 *$ & $0.0138^{* *}$ & $0.0132 *$ \\
\hline & $(0.00642)$ & $(0.00658)$ & $(0.00613)$ & $(0.00668)$ \\
\hline \multirow[t]{2}{*}{ Training } & $-0.0410 * * *$ & $-0.0395 * * *$ & $-0.0639 * * *$ & $-0.0311 * *$ \\
\hline & $(0.0124)$ & $(0.0125)$ & $(0.0147)$ & $(0.0128)$ \\
\hline \multirow[t]{2}{*}{ TechStaff } & $-1.991 * * *$ & $-1.805^{* * *}$ & $-1.871 * * *$ & $-1.876^{* * *}$ \\
\hline & (0.609) & $(0.607)$ & $(0.580)$ & $(0.626)$ \\
\hline \multirow[t]{2}{*}{ CExp } & -0.146 & -0.163 & -0.0590 & $-0.216^{*}$ \\
\hline & $(0.0958)$ & $(0.0987)$ & $(0.0919)$ & $(0.115)$ \\
\hline \multirow[t]{2}{*}{ Gov_Loan } & $-0.247 * * *$ & $-0.227 * * *$ & $-0.203 * * *$ & $-0.254 * * *$ \\
\hline & $(0.0664)$ & $(0.0682)$ & $(0.0661)$ & $(0.0685)$ \\
\hline \multirow[t]{2}{*}{ TSEmpR*Manu } & $1.296 * *$ & & & \\
\hline & (0.499) & & & \\
\hline \multirow[t]{2}{*}{ CEdScr*Manu } & & $0.114^{* *}$ & & \\
\hline & & $(0.0475)$ & & \\
\hline
\end{tabular}




\begin{tabular}{|c|c|c|c|c|}
\hline & (1) & $(2)$ & (3) & (4) \\
\hline Variables & LnProd & LnProd & LnProd & LnProd \\
\hline \multirow[t]{2}{*}{ Training*Manu } & & & $0.0673 * * *$ & \\
\hline & & & $(0.0208)$ & \\
\hline \multirow[t]{2}{*}{ CPJobs*Manu } & & & & $0.225^{*}$ \\
\hline & & & & (0.119) \\
\hline \multirow[t]{2}{*}{ Constant } & $2.195^{* * *}$ & $2.114 * * *$ & $1.983 * * *$ & $2.094 * * *$ \\
\hline & $(0.633)$ & $(0.634)$ & $(0.588)$ & $(0.659)$ \\
\hline Observations & 58 & 58 & 58 & 58 \\
\hline R-squared & 0.790 & 0.785 & 0.805 & 0.775 \\
\hline
\end{tabular}

Standard errors in parentheses

*** $\mathrm{p}<0.01, * * \mathrm{p}<0.05, * \mathrm{p}<0.1$

Table 6.20 Determinants of productivity with interactions: Sub-sector dummies

\begin{tabular}{|c|c|c|c|c|}
\hline & (1) & $(2)$ & (3) & (4) \\
\hline VARIABLES & LnProd & LnProd & LnProd & LnProd \\
\hline \multirow[t]{2}{*}{ LnEmp } & 0.0210 & 0.00900 & 0.0177 & 0.0337 \\
\hline & $(0.0966)$ & $(0.101)$ & $(0.103)$ & $(0.0986)$ \\
\hline \multirow[t]{2}{*}{ Age } & $0.0510^{*}$ & 0.0287 & $0.0458^{*}$ & 0.0417 \\
\hline & $(0.0263)$ & $(0.0277)$ & $(0.0272)$ & $(0.0269)$ \\
\hline \multirow[t]{2}{*}{ MNC } & -0.577 & -0.565 & -0.588 & -0.371 \\
\hline & $(0.358)$ & $(0.367)$ & $(0.378)$ & $(0.364)$ \\
\hline \multirow[t]{2}{*}{ CFExp } & $0.531^{* * *}$ & $0.341 * *$ & $0.489 * * *$ & $0.337^{* *}$ \\
\hline & $(0.127)$ & $(0.131)$ & $(0.130)$ & $(0.132)$ \\
\hline \multirow[t]{2}{*}{ CEdu } & 0.0533 & $0.0955^{* *}$ & 0.0637 & $0.0684^{*}$ \\
\hline & $(0.0395)$ & $(0.0404)$ & $(0.0406)$ & $(0.0396)$ \\
\hline \multirow[t]{2}{*}{ MncExp } & $0.0243^{* *}$ & $0.0269 * * *$ & $0.0256^{* *}$ & $0.0250 * *$ \\
\hline & $(0.00928)$ & $(0.00976)$ & $(0.00990)$ & $(0.00960)$ \\
\hline \multirow[t]{2}{*}{ Source_Mnc } & $0.278^{* * *}$ & $0.319 * * *$ & $0.245^{* *}$ & $0.273 * * *$ \\
\hline & $(0.0902)$ & $(0.0940)$ & $(0.0955)$ & $(0.0924)$ \\
\hline \multirow[t]{2}{*}{ FExp } & $-0.0124 * * *$ & $-0.0113 * * *$ & $-0.0104 * * *$ & $-0.00928 * *$ \\
\hline & $(0.00345)$ & $(0.00347)$ & $(0.00351)$ & $(0.00350)$ \\
\hline \multirow[t]{2}{*}{ FEdu } & 0.0103 & $0.0148^{* *}$ & $0.0133^{*}$ & 0.0114 \\
\hline & $(0.00664)$ & $(0.00647)$ & $(0.00670)$ & $(0.00677)$ \\
\hline \multirow[t]{2}{*}{ Training } & $-0.0357^{* * *}$ & $-0.0362 * * *$ & $-0.0400 * * *$ & -0.0172 \\
\hline & $(0.0122)$ & $(0.0125)$ & $(0.0130)$ & $(0.0151)$ \\
\hline \multirow[t]{2}{*}{ TechStaff } & $-2.118 * * *$ & $-2.137 * * *$ & $-1.845^{* * *}$ & $-1.673 * * *$ \\
\hline & $(0.618)$ & $(0.641)$ & $(0.627)$ & $(0.613)$ \\
\hline CExp & $-0.230 * *$ & -0.0850 & -0.160 & -0.0749 \\
\hline
\end{tabular}




\begin{tabular}{lllll}
\hline & $(1)$ & $(2)$ & $(3)$ & $(4)$ \\
VARIABLES & LnProd & LnProd & LnProd & LnProd \\
\hline \multirow{2}{*}{ Gov_Loan } & $(0.106)$ & $(0.0965)$ & $(0.103)$ & $(0.0973)$ \\
& $-0.208^{* * *}$ & $-0.288^{* * *}$ & $-0.247^{* * *}$ & $-0.227^{* * *}$ \\
ForETSP*Manu & $(0.0688)$ & $(0.0688)$ & $(0.0691)$ & $(0.0694)$ \\
CFExp*Manu & $0.0331^{* *}$ & & & \\
TSr_Mnc*Manu & $(0.0126)$ & & & \\
Training*Software & & $0.668^{* *}$ & & \\
Constant & & $(0.303)$ & & \\
& & & $0.196^{*}$ & \\
& & & $(0.110)$ & $\left(0.0467^{* *}\right.$ \\
Observations & $2.144^{* * *}$ & $2.204^{* * *}$ & $2.120^{* * *}$ & $1.607^{* *}$ \\
R-squared & $(0.626)$ & $(0.657)$ & $(0.671)$ & $(0.618)$ \\
\hline
\end{tabular}

Standard errors in parentheses

$* * * p<0.01, * * p<0.05, * p<0.1$

The interaction of technical staff to employee ratio (TechStaff) and principal subsector manufacturing (Manu) gives a positively significant coefficient showing that the effect of technical staff to employee ration in firms active in the subsector manufacturing is more pronounced than in the other subsectors. This also holds true for CEOs' education (CEdu), total days of training (Training) and CEO's previous jobs (CExp). Finally, the interaction between total days of training and the subsector Computer programming shows that the effects of training on productivity are more negative in the computer programming subsector.

\subsection{Discussion}

In this chapter, we analyze the determinants of innovation performance and labor productivity and the relationships between innovation performance (process and product innovation), for the Pakistani ICT industry, using primary data collected in a firm-level survey. The results of our econometric analysis are laid out here in the light of our research questions and hypotheses. 


\subsubsection{Basic Firm Characteristics}

(RQA1) Our results suggest that MNCs are negatively correlated with productivity and innovative performance. This goes against our hypothesis as we had assumed that MNCs would be more productive. Though there could be many explanations for this unexpected result, foremost of all is that MNCs have a harder time operating in a competitive market with domestic players, because of the overhead costs due to security concerns and electricity outages known as load-shedding. Domestic firms usually don't spend much on security, don't provide full backup power, usually don't pay all taxes and pay lower wages. This leaves the MNCs less productive. Moreover, more than half of the MNCs (12 of 23) we interviewed were operating primarily in the Telecom sector. This sector attracted the lion's share of FDI in the early years of deregulation policy. The Telecommunication de-regulation policy prepared in 2003 with the objective to de-regulate and liberalize the telecommunication sector withdrew the exclusive rights of Pakistan Telecommunication Company Limited (PTCL) to provide basic telephone services (local, long distance, international and leased line services), which it enjoyed under The Pakistan Telecommunication (Re-Organization) Act 1996. Those exclusive rights expired on 31st December 2002 (Pakistan, 2003). From 2003 onwards, till 2008, telecommunication firms were making windfall profits but the years after 2008 were marked with slow growth ascribed to market saturation and lack of innovation due to the delay in launching $3 G$ services $^{103}$. However, MNCs do tend to do relatively better in the ICT manufacturing and assembly subsector as is evident from the interaction terms.

(RQA2) Firm size (employees) is an important determinant of R\&D (both decision and intensity) and (the likelihood of) process innovation in firms. In case of RnD intensity, it is clear that MNCs are more R\&D intensive than their domestic counterparts. This is also corroborated by Table 6.21 showing the mean (RnD_Stf) for MNC firms to be much higher than for domestic firms. We fail to find a similarly significant and positive relationship for MNCs and the R\&D decision where interestingly the mean values for MNC and domestic firms are almost the same as given in Table 6.22.

Table 6.21 Average R\&D staff by firm type

\begin{tabular}{lllclc}
\hline RnD_Stf & Obs & Mean & Std. Dev. & Min & Max \\
\hline Domestic & 69 & 0.61 & 1.60 & 0 & 7 \\
MNC & 23 & 4.65 & 12.67 & 0 & 50 \\
\hline
\end{tabular}

Table 6.22 Average R\&D decision by firm type

\begin{tabular}{llllll}
\hline RnD & Obs & Mean & Std. Dev. & Min & Max \\
\hline Domestic & 70 & 0.16 & 0.37 & 0 & 1
\end{tabular}

\footnotetext{
${ }^{103} 3 \mathrm{G}$ services are yet to be launched in Pakistan and the auction procedure for issuing licenses for $3 G$ has been marked not only by delays but controversies and legal battles.
} 
$R \& D$ decision variable or $R \& D$ intensity variable. Moreover, for process innovation, the predicted values of R\&D (both intensity and decision) are also significant showing that innovation output in case of processes is dependent on both R\&D decision and intensity. Product innovation however is not dependent on innovation inputs (R\&D decision or R\&D intensity). The number of firms that do process innovations when there is no formal R\&D going on is less than the number of firms which don't whereas the opposite is true for product innovations where the number of firms which do product innovations when there is no formal R\&D is 4 times higher than the number of firms which don't. This suggests that product innovation output is not dependent on R\&D decision, in-line with our empirical finding and corroborated by Table 6.23. Similarly, Table 6.24 and 6.25 extend on this for the Firm Type dimension.

Table 6.23 Process and product innovations by R\&D decision

\begin{tabular}{lll}
\hline Procln & No R\&D & R\&D \\
\hline No & 47 & 6 \\
Yes & 31 & 9 \\
Prodln & & \\
No & 15 & 1 \\
Yes & 63 & 14 \\
\hline
\end{tabular}

(RQA3) Firms' age is positively influencing R\&D Decision meaning that older firms are more likely to perform R\&D than younger ones, whereas they are less like to engage in process innovation. Our interpretation of this finding is that this area (process innovation) is a relatively new field for developing economies like Pakistan where after farming the focus has been traditionally on manufacturing. This explains why most of the firms engaged in process innovations are younger firms.

Table 6.24 R\&D decision by Firm type

\begin{tabular}{lllll}
\hline \multirow{2}{*}{ Firm Type } & \multicolumn{3}{l}{ RnD Decision } \\
\cline { 2 - 5 } & No & \multicolumn{2}{l}{ Yes } & \\
\hline Domestic & Count & & Count & \\
MNC & 59 & $84.30 \%$ & 11 & $15.70 \%$ \\
\hline
\end{tabular}

Table 6.25 Process and product innovations by Firm type

\begin{tabular}{lll}
\hline & Proclnno_Dummy & \\
\cline { 2 - 3 } Firm Type & No Yes
\end{tabular}




\begin{tabular}{lccll} 
& Count & \multicolumn{3}{c}{ Count } \\
\hline Domestic & 44 & $62.90 \%$ & 26 & $37.10 \%$ \\
MNC & 9 & $39.10 \%$ & 14 & $60.90 \%$ \\
\hline
\end{tabular}

\subsubsection{Innovative Performance}

(RQB1) Innovative performance is found not to influence productivity as the coefficients of the two innovative performance variables (product and process innovation) are not significant. In other words, innovation performance is not linked to productivity performance. Similar findings have been found in other studies (Crespi et al., 2014; Kesidou \& Szirmai, 2008). We take it to mean that in a developing country context the returns on R\&D and the resulting innovation are often delayed and therefore not reflected in productivity. Moreover, due to the absence of an innovation system like research institutes, research grants, science parks etc. innovation is a very costly activity with uncertain outcomes. All these factors contribute to firms' loss of productivity while engaging in innovation.

\subsubsection{Absorptive Capacity and Human Capital}

(RQC1) The CEOs' education is positively associated with Productivity, R\&D Staff and the decision to perform R\&D. It is however negatively associated with innovative performance, both process and product. This somewhat unexpected result might be explained by the fact that formal education does make you a better manager but may be a hindrance in innovative endeavors which required out of the box thinking.

(RQC2) The number of a CEO's previous jobs has a negative impact on productivity whereas it has a positive impact on Process Innovative Performance. We interpret this to mean that in order to enhance the productivity of a firm you need a CEO who has been there for a long time and perhaps who has a track record of serving a firm for a long time while having proven his worth. On the other hand, CEOs who have had more exposure to various firms would be expected to be more innovative due to their diverse experience.

(RQC3) Having more foreign qualified technical staff members in a firm increases the likelihood of it being more productive, but it has quite the opposite effect on innovative performance. We interpret this to show that foreign qualification takes you further away from the specific requirements related to innovation in a developing country context.

(RQC3\&4) Paradoxically foreign qualified (education) staff intensity positively affects labor productivity, while foreign experienced staff intensity has quite the opposite effect. We interpret this finding as follows. Those people who get a job exposure abroad usually have higher expectations from their employers on their return to their home countries because of their exposure to the foreign working environment which 
is no doubt very employee friendly compared to Pakistan conditions. This can lead to unfulfilled jobs expectations when they return, creating discontentment and thereby loss of productivity. This is not shared by those students who have gone abroad for education though they too come back with a superior skill set and valuable exposure. (RQC5) Training for technical staff seem to be having quite the opposite effects on Productivity (negative) and Product Innovative Performance (positive). We interpret this to mean that trainings carry a cost which influences productivity negatively, but the outcome of trainings is more innovative outputs.

(RQC6) Technical staff to employee ratio is negatively associated with Productivity and positively associated with Innovative Performance. This is explained by the fact that in order to innovate, a firm needs more technical people but in order to increase the productivity (which is measured in turnover per employee) the presence of marketing, sales and other operational people might be key.

(RQC7\&8) Though insignificant for product innovation, R\&D decision and R\&D intensity (measured in terms of number of dedicated R\&D staff) are positively correlated with process innovation.

\subsubsection{Labor Mobility}

(RQD1) CEOs MNC experience is negatively associated with R\&D Staff and the decision to perform R\&D. This might be explained by the fact that MNCs in Pakistan are actually not into R\&D. Looking at the percentage of MNCs doing R\&D illustrates that. Moreover, most of the (interviewed and actual) MNCs have Telecommunications as their principal subsector and that is not an R\&D intensive sector as foreign companies are here to provide services.

(RQD2) The percentage of technical staff with MNC experience is negatively correlated with both product and process innovative performance, but is positively related to productivity. This shows that as MNCs' focus in developing countries is not to innovate, but rather to be productive, their technical staff gets groomed in those skills (at the expense of the other).

(RQD3) CEOs foreign experience positively predicts productivity, as per expectation.

\subsubsection{Demonstration Effect}

(RQE1) The importance of MNCs as a source of technology is positively related to productivity. We interpret this as demonstration effects because companies who have reported MNC to be an important source are more productive. 


\subsection{Conclusions}

We attempted to delve further into the mechanisms and channels of spillovers in a developing country context within a specialized sector, that of ICT while at the same time analyzing its subsectors for intra-sector differences. Our study has contributed to the existing body of knowledge in by exploring the effects of a set of variables on innovative and productive performance of firms, while relating them to the established mechanisms of spillovers.

Our study has validated some of the established findings in literature. With regards to absorptive capacity and human capital our findings corroborated that CEOs' education is positively associated with Productivity, R\&D Staff and the decision to perform R\&D. Similarly the number of a CEO's previous jobs has a positive impact on Process Innovative Performance. We also found that more foreign qualified technical staff members in a firm increases the likelihood of it being more productive and foreign qualified (education) staff intensity positively affects labor productivity. Training for technical staff and Technical staff to employee ration positively predicts Product Innovative Performance. Firms doing R\&D and those having more number of dedicated R\&D staff are more likely to be involved in process innovations. As for labor mobility, we could confirm that CEOs foreign experience positively predicts productivity. Moreover the finding that firms which point to MNCs as their primary source for technology are more productive validates the demonstration effect.

Some of our findings, with regard to the role of education and performance of multinationals were unexpected and went against established views in literature. This could be due to a number of reasons which we would like to highlight. First and foremost, the results point to the specific conditions and challenges facing both foreign and domestic firms in a developing country context. Next, there may be methodological issues, which need to be addressed in further research. Though the sample size used is as per econometric standards big enough to perform such an analysis ${ }^{104}$, we feel that more robust and reliable results could have been achieved with a bigger sample size. Similarly, the unavailability of good instrumental variables has forced us to tackle the endogeneity problems by using predicted estimates for the variables in question. Moreover, the difference in application of the concept of R\&D across the various subsectors could have also influenced our results of innovative performance.

\footnotetext{
${ }^{104}$ Though generally, for sample sizes it is true that the bigger the better, Verbeek (2004) states "Unfortunately, there is no unambiguous definition of what is 'sufficiently large'. In simple circumstances a sample size of 30 may be sufficient, whereas in more complicated or extreme cases a sample of 1000 may still be insufficient...". However, generally there are a few 'rules of thumb' in practical use. These include Harris' (1985) formula according to which the number of participants should exceed the number of predictors by at least 50 and Green's (1991) formula $\mathrm{N}>50+8 \mathrm{~m}$ (where $\mathrm{m}$ is the number of independent variables) for testing multiple correlation and $\mathrm{N}>104+\mathrm{m}$ for testing individual predictors and the assertion by VanVoorhis \& Morgan, 2007), that while using 6 or more predictors, the absolute minimum of participants per predictor should be 10 , although it is better to go for 30 participants per predictor.
} 
For instance, it is well known that in the Computer programming subsector, firms engage in innovation activities, but this is usually not referred to as R\&D and is not undertaken by scientists or researchers but rather conducted by programmers who come up with new algorithms, routines and programs. This is also evident from the fact that only 2 of the 43 Computer Programming firms indicate that they formally do R\&D while 32 of them had product innovations in the last five years (see table 6.4 and 6.5). Such intra-sectoral differences make it difficult to interpret the results. Another example would be the results of subsector manufacturing and assembly which stand out as compared to the other three subsectors in many of the variables. These challenges have motivated us to further analyze the knowledge and labor flows from a network perspective, which will be discussed in the next chapter. 


\section{Chapter 7. Social capital, networks and firm performance}

\subsection{Introduction}

Advances in understanding of the processes of economic growth and development have called for a periodic redefinition of the concept of capital. In the 1950s, it was limited to physical inputs. Later, in the 1960s, the concept of human capital was added, followed by knowledge capital in the 1990s, in order to better explain growth. In recent years, 'social capital' has been employed in a similar fashion. Although there are many differing definitions of social capital, the common denominator is the possession of resources inherently linked with having a network of relationships which can be drawn upon for accessing technology, technical information and/or market information. More recently the concept of social capital has attained center stage in economics research literature. The causal link between social capital and economic growth is well established in literature (see Durlauf \& Fafchamps (2003) for an overview). Scholars have attempted to explain both economic performance (Akçomak and ter Weel, 2009; Knack and Keefer, 1997) and innovative performance (Dakhli \& Clercq, 2004; Kesidou and Szirmai, 2008), in terms of social capital. Two different approaches have evolved for measuring or assessing social capital from the network related data of countries or other economic actors like firms or individuals. One is called the sociocentric or macro perspective, which focuses on the pattern of connections in the network as a whole (be it among countries, firms or individuals), as being the distinctive contribution of social capital (Barnes, 1974). The other, termed as egocentric or the micro perspective is when one seeks to anchor social networks around particular points of reference which could be countries, firms or individuals (Mitchell, 1969). There are obvious similarities between the micro concept of social capital and the economic concepts of human and physical capital because the creation and maintenance of networks requires investment of scarce resources, primarily time, and the resulting opportunity cost.

Within the micro perspective it is well understood that the creation and maintenance of networks is a costly affair, i.e. big is not always better when it comes to networks. A whole new strand of literature is concerned with such 'constraints' resulting from bigger and denser ego-networks. Our study follows the ego-centric approach and we too explore the notion of constraint in relation to innovative and economic performance of firms. 
The economic actors we analyze from a network perspective are the 94 firms which we interviewed during our survey of the ICT industry in Pakistan. We adopt the definition of social capital given by Nahapiet \& Ghoshal, (1998) who state: "...the sum of the actual and potential resources embedded within, available through, and derived from the network of relationships possessed by an individual or social unit. Social capital thus comprises both the network and the assets that may be mobilized through that network." In light of this definition we derive our regression variables from the network matrices which have captured not only the various relationships (links) but also the resource exchanges of technology, technical information and market information in terms of weighted graphs. The weights in these graphs depict the abundance of resource exchange as a 'heavier' and thereby 'stronger' link. This is in line with the two distinct features of social capital as noted by Portes, (2000) i.e. firstly the network of the relationships which allows individuals to access resources possessed by their partners, and secondly the quality and quantity of resources possessed by a member of the network. Our methodology, in a way, combines both structural elements of a network and the resource dimension. We achieve this by using variables which represent structural information like constraint and centrality (degree, closeness and betweenness) but construct these variables using matrices which contain resource exchange weights and frequencies, both being dimensions which shed light on the strength of ties, not the structural characteristics as such. We have found significant relationships between constraint and centrality variables and the innovative performance and economic performance of firms.

\subsection{Literature Review}

Networks help in gaining information about innovations (Burt, 1987; Coleman, et al., 1966; Kesidou and Szirmai, 2008; Rogers, 2003), for the exchange of fine-grained information (Uzzi, 1997), for accessing information about entrepreneurial opportunities (Burt, 1992) or for information about job opportunities (Portes, 2000). Similarly network benefits could also be in form of material resources. For instance, centrally located actors in a network are believed to be more powerful (Ibarra, 1993). Power can be used to mobilize resources. Although there is not much debate about the potential gains from social capital (read networks) - which are mainly intangible assets like technical and market knowledge or tangible assets like technology - the realization mechanisms vary a lot and therefore remain an area of extensive research. These differences could be related to industry context (Rowley, Behrens, \& Krackhardt, 2000), task context (Moran, 2005) or actor age (Chang, 2011). In order to develop hypotheses about the impact of social capital on innovative and economic performance, we first classify the mechanisms of realization below and then place our study into that hierarchy. 


\subsubsection{Advantages from position in a network: \\ (General embeddedness)}

The foremost question in research on network structures is about the influence network positions have on performance. Embeddedness, as it is generally termed, is broadly defined as "the process by which social relationships shape actions" (Uzzi, 1996). Literature tells us that power arises from occupying advantageous positions in networks of relations. Determining the relative position of an actor in a network is most notably achieved by either betweenness (Freeman, 1977) or centrality (Freeman, 1977, 1979).

Evidence is quite conclusive about more central and embedded firms outperforming others (Soh, 2003; Zaheer \& Bell, 2005). Sophisticated software tools have enabled more detailed empirical network studies which have been on the rise in the last decade. In our study we start with exploring this level of relationships as it would be interesting to corroborate these findings for a high-tech sector (ICT) operating in the context of a third-world country.

\subsubsection{Advantages from structure/configuration of a network: (Structural embeddedness)}

The functions of networks derive from their configuration or structure. One way of comprehending this would be to think of the position within a network as a one-tier measure which tells you about the relative position of the ego with respect to others. Whereas, network structure goes beyond that by taking into consideration another tier or level of links, those of the ego's alters (or even beyond that). Structural embeddedness literature is broadly divided into two strands, those that favor network closures (Coleman, 1994) and those that advocate structural holes (Burt, 1992). The closure argument refers to ego networks "...in which everyone is connected so that no one can escape the notice of others, which in operational terms usually means a dense (local) network" (Burt, 2001) and can also be termed a highly clustered network. Improved communication and informal social sanctions that make trusting another actor in the network less of a risk (e.g. due to the resulting gossip related censure) are the two main benefits of such a configuration in network theory. Similarly, due to the ease of flow of information, reputations are more well-known in these closed networks, enabling an actor to more easily identify a trustworthy partner in a network and also to side-line and take action against cheaters (Rooks, Tazelaar, \& Snijders, 2011).

However, if a network is too closed, it could lead to 'social blindness', which means that the network closes-in on itself and gets inaccessible to the outside world (Uzzi, 1997). The anti-thesis of the closure theory is Burt's (1992) structural hole argument. Burt takes Granovetter's (1973) seminal insight - about weak ties being more likely than stronger ones to act as bridges to heterogeneous information - a step fur- 
ther by arguing that the value of these weak ties doesn't stem from their lack of strength per se. Rather, he asserts, its derived from their greater propensity to connect otherwise disconnected groups making it more likely that such ties will serve as bridges transporting information that is likely to be novel and therefore more valuable. He ascribes value to the power of brokerage which is vested in being connected to otherwise disconnected segments. These weaker connections between groups are considered by him as "holes in the social structure of the market." Those nodes which attain the role of such a bridge have access to different networks of information which could possibly be heterogeneous information and therefore non-redundant. This lends a competitive advantage to those nodes as they can now trade this information between the two groups or use it for their own benefit. As research has shown that in context of innovation such heterogeneous information could be critical, we attempt to ascertain the presence of such structural holes in our dataset. The measure proposed by Burt (2001) to evaluate an actor's connections for the presence and degree of structural holes is network constraint. Network constraint "measures the extent to which a person's contacts are redundant". An actor with a lower network constraint score (higher structural holes) has fewer redundant contacts which could have been a drain on the actor's resources (time, money) despite their inability to deliver any novel resource. Such a position would expectedly generate more value for the actor because it will have access to heterogeneous information and other such opportunities.

\subsubsection{Advantages from relation quality with other actors of the network: (Relational embeddedness)}

Relational embeddedness has been defined in two, arguably different, ways. On the one hand there are those scholars who emphasize the 'quality' of the alters (whom you know vs how many you know) of an ego as a defining factor for this concept. On the other hand, literature is full of references to the strength (or lack thereof) of a tie (how well you know vs how many you know) as the distinguishing characteristic.

In the latter tradition, weak ties are considered to be conduits of novel information between clusters of strongly interconnected nodes. Granovetter (1973) illustrated this in the context of knowledge of job opportunities in his seminal article "Strength of weak ties". Strong ties, on the other hand, are associated with trust, transfer of tacit knowledge and collective problem solving (Granovetter, 1983; Uzzi, $1996,1997)$. Both the tie types have their own benefits and drawbacks, for instance, too many strong ties might lead to 'social blindness' where the ego closes its network and becomes isolated to the outside world, and thereby limits its chances of novel information. This has led researchers to attempt understanding the contextual characteristics of both weak and strong ties (Rowley et al., 2000). 
More recently researchers have also attempted to synthesize the Coleman and Burt theoretical perspectives (Rooks, Szirmai, \& Sserwanga, 2012). In the light of these advances we have developed our research questions as follows:

\subsection{Research Questions and Hypotheses}

In the previous chapter, we explored the determinants of innovative performance and economic performance with a special focus on R\&D and spillover related variables like labor mobility and CEOs' prior experience and education. We laid special emphasis on the differences between MNCs and domestic firms, using interaction terms to ascertain the extent to which these firm types differ in the above mentioned mechanisms. Similarly, we also explored such differences among the various subsectors studied. In this chapter we explore the same dependent variables (innovative performance and economic performance) but with a focus on social capital predictors. We attempt to find whether 'better connected' firms are more innovative and more productive. We use various theoretical conceptions to operationalize what it could mean to be better connected in a firm-level study.

\subsubsection{General embeddedness}

As a first step, we explore whether a more central position of a firm (general embeddedness) can explain innovative as well as economic performance. To achieve this we employ network matrices constructed using data on the link characteristics of 'expected resource'. We have a total of three matrices holding information about expected resource; one each on Technical Knowledge, Market Knowledge and Technology. As a firm could possibly have responded to the question asking which resource it expected from its partner firm within a range of none to all three resources, we have constructed two further matrices derived from the three above. One of these derived matrices is based on the existence of a link between firm A and firm B if firm A expects any of the three resources, i.e. an OR-ing of the three original expected resource matrices. This approach has enriched our network construction because otherwise there were very few connections between firms were we to base our networks on each of the original expected resource matrices. Apart from this, it is also rationally justifiable, and perhaps required, because in this study/research question we are interested in link characteristics irrespective of the exact resource exchanged between the nodes. The second matrix derived from the three original ones is based on summing them up, i.e. an AND-ing operation where the resultant matrix would hold a value of 0 in case no link existed but a value of 1 for the case that all three resource types were expected. This approach also enriches our network construction but at the same time also entails information on link 'strength' because a company expecting all three resources from another definitely has a stronger relationship as compared to one which would expect 
none or just 1 or 2 resources. These derived matrices are then used to generate the standard centrality measures of out-degree, out-closeness and betweenness. Using these constructed network variables we attempt to predict innovativeness and productivity of firms. We hypothesize that firms that are more central (on any or each of the centrality measures) would exhibit superior innovative and economic performance as compared to their less central peers.

As our data are asymmetric (directed), the out-degree is the number of ties initiated by A. For matrices which have weighted or valued data, the degrees (in and out) will consist of the sums of the values of the ties.

Degree centrality of node $i$ is given by:

$$
C_{D}(i)=\sum_{j=1}^{n} X_{i j}
$$

Where $X_{i j}$ is 1 only if node $i$ and $j$ are connected by an edge and 0 otherwise.

Another measure of centrality is closeness centrality. Closeness determines the independence of a node from all other nodes in the graph. The perfectly 'close' node would be directly connected to each node in the network, i.e. would have the shortest possible distance to each node and would thereby be independent of intermediaries. Closeness centrality can be thought of as an index of the expected time-until-arrival for resources travelling through the network via optimal paths. In order to calculate closeness centrality, we compute its reciprocal, i.e. farness and take its inverse. Farness of a node is the sum of the lengths of the geodesics to every other vertex. If the data is directed like in our case, the UCINET routine we used provides separate measures for in-closeness and out-closeness.

Closeness ${ }^{105}$ centrality of node $i$ is given by:

$$
C_{C}(i)=\sum_{j=1}^{n}\left[D_{i j}\right]^{-1}
$$

where $D_{i j}$ is the shortest distance (geodesic path) between the focal node $i$ and $j$. Without taking the inverse it would give the value of farness.

Another measure of centrality we use is betweenness centrality. Betweenness views a node as being in an advantageous position by being located on the geodesic paths between other pairs of nodes in the network. Just as closeness makes you independent, betweenness makes others' dependent on you and thereby grants you power. If, however, two nodes are connected by more than one geodesic path, and the focal node is not on all of them, its power gets diminished accordingly. Adding up the number of times that a node is "between" other nodes gives us a measure of ego's

\footnotetext{
${ }^{105}$ Some scholars refer to the given formulae as 'reach centrality' and calculate closeness centrality by first adding up the geodesic distances of all the paths (from the node to every other vertex) and then taking the inverse. This however is a bad measure for disconnected networks (for a detailed discussion see Freeman (1979) and Opsahl et al. (2010)). Moreover, the software program which we used to compute closeness employs the given formulae. Hence, in order to avoid any confusions we refer to it as closeness.
} 
betweenness centrality. We can normalize this measure by expressing it as a percentage of the maximum possible betweenness that an actor could have had.

Mathematically, betweenness centrality of node $i$ is given by:

$$
C_{B}(i)=\sum_{j<k}^{n} g_{j k}(i) / g_{j k}
$$

where $g_{j k}$ is the number of geodesics (shortest paths) connecting nodes $i$ and $j$, and $g_{j k}(i)$ is the number of geodesics connecting nodes $i$ and $j$ while passing through (containing) $k$.

Hypothesis 1b: More central firms are more productive

Hypothesis 1a: More central firms are more innovative

\subsubsection{Structural embeddedness}

The second approach is to look at our network from the structural perspective. We attempt to ascertain whether or not structural holes in the network of an ego are contributing towards their innovative and economic performance. In order to measure structural holes, the opposite concept of structural holes, that of redundancy is employed. The general meaning of redundancy is clear: an actor's ego network has redundancy to the extent that its contacts are connected to each other as well. Employing Burt's equations we first calculate the constraint values using two different network matrices. The first one is calculated from the same matrix as above (expected resource) and we also use the same technique of AND-ing to get a richer and weighted matrix. The second matrix we use for calculating constraint values is constructed through another variable, 'interaction frequency'. Interaction frequency entails the frequency of interaction between the interviewed firm and its reported partners. To calculate the degree of constraint to ego by his alters we use Burt's (1992) constraint measure (equation 2.4, pg. 55) which is as follows:

$$
c_{i j}=\left(p_{i j}+\sum_{q} p_{i j} p_{q j}\right)^{2}, \quad \text { for } q \neq i, j .
$$

where $c_{i j}$ is the constraint of firm $i$ by its contact, firm $j, p_{i j}$ gives the amount of time and energy invested by firm $i$ in its contact, firm $j$ and $\sum_{q} p_{i j} p_{q j}$ gives the degree to which firm $j$ is connected to other contacts $q$ of the ego $i$.

As per our survey questionnaire, a firm could interact with its partner at least once per day, at least once per week, at least once per month, at least once per six months and at least once per year. These interaction frequencies were assigned weights ranging from 1-5 and we followed the big=bad principle as network algorithms are programmed to treat weights as 'distances' and the more distant a partner, the worse it is for the relationship. We hypothesize that firms which have a network of mutually disconnected firms are more innovative and productive. This is because in the ICT industry, the importance of novel information can't be overstated. Similarly, 
it's an industry with a lot of interdependencies and in such a case it becomes inevitable to service only the most important of your contacts given the natural resource limitations. Such network characteristics are formalized as structural holes and the inverse of them are constraint measures, which we have taken as an (inverse) indicator. This finding is in a way in line with

Hypothesis 2a: Less constrained firms are more innovative

Hypothesis $2 b$ : Less constrained firms are more productive

\subsubsection{Relational embeddedness}

The third and final approach employed in this chapter is to analyze our firm network from the relational perspective. For this, we mix parts of the approaches used in the previous two sections. We use basic centrality measures but on a matrix which holds information on strength of relationships, i.e. interaction frequency. We hypothesize that the more a firm interacts with its partner firms, the more innovative and productive it gets.

Hypothesis 3a: More frequent interaction predicts innovative performance

Hypothesis $3 b$ : More frequent interaction predicts economic performance

\subsection{The Questionnaire}

Firm-level network data is difficult to find and this is even more the case for developing countries. Woolcock (1998) points out this shortcoming of the literature on social capital and firm growth asserting that the focus remains on advanced economies, even though it has been argued that in developing countries, social capital may be of immense importance. As no secondary network data were available for Pakistan, we undertook our own network survey. For this purpose, a part of our main survey conducted in the ICT industry of Pakistan attempts to gather data on the network of relationships in which firms are embedded ${ }^{106}$. The survey was designed keeping our research questions in view, which we shared in the previous section. Each research question demanded some specific information in order to make validation possible ${ }^{107}$. Each firm we interviewed was asked to list ten of its 'partners' or 'collaborators'. Then, it was asked in meticulous detail to not only define the partner (which could theoretically be one of the firms on our survey) in terms of its location, principal business subsector and other such characteristics but also to describe how strong that relationship is and what resource it expected from this partner. We call the partner related characteristics as 'node characteristics', and the interaction related ones as 'link characteristics'.

\footnotetext{
${ }^{106}$ For details see Annex VI, questions $74-86$ are networks related.

${ }^{107}$ We discussed the survey and survey design in the previous chapter. Here we focus on the specific questions concerning networks.
} 
We have focused on the 'information and technology' network of firms which means on those relationships where the expected resource is technological knowledge, market knowledge or technology itself. These three commodities are crucial for firms, particularly in high-tech sectors like the studied ICT sector. Moreover, we create a complete profile of their interaction modes, frequencies and types. Firms were also asked about how the first interaction came about, giving clues whether references, friendships or exogenous reasons such as better products play a decisive role in choice of a technology or knowledge source. The main objectives of the network part of our survey conducted were to collect information necessary to assess their:

\section{i. Node characteristics}

a. Category: To which business category the partner firm belongs out of the following possible categories: B2B Customers, Principal, Competitors, Suppliers, Consultants, Innovation Centre, University, Research Lab, Parent organization.

b. Location: In which location from the following choices does the partner firm operate: Same Market, Same City, Same Country, International.

c. Firm type: Which type of firm it is: Foreign owned, Domestically owned.

\section{ii. Link characteristics}

a. Interaction type: Which type(s) of interaction exist(s) with the partner firm: Informal, Pecuniary, Formal and Non-pecuniary.

b. Interaction mode: Which mode(s) of interaction are usually employed with the partner firm: Face to face, Telephone, Email, Conference, Trade fair. This is important to establish because tacit and fine grained knowledge usually needs more personal interaction to take place.

c. Interaction frequency: With which frequency does the interaction take place with the partner: At least once per Day, At least once per Week, At least once per Month, At least once per six months, At least once per Year. This information forms the basis to establish tie strength.

d. Expected resource: Which resource(s) are expected from the partner firm: Technical Knowledge, Market knowledge, Technology? This information forms the basis of not only the information regarding the resource itself, but it also gives insight in the strength of the relationship in terms of how many of the three possible resources are expected.

e. First interaction: Whether the very first interaction with the respective organization was due to: Referral, Friendship or some Exogenous reason (e.g. better technology, lower price)? We use a variable con- 
strued on this information as a proxy for the three centrality measures which we tested: NormOutdegree nBetweeness and outCloseness. Intuitively those firms which receive a high (first interaction through friendship or referral) score are more popular or in other words more central to other firms.

Using the information gathered we have constructed asymmetric (directed) matrices. While constructing the matrices, as per convention for directed data, we have taken the sender of a resource to be the row and the target of the resource to be the column.

\subsection{Model specification}

\subsubsection{Variables}

Table 7.1 below lists and describes all the variables used in our subsequent econometric model discussion and analysis.

Table 7.1 Variables and their description

\begin{tabular}{|c|c|c|c|c|c|c|}
\hline Variable & Obs & Mean & Std. Dev. & Min & Max & Description \\
\hline LnProd & 78.0 & 0.8 & 1.6 & -2.3 & 5.2 & Ln of turnover per employee in current prices 2010 \\
\hline Number_Inno & 93.0 & 3.6 & 4.3 & 0.0 & 27.0 & Number of product innovations in last 5 years \\
\hline GTotInno & 93.0 & 5.2 & 6.1 & 0.0 & 40.0 & $\begin{array}{l}\text { Total number of product and process innovations in last } 5 \\
\text { years (Number_Inno + TotPrInno) }\end{array}$ \\
\hline Procln & 93.0 & 0.4 & 0.5 & 0.0 & 1.0 & $\begin{array}{l}\text { Process Innovation Dummy }=1 \text { if firm had at least } 1 \text { process } \\
\text { innovation in last } 5 \text { years }\end{array}$ \\
\hline Prodln & 93.0 & 0.8 & 0.4 & 0.0 & 1.0 & $\begin{array}{l}\text { Product Innovation Dummy }=1 \text { if firm had at least } 1 \text { process } \\
\text { innovation in last } 5 \text { years }\end{array}$ \\
\hline Emp & 86.0 & 204 & 678 & 1.0 & 4500 & Ln of total employees in 2010 \\
\hline Age & 93.0 & 9.7 & 9.4 & 1.0 & 59.0 & Age of firm in years \\
\hline MNC & 93.0 & 0.3 & 0.4 & 0.0 & 1.0 & Firm type dummy where Domestic $=0, M N C=1$ \\
\hline CFExp & 93.0 & 0.5 & 1.2 & 0.0 & 9.0 & Number of foreign jobs the CEO has previously held \\
\hline CEdu & 93.0 & 5.7 & 3.3 & 1.0 & 14.0 & $\begin{array}{l}\text { Diploma IT=1, Simple Bachelors =2, Simple Masters=3, } \\
\text { Chartered Accountant=4, M.Sc. }=5, \mathrm{BCS}=6, \mathrm{~B} . \mathrm{Sc} . \\
\text { Engineering=7, M. Phil.=8, MBA=9, MCS=10, M.Sc. } \\
\text { Engineering=11, M.Sc. Engineering (Foreign) }=12, \mathrm{PhD} \\
\text { Engineering=13, PhD Engineering (Foreign) }=14\end{array}$ \\
\hline Source_Mnc & 93.0 & 2.9 & 1.5 & 0.0 & 5.0 & Level of importance of technology source: MNC \\
\hline CExp & 93.0 & 1.8 & 2.1 & 0.0 & 10.0 & Total number of previous jobs held by CEO \\
\hline Firstlnt1n2 & 76.0 & 0.4 & 1.2 & 0.0 & 6.0 & First Interaction from Referral and Friendship \\
\hline Dom_Prox & 93.0 & 0.2 & 0.4 & 0.0 & 1.0 & $\begin{array}{l}\text { Domestic Proximity Dummy = } 1 \text { if firm located close to a } \\
\text { Domestic firm }\end{array}$ \\
\hline
\end{tabular}




\begin{tabular}{|c|c|c|c|c|c|c|}
\hline Variable & Obs & Mean & Std. Dev. & Min & Max & Description \\
\hline Mnc_Prox & 93.0 & 0.2 & 0.4 & 0.0 & 1.0 & MNC Proximity Dummy = 1 if firm located close to a MNC \\
\hline STrad & 93.0 & 0.1 & 0.3 & 0.0 & 1.0 & Principal subsector dummy Trading $=1$ \\
\hline STelco & 93.0 & 0.2 & 0.4 & 0.0 & 1.0 & Principal subsector dummy Telecommunication = 1 \\
\hline SManu & 93.0 & 0.2 & 0.4 & 0.0 & 1.0 & Principal subsector dummy Manufacturing and Assembly = 1 \\
\hline Source_Mnc & 93.0 & 2.9 & 1.5 & 0.0 & 5.0 & Level of importance of technology source: MNC \\
\hline FExp & 77.0 & 21.6 & 25.6 & 0.0 & 100.0 & Percentage of Technical staff who have foreign experience \\
\hline Gov_Loan & 93.0 & 5.1 & 1.9 & 1.0 & 6.0 & Level of importance of Gov. Ioan \\
\hline FEdu & 67.0 & 8.7 & 16.8 & 0.0 & 100.0 & $\begin{array}{l}\text { Percentage of technical staff who have foreign MS and/or } \\
\text { PhD degrees }\end{array}$ \\
\hline FDegree & 68.0 & 2.9 & 8.6 & 0.0 & 60.0 & $\begin{array}{l}\text { Total number of staff who have a foreign Masters or PhD } \\
\text { degree as their highest formal education }\end{array}$ \\
\hline Training & 93.0 & 6.6 & 9.2 & 0.0 & 40.0 & Total days of internal and external trainings per year \\
\hline TechStaff & 85.0 & 0.6 & 0.2 & 0.1 & 1.0 & $\begin{array}{l}\text { Ratio of technical staff to total employees (technical staff } \\
\text { intensity) }\end{array}$ \\
\hline outCloseness & 75.0 & 0.5 & 0.1 & 0.4 & 0.6 & $\begin{array}{l}\text { Out Closeness centrality calculated from Expected Resource } \\
\text { matrix }\end{array}$ \\
\hline nBetweeness & 75.0 & 0.2 & 0.4 & 0.0 & 1.8 & $\begin{array}{l}\text { Normalized Betweenness centrality calculated from Expected } \\
\text { Resource matrix }\end{array}$ \\
\hline NrmOutdeg & 75.0 & 1.5 & 1.1 & 0.4 & 4.0 & $\begin{array}{l}\text { Normalized Outdegree centrality calculated from Expected } \\
\text { Resource matrix }\end{array}$ \\
\hline ConstraintIF & 76.0 & 0.5 & 0.4 & 0.1 & 1.0 & $\begin{array}{l}\text { Constraint measure calculated from Interaction Frequency } \\
\text { matrix based on Burt's formula }\end{array}$ \\
\hline OutdegreelF & 76.0 & 10.1 & 8.8 & 1.0 & 34.0 & $\begin{array}{l}\text { Outdegree centrality calculated from Interaction Frequency } \\
\text { matrix based on Burt's formula }\end{array}$ \\
\hline
\end{tabular}

\subsubsection{Hypotheses}

Here we summarize the hypotheses developed in sections 7.3.1, 7.3.2 and 7.3.3.

\subsubsection{Hypothesis 1a: More central firms are more innovative}

In order to test the hypothesis that more central firms are more innovative we relate innovative performance to its determinants. To do so we separately use two different indicators for innovative performance as the dependent variable, firstly the dummy variable depicting whether or not a firm has done any innovation (separately for product and process innovations) in the last five years and secondly a continuous variable capturing the total number of product and process innovations in the past five years. We use a Probit model for the case where our dependent variable is the innovation dummy and a simple regression model for the case where the dependent variable comprises the total number of innovations. Apart from a few control variables like firm size, firm age and firm type (dummy) we add two of the three main centrality 
measures (out-closeness, and out-degree ${ }^{108}$ ) as explanatory variables. In these regressions there is a possibility of endogeneity (simultaneity). Intuitively, the direction of causality could run in both directions, i.e. it is possible that firms which are central show up to be innovative whereas in reality it could be the other way round as well; firms which are innovative are central. After running the regressions with our main centrality variables, in order to address this issue, we add an IV variable and test for the presence of endogeneity using the Durbin-Wu-Hausman (DWH) test.

\subsubsection{Hypothesis $1 b$ : More central firms are more productive}

To test this hypothesis we use the same approach as above and substitute the dependent variable for innovativeness with productivity which is taken to be Ln of turnover per employee. We also attempt to use productivity growth (between FY2008 and FY2010) as the dependent variable but that doesn't lead to consistent results because the small number of data points available for turnover in 2008.

\subsubsection{Hypothesis $2 a / 2 b$ : Less constrained firms are more innovative/productive}

To validate Burt's notion of structural holes contributing positively toward firm performance, we separately regress variables for innovativeness and productivity on the constraint variables constructed from the expected resource matrix and the interaction frequency matrix. Endogeneity can be ruled out as constraints or structural holes are a measure not directly of the ego, but rather its alters and one can safely assume that the behavior of one's alters amongst themselves is not influenced by its innovative or economic performance.

\subsubsection{Hypothesis 3a/3b: More frequent interaction is positively related to positive innovative/economic performance}

To ascertain the impact of frequency of interaction on innovative and economic performance we regress the performance variables on the constructed interaction frequency variable. Various control variables are included as explanatory variables for these regressions. Here too, endogeneity can be ruled out intuitively as there is no reason to believe that more innovative/productive firms would interact more with their partners. However, the vice versa - partners interacting more with an innovative and productive firm (to acquire knowledge and skills) - could well be true, hence we investigate it.

\footnotetext{
${ }^{108}$ Using betweenness centrality gives inconsistent results because out of the 94 observations 78 hold a value of either zero or no-response which makes this variable unreliable.
} 


\subsection{Results and Discussion}

\subsubsection{Centrality}

Table 7.2 shows the regression results of the innovation equation using the outdegree centrality metric (NrmOutdeg). In column 1 we have given the results with the dependent variable being the process innovation dummy (Procln) and in the $2^{\text {nd }}$ column with the dependent variable product innovation dummy (Prodln). These two are probit regressions. In the next two columns we present the regression results while taking the total number of innovations, both product and process (GTotInno) and the number of product innovations (Number_Inno) as the dependent variable. The same process is repeated in table 7.3 but using the out-closeness centrality metric as the explanatory variable. The specifications of the models (in terms of covariates) are similar to the specification of the innovation equation in Chapter 6 . However, there we only used the product innovation and process innovation dummies as dependent variables and here we explore deeper using 2 additional indicators for innovative performance.

Our results show that firms that are more central in terms of either out-degree or out-closeness do not have better innovative performance. Our results show that General Embeddedness does not play a significant role in predicting innovativeness. Thus hypothesis 1 a does not find support in our analysis. Although the position advantages of central firms for innovativeness are well-established in the literature, our results suggest that these might be too simplistic measures to predict success in a high-tech industry like ICT.

Table 7.2 Centrality (Out-degree) and Innovative Performance ${ }^{109}$

\begin{tabular}{|c|c|c|c|c|}
\hline & (1) & (2) & (3) & (4) \\
\hline VARIABLES & $\begin{array}{l}\text { Procln } \\
\text { (Probit) }\end{array}$ & $\begin{array}{l}\text { Prodln } \\
\text { (Probit) }\end{array}$ & $\begin{array}{l}\text { GTotInno } \\
\text { (OLS) }\end{array}$ & $\begin{array}{c}\text { Number_Inno } \\
\text { (OLS) }\end{array}$ \\
\hline \multirow[t]{2}{*}{ LnEmp } & $0.603^{* *}$ & 0.269 & $1.233^{* *}$ & 0.551 \\
\hline & $(0.247)$ & $(0.462)$ & $(0.577)$ & $(0.371)$ \\
\hline \multirow[t]{2}{*}{ TechStaff } & -0.471 & 2.401 & 0.835 & 0.884 \\
\hline & $(1.063)$ & (1.669) & $(2.824)$ & $(1.818)$ \\
\hline \multirow[t]{2}{*}{ FDegree } & $-0.0443^{*}$ & $-0.158^{*}$ & -0.0893 & -0.0564 \\
\hline & $(0.0254)$ & (0.0905) & $(0.0695)$ & $(0.0448)$ \\
\hline \multirow[t]{2}{*}{ Age } & $-0.146 * *$ & 0.0658 & 0.0227 & 0.0522 \\
\hline & $(0.0711)$ & $(0.108)$ & (0.119) & $(0.0769)$ \\
\hline \multirow[t]{2}{*}{ Type } & 0.677 & 0.392 & 0.0391 & 0.504 \\
\hline & $(0.770)$ & $(0.991)$ & $(1.852)$ & (1.192) \\
\hline CEdu & $-0.202 * *$ & $-0.238^{*}$ & -0.269 & -0.0920 \\
\hline
\end{tabular}

${ }^{109}$ Results in Table 7.2 are based on the expected resource matrix. 


\begin{tabular}{lcccc}
\hline \multirow{2}{*}{ VARIABLES } & $(1)$ & $(2)$ & $(3)$ & $(4)$ \\
& $\begin{array}{c}\text { Procln } \\
(\text { Probit })\end{array}$ & $\begin{array}{c}\text { Prodln } \\
(\text { Probit })\end{array}$ & $\begin{array}{c}\text { GTotlnno } \\
(\text { OLS) }\end{array}$ & $\begin{array}{c}\text { Number_Inno } \\
(\text { OLS) }\end{array}$ \\
\hline \multirow{3}{*}{ MncExp } & $(0.0877)$ & $(0.139)$ & $(0.189)$ & $(0.122)$ \\
& $-0.0267^{*}$ & 0.0500 & -0.0412 & -0.0187 \\
NrmOutdeg & $(0.0160)$ & $(0.0643)$ & $(0.0426)$ & $(0.0274)$ \\
& 0.289 & 1.760 & $1.135^{*}$ & 0.356 \\
Constant & $(0.249)$ & $(1.492)$ & $(0.648)$ & $(0.417)$ \\
& -0.0366 & -1.544 & 0.294 & -0.136 \\
& $(1.001)$ & $(1.689)$ & $(2.734)$ & $(1.760)$ \\
Observations & & & & 49 \\
R-squared & 49 & 49 & 49 & 0.184 \\
\hline
\end{tabular}

Standard errors in parentheses

*** $p<0.01,{ }^{* *} p<0.05,{ }^{*} p<0.1$

Table 7.3 Centrality (Out-closeness) and Innovative performance ${ }^{110}$

\begin{tabular}{lcccc}
\hline \multirow{2}{*}{ VARIABLES } & $\begin{array}{c}(1) \\
\text { Procln } \\
(\text { Probit) }\end{array}$ & $\begin{array}{c}\text { Prodln } \\
(\text { Probit) }\end{array}$ & $\begin{array}{c}(3) \\
\text { GTotlnno } \\
(\text { OLS })\end{array}$ & $\begin{array}{c}(4) \\
\text { Number_Inno } \\
(\text { OLS) }\end{array}$ \\
\hline LnEmp & $0.641^{* * *}$ & 0.524 & $1.443^{* *}$ & $0.619^{*}$ \\
TechStaff & $(0.248)$ & $(0.458)$ & $(0.556)$ & $(0.354)$ \\
& -0.821 & 2.459 & 0.496 & 0.797 \\
FDegree & $(1.111)$ & $(1.726)$ & $(2.960)$ & $(1.886)$ \\
& $-0.0418^{*}$ & $-0.0890^{*}$ & -0.0728 & -0.0511 \\
Age & $(0.0252)$ & $(0.0498)$ & $(0.0694)$ & $(0.0442)$ \\
& $-0.139^{*}$ & 0.0594 & 0.0329 & 0.0546 \\
Type & $(0.0725)$ & $(0.128)$ & $(0.124)$ & $(0.0791)$ \\
& 0.983 & 0.663 & 1.214 & 0.870 \\
CEdu & $(0.764)$ & $(1.068)$ & $(1.789)$ & $(1.140)$ \\
& $-0.205^{* *}$ & -0.183 & -0.283 & -0.0961 \\
MncExp & $(0.0868)$ & $(0.130)$ & $(0.193)$ & $(0.123)$ \\
& $-0.0292^{*}$ & 0.0505 & -0.0484 & -0.0209 \\
outCloseness & $(0.0163)$ & $(0.0942)$ & $(0.0430)$ & $(0.0274)$ \\
& 4.492 & 3.051 & 12.17 & 3.614 \\
Constant & $(3.362)$ & $(5.086)$ & $(8.994)$ & $(5.730)$ \\
& -2.006 & -2.879 & -5.541 & -1.886 \\
& $(1.653)$ & $(3.062)$ & $(4.501)$ & $(2.868)$
\end{tabular}

${ }^{110}$ Results in Table 7.3 are based on the expected resource matrix. 
Standard errors in parentheses

*** $\mathrm{p}<0.01, * * \mathrm{p}<0.05, * \mathrm{p}<0.1$

Table 7.4 presents the regression results of the productivity equation using the outdegree and out-closeness centrality metrics. We use the two centrality metrics separately as estimators in the productivity equations with the dependent variable being the log value of productivity (LnProd). Here again we use a specification similar to that used in the productivity equation of Chapter 6 . Interestingly the results of most explanatory variables are similar (both in terms of significance and coefficient signs) to those in Chapter 6 . The results of both our centrality metrics however are insignificant leading us to conclude that centrality has no impact on productivity. This way our hypothesis $1 \mathrm{~b}$, that more central firms outperform their counterparts economically is rejected.

Table 7.4 Centrality (Out-degree and Out-closeness) and Economic Performance ${ }^{111}$

(1)

\begin{tabular}{|c|c|c|}
\hline VARIABLES & $\begin{array}{c}\text { LnProd } \\
\text { (OLS) }\end{array}$ & $\begin{array}{l}\text { LnProd } \\
\text { (OLS) }\end{array}$ \\
\hline \multirow[t]{2}{*}{ LnEmp } & 0.208 & $0.207^{*}$ \\
\hline & (0.125) & $(0.117)$ \\
\hline \multirow[t]{2}{*}{ Age } & 0.0180 & 0.0193 \\
\hline & (0.0188) & $(0.0193)$ \\
\hline \multirow[t]{2}{*}{ Type } & -0.571 & -0.546 \\
\hline & $(0.437)$ & $(0.412)$ \\
\hline \multirow[t]{2}{*}{ CFExp } & 0.177 & 0.176 \\
\hline & (0.119) & $(0.119)$ \\
\hline \multirow[t]{2}{*}{ MncExp } & $0.0172^{*}$ & $0.0171^{*}$ \\
\hline & (0.0105) & $(0.0104)$ \\
\hline \multirow[t]{2}{*}{ Source_Mnc } & 0.146 & 0.144 \\
\hline & $(0.0972)$ & $(0.0974)$ \\
\hline \multirow[t]{2}{*}{ FExp } & -0.00622 & -0.00634 \\
\hline & $(0.00622)$ & $(0.00625)$ \\
\hline \multirow[t]{2}{*}{ Training } & -0.00289 & -0.00334 \\
\hline & $(0.0168)$ & $(0.0168)$ \\
\hline \multirow[t]{2}{*}{ TechStaff } & -0.658 & -0.712 \\
\hline & (0.658) & $(0.710)$ \\
\hline Gov_Loan & $-0.147^{*}$ & $-0.141^{*}$ \\
\hline
\end{tabular}

${ }^{111}$ Results in Table 7.3 are based on the expected resource matrix 
(1)

\begin{tabular}{lcc} 
VARIABLES & $\begin{array}{c}\text { LnProd } \\
(\mathrm{OLS})\end{array}$ & $\begin{array}{c}\text { LnProd } \\
(\mathrm{OLS})\end{array}$ \\
\hline NrmOutdeg & $\begin{array}{c}(0.0753) \\
0.0168\end{array}$ & \\
& $(0.148)$ & \\
outCloseness & & $0.511)$ \\
Constant & 0.975 & $(2.324)$ \\
& $(0.757)$ & 0.734 \\
Observations & 58 & $(1.257)$ \\
R-squared & 0.626 & 58 \\
\hline
\end{tabular}

Standard errors in parentheses

$* * * \mathrm{p}<0.01, * * \mathrm{p}<0.05, * \mathrm{p}<0.1$

We now use an IV approach to assess whether endogeneity is a problem. ${ }^{112}$

In order to estimate a simultaneous equations one should decide whether it is necessary to use an instrumental variable, i.e., whether a set of estimates obtained by least squares is consistent or not. Davidson \& MacKinnon (1993) suggest an augmented regression test, also known as the Durbin-Wu-Hausman (DWH) test, which can easily be formed by including the residuals of the endogenous right-hand side variable, as a function of all exogenous variables, in a regression of the original model. Following this, we would first perform a regression while taking the endogenous variable (NrmOutDegree) as dependent and adding the proxy variable to the covariates.

From our dataset we select a variable which qualifies the criteria to be used as an instrumental variable for the endogenous variables in question (centrality metrics). It is established from literature that the instrumental variable should be correlated with the independent variable but not with the error term. For this purpose we select a variable which is constructed using the matrix of first interaction (Firstlnt1n2) which records whether the first interaction with a firm, from which the respondent sought a resource from, was due to a referral, due to friendship or due to some exogenous reason. We combined the first two possible options to give a value of one, i.e. for the cases that the first interaction with the partner firm was either a result of a referral or an a priori 'friendship', the dummy attains a value of one and otherwise (for the case that the partner was chosen purely on merit) it has a value of zero. This is a reasonable and intuitive instrumental variable for a central firm, as it can be conceptually argued

\footnotetext{
${ }^{112}$ As the OLS estimates in tables 7.2 and 7.3 do not include significant coefficients for the centrality variables, we do not need to worry whether a significant coefficient is caused by endogeneity. Theoretically, it is conceivable that the lack of significant coefficients might also have been caused by endogeneity. Therefore we do included a test of endogeneity here.
} 
that firms which are referred to more or are contacted due to friendship a lot are more 'central' than other firms which are less referred to and contacted due to friendship.

After performing this regression (see column 1 table 7.5) we get residuals NODInno_Res and then include them in the augmented regression, column 2 (table 7.5) for Process Innovation and column 3 for Product Innovation. As the coefficients for the residual are not significantly different from zero our regression is consistent. This leads us to conclude that the variable in question for endogeneity (NrmOutDegree) does not suffer from simultaneity. The same procedure is repeated for the other centrality variable in question (outCloseness) but consistent results are not achieved because the log likelihood function is not concave.

We perform the DWH for productivity (see table 7.6) as well and again find that endogeneity of the centrality variables is not a problem.

Table 7.5 Durbin-Wu-Hausman test for endogeneity of centrality metrics ${ }^{113}$ with innovative performance 114

\begin{tabular}{|c|c|c|c|}
\hline VARIABLES & $\begin{array}{c}\text { (1) } \\
\text { NrmOutdeg }\end{array}$ & $\begin{array}{c}(2) \\
\text { Procln } \\
\text { (Probit) }\end{array}$ & $\begin{array}{c}\text { (3) } \\
\text { Prodln } \\
\text { (Probit) }\end{array}$ \\
\hline \multirow[t]{2}{*}{ LnEmp } & 0.182 & $1.002 * *$ & -1.666 \\
\hline & (0.147) & $(0.469)$ & $(323.0)$ \\
\hline \multirow[t]{2}{*}{ TechStaff } & 0.0273 & 0.0196 & 2.504 \\
\hline & $(0.746)$ & (1.301) & $(48.57)$ \\
\hline \multirow[t]{2}{*}{ FDegree } & 0.0272 & -0.0203 & -0.466 \\
\hline & $(0.0161)$ & (0.0399) & $(48.38)$ \\
\hline \multirow[t]{2}{*}{ Age } & -0.00982 & $-0.140^{*}$ & 0.154 \\
\hline & (0.0299) & $(0.0843)$ & $(17.47)$ \\
\hline \multirow[t]{2}{*}{ MNC } & $0.800 *$ & 1.860 & -8.347 \\
\hline & $(0.458)$ & $(1.323)$ & $(1,424)$ \\
\hline \multirow[t]{2}{*}{ CEdu } & 0.0590 & -0.181 & -0.888 \\
\hline & (0.0478) & $(0.113)$ & $(105.0)$ \\
\hline \multirow[t]{2}{*}{ MncExp } & -0.00114 & $-0.0312 *$ & 0.0441 \\
\hline & $(0.0103)$ & $(0.0179)$ & $(2.022)$ \\
\hline \multirow[t]{2}{*}{ NrmOutdeg } & & -0.916 & 12.88 \\
\hline & & $(1.306)$ & $(1,780)$ \\
\hline \multirow[t]{2}{*}{ NODInno_Res } & & 1.190 & -11.05 \\
\hline & & $(1.332)$ & $(1,779)$ \\
\hline
\end{tabular}

Firstlnt1n2

0.184

\footnotetext{
${ }^{113}$ Regressions using the out-closeness centrality variable were inconsistent as the log likelihood function was not concaved and are therefore not presented here.

${ }^{114}$ Centrality variables out-degree and out-closeness are calculated based on the Expected Resource Matrix, whereas the proxy variable FirstInt1n2 is calculated based on the First Interaction matrix
} 


\begin{tabular}{lccc}
\hline VARIABLES & $\begin{array}{c}(1) \\
\text { NrmOutdeg }\end{array}$ & $\begin{array}{c}(2) \\
\text { Procln } \\
\text { (Probit) }\end{array}$ & $\begin{array}{c}\text { (3) } \\
\text { Prodln } \\
\text { (Probit) }\end{array}$ \\
\hline Constant & $(0.158)$ & & 2.849 \\
& -0.438 & -1.255 & $(780.3)$ \\
Observations & $(0.727)$ & $(1.514)$ & 42 \\
R-squared & 42 & 42 & \\
\hline
\end{tabular}

Standard errors in parentheses

$* * * p<0.01, * * p<0.05, * p<0.1$

Table 7.6 Durbin-Wu-Hausman test for endogeneity of centrality metrics with economic performance ${ }^{115}$

\begin{tabular}{|c|c|c|c|c|}
\hline VARIABLES & $\begin{array}{c}\text { (1) } \\
\text { NrmOutdeg }\end{array}$ & $\begin{array}{c}\text { (2) } \\
\text { LnProd }\end{array}$ & $\begin{array}{c}\text { (3) } \\
\text { outCloseness }\end{array}$ & $\begin{array}{c}(4) \\
\text { LnProd }\end{array}$ \\
\hline \multirow[t]{2}{*}{ LnEmp } & $0.253^{*}$ & 0.708 & 0.0108 & $0.464^{*}$ \\
\hline & $(0.146)$ & $(0.427)$ & $(0.00870)$ & $(0.245)$ \\
\hline \multirow[t]{2}{*}{ Age } & 0.0357 & 0.0748 & -0.00218 & -0.0337 \\
\hline & $(0.0240)$ & $(0.0538)$ & $(0.00143)$ & $(0.0375)$ \\
\hline \multirow[t]{2}{*}{ MNC } & 0.448 & 0.548 & 0.0110 & 0.0473 \\
\hline & $(0.466)$ & $(0.696)$ & $(0.0278)$ & (0.439) \\
\hline \multirow[t]{2}{*}{ CFExp } & 0.0326 & $0.302^{* *}$ & 0.00650 & $0.371 * * *$ \\
\hline & (0.139) & $(0.115)$ & $(0.00831)$ & $(0.130)$ \\
\hline \multirow[t]{2}{*}{ MncExp } & -0.00961 & -0.00322 & $4.54 \mathrm{e}-05$ & 0.0162 \\
\hline & $(0.0114)$ & $(0.0152)$ & $(0.000678)$ & $(0.0101)$ \\
\hline \multirow[t]{2}{*}{ Source_Mnc } & 0.0951 & $0.418^{* *}$ & 0.00490 & $0.332 * * *$ \\
\hline & $(0.113)$ & $(0.160)$ & $(0.00674)$ & $(0.118)$ \\
\hline \multirow[t]{2}{*}{ FExp } & 0.00341 & -0.000982 & 0.000288 & -0.00189 \\
\hline & (0.00695) & $(0.00752)$ & $(0.000414)$ & $(0.00727)$ \\
\hline \multirow[t]{2}{*}{ Training } & -0.00705 & -0.0222 & 0.000387 & -0.00400 \\
\hline & $(0.0214)$ & $(0.0232)$ & $(0.00128)$ & $(0.0185)$ \\
\hline \multirow[t]{2}{*}{ TechStaff } & -0.0722 & -0.690 & $0.119 * *$ & 1.791 \\
\hline & $(0.767)$ & $(0.657)$ & $(0.0457)$ & $(2.031)$ \\
\hline \multirow[t]{2}{*}{ Gov_Loan } & -0.0445 & $-0.248 * *$ & $-0.0127^{* *}$ & $-0.412^{*}$ \\
\hline & $(0.0807)$ & $(0.101)$ & $(0.00481)$ & $(0.206)$ \\
\hline \multirow[t]{2}{*}{ NrmOutdeg } & & -1.832 & & \\
\hline & & $(1.386)$ & & \\
\hline \multirow[t]{2}{*}{ NODProd_Res } & & 2.018 & & \\
\hline & & $(1.388)$ & & \\
\hline Firstlnt1n2 & 0.0986 & & 0.00964 & \\
\hline
\end{tabular}

${ }^{115}$ Centrality variables out-degree and out-closeness are calculated based on the Expected Resource Matrix, whereas the proxy variable FirstInt1n2 is calculated based on the First Interaction matrix 


\begin{tabular}{lcccc}
\hline VARIABLES & $\begin{array}{c}(1) \\
\text { NrmOutdeg }\end{array}$ & $\begin{array}{c}(2) \\
\text { LnProd }\end{array}$ & $\begin{array}{c}(3) \\
\text { outCloseness }\end{array}$ & $\begin{array}{c}(4) \\
\text { LnProd }\end{array}$ \\
\hline outCloseness & $(0.160)$ & & $(0.00953)$ & -19.00 \\
OCProd_Res & & & $(14.43)$ \\
Constant & & & 20.28 \\
& & & & $(14.56)$ \\
Observations & -0.170 & 0.302 & $0.419 * * *$ & 8.454 \\
R-squared & $(0.849)$ & $(0.813)$ & $(0.0506)$ & $(6.009)$ \\
\hline
\end{tabular}

Standard errors in parentheses

*** $p<0.01,{ }^{* *} p<0.05,{ }^{*} p<0.1$

\subsubsection{Constraint and structural holes}

Table 7.8 depicts the results of testing the structural holes argument by predicting innovativeness by constraint (the inverse of structural holes). We have used two different dependent variables as measures of innovativeness. First, we use the number of product innovations (Number_Inno) in last five years as the dependent variable and then we use the grand total (total product and process innovations - GTotInno) as the dependent variable. Our predictor, ConstraintIF loses a bit of significance in the regression with grand total of innovations as the dependent variable but still lies within $10 \%$ confidence limits.

Similar results are achieved while predicting productivity with ConstraintIF in table 7.9. A significant value with a negative coefficient corroborates Burt's argument that firms which are 'constrained' by redundant ties underperform both in terms of their innovative and economic performance. The reverse argument being true is that firms with plenty of structural holes outperform firms with redundant ties. It should be noted that the discussion of structural holes is known to be more pronounced in the context of certain sectors. This has to do with the need of fine-grained information especially in high-tech sectors where communal sharing values are not dominant (Xiao \& Tsui, 2007). Unlike Chinese firms, which tend to have strong communal sharing values, firms in our sample (and the population in general) are not quite as inclusive and cooperative on the firm-wide level hence information and control benefits of structural holes are valuable. 
Table 7.7 Innovativeness and Structural Holes/Constraints ${ }^{116}$

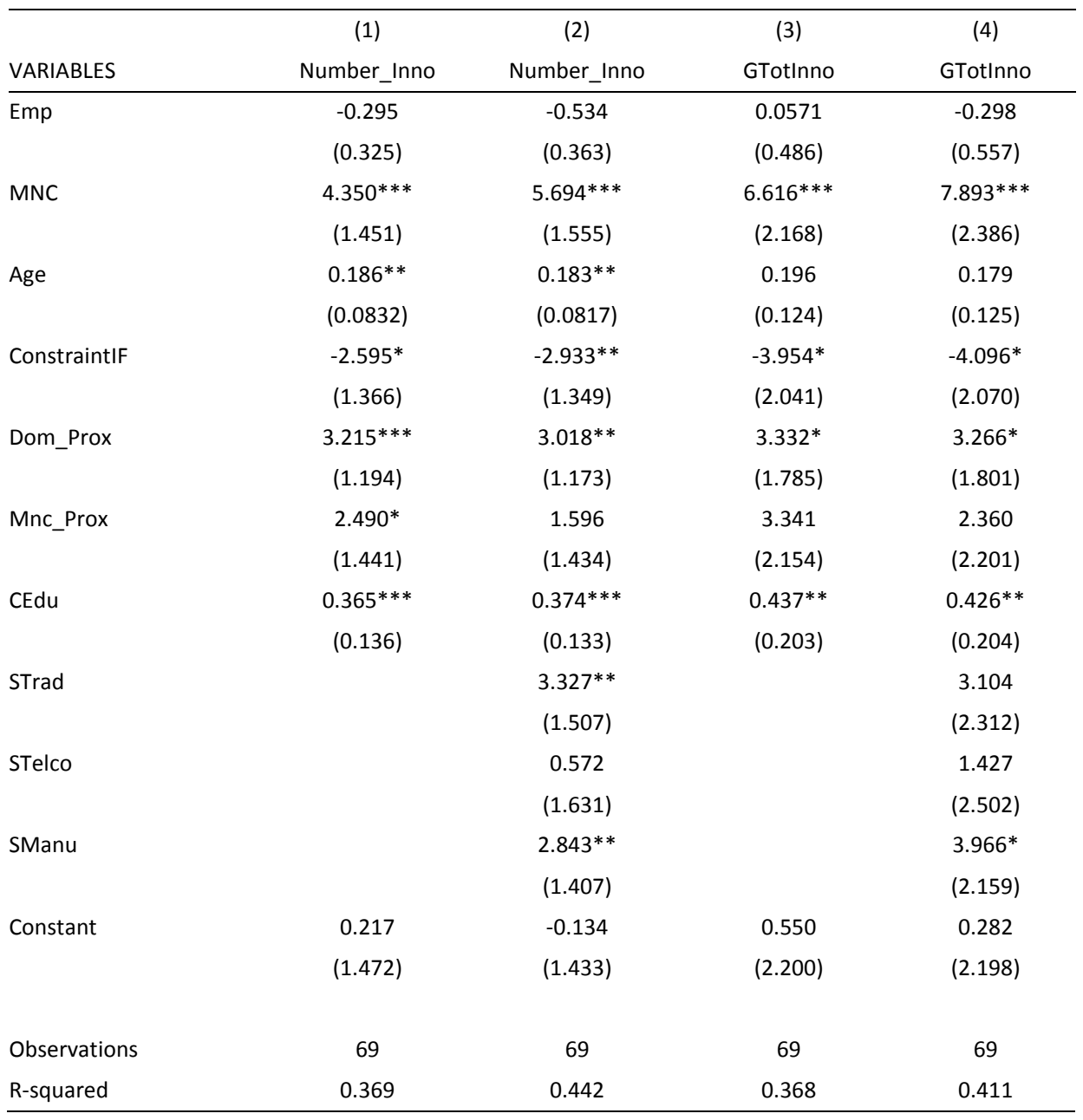

Standard errors in parentheses

*** $p<0.01, * * p<0.05, * p<0.1$

${ }^{116}$ Results in Table 7.7 are based on the interaction frequency matrix 
Table 7.8 Productivity and Structural Holes/Constraints ${ }^{117}$

\begin{tabular}{|c|c|c|}
\hline VARIABLES & $\begin{array}{c}\text { (1) } \\
\text { LnProd }\end{array}$ & $\begin{array}{c}\text { (2) } \\
\text { LnProd }\end{array}$ \\
\hline \multirow[t]{2}{*}{ LnEmp } & -0.000114 & -0.000129 \\
\hline & $(0.000343)$ & $(0.000342)$ \\
\hline \multirow[t]{2}{*}{ Age } & 0.0402 & 0.0157 \\
\hline & $(0.0297)$ & $(0.0326)$ \\
\hline \multirow[t]{2}{*}{ MNC } & -0.698 & -0.478 \\
\hline & $(0.440)$ & $(0.517)$ \\
\hline \multirow[t]{2}{*}{ CFExp } & $0.463^{* * *}$ & $0.428 * * *$ \\
\hline & $(0.126)$ & $(0.126)$ \\
\hline \multirow[t]{2}{*}{ CEdu } & $0.0856^{*}$ & 0.0513 \\
\hline & $(0.0483)$ & $(0.0510)$ \\
\hline \multirow[t]{2}{*}{ Source_Mnc } & $0.265^{* *}$ & $0.266^{* *}$ \\
\hline & $(0.112)$ & $(0.114)$ \\
\hline \multirow[t]{2}{*}{ FExp } & $-0.0194^{* *}$ & $-0.0143^{*}$ \\
\hline & $(0.00717)$ & $(0.00754)$ \\
\hline \multirow[t]{2}{*}{ FEdu } & $0.0236^{* *}$ & 0.0171 \\
\hline & $(0.0101)$ & $(0.0105)$ \\
\hline \multirow[t]{2}{*}{ Training } & -0.0263 & -0.0300 \\
\hline & $(0.0178)$ & $(0.0178)$ \\
\hline \multirow[t]{2}{*}{ TechStaff } & $-2.227^{* * *}$ & $-1.862^{* *}$ \\
\hline & $(0.764)$ & (0.799) \\
\hline \multirow[t]{2}{*}{ ConstraintIF } & $-1.129 * *$ & $-0.873^{*}$ \\
\hline & $(0.465)$ & $(0.488)$ \\
\hline \multirow[t]{2}{*}{ STrad } & & 0.198 \\
\hline & & $(0.585)$ \\
\hline \multirow[t]{2}{*}{ STelco } & & 0.742 \\
\hline & & $(0.587)$ \\
\hline \multirow[t]{2}{*}{ SManu } & & $0.859 *$ \\
\hline & & $(0.469)$ \\
\hline \multirow[t]{2}{*}{ Constant } & $1.769 * *$ & 1.265 \\
\hline & $(0.700)$ & $(0.792)$ \\
\hline Observations & 49 & 49 \\
\hline R-squared & 0.677 & 0.712 \\
\hline
\end{tabular}

Standard errors in parentheses

$* * * \mathrm{p}<0.01, * * \mathrm{p}<0.05, * \mathrm{p}<0.1$

${ }^{117}$ Results in Table 7.8 are based on the interaction frequency matrix 


\subsubsection{Frequency of interaction}

We then move to our third set of hypotheses; to test whether more frequent interaction causes better innovative and economic performance. Results in Table 7.10 and 7.11 show that our hypothesis that higher frequency of interaction has a positive impact on innovativeness and productivity is supported. This result is plausible because the importance of information in high-tech sectors is well-established and frequent interaction is one mechanism ensuring a positive flow of this vital resource.

It is important to note that while using the interaction frequency matrix to calculate OutdegreelF variable intuitively there should be no issue of endogeneity. This variable is directed, i.e. it gives the responding firms frequency of interaction with its partner and not vice versa. A firm which interacts more with other highly innovative and productive firms could be learning more from them and consequently innovating more (or being more productive), whereas it is difficult to argue that a firm which is more innovative/productive would as a result of this interact more with other firms. Please note that its partners interacting with the focal firm is another case, and yes they would interact with the innovative firm more, but this is not being measured in this variable. 
Table 7.9 Innovative Performance and Frequency of Interaction ${ }^{118}$

(1)

\begin{tabular}{|c|c|}
\hline VARIABLES & Number_Inno \\
\hline \multirow[t]{2}{*}{ LnEmp } & -0.000325 \\
\hline & (0.00110) \\
\hline \multirow[t]{2}{*}{ MNC } & $-4.021 * * *$ \\
\hline & (1.499) \\
\hline \multirow[t]{2}{*}{ Age } & $0.145^{*}$ \\
\hline & $(0.0775)$ \\
\hline \multirow[t]{2}{*}{ STelco } & 0.941 \\
\hline & $(1.740)$ \\
\hline \multirow[t]{2}{*}{ STrad } & $2.558^{*}$ \\
\hline & $(1.504)$ \\
\hline \multirow[t]{2}{*}{ SManu } & $2.660 * *$ \\
\hline & $(1.307)$ \\
\hline \multirow[t]{2}{*}{ FExp } & $0.0371^{*}$ \\
\hline & $(0.0188)$ \\
\hline \multirow[t]{2}{*}{ Dom_Prox } & 1.689 \\
\hline & $(1.168)$ \\
\hline \multirow[t]{2}{*}{ MncExp } & -0.0255 \\
\hline & $(0.0361)$ \\
\hline \multirow[t]{2}{*}{ Net_Loc } & -1.007 \\
\hline & $(0.647)$ \\
\hline \multirow[t]{2}{*}{ OutdegreelF } & $0.191^{* * *}$ \\
\hline & $(0.0592)$ \\
\hline \multirow[t]{2}{*}{ Constant } & 2.085 \\
\hline & $(1.473)$ \\
\hline Observations & 61 \\
\hline R-squared & 0.431 \\
\hline
\end{tabular}

Standard errors in parentheses

$* * * \mathrm{p}<0.01,{ }^{* *} \mathrm{p}<0.05,{ }^{*} \mathrm{p}<0.1$

${ }^{118}$ Results in Table 7.9 are based on the interaction frequency matrix 
Table 7.10 Productivity and Frequency of Interaction ${ }^{119}$

\begin{tabular}{|c|c|}
\hline VARIABLES & $\begin{array}{c}\text { (1) } \\
\text { LnProd }\end{array}$ \\
\hline \multirow[t]{2}{*}{ LnEmp } & $-1.19 e-06$ \\
\hline & $(0.000360)$ \\
\hline \multirow[t]{2}{*}{ Age } & 0.0329 \\
\hline & $(0.0313)$ \\
\hline \multirow[t]{2}{*}{ MNC } & -0.463 \\
\hline & $(0.471)$ \\
\hline \multirow[t]{2}{*}{ CFExp } & $0.452 * * *$ \\
\hline & $(0.133)$ \\
\hline \multirow[t]{2}{*}{ CEdu } & $0.0891^{*}$ \\
\hline & $(0.0516)$ \\
\hline \multirow[t]{2}{*}{ Source_Mnc } & 0.207 \\
\hline & $(0.126)$ \\
\hline \multirow[t]{2}{*}{ FExp } & $-0.0193 * *$ \\
\hline & $(0.00761)$ \\
\hline \multirow[t]{2}{*}{ FEdu } & $0.0184^{*}$ \\
\hline & $(0.0104)$ \\
\hline \multirow[t]{2}{*}{ Training } & -0.0166 \\
\hline & $(0.0185)$ \\
\hline \multirow[t]{2}{*}{ TechStaff } & $-2.391 * * *$ \\
\hline & $(0.810)$ \\
\hline \multirow[t]{2}{*}{ OutdegreelF } & $0.0496^{*}$ \\
\hline & $(0.0461)$ \\
\hline \multirow[t]{2}{*}{ Constant } & 1.150 \\
\hline & $(0.701)$ \\
\hline Observations & 49 \\
\hline R-squared & 0.637 \\
\hline
\end{tabular}

Standard errors in parentheses

*** $\mathrm{p}<0.01, * * \mathrm{p}<0.05,{ }^{*} \mathrm{p}<0.1$

${ }^{119}$ Results in Table 7.10 are based on the interaction frequency matrix 


\subsection{Conclusions}

In this chapter we examine the influence of various network characteristics on the innovative and economic performance of firms. The data for our analysis was gathered using a survey we conducted in 2010. The survey included detailed questions about networks (partner firms) of the respondents (domestic and multinational firms). The main aim here is to establish what it means to be 'better connected' in an organizational context. We explore our dataset for three different kind of advantages associated with networks namely general embeddedness, structural embeddedness and relational embeddedness.

We start out by checking for the importance of general embeddedness metrics (out-degree and out-closeness centrality) in predicting innovative and economic performance. Throughout this chapter we use specifications for both the innovation and productivity equations very similar to those used in chapter 6 . Interestingly the results of most explanatory variables are similar (both in terms of significance and coefficient sign) to those in Chapter 6 . With regards to the new explanatory variables which we are interested in exploring in this chapter, we have mixed results for general embeddedness. Innovative performance and economic performance are unaffected by both centrality metrics used. This way our hypotheses $1 \mathrm{a}$, that more central firms outperform their counterparts in terms of innovative performance and $1 b$, that more central firms outperform their counterparts economically are rejected.

We then move to testing Burt's hypothesis of structural holes. A significant value with a negative coefficient of our predictor, ConstraintIF corroborates Burt's argument that firms which are 'constrained' by redundant ties underperform both in terms of their innovative and economic performance. Conversely this means firms with plenty of structural holes outperform firms with redundant ties.

The third and last set of hypothesis we test is regarding the impact of interaction frequency on innovativeness and productivity. In this case too, a positive and significant link between interaction frequency and both innovativeness and productivity is established As the importance of information in high-tech sectors is well-established and frequent interaction is one mechanism ensuring a positive flow of this vital resource, this finding is also in line with previous research and intuitive at the same time.

To sum it up, position advantages from general embeddedness, though established in literature, do not seem play a significant role in predicting innovativeness. While predicting productivity, a positive and significant impact of out-degree centrality is established for firms in our sample. On the other hand advantages from structural embeddedness and relational embeddedness are corroborated by our findings for both innovative and economic performance. 


\section{Chapter 8. Concluding Remarks}

We set out with the research aim to assess the benefits from FDI inflows in a high-tech sector. The motivation behind this was manifold. We wanted to examine whether FDI inflows help the host economy in terms of learning and increased productivity and at the same time we also wanted to find out if such effects are pronounced in the ICT sector. The ICT sector provides developing countries like Pakistan a level playing field for expanding their activities and becoming competitive, unlike sectors which are more capital and infrastructure intensive. Furthermore we were interested in finding out the determinants of such knowledge flows in order to be able to better harness them.

However, in order to put the economy in general and the ICT sector in specific into the broader context of development and growth, it was necessary that we first understood the historical background of the economy as a whole. Therefore, we took a step back and first studied the initial conditions right from the creation of Pakistan, in order to understand the historical context and how it shaped Pakistan's growth trajectory. We continued by looking at the various regimes which ruled the country and analyzed how their policies affected growth and development. We established that Pakistan's path to social and economic development has not been straightforward. Unfavorable initial conditions, having a rival country as a neighbor, lack of an adequate policy framework and the civil-military divide were all handicaps, many of which are still present today. Despite all odds, there were periods of robust growth but largely at the expense of social development as shown by the various indicators. We then shifted our focus to studying the industrial and services sectors of the economy in detail. Here our goal was to assess the impact of structural changes within the economy on productivity. We found that for the whole economy structural changes do contribute positively to productivity growth, though within sector productivity increases are much more important. Productivity contributions of structural shifts within the manufacturing sector were negligible or even negative.

The shift-share method captures the effects of structural change reasonably well, but fails to capture the effects of inter-sectoral technology spillovers. Thus, the ICT sector in developing countries may potentially be one such sector for which the contributions to growth may be larger than computed by the shift-share method because of the possibility for strong externalities (Fagerberg, 2000; Peneder, 2003). It is therefore suggested to see the sectoral contributions to productivity growth as lower-bound estimates for assessing the importance of structural change. For this reason and to capture the spillover effects, we singled out the ICT sector for its unique characteristics and first studied it based on secondary data available. We found that though the groundwork for transitioning to a knowledge economy is laid, in order to be able to 
become competitive at the level of existing global players such as India and China, a lot of improvement is necessary. Policy instruments should ensure that a push from outside, for instance to encourage more FDI and a pull from inside, for instance to devise a framework which would help firms to absorb spillovers, are achieved at the same time. We then attempted to analyze the ICT sector directly by conducting a firm-level survey, which measured growth and identified spillover channels and mechanisms.

Our study contributed to the existing body of knowledge by exploring the effects of a set of variables on the innovative and productive performance of firms, while relating them to the established mechanisms of spillovers. Our study has validated some of the established findings in literature. With regards to absorptive capacity and human capital our findings corroborated that CEOs' education is positively associated with Productivity, R\&D Staff and the decision to perform R\&D. Similarly the number of a CEO's previous jobs has a positive impact on Process Innovative Performance. We also found that more foreign qualified technical staff members in a firm increases the likelihood of it being more productive and foreign qualified (education) staff intensity positively affects labor productivity. Training for technical staff and Technical staff to employee ration positively predicts Product Innovative Performance. Firms doing R\&D and those having more number of dedicated R\&D staff are more likely to be involved in process innovations. As for labor mobility, we could confirm that CEOs foreign experience positively predicts productivity. Moreover the finding that firms which point to MNCs as their primary source for technology are more productive validates the demonstration effect.

Some of our findings, with regard to the role of education and performance of multinationals were unexpected and went against established views in literature. This could be due to a number of reasons which we would like to highlight. First and foremost, the results point to the specific conditions and challenges facing both foreign and domestic firms in a developing country context. Next, there may be methodological issues, which need to be addressed in further research. Though the sample size used is as per econometric standards big enough to perform such an analysis, we feel that more robust and reliable results could have been achieved with a bigger sample size. We tackle the endogeneity problem by employing an instrumental variable from our data set. Moreover, the difference in application of the concept of R\&D across the various subsectors could have also influenced our results of innovative performance. For instance, it is well known that in the Computer programming subsector, firms engage in innovation activities, but this is usually not referred to as R\&D and is not undertaken by scientists or researchers but rather conducted by programmers who come up with new algorithms, routines and programs. Such intra-sectoral differences make it difficult to interpret the results. Another example would be the results of subsector manufacturing and assembly which stand out as compared to the other three subsectors in many of the variables.

These challenges motivated us to further analyze the knowledge and labor flows from a network perspective. We wanted to assess the importance of social capital 
together with other characteristics on the innovative and economic performance of firms. We based our network analysis on the same survey which we conducted in 2010. The survey included detailed questions about networks (partner firms) of the respondents (domestic and multinational firms). The main aim here was to establish what it means to be 'better connected' in an organizational context. We explored our dataset for three different kind of advantages associated with networks namely general embeddedness, structural embeddedness and relational embeddedness.

We started out by checking for the importance of general embeddedness metrics in predicting innovative and economic performance. We got mixed results for general embeddedness. Innovative performance is unaffected by both centrality metrics used and productivity is positively and significantly predicted by out-degree centrality. We also tested Burt's hypothesis of structural holes and found it to be significantly positive meaning that firms with plenty of structural holes outperform firms with redundant ties. We also tested our data set for the impact of interaction frequency on innovativeness and productivity. Here too a positive and significant link between interaction frequency and both innovativeness and productivity was established corroborating the importance of information in high-tech sectors which is ensured through frequent interactions between firms. 



\section{Chapter 9. Valorization}

In accordance with Article 23 of the regulation governing the attainment of doctoral degrees at Maastricht University, this section discusses the valorization opportunities offered by this doctoral thesis. Following the corresponding guidelines, these opportunities are analyzed in terms of the social and economic relevance of the thesis, the potential target groups to whom the results can be interesting and the degree of innovativeness of the research methods used.

The social relevance of our thesis mainly lies in the fact that a better understanding of the channels and mechanisms of spillovers guides governments to design policies which would help domestic firms in effectively learning from their MNC counterparts.

The main results, practical findings, and policy recommendations of this dissertation can be relevant for a wide target audience: scientific, technical, business, institutional and governmental audiences as well as the general public at large. This is particularly true for audiences in a developing country context. Though similar research has been carried out elsewhere, our study is unique for Pakistan and other developing countries. Moreover, studying a developing country's high tech-sector for spillovers is fairly novel as well and the network analysis makes it even more worthwhile.

In short, the social value created in this dissertation is most relevant for two target audiences in the following ways:

\subsection{For policy makers}

Some findings of our dissertation are quite relevant for policy makers. Our analysis of Pakistan's socio-economic trajectory establishes the need to ensure the continuity in macro-economic policies at national level. Results of the shift and share analysis could help policy makers identify growth enhancing and growth reducing structural change, which in turn could guide them in selecting sectors which should be focused on more. The unavailability of data pointed out also highlights serious statistical shortcomings in Pakistan. The analysis of the evolution and growth of Pakistan's ICT sector deepens the understanding of its role in economic development. It also identifies some of the strengths and weaknesses of the sector.

Similarly, our firm-level survey reveals that foreign qualified and experienced staff positively affect productivity of firms. This calls for policies that would encourage and ensure a brain-gain and a reverse brain-drain. Moreover, the positive effect which trainings for technical staff have on innovative performance highlights the importance 
of holding such trainings. For a developing country with ambitions to tap into the knowledge economy but where domestic firms can not readily afford to arrange trainings on their own, it would be of paramount importance that technical training institutes are fostered and trainings imparted for free or at subsidized rates. Our network analysis revealed the positive impact of frequent firm to firm interaction on both productivity and innovativeness. As interaction is easier (and usually more frequent) in geographically closely located firms, this highlights the importance of science and technology parks.

\subsection{For firms (MNC and domestic)}

From a firm's perspective, some of our findings are very relevant as they lay down some guidelines which firms could incorporate in their respective business strategies. Firstly, the findings relevant for policy makers are equally valuable to firms, as they can benefit in terms of innovative and economic performance gains by utilizing them. Most of the findings are equally applicable to MNC and domestic firms such as the business opportunities highlighted in the ICT sector. Similarly, corroborating Burt's hypothesis of structural holes in a developing country context means that firms' corporate culture should discourage wasting time with redundant ties. The importance of interaction frequency for both innovativeness and productivity calls for providing employees with opportunities to interact with partner firms, be it through co-location or other practical means. Moreover, some findings are particularly pertinent for domestic firms, such as the fact that firms which point to MNCs as their primary source for technology are more productive.

\subsection{Dissemination}

Effective communication, dissemination and exploitation of the results of this research play an essential role in succeeding to reach the maximum social value creation. In addition, it is necessary to exploit a wide range of tools to reach such a diverse target audience. These tools include publications in peer-reviewed journals (open accesses wherever feasible), specialist website and presentations in scientific conferences and seminars (scientific community); commercial, financial and industrial publications (business organizations), popular newspapers, magazines, blogs, social media, and the Internet (the general public); reports and policy briefs (international organizations and policy makers).

We not only hope that our recommendations for valorization will be useful for the target audiences e.g. policy adoption at governmental level, but also do our own efforts in this regard by engaging with various actors at different forums. In this regard we have already succeeded in a few engagements such as presentations of our results 
and findings at academic conferences, lectures are policy institutes and publishing in national dailies. Excerpts from findings were presented at an IEEE conference at Institute of Business Administration Karachi on 24th July 2011, in the 1st IEEE Engineering Management Conference at NUST on 20th March 2012, and the COMSTECH International Conference on Science Policies and Restructuring of National Systems of Innovation, Islamabad, Pakistan held 3rd to 5th October 2012. Similarly, a lecture was delivered at a COMSTECH Training Course at the COMSTECH Head office in Islamabad held between the 5th and 9th March, 2012. Chapters 4, 6 and 7 will be adapted for publishing in international peer-reviewed journals. 



\section{Bibliography}

Abbas, T., \& Charles, T. (2003). Handbook of mixed methods in social \& behavioral research. Retrieved from https://scholar.google.com.pk/scholar?q=Handbook+of+mixed+methods+in+social+\%26+behavioral+ research\&btnG=\&hl=en\&as_sdt=0\%2C5\#0

Acs, Z. J., \& Audretsch, D. B. (1987). Innovation, market structure, and firm size. The Review of Economics and Statistics, 69(4), 567-574. Retrieved from http://www.jstor.org/stable/1935950

Acs, Z. J., \& Audretsch, D. B. (1988). Innovation in large and small firms: an empirical analysis. The American Economic Review, 78(4), 678-690. Retrieved from http://www.jstor.org/stable/1811167

Aghion, P., Bloom, N., Blundell, R., Griffith, R., \& Howitt, P. (2002). Competition and innovation: An inverted U relationship. Quarterly Journal of Economics, 120(2), 701-728. Retrieved from http://www.nber.org/papers/w9269

Ahmad, I., Shah, S., \& Zahid, M. (2004). Why The Green Revolution Was Short Run Phenomena In The Development Process Of Pakistan: A Lesson For Future. Retrieved from http://mpra.ub.unimuenchen.de/9520

Ahmed, Q., \& Hyder, K. (2007). Determinants of Total Factor Productivity in Pakistan. Retrieved from http://mpra.ub.uni-muenchen.de/16253/

Aitken, B. B. J., \& Harrison, A. A. E. (1999). Do domestic firms benefit from direct foreign investment? Evidence from Venezuela. American Economic Review, 89(3), 605-618. Retrieved from http://www.jstor.org/stable/10.2307/117035

Aitken, B., Hanson, G., \& Harrison, A. (1997). Spillovers, foreign investment, and export behavior. Journal of International Economics. Retrieved from http://www.sciencedirect.com/science/article/pii/S002219969601464X

Aitken, B., \& Harrison, A. (1999). Do domestic firms benefit from direct foreign investment? Evidence from Venezuela. American Economic Review. Retrieved from http://www.jstor.org/stable/117035

Akçomak, I., \& Weel, B. Ter. (2009). Social capital, innovation and growth: Evidence from Europe. European Economic Review. Retrieved from http://www.sciencedirect.com/science/article/pii/S0014292108000998

Ali, A. (2010). Economic cost of terrorism: A case study of Pakistan. Strategic Studies. Retrieved from http://arz-e-pak.com/documents/ebooks/EcoCostOfTerrorism.pdf

Almodóvar, P., Saiz-Briones, J., \& Silverman, B. S. (2013). Learning through foreign market participation: the relative benefits of exporting, importing, and foreign direct investment. The Journal of Technology Transfer, 39(6), 915-944. doi:10.1007/s10961-013-9324-9

Altaf, S. (2011). So much aid, so little development: Stories from Pakistan. Retrieved from http://scholar.google.com.pk/scholar?hl=en\&q=So+Much+Aid,+So+Little+Development:+Stories+fro $m+$ Pakistan\&btnG=\&as_sdt=1,5\&as_sdtp=\#2

Alvarez, R., \& López, R. A. (2008). Is Exporting a Source of Productivity Spillovers? Review of World Economics, 144(4), 723-749. doi:10.1007/s10290-008-0167-7

Amin, A., \& Cohendet, P. (2004). Architectures of knowledge: firms, capabilities and communities. Retrieved from http://dro.dur.ac.uk/archive/00002833/

Amjid, S., Bilal, M., Nazir, M., \& Hussain, A. (2011). Biogas, renewable energy resource for Pakistan. Renewable and Sustainable .... Retrieved from http://www.sciencedirect.com/science/article/pii/S136403211100089X

Ark, B. Van, \& Timmer, M. (2003). Asia's Productivity Performance and Potential : The Contribution of Sectors and Structural Change. 
Audretsch, D. D. B., \& Feldman, M. M. P. (2004). Knowledge spillovers and the geography of innovation. Handbook of Regional and Urban Economics, 4(December 2002). Retrieved from http://www.sciencedirect.com/science/article/pii/S157400800480018X

Audretsch, D., \& Feldman, M. (1996). R\&D spillovers and the geography of innovation and production. The American Economic Review. Retrieved from http://www.jstor.org/stable/2118216

Audretsch, D., \& Stephan, P. (1996). Company-scientist locational links: The case of biotechnology. The American Economic Review. Retrieved from http://www.jstor.org/stable/2118217

Autant-Bernard, C. (2001a). Science and knowledge flows: evidence from the French case. Research Policy. Retrieved from http://www.sciencedirect.com/science/article/pii/S0048733300001311

Autant-Bernard, C. (2001b). The geography of knowledge spillovers and technological proximity. Economics of Innovation and New Technology. Retrieved from http://www.tandfonline.com/doi/abs/10.1080/10438590100000010

Baba, Y., Shichijo, N., \& Sedita, S. (2009). How do collaborations with universities affect firms' innovative performance? The role of "Pasteur scientists" in the advanced materials field. Research Policy. Retrieved from http://www.sciencedirect.com/science/article/pii/S0048733309000067

Baier, S., Dwyer, G., \& Tamura, R. (2006). How important are capital and total factor productivity for economic growth? Economic Inquiry. Retrieved from http://onlinelibrary.wiley.com/doi/10.1093/ei/cbj003/full?url_ver=Z39.88-

2004\&rft_val_fmt=info:ofi/fmt:kev:mtx:journal\&rft.genre=article\&rft.jtitle=Review of Income and Wealth\&rft.atitle=A New Set of International Comparisons of Real Product and Price Levels Estimates for 130 Countries, 1950

1985\&rft.volume=34\&rft.spage=1\&rft.epage=25\&rft.date=1988\&rft.aulast=Summers\&rft.aufirst=Ro bert\&rfr_id=info:sid/wiley.com:OnlineLibrary

Balsvik, R. (2006). Is mobility of labour a channel for spillovers from multinationals to local domestic firms ? *, (August), 1-33.

Balsvik, R. (2011). Is labor mobility a channel for spillovers from multinationals? Evidence from Norwegian manufacturing. The Review of Economics and Statistics. Retrieved from http://www.mitpressjournals.org/doi/abs/10.1162/REST_a_00061

Baqir, M., \& Parvez, S. (2000). IT Policy. Computer News. Retrieved from http://scholar.google.com.pk/scholar?q=Baqir,+M.N.+and+Parvez,+S.+-IT+Policy ,+Computer+News \&btnG=\&hl=en\&as_sdt=0,5\#0

Barnes, J. A. (1974). Social Networks. Modules in Anthropology, 26.

Baumol, W. (1967). Macroeconomics of unbalanced growth: the anatomy of urban crisis. The American Economic Review. Retrieved from http://www.jstor.org/stable/1812111

Bayoumi, T., Coe, D., \& Helpman, E. (1999). R\&D spillovers and global growth. Journal of International Economics. Retrieved from http://www.sciencedirect.com/science/article/pii/S002219969800018X

Belderbos, R., \& Mohnen, P. (2013). Intersectoral and international R\&D spillovers. Retrieved from http://ideas.repec.org/p/bre/wpaper/798.html

Benavente, J. M. (2006a). The role of research and innovation in promoting productivity in Chile. ... of Innovation and New Technology, 15(4-5), 301-315. Retrieved from http://www.tandfonline.com/doi/abs/10.1080/10438590500512794

Benavente, J. M. (2006b). The role of research and innovation in promoting productivity in Chile. ... of Innovation and New Technology. Retrieved from http://www.tandfonline.com/doi/abs/10.1080/10438590500512794

Bhide, A. (2000). The origin and evolution of new businesses. Retrieved from http://scholar.google.com.pk/scholar?q=The+Origin+and+Evolution+of+New+Businesses\&btnG=\&hl= en\&as_sdt $=0,5 \# 0$

Bhutto, A., Bazmi, A., \& Zahedi, G. (2012). Greener energy: issues and challenges for Pakistan - solar energy prospective. Renewable and Sustainable Energy .... Retrieved from http://www.sciencedirect.com/science/article/pii/S1364032112001372

Blomstrom, M. (1992). Host country benefits of foreign investment. Retrieved from http://www.nber.org/papers/w3615 
Blomström, M. (1997). The Impact of Foreign Investment on Host Countries : A Review of the Empirical Evidence The Impact of Foreign Investment on Host Countries : A Review of the Empirical Evidence *, (1745).

Blomstrom, M., \& Kokko, A. (1998). Multinational Corporations and Spillovers. Journal of Economic Surveys, 12(3), 247-277. doi:10.1111/1467-6419.00056

Blomström, M., \& Kokko, A. (1997). How foreign investment affects host countries. Retrieved from http://citeseerx.ist.psu.edu/viewdoc/download?doi=10.1.1.194.5427\&rep=rep1\&type=pdf

Blomström, M., \& Persson, H. (1983). Foreign investment and spillover efficiency in an underdeveloped economy: evidence from the Mexican manufacturing industry. World Development. Retrieved from http://www.sciencedirect.com/science/article/pii/0305750X83900165

Blomström, M., \& Sjöholm, F. (1999). Technology transfer and spillovers: does local participation with multinationals matter? European Economic Review. Retrieved from http://www.sciencedirect.com/science/article/pii/S0014292198001044

Blood, P. (1996). Pakistan: a country study. Retrieved from http://books.google.com.pk/books?hl=en\&lr=\&id=DRMTO7mn7hIC\&oi=fnd\&pg=PR3\&dq=Pakistan:+ $A+C o u n t r y+S t u d y \& o t s=S e C j 1 f z 8 x S \&$ sig=rSgyg8sl84ySVzBdZ5k6g8sUP2A

Blundell, R. (1999). Market share, market value and innovation in a panel of British manufacturing firms. The Review of ..., 66(3), 529-554. Retrieved from http://restud.oxfordjournals.org/content/66/3/529.short

Blyde, J., Kugler, M., \& Stein, E. (2004). Exporting vs. outsourcing by MNC subsidiaries: which determines FDI spillovers? Retrieved from

http://scholar.google.com.pk/scholar?q=Exporting+vs.+Outsourcing+by+MNC+Subsidiaries:+Which+ Determines+FDI+Spillovers?\&btnG=\&hl=en\&as_sdt $=0,5 \# 0$

Bönte, W. (2008). Inter-firm trust in buyer-supplier relations: Are knowledge spillovers and geographical proximity relevant? Journal of Economic Behavior \& Organization. Retrieved from http://www.sciencedirect.com/science/article/pii/S0167268107001667

Boschma, R. A., \& ter Wal, A. L. J. (2007). Knowledge Networks and Innovative Performance in an Industrial District: The Case of a Footwear District in the South of Italy. Industry \& Innovation, 14(2), 177-199. doi:10.1080/13662710701253441

Bottazzi, L., \& Peri, G. (1999). Innovation, demand and knowledge spillovers: theory and evidence from European regions. Retrieved from ftp://ftp.igier.unibocconi.it/wp/1999/153.pdf

Braga, C., \& Fink, C. (1998). Relationship between Intellectual Property Rights and Foreign Direct Investment, The. Duke J. Comp. \& Int'l L. Retrieved from http://heinonlinebackup.com/hol-cgibin/get_pdf.cgi?handle=hein.journals/djcil9\&section=11

Branstetter, L. (2001). Are knowledge spillovers international or intranational in scope?: Microeconometric evidence from the US and Japan. Journal of International Economics. Retrieved from http://www.sciencedirect.com/science/article/pii/S0022199600000684

Breschi, S., \& Lissoni, F. (2001). Knowledge spillovers and local innovation systems: a critical survey. Industrial and Corporate Change. Retrieved from http://icc.oxfordjournals.org/content/10/4/975.short

Bresnahan, T., \& Trajtenberg, M. (1995). General purpose technologies “Engines of growth"? Journal of Econometrics. Retrieved from http://www.sciencedirect.com/science/article/pii/030440769401598T

Brown, G. (2006). Pakistan: on the edge of instability. International Socialism. Retrieved from http://www.isj.org.uk/index.php4?id=184..

Brynjolfsson, E., \& Hitt, L. (2000). Beyond computation: Information technology, organizational transformation and business performance. The Journal of Economic Perspectives. Retrieved from http://www.jstor.org/stable/2647074

Burt, R. (1987). Social contagion and innovation: Cohesion versus structural equivalence. American Journal of Sociology. Retrieved from http://www.jstor.org/stable/10.2307/2779839

Burt, R. (1992). The social structure of competition. Networks and Organizations: Structure, Form, and .... Retrieved from http://personal.stevens.edu/ ysakamot/BIA658/man/week4/burt.pdf 
Burt, R. (2001). Structural holes versus network closure as social capital. Social Capital: Theory and Research, (May 2000). Retrieved from

http://scholar.google.de/scholar?hl=en\&q=structural+holes+versus+network+closure+as+social+capi tal\&btnG=\&as_sdt=1,5\&as_sdtp=\#0

Byerlee, D., \& Siddiq, A. (1994). Has the Green Revolution been sustained? The quantitative impact of the seed-fertilizer revolution in Pakistan revisited. World Development. Retrieved from http://www.sciencedirect.com/science/article/pii/0305750X94900086

Caniëls, M., \& Romijn, H. (2003). Firm-level knowledge accumulation and regional dynamics. Industrial and Corporate Change. Retrieved from http://icc.oxfordjournals.org/content/12/6/1253.short

Caniëls, M., \& Romijn, H. (2005). What drives innovativeness in industrial clusters? Transcending the debate. Cambridge Journal of Economics. Retrieved from http://cje.oxfordjournals.org/content/29/4/497.short

Cantin, É., \& Taylor, M. (2008). Making the "workshop of the world": China and the transformation of the international division of labour. Global Economy Contested: Power and Conflict across .... Retrieved from https://scholar.google.com.pk/scholar?q=china+workshop+of+the+world\&btnG=\&hl=en\&as_sdt=0\% 2C5\#4

Cantwell, J., \& Piscitello, L. (2005). Recent location of foreign-owned research and development activities by large multinational corporations in the European regions: the role of spillovers and. Regional Studies. Retrieved from http://www.tandfonline.com/doi/abs/10.1080/0034340052000320824

Carty, G., Illustrator-Mueller, M., \& Illustrator-Coda, R. (2002). Broadband networking. Retrieved from http://dl.acm.org/citation.cfm?id=601354

Cassiman, B., \& Veugelers, R. (1998). R\&D cooperation and spillovers: some empirical evidence. Retrieved from https://repositori.upf.edu/handle/10230/362

Castellani, D., \& Zanfei, A. (2003). Technology gaps, absorptive capacity and the impact of inward investments on productivity of European firms*. Economics of Innovation and New .... Retrieved from http://www.tandfonline.com/doi/pdf/10.1080/714933761

Caves, R. (1974). Multinational firms, competition, and productivity in host-country markets. Economica. Retrieved from http://www.jstor.org/stable/2553765

Cerulli, G., \& Poti, B. (2009). Measuring intersectoral knowledge spillovers: An application of sensitivity analysis to italy. Economic Systems Research. Retrieved from http://www.tandfonline.com/doi/abs/10.1080/09535310903569216

Chang, K. (2011). The Companies We Keep: Effects of Relational Embeddedness on Organizational Performance1. Sociological Forum. Retrieved from http://onlinelibrary.wiley.com/doi/10.1111/j.1573-7861.2011.01261.x/full

Chang, S., \& Xu, D. (2008). Spillovers and competition among foreign and local firms in China. Strategic Management Journal. Retrieved from http://onlinelibrary.wiley.com/doi/10.1002/smj.674/abstract

Child, F., \& Kaneda, H. (1975). Links to the green revolution: a study of small-scale, agriculturally related industry in the Pakistan Punjab. Economic Development and Cultural Change. Retrieved from http://www.jstor.org/stable/1152982

Chuang, Y., \& Lin, C. (1999). Foreign direct investment, R\&D and spillover efficiency: Evidence from Taiwan's manufacturing firms. The Journal of Development Studies. Retrieved from http://www.tandfonline.com/doi/abs/10.1080/00220389908422583

Cincera, M., \& Potterie, B. D. La. (2001). International R\&D spillovers: a survey. Cahiers Economiques de Bruxelles. Retrieved from http://solvay.ulb.ac.be/cours/vanpottelsberghe/resources/resources/Pap_CahierBxl_3.pdf

Clark, C. (1967). The conditions of economic progress. The Conditions of Economic Progress. Retrieved from http://www.cabdirect.org/abstracts/19671803430.html

Coe, D., \& Helpman, E. (1995). International r\&d spillovers. European Economic Review. Retrieved from http://www.sciencedirect.com/science/article/pii/001429219400100E

Coe, D. T., \& Helpman, E. (1995). International R\&D spillovers. European Economic Review, 39(5), 859-887. doi:10.1016/0014-2921(94)00100-E 
Coe, D. T., Helpman, E., \& Hoffmaister, A. W. (1997). North-South R\&D Spillovers. Economic Journal, 107(440), 134-49. Retrieved from http://ideas.repec.org/a/ecj/econjl/v107y1997i440p134-49.html

Cohen, W., \& Levinthal, D. (1990). Absorptive capacity: a new perspective on learning and innovation. Administrative Science Quarterly. Retrieved from http://www.jstor.org/stable/10.2307/2393553

Cohen, W. M., Levin, R. C., \& Mowery, D. C. (1987). Firm size and R\&D intensity: A re-examination. The Journal of Industrial Economics, 35(4), 543-565. Retrieved from http://www.nber.org/papers/w2205

Cohendet, P. (2005). On knowing communities. Draft Paper for the Conference" .... Retrieved from http://advancingknowledge.groups.si.umich.edu/drafts/Cohendet-knowing communities.doc

Coleman, J. (1994). Foundations of social theory. Retrieved from http://books.google.com/books?hl=en\&lr=\&id=a4DI8tiX4b8C\&oi=fnd\&pg=PR15\&dq=coleman+1990+ Foundations+of+Social+Theory\&ots=qB6qSZJVMn\&sig=y3LekXzoGNg8DY9RwUKzf5r3zd8

Coleman, J. S., Katz, E., Menzel, H., \& Research, C. U. B. of A. S. (1966). Medical innovation: a diffusion study. Bobbs-Merrill Co. Retrieved from http://books.google.com/books?id=TjBrAAAAMAAJ\&pgis=1

Commission, I. I. in S. (1997). Information and Communications Technology in UK Schools: an independent inquiry. ... , UK. Author: Chair Dennis .... Retrieved from http://www.opengrey.eu/item/display/10068/417025

Crepon, B., Duguet, E., \& Mairessec, J. (1998). Research, Innovation And Productivi [Ty: An Econometric Analysis At The Firm Level. ... Innovation and New Technology. Retrieved from http://www.tandfonline.com/doi/abs/10.1080/10438599800000031

Crespi, G., Criscuolo, C., \& Haskel, J. (2008). Productivity, exporting, and the learning by exporting hypothesis: direct evidence from UK firms. Canadian Journal of .... Retrieved from http://onlinelibrary.wiley.com/doi/10.1111/j.1540-5982.2008.00479.x/full

Crespi, G., Tacsir, E., \& Vargas, F. (2014). Innovation dynamics and productivity: evidence for Latin America. Retrieved from https://ideas.repec.org/p/unm/unumer/2014092.html

Crespo, N., \& Fontoura, M. P. M. (2007). Determinant factors of FDI spillovers-what do we really know? World Development, 35(3), 410-425. doi:10.1016/j.worlddev.2006.04.001

Cusumano, M. (2004). The business of software: What every manager, programmer, and entrepreneur must know to thrive and survive in good times and bad. Retrieved from

http://books.google.com.pk/books?hl=en\&lr=\&id=REP6K6P_eJYC\&oi=fnd\&pg=PA1\&dq=Michael+Cus umano's+The+Business+of+Software\&ots=NdZT3Dt1IA\&sig=8-des_AEI_CteFUwTjhWczst0dk

Dakhli, M., \& Clercq, D. De. (2004). Human capital, social capital, and innovation: a multi-country study. Entrepreneurship \& Regional Development. Retrieved from http://www.tandfonline.com/doi/abs/10.1080/08985620410001677835

Damanpour, F. (1992). Organizational size and innovation. Organization Studies. Retrieved from http://oss.sagepub.com/content/13/3/375.short

Davidson, R., \& MacKinnon, J. (1993). Estimation and inference in econometrics. OUP Catalogue. Retrieved from https://ideas.repec.org/b/oxp/obooks/9780195060119.html

DeBresson, C. (1999). An entrepreneur cannot innovate alone: networks of enterprises are required. DRUID Conference on Systems of Innovation. Retrieved from http://www.druid.dk/uploads/tx_picturedb/ds1999-53.pdf

DeBresson, C., \& Hu, X. (1999). Identifying clusters of innovative activity: a new approach and a toolbox. BOOSTING INNOVATION THE CLUSTER .... Retrieved from http://books.google.com.pk/books?hl=en\&lr=\&id=BdepQ575VIMC\&oi=fnd\&pg=PA27\&dq=Debresson +and+Hu+1999\&ots=VYSEDPjL1R\&sig=i-OWDyHD9Nk3xg8uwkN1rPv0_cw

Dedrick, J., Gurbaxani, V., \& Kraemer, K. (2003). Information technology and economic performance: A critical review of the empirical evidence. ACM Computing Surveys (CSUR). Retrieved from http://dl.acm.org/citation.cfm?id=641866

Denison, E. (1985). Trends in American economic growth, 1929-1982: 1929-1982. Retrieved from http://books.google.com.pk/books?hl=en\&lr=\&id=LDcMr4avqQAC\&oi=fnd\&pg=PR15\&dq=Denison:+ 1985\&ots=KM88d8cQLI\&sig=0KaMwQ2JNqf-yQecGMHdKfKHtYw 
Desrochers, P., \& Leppala, S. (2010). Opening up the "Jacobs Spillovers" black box: local diversity, creativity and the processes underlying new combinations. Journal of Economic Geography, 11(5), 843-863. doi:10.1093/jeg/lbq028

Dijk, J. Van, \& Hacker, K. (2003). The digital divide as a complex and dynamic phenomenon. The Information Society. Retrieved from http://www.tandfonline.com/doi/abs/10.1080/01972240309487

Din, M. (2007). An Analysis of Pakistan's Growth Experience 1983-84-1987-88 and 2002-03 to 2005-06.

... Update. Background Paper Series-ADB Pakistan. Retrieved from http://scholar.google.de/scholar?q=an+analysis+of+Pakistan's+gorwth+experience+din+2007\&btnG= \&hl=en\&as_sdt $=0,5 \# 0$

Dumont, M., \& Tsakanikas, A. (2001). Knowledge spillovers through R\&D networking. Innovative Networks: Co-Operation in .... Retrieved from http://books.google.com.pk/books?hl=en\&lr=\&id=GQ730W298zYC\&oi=fnd\&pg=PA209\&dq=Knowle dge+spillovers+through+R\&D+networking\&ots=oOpGlhGEFI\&sig=kzhn-kfETeR9mZp5Rd1hotOY4Q8

Dunning, J. (1995). Reappraising the eclectic paradigm in an age of alliance capitalism. Journal of International Business Studies. Retrieved from http://www.jstor.org/stable/155557

Dunning, J. (1997). Alliance capitalism and global business. Retrieved from http://books.google.com.pk/books?hl=en\&lr=\&id=F1kzKFfnwTMC\&oi=fnd\&pg=PR7\&dq=Alliance+Ca pitalism\&ots=_KPyNm2qdE\&sig=xSkIbS2GV06s5qgWDwN7mKImvRk

Dunning, J., \& Lundan, S. (2008). Multinational enterprises and the global economy. Retrieved from http://books.google.com.pk/books?hl=en\&lr=\&id=Hz6S4BGmGxUC\&oi=fnd\&pg=PR1\&dq=dunning+lu ndan+2007\&ots=HRObSQgBYD\&sig=8EJy49YWIbR6rARQL1RdF1LTSrQ

Durlauf, S., \& Fafchamps, M. (2003). Empirical studies of social capital: a critical survey. Retrieved from http://scholar.google.com.pk/scholar?q=Durlauf+and+Fafchamps++social+capital+economic+growth \&btnG $=\& h l=e n \& a s \_s d t=0,5 \# 0$

Easterly, W. (2003). The Political Economy of Growth Without Development: A Case Study of Pakistan. ... Prosperity: Analytic Narratives on Economic Growth. Retrieved February 27, 2014, from http://williameasterly.files.wordpress.com/2010/08/9_easterly_thepoliticaleconomyofgrowthwithoutdevelopmentpakistan.pdf

Effie Kesidou and Adam Szirmai. (2008). Working Paper Series, (31).

Eisenhardt, K., \& Tabrizi, B. (1995). Accelerating adaptive processes: Product innovation in the global computer industry. Administrative Science Quarterly. Retrieved from http://www.jstor.org/stable/2393701

Engelbrecht, H. (1997). International R\&D spillovers, human capital and productivity in OECD economies: An empirical investigation. European Economic Review. Retrieved from http://www.sciencedirect.com/science/article/pii/S0014292196000463

Fabricant, S. (1942). Employment in Manufacturing, 1899-1939: An Analysis of Its Relation to the Volume of Production. National Bureau of Economic Research, Inc. Retrieved from http://econpapers.repec.org/RePEc:nbr:nberbk:fabr42-1

Fabrizio, K. R. (2009). Absorptive capacity and the search for innovation. Research Policy, 38(2), 255-267. Retrieved from http://www.sciencedirect.com/science/article/pii/S0048733308002771

Fagerberg, J. (2000). Technological progress, structural change and productivity growth: a comparative study. Structural Change and Economic Dynamics. Retrieved from http://www.sciencedirect.com/science/article/pii/S0954349X00000254

Falki, N. (2009). Impact of foreign direct investment on economic growth in Pakistan. International Review of Business Research .... Retrieved from http://www.bizresearchpapers.com/10.Nuzhat.pdf

Falvey, R., Foster, N., \& Greenaway, D. (2004). Imports, exports, knowledge spillovers and growth. Economics Letters. Retrieved from http://www.sciencedirect.com/science/article/pii/S0165176504001703

Fan, S. (1991). Effects of technological change and institutional reform on production growth in Chinese agriculture. American Journal of Agricultural Economics. Retrieved from http://ajae.oxfordjournals.org/content/73/2/266.short 
Fare, R., \& Grosskopf, S. (1994). Productivity growth, technical progress, and efficiency change in industrialized countries. American Economic .... Retrieved from http://down.cenet.org.cn/upfile/13/2011129101317130.pdf

Farla, K., Crombrugghe, D. De, \& Verspagen, B. (2013). UNU-MERIT Working Paper Series, (31).

Fink, C., \& Maskus, K. (2005). Intellectual property and development: lessons from recent economic research. Retrieved from http://books.google.com.pk/books?hl=en\&lr=\&id=c--

C5LYu0_YC\&oi=fnd\&pg=PR5\&dq=(Fink+and+Maskus,+2005\&ots=WKaESkbt2W\&sig=zeiO8rjBYymfF6 WaONZylBeXYGc

Fosfuri, A., Motta, M., \& Rønde, T. (2001). Foreign direct investment and spillovers through workers' mobility. Journal of International Economics. Retrieved from http://www.sciencedirect.com/science/article/pii/S0022199600000696

Fosfuri, A., \& Tribó, J. (2008). Exploring the antecedents of potential absorptive capacity and its impact on innovation performance. Omega. Retrieved from http://www.sciencedirect.com/science/article/pii/S0305048306000946

Freeman, L. (1977). A set of measures of centrality based on betweenness. Sociometry. Retrieved from http://www.jstor.org/stable/10.2307/3033543

Freeman, L. (1979). Centrality in social networks conceptual clarification. Social Networks. Retrieved from http://www.sciencedirect.com/science/article/pii/0378873378900217

Fritsch, M., \& Franke, G. (2004). Innovation, regional knowledge spillovers and R\&D cooperation. Research Policy. Retrieved from http://www.sciencedirect.com/science/article/pii/S0048733303001239

Fu, X., Pietrobelli, C., \& Soete, L. (2011). The Role of Foreign Technology and Indigenous Innovation in the Emerging Economies: Technological Change and Catching-up. World Development, 39(7), 1204-1212. Retrieved from http://www.sciencedirect.com/science/article/pii/S0305750X11000647

Fuentes, C. De. (2008). Different patterns of knowledge spillovers mechanisms in two Mexican localities. Retrieved from https://smartech.gatech.edu/handle/1853/39353

Fullbrook, D. (2010). Food as security. Food Security. Retrieved from http://link.springer.com/article/10.1007/s12571-009-0050-y

Gardezi, H., \& Rashid, J. (1983). Pakistan, the roots of dictatorship: The political economy of a praetorian state. Retrieved from

http://scholar.google.de/scholar?q=Pakistan:+The+roots+of+dictatorship:+The+political+economy+o $\mathrm{f}+\mathrm{a}+$ praetorian+state\&btnG$=\& \mathrm{hl}=\mathrm{en} \& \mathrm{as} \_\mathrm{sdt}=0,5 \# 0$

Gerlach, M. (1992). Alliance Capitalism. Berkeley. Retrieved from http://scholar.google.com.pk/scholar?q=Alliance+Capitalism\&btnG=\&hl=en\&as_sdt=0,5\#3

Gerschenkron, A. (1962). Economic backwardness in historical perspective. Economic Backwardness in Historical Perspective. Retrieved from http://www.cabdirect.org/abstracts/19641800248.html

Gilbert, R. (2006). Looking for Mr. Schumpeter: Where are we in the competition-innovation debate? Innovation Policy and the Economy, Volume 6, 159-215. Retrieved from http://www.nber.org/chapters/c0208.pdf

Girma, S. (2001). Who benefits from foreign direct investment in the UK? Scottish Journal of Political .... Retrieved from http://onlinelibrary.wiley.com/doi/10.1111/1467-9485.00189/abstract

Girma, S. (2005). Absorptive Capacity and Productivity Spillovers from FDI: A Threshold Regression Analysis*. Oxford Bulletin of Economics and Statistics. Retrieved from http://onlinelibrary.wiley.com/doi/10.1111/j.1468-0084.2005.00120.x/full

Girma, S., \& Görg, H. (2005). Foreign direct investment, spillovers and absorptive capacity: Evidence from quantile regressions. Deutsche Bundesbank Discussion Paper No. 13/2005. Retrieved from http://www.econstor.eu/handle/10419/19521

Glaeser, E., Kallal, H., Scheinkman, J., \& Shleifer, A. (1991). Growth in cities. Retrieved from http://www.nber.org/papers/w3787

Glass, A., \& Saggi, K. (2002). Multinational firms and technology transfer. The Scandinavian Journal of Economics. Retrieved from http://onlinelibrary.wiley.com/doi/10.1111/1467-9442.00298/abstract

Globerman, S. (1979). Foreign direct investment and'spillover'efficiency benefits in Canadian manufacturing industries. Canadian Journal of Economics. Retrieved from http://www.jstor.org/stable/134570 
Görg, H., \& Greenaway, D. (2004). Much Ado about Nothing? Do Domestic Firms Really Benefit from Foreign Direct Investment? The World Bank Research Observer, 19(2), 171-197. doi:10.1093/wbro/lkh019

Görg, H., \& Strobl, E. (2005a). Foreign direct investment and local economic development: Beyond productivity spillovers. Does Foreign Direct Investment Promote .... Retrieved from http://books.google.com.pk/books?hl=en\&lr=\&id=QuYPDMsVn0C\&oi=fnd\&pg=PA137\&dq=pecuniary+spillovers+strobl\&ots=|3attTKAU4\&sig=Lj9QIEtuEAz GStNUiHjThn6SI2A

Görg, H., \& Strobl, E. (2005b). Spillovers from Foreign Firms through Worker Mobility: An Empirical Investigation*. The Scandinavian Journal of Economics. Retrieved from http://onlinelibrary.wiley.com/doi/10.1111/j.1467-9442.2005.00427.x/full

Government. (2013). Consultation on the Order for replacing the subject of ICT with computing. Retrieved March 21, 2014, from https://www.gov.uk/government/uploads/system/uploads/attachment_data/file/205921/ICT_to_co mputing_consultation_report.pdf

Granovetter, M. (1973). The strength of weak ties. American Journal of Sociology. Retrieved from http://www.jstor.org/stable/10.2307/2776392

Granovetter, M. (1983). The strength of weak ties: A network theory revisited. Sociological Theory. Retrieved from http://www.soc.ucsb.edu/faculty/friedkin/Syllabi/Soc148/Granovetter 1983.pdf

Green, S. (1991). How many subjects does it take to do a regression analysis. Multivariate Behavioral Research. Retrieved from http://www.tandfonline.com/doi/abs/10.1207/s15327906mbr2603_7

Greenwood, J., Hercowitz, Z., \& Krusell, P. (1997). Long-run implications of investment-specific technological change. The American Economic Review. Retrieved from http://www.jstor.org/stable/2951349

Griffith, R. (2003). R\&d and absorptive capacity: Theory and empirical evidence*. The Scandinavian Journal .... Retrieved from http://onlinelibrary.wiley.com/doi/10.1111/1467-9442.00007/full

Griffith, R., \& Huergo, E. (2006). Innovation and productivity across four European countries. Oxford Review of .... Retrieved from http://oxrep.oxfordjournals.org/content/22/4/483.short

Griffith, R., Huergo, E., Mairesse, J., \& Peters, B. (2006). Innovation and productivity across four European countries. Oxford Review of Economic Policy, 22(4), 483-498. Retrieved from http://discovery.ucl.ac.uk/16501/

Griliches, Z. (1979). Issues in assessing the contribution of research and development to productivity growth. The Bell Journal of Economics. Retrieved from http://www.jstor.org/stable/3003321

Griliches, Z. (1992). The search for R\&D spillovers. Retrieved from http://www.nber.org/papers/w3768

Grossman, G., \& Helpman, E. (1991). Trade, knowledge spillovers, and growth. European Economic Review. Retrieved from http://www.sciencedirect.com/science/article/pii/001429219190153A

Haaland, J. I., \& Wooton, I. (1999). International Competition for Multinational Investment. Scandinavian Journal of Economics, 101(4), 631-649. doi:10.1111/1467-9442.00177

Haddad, M., \& Harrison, A. (1993). Are there positive spillovers from direct foreign investment?: Evidence from panel data for Morocco. Journal of Development Economics. Retrieved from http://www.sciencedirect.com/science/article/pii/030438789390072U

Hall, B., Lotti, F., \& Mairesse, J. (2009). Innovation and productivity in SMEs: empirical evidence for Italy. Small Business Economics. Retrieved from http://link.springer.com/article/10.1007/s11187-0099184-8

Hall, B., \& Mairesse, J. (1995). Exploring the relationship between R\&D and productivity in French manufacturing firms. Journal of Econometrics. Retrieved from http://www.sciencedirect.com/science/article/pii/030440769401604X

Haltiwanger, J., Lane, J., \& Spletzer, J. (1999). Productivity differences across employers: The roles of employer size, age, and human capital. The American Economic Review. Retrieved from http://www.jstor.org/stable/10.2307/117087

Hamberg, D. (1964). Size of firm, oligopoly, and research: The evidence. Canadian Journal of Economics and Political Science, 30(1), 62-75. Retrieved from http://www.jstor.org/stable/139170 
Hamid, A., \& Pichler, J. (2009). Human Capital Spillovers, Productivity and Growth in the Manufacturing Sector of Pakistan. Pakistan Development Review. Retrieved from

http://search.ebscohost.com/login.aspx?direct=true\&profile=ehost\&scope=site\&authtype=crawler\&j $\mathrm{rnl}=00309729 \& A N=55421467 \& \mathrm{~h}=\mathrm{rFSnBnZNqVoOgdAR3incDpaoN2el6 \% 2BANI4LAluTHdJNpEedx92Vy}$ iozB\%2FzLMkKyPwXmElHal7dpx9cqOjUcBbg\%3D\%3D\&crl=c

Hanna, N. (2003). Why National Strategies are needed for ICT-enabled Development. World Bank Staff Paper. Washington, DC: World .... Retrieved from http://wsispapers.choike.org/national_strategies.pdf

Hansen, J. A. (1992). Innovation, firm size, and firm age. Small Business Economics, 4(1), 37-44. Retrieved from http://link.springer.com/article/10.1007/BF00402214

Harberger, A. (1998). A Vision of the Growth Process t. The American Economic Review. Retrieved from http://www.international.ucla.edu/media/files/growth.pdf

Harris, P. (1985). Testing for variance homogeneity of correlated variables. Biometrika. Retrieved from http://biomet.oxfordjournals.org/content/72/1/103.short

Herstatt, C., \& Hippel, E. Von. (1992). From experience: Developing new product concepts via the lead user method: A case study in a "low-tech" field. Journal of Product Innovation Management. Retrieved from http://www.sciencedirect.com/science/article/pii/0737678292900317

Hijzen, A., \& Swaim, P. (2008). Do multinationals promote better pay and working conditions? Organisation for Economic Cooperation .... Retrieved from http://search.proquest.com/openview/4a5b59484e45d65a1f21fcbe46c76020/1?pqorigsite=gscholar

Hippel, E. Von. (2007). The sources of innovation. Retrieved from http://link.springer.com/chapter/10.1007/978-3-8349-9320-5_10

Hirschman, A. (1958). The strategy of economic development. Retrieved from http://www.sidalc.net/cgi$\mathrm{bin} /$ wxis.exe/?IsisScript=BAC.xis\&method=post\&formato=2\&cantidad=1\&expresion=mfn=034061

Holz, C. (2008). China's economic growth 1978-2025: what we know today about China's economic growth tomorrow. World Development. Retrieved from http://www.sciencedirect.com/science/article/pii/S0305750X08001502

Hothway, R., \& Kugelman, M. (2009). Powering Pakistan. Retrieved from http://scholar.google.com.pk/scholar?q=Powering+Pakistan\&btnG=\&hl=en\&as_sdt=0,5\#0

Hou, N. (2009). Arms Race, Military Expenditure and Economic Growth. Retrieved from http://core.kmi.open.ac.uk/download/pdf/76788.pdf

Huber, F. (2011). Do clusters really matter for innovation practices in Information Technology? Questioning the significance of technological knowledge spillovers. Journal of Economic Geography, 12(1), 107126. doi:10.1093/jeg/lbq058

Huizinga, H. (1995). Taxation and the transfer of technology by multinational firms. Canadian Journal of Economics. Retrieved from http://www.jstor.org/stable/136054

Husain, I. (2000). Pakistan: The economy of an elitist state. OUP Catalogue. Retrieved from http://ideas.repec.org/b/oxp/obooks/9780195793796.html

Hussain, I. (2004). Economic Management in Pakistan 1999-2002. OUP Catalogue. Retrieved from http://ideas.repec.org/b/oxp/obooks/9780195799705.html

Ibarra, H. (1993). Network centrality, power, and innovation involvement: Determinants of technical and administrative roles. Academy of Management Journal. Retrieved from http://amj.aom.org/content/36/3/471.short

International Telecommunication Union. (1997). VOCABULARY OF TERMS FOR BROADBAND ASPECTS OF ISDN. (Vol. 113).

Jacob, J., \& Szirmai, A. (2007). International Knowledge Spillovers to Developing Countries: The Case of Indonesia. Review of Development Economics, 11(3), 550-565. doi:10.1111/j.14679361.2007.00360.x

Jaffe, A. (1986). Technological opportunity and spillovers of R\&D: evidence from firms' patents, profits and market value. Retrieved from http://www.nber.org/papers/w1815 
Jaffe, A. (1996). Economic analysis of research spillovers: implications for the advanced technology program. Economic Assessment Office, the Advanced Technology .... Retrieved from http://scholar.google.com.pk/scholar?q=ECONOMIC+ANALYSIS+OF+RESEARCH+SPILLOVERS++IMPLIC ATIONS+FOR+THE+ADVANCED+TECHNOLOGY+PROGRAM\&btnG=\&hl=en\&as_sdt=0,5\#0

Jaffe, A., \& Trajtenberg, M. (1996). Flows of knowledge from universities and federal laboratories: Modeling the flow of patent citations over time and across institutional and geographic boundaries.

Proceedings of the National .... Retrieved from http://www.pnas.org/content/93/23/12671.short

Jaffe, A., \& Trajtenberg, M. (1999). International knowledge flows: evidence from patent citations. Economics of Innovation and New .... Retrieved from http://www.tandfonline.com/doi/abs/10.1080/10438599900000006

Jaffe, A., Trajtenberg, M., \& Fogarty, M. (2000). Knowledge spillovers and patent citations: Evidence from a survey of inventors. NBER/Sloan . Retrieved from http://www.nber.org/sloan/sloan.pdf?origin=publicationDetail\#page=27

Jaffe, A., Trajtenberg, M., \& Henderson, R. (1992). Geographic localization of knowledge spillovers as evidenced by patent citations. Retrieved from http://www.nber.org/papers/w3993

Jalal, A. (2012). The Oxford Companion to Pakistani History. Retrieved from http://econpapers.repec.org/RePEc:oxp:obooks:9780195475784

Javorcik, B. S. B. (2004). Does Foreign Direct Investment Increase the Productivity of Domestic Firms ? In Search of Spillovers through Backward Linkages Does Foreign Direct Investment Increase the Productivity of Domestic Firms ? In Search of Spillovers Through Backward Linkages. American Economic Review, 94(3), 605-627. Retrieved from http://www.jstor.org/stable/3592945

Jenkins, R. (1990). Comparing foreign subsidiaries and local firms in LDCs: Theoretical issues and empirical evidence. The Journal of Development Studies. Retrieved from http://www.tandfonline.com/doi/abs/10.1080/00220389008422148

Jeon, B., Tang, L., \& Zhu, L. (2005). Information technology and bilateral FDI: theory and evidence. Journal of Economic Integration. Retrieved from http://sejong.metapress.com/index/9jukpg6tbg6h75dw.pdf

Jordaan, J. (2005). Determinants of FDI-induced externalities: New empirical evidence for Mexican manufacturing industries. World Development. Retrieved from http://www.sciencedirect.com/science/article/pii/S0305750X05001609

Kaiser, U. (2002). Measuring knowledge spillovers in manufacturing and services: an empirical assessment of alternative approaches. Research Policy. Retrieved from http://www.sciencedirect.com/science/article/pii/S0048733300001591

Kaldor, N. (1966). Causes of the slow rate of economic growth of the United Kingdom: an inaugural lecture. Retrieved from

http://scholar.google.com.pk/scholar?q=Causes+Of+The+Slow+Rate+Of+Economic+Growth+Of+The+ United+Kingdom\&btnG=\&hl=en\&as_sdt=0,5\#0

Kathuria, V. (2002). Liberalisation, FDI, and productivity spillovers-an analysis of Indian manufacturing firms. Oxford Economic Papers. Retrieved from http://oep.oxfordjournals.org/content/54/4/688.short

Keller, W. (2001). Knowledge spillovers at the world's technology frontier. Retrieved from http://scholar.google.com.pk/scholar?hl=en\&q=Knowledge+Spillovers+at+the+World's+Technology+ Frontier,\&btnG=\&as_sdt=1,5\&as_sdtp=\#0

Keller, W. (2002). Trade and the Transmission of Technology. Journal of Economic Growth. Retrieved from http://link.springer.com/article/10.1023/A:1013461025733

Kemal, A. (2006). Key Issues in Industrial Growth in Pakistan. Lahore Journal of Economics. Retrieved from http://search.ebscohost.com/login.aspx?direct=true\&profile=ehost\&scope=site\&authtype=crawler\&j rnl=18115438\&AN=23909362\&h=eXj8pmcvl2OG9DjfBPsVA1u1VO7XP2foHnvUqchOSq9rUJmNtTLqM DCrjZfpoPvmGXfCTn2PkTjQ0pAXBd0BIA\%3D\%3D\&crl=c

Kesidou, E., Caniëls, M., \& Romijn, H. (2009). Local Knowledge Spillovers and Development: An Exploration of the Software Cluster in Uruguay. Industry and Innovation. Retrieved from http://www.tandfonline.com/doi/abs/10.1080/13662710902764444 
Kesidou, E., \& Romijn, H. (2008). Do Local Knowledge Spillovers Matter for Development? An Empirical Study of Uruguay's Software Cluster. World Development, 36(10), 2004-2028.

doi:10.1016/j.worlddev.2008.01.003

Kesidou, E., \& Szirmai, A. (2008). Local knowledge spillovers, innovation and export performance in developing countries: empirical evidence from the Uruguay software cluster. The European Journal of Development ..., 20(2), 281-298. doi:10.1080/09578810802060769

Khan, F. (2012). Eating Grass: The Making of the Pakistani Bomb. Retrieved from http://books.google.com.pk/books?hl=en\&lr=\&id=yGgrNAsKZjEC\&oi=fnd\&pg=PR5\&dq=Feroz+Hassa $\mathrm{n}+$ Khan,+Eating+Grass:+The+Making+of+the+Pakistani+Bomb\&ots=AnAYeiUMUH\&sig=zAuMMTRLTs zXB1zxoPuGv5fD55w

Khan, S. (2005). Macro determinants of total factor productivity in Pakistan, (8693). Retrieved from http://mpra.ub.uni-muenchen.de/8693/

Khan, T., \& Qazi, J. (2014). Measles outbreaks in pakistan: causes of the tragedy and future implications. Epidemiology Reports. Retrieved from http://www.hoajonline.com/epidemiolrep/2054-9911/2/1

Kinoshita, Y. (2001). R\&D and technology spillovers through FDI: innovation and absorptive capacity. Retrieved from http://ideas.repec.org/p/cpr/ceprdp/2775.html

Knack, S., \& Keefer, P. (1997). Does social capital have an economic payoff? A cross-country investigation. The Quarterly Journal of Economics. Retrieved from http://qje.oxfordjournals.org/content/112/4/1251.short

Krugman, P. (1991). Geography and trade. Retrieved from http://books.google.com.pk/books?hl=en\&lr=\&id=AQDodCHOgJYC\&oi=fnd\&pg=PP7\&dq=krugman+1 991\&ots=Pze15iOG9r\&sig=Z16iMpbFH6385wfDrIDHz5r2QwY

Kubielas, S. (2009). Technology gap approach to industrial dynamics and sectoral systems of innovation in transforming CEE economies. Retrieved from http://www.kites.unibocconi.it/wps/allegatiCTP/Kubielas.pdf

Kugelman, M., \& Hathaway, R. (2009). Running on empty: Pakistan's water crisis. Woodrow Wilson International .... Retrieved from http://dspace.cigilibrary.org/jspui/handle/123456789/27224

Kumar, N., \& Saqib, M. (1996). Firm size, opportunities for adaptation and in-house R \& D activity in developing countries: the case of Indian manufacturing. Research Policy, 25(5), 713-722. Retrieved from http://www.sciencedirect.com/science/article/pii/0048733395008543

Kumar, S. (2002). Politics in Pakistan post-September 11, 2001. Strategic Analysis. Retrieved from http://www.tandfonline.com/doi/abs/10.1080/09700160208450040

Kuznets, S. (1979). Growth and structural shifts. Economic Growth and Structural .... Retrieved from http://scholar.google.com.pk/scholar?q=Growth+and+Structural+Shifts\&btnG=\&hl=en\&as_sdt=0,5\# 0

Kuznets, S., \& Murphy, J. (1966). Modern economic growth: Rate, structure, and spread. Retrieved from http://econhist.userweb.mwn.de/ehebir/MEG.pdf

Lane, P., Koka, B., \& Pathak, S. (2006). The reification of absorptive capacity: a critical review and rejuvenation of the construct. Academy of Management Review. Retrieved from http://amr.aom.org/content/31/4/833.short

Lavoy, P. (2005). Pakistan's Strategic Culture: A Theoretical Excursion. Strategic Insights. Retrieved from http://www.nps.edu/Academics/centers/ccc/publications/OnlineJournal/2005/Oct/lavoyOct05.html

Lawson, C., \& Lorenz, E. (1999). Collective learning, tacit knowledge and regional innovative capacity. Regional Studies. Retrieved from http://www.tandfonline.com/doi/abs/10.1080/713693555

Leahy, D., \& Neary, J. (2007). Absorptive capacity, R\&D spillovers, and public policy. International Journal of Industrial Organization. Retrieved from http://www.sciencedirect.com/science/article/pii/S0167718707000501

Lee, C. (2011). Trade, productivity, and innovation: Firm-level evidence from Malaysian manufacturing. Journal of Asian Economics. Retrieved from http://www.sciencedirect.com/science/article/pii/S1049007811000418 
Lee, S., \& Guo, X. (2004). Information and communications technology (ICT) and spillover: A panel analysis. Econometric Society 2004 Far Eastern Meetings. Retrieved from http://ideas.repec.org/p/ecm/feam04/722.html

Levin, R. C., Cohen, W. M., \& Mowery, D. C. (1985). R \& D appropriability, opportunity, and market structure: new evidence on some Schumpeterian hypotheses. The American Economic Review, 75(2), $20-24$. Retrieved from http://www.jstor.org/stable/1805564

Lewis, W. (1978). The evolution of the international economic order. Retrieved from http://www.princeton.edu/rpds/papers/WP_74.pdf

Lipsey, R., \& Sjöholm, F. (2004). Foreign direct investment, education and wages in Indonesian manufacturing. Journal of Development Economics. Retrieved from http://www.sciencedirect.com/science/article/pii/S0304387803001445

Loeckera, J. De. (2013). Detecting learning by exporting. American Economic Journal: Microeconomics. Retrieved from http://www.ingentaconnect.com/content/aea/aejmi/2013/00000005/00000003/art00001

Lundvall, B., \& Kristensen, F. (1997). Organisational change, innovation and human resource development as a response to increased competition. Retrieved from http://ideas.repec.org/p/aal/abbswp/9716.html

Lunn, J., \& Martin, S. (1986). Market structure, firm structure and research and development. Quarterly Review of Economics and ..., 26(1), 31-44. Retrieved from http://www.krannert.purdue.edu/faculty/smartin/vita/MFRD.pdf

Madden, G., \& Savage, S. (2000). R\&D spillovers, information technology and telecommunications, and productivity in ASIA and the OECD. Information Economics and Policy. Retrieved from http://www.sciencedirect.com/science/article/pii/S016762450000024X

Maddison, A. (1987). Growth and Slowdown in Advanced Capitalist Economies: Techniques of Quantitative Assessment. Journal of Economic Literature, 25(2), 649. Retrieved from http://search.ebscohost.com/login.aspx?direct=true\&db=buh\&AN=5293763\&site=ehost-live

Maddison, A. (2013). Class structure and economic growth: India and Pakistan since the Moghuls. Retrieved from http://books.google.com.pk/books?hl=en\&lr=\&id=-

bJYAQAAQBAJ\&oi=fnd\&pg=PP1\&dq=social+development+of+Pakistan+angus\&ots=q5gVIxR7qM\&sig =TvIVWhaXvO5Gtbu2oaRUJNOsyNM

Malecki, E. (1997). Technology and economic development: the dynamics of local, regional, and national change. University of Illinois at Urbana-Champaign's Academy .... Retrieved from http://papers.ssrn.com/sol3/papers.cfm?abstract_id=1496226

Maliranta, M. (2009). Is inter-firm labor mobility a channel of knowledge spillovers? Evidence from a linked employer-employee panel. Industrial and Corporate .... Retrieved from http://icc.oxfordjournals.org/content/18/6/1161.short

Markusen, J., \& Venables, A. (1999). Foreign direct investment as a catalyst for industrial development. European Economic Review. Retrieved from http://www.sciencedirect.com/science/article/pii/S0014292198000488

Maurseth, P., \& Verspagen, B. (2002). Knowledge spillovers in Europe: a patent citations analysis. The Scandinavian Journal of .... Retrieved from http://onlinelibrary.wiley.com/doi/10.1111/14679442.00300/abstract

McCartney, M. (2011). Pakistan, Growth, Dependency, and Crisis. Lahore Journal of Economics. Retrieved from http://search.ebscohost.com/login.aspx?direct=true\&profile=ehost\&scope=site\&authtype=crawler\&j $\mathrm{rnl}=18115438 \& A N=66573372 \& \mathrm{~h}=\mathrm{x}+7 \mathrm{Vmfl6YjGA} / \mathrm{tNCGLEteaZqIXWwVmvLHiY/m1na9kZcaxMQwQPG}$ BBNKGczlkgZExv2U1X3+sJBvpvsxk6ifnA==\&crl=c

McMillan, M., \& Rodrik, D. (2011). Globalization, structural change and productivity growth. Retrieved from http://www.nber.org/papers/w17143

Meijers, H. (2007). Working Paper Series ICT Externalities : Evidence from cross country data, (31). 
Mel, S. De, McKenzie, D., \& Woodruff, C. (2009). Innovative firms or innovative owners? Determinants of innovation in micro, small, and medium enterprises. IZA Working Paper No. 3962. Retrieved from http://papers.ssrn.com/sol3/papers.cfm?abstract_id=1336059

Michael, S. (2007). Terrorism a Socio-Economic and Political Phenomenon with Special Reference to Pakistan. Journal of Management and Social Sciences. Retrieved from http://biztek.edu.pk/downloads/research/jmss_v3_n1/4 terrorism a socio economic and.pdf

Mitchell, J. (1969). Social networks in urban situations: Analysis of personal relationships in central African towns. Retrieved from http://books.google.com/books?hl=en\&lr=\&id=8RrpAAAAIAAJ\&oi=fnd\&pg=PA1\&dq=Mitchell,+1969 +social+network\&ots=noRXUsUhPO\&sig=qWSNUkG1IGyGbhISBfbSZHWAxYO

Mohiuddin, Y. (2007). Pakistan: a global studies handbook. Retrieved from https://books.google.com.pk/books?hl=en\&lr=\&id=OTMy0B9OZjAC\&oi=fnd\&pg=PR7\&dq=Pakistan:+ A+Global+Studies+Handbook\&ots=BnTGVWIHpB\&sig=ELliHV_DHxWr7hqtS6JV7sblHAI

Mohiuddin, Y., \& Kazi, S. (1991). Discrimination in the Pakistan Labour Market: Myth and Reality. The Pakistan Development Review. Retrieved from http://www.jstor.org/stable/41259514

Mohmand, S., \& Ghazdar, H. (2007). Social structures in rural Pakistan. ... Reduction and ADB's Contribution in Rural Pakistan. .... Retrieved from

http://scholar.google.com.pk/scholar?q=social+structures+in+rural+pakistan\&btnG=\&hl=en\&as_sdt= $0,5 \# 1$

Mohnen, P. (1996). R\&D externalities and productivity growth. STI Review. Retrieved from http://scholar.google.com.pk/scholar?q=mohnen+1996\&btnG=\&hl=en\&as_sdt=0,5\#1

Monjon, S., \& Waelbroeck, P. (2003). Assessing spillovers from universities to firms: evidence from French firm-level data. International Journal of Industrial Organization. Retrieved from http://www.sciencedirect.com/science/article/pii/S0167718703000821

Moran, P. (2005). Structural vs. relational embeddedness: Social capital and managerial performance. Strategic Management Journal, 1151(April), 1129-1151. doi:10.1002/smj.486

Nahapiet, J., \& Ghoshal, S. (1998). Social capital, intellectual capital, and the organizational advantage. Academy of Management Review. Retrieved from http://amr.aom.org/content/23/2/242.short

Narula, R., \& Dunning, J. (1998). Explaining international R\&D alliances and the role of governments. International Business Review. Retrieved from http://www.sciencedirect.com/science/article/pii/S0969593198000195

Narula, R., \& Hagedoorn, J. (1999). Innovating through strategic alliances: moving towards international partnerships and contractual agreements. Technovation. Retrieved from http://www.sciencedirect.com/science/article/pii/S0166497298001278

Naudé, W., \& Szirmai, A. (2012). The importance of manufacturing in economic development: Past, present and future perspectives. Retrieved from http://collections.unu.edu/eserv/UNU:157/wp2012-041.pdf

Nelson, R., \& Sidney, G. (1982). Winter. 1982. An Evolutionary Theory of Economic Change. Retrieved from http://scholar.google.com.pk/scholar?q=Nelson+and+Winter, $+1982 \& b t n G=\& h l=e n \& a s \_s d t=0,5 \# 1$

Nicholson, M. (2007). The impact of industry characteristics and IPR policy on foreign direct investment. Review of World Economics. Retrieved from http://link.springer.com/article/10.1007/s10290-0070097-9

Nieto, M., \& Quevedo, P. (2005). Absorptive capacity, technological opportunity, knowledge spillovers, and innovative effort. Technovation, 25(10), 1141-1157. Retrieved from http://www.sciencedirect.com/science/article/pii/S0166497204000902

Noman, O. (1990). Pakistan: A political and economic history since 1947. Retrieved from https://scholar.google.com.pk/scholar?q=Pakistan\%3A+A+Political+and+Economic+History+since+19 $47 \& b t n G=\& h l=e n \& a s \_s d t=0 \% 2 C 5 \# 0$

O'Mahony, M., \& Vecchi, M. (2009). R\&D, knowledge spillovers and company productivity performance. Research Policy. Retrieved from http://www.sciencedirect.com/science/article/pii/S0048733308002151

OECD. (2002). Measuring the Information Economy 2002 (Vol. 12). OECD Publishing. Retrieved from http://books.google.com/books?id=dfkih7bxr7kC\&pgis=1 
Oerlemans, L., \& Meeus, M. (2005). Do organizational and spatial proximity impact on firm performance? Regional Studies. Retrieved from http://www.tandfonline.com/doi/abs/10.1080/0034340052000320896

Opsahl, T., Agneessens, F., \& Skvoretz, J. (2010). Node centrality in weighted networks: Generalizing degree and shortest paths. Social Networks. Retrieved from http://www.sciencedirect.com/science/article/pii/S0378873310000183

Orlando, M. (2000). On the importance of geographic and technological proximity for R\&D spillovers: An empirical investigation. FRB of Kansas City Research Working Paper No. 00- ... Retrieved from http://papers.ssrn.com/sol3/papers.cfm?abstract_id=271824

Owen-Smith, J., \& Powell, W. (2004). Knowledge networks as channels and conduits: The effects of spillovers in the Boston biotechnology community. Organization Science. Retrieved from http://pubsonline.informs.org/doi/abs/10.1287/orsc.1030.0054

Pakistan, M. of I. T. (2003). De-Regulation Policy for the Telecommunication Sector, (July).

PASHA. (2008). SOFTW ARE / B P O 2008 STATE.

Patibandla, M., \& Petersen, B. (2002). Role of transnational corporations in the evolution of a high-tech industry: the case of India's software industry. World Development. Retrieved from http://www.sciencedirect.com/science/article/pii/S0305750X02000608

Pavitt, K., Robson, M., \& Townsend, J. (1987). The size distribution of innovating firms in the UK: 1945-1983. The Journal of Industrial Economics, 35(3), 297-316. Retrieved from http://www.jstor.org/stable/2098636

Peneder, M. (2003). Industrial structure and aggregate growth. Structural Change and Economic Dynamics. Retrieved from http://www.sciencedirect.com/science/article/pii/S0954349X02000528

Peri, G. (2009). Technology Spillovers. In R. S. Rajan \& A. R. Kenneth (Eds.), Princeton Encyclopedia of the World Economy. Princeton University Press.

Peri, G., \& Urban, D. (2006). Catching-up to foreign technology? Evidence on the "Veblen-Gerschenkron" effect of foreign investments. Regional Science and Urban Economics, 36(1), 72-98. doi:10.1016/j.regsciurbeco.2005.09.001

Perkovich, G. (2008). Could Anything Be Done to Stop Them? Lessons from Pakistan's Proliferating Past. Pakistan's Nuclear Future: Worries Beyond War. Retrieved from http://kms1.isn.ethz.ch/serviceengine/Files/ISN/47514/ichaptersection_singledocument/AD03FED7305A-4260-A2F6-FD98CB04709D/en/Chapter+3.pdf

Pesola, H. (2006). FDI , LABOUR MOBILITY AND WAGES.

Planning Commission of Pakistan. (2013). The Causes and Impacts of Power Sector Circular Debt in Pakistan. Retrieved July 2, 2014, from http://www.pc.gov.pk/hot links/2013/Final_USAID-Pakistan Circular Debt Report-Printed Mar 25, 2013.pdf

Plepys, A., \& Boada, A. (2005). The Dark Side of Information Technology and Communications (El Lado Oscuro De Las Tecnologías De La Información Y Las Comunicaciones). Retrieved from http://papers.ssrn.com/abstract=1511763

Polanyi, M. (1967). The tacit dimension. Retrieved from http://philpapers.org/rec/POLTTD

Portes, A. (2000). The two meanings of social capital. Sociological Forum. Retrieved from http://link.springer.com/article/10.1023/A:1007537902813

Prevenzer, M. (1997). The dynamics of industrial clustering in biotechnology. J Small Bus Econ 9: 255-271. Retrieved from https://scholar.google.com.pk/scholar?q=+The+dynamics+of+industrial+clustering+in+biotechnology Intellectual+human+capital+and+the+birth+of+U.S.+biotechnology+enterprises\&btnG=\&hl=en\&as_S $\mathrm{dt}=0 \% 2 \mathrm{C} 5 \# 0$

PSEB. (2010). Pakistan IT Market Assessment.

Putnam, J., \& Evenson, R. (1994). Inter-sectoral technology flows: Estimates from a patent concordance with an application to Italy. Mimeograph, Yale University, New Haven, CT. Retrieved from http://scholar.google.com.pk/scholar?q=Putnam+and+Evenson+(1994)\&btnG=\&hl=en\&as_sdt=0,5\#0 
Qazi, A. (2011). Ascertaining knowledge flows through labor mobility in the ICT sector of Pakistan. Information and Communication Technologies (ICICT .... Retrieved from http://ieeexplore.ieee.org/xpls/abs_all.jsp?arnumber $=5983557$

Qiang, C., Pitt, A., \& Ayers, S. (2004). Contribution of information and communication technologies to growth. Retrieved from http://books.google.com.pk/books?hl=en\&lr=\&id=jYneJy0km6QC\&oi=fnd\&pg=PR5\&dq=Contribution +of+Information+and+Communication+Technologies+to+Growth\&ots=5FJek04WY\&sig=olNe5AZnMrfO-6MkL9ofTcfg_DM

Raheman, A., Afza, T., Qayyum, A., Bodla, M., Review, D., \& Sciences, M. (2008). Estimating Total Factor Productivity and Its Components: Evidence from Major Manufacturing Industries of Pakistan. The Pakistan Development ..., (Winter), 677-694. Retrieved from http://www.jstor.org/stable/41261247

Rallet, A., \& Torre, A. (1999). Is geographical proximity necessary in the innovation networks in the era of global economy? GeoJournal. Retrieved from http://link.springer.com/article/10.1023/A:1007140329027

Rashid, A. (1999). Taliban: Exporting Extremism, The. Foreign Aff. Retrieved from http://heinonlinebackup.com/hol-cgi-bin/get_pdf.cgi?handle=hein.journals/fora78\&section=97

Rashid, A. (2004). Sectoral Linkages; Identifying the Key Growth Stimulating Sector of the Pakistan Economy. Retrieved from http://mpra.ub.uni-muenchen.de/27210/

Rasiah, R. (1995). Foreign capital and industrialization in Malaysia. Retrieved from http://www.getcited.org/pub/103196898

Raychaudhuri, T., Habib, I., \& Kumar, D. (1983). The Cambridge economic history of India. Retrieved from http://books.google.com.pk/books?hl=en\&lr=\&id=9ew8AAAAIAAJ\&oi=fnd\&pg=PR8\&dq=economic $+h$ istory+of+pakistan\&ots=30HsUqjwAW\&sig=R4N-E7YFI4IUJBfXZ6HR2ZQA_ow

Riaz, H. (2013). Public health failings behind Pakistan's measles surge. The Lancet. Retrieved from http://www.lancet.com/journals/lancet/article/PIIS0140-6736(13)60072-0

Ritala, P., \& Hurmelinna-Laukkanen, P. (2013). Incremental and radical innovation in coopetition-the role of absorptive capacity and appropriability. Journal of Product .... Retrieved from http://onlinelibrary.wiley.com/doi/10.1111/j.1540-5885.2012.00956.x/full

Rodriguez-Clare, A. (1996). Multinationals, linkages, and economic development. The American Economic Review. Retrieved from http://www.jstor.org/stable/2118308

Rodrik, D. (2003). In search of prosperity: Analytic narratives on economic growth. Retrieved from http://books.google.com.pk/books?hl=en\&lr=\&id=3ZILOb6R86EC\&oi=fnd\&pg=PP2\&dq=The+Political + Economy+of+Growth+Without+Development:+A+Case+Study+of+Pakistan\&ots=3eRJq5DjqR\&sig=1 gfcr5ALeGlyq-GO3-RrUrSZhNs

Rogers, E. M. (2003). Diffusion of Innovations, 5th Edition (Google eBook). Simon and Schuster. Retrieved from http://books.google.com/books?id=9U1K5LjUOwEC\&pgis=1

Romer, P. (1986). Increasing returns and long-run growth. The Journal of Political Economy. Retrieved from http://www.jstor.org/stable/1833190

Romer, P. (1990). Endogenous technological change. Journal of Political Economy. Retrieved from http://www.jstor.org/stable/10.2307/2937632

Rooks, G., Szirmai, A., \& Sserwanga, A. (2012). Network structure and innovative performance of African entrepreneurs: The case of Uganda. Journal of African Economies, 21(4), 609-636. doi:10.1093/jae/ejs011

Rooks, G., Tazelaar, F., \& Snijders, C. (2011). Gossip and Reputation in Business Networks. European Sociological Review. Retrieved from http://esr.oxfordjournals.org/content/27/1/90.short

Rowley, T. I. M., Behrens, D., \& Krackhardt, D. (2000). Redundant governance structures: an analysis of structural and relational embeddedness in the steel and semiconductor industries. Strategic Management Journal, 369-386. Retrieved from http://www.cs.unibo.it/ ruffino/Letture SNA/2000 Redundant Governance Structure.pdf

Rowthorn, R., \& Ramaswamy, R. (1997). Deindustrialization: causes and implications. Retrieved from http://papers.ssrn.com/sol3/papers.cfm?abstract_id=882291 
Sabir, M., \& Ahmed, Q. (2003). Macroeconomic Reforms and Total Factor Productivity Growth in Pakistan: An Empirical Analysis. Retrieved from http://www.spdc.org.pk/Publications/Conference Papers/CP55.pdf

Saggi, K. (2002). Trade, foreign direct investment, and international technology transfer: A survey. The World Bank Research Observer. Retrieved from http://wbro.oxfordjournals.org/content/17/2/191.short

Scherer, F. (1984). Using Linked Patent and R\&D Data to Measure InterindustryTechnology Flows. $R \& D$, Patents, and Productivity. Retrieved from http://www.nber.org/chapters/c10061.pdf

Scherer, F. M. (1967). Market structure and the employment of scientists and engineers. The American Economic Review, 57(3), 524-531. Retrieved from http://www.jstor.org/stable/1812118

Shah, S. (2010). War on Terrorism: Self Defense, Operation Enduring Freedom, and the Legality of US Drone Attacks in Pakistan. Wash. U. Global Stud. L. Rev. Retrieved from http://heinonlinebackup.com/holcgi-bin/get_pdf.cgi?handle=hein.journals/wasglo9\&section $=6$

Shaukat, M. (2009). Developments of Information Technology, Telecom and E-Commerce in Business Environment of Pakistan: An Analysis of Banking and Manufacturing Sectors. Pakistan Journal of Social Sciences (PJSS). Retrieved from

http://search.ebscohost.com/login.aspx?direct=true\&profile=ehost\&scope=site\&authtype=crawler\&j

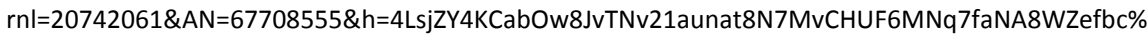
2F9vKseEbNPEZ65pHiCOy2k5IrAaeLpayuow\%3D\%3D\&crl=c

Siddiqui, R., Jalil, H., \& Nasir, M. (2008). The cost of unserved energy: evidence from selected industrial cities of Pakistan. The Pakistan Development .... Retrieved from http://www.jstor.org/stable/23234709

Silva, A., Afonso, O., \& Africano, A. (2012). Learning-by-exporting: What we know and what we would like to know. The International Trade Journal. Retrieved from http://www.tandfonline.com/doi/abs/10.1080/08853908.2012.682022

Sjöholm, F. (1999). Technology gap, competition and spillovers from direct foreign investment: evidence from establishment data. The Journal of Development Studies. Retrieved from http://www.tandfonline.com/doi/abs/10.1080/00220389908422611

Soh, P. (2003). The role of networking alliances in information acquisition and its implications for new product performance. Journal of Business Venturing. Retrieved from http://www.sciencedirect.com/science/article/pii/S0883902603000260

Stiglitz, J. (2008). Economic foundations of intellectual property rights. Duke Law Journal. Retrieved from http://www.jstor.org/stable/40040630

Stiroh, K. (2002). Information technology and the US productivity revival: what do the industry data say? American Economic Review. Retrieved from http://www.jstor.org/stable/3083263

Stock, G. N., Greis, N. P., \& Fischer, W. A. (2002). Firm size and dynamic technological innovation. Technovation, 22(9), 537-549. Retrieved from http://www.sciencedirect.com/science/article/pii/S016649720100061X

Subodh, K. (2002). Market concentration, firm size and innovative activity: a firm-level economic analysis of selected Indian industries under economic liberalization. WIDER Working Paper No. 2002/108. Retrieved from http://www.econstor.eu/handle/10419/52909

Suyanto, Salim, R. A., \& Bloch, H. (2009). Does Foreign Direct Investment Lead to Productivity Spillovers? Firm Level Evidence from Indonesia. World Development, 37(12), 1861-1876. Retrieved from http://www.sciencedirect.com/science/article/pii/S0305750X09000977

Suzuki, K. (1993). R\&D spillovers and technology transfer among and within vertical keiretsu groups: Evidence from the Japanese electrical machinery industry. International Journal of Industrial Organization. Retrieved from http://www.sciencedirect.com/science/article/pii/0167718793900269

Syrquin, M. (1988). Patterns of structural change. Retrieved from http://econpapers.repec.org/RePEc:eee:devchp:1-07

Szirmai, A. (2008). Explaining success and failure in development. Retrieved from http://merit.unu.edu/publications/wppdf/2008/wp2008-013.pdf

Tang, J. (2006). Competition and innovation behaviour. Research Policy, 35(1), 68-82. Retrieved from http://www.sciencedirect.com/science/article/pii/S0048733305001769 
Terleckyj, N. (1974). Effects of R\&D on the productivity growth of industries: an exploratory study. Retrieved from

http://scholar.google.com.pk/scholar?hl=en\&q=Terleckyj+1974\&btnG=\&as_sdt=1,5\&as_sdtp=\#3

Thursby, M., \& Thursby, J. (2006). Here or There?: A Survey of Factors in Multinational R\&D Location--Report to the Government-University-Industry Research Roundtable. Retrieved from

http://books.google.com/books?hl=en\&lr=\&id=KM9TAgAAQBAJ\&oi=fnd\&pg=PR1\&dq=Thursby+and+ Thursby+(2006)\&ots=yu8LxWerWj\&sig=5_JQg-Gg0CjYaOu9EzYaSehuaps

Timmer, C. (2005). Food security and economic growth: an Asian perspective. Asian-Pacific Economic Literature. Retrieved from http://onlinelibrary.wiley.com/doi/10.1111/j.1467-8411.2005.00155.x/full

Tregenna, F. (2011). Manufacturing productivity, deindustrialization, and reindustrialization. Retrieved from http://www.econstor.eu/handle/10419/54092

Tsai, W. (2001). Knowledge transfer in intraorganizational networks: Effects of network position and absorptive capacity on business unit innovation and performance. Academy of Management Journal, 44(5), 996-1004. Retrieved from http://amj.aom.org/content/44/5/996.short

Usher, A. (2013). A History of Mechanical Inventions: Revised Edition. Retrieved from http://scholar.google.com.pk/scholar?q=Usher,+1954\&btnG=\&hl=en\&as_sdt=0,5\#1

Uzzi, B. (1996). The sources and consequences of embeddedness for the economic performance of organizations: The network effect. American Sociological Review. Retrieved from http://www.jstor.org/stable/10.2307/2096399

Uzzi, B. (1997). Social structure and competition in interfirm networks: The paradox of embeddedness. Administrative Science Quarterly. Retrieved from http://www.jstor.org/stable/10.2307/2393808

VanVoorhis, C., \& Morgan, B. (2007). Understanding power and rules of thumb for determining sample sizes. Tutorials in Quantitative Methods .... Retrieved from http://www.researchgate.net/profile/Betsy_Morgan/publication/49619425_Understanding_Power_ and_Rules_of_Thumb_for_Determining_Sample_Sizes/links/00b49532f30cf6bf97000000.pdf

Venturini, F. (2015). The modern drivers of productivity. Research Policy. Retrieved from http://www.sciencedirect.com/science/article/pii/S0048733314001863

Verbeek, M. (2004). A Guide to Modern Econometrics (2nd ed.).

Verspagen, B. (1997a). Estimating international technology spillovers using technology flow matrices. Weltwirtschaftliches Archiv. Retrieved from http://link.springer.com/article/10.1007/BF02707461

Verspagen, B. (1997b). Measuring intersectoral technology spillovers: estimates from the European and US patent office databases. Economic Systems Research. Retrieved from http://www.tandfonline.com/doi/abs/10.1080/09535319700000004

Verspagen, B. (2003). Intellectual property rights in the world economy. Retrieved from http://link.springer.com/chapter/10.1007/978-1-4757-3750-9_21

Veugelers, R., \& Backer, K. De. (1999). Access to external knowledge: an empirical analysis of alliances as spillover channel. DTEW Research Report 9921. Retrieved from https://lirias.kuleuven.be/handle/123456789/223270

Vinding, A. L. (2006). Absorptive capacity and innovative performance: A human capital approach. Economics of Innovation and New Technology. Retrieved from http://www.tandfonline.com/doi/abs/10.1080/10438590500513057

Wang, J., \& Blomström, M. (1992). Foreign investment and technology transfer: A simple model. European Economic Review. Retrieved from http://www.sciencedirect.com/science/article/pii/001429219290021N

Wang, L., Meijers, H., \& Szirmai, A. (2013). Technological spillovers and industrial growth in Chinese regions. UNU-MERIT Working Paper .... Retrieved from http://www.researchgate.net/profile/Lili_Wang34/publication/272072317_Technological_spillovers _and_industrial_growth_in_Chinese_regions/links/54d9d49b0cf24647581f8967.pdf

WAPDA. (2013). Hydro Potential In Pakistan. Retrieved July 2, 2014, from http://www.wapda.gov.pk/pdf/potentialpakistan.pdf

Wei, Y., \& Liu, X. (2006). Productivity spillovers from R\&D, exports and FDI in China's manufacturing sector. Journal of International Business Studies, 37(4), 544-557. doi:10.1057/palgrave.jibs.8400209 
Wilson, J. (2008). Telecom Regulatory \& Policy Environment in Pakistan: Results of the 2008 TRE Survey. Available at SSRN 1555470. Retrieved from http://papers.ssrn.com/sol3/papers.cfm?abstract_id=1555470

Woolcock, M. (1998). Social capital and economic development: Toward a theoretical synthesis and policy framework. Theory and Society. Retrieved from http://www.springerlink.com/index/rj58534767m2j644.pdf

Xiao, Z., \& Tsui, A. (2007). When brokers may not work: The cultural contingency of social capital in Chinese high-tech firms. Administrative Science Quarterly. Retrieved from http://asq.sagepub.com/content/52/1/1.short

Xu, B., \& Wang, J. (1999). Capital goods trade and R\&D spillovers in the OECD. Canadian Journal of Economics. Retrieved from http://www.jstor.org/stable/136481

Zaheer, A., \& Bell, G. (2005). Benefiting from network position: firm capabilities, structural holes, and performance. Strategic Management Journal. Retrieved from http://onlinelibrary.wiley.com/doi/10.1002/smj.482/abstract

Zhao, M. (2006). Conducting R\&D in countries with weak intellectual property rights protection. Management Science. Retrieved from http://pubsonline.informs.org/doi/abs/10.1287/mnsc.1060.0516

Zhu, L., \& Jeon, B. (2007). International R\&D Spillovers: Trade, FDI, and Information Technology as Spillover Channels*. Review of International Economics. Retrieved from http://onlinelibrary.wiley.com/doi/10.1111/j.1467-9396.2007.00691.x/full

Zucker, L., Darby, M., \& Brewer, M. (1994). Intellectual capital and the birth of US biotechnology enterprises. Retrieved from http://www.nber.org/papers/w4653 


\section{Appendices}

\section{Appendix I: Pakistan's Horizontal Irradiation}

Global Horizontal Irradiation

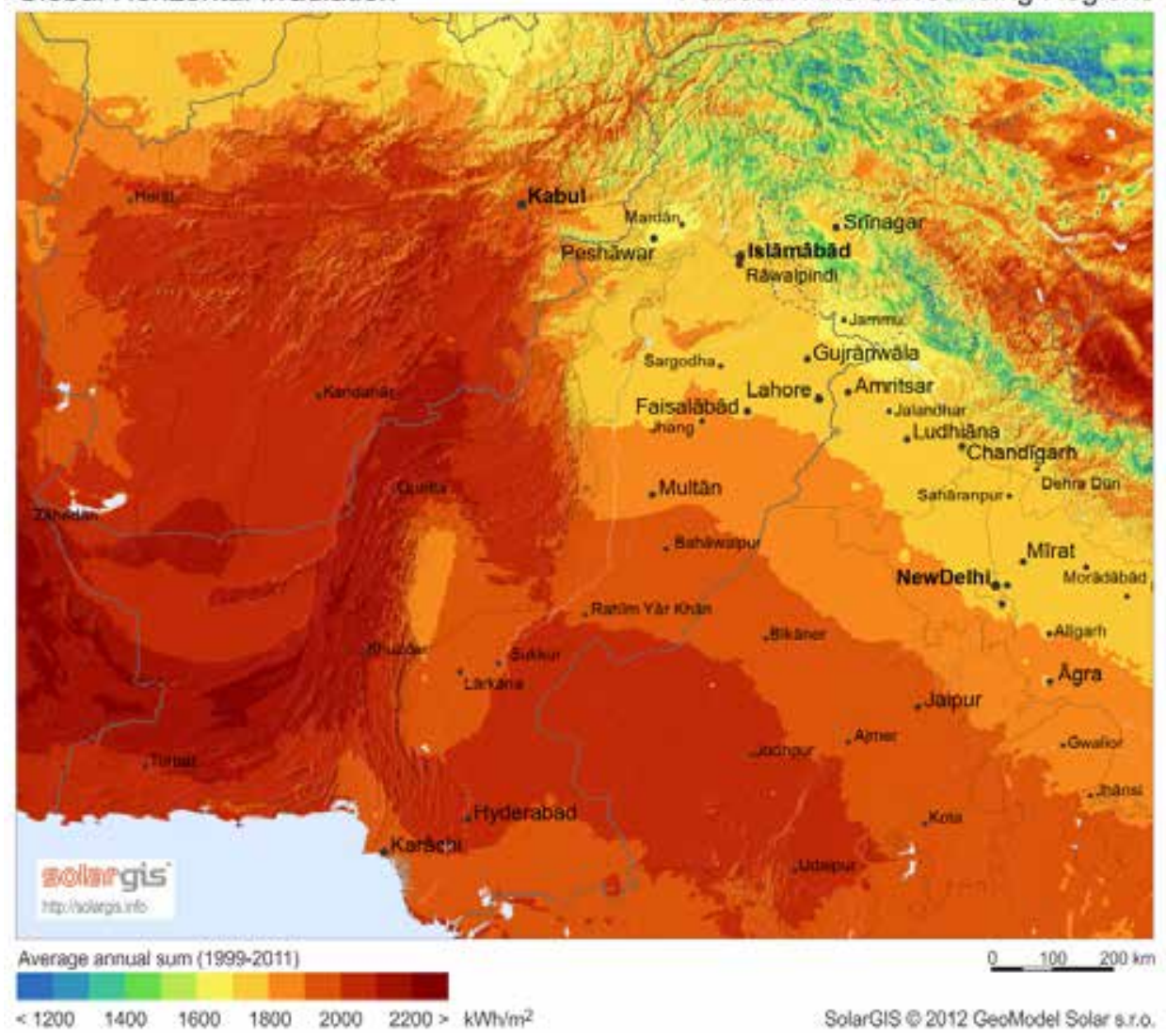




\section{Appendix II: CMI Concepts and Definitions}

1. Average daily persons employed include employees, working proprietors and unpaid family workers.

2. Census value added is one of the concepts used in Pakistan's CMIs. It equals value of industrial production minus industrial cost. The value can be measured at different prices, e.g. market prices, producer prices, basic prices or factor cost. In more detail census value added is defined as the value of census output less the value of census input, which covers: (a) value of materials and supplies for production (including cost of all fuel and purchased electricity); and (b) cost of industrial services received (mainly payments for contract and commission work and repair and maintenance work).

3. Contribution to GDP or gross value added (GVA) as measured by National Accounts equals census value added plus non-industrial receipts minus nonindustrial cost. The concept of National Accounts is ideally represented by the contribution of the establishments in each branch of activity to the Gross Domestic Product of the economy. It is, therefore, also called contribution to GDP, here. For the measure of total value added, the cost of non-industrial services is deducted from and the receipts for non-industrial services are added to census value added. The estimates, whether in terms of census value added or total value added, are gross of depreciation and other provisions for capital consumption, unless otherwise stated. The valuation may be in factor values, at basic prices, at producers' prices or at market prices, depending on the treatment of indirect taxes and subsidies.

4. Depreciation measures the decline in the current values of the stock of fixed assets owned and used by producers as a result of physical deterioration, normal obsolescence and normal accident damages during the accounting period. In National Accounts the concept of "consumption of fixed capital" is employed which differs in some respects to "depreciation" which is the term employed in commercial bookkeeping.

5. Employees mean all persons whether part time or full time who work in the establishments and receive remuneration in cash or in kind. Working proprietors, unpaid family workers and home workers are excluded. The categories of the employee are given below:

a) Production workers are engaged in work directly associated with production like manufacturing, assembling, packing, repairing etc. Working supervisors and persons engaged for repairs and maintenance are also included. 
b) Non-Production workers include administrative and professional employees, white-collar office employees, drivers, watchmen/guards, peons, sweepers, etc.

c) Employment cost includes wages and salaries paid plus cash and noncash benefits paid to the workers. Remuneration of the workers is given below:

6. Wages and salaries means payment made to employees as remunerations for their work. It includes dearness allowance and payment for leaves.

a) Other cash payments include conveyance allowance; house rent allowance compensatory and other such allowances, bonus, employer's contribution towards social security scheme and provident fund $\&$ commission. Amount of gratuity and pension is excluded.

b) Non-cash benefits are goods and services provided to employees free of cost or at subsidized rates. These include rent free accommodation, medical \& transport facilities, cheap/free consumer goods including food, beverages \& clothing, etc.

7. Gross Fixed Capital Formation (GFCF) or fixed investment measures the additions of fixed assets to the physical capacity to produce goods and services. GFCF includes:

- Acquisition less disposal of new or existing produced assets, such as:
o dwellings
other building structures
- plant, machinery \& transport equipment
- furniture \& fixtures

- Cost of ownership transfers on non-produced assets such as land

- Major improvement to land

- $\quad$ Fixed assets produced for own final use (investment)

Cost of land does not become part of GFCF since at national level, the sale of land by one economic entity would be offset by a purchase of same by another economic entity.

8. Industrial cost consists of cost of raw materials, fuels and electricity consumed, payments for work done, payments for repairs and maintenance and cost of goods purchased for resale. Some of these components are defined below: -

a) Fuels consist of firewood, coal, charcoal, kerosene oil, petrol, diesel, gas and other such items which are consumed in generating heat \& power. 
b) Raw-materials include raw and semi-finished materials, assembling parts etc., which are physically incorporated in the products and byproducts made. Chemicals, lubricants and packing materials which are consumed in the production and spare parts charged to current operating expenses are included. Raw-material given to other establishment for manufacturing goods (semi-finished and finished) on behalf of the establishment is included, whereas raw material supplied by others for manufacturing goods on their behalf is excluded.

9. Intermediate Consumption consists of goods and services, which are entirely used up by producers in the course of production to produce goods and services during the accounting period. Intermediate consumption comprises industrial cost plus non-industrial cost. It excludes labor cost, financial costs like interest payments. Intermediate consumption is valued at purchasers' prices. That means that production taxes which are levied with the supplier and which thus have to be borne by the establishment as a purchaser are included. Taxes levied on products or on production of the establishment itself which have to be paid to the fiscal authorities are not included.

10. Non-Industrial Cost consists of payments for transport, insurances, copy rights/royalties, postage, telephone, fax \& internet charges, printing and stationery, legal and professional services, advertising \& selling services, traveling, etc. For valuation and for exclusions and inclusions see "intermediate consumption".

11. Non-Industrial Receipts include receipts for transport services, repair \& maintenance, rental and lease of buildings \& equipment for storage and warehouses, agency commissions, etc. For valuation and for exclusions and inclusions see No 9 "intermediate consumption".

\section{Prices}

a) Market price is the producers' price plus sales tax.

b) Producers' price is the basic price plus taxes on the output invoiced to the purchaser less subsidies on the output received by the producer from the government.

c) Basic price is the amount received by the producer from the purchaser for a unit of output. It includes taxes less subsidies on production, such as, license fees or taxes on ownership or use of land, building or the assets used in production or labor employed. It excludes taxes less subsidies on output as well as transport charges.

d) Factor cost is the basic price minus other taxes on production defined at 14.b below.

13. Stocks include value of raw materials, spare parts, packing materials, fuels and other inputs materials (like chemicals and dyes, lubricants etc.), semi- 
finished products and by products and goods expressly purchased for resale at the beginning/end of the year.

14. Taxes on production and imports consist of two main groups:

a) Taxes on products payable on goods and services when they are produced, delivered, sold, transferred or otherwise disposed of by their producers, e.g. excise duties or taxes and duties on imports.

i. Excise duties consists of special taxes levied on specific kinds of goods, typically alcoholic beverages, tobacco and fuels; they may be imposed at any stage of production or distribution and are usually assessed by reference to the weight or strength or quantity of the product.

ii. A value added type of tax (VAT) is a tax on goods or services collected in stages by enterprises but which is ultimately charged in full to the final purchasers. In Pakistan, this applies to General Sales Tax.

b) Other taxes on production do not vary with weight, strength or quantity of output but are levied on inputs. They mainly consist of taxes on the ownership or use of land, building or other assets used in production or on the labour employed, or compensation of employees paid. In Pakistan, they are mainly levied by the Provinces and the Districts.

15. Value of production consists of the value of finished products and byproducts, receipts for work done for others, receipts for repairs and maintenance, value of sale of semi-finished products and byproducts, wastes and used goods, value of electricity sold, value of sales of goods purchased for resale, the net increase in the value of work in process and the value of fixed assets produced by the establishment for its own final use (investment). Valuation can be made at different concepts of prices (see under "prices" above). 


\section{Appendix III: ISIC Broad Structure}

\begin{tabular}{ccl}
\hline Section & Divisions & Description \\
\hline A & $01-03$ & Agriculture, forestry and fishing \\
B & $05-09$ & Mining and quarrying \\
C & $10-33$ & Manufacturing \\
D & 35 & Electricity, gas, steam and air conditioning supply \\
E & $36-39$ & Water supply; sewerage, waste management and remediation \\
F & $41-43$ & Construction \\
G & $45-47$ & Wholesale and retail trade; repair of motor vehicles and motorcycles \\
H & $49-53$ & Transportation and storage \\
I & $55-56$ & Accommodation and food service activities \\
J & $58-63$ & Information and communication \\
K & $64-66$ & Financial and insurance activities \\
L & 68 & Real estate activities \\
M & $69-75$ & Professional, scientific and technical activities \\
N & $77-82$ & Administrative and support service activities \\
O & 84 & Public administration and defence; compulsory social security \\
P & 85 & Education \\
Q & $86-88$ & Human health and social work activities \\
R & $90-93$ & Arts, entertainment and recreation \\
S & $94-96$ & Other service activities \\
T & $97-98$ & Activities of households as employers; undifferentiated goods- and \\
services- producing activities of households for own use
\end{tabular}




\section{Appendix IV: ISIC of All Economic Activities, Rev.3}

- A - Agriculture, hunting and forestry

- 01 - Agriculture, hunting and related service activities

- 02 - Forestry, logging and related service activities

- B - Fishing

- 05 - Fishing, operation of fish hatcheries and fish farms; service activities incidental to fishing

- $\quad$ C - Mining and quarrying

- 10 - Mining of coal and lignite; extraction of peat

- 11 - Extraction of crude petroleum and natural gas; service activities incidental to oil and gas extraction excluding surveying

- 12 - Mining of uranium and thorium ores

- 13 - Mining of metal ores

- 14 - Other mining and quarrying

- D - Manufacturing

- 15 - Manufacture of food products and beverages

- 16 - Manufacture of tobacco products

- 17 - Manufacture of textiles

- 18 - Manufacture of wearing apparel; dressing and dyeing of fur

- 19 - Tanning and dressing of leather; manufacture of luggage, handbags, saddlery, harness and footwear

- 20 - Manufacture of wood and of products of wood and cork, except furniture; manufacture of articles of straw and plaiting materials

- 21 - Manufacture of paper and paper products

- 22 - Publishing, printing and reproduction of recorded media

- 23 - Manufacture of coke, refined petroleum products and nuclear fuel

- 24 - Manufacture of chemicals and chemical products

- 25 - Manufacture of rubber and plastics products

- 26 - Manufacture of other non-metallic mineral products

- 27 - Manufacture of basic metals

- 28 - Manufacture of fabricated metal products, except machinery and equipment

- 29 - Manufacture of machinery and equipment n.e.c.

- 30 - Manufacture of office, accounting and computing machinery

- 31 - Manufacture of electrical machinery and apparatus n.e.c.

- 32 - Manufacture of radio, television and communication equipment and apparatus 
- 33 - Manufacture of medical, precision and optical instruments, watches and clocks

- 34 - Manufacture of motor vehicles, trailers and semi-trailers

- 35 - Manufacture of other transport equipment

- 36 - Manufacture of furniture; manufacturing n.e.c.

- 37 - Recycling

- $\quad$ - Electricity, gas and water supply

- 40 - Electricity, gas, steam and hot water supply

- 41 - Collection, purification and distribution of water

- $\quad \mathrm{F}$ - Construction

- 45 - Construction

- G - Wholesale and retail trade; repair of motor vehicles, motorcycles and personal and household goods

- 50 - Sale, maintenance and repair of motor vehicles and motorcycles; retail sale of automotive fuel

- 51 - Wholesale trade and commission trade, except of motor vehicles and motorcycles

- 52 - Retail trade, except of motor vehicles and motorcycles; repair of personal and household goods

- $\quad \mathrm{H}$ - Hotels and restaurants

- 55 - Hotels and restaurants

- I - Transport, storage and communications

- 60 - Land transport; transport via pipelines

- 61 - Water transport

- 62 - Air transport

- 63 - Supporting and auxiliary transport activities; activities of travel agencies

- 64 - Post and telecommunications

- J - Financial intermediation

- 65 - Financial intermediation, except insurance and pension funding

- 66 - Insurance and pension funding, except compulsory social security

- 67 - Activities auxiliary to financial intermediation

- $\quad \mathrm{K}$ - Real estate, renting and business activities

- 70 - Real estate activities

- 71 - Renting of machinery and equipment without operator and of personal and household goods

- 72 - Computer and related activities

- 73 - Research and development 
- $\quad 74$ - Other business activities

- L - Public administration and defence; compulsory social security

- 75 - Public administration and defence; compulsory social security

- $\quad \mathrm{M}$ - Education

- 80 - Education

- $\quad \mathrm{N}$ - Health and social work

- 85 - Health and social work

- $\quad$ - Other community, social and personal service activities

- 90 - Sewage and refuse disposal, sanitation and similar activities

- 91 - Activities of membership organizations n.e.c.

- 92 - Recreational, cultural and sporting activities

- 93 - Other service activities

- $\quad$ P - Private households with employed persons

- 95 - Private households with employed persons

- Q - Extra-territorial organizations and bodies

- 99 - Extra-territorial organizations and bodies 


\section{Appendix V: Data sources chapter 5}

PSEB Best Practices Study (2005) comprises a detailed survey of company performance, organizational characteristics, and infrastructure and policy challenges of Pakistan's largest software companies. A convenience sample of 50 of the country's largest companies was created and face-to-face interviews and on-the-spot surveys were carried out with these companies. A response rate of $96 \%$ ensured very high integrity for this analysis. An additional 12 companies filled out an online version of the survey for a total sample size of 60 companies. The sample included data for FY2004 for software development operations (products and services) and purposefully excluded business process outsourcing (BPO).

PSEB BPO Report 2006 is prepared by BearingPoint Inc. who in this study deeply analyze the global and domestic IT markets and then develop a strategy for the "OffShoring" industry in Pakistan. This strategy development program has also been initiated because all global industry indicators continue to project high growth in ITPS and expansion in the types of business processes being outsourced.

Analysis of Pakistan's IT industry: Shortcomings and Recommendations for IT Growth 2007 is prepared by the ICT Cell of PTA. It attempts to provide an in-depth analysis of the IT landscape of Pakistan. Secondly, it will pinpoint the reasons for the slow growth of the IT industry i.e. slow growth of broadband etc.

Pakistan Software Industry Review 2007 is prepared by Gartner Inc. for PSEB in 2007 and presents a detailed analysis of the Pakistani software industry, its strengths, weaknesses, competitiveness and the challenges it faces. For this report Gartner utilized the inputs from its dedicated International Sourcing research group (RG), which advises clients on offshore opportunities and risks. They also reviewed a number of valuable reports and studies that PSEB has commissioned in recent years. Finally, PSEB arranged a series of face-to-face meetings with key stakeholders of the sector.

P@SHA Annual Review (2008) involved a detailed survey of company performance, organizational characteristics, and infrastructure and policy challenges of P@SHA member companies. P@SHA member companies are an approximate sub-set of PSEB membership and hence represent a sample from within the broader population. The survey resulted in responses from 80 software and BPO companies (from around 250 who were contacted) for a response rate of about $33 \%$. Up to 25 of these 80 were also represented in PSEB (2005) sample. P@SHA (2008) also, for the first time, systematically surveyed business process outsourcing (BPO) companies. The data collected included actual data for FY2006 and estimates for FY2007. 
PSEB IT Market Assessment (2010) is a detailed survey of company performance, organizational characteristics, and infrastructure and policy challenges of Pakistan Software Export Bureau (PSEB) member companies. The survey includes a much expanded revenue classification scheme that builds upon the data collected earlier and includes domestic and export earnings within a set of 20 domains and 35 product-service categories (e.g. offerings, tools, and platforms). The PSEB (2010) data includes companies specializing in software products development and services delivery, business process outsourcing, mobile applications, gaming and animation, and systems integration. A total of 75 companies (from a convenience sample of about 300 ) responded to the survey for a response rate of $25 \%$.

National ICT Policy 2012 has been prepared with the input and involvement of a number of stakeholders namely, the Pakistan Software Houses Association for IT \& ITES (P@SHA), members of civil society, the technology industry in general, the telecommunication community, the services sector, academia, media and socio-political activists as well as various government entities. This document contains actionable milestones and fundable projects, reflecting the point of views of primary stakeholders and the technology industry. It is reviewed annually to assess the impact of the policy at that stage as well as the effectiveness of the recommended intervention programs. This document was then selectively presented for initial feedback and reactions and the feedback was incorporated after discussion.

PTA Annual Report 2013 is the most recent official resource available, which not only contains valuable statistical data on Pakistan's ICT sector, but also the opinions of highranking government officials on the challenges faced by the industry. This is report is published annually by the Pakistan Telecommunication Authority (PTA). 



\section{Appendix VI: Questionnaire for Survey of ICT Firms in Pakistan}

This survey is being conducted by a research team at UNU-MERIT. UNU-MERIT is a joint research and training centre of the United Nations University (UNU) and Maastricht University, The Netherlands.

The joint Institute was created on $1^{\text {st }}$ January 2006 following the integration of the former UNU-Institute for New Technologies (INTECH) in Maastricht, and the Maastricht Economic Research Institute on Innovation and Technology, MERIT, at Maastricht University. Its mission is to provide insights into the social, political and economic factors that drive technological change and innovation. The Centre's research and training programs address a broad range of policy questions relating to the national and international governance of science, technology and innovation, with a particular focus on the creation, diffusion and access to knowledge. (See more about us at http://www.merit.unu.edu/).

This survey has also been endorsed by the Pakistan Technology Board, Islamabad.

Data from the questionnaire will be used for research purposes only and will be treated with full confidentiality. Complete firm anonymity is guaranteed.

Our research team consists of the following main members:

Prof. Dr. Adam Szirmai

Professor of Development Economics, UNU-MERIT and Maastricht School of Governance

Prof. Robin Cowan

Professor of Economics of Technical Change, UNU-MERIT, Professor of Economics at the Bureau d'Economie Theorique et Appliquée (BETA) and at the Université Louis Pasteur.

\section{A. B. Qazi (Contact Person)}

B.Sc. Electrical Engineering, M.Sc. Information and Communication Systems, Germany, PhD Scholar (UNU-MERIT). qazi@merit.unu.edu

Note: If your organization wishes to receive a summary of the results of this research, we will be glad to send you a copy. Please sign below:

Our organization, would like to receive a summary of the results of this research. 


\section{General Questions:}

\section{Particulars of Firm/General Information}

Q1. What is the name of your firm?

Q2. What is the address of your firm?

Q3. What is the form of ownership of your organization?

(Please tick only one from the choices below)

Domestically owned firm

Domestically owned foreign joint venture

State owned firm

State owned domestic joint venture

State owned foreign joint venture

$\bigcirc$ Other, specify:

Q4. What are the main areas of operation of your firm?

(Please tick more than one category if applicable)

$\bigcirc$ ICT manufacturing

ICT trading

Computer programming, software

consulting and related activities

Telecommunications 


\section{Main Questions:}

\section{Innovative Performance:}

\section{Product (good or service) innovation}

A product innovation is the market introduction of a new good or service or a significantly improved good or service with respect to its capabilities, such as improved software, user friendliness, components or sub-systems. The innovation (new or improved) must be new to your enterprise, but it does not need to be new to your sector or market. It does not matter if the innovation was originally developed by your enterprise or by other enterprises.

\section{Good/Service Innovation}

Q5. Has your organization introduced new or significantly improved products/services in the last 5 years (between 2006 and

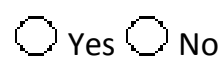
2010)?

\section{Number and scope of goods/service innovations}

Number

Q6. What is the total number of newly introduced goods/services in the last 5 years?

Q7. How many of these newly introduced goods/services were 'New to World'? (These goods/services were not available anywhere in the World)

Q8. How many of the newly introduced services were 'New to your Market'? (Your enterprise introduced a new or significantly improved good or service onto your market before your competitors. It may have already been available in other markets)

Q9. How many of the newly introduced goods/services were only 'New to your Firm'? (Your enterprise introduced a new or significantly improved good or service that was already available from your competitors in your market)

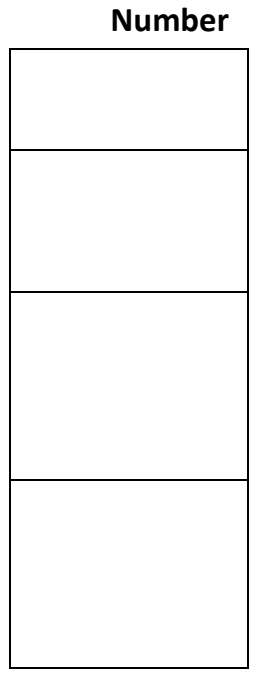

Q10. List the five technologically most important innovations of your firm in the last five years $(2005-2010)$ :

Top five Innovations of last 5 years

1.

2.

3. 
4.

5.

Turnover from Innovations

Q11. What was the percentage of your total turnover in 2009 from goods and service innovations introduced during the last 5 years that were new to the World

Q12. What was the percentage of your total turnover in 2009 from goods and service innovations introduced during the last 5 years that were new to your market

Q13. What was the percentage of your total turnover in 2009 from goods and service innovations introduced during the last 5 years that were only new to your firm

\begin{tabular}{|c|}
\hline$\%$ \\
\hline$\%$ \\
\hline$\%$ \\
\hline
\end{tabular}

\section{Process innovation}

A process innovation is the implementation of a new or significantly improved production process, distribution method, or support activity for your goods or services. The innovation (new or improved) must be new to your enterprise, but it does not need to be new to your sector or market. It does not matter if the innovation was originally developed by your enterprise or by other enterprises. Please include purely organizational innovations.

\section{Number and scope of process innovations}

Number

Q14. How many new or significantly improved services or methods of manufacturing or producing goods did your enterprise introduce in the last 5 years?

Q15. How many new or significantly improved logistics, delivery or distribution methods for your inputs, goods or services did your enterprise introduce in the last 5 years?

Q16. How many new or significantly improved supporting activities for your processes, such as maintenance systems or operations for purchasing, accounting, or computing did your enterprise introduce in the last 5 years?

\begin{tabular}{|l|}
\hline \\
\hline \\
\hline \\
\hline
\end{tabular}




\section{Economic Performance:}

\begin{tabular}{|l|l|l|l|}
\hline Turnover (in Rupees) & 2009/10* & 2007/08 & 2002/03 \\
\hline $\begin{array}{l}\text { Q17. What is/was your enterprise's total turn- } \\
\text { over for: (Turnover is defined as the market } \\
\text { sales of goods and services) }\end{array}$ & & & \\
\hline $\begin{array}{l}\text { Q18. What is the percentage of exports from } \\
\text { sales? }\end{array}$ & & & \\
\hline
\end{tabular}

*Current fiscal year (i.e. from $1^{\text {st }}$ July 2009 till $30^{\text {th }}$ June 2010 ) with estimate for missing month(s)

\section{Profitability}

Q19. In the year 2009/10*, has your firm's profitability:

$$
\bigcirc \text { Increased } \bigcirc \text { Remained Constant } \bigcirc \text { Decreased }
$$

*Current fiscal year (i.e. from $1^{\text {st }}$ July 2009 till $30^{\text {th }}$ June 2010 ) with estimate for missing month(s)

Q20. What was your Annual Investment for $\mathbf{2 0 1 0}$ (Tick whichever is closest)

In Rupees

$\bigcirc$ No investment

$\bigcirc$ Less than 10,000

Less than 100,000

Less than $1,000,000$

More than $1,000,000$

*Current fiscal year (i.e. from $1^{\text {st }}$ July 2009 till $30^{\text {th }}$ June 2010) with estimate for missing month(s)

\section{Employment}

Q21. What is/was the total number of persons employed, including working proprietors in

Q22. Of these how many are working proprietors

Q23. Of these how many are technical staff**

*2010 means at the time of interview and 2007/08 means the average for that fiscal year 
** Technical staff means employees in mid and high level technical positions (engineers, programmers etc.)

\section{Working hours}

Hours

Q24. What are the average working hours in your firm per week

Q25. Out of which paid overtime hours per week

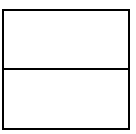

\section{Absorptive Capacity}

Educational background of employees at the time of the interview

Q26. What is the total number of persons employed having no matriculation degree?

Q27. What is the total number of persons employed having Matriculation as their highest academic degree

Q28. What is the total number of persons employed having F.Sc. as their highest academic degree

Q29. What is the total number of persons employed having Bachelor's/Diploma as highest academic degree

Q30. Of these, how many are Engineers and Computer Scientists

Q31. What is the total number of persons employed with a Master's as highest academic degree

Q32. Of these, how many are Engineers and Computer Scientists

Q33. What is the total number of staff having $\mathrm{PhD}$ or higher as highest academic degree

Q34. Of these, how many are Engineers and Computer Scientists?

Q35. What is the total number of persons employed with a foreign Masters or PhD degrees

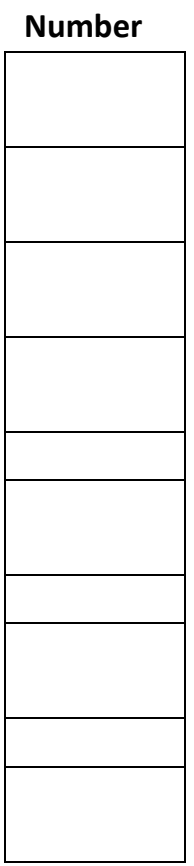

\section{Experience (within ICT sector) and academic background of Proprietor*/CEO}

Q36. How many previous jobs were held by the Proprietor/CEO

Q37. Has the Proprietor/CEO prior experience of working with an

Q38. If yes, please provide the name of the MNC 
Q39. Has the Proprietor/CEO prior experience of working outside Pakistan

Q40. What is the highest academic degree of the Proprietor/CEO

* In case of more than one proprietor provide information on the one with executive powers.

May you please tell us something about the prior work experience of your employees? If you do not know the exact numbers, please give us estimates.

Prior work experience (within ICT sector)

Number

Q41. What is the average number of previous jobs held by technical staff* prior to joining your firm?

Q42. How many of your technical staff have prior experience of working with an MNC in Pakistan

Q43. How many of your technical staff have prior experience of working outside Pakistan

*Technical staff are employees in mid and high level technical positions (engineers, programmers etc.).

Please tell us something about the labor turnover in your firm. If you do not know the exact numbers, please give us estimates.

Q44. What is the total number of technical staff that left your organization to join MNCs in Pakistan in the 12 months preceding this interview

Q45. What is the total number of technical staff that left your organization to join domestic firms in the 12 months preceding this interview

Q46. What is the total number of technical staff that left your organization to start their own organization

Q47. What is the total number of technical staff that joined your organization from MNCs in Pakistan

Q48. What is the total number of technical staff that joined your organization from domestic firms

Q49. Is the average age of most staff leaving to join competition above or below 25 years?

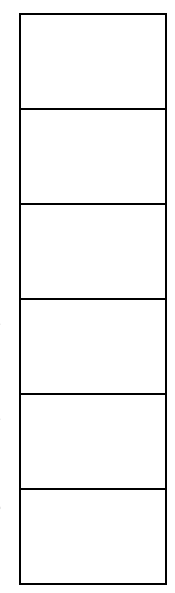


Q50. In which year was your firm founded?

(If founded abroad, please state year in which your firm started its operations in Pakistan and if your firm is the result of a merger with a Pakistani firm, please mention date of merger.)

Q51. Does your firm have an R\&D section?

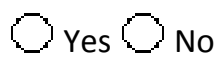

Q52. If yes, what is your annual R\&D budget?

Rs.

Q53. What is the number of technical staff engaged in R\&D activities?

Q54. Does your firm use the Internet? If yes, for which purposes do you use it?

\section{Purposes}

For emailing

$\square$ For searches on the world wide web

$\square$ For selling products or services to customers

$\square$ For online advertising

Q55. Does your firm have a Homepage?

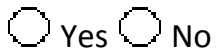

Q56. Please provide us with the following information regarding on-job training:

What is the average time spent per year by your average techDays per year nical staff in the following types of on-job trainings

Days spent in In-House training

Days spent in external trainings within Pakistan

Days spent in external trainings out of Pakistan but within your firm

Days spent in external trainings out of Pakistan

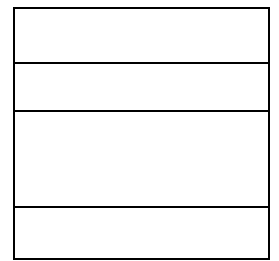

\section{Spillovers}

Q57. Is your organization a spinoff? If not, go to Question 62.

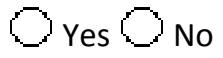
Your organization's relationship with its Parent enterprise Q58. Parent organization (University, MNC or another enterprise) Q59. Is your parent enterprise located within the same region or not?

Q60. Does your firm develop products mainly for parent enterprise?

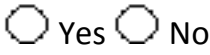

$\bigcirc$ Yes $\bigcirc$ No 
Q61. Is your parent firm an important source of information or assistance in your efforts to upgrade or innovate?

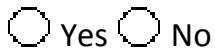

Q62. During the three years from 2008 to 2010, how important were each of the following information sources to your enterprise's innovation activities? Please identify information sources that provided information for new innovation projects or contributed to the completion of existing innovation projects. In case you think a specific category from below was not a source of information to your company at all, please mark it as Not Applicable.

\begin{tabular}{|c|c|c|c|c|c|c|}
\hline Source of Information & $\begin{array}{l}\text { Not } \\
\text { Imp. }\end{array}$ & $\begin{array}{l}\text { Somewhat } \\
\text { Imp. }\end{array}$ & Imp. & Very Imp. & Crucial & N/A \\
\hline \multicolumn{7}{|l|}{ Internal } \\
\hline \multicolumn{7}{|l|}{$\begin{array}{l}\text { Within your enter- } \\
\text { prise }\end{array}$} \\
\hline New personnel & 0 & 0 & 0 & 0 & 0 & 0 \\
\hline \multicolumn{7}{|l|}{ Market sources } \\
\hline Parent firm & & & & & & $D$ \\
\hline \multicolumn{7}{|l|}{$\begin{array}{l}\text { Suppliers of equip- } \\
\text { ment, materials, } \\
\text { components, or } \\
\text { software }\end{array}$} \\
\hline Clients or customers & & & & & & 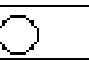 \\
\hline \multicolumn{7}{|l|}{$\begin{array}{l}\text { MNC Competitors or } \\
\text { other enterprises } \\
\text { in your sector }\end{array}$} \\
\hline \multicolumn{7}{|l|}{$\begin{array}{l}\text { Domestic Competitors } \\
\text { or other enter- } \\
\text { prises in your sec- } \\
\text { tor }\end{array}$} \\
\hline Consultants & 0 & 0 & 0 & 0 & 0 & 0 \\
\hline Private R\&D institutes & 0 & 0 & 0 & 0 & $\Omega$ & 0 \\
\hline Commercial labs & 0 & 0 & 0 & 0 & 0 & 0 \\
\hline
\end{tabular}




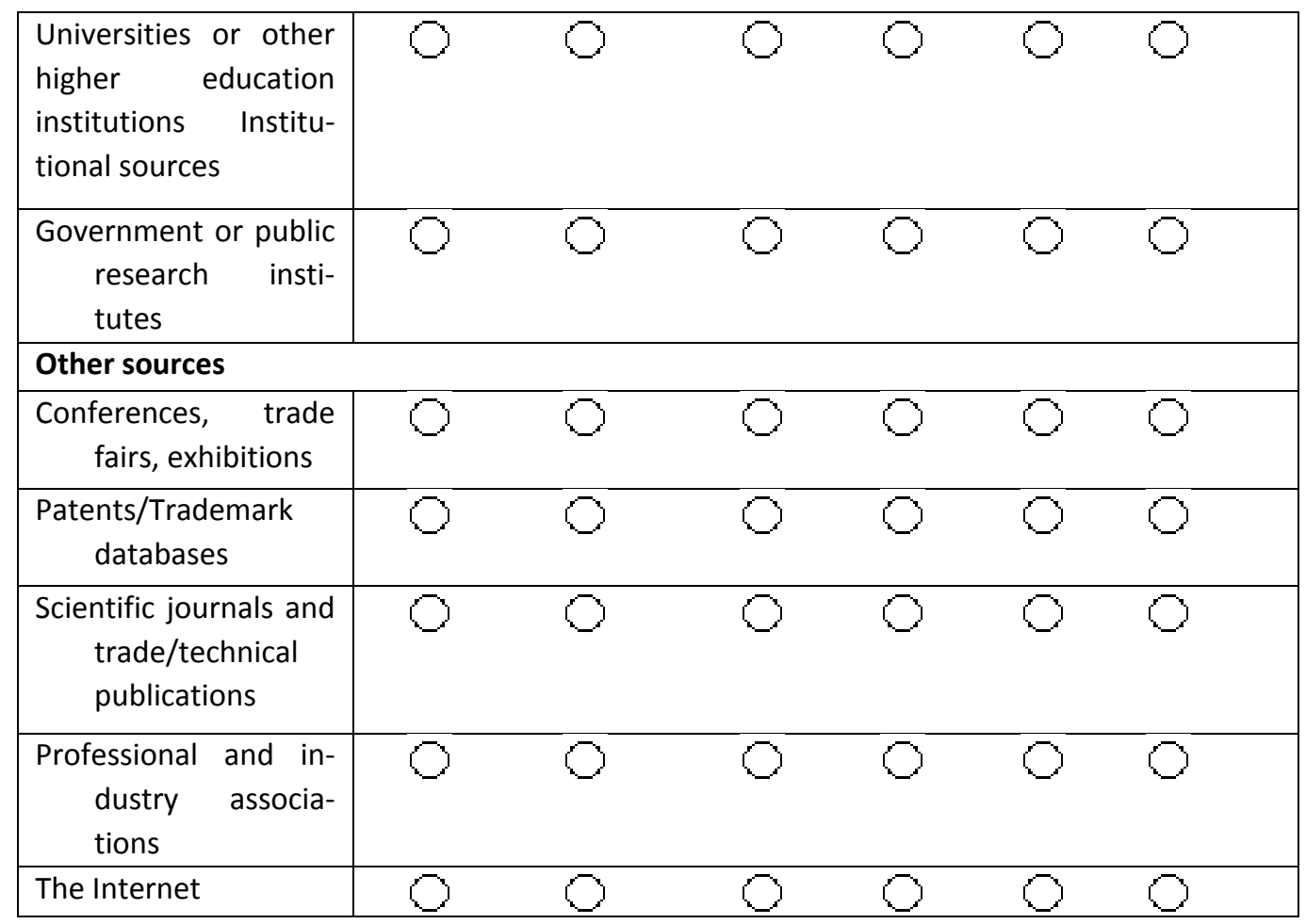

Q63. During the three years from 2008 to 2010, how important were each of the following sources for acquiring technology for acquiring technology? In case you think a specific category from below was not a source for acquiring technology at all, please mark it as Not Applicable.

\begin{tabular}{|c|c|c|c|c|c|c|}
\hline $\begin{array}{c}\text { Source of Technology } \\
\text { Acquisition }\end{array}$ & $\begin{array}{l}\frac{\dot{d}}{\underline{\xi}} \\
\frac{0}{2}\end{array}$ & 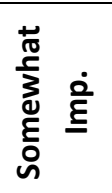 & $\stackrel{\stackrel{\circ}{\xi}}{\underline{\xi}}$ & $\frac{\dot{0}}{\frac{\mathbf{g}}{\mathbf{g}}}$ & $\begin{array}{l}\overline{\frac{\pi}{\pi}} \\
\frac{2}{2} \\
\frac{2}{2}\end{array}$ & $\frac{\varangle}{z}$ \\
\hline MNCs within Pakistan & & 0 & & & &  \\
\hline Domestic companies & & & & & & 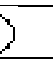 \\
\hline Parent firm & & & & & & 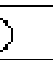 \\
\hline Principal firm & & & & & & 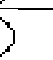 \\
\hline Universities & & & & & & 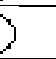 \\
\hline R\&D Institutes & & 0 &  & 2 & & 2 \\
\hline Others, please specify & & & & 7 & & 0 \\
\hline
\end{tabular}


Q64. Is your business located (If required, tick more than one)

Within a cluster of ICT firms

Close to an ICT MNC

$\square$ Close to a domestic ICT firm

C Close to a University

$\square$ Close to a Research Institute

\section{(For Domestic firms only)}

Q65. Does your organization perceive MNC presence more as a threat or an opportunity overall?

Q66. Does your organization gain more, gain and lose equally or lose more trained staff from/to MNCs?

$\bigcirc$ Gains More $\bigcirc$ 50/50 Loses more

Q67. In your interaction with MNCs, do you usually pay for the services which you get from them or do you get them free of charge?

$\bigcirc$ Pay $\bigcirc$ Free of Charge

Q68. Do you cooperate with $\mathrm{MNC}(\mathrm{s})$ on projects?

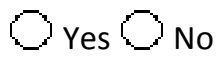

Q68. Have you increased your innovative activities due to competition of MNCs?

\section{(For MNCs only)}

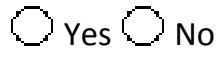

Q69. Does your organization perceive domestic firms more as a threat or an opportunity overall?

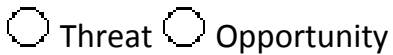

Q70. Does your organization gain or lose more trained staff from/to domestic firms?

$\bigcirc$ Gains More $\bigcirc 50 / 50 \bigcirc$ Loses more

Q71. In your interaction with domestic firms, do you usually pay for the services which you get from them or do you get them free of charge?

$\bigcirc$ Pay $\bigcirc$ Free of Charge

Q72. Do you cooperate with domestic firms on projects?

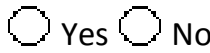

Q73. Have you increased your innovative activities due to competition of domestic firms?

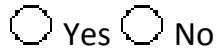




\section{Network Characteristics}

Q74. List ten most important organizations in order of importance which you look towards for knowledge, technology acquisition or technology support. 


\begin{tabular}{|c|c|c|}
\hline  & 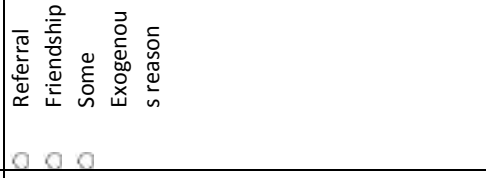 & 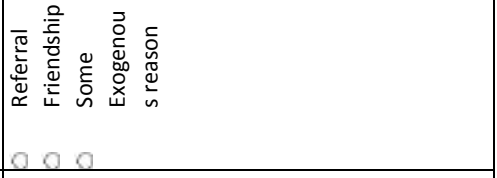 \\
\hline 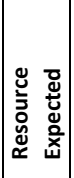 & 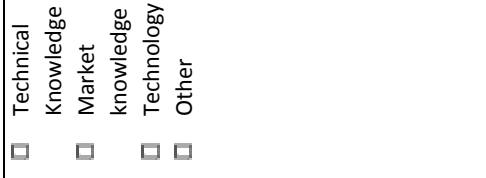 & 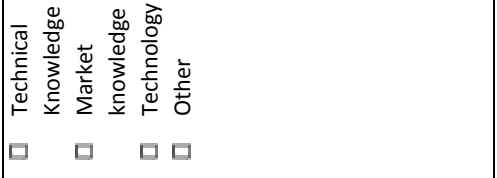 \\
\hline 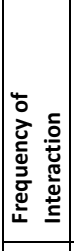 & 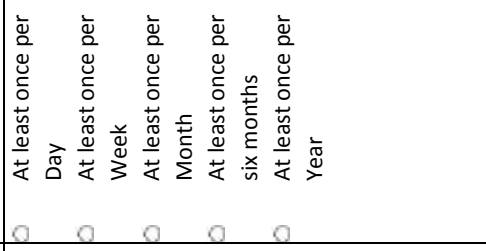 & 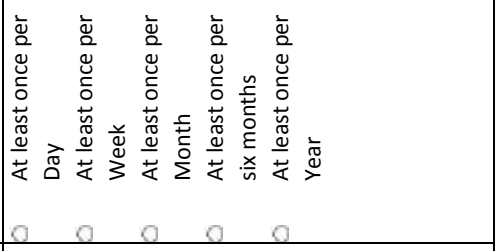 \\
\hline 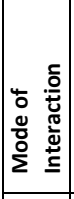 & 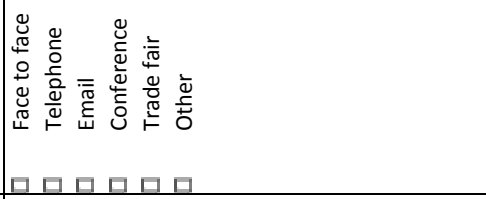 & 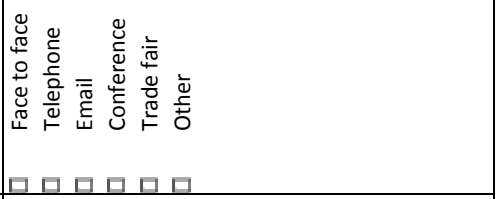 \\
\hline 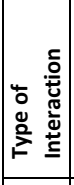 & 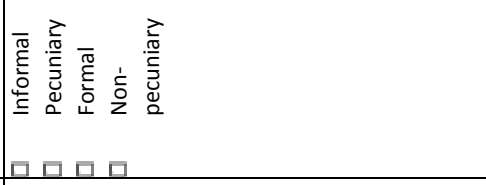 & 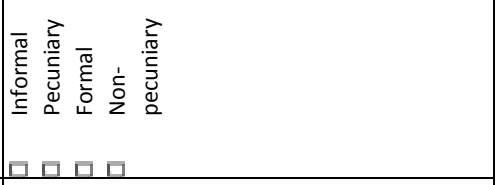 \\
\hline 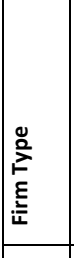 & 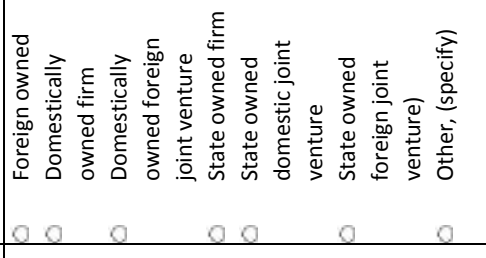 & 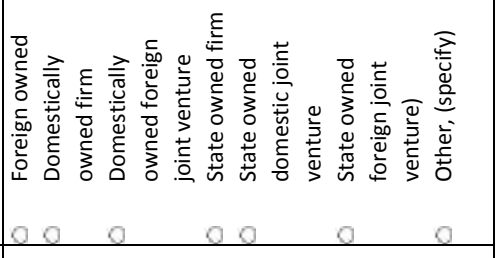 \\
\hline 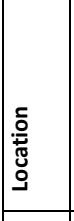 & 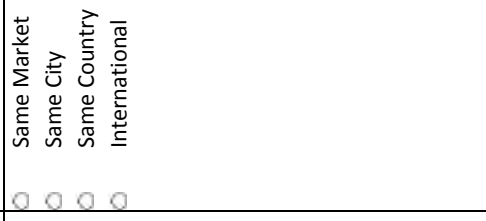 & 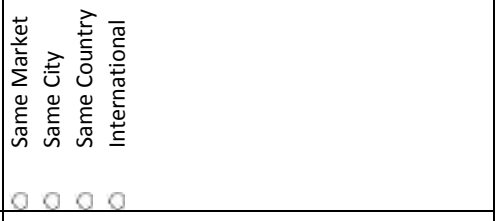 \\
\hline 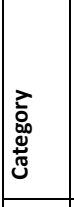 & 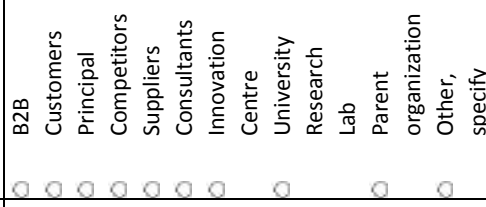 & 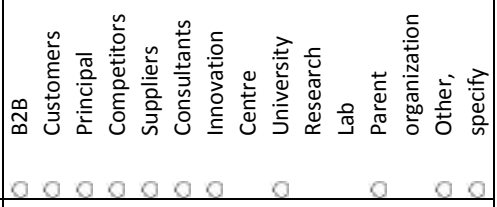 \\
\hline 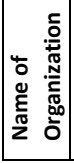 & & \\
\hline
\end{tabular}




\begin{tabular}{|c|c|c|}
\hline 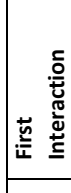 & 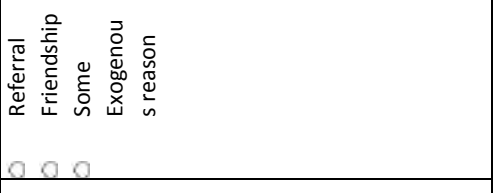 & 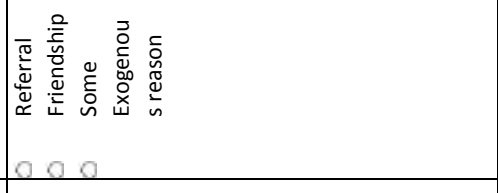 \\
\hline 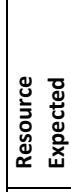 & 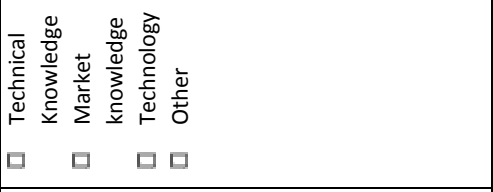 & 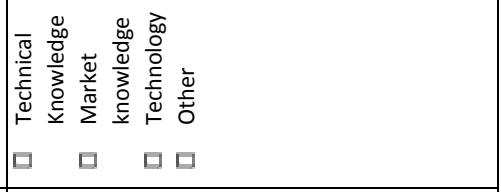 \\
\hline 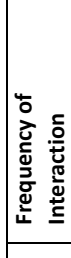 & 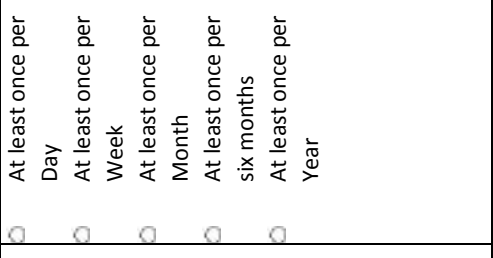 &  \\
\hline 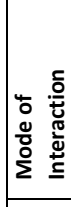 & 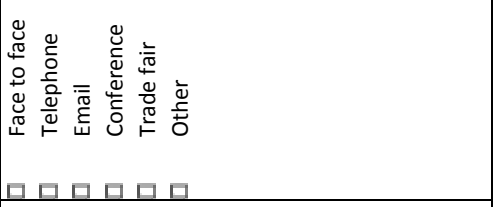 & 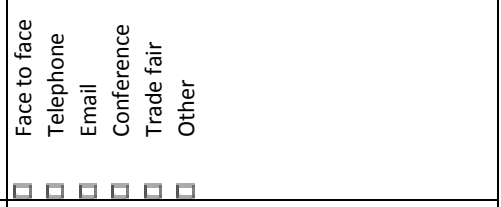 \\
\hline & 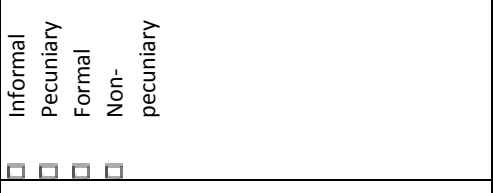 & 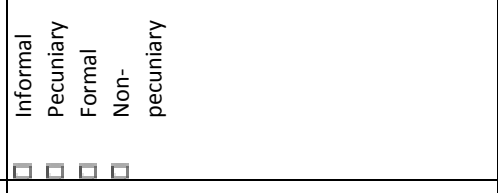 \\
\hline t: & 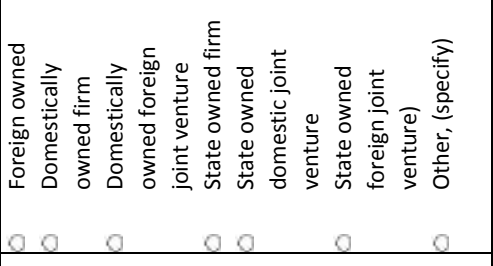 & 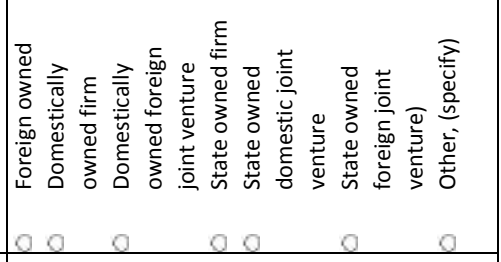 \\
\hline סَّ & 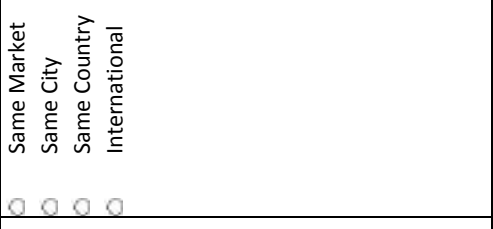 & 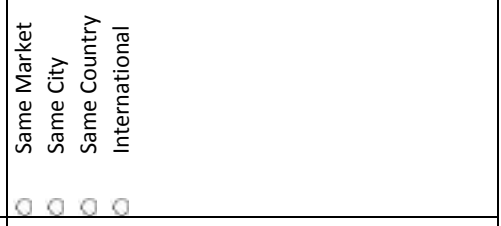 \\
\hline 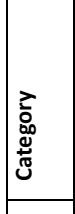 & 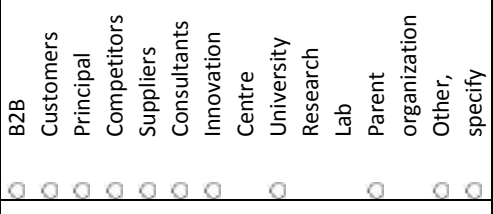 & 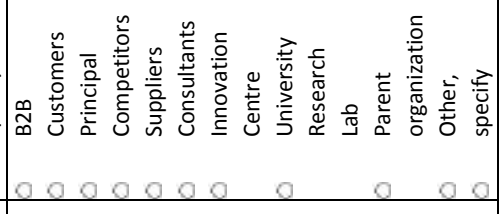 \\
\hline & & \\
\hline
\end{tabular}




\begin{tabular}{|c|c|c|}
\hline 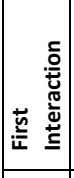 & 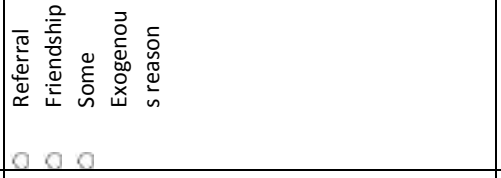 &  \\
\hline 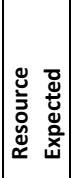 & 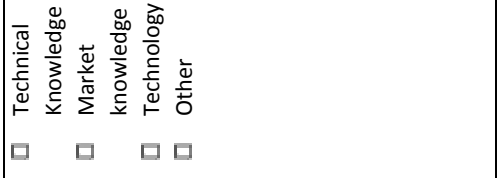 &  \\
\hline  &  & 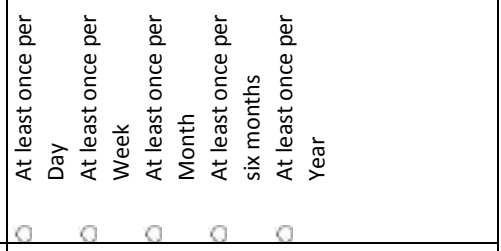 \\
\hline 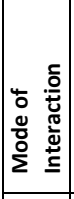 & 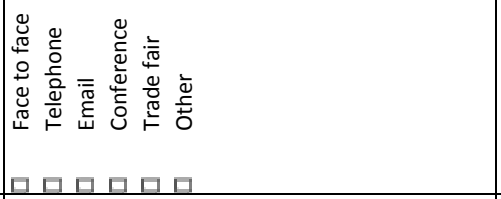 & 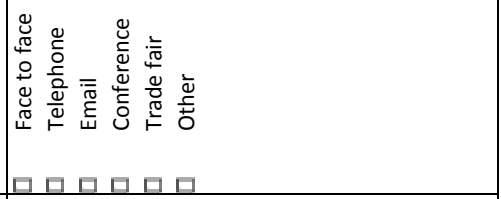 \\
\hline 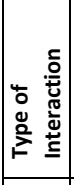 &  & 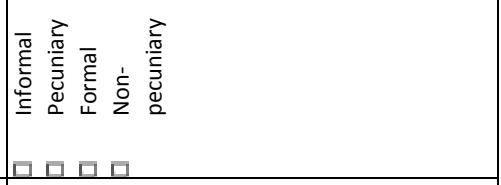 \\
\hline  &  & 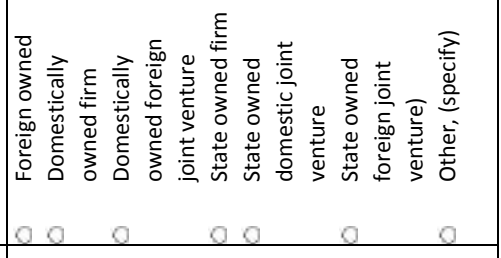 \\
\hline 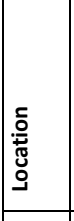 & 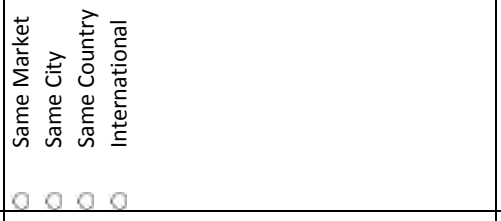 & 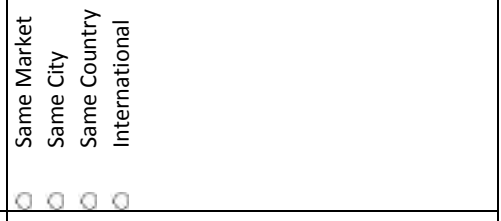 \\
\hline 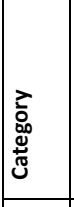 & 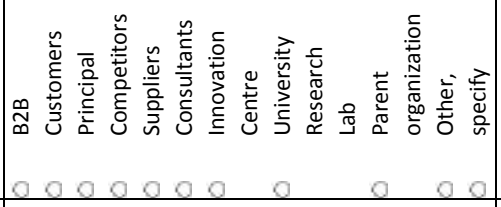 &  \\
\hline 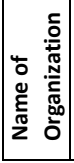 & & \\
\hline
\end{tabular}




\begin{tabular}{|c|c|c|}
\hline & 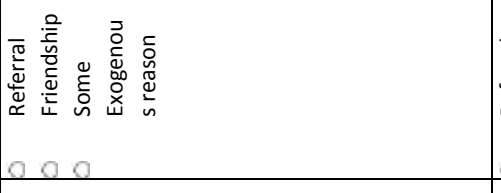 & 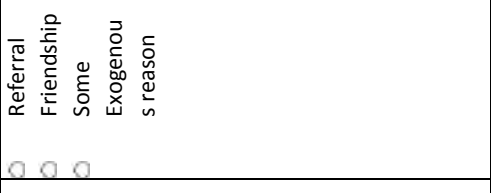 \\
\hline 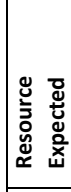 & 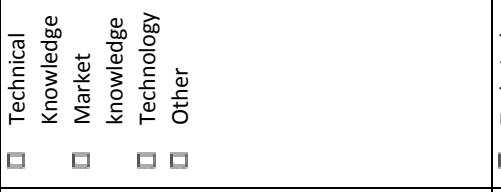 & 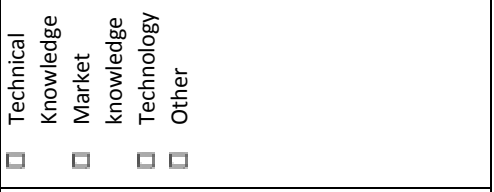 \\
\hline 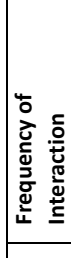 & 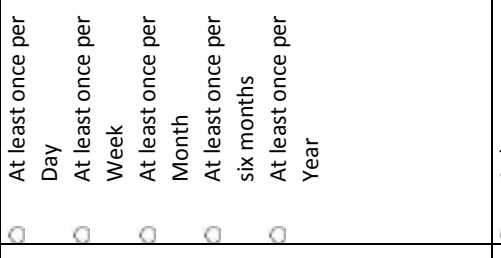 & 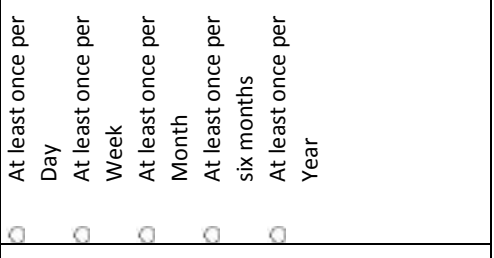 \\
\hline  & 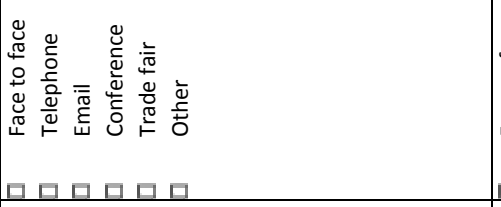 & 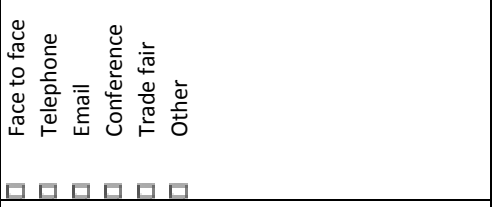 \\
\hline & 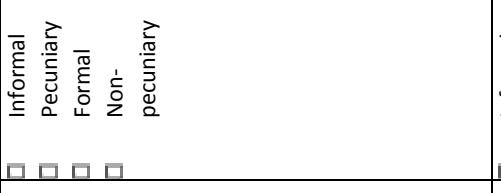 & 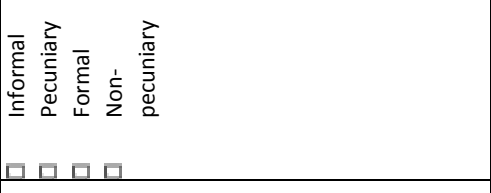 \\
\hline 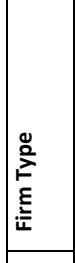 & 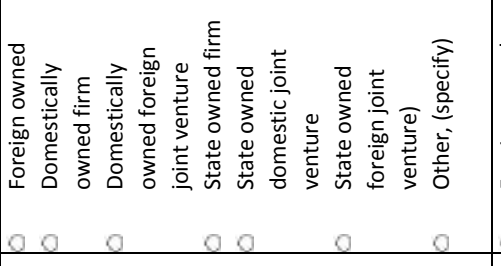 & 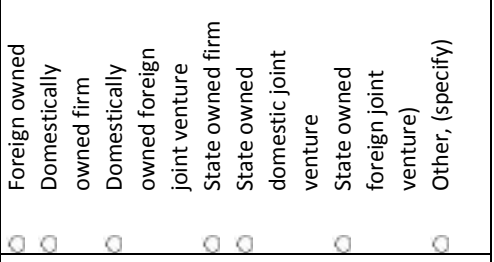 \\
\hline סِّ & 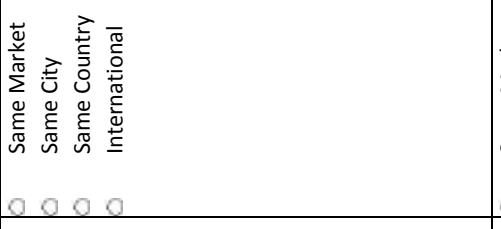 & 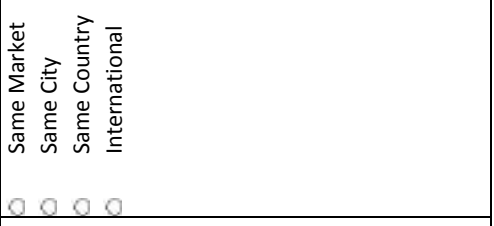 \\
\hline 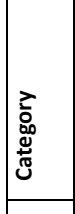 & 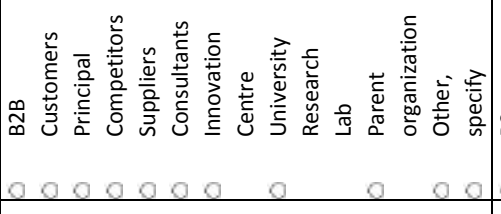 & 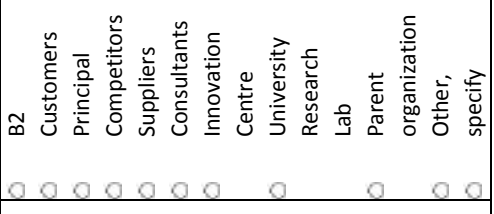 \\
\hline & & \\
\hline
\end{tabular}




\begin{tabular}{|c|c|c|}
\hline 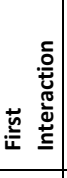 & 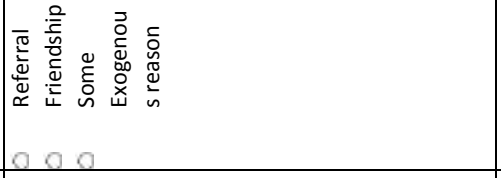 & 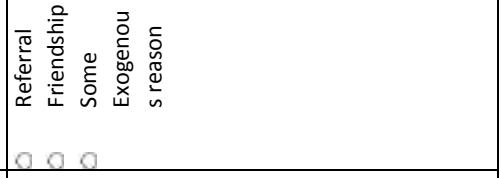 \\
\hline & 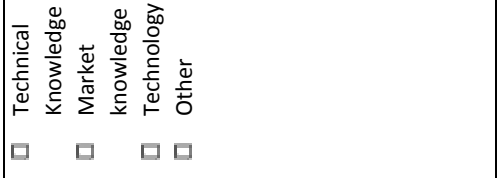 &  \\
\hline & 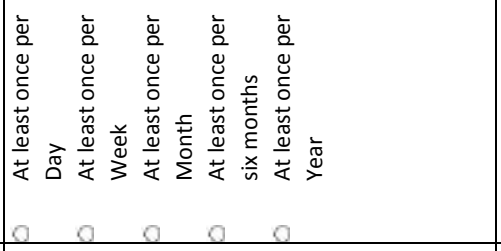 &  \\
\hline 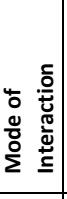 & 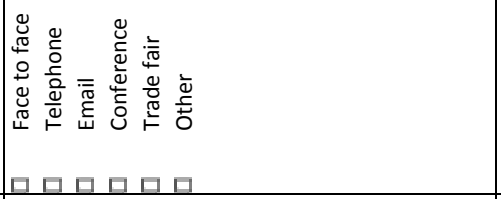 & 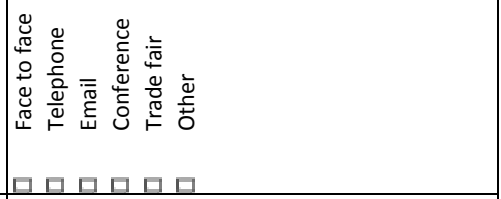 \\
\hline 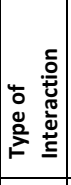 & 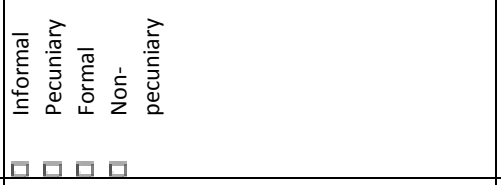 & 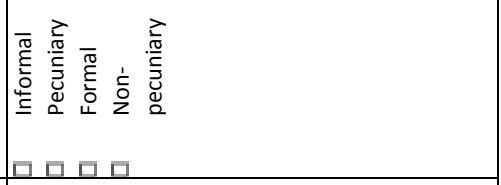 \\
\hline $\mid$ & 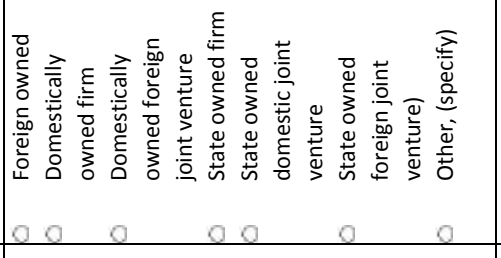 & 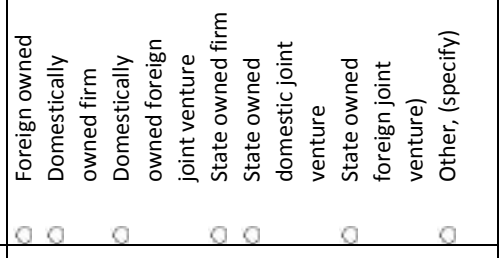 \\
\hline 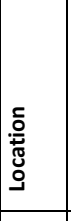 &  & 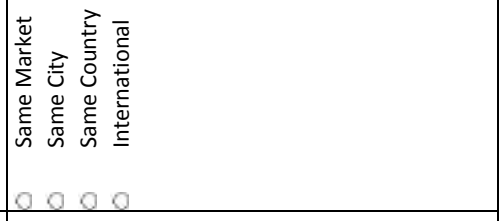 \\
\hline 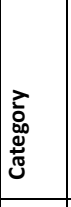 & 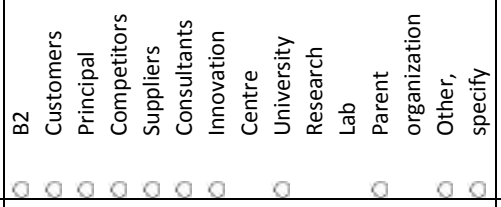 & 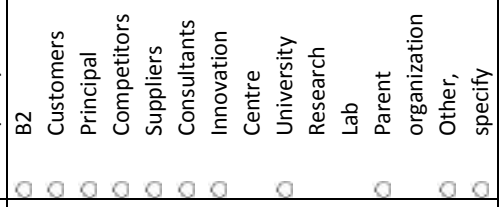 \\
\hline 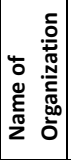 & & \\
\hline
\end{tabular}


Q83. Does your organization belong to some professional organization? If yes, which one(s)?

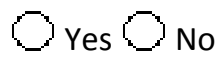

Q84. Please rate the following factors according the role they have played in obstructing your innovative and economic performance on a scale of 1 to 5 where 1 is least obstructive and 5 is most obstructive.

\begin{tabular}{llll}
\hline Sources & High cost of the innovation project \\
Lack of financing \\
Lack of skilled personnel \\
Long administrative/ approval process within the \\
Lack of information on technology itself \\
Lack of security in Pakistan \\
Lack of political stability in Pakistan \\
Domestic economic conditions (recession, inflation) \\
Wegislation/legal restrictions/administrative proce- \\
Weak customer demand
\end{tabular}

Q85. How has the security situation and political instability affected the innovating activities of your firm?

\begin{tabular}{l|lll}
\hline Activity & Increased & Remained Constant \\
R\&D efforts & Decreased \\
Marketing efforts \\
Trainings \\
Attending Conferences \\
Launching new products \\
Hiring new staff \\
Investment:
\end{tabular}


Q86. During the study period, what was the government's role in assisting the following activities?

\begin{tabular}{|c|c|c|c|c|c|c|}
\hline & $\begin{array}{l}\text { Not } \\
\text { Imp }\end{array}$ & $\begin{array}{l}\text { Somewhat } \\
\text { Imp }\end{array}$ & Imp. & Very Imp. & Crucial & N/A \\
\hline \multicolumn{7}{|l|}{ R\&D Funding } \\
\hline \multicolumn{7}{|l|}{ Training } \\
\hline \multicolumn{7}{|l|}{ Subsidies } \\
\hline \multicolumn{7}{|l|}{ Tax Rebates } \\
\hline \multicolumn{7}{|l|}{ Technical support } \\
\hline \multicolumn{7}{|l|}{ Infrastructure } \\
\hline \multicolumn{7}{|l|}{ support } \\
\hline \multicolumn{7}{|l|}{ Loans and grants } \\
\hline Others: & & & & & & \\
\hline
\end{tabular}

Q87. Is there anything you would like to comment about regarding this survey, the ICT market in Pakistan or any other relevant topic?

Q88. Would you like to comment on the quality of the survey or suggest any improvements? 


\section{Appendix VII: Concordance table for various data sources}

\begin{tabular}{|c|c|c|}
\hline Value Added (UNSD data) & Labor (LABORSTA data) & Final categories employed \\
\hline $\begin{array}{l}\text { Agriculture, hunting, forestry, } \\
\text { fishing }\end{array}$ & $\begin{array}{l}\text { Agriculture, Hunting, Forestry and } \\
\text { Fishing }\end{array}$ & $\begin{array}{l}\text { Agriculture, Hunting, Forestry and } \\
\text { Fishing (ISIC A-B) }\end{array}$ \\
\hline Mining, Manufacturing, Utilities & Mining and Quarrying & Mining and Utilities (ISIC C and E) \\
\hline Manufacturing & Manufacturing & Manufacturing (ISIC D) \\
\hline Mining, Utilities & Electricity, Gas and Water & Construction (ISIC F) \\
\hline Construction & Construction & $\begin{array}{l}\text { Wholesale and Retail Trade and } \\
\text { Restaurants and Hotels (ISIC G-H) }\end{array}$ \\
\hline $\begin{array}{l}\text { Wholesale, retail trade, } \\
\text { restaurants and hotels }\end{array}$ & $\begin{array}{l}\text { Wholesale and Retail Trade and } \\
\text { Restaurants and Hotels }\end{array}$ & $\begin{array}{l}\text { Transport, Storage and } \\
\text { Communication (ISIC I) }\end{array}$ \\
\hline $\begin{array}{l}\text { Transport, storage and } \\
\text { communication }\end{array}$ & $\begin{array}{l}\text { Transport, Storage and } \\
\text { Communication }\end{array}$ & Other Activities (ISIC J-P) \\
\hline Other Activities & $\begin{array}{l}\text { Financing, Insurance, Real Estate and } \\
\text { Business Services } \\
\text { Community, Social and Personal } \\
\text { Services } \\
\text { Activities not Adequately Defined }\end{array}$ & \\
\hline
\end{tabular}


Appendix VIII: Correlation tables corresponding to the regression tables

For Table 6.13

\begin{tabular}{|c|c|c|c|c|c|c|c|c|c|c|c|c|}
\hline & 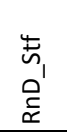 & $\underset{\substack{c\\
}}{0}$ & $\begin{array}{l}\stackrel{\varrho}{E} \\
\stackrel{山}{\Xi}\end{array}$ & $\underset{ه}{\stackrel{\alpha}{\alpha}}$ & $\begin{array}{l}\text { ț } \\
\text { ò } \\
\text { a } \\
\end{array}$ & $\underset{\Sigma}{u}$ & 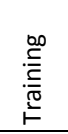 & 굼 & $\underset{\substack{0 \\
\stackrel{0}{x}}}{\stackrel{0}{u}}$ & $\begin{array}{l}x \\
o \\
\stackrel{0}{0} \\
\text { ú } \\
\stackrel{c}{\Sigma}\end{array}$ & $\begin{array}{l}\stackrel{x}{0} \\
\stackrel{0}{2} \\
\text { है } \\
\text { o }\end{array}$ &  \\
\hline RnD_Stf & 1.0 & & & & & & & & & & & \\
\hline$R n D$ & 0.6 & 1.0 & & & & & & & & & & \\
\hline LnEmp & 0.4 & 0.4 & 1.0 & & & & & & & & & \\
\hline Age & 0.2 & 0.4 & 0.4 & 1.0 & & & & & & & & \\
\hline Export & -0.1 & -0.2 & -0.2 & -0.1 & 1.0 & & & & & & & \\
\hline MNC & 0.3 & 0.0 & 0.4 & -0.2 & -0.2 & 1.0 & & & & & & \\
\hline Training & 0.2 & 0.3 & 0.3 & 0.1 & 0.0 & 0.2 & 1.0 & & & & & \\
\hline CEdu & 0.1 & 0.2 & 0.0 & 0.2 & 0.2 & -0.3 & -0.1 & 1.0 & & & & \\
\hline CMExpD & 0.0 & -0.1 & 0.6 & 0.1 & -0.1 & 0.5 & 0.2 & -0.1 & 1.0 & & & \\
\hline Mnc_Prox & 0.0 & 0.1 & 0.2 & 0.0 & 0.0 & 0.2 & 0.2 & -0.1 & 0.2 & 1.0 & & \\
\hline Dom_Prox & 0.0 & 0.1 & -0.1 & 0.1 & 0.0 & -0.2 & -0.1 & 0.0 & -0.2 & -0.2 & 1.0 & \\
\hline MncExp & 0.2 & 0.1 & 0.6 & 0.1 & -0.3 & 0.4 & 0.2 & -0.2 & 0.5 & -0.1 & 0.0 & 1.0 \\
\hline
\end{tabular}

For Table 6.14

\begin{tabular}{|c|c|c|c|c|c|c|c|c|c|c|c|}
\hline & 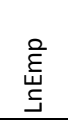 & $\begin{array}{l}\frac{c}{U} \\
\stackrel{0}{0} \\
\text { a }\end{array}$ & 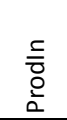 & 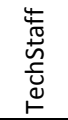 & 离 & 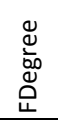 & $\underset{ه}{\stackrel{0}{4}}$ & $\sum_{\Sigma}^{U}$ & 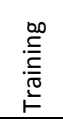 & 굼 & 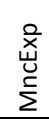 \\
\hline LnEmp & 1.0 & & & & & & & & & & \\
\hline Procln & 0.3 & 1.0 & & & & & & & & & \\
\hline Prodln & 0.1 & 0.1 & 1.0 & & & & & & & & \\
\hline TechStaff & -0.2 & -0.2 & 0.2 & 1.0 & & & & & & & \\
\hline CExp & 0.6 & 0.1 & 0.3 & -0.1 & 1.0 & & & & & & \\
\hline FDegree & 0.6 & 0.0 & -0.2 & -0.2 & 0.4 & 1.0 & & & & & \\
\hline Age & 0.4 & -0.1 & 0.2 & 0.1 & 0.3 & 0.1 & 1.0 & & & & \\
\hline MNC & 0.4 & 0.2 & 0.1 & -0.1 & 0.4 & 0.2 & -0.2 & 1.0 & & & \\
\hline Training & 0.4 & 0.2 & 0.2 & -0.1 & 0.3 & 0.2 & 0.3 & 0.1 & 1.0 & & \\
\hline CEdu & -0.1 & -0.2 & -0.1 & 0.3 & 0.0 & 0.0 & 0.0 & -0.3 & -0.1 & 1.0 & \\
\hline MncExp & 0.6 & 0.1 & 0.2 & -0.3 & 0.6 & 0.3 & 0.0 & 0.5 & 0.2 & -0.3 & 1.0 \\
\hline
\end{tabular}




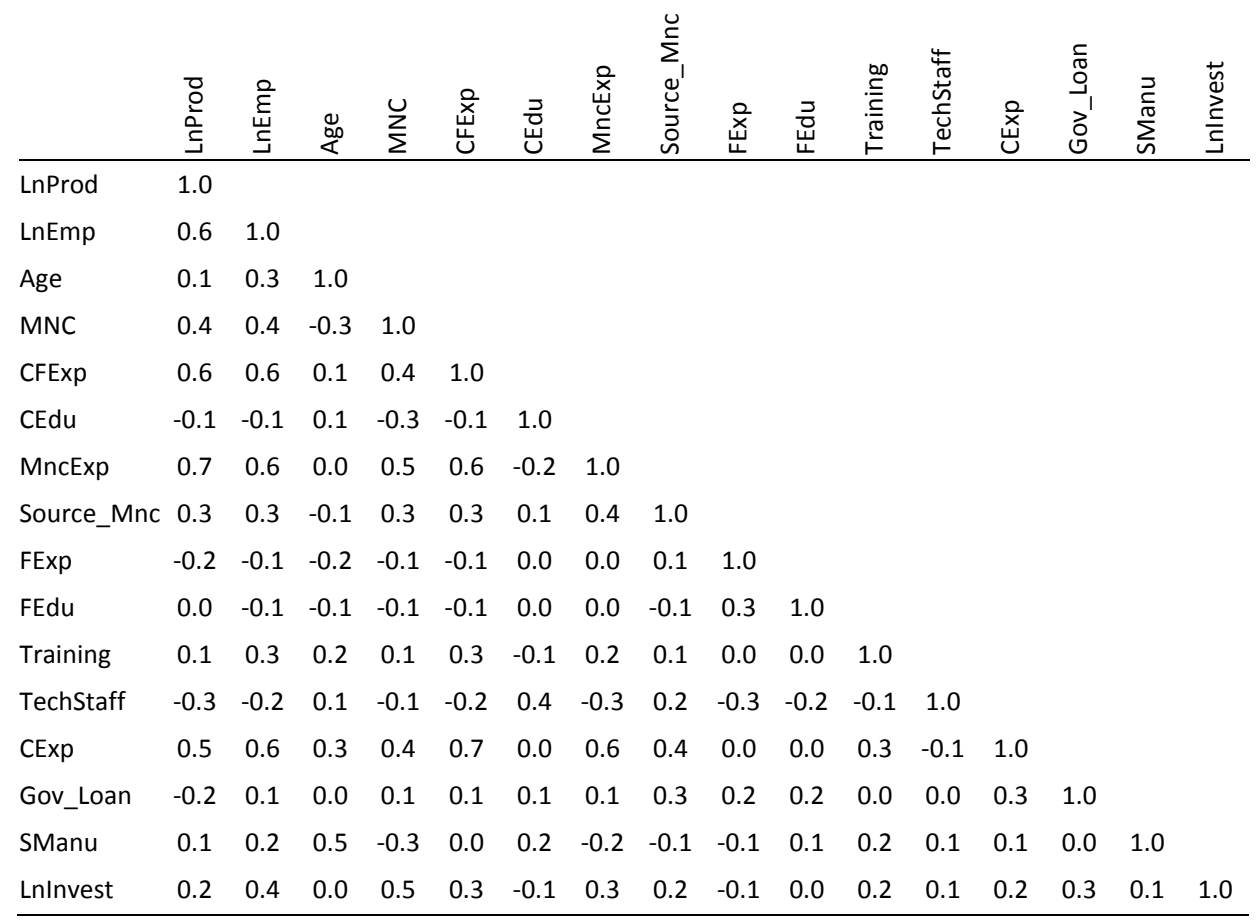

For Table 7.2

\begin{tabular}{|c|c|c|c|c|c|c|c|c|c|c|c|c|c|}
\hline & $\begin{array}{l}\frac{c}{\mathrm{O}} \\
\frac{\mathrm{L}}{2}\end{array}$ & 듷 & 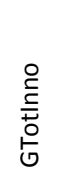 & 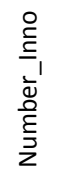 & $\begin{array}{l}\stackrel{\varrho}{E} \\
\text { ష్ }\end{array}$ & 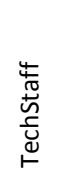 & 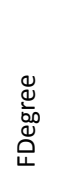 & $\underset{\mathbb{C}}{\stackrel{0}{<}}$ & $\stackrel{u}{\Sigma}$ & 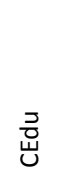 & $\begin{array}{l}\stackrel{0}{x} \\
\text { 岂 } \\
\stackrel{\Sigma}{\Sigma}\end{array}$ & 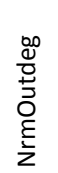 & 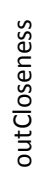 \\
\hline Procln & 1.0 & & & & & & & & & & & & \\
\hline Prodln & 0.1 & 1.0 & & & & & & & & & & & \\
\hline GTotInno & 0.5 & 0.4 & 1.0 & & & & & & & & & & \\
\hline Number_Inno & 0.1 & 0.4 & 0.7 & 1.0 & & & & & & & & & \\
\hline LnEmp & 0.2 & 0.2 & 0.4 & 0.3 & 1.0 & & & & & & & & \\
\hline TechStaff & -0.2 & 0.1 & 0.0 & 0.1 & -0.2 & 1.0 & & & & & & & \\
\hline FDegree & 0.0 & -0.2 & 0.2 & 0.0 & 0.5 & -0.2 & 1.0 & & & & & & \\
\hline Age & -0.1 & 0.2 & 0.2 & 0.3 & 0.3 & 0.1 & 0.1 & 1.0 & & & & & \\
\hline MNC & 0.2 & 0.1 & 0.1 & -0.1 & 0.4 & -0.1 & 0.1 & -0.3 & 1.0 & & & & \\
\hline CEdu & -0.3 & -0.1 & -0.1 & 0.0 & 0.0 & 0.3 & 0.0 & 0.1 & -0.3 & 1.0 & & & \\
\hline MncExp & 0.1 & 0.2 & 0.2 & 0.0 & 0.6 & -0.4 & 0.2 & -0.1 & 0.5 & -0.2 & 1.0 & & \\
\hline NrmOutdeg & 0.1 & 0.1 & 0.4 & 0.2 & 0.4 & 0.1 & 0.4 & 0.2 & -0.1 & 0.2 & 0.1 & 1.0 & \\
\hline outCloseness & 0.2 & 0.0 & 0.3 & 0.1 & 0.3 & 0.2 & 0.2 & -0.2 & 0.3 & 0.2 & 0.2 & 0.4 & 1.0 \\
\hline
\end{tabular}




\begin{tabular}{|c|c|c|c|c|c|c|c|c|c|c|c|c|c|}
\hline & 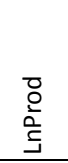 & 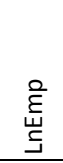 & $\underset{\square}{\stackrel{0}{\leftarrow}}$ & $\sum_{\Sigma}^{u}$ & $\begin{array}{l}\frac{0}{x} \\
\text { 岀 } \\
\end{array}$ & 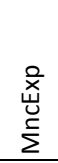 & 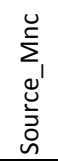 & 选 & 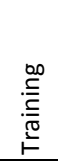 & 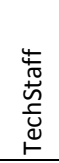 & 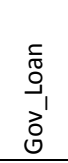 & 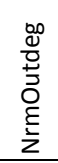 & 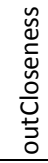 \\
\hline LnProd & 1.0 & & & & & & & & & & & & \\
\hline LnEmp & 0.7 & 1.0 & & & & & & & & & & & \\
\hline Age & 0.1 & 0.3 & 1.0 & & & & & & & & & & \\
\hline MNC & 0.4 & 0.4 & -0.2 & 1.0 & & & & & & & & & \\
\hline CFExp & 0.6 & 0.6 & 0.0 & 0.4 & 1.0 & & & & & & & & \\
\hline MncExp & 0.6 & 0.6 & 0.0 & 0.4 & 0.6 & 1.0 & & & & & & & \\
\hline Source_Mnc & 0.3 & 0.3 & -0.1 & 0.2 & 0.2 & 0.4 & 1.0 & & & & & & \\
\hline FExp & -0.1 & -0.1 & -0.2 & -0.1 & -0.1 & 0.2 & 0.1 & 1.0 & & & & & \\
\hline Training & 0.2 & 0.4 & 0.1 & 0.1 & 0.3 & 0.2 & 0.0 & 0.1 & 1.0 & & & & \\
\hline TechStaff & -0.2 & -0.1 & 0.1 & 0.0 & -0.1 & -0.4 & 0.1 & -0.3 & 0.0 & 1.0 & & & \\
\hline Gov_Loan & -0.1 & 0.0 & 0.0 & 0.1 & 0.1 & 0.1 & 0.2 & 0.2 & 0.0 & 0.1 & 1.0 & & \\
\hline NrmOutdeg & 0.2 & 0.4 & 0.3 & -0.2 & 0.1 & 0.1 & 0.2 & -0.1 & 0.1 & 0.0 & -0.1 & 1.0 & \\
\hline outCloseness & 0.3 & 0.3 & -0.2 & 0.3 & 0.2 & 0.2 & 0.3 & -0.1 & 0.2 & 0.3 & -0.2 & 0.3 & 1.0 \\
\hline
\end{tabular}

For Table 7.7

\begin{tabular}{|c|c|c|c|c|c|c|c|c|c|c|c|c|}
\hline & $\begin{array}{l}\text { 읃 } \\
\text { 号 } \\
\stackrel{0}{0}\end{array}$ & 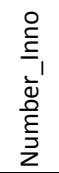 &  & $\sum_{\Sigma}^{u}$ & $\underset{\leftarrow}{\stackrel{\infty}{\alpha}}$ & 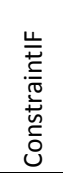 & 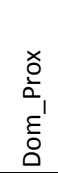 & 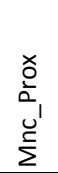 & 굼 & $\begin{array}{l}\bar{D} \\
\stackrel{ர}{n}\end{array}$ & $\frac{O}{\frac{O U}{U}}$ & $\sum_{n}^{\vec{T}}$ \\
\hline GTotInno & 1.0 & & & & & & & & & & & \\
\hline Number_Inno & 0.9 & 1.0 & & & & & & & & & & \\
\hline LnEmp & 0.4 & 0.3 & 1.0 & & & & & & & & & \\
\hline MNC & 0.4 & 0.2 & 0.5 & 1.0 & & & & & & & & \\
\hline Age & 0.2 & 0.3 & 0.4 & -0.2 & 1.0 & & & & & & & \\
\hline ConstraintIF & -0.3 & -0.2 & -0.3 & -0.1 & -0.1 & 1.0 & & & & & & \\
\hline Dom_Prox & 0.1 & 0.2 & 0.0 & -0.3 & 0.3 & 0.1 & 1.0 & & & & & \\
\hline Mnc_Prox & 0.3 & 0.3 & 0.1 & 0.3 & 0.0 & -0.2 & -0.2 & 1.0 & & & & \\
\hline CEdu & 0.2 & 0.2 & 0.0 & -0.1 & 0.1 & 0.0 & 0.0 & 0.0 & 1.0 & & & \\
\hline STrad & 0.0 & 0.1 & -0.1 & -0.2 & 0.0 & 0.2 & 0.1 & 0.0 & -0.1 & 1.0 & & \\
\hline STelco & 0.3 & 0.1 & 0.6 & 0.6 & 0.1 & -0.2 & -0.2 & 0.1 & 0.0 & -0.2 & 1.0 & \\
\hline SManu & 0.2 & 0.2 & 0.2 & -0.2 & 0.3 & -0.2 & 0.1 & 0.1 & 0.1 & -0.2 & -0.3 & 1.0 \\
\hline
\end{tabular}




\begin{tabular}{|c|c|c|c|c|c|c|c|c|c|c|c|c|c|c|c|}
\hline & 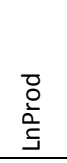 & $\begin{array}{l}\stackrel{\varrho}{E} \\
\stackrel{\amalg}{\Xi} \\
\end{array}$ & 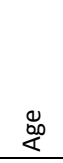 & $\sum_{\Sigma}^{u}$ & $\begin{array}{l}\stackrel{0}{x} \\
\text { 岀 }\end{array}$ & 勇 & 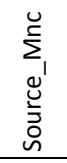 & 站 & $\begin{array}{l}\text { 문 } \\
\text { 出 }\end{array}$ & 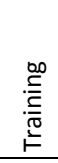 & 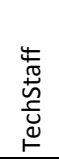 & 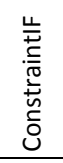 & $\begin{array}{l}0 \\
\frac{0}{2} \\
5 \\
\end{array}$ & $\frac{8}{\frac{8}{U}}$ & $\sum_{\substack{\Gamma \\
\Gamma}}^{\substack{\pi \\
N}}$ \\
\hline LnProd & 1.0 & & & & & & & & & & & & & & \\
\hline LnEmp & 0.6 & 1.0 & & & & & & & & & & & & & \\
\hline Age & 0.1 & 0.3 & 1.0 & & & & & & & & & & & & \\
\hline MNC & 0.4 & 0.4 & -0.2 & 1.0 & & & & & & & & & & & \\
\hline CFExp & 0.6 & 0.6 & 0.1 & 0.4 & 1.0 & & & & & & & & & & \\
\hline CEdu & 0.0 & -0.1 & 0.1 & -0.2 & -0.1 & 1.0 & & & & & & & & & \\
\hline Source_Mnc & 0.4 & 0.4 & -0.1 & 0.3 & 0.3 & 0.2 & 1.0 & & & & & & & & \\
\hline FExp & -0.2 & -0.1 & -0.2 & -0.1 & 0.0 & 0.1 & 0.1 & 1.0 & & & & & & & \\
\hline FEdu & 0.0 & -0.1 & -0.1 & -0.1 & -0.1 & 0.0 & 0.0 & 0.5 & 1.0 & & & & & & \\
\hline Training & 0.1 & 0.4 & 0.2 & 0.2 & 0.3 & 0.0 & 0.1 & 0.1 & 0.0 & 1.0 & & & & & \\
\hline TechStaff & -0.3 & -0.3 & 0.1 & -0.1 & -0.2 & 0.4 & 0.1 & -0.2 & -0.2 & -0.1 & 1.0 & & & & \\
\hline ConstraintIF & -0.3 & -0.3 & 0.0 & 0.0 & -0.2 & 0.1 & 0.0 & 0.1 & 0.3 & -0.2 & 0.1 & 1.0 & & & \\
\hline STrad & 0.0 & -0.2 & -0.1 & -0.2 & -0.1 & -0.1 & -0.1 & 0.0 & 0.1 & -0.2 & -0.2 & 0.1 & 1.0 & & \\
\hline STelco & 0.6 & 0.6 & -0.1 & 0.7 & 0.5 & 0.0 & 0.4 & -0.1 & -0.1 & 0.2 & -0.1 & -0.3 & -0.2 & 1.0 & \\
\hline SManu & 0.1 & 0.2 & 0.5 & -0.3 & 0.0 & 0.2 & -0.2 & -0.1 & 0.1 & 0.2 & 0.0 & -0.1 & -0.2 & -0.3 & 1.0 \\
\hline
\end{tabular}

For Table 7.9

\begin{tabular}{|c|c|c|c|c|c|c|c|c|c|c|c|c|}
\hline & 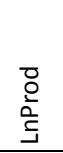 & $\begin{array}{l}\stackrel{\circ}{E} \\
\stackrel{\text { ऽ}}{\Xi}\end{array}$ & $\stackrel{u}{\Sigma}$ & 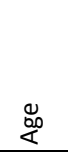 & $\frac{\frac{O}{U}}{\frac{0}{n}}$ & 晃 & 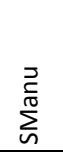 & $\begin{array}{l}\stackrel{0}{x} \\
\text { 出 } \\
\end{array}$ & 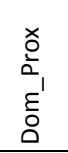 & $\begin{array}{l}\stackrel{0}{x} \\
\text { 岂 } \\
\Sigma\end{array}$ & 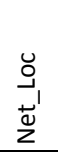 &  \\
\hline LnProd & 1.0 & & & & & & & & & & & \\
\hline LnEmp & 0.6 & 1.0 & & & & & & & & & & \\
\hline MNC & 0.3 & 0.4 & 1.0 & & & & & & & & & \\
\hline Age & 0.2 & 0.4 & -0.3 & 1.0 & & & & & & & & \\
\hline STelco & 0.5 & 0.5 & 0.5 & 0.1 & 1.0 & & & & & & & \\
\hline STrad & 0.0 & -0.2 & -0.2 & -0.1 & -0.2 & 1.0 & & & & & & \\
\hline SManu & 0.1 & 0.2 & -0.3 & 0.3 & -0.3 & -0.2 & 1.0 & & & & & \\
\hline FExp & -0.1 & -0.1 & -0.1 & -0.2 & -0.1 & 0.2 & -0.1 & 1.0 & & & & \\
\hline Dom_Prox & -0.2 & 0.0 & -0.3 & 0.3 & -0.2 & 0.2 & 0.0 & 0.1 & 1.0 & & & \\
\hline MncExp & 0.6 & 0.6 & 0.5 & 0.0 & 0.6 & 0.0 & -0.2 & 0.1 & -0.1 & 1.0 & & \\
\hline Net_Loc & 0.2 & 0.4 & 0.1 & 0.0 & 0.4 & -0.1 & -0.1 & 0.0 & -0.3 & 0.1 & 1.0 & \\
\hline OutdegreelF & 0.1 & 0.1 & -0.2 & 0.1 & 0.1 & -0.2 & 0.1 & -0.1 & 0.1 & 0.0 & 0.1 & 1.0 \\
\hline
\end{tabular}




\begin{tabular}{|c|c|c|c|c|c|c|c|c|c|c|c|}
\hline & Еે & 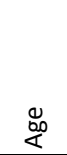 & $\sum_{\Sigma}^{u}$ & $\begin{array}{l}\text { 离 } \\
\text { 岁 }\end{array}$ & 䓛 &  & 离 & 㞼 & 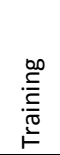 & 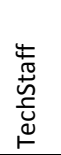 & 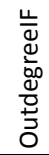 \\
\hline LnEmp & 1.0 & & & & & & & & & & \\
\hline Age & 0.3 & 1.0 & & & & & & & & & \\
\hline MNC & 0.4 & -0.2 & 1.0 & & & & & & & & \\
\hline CFExp & 0.6 & 0.1 & 0.4 & 1.0 & & & & & & & \\
\hline CEdu & -0.1 & 0.1 & -0.2 & -0.1 & 1.0 & & & & & & \\
\hline Source_Mnc & 0.4 & -0.1 & 0.3 & 0.3 & 0.2 & 1.0 & & & & & \\
\hline FExp & -0.1 & -0.2 & -0.1 & 0.0 & 0.1 & 0.1 & 1.0 & & & & \\
\hline FEdu & -0.1 & -0.1 & -0.1 & -0.1 & 0.0 & 0.0 & 0.5 & 1.0 & & & \\
\hline Training & 0.4 & 0.2 & 0.2 & 0.3 & 0.0 & 0.1 & 0.2 & 0.0 & 1.0 & & \\
\hline TechStaff & -0.3 & 0.1 & -0.1 & -0.2 & 0.4 & 0.1 & -0.2 & -0.2 & -0.1 & 1.0 & \\
\hline OutdegreelF & 0.1 & 0.2 & -0.2 & -0.1 & -0.1 & -0.2 & -0.1 & -0.2 & 0.1 & 0.0 & 1.0 \\
\hline
\end{tabular}





\section{Summary}

This thesis contributes to the literature in a number of ways. It primarily seeks to assess the role of FDI in a developing country context and its associated spillovers within a high-tech sector where the likelihood of knowledge flows and learning is the highest. Given the special nature of ICT - both in terms of attracting FDI and its potential for spillovers - it focuses on the ICT sector in Pakistan. However, in order to put the ICT sector into the broader context of development, it first seeks to understand the historical background of the economy as a whole. Therefore, taking a step back, we first study the initial conditions which have significantly shaped Pakistan's growth and development trajectory. For this purpose chapter 3 gives an overview of long-term economic and political developments in Pakistan which provides a background for the subsequent analysis of Pakistan's sectoral productivity and the performance of the ICT sector in Pakistan. Economic developments are discussed in the context of various civilian and military ruled periods. We established that Pakistan's path to social and economic development has not been straightforward. Unfavorable initial conditions, having a rival country as a neighbor, lack of an adequate policy framework and the civil-military divide were all handicaps, many of which are still present today. Despite all odds, there were periods of robust growth but largely at the expense of social development as shown by the various indicators. Towards the end of the chapter some of the most important challenges faced by the country are highlighted together with a discussion of how they came into being.

While Chapter 3 concentrates mainly on the different periods and their salient policy features, Chapter 4 takes the discussion into inter and intra sectoral productivity with the aim to understand the trends in two particular sectors, manufacturing and services. The reasons why we were interested in understanding the evolution of these two sectors in particular are two-fold. Firstly, empirical evidence unequivocally advocates the role of manufacturing for development. Developing countries which have managed to converge towards a developed economy have mostly gone through a more or less similar process during their transition period. The second reason has to do with the more recent trend; developed countries transforming from manufacturing centric into services centric economies. Another recent development is the rapidly increasing role of information and communications technologies (ICTs) for growth. The chapter employs the shift and share analysis to account for productivity growth on a dataset of all industrial sectors spanning over 3 decades with the goal to observe if the economy has been shifting resources from an agrarian economy to a manufacturing one, and more recently in becoming a service-oriented economy. The special role which the service sector in general and ICT in particular has played in helping countries 
catch up is one reason for the special attention which is given to the ICT sector. Another reason is its relevance to FDI; it being the sector with the most inflows by far. Last but not least, the sector is important because ICTs, by virtue of being general purpose technologies, are closely related with productivity growth in the wider economy. A shift-share analysis is performed in order to look at the broader structural change and thereby attempt to quantify the contribution of the ICT sector. However, the weakness of the underlying data on the ICT component of services prevented us from singling out the contribution of this sector to structural change. While assessing the impact of structural changes within the economy on productivity we found that for the whole economy structural changes do contribute positively to productivity growth, though within sector productivity increases are much more important. Productivity contributions of structural shifts within the manufacturing sector were negligible or even negative.

Chapter 5 provides an overview of the ICT sector of Pakistan and serves as a backdrop for our survey in this sector. It also presents a historical perspective highlighting some important events that led to the evolution (and later decline) of this sector. This chapter establishes that though the ground work for transitioning to a knowledge economy is laid, in order to be able to become competitive at the level of existing global players like India and China, a lot of hard work needs to be put in. These efforts cannot just be limited to the organizational domain but rather would need strong support from policy makers as well. The right set of policy instruments would not just focus on pushing from the outside e.g. encouraging more FDI, but also pulling from the inside i.e. to devise a framework which would help firms to absorb spillovers.

In our pursuit of spillovers from ICT and to understand the causes of such externalities we then empirically estimated the existence, channels and mechanisms of spillovers based on primary data gathered from our survey. Thus, chapter 6 undertakes an empirical examination of spillovers in the Pakistan ICT sector and its subsectors. ICT being an advanced technology sector makes it more likely for innovations resulting in knowledge spillovers. Our study contributed to the existing body of knowledge by exploring the effects of a set of variables on the innovative and productive performance of firms, while relating them to the established mechanisms of spillovers. Our results validated some of the established findings in literature. With regards to absorptive capacity and human capital our findings corroborated that CEOs' education is positively associated with Productivity, R\&D intensity and the decision to perform R\&D. Similarly the number of a CEO's previous jobs has a positive impact on Process Innovative Performance. We also found that more foreign qualified technical staff members in a firm increase the likelihood of it being more productive and foreign qualified (education) staff intensity positively affects labor productivity. Training for technical staff and Technical staff to employee ration positively predicts Product Innovative Performance. Firms doing R\&D and those having more number of dedicated R\&D staff are more likely to be involved in process innovations. As for labor mobility, we could confirm that CEOs foreign experience positively predicts productivity. More- 
over, the finding that firms which point to MNCs as their primary source for technology are more productive validates the demonstration effect.

Some of our findings, with regard to the role of education and performance of multinationals were unexpected and went against established views in literature. This could be due to the specific conditions and challenges faced by both foreign and domestic firms in a developing country context or due to methodological issues pointed out, which need to be addressed in future research.

Chapter 7 looks at the spillover debate from a social capital perspective. Network data gathered through our extended questionnaire is analyzed for two distinct features of social capital. Firstly the network of contacts which grants individuals access to resources belonging to their contacts, and secondly the quality and quantity of those resources. Our methodology, in a way, combines both structural elements of a network and the resource dimension. We achieve this by using variables which represent structural information like constraint and centrality (degree, closeness and betweenness) but construct these variables using matrices which contain resource exchange weights and frequencies, both being dimensions which shed light on the strength of ties, not the structural characteristics as such. We started out by validating the importance of general embeddedness metrics in predicting innovative and economic performance. We got mixed results for general embeddedness. Innovative performance is unaffected by both centrality metrics used and productivity is positively and significantly predicted by out-degree centrality. We also tested Burt's hypothesis of structural holes and found it to be significantly positive meaning that firms with plenty of structural holes outperform firms with redundant ties. We also tested our data set for the impact of interaction frequency on innovativeness and productivity. Here too a positive and significant link between interaction frequency and both innovativeness and productivity was established corroborating the importance of information in hightech sectors which is ensured through frequent interactions between firms.

The final chapter summarizes the conclusions emerging from our empirical analysis. 



\section{About the author}

Abdul Baseer Qazi has a diverse academic background, with a bachelor's degree in electrical engineering (cum laude) from the NWFP UET in Peshawar and a dual Master's degree from the Technical University of Hamburg-Harburg in Information and Communication Systems and Technology Management (cum laude) from the Northern Institute of Technology in Hamburg. He also holds a 1-year diploma in Computer Sciences (cum laude) from the NWFP Board of Technical Education.

Mr. Qazi has been receiving scholarships and stipends throughout his professional education as a result of his outstanding academic performance. He received a stipend from the local government for his 4 years engineering degree. His studies at the TUHH/NIT were fully sponsored by Siemens. He was also part of the prestigious Siemens Student Program during this period which in addition to bearing the tuition fee not only provided him with a stipend and on-campus accommodation, but also arranged and paid for various EU-wide seminars, trainings and events. His studies at the UNU-MERIT were also fully sponsored.

Mr. Qazi got his first job exposure while working as a research assistant in the German Aerospace Center on the European GPS project 'Galileo' in 1999. Afterwards he had the unique opportunity of working for 3 Fortune 500 firms, Siemens, IBM and Philips. He was part of the Management Development Program of Philips. In Pakistan, he worked as an Assistant Professor at the privately run engineering university, CECOS and two years later assumed responsibility as the Chairman of Computer System Engineering department at the Peshawar College of Engineering. His interest in economic issues and technology transfer to developing countries got intensified while teaching Engineering Economics and Management for Engineers both at Peshawar College of Engineering and as visiting faculty at the NWFP UET, Peshawar. It was at this stage that he made up his mind to further pursue this objective by getting enrolled in a PhD program in an institute of international repute in the subject.

Mr. Qazi has successfully ventured several startup firms during his studies and also while working. PrintWorks, Cosmo Computer Works, KTC-International and BrickWorks are a few to name.

Currently he serves at Muhammad Ali Jinnah University in Islamabad.

Mr. Qazi is fluent in German, English, Urdu, Pashto, Punjabi and Hindi, and has basic knowledge of Dutch and Arabic. 


\section{- UNIVERSITY}

UNU-MERIT

\section{5}

\section{Giorgio Triulzi}

Looking for the Right Path: Technology Dynamics, Inventive Strategies and Catching-up in the

Semiconductor Industry

\section{Abdul Baseer Qazi}

Knowledge flows and networks in the ICT sector: The case of Pakistan

\section{Ajay Thutupalli}

Technology Paradigm Shifts in Agriculture: Drivers of Sustainability and Catch up

\section{Eduardo Urias}

Improving access to HIV/AIDS treatment in Brazil: When are compulsory licenses effective in price negotiations?

\section{Francesca Guadagno}

Why have so few countries industrialised?

\section{Daniel Opolot}

The evolution of beliefs and strategic behavior

\section{Alejandro Lavopa}

Structural Transformation and Economic

Development: Can Development Traps be Avoided?

\section{Jinjin Zhao}

Urban water management reform: The case of China

\section{4}

\section{Dirk Crass}

The Impact of Brands on Innovation and Firm Performance: Empirical Evidence from Germany

\section{Samyukta Bhupatiraju}

The Geographic Dimensions of Growth and Development

\section{François Lafond}

The evolution of knowledge systems

\section{Annalisa Primi}

Promoting Innovation in Latin America: What Countries Have Learned (and What They Have Not) in Designing and Implementing Innovation and Intellectual Property Policies

\section{Fatoumata Lamarana Diallo}

Evaluation of Meal and Deworming Programs for Primary Schools in Rural Senegal

\section{3}

\section{Anant Kamath}

Information Sharing through Informal Interaction in Low-Tech Clusters

\section{Flavia Pereira de Carvalho}

What we talk about when we talk about Brazilian Mulitantionals: an investigation on Brazilian FDI, economic structure, innovation and the relationship between them

\section{Jun Hou}

Complementarity in Innovation and Development: A Cross-country Comparison

\section{Rufin Baghana} Impacts of Government Incentives to R\&D, Innovation and Productivity:

A Microeconometric Analysis of the Québec Case

\section{Lilia I. Stubrin}

High-Tech Activities in Emerging Countries: A Network perspective on the Argentinean biotech activity

\section{2}

\section{Abdul Waheed} Innovation Determinants and Innovation as a Determinant: Evidence from Developing Countries

\section{Bilal Mirza}

Energy Poverty and Rural Energy Markets in Pakistan

\section{Benjamin Engelstätter} Enterprise Software and Video Games: An Empirical Analysis 
Fulvia Farinelli

Natural Resources, Innovation and Export Growth:

The Wine Industry in Chili and Argentina

\section{Rodolfo Lauterbach}

Innovation in Manufacturing: From Product Variety and Labor Productivity Growth to Economic

Development in Chile

\section{Kirsten Wiebe}

Quantitative Assessment of Sustainable

Development and Growth in Sub-Saharan Africa.

\section{Julio Miguel Rosa}

Organizational Strategies, Firms' Performance and Spatial Spillovers. The Canadian Case in Research and Development.

\section{Johannes Wilhelmus Marie Boels}

Joseph Schumpeter, honderd jaar economische ontwikkeling. Een historisch-theoretische beschouwing.

\section{1}

\section{Daniel Vertesy}

Interrupted Innovation: Emerging economies in the structure of the global aerospace industry.

\section{Tina Saebi}

Successfully managing alliance portfolios: an alliance capability view.

\section{Nora Engel}

Tuberculosis in India - A case of innovation and control.

\section{Evans Mupela}

Connectivity and growth in Sub-Saharan Africa: The role of communication satellites

\section{Nantawan Kwanjai}

Cross cultural intelligence amid intricate cultural webs: A tale of the UnDutchables in the land of 1002 smiles

\section{Lina Sonne}

Innovation in Finance to Finance Innovation: Supporting pro-poor entrepreneur-based innovation

\section{0}

\section{Fernando Santiago}

Human Resources Management Practices and Learning for Innovation in Developing Countries: Pharmaceutical Firms in Mexico

\section{Zakaria Babutsidze}

Essays on Economies with Heterogenous Interacting Consumers

\section{Bertha Vallejo}

Learning and Innovation Under Changing Market Conditions: The Auto Parts Industry in Mexico

\section{Donatus Ayitey}

Technical Change, Competitiveness and Poverty Reduction: A Study of the Ghanaian Apparel Industry

\section{Sergey Fillipov}

Multinational Subsidiary Evolution: Corporate Change in New EU Member States

\section{Asel Doranova}

Technology Transfer and Learning under the Kyoto regime; Exploring the Technological Impact of CDM projects in developing countries

\section{9}

\section{Alexis Habiyaremye}

From Primary Commodity Dependence to Diversification and Growth". "Absorptive Capacity and Technological Catch Up in Botswana and Mauritius".

\section{Yoseph Getachew}

The Role of Public Capital in Economic Development

\section{Sandra Leitner}

Embodied Technological Change and Patterns of Investment in Austrian Manufacturing

\section{Semih Akçomak}

The Impact of Social Capital on Economic and Socia Outcomes

\section{Abraham Garcia}

The Role of Demand in Technical Change 


\section{Saurabh Arora}

Coherence in socio-technical systems: a network perspective on the innovation process

\section{8}

\section{Rutger Daems}

Medicines for the developing world

\section{Johannes Hanel}

Assessing Induced Technology: Sombart's

Understanding of Technical Change in the History of Economics

\section{Rifka Weehuizen}

Mental Capital: the economic significance of mental health

\section{Danielle Cloodt}

The relationship between R\&D partnership formation, social embeddedness and innovative performance

\section{Sabine Fuss}

Sustainable Energy Development under Uncertainty

\section{7}

\section{Tobias Kronenberg}

Reconciling Environmental Conservation with Economic Prosperity: The Feasibility of Double Dividends in the Short and Long Run

\section{Viktoria Kravtsova}

Assessing the Impact of Foreign Direct Investment in Transition Economies

\section{Suhail Sultan}

The Competitive Advantage of Small and Medium Sized Enterprises: The Case of Jordan's Natural Stone Industry

\section{6}

\section{Bulat Sanditov}

Essays on Social Learning and Imitation

\section{Mamata Parhi}

Dynamics of New Technology Diffusion: A Study of the Indian Automotive Industry

\section{Andreas Reinstaller}

Social structures and the innovation process: Their role in the demand of firms and consumers

\section{Rose Kiggundu}

Innovation systems and development: the journey of a Beleaguered Nile Perch Fishery in Uganda

\section{Thomas Pogue}

The Evolution of Research Collaboration in South African Gold Mining: 1886-1933

\section{Geoffrey Gachino}

Foreign Direct Investment, Spillovers and Innovation: The Case of Kenyan Manufacturing Industry

\section{0. Önder Nomaler}

Technological Change, International Trade and Growth: An Evolutionary, Multi-Agents-Based Modeling Approach

\section{5}

\section{Samia Satti Osman Mohamed-Nour} Change and Skill Development in the Arab Gulf Countries

\section{Elad Harison}

Intellectual Property Rights: Economics and Policy Analysis

\section{Daniel Dalohoun}

The relationship between R\&D partnership formation, social embeddedness and innovative performance: a multi-level approach of social embeddedness

\section{Müge Ozman}

Networks, Organizations and Knowledge

\section{Bas Straathof}

Product variety and economic growth: The counteracting effects of scale and idiosyncrasy

\section{Wilfred Schoenmakers}

Knowledge Flows between Multinational Companies: A Patent Data Analysis

\section{Myriam Cloodt}

Mergers and Acquisitions (M\&As) in High-Tech Industries: Measuring the Post-M\&A Innovative Performance of Companies 
2004

\section{Paola Criscuolo}

R\&D Internationalisation and Knowledge Transfer. Impact on MNEs and their Home Countries

\section{Maarten Verkerk}

Trust and Power on the Shop Floor

\section{Gottfried Leibbrandt}

Adoption, harmonization and succession of network technologies across countries

\section{Mark Sanders}

Skill Biased Technical change - Its Origins, the Interaction with the Labour Market and Policy Implications

\section{3}

\section{Nadine Roijakkers}

Inter-firm cooperation in high-tech industries: a study of R\&D partnerships in pharmaceutical biotechnology

\section{Viki Sonntag}

Speed, Scale and Sustainability

\section{Masaru Yarime}

From End-of-Pipe Technology to Clean Technology

\section{Stéphane Malo}

The combinatorial Chemistry Revolution -

Sustaining a Superior Performance Position through Technological Learning

\section{2}

\section{Annelies Hogenbirk}

Determinants of Inward Foreign Direct Investment: the Case of the Netherlands

\section{1}

\section{John Adeot}

Technology Investment in Pollution Control in SubSaharan Africa: The Case of the Nigerian Manufacturing Industry

\section{Edward Huizenga}

Innovation Management: How Frontrunners Stay Ahead. An Empirical Study on Key Success Factors in the ICT sector

\section{0}

\section{Machiel van Dijk}

Technological Change and the Dynamics of Industries. Theoretical Issues and Empirical evidence from Dutch Manufacturing

\section{9}

\section{Jan Cobbenhagen}

Managing Innovation at the Company Level: A Study on Non-Sector-Specific Success Factors

19. Marjolein Caniëls

Regional Growth Differentials: The Impact of Locally Bounded Knowledge Spillovers

\section{8}

\section{Aldo Geuna}

Resource allocation and knowledge production: Studies in the economics of university research

\section{6}

\section{Reinoud Joosten}

Dynamics, Equilibria, and Values

\section{Hugo Kruiniger} Investment, R\&D, and the Financing Decisions of the Firm

\section{5}

\section{Hans van Meij}

Endogenous Technological Change: The Case of Information Technology. Theoretical Considerations and Empirical Results

\section{René Kemp}

Environmental Policy and Technical Change. A Comparison of the Technological Impact of Policy Instruments

\section{Rohini Acharya}

The Impact of New Technologies on Economic Growth and Trade. A Case Study of Biotechnology 


\section{Geert Duysters}

The Evolution of Complex Industrial Systems. The Dynamics of Major IT Sectors

\section{Marjan Groen}

Technology, Work and Organisation, A Study of the Nursing Process in Intensive Care Units

\section{4}

10. Huub Meijers

On the Diffusion of Technologies in a Vintage Framework; Theoretical Considerations and Empirical Results

\section{Theon van Dijk}

The Limits of Patent Protection. Essays on the Economics of Intellectual Property Rights

\section{Hans Voordijk}

Naar Integrale Logistiek in Bedrijfsketens, Ontwikkelingen in de Bouw

\section{3}

\section{Paul Diederen}

Technological Progress in Enterprises and Diffusion of Innovations. Theoretical Reflections and Empirical Evidence.

\section{Ben Dankbaar}

Economic Crisis and Institutional Change. The crisis of Fordism from the perspective of the automobile industry

\section{Hanno Roberts}

Accountability and Responsibility: The Influence of Organisation Design on Management Accounting

\section{2}

\section{Bart Verspagen}

Uneven Growth Between Interdependent Economies. An Evolutionary View on Technology Gaps, Trade and Growth

\section{Sjoerd Romme}

A Self-organization Perspective on Strategy Formation

\section{9}

\section{John Spangenberg}

Economies of Scale, and Atmosphere in Research Organisations

\section{8}

\section{John Hagedoorn}

Evolutionary and heterodox innovation analysis: a study of industrial and technological development in process control and information technology 


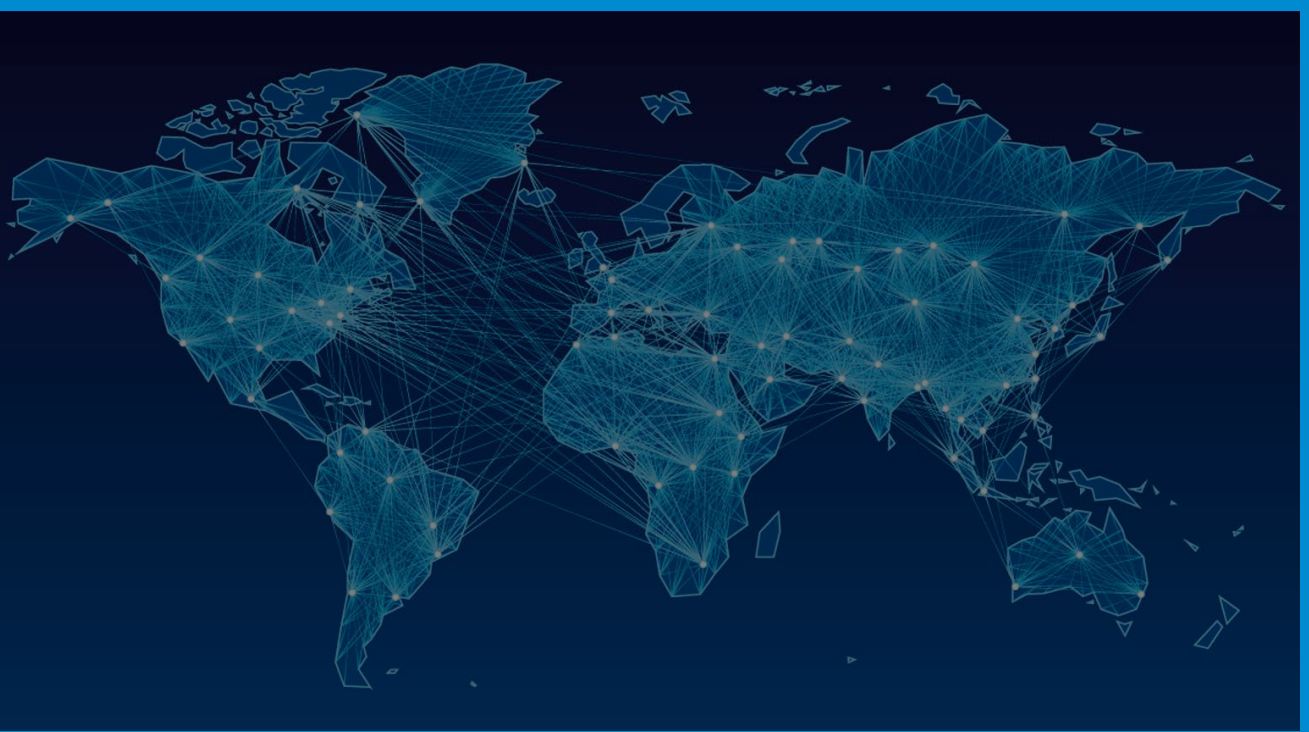

